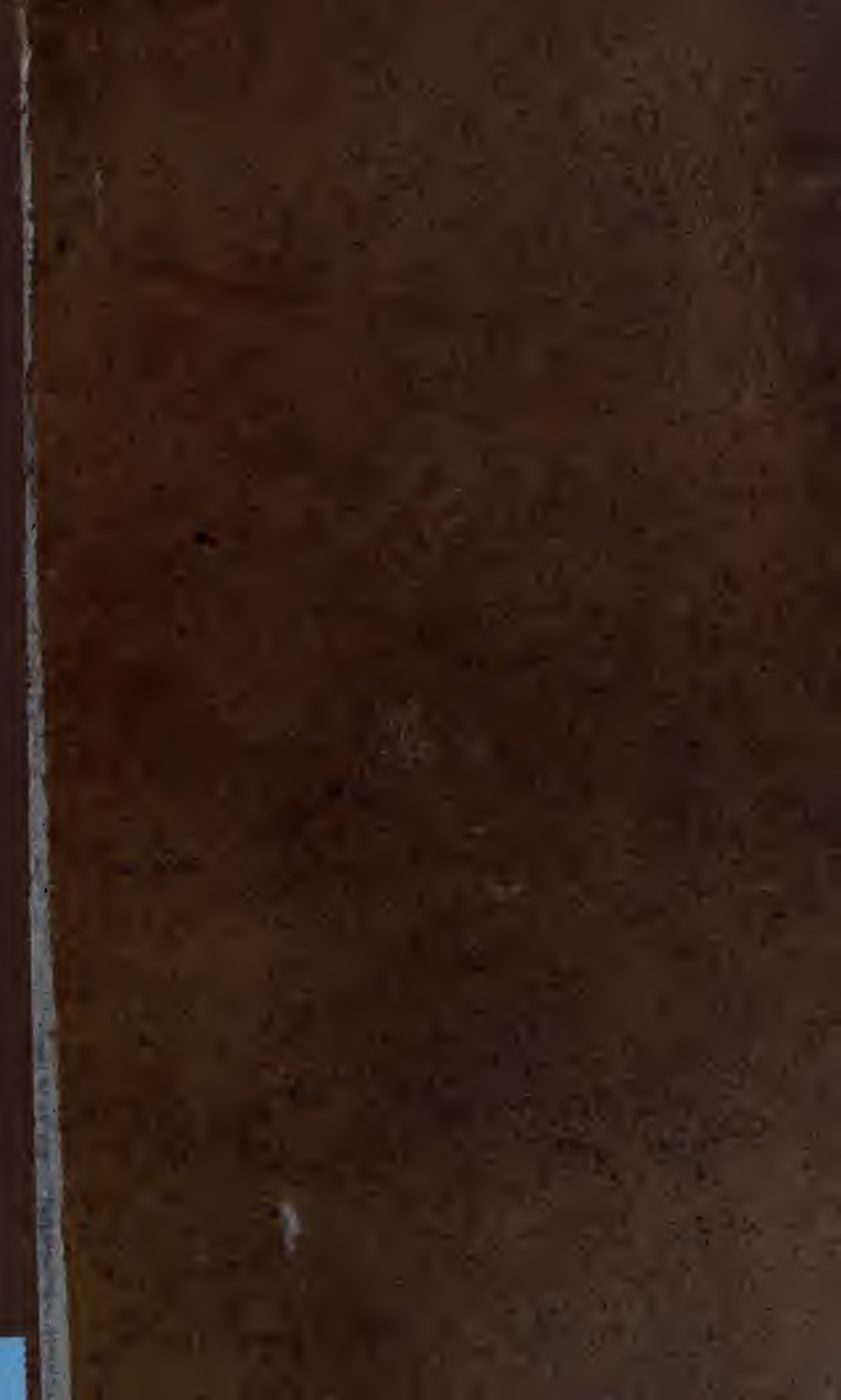




\section{1}

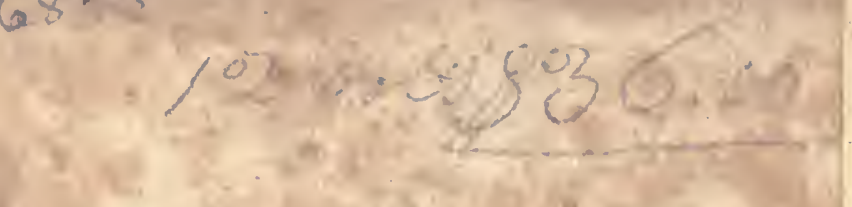

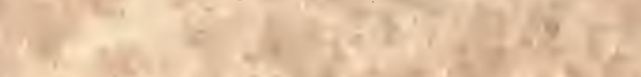

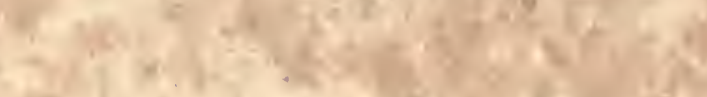

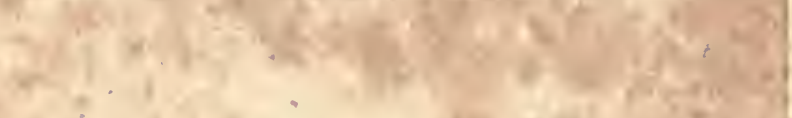

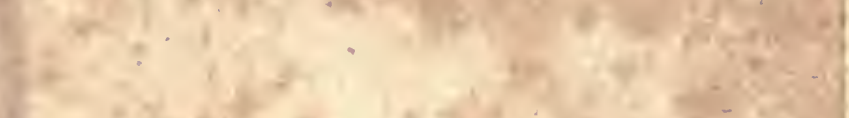

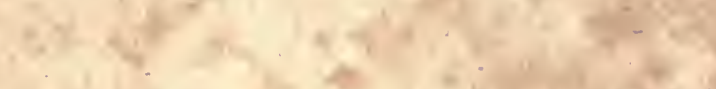

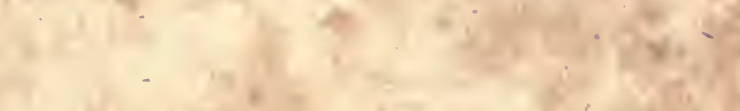

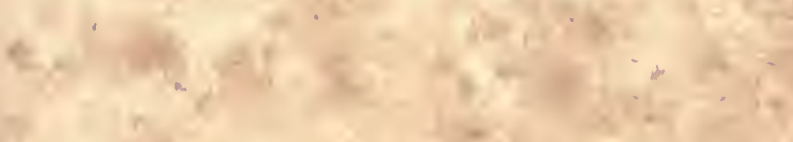

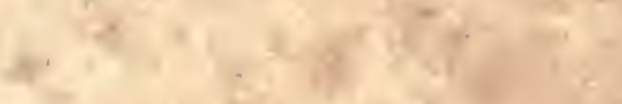

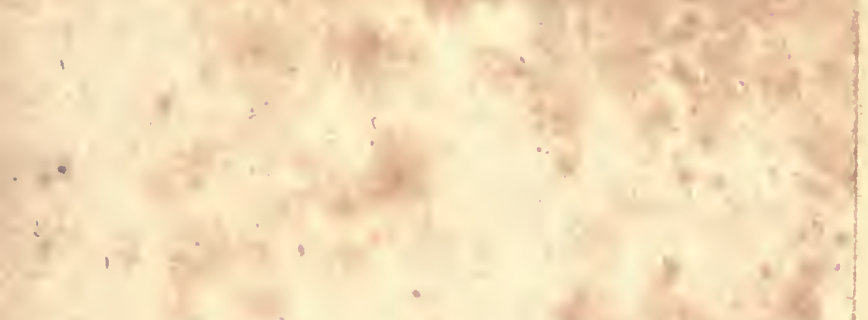

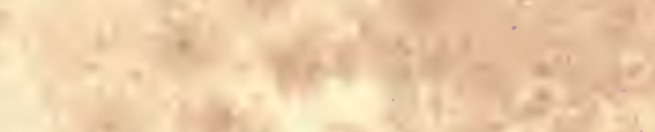

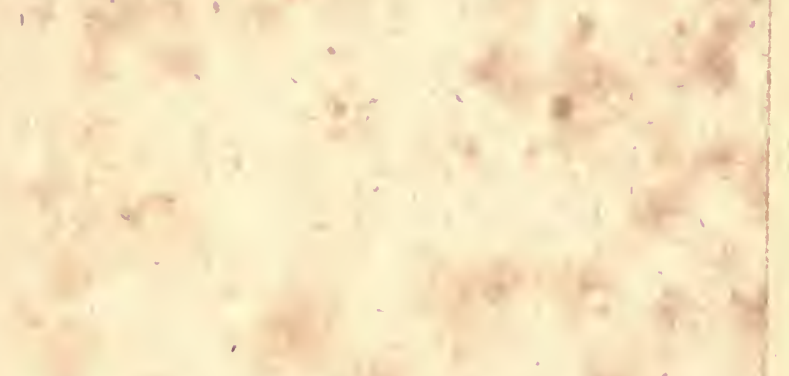
ans. 1

*.

$$
\begin{aligned}
& i+i^{2}
\end{aligned}
$$

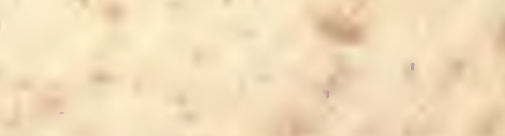

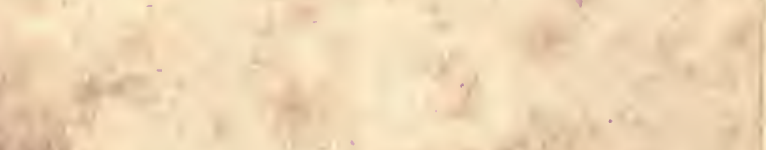

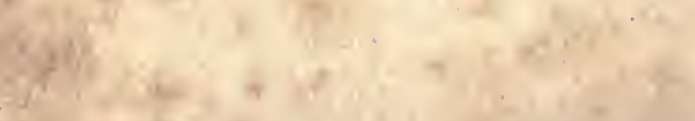


$12 \mathrm{Vac}=\mathrm{kh}$

Whist thendidy

G harimee

hointic 



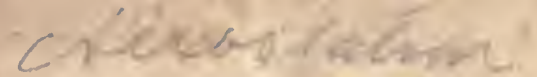

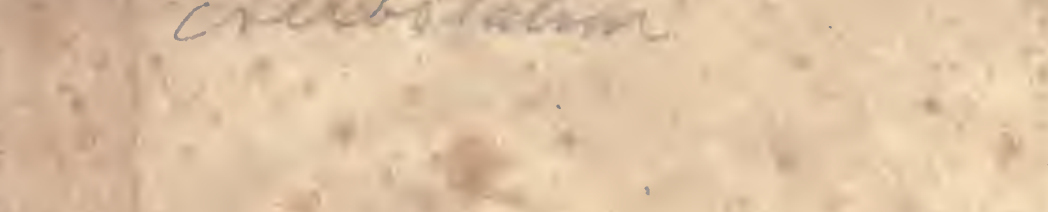

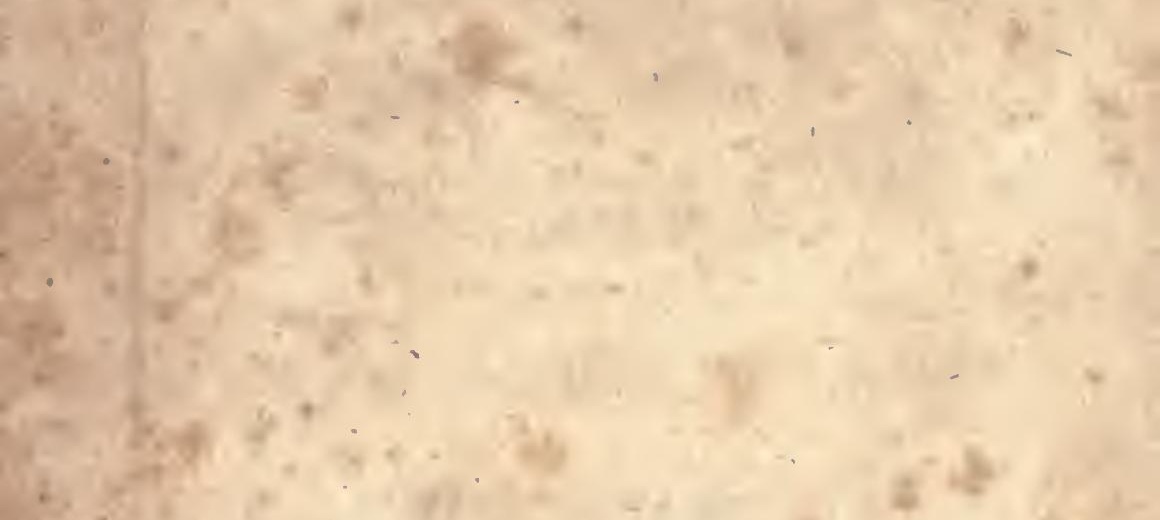

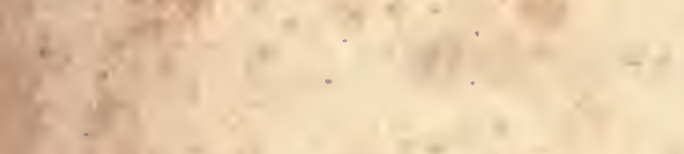

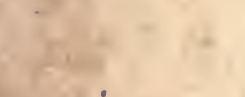

$(-7)=$

$37 y^{3}$

$$
4+2
$$$$
\text { y }
$$
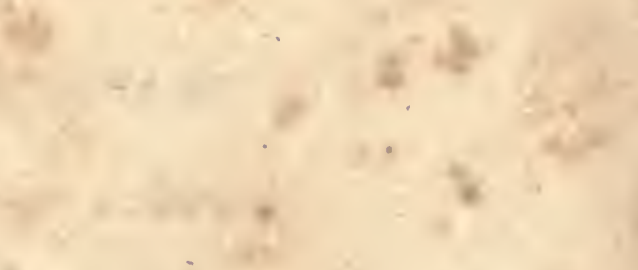

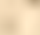

and

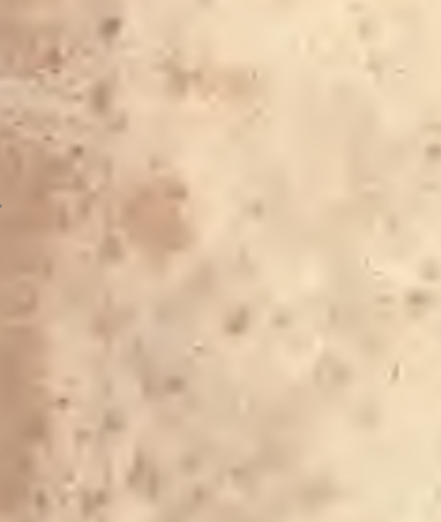

$+4$

1. 19

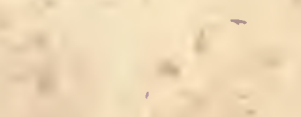

i.

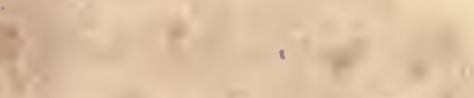

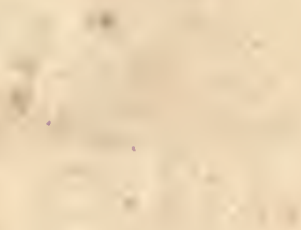

나

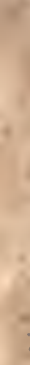

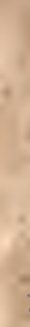

se 


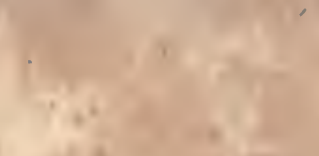

$x^{4}+5 x=20$

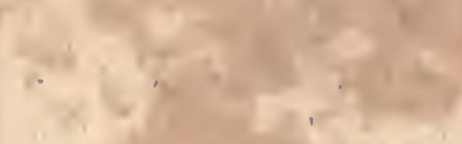

(8. $\left.+2 e^{2}\right)$

(x)

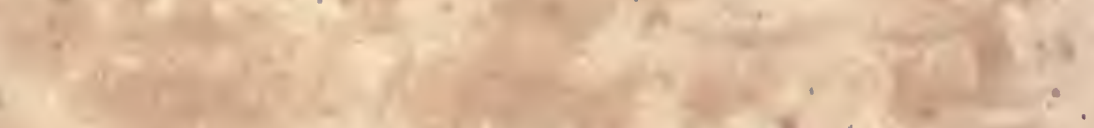
$0 \times 3$ in $3 \times 3$

x. +3

B.wing xids?

$\sqrt{2}$

$-5$

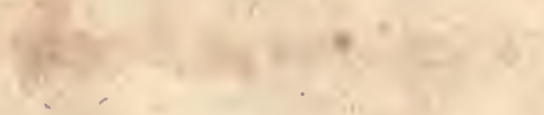

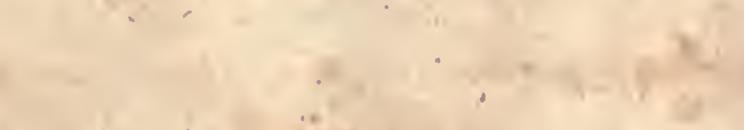

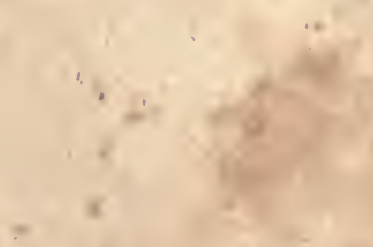

$+4$

a

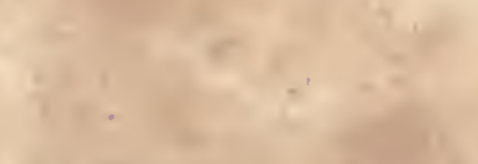

IV

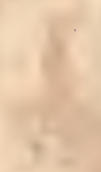

$+$

13

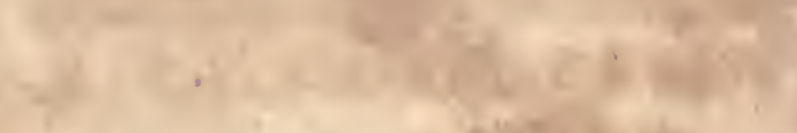

the

-

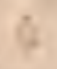




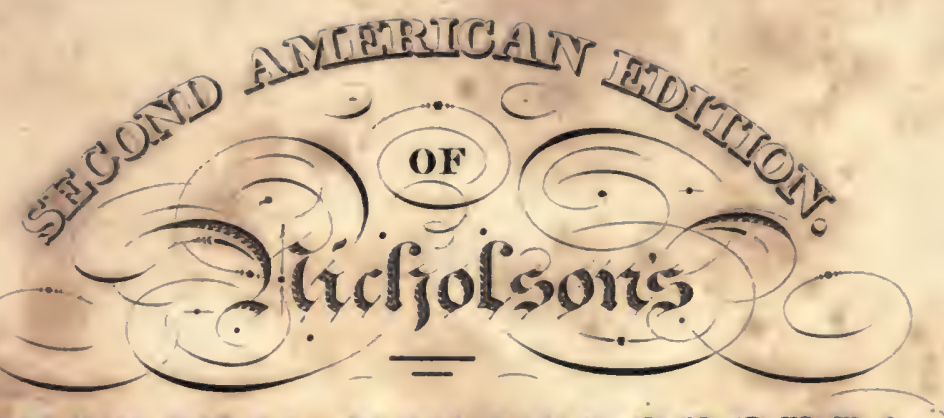

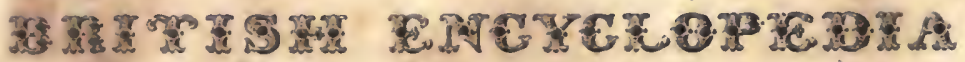

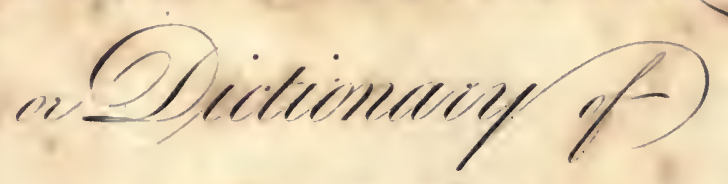

\title{
AR'T S SCWWNCES
}

illustrated 15y upwards of 180 elegant Engravings.

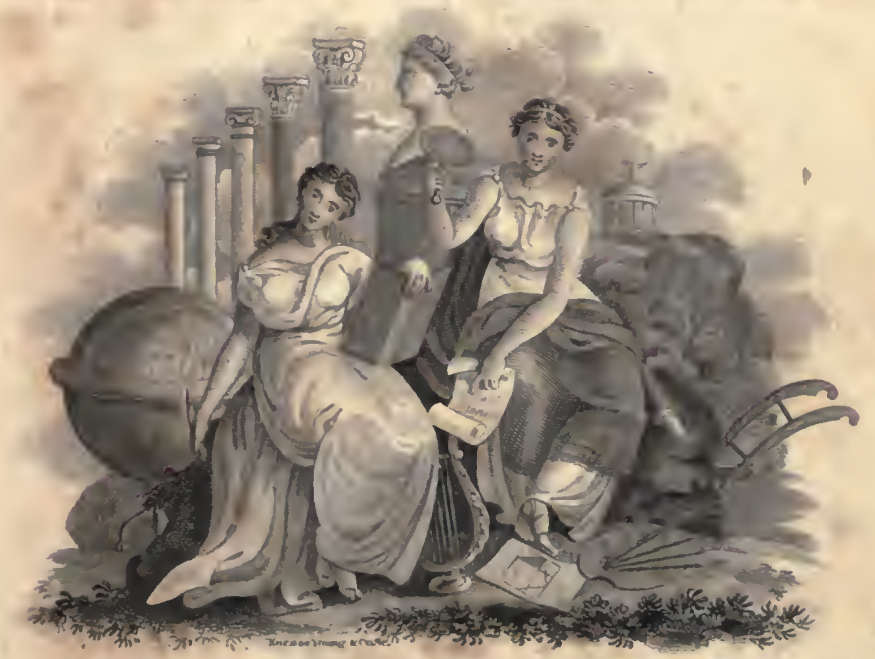

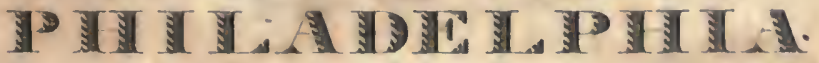

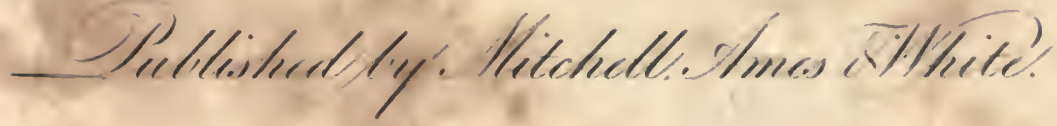

\author{
W. Brown Printer.
}

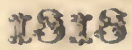


a.

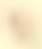

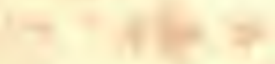

$x^{2}$

$+2$

$+2$

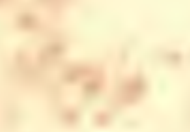

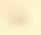

$-$

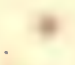

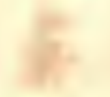

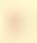

西

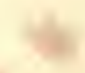

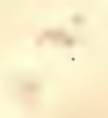

$x^{2}$

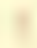

1

\section{- . e.}

1

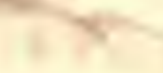

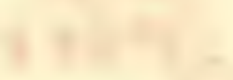

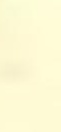


Digitized by the Internet Archive in 2007 with funding from Microsoft Corporation 
$+$
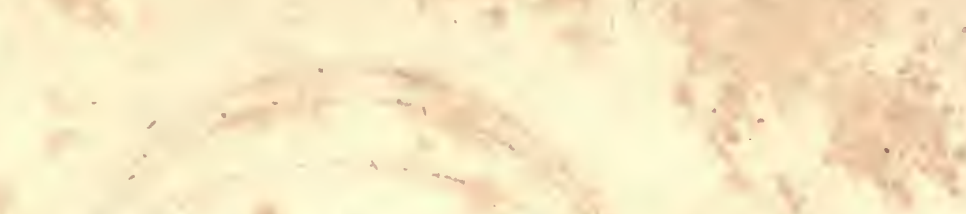

$+2$

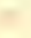

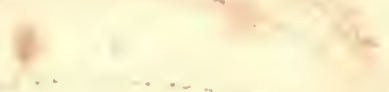

a

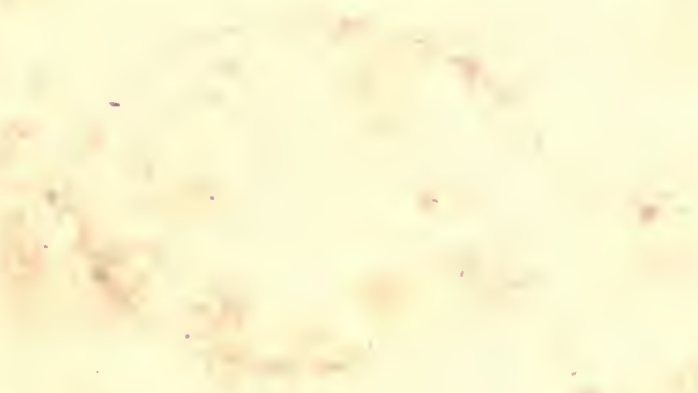

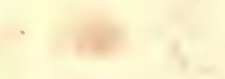

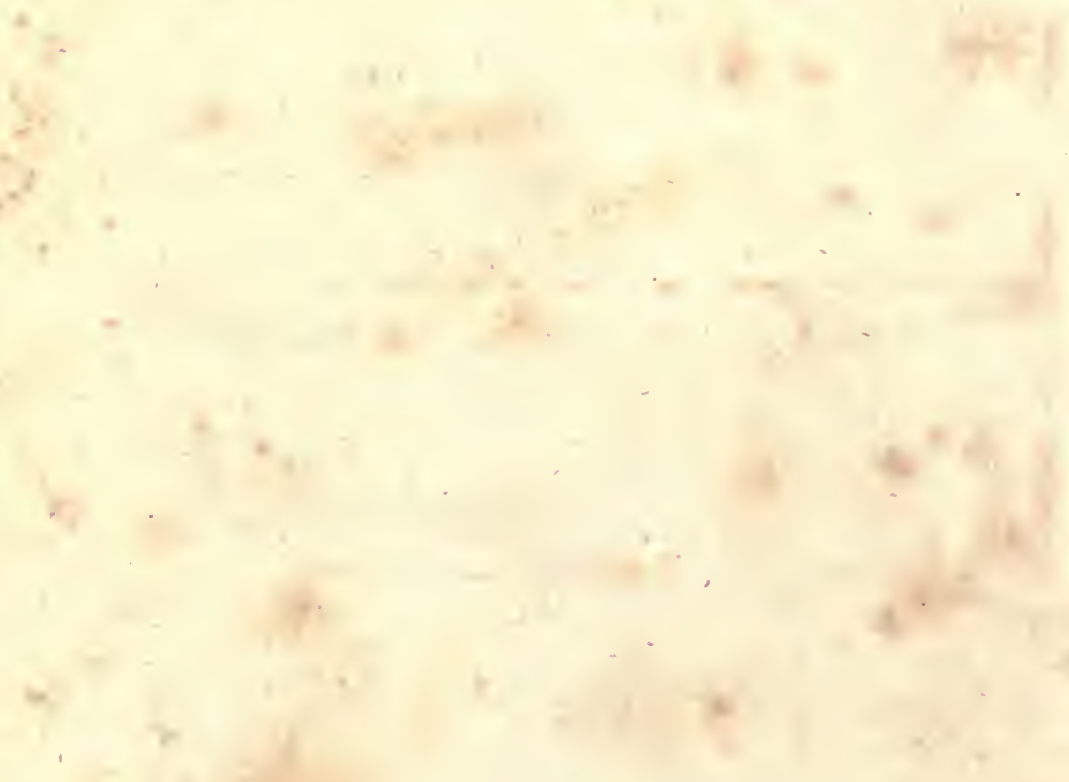




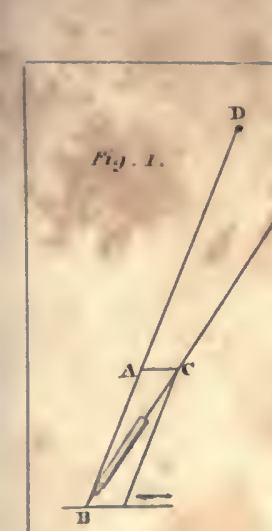

Acoustrics.

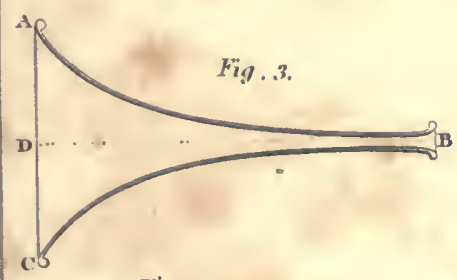

Fiij. 5.

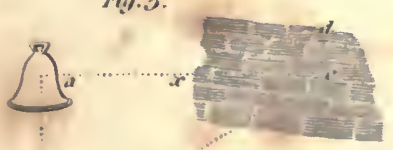

$m$
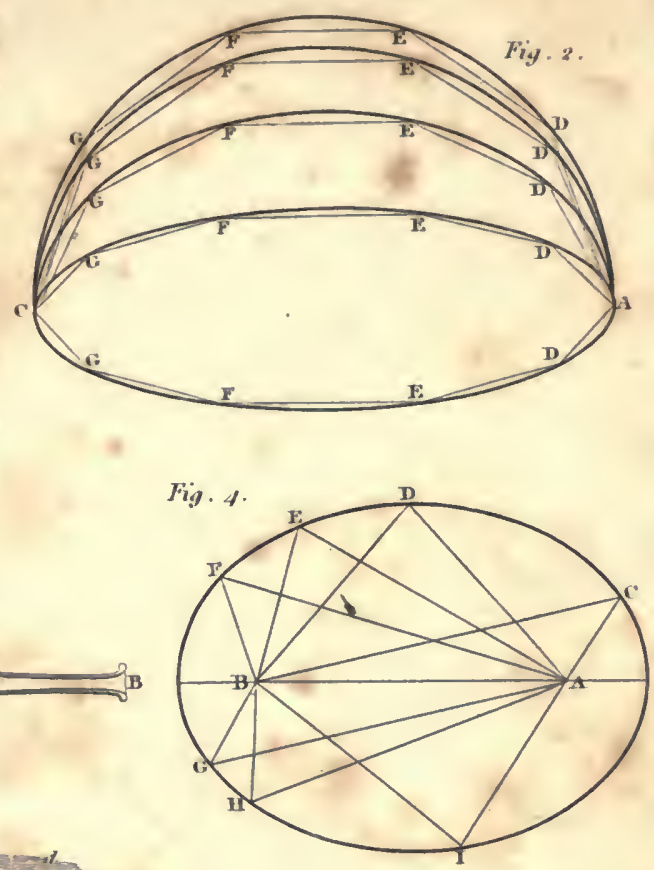

Fig. 7 .

Fiig. 6 .

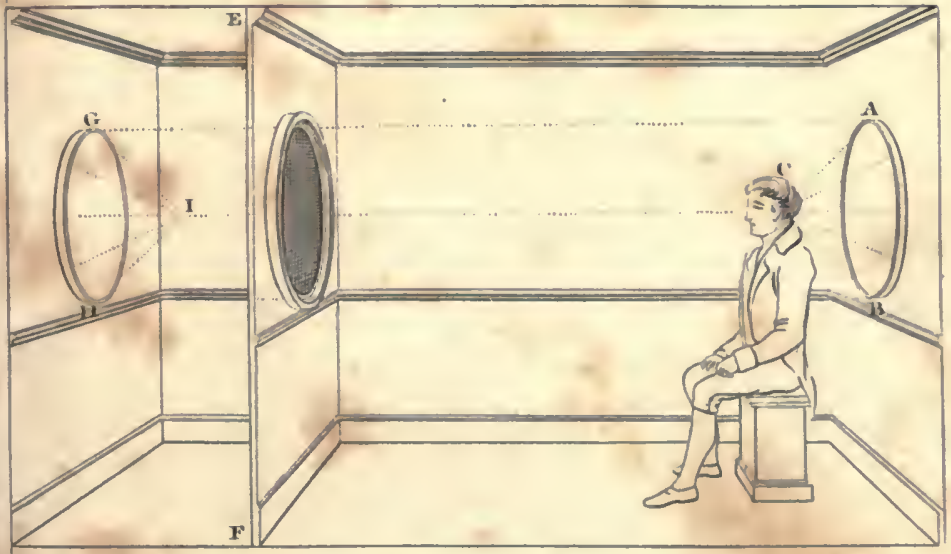




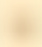

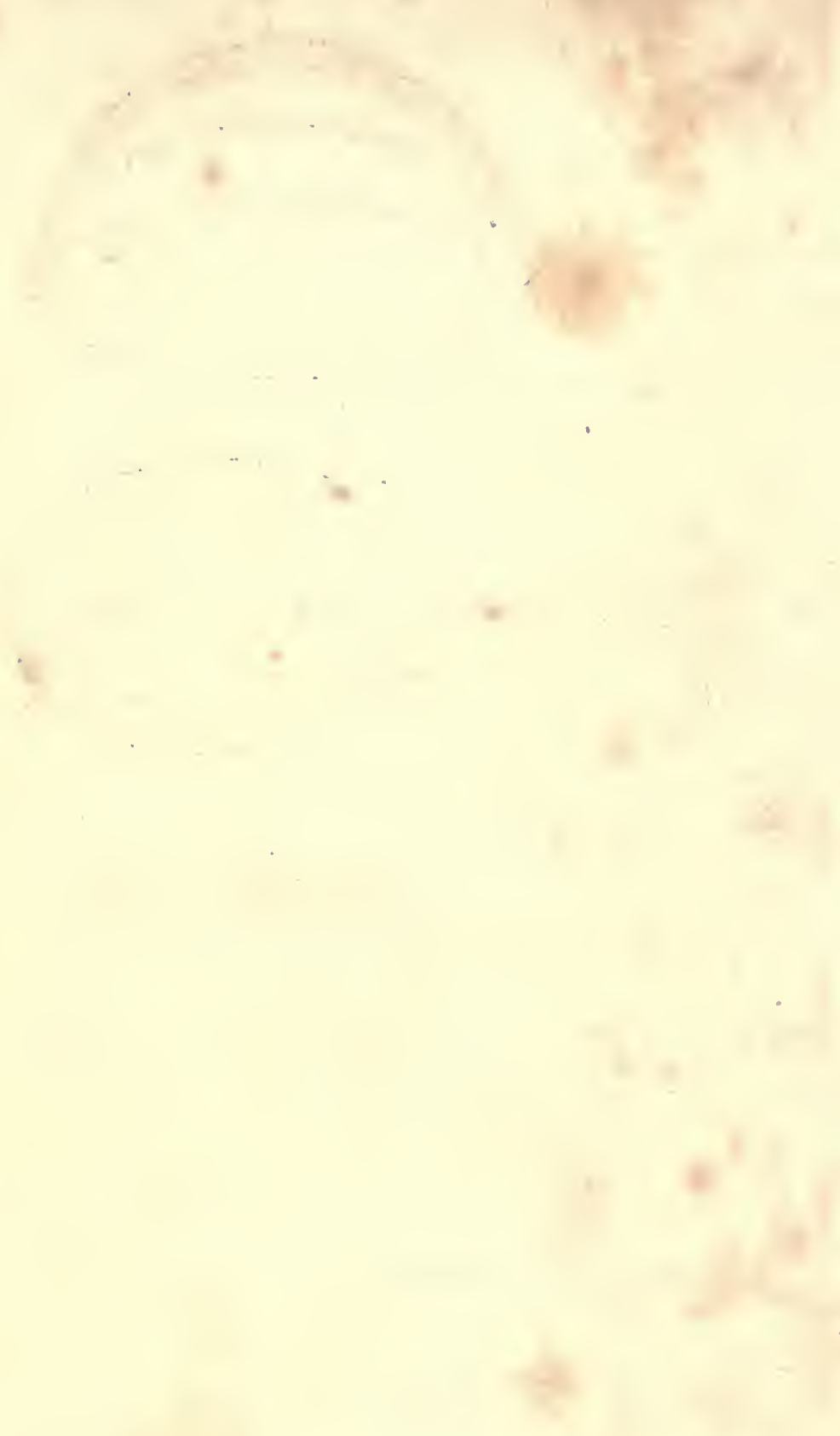





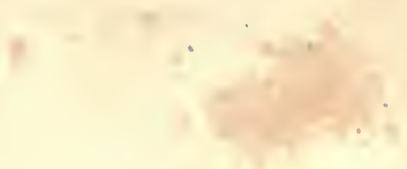

$x$ 
MERCSTATIOV.

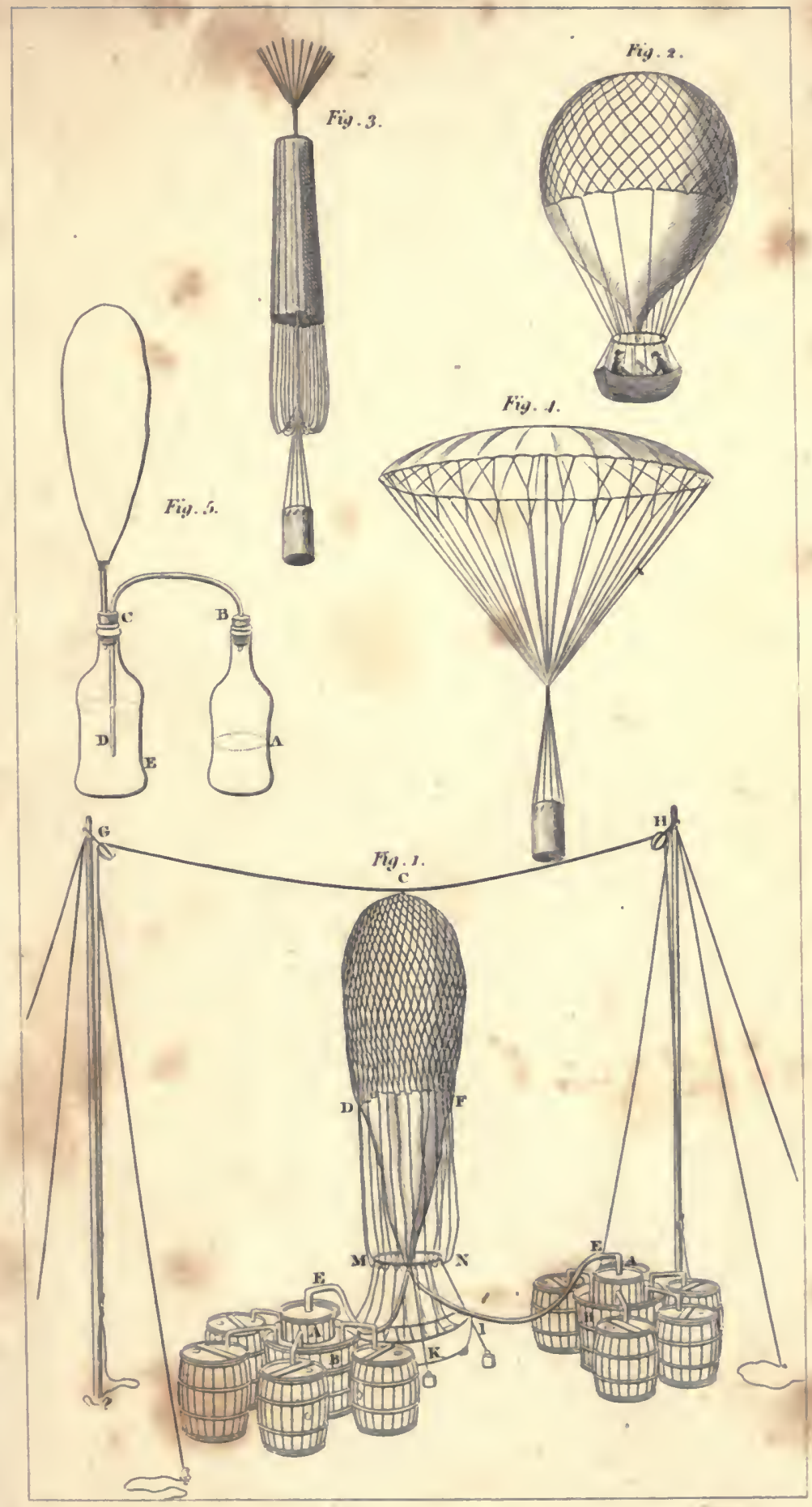




$$
\because
$$




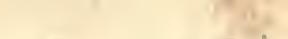

is

$+$ 
, $r$

a.

$+1$

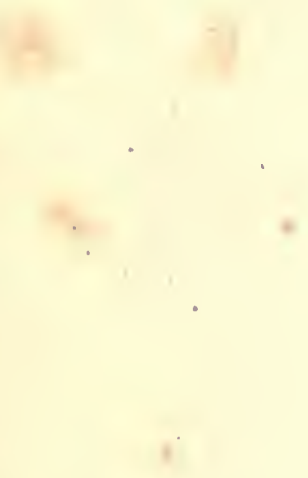

$+\infty$

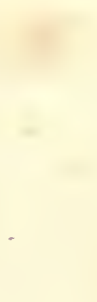


- A : ATOMY。

तथ/य 4.
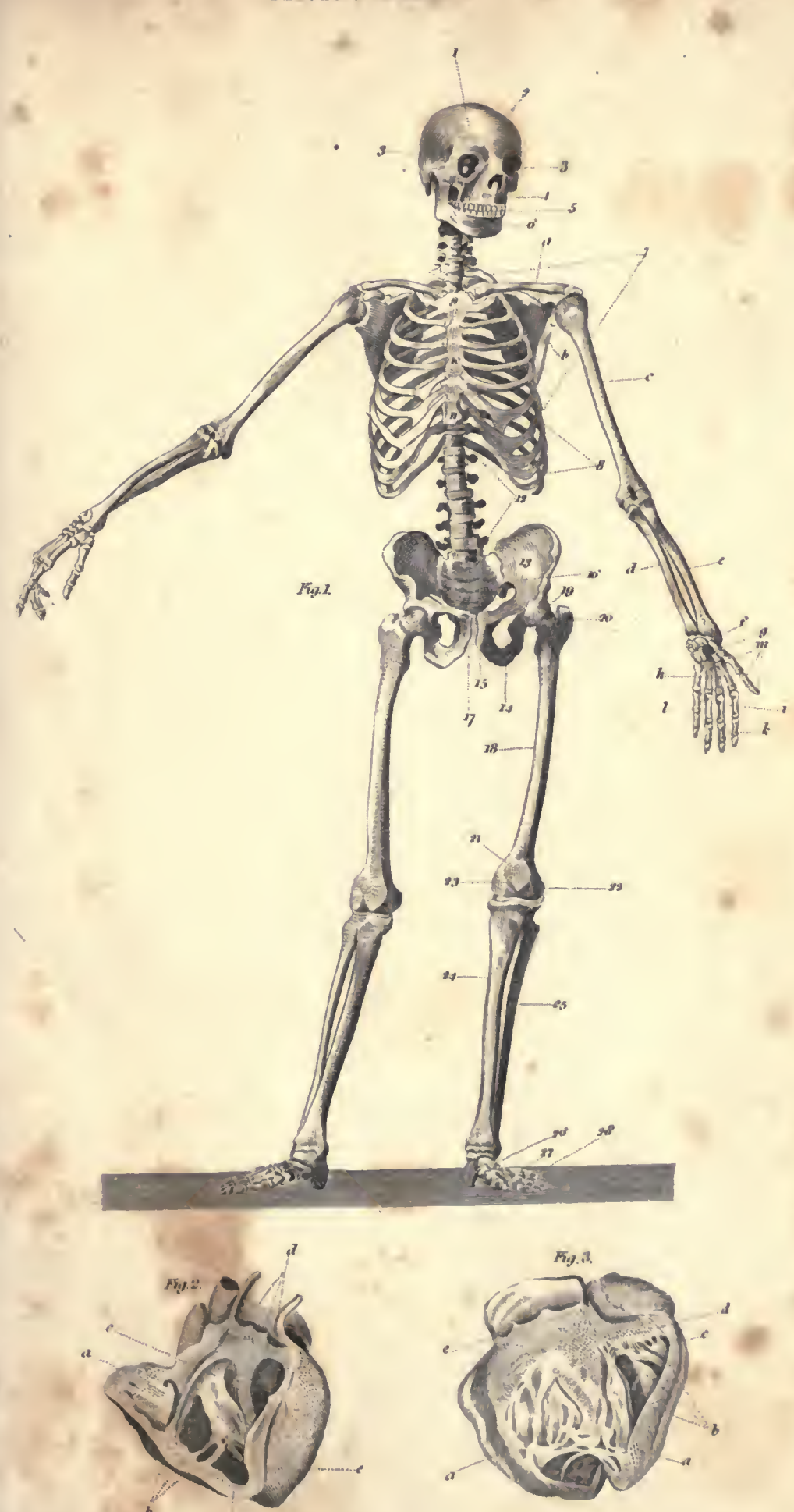

hineses se. 
.

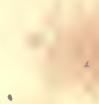

.

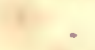

$+2$

r

-

$+1$

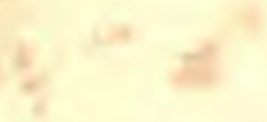

L

.

4

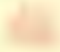




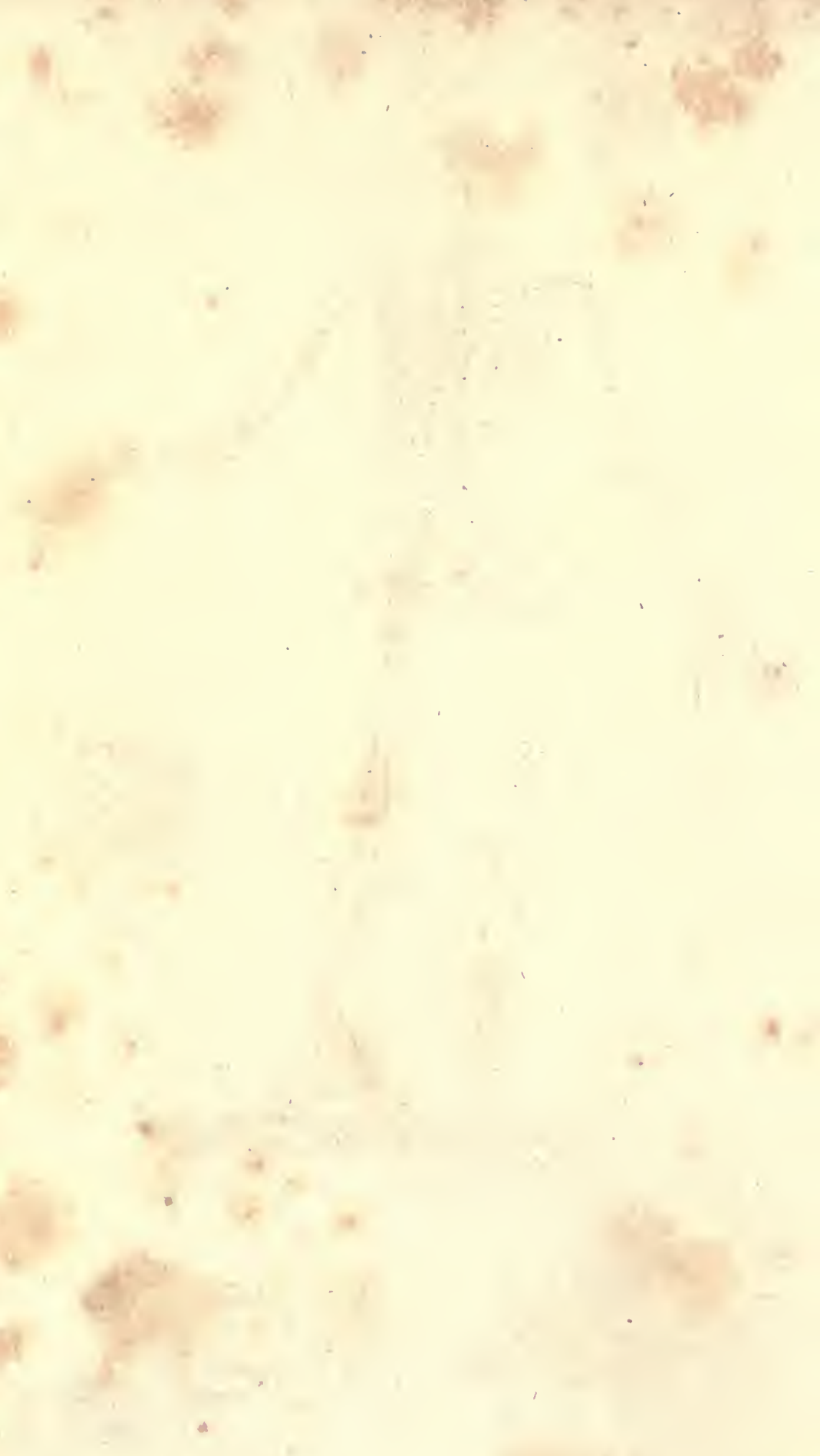




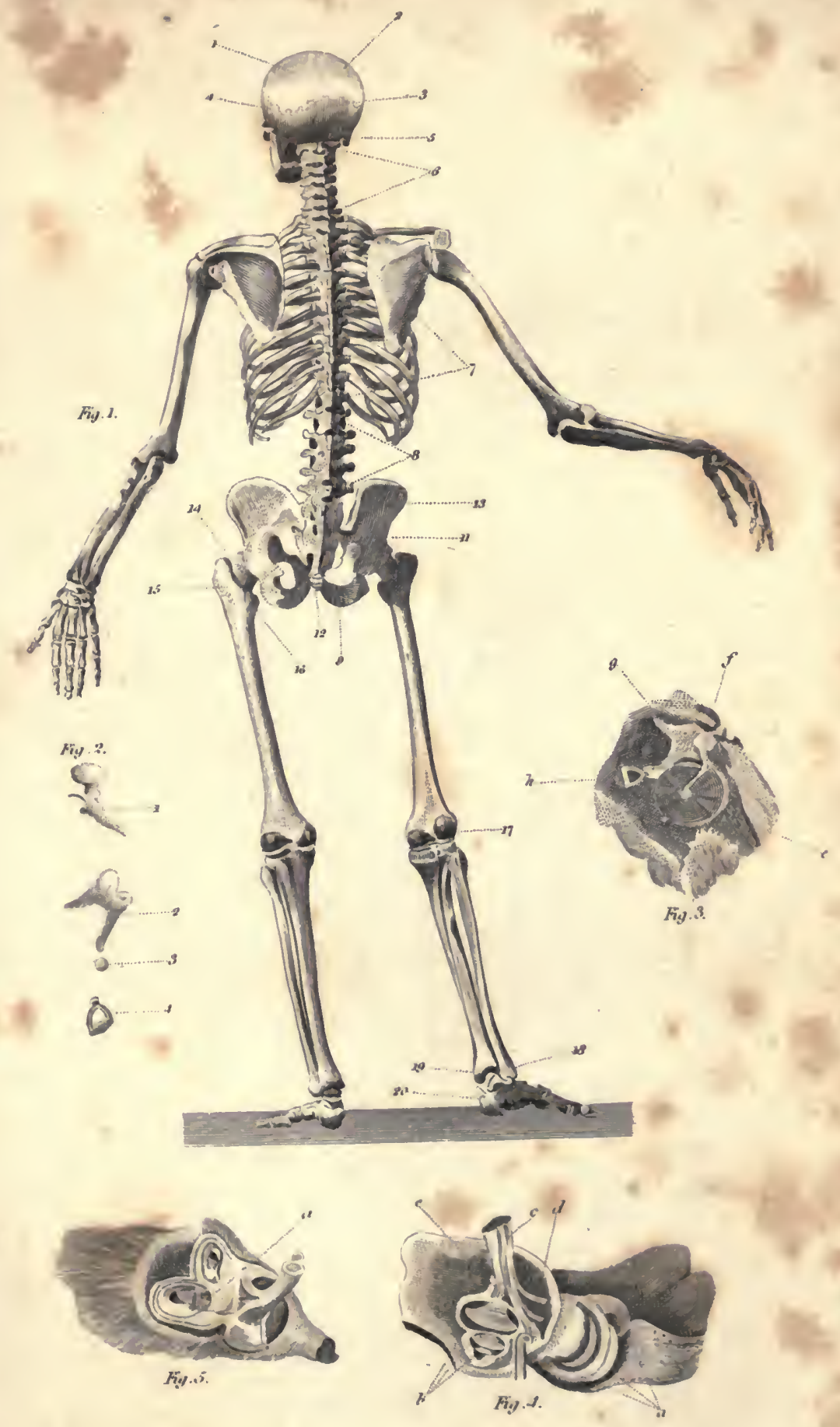




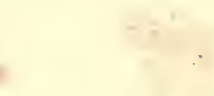

y.

12ne

$+2$

n

$$
\text { , }
$$

4.

$$
\text { . } 0
$$



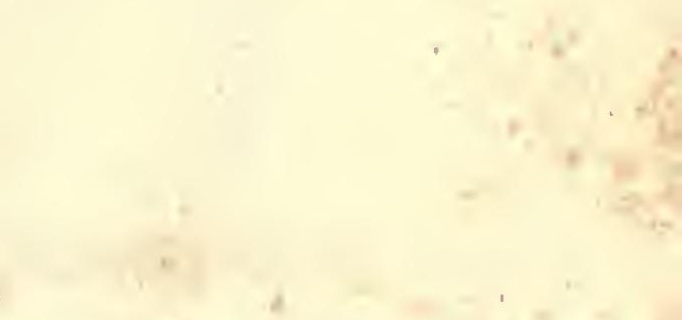

4

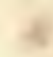

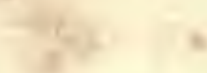

I. 
$x+2$

is

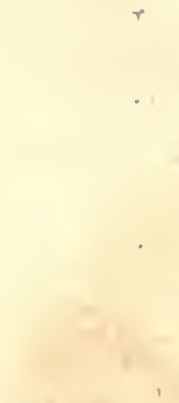

3

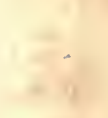

4.

$\underbrace{\infty}_{-\infty}+\infty$

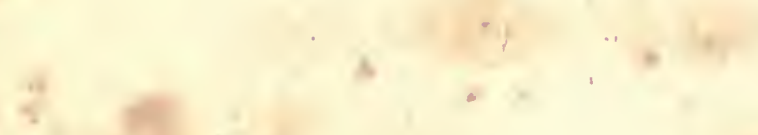

$$
\begin{aligned}
& \text { + }
\end{aligned}
$$

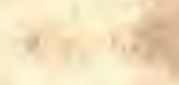

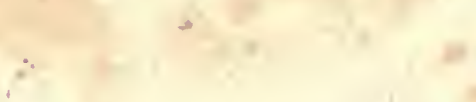

\section{a}

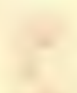

$$
\begin{aligned}
& +4+4=
\end{aligned}
$$


ANAT DNIY。

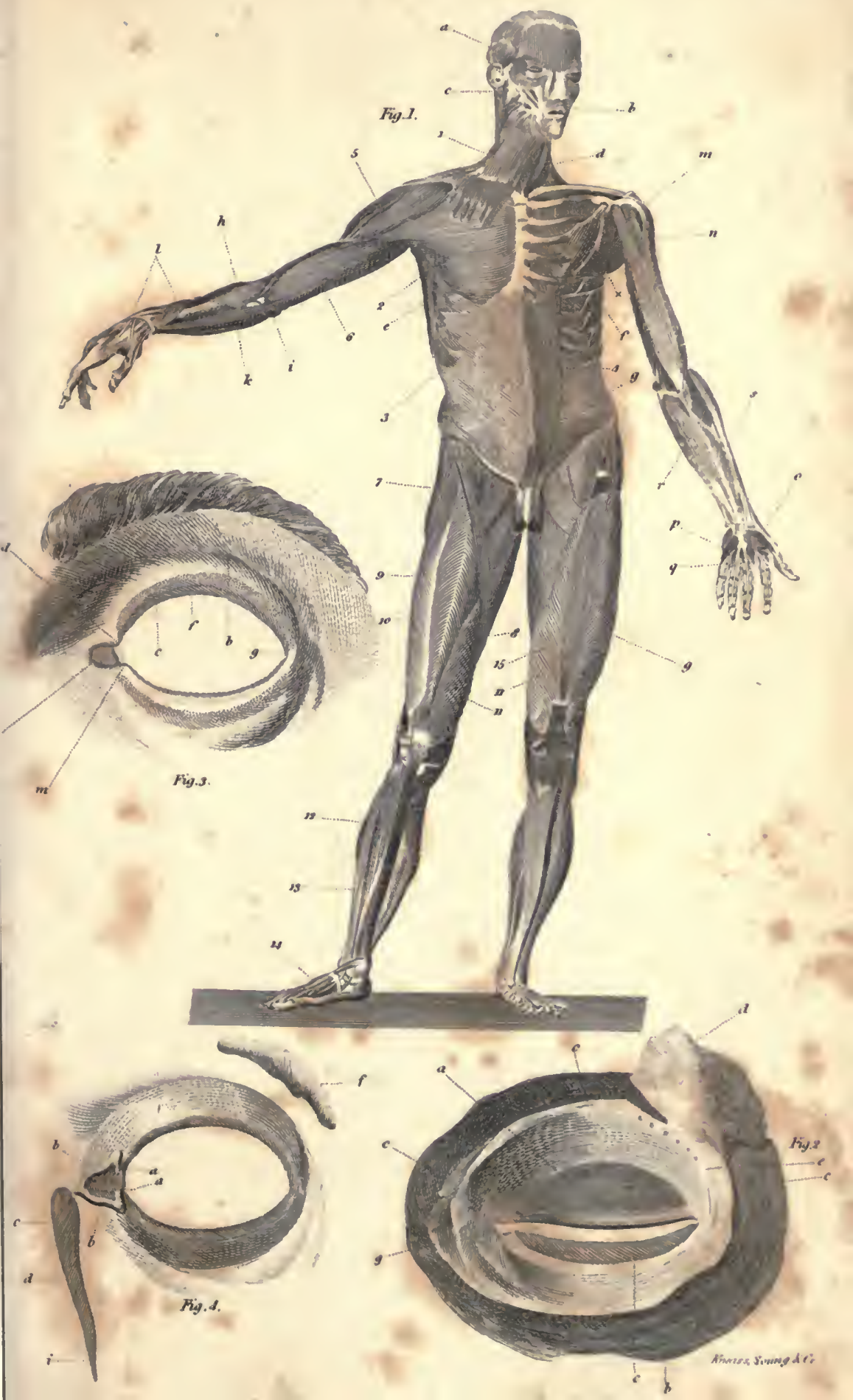




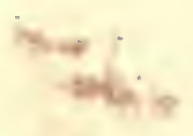

.

r
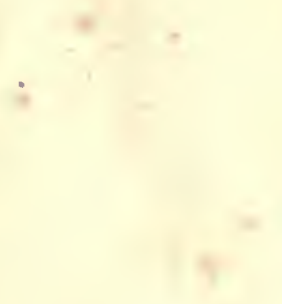

a

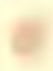

1

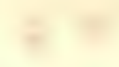

. 
$+\frac{1}{2+2}$
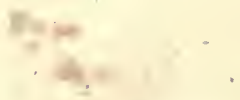

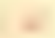

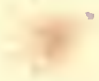

4

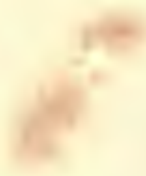

$$
\frac{1}{1}+2
$$

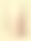

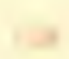

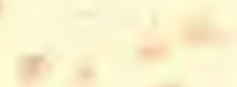

$$
\begin{aligned}
& +4
\end{aligned}
$$

$\cdot \dot{0}$$$
+1+2=0
$$

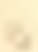

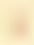

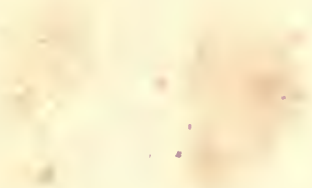



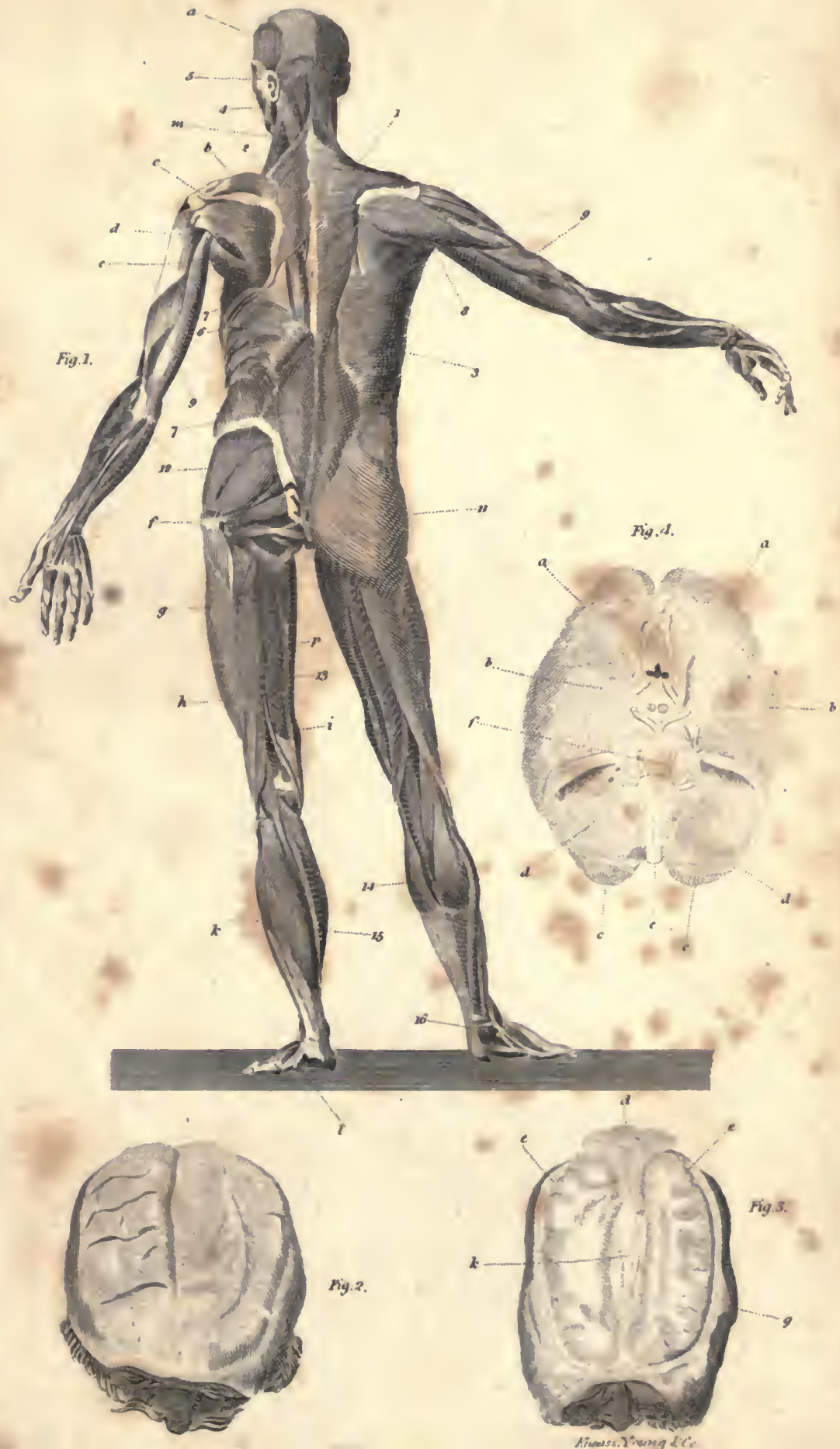


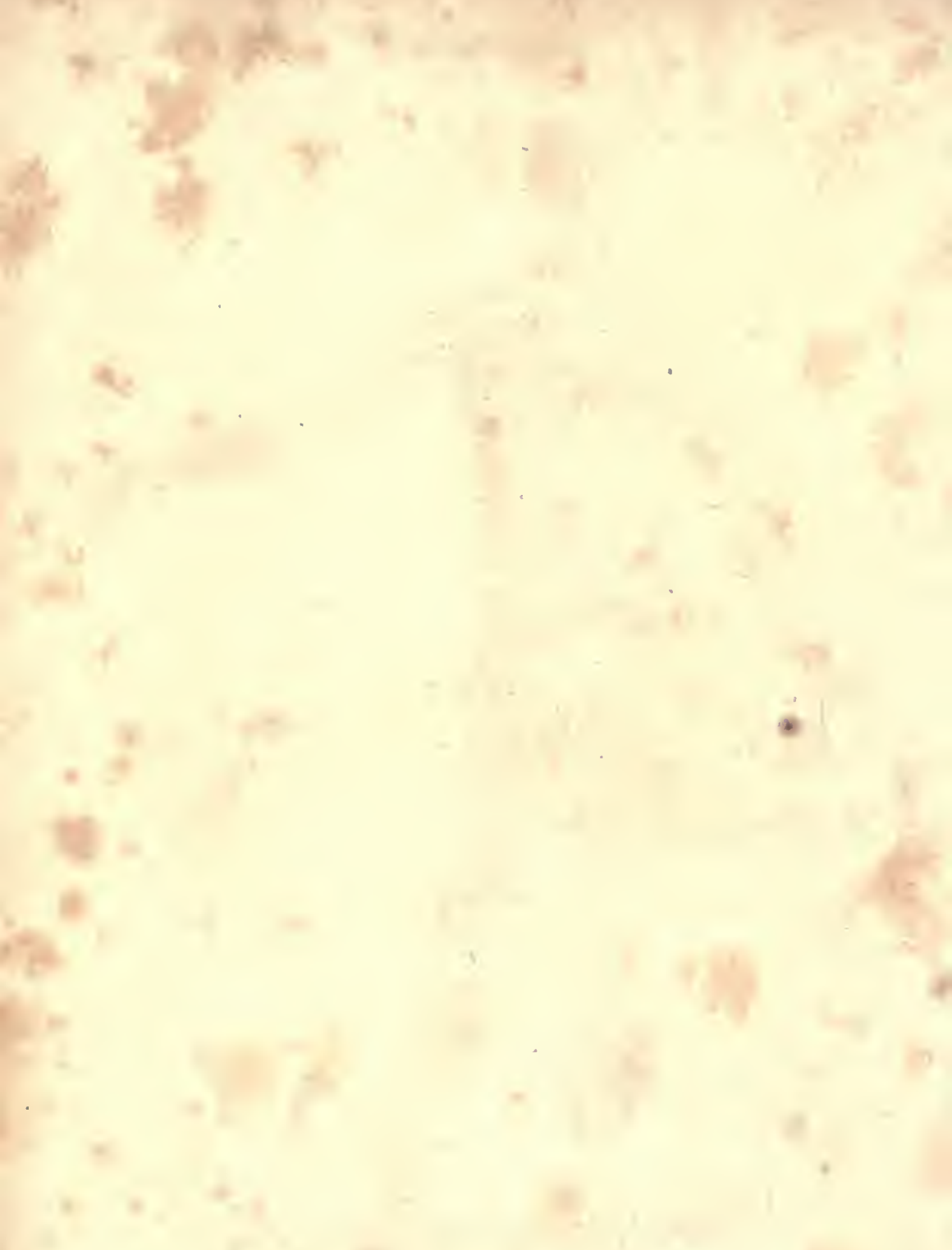




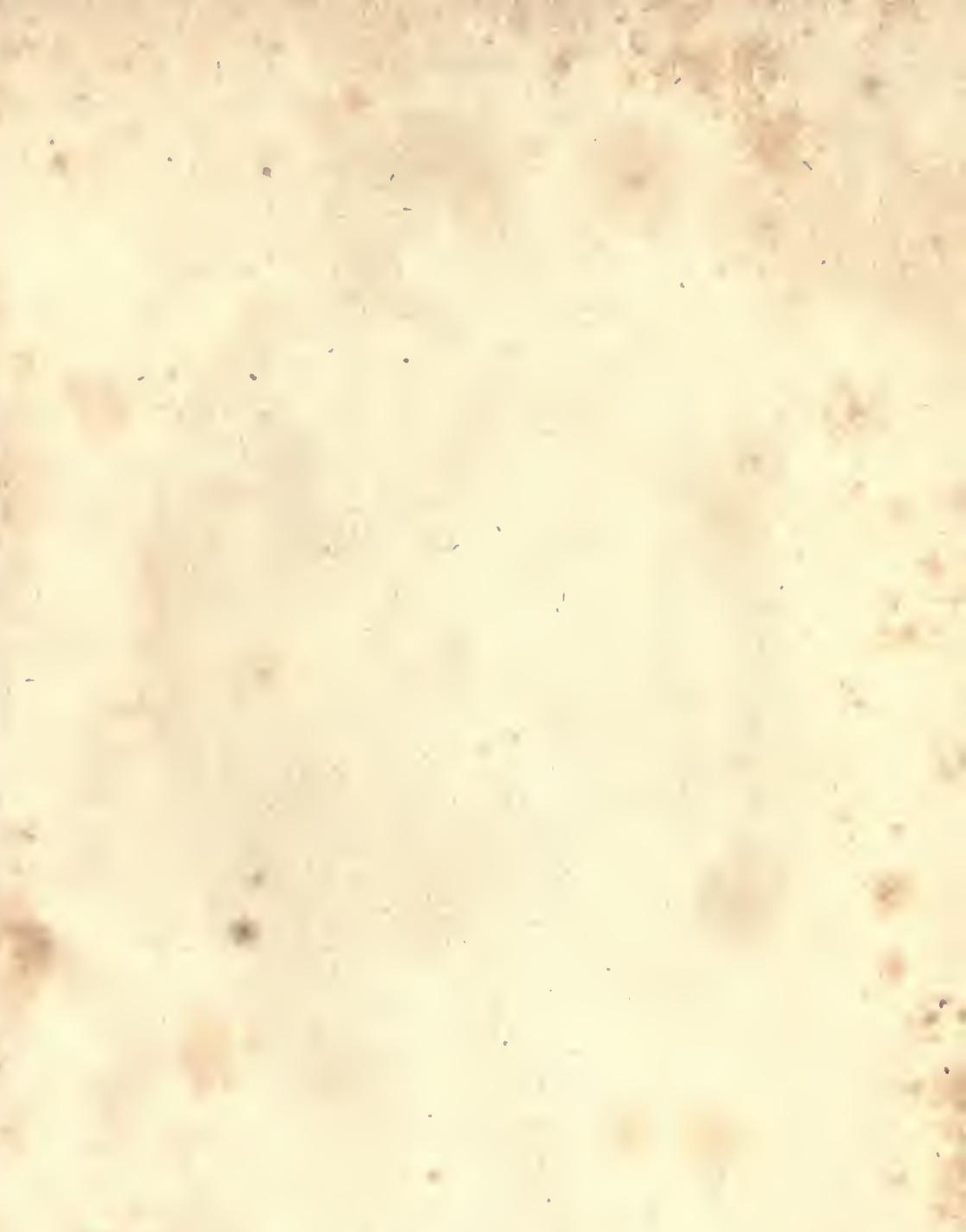

= 


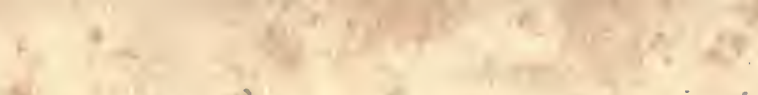

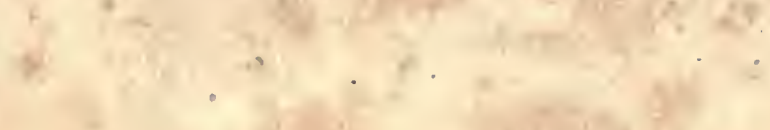

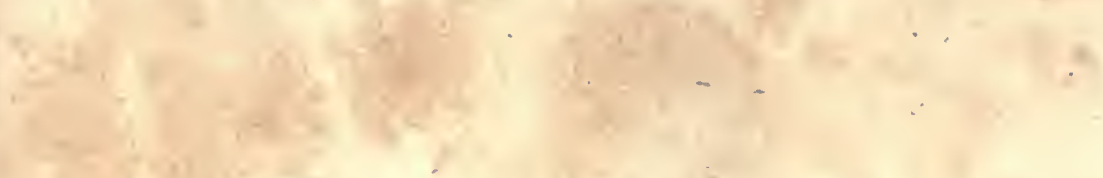

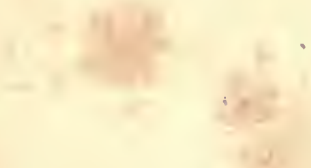

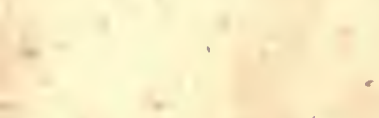

$4+4$

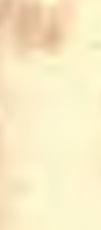

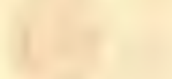

- 7r

4

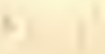

7 





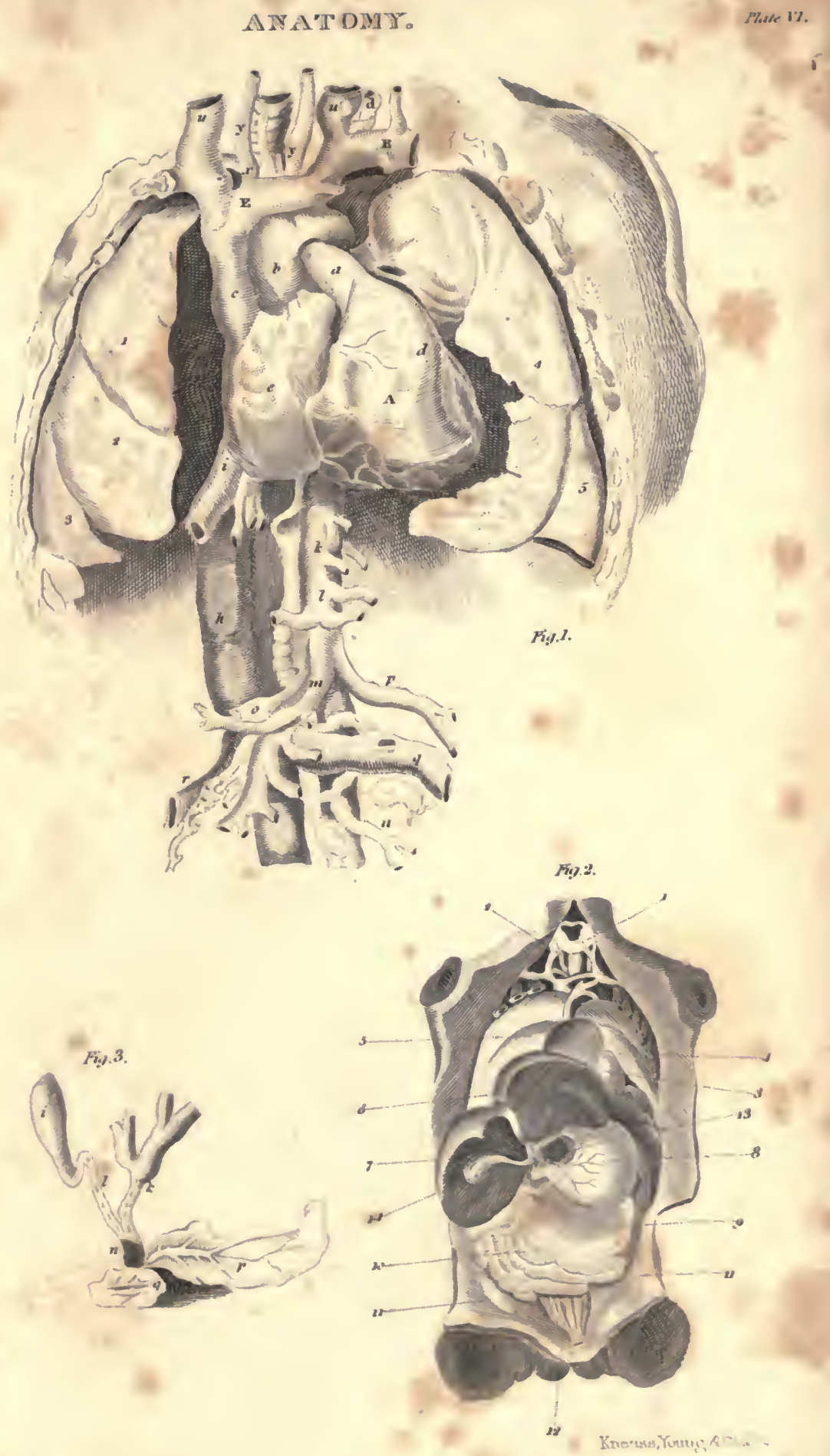




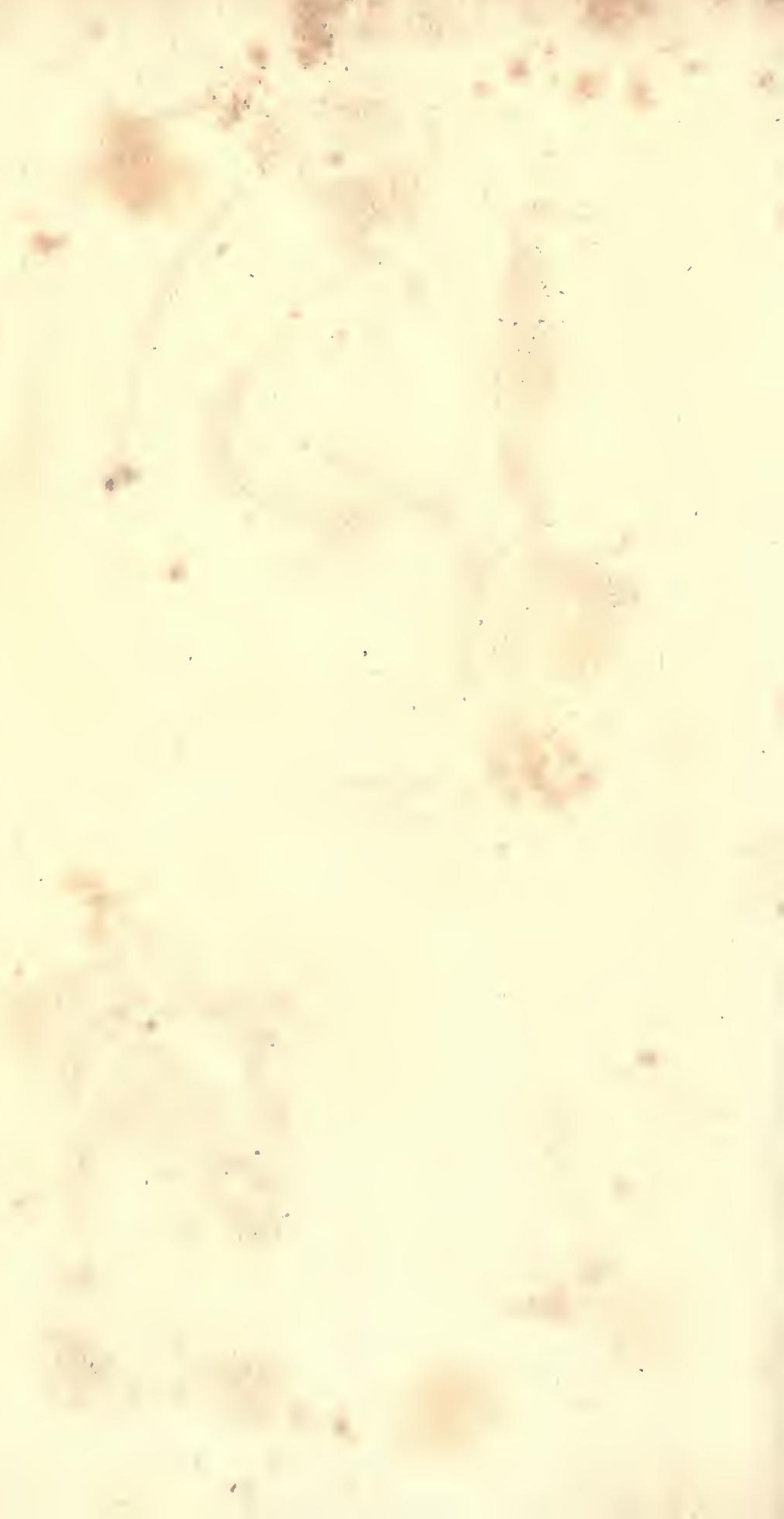




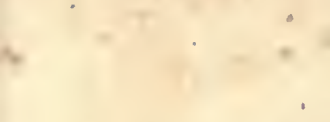
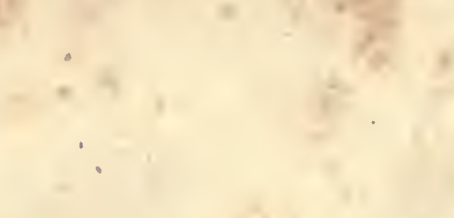

$+=$

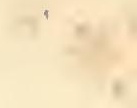

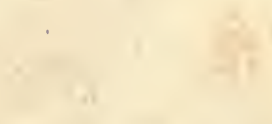




\section{.}
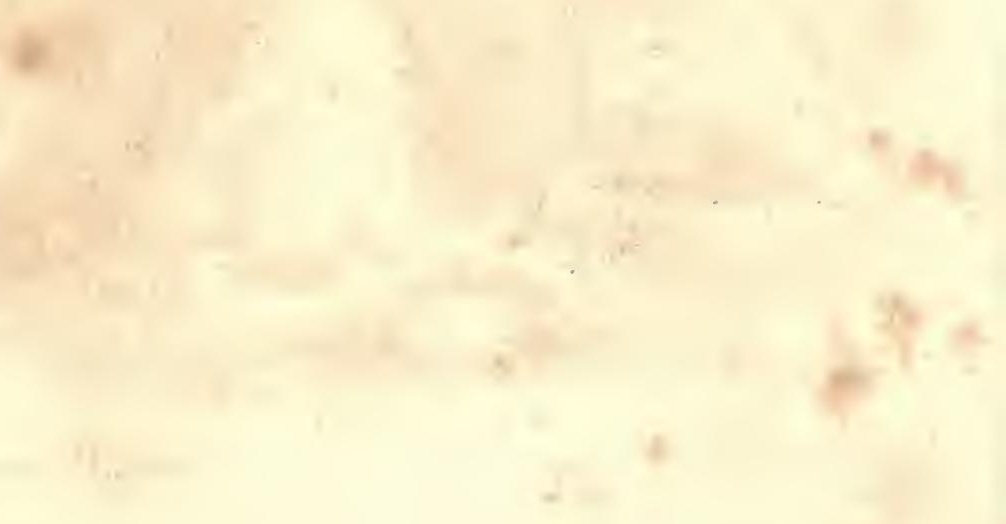

I. 


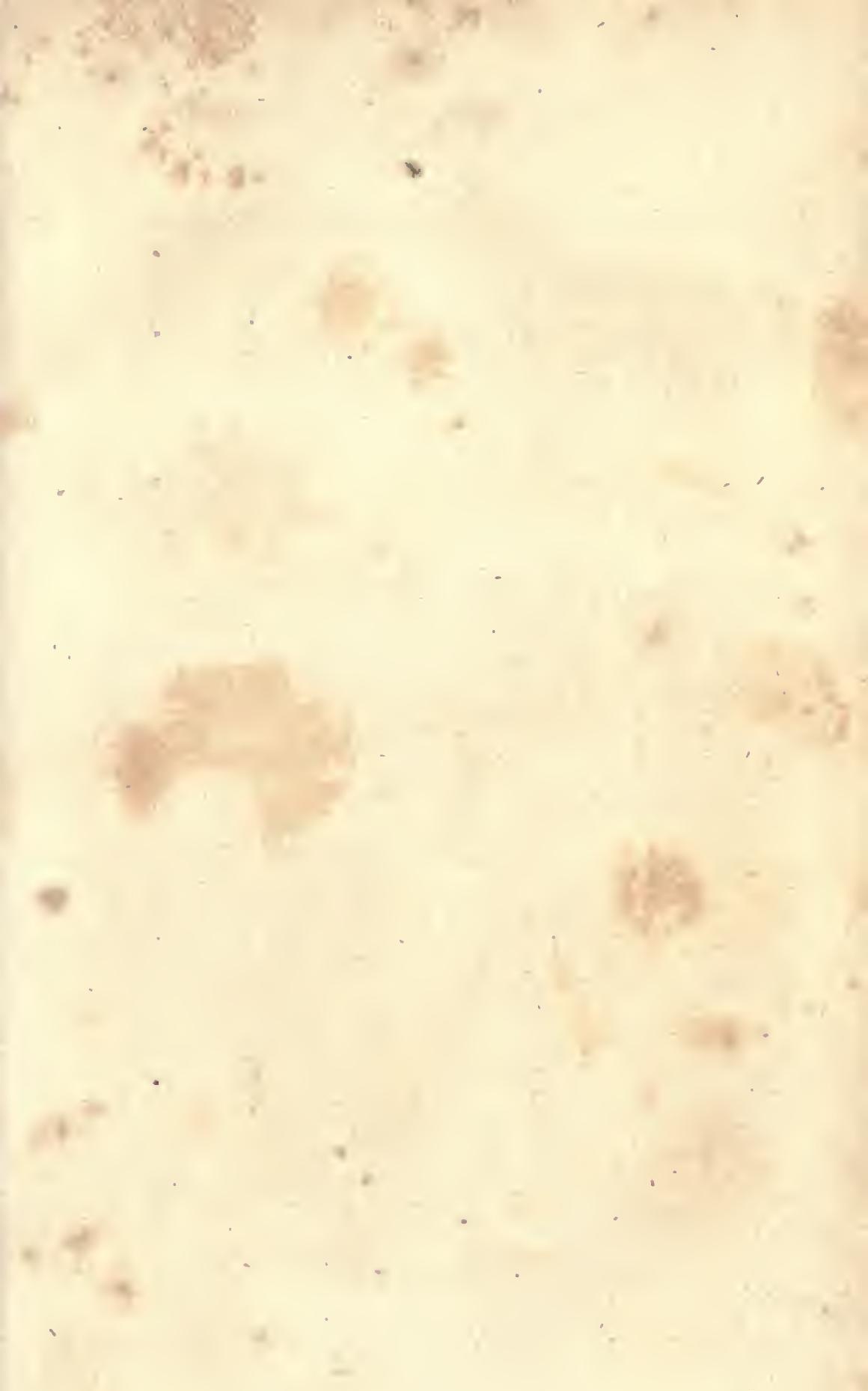




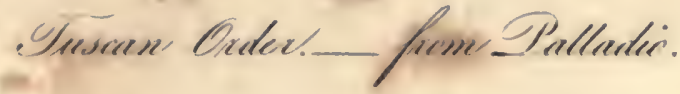
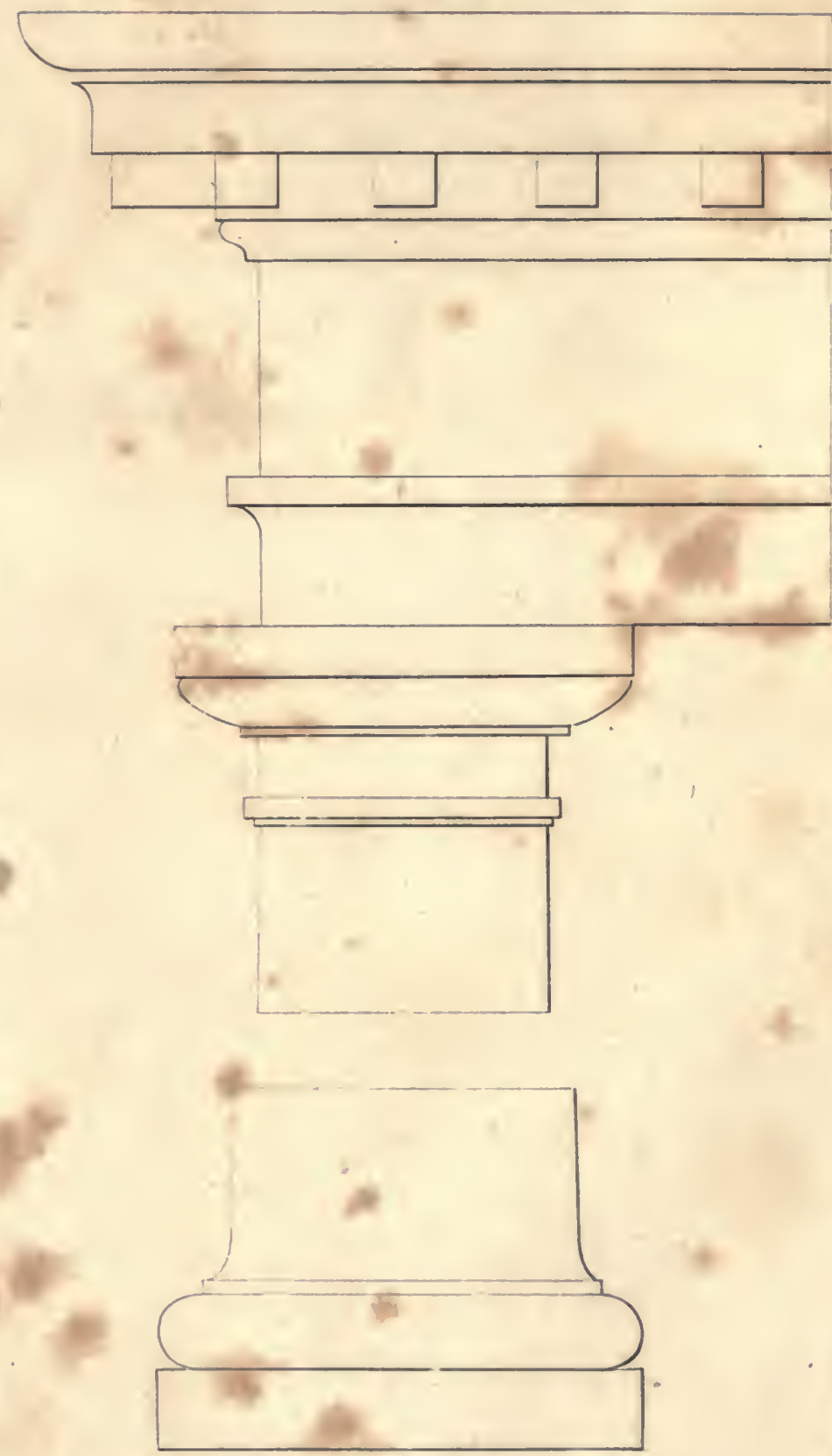


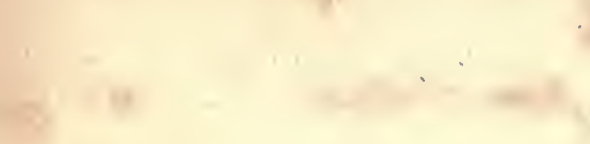

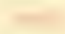

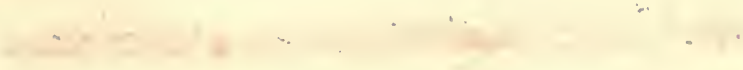

$x+20$

$\cdot$

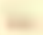

$-$
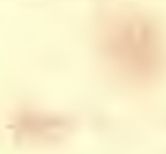

(1)
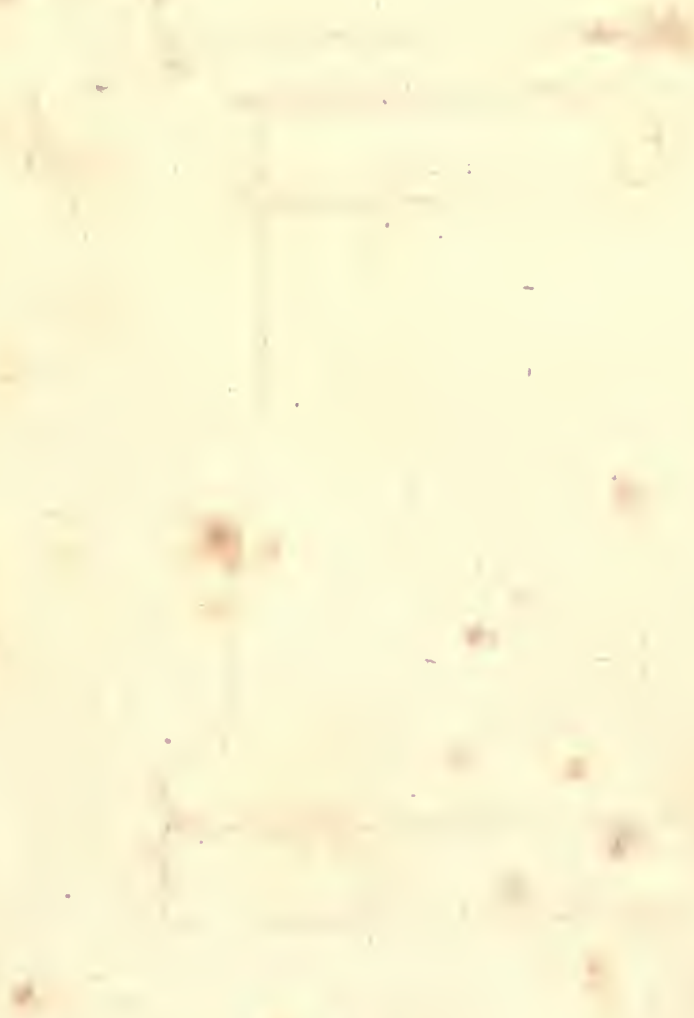

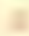


$8+4$

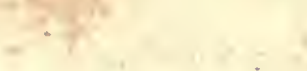

$\therefore-\frac{1}{2} \geq x$

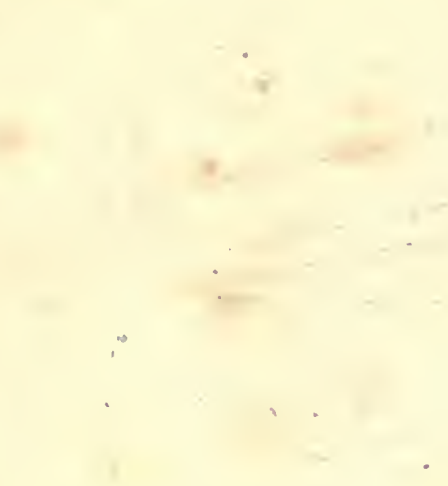

$1+2-$ 


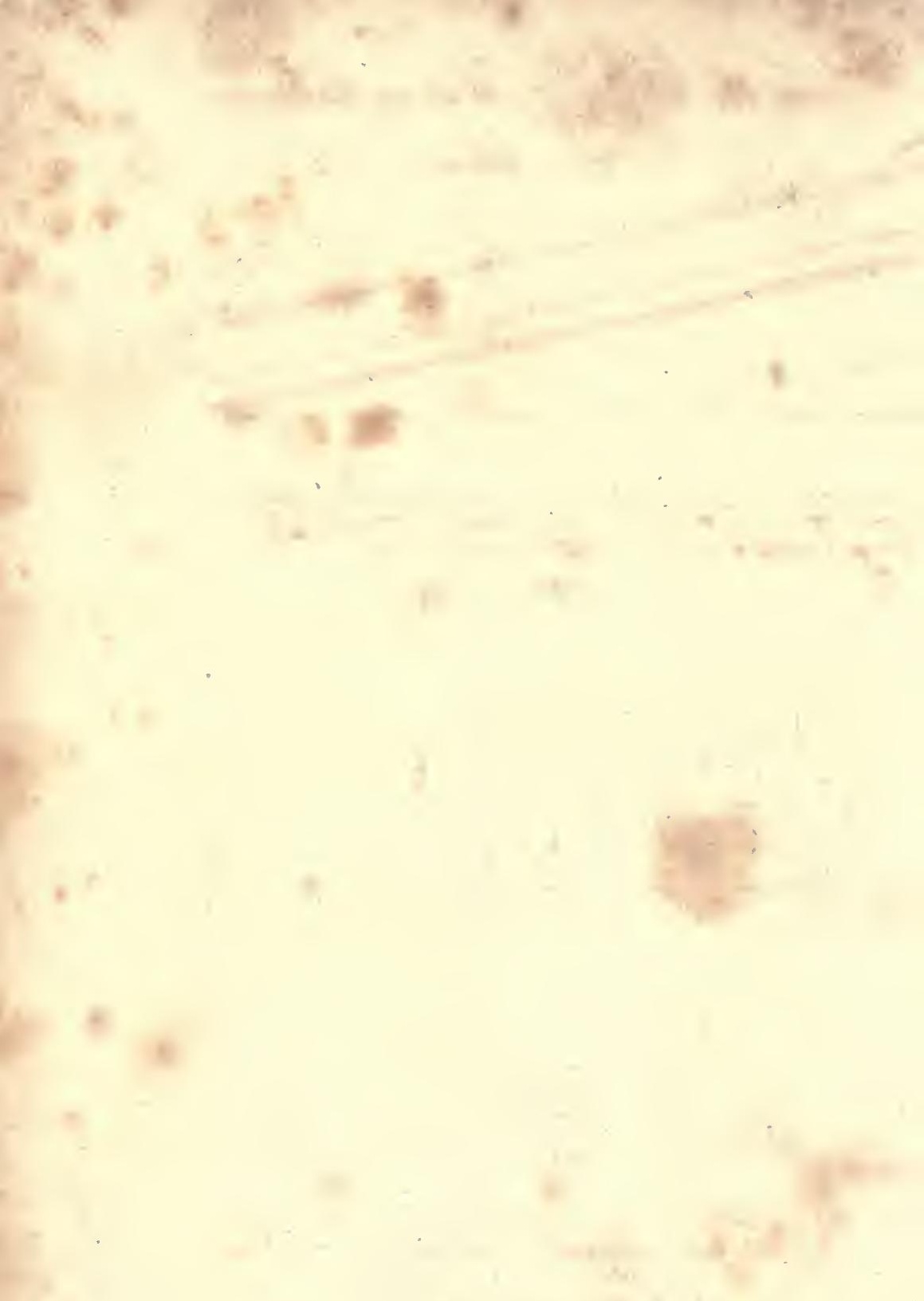


y

.12

$T$ 


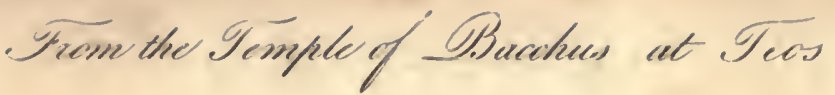
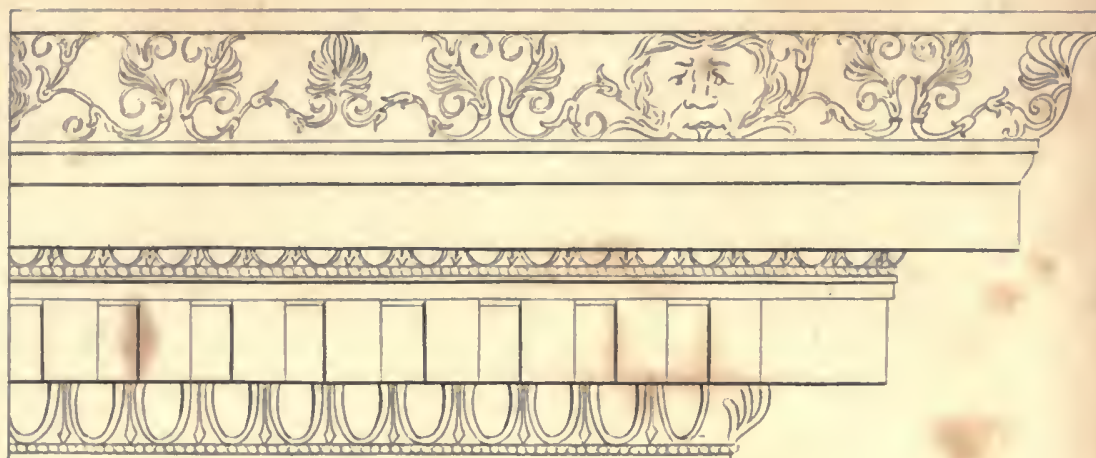

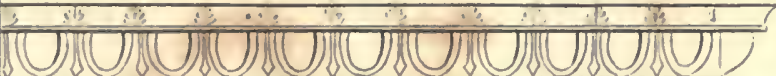

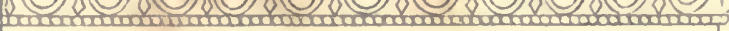

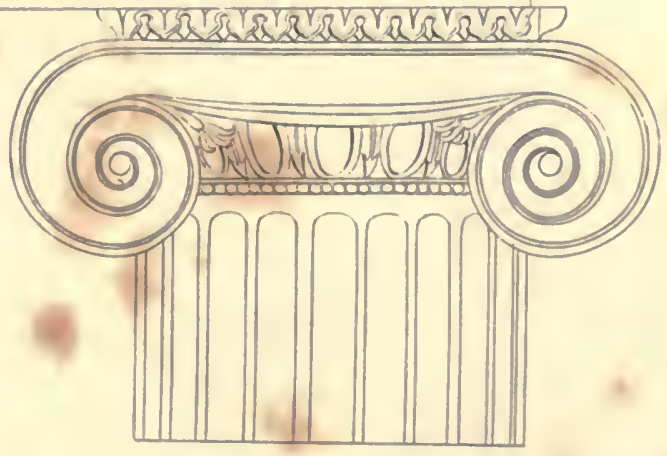

Thas de. 
- 


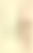
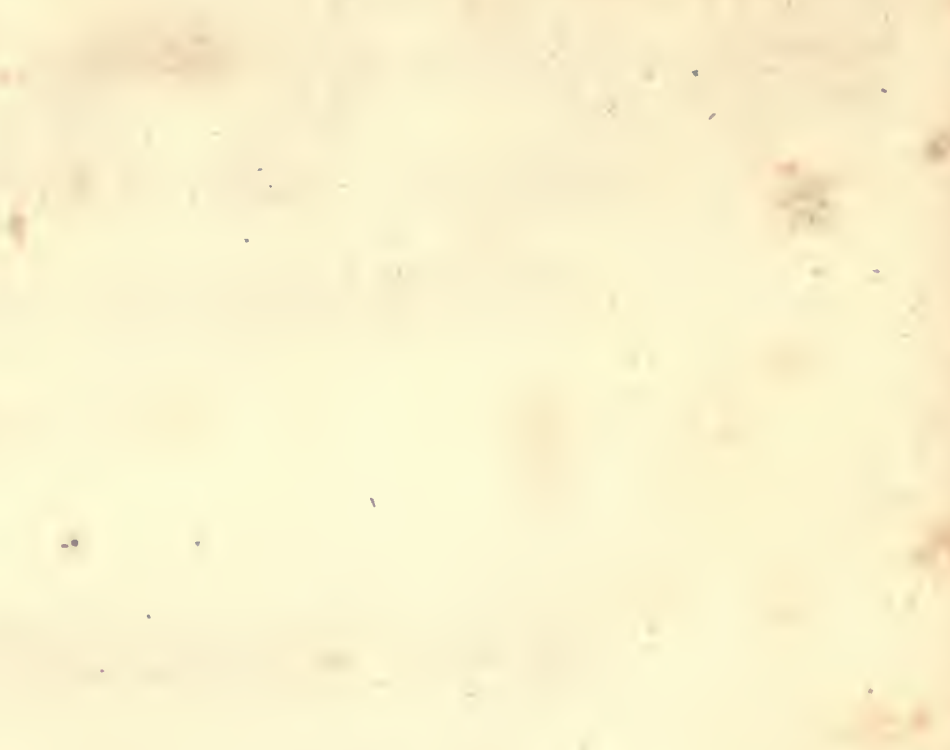

1

(2) 


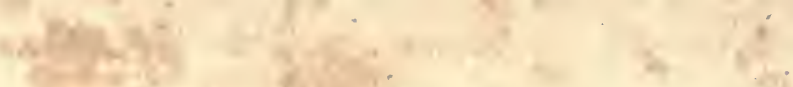

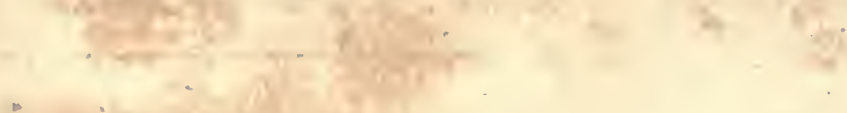

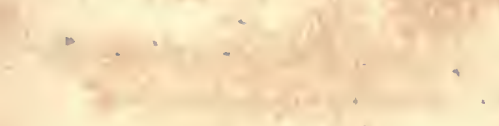

*.1

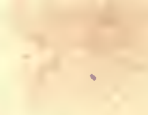

$\cdot x^{2}+2+2=$
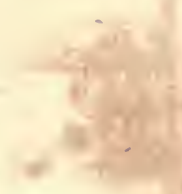

$\because$
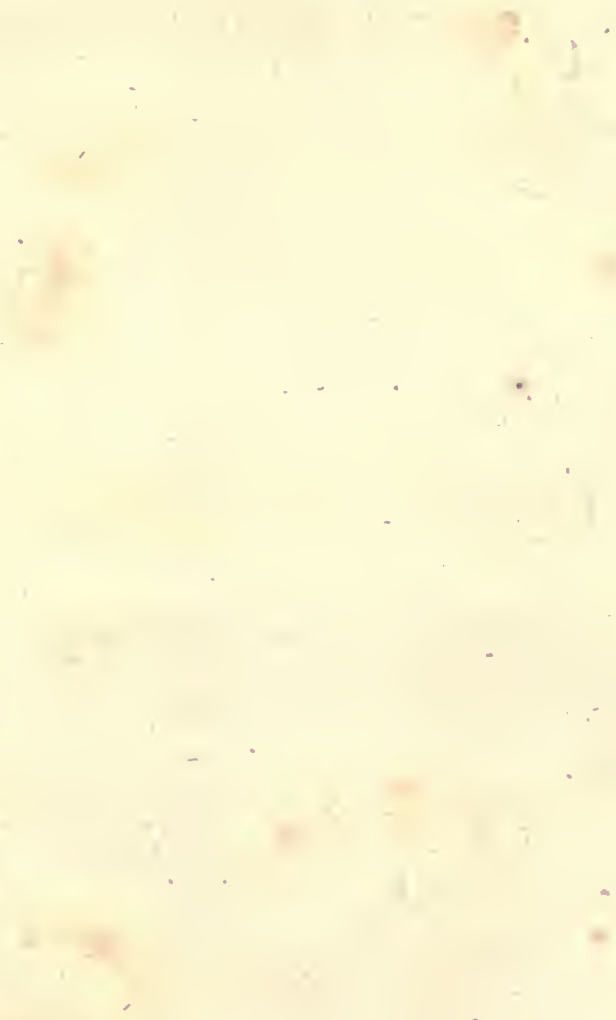


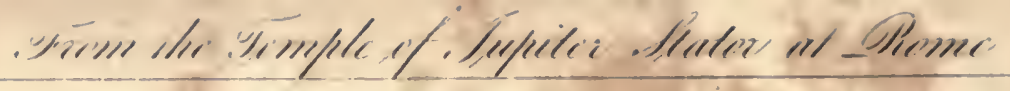
(1)

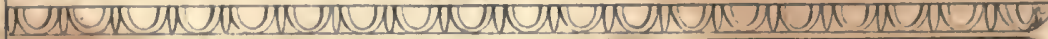

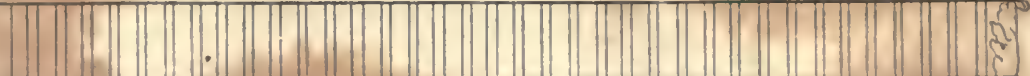

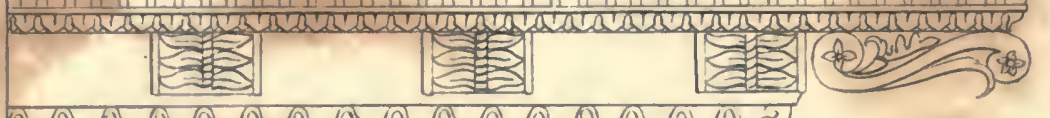

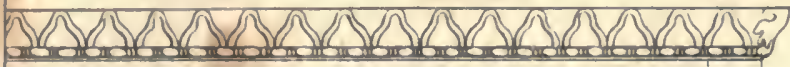

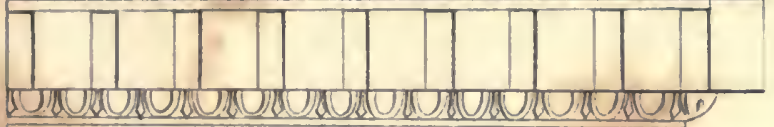

II

(n)

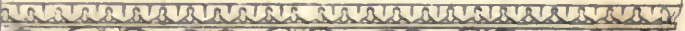

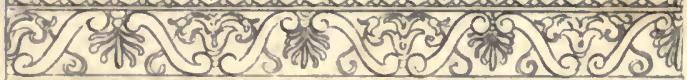
$x=\mathrm{c}$ -

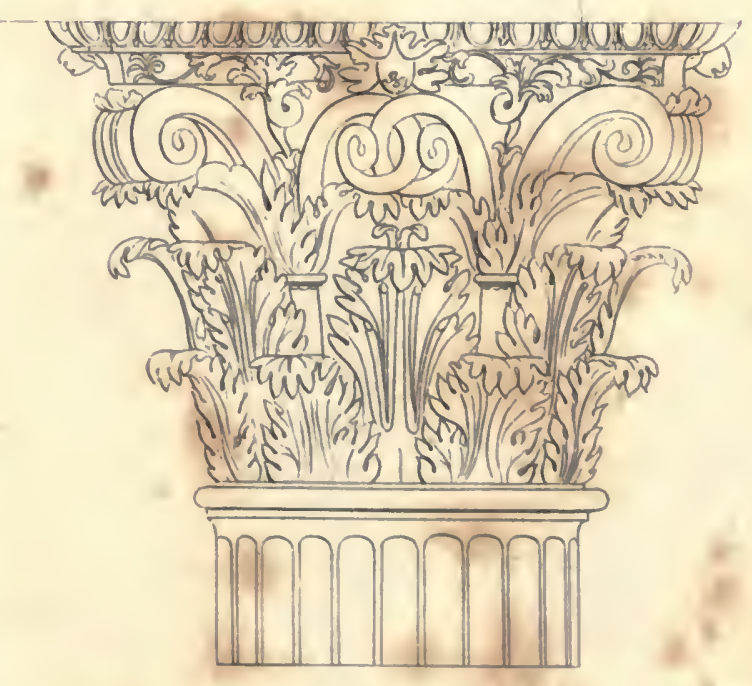





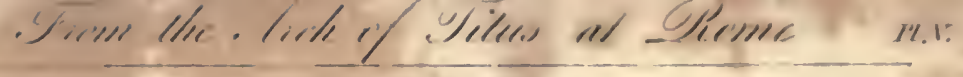

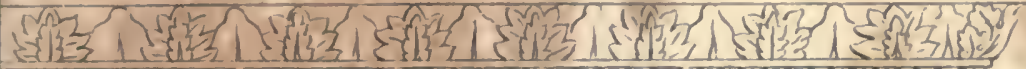

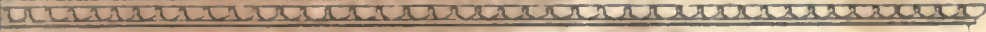

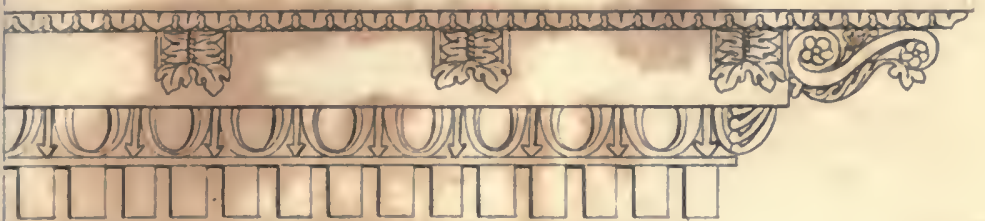

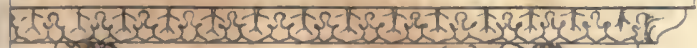

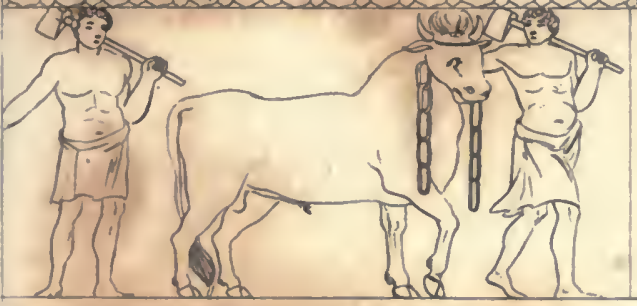

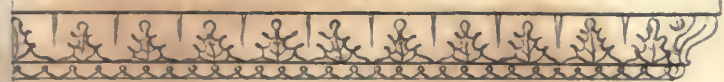

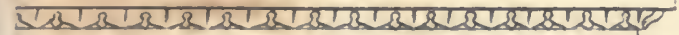

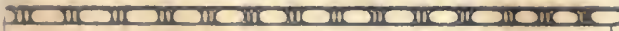

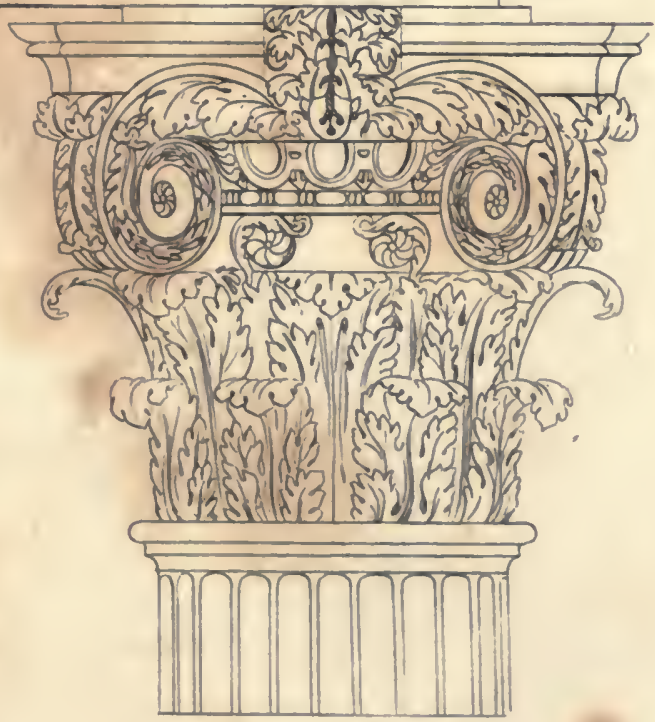




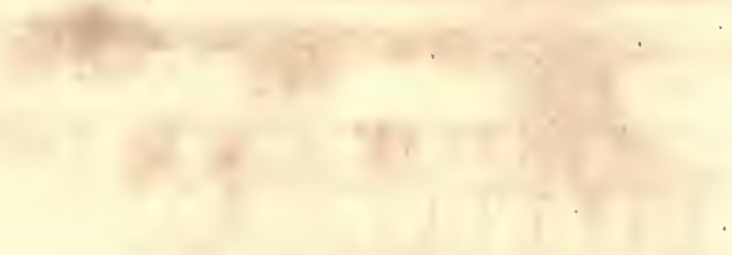

- no

(2n

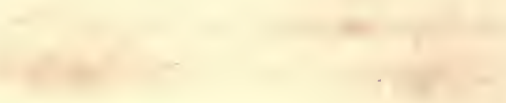

$=$ 


\section{AMERICAN EDITION}

OF THE

\section{BRITISH ENCYCLOPEDIA,}

OR

DICTIONARY

or

\section{ARTS AND SCIENCES.

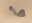

COMPRISING

AN ACCURATE AND POPULAR VIEW

OF THE PRESENT

IMPROVED STATE OF HUMAN KNOWLEDGE.

\section{BY WILLIA.Y NICHOLSON,}

Author and Proprietur of the Philosophical Journal, and rarious other Chemical, Philosophical, and Matbematical Works.

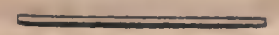

ILLUSTRATED WITII

UPWARDS OF 180 ELEGANT ENGRAVINGS.

$$
\text { VOL. I. A....ARE. }
$$

\section{PHILADELPHIA :}

PUBLISHED BY MITCHELL, AMES, AND WHITE.

W. Brown, Printer, Prune Street.

1818. 



\section{PREFACE.}

THE experience of more than a century las eminently proved the alvantages of such works as exhibit, under an alphabetical arrangement, the complete circle of human knowledge. Dictionaries of language, of general terms, and of particular branches of science and art, have been multiplied by the labours of men fully qualified to clisplay the subjects they have undertaken to discuss; and the first characters in the various nations of Emrope have been proul to rank their names and unite their exertions in the production of immense works, containing every subject which can engage the intellectual research or active occupation of man. The order of the alphabet has been so skilfully combined with that order which is indicated by the natural relations of the materials, that works of this description have been received with the most striking approbation; and, notwithstanding the great lalour and expense required to keep pace with the rapid improvements and discoveries of nodern times, the number of Dictionaries of all descriptions have been so great, that it would be difficult, and perhaps useless, even to name them, ant point out their respective merits.

From the great Encyclopelias, each of which may be said to constitute an entire library, to those smaller compositions intended for mere reference :-from the hurried compilations of book-makers to those elaborate and luminous works in which men of the highest reputation 
have recorded their comprehensive views, and their most striking discoveries, it is not difficult to observe and de. duce the distinct and separate utilities of each, and the duties to be expected from the editors and proprietors of such undertakings. Among the most obvious of these it is indispensable that a new work should be called for, by circumstances which point out advantages of size, plan, and materials, not before adopted, and that the means to be employed, in the actual performance, should be such as must determine its worth and authority with every description of readers.

We are already in possession of the large Cyclopedia of Dr. REEs, which has advanced to its twelfth volume, by a progress that insures its regular completion, and in a style of execution which is truly honourable to the skill and diligence of those who have undertaken it ; to the activity and enterprize of the proprietors, and to a nation which has ever taken the lead in science and the arts. On the smaller 'Dictionaries it is needless to enlarge. After various deliberate consultations between the Proprietors, the Editor, and the principal gentlemen engaged in the different departments, it was concluded, that a new Dictionary, appropriated exclusively to the Arts and Sciences, and containing a dense, accurate, and ample exhibition of our whole lnnouledge respecting them, might with the greatest advantage be comprehended in the limits of six large octavo volumes. It was accordingly decided, that the undertaking should be entered upon with vigour and activity, at the same time that the utmost attention should be paid to the means by which alone it was possible to insure the value of the intended work. The year preceding its appear. 
ance was employed in digesting the plan, establishing correspondences, investigating the various sources of information, and settling the order and disposition of the materials ; and it was not until after those materials were in considerable forwardness, and the whole arrangement was before the Editor, that the Proprietors thought themselves enabled to disclose their views, and express their confidence in the public support.

If the value of a composition of the magnitude and extent of the British Encyclopedia could be seen at once by a cursory or even by a diligent examination; or if the variety of subjects it comprehends would admit of the supposition, that a decision on its merits could he made, in a reasonable time, by general readers, it might then be consistent with the becoming reserve of men, speaking of their own labours, to submit them wholly to the ultimate voice of a discerning public. But when, by compilation from the works of authors, standing high in celebrity for knowledge and for talents; by the occasional abridgment and elucilation of the products of these researches; and by the insertion, in almost erery sheet, of treatises or disquisitions composed expressly for the purpose, the whole composition of a Dictionary of Science shall bear the marks of originality, it becomes a duty in the Editor, with regard to. himself and the other writers, that he should, to a certain extent, point out what has been done in this respect.

It would be truly gratifying to the Editor if he might attempt in this place to express his sentiments of the treatises which have passed under his view in the conduct and disposition of the present work, and declare his obligations individually to each of the writers who 
have honoured him with their assistance in the completion of the undertaking; but he fears that the lan. guage of approbation which he would in justice feel himself compelled to use, might be misconstrued into an unbecoming endeavour to enhance, beyond its merits, the value of the publication. Some of the authors of the British Encyclopedia have chosen to reserve their names. 'The Editor' has written and composed upwards of two hundred articles on Chenistry, Natural Philosophy, and Mechanics, and practical subjects relating to them, besides several of the lives of great men. The Mathematical Articles, including the mixed suljects of Astronony, $\mathbf{O}_{\mathbf{p}}$ tics, Phonics, Statics, and many others, were drawn up by a popular anthor, who is well known for his writings on those subjects. 'The article Conic Sections was written by James Ivory, Esq. of the Royal Military College of Marlow. To the Rev. Dr. Carepexter, of Exeter, our readers are indebted for the articles Grammar, Language, Mental and Moral Philosophy, Understanding, the Origin of Writing, and many others connected with the philosophy of the mind. For the articles Criticism, History, Poetry, and Rhetoric, our obligations are due to the.Rev. WM. Shephern, author of the life of Poggio Bracciolini. To J. J. GneLLier, Esq. of the Royal Exchange Insurance Company, are to be ascribed many valuable articles on Political Economy, the Doctrine of Annuities, Reversions, Assur. ance, \&c.

In our Medical Department, the articles Dietetics, Diseases and 'Treatment of Infancy, Materia Medica, Medicine, Midwifery, and Pharmacy, were written by J. M. Good, Esq. the learned translator of "Lucretius," 
and author of many works in medicine, and the sciences connected with it. 'Those on Anatomy, Comparative Anatomy, the Natural History of Man, Physiology, Surgery, \&c. were drawn up by W. IAa wrexce, Esq. of St. Bartholomew's Hospital.

'To a very ingenious pupil of Dr. Surtu, the celebrated President of the Linnean Society, we are indebted for the introductory treatise on Botany. Dynamics, $\mathbf{H y}$ draulics, Music, Fortification, Perspective, and many other articles in Mathematics and Experimental Philosophy; and also those on Farriery and Gardening, were composed by Capt. Willamson, a gentleman well known to the literary and philosophical world. 'The articles Distillery and Galvanism were written by Mr. Sylvester of Derloy, whuse discoveries in the latter new and promising department of experimental research are well kuown to philosophers. To .W. Y. Ottuey, Esq. we acknowledge ourselves indebted for the article Painting. And to Mr. J. P. MAlcolm, author of "The Antiquities of London," are to be ascribed those on Heraldry, 'Topography, and other articles conuected with the Arts.

James Parkinson, Esq. author of an elaborate and extensive work on the "Organic Remains of a former World," composed the articles Geology, Oryctology, Rocks, and Shells, which appear in this Dictionary. Those on Dyeing, and on the Manufacture of Cotton, leduced from actual observation, with several others relating to practical Mechanics, and subjects of a mixed nature, were furnished by W. Boswell, Esq.; and those on Weaving and Short-hand by Mr. NigirtisGale. Mr. Peter Nicholson is the author of the 
treatises on Architecture and Building; and the processes of particular Arts and Manufactures were either communicated by professional men, or in various instances drawn up under their inspection.

When the reader shall have directed his attention to the ample quantity of original and excellent matter contained in the articles here pointed out, besides ofhers more concise, and interspersed through the work, he will be enabled to form some judgment of its utility and comparative cheapness.

It is now a year since the Proprietors and Conductors of this work solicited the public encouragement, with a full determination to spare no exertions in performing the duties required in their arduous undertaking. The event, they trust, has gratified their expectation. - The British Encyclopedia was commenced, has been regularly continued, and is now completed in six handsome volumes, agreeably to the Prospectus. In the typographical execution of this Dictionary, and in the engravings with which it is illustrated, they feel confident they may claim a superiority over every other work of the same kind. An extensive sale has already given proof of the approbation they have laboured to deserve; and they trust, that as the British Encyclopedia continues to increase in circulation, it will maintain the reputation it has already acquired. 


\section{BRITISH ENCYCL.OPEDIA.}

\section{ABA}

The first letter of the alphahet, and

one of the five vowels, is pronounced variously; sometimes open, as in the words talk, rulk ; and at others close, as in cake, wake.

$\Lambda$ is also usecl, on many occasions, as a elaracter, mark, or abbreviation. Thus, in the calendar, it is the first of the dominical letters ; among logicians, it denotes an miversal affirmative proposition; as a numeral, $A$ signified 1 among the firceks; but among the Romans, it denoted 500, and with a clash over it, thus $\bar{\AA}, 5000$. A, $\vec{a}$, or $\bar{a} a$, among physicians, denote ana, or an equal weiglit, or quantity, of several ingredients.

AAM, or HAAM, a liquid measure used by the Dutch, equal to 288 pints English measure.

ABACK, in sea langratge, signifies the situation of the sails when their surfaces are flatted against the mast. They may be brought ahack, either by a sulden change of wind, or an alteration in the ship's course. They are laid aback, to offect an inmediate retreat, without turning either to the right or left, to avoid some immediate danger in a narrow channel, or when she lias advanced beyond her station in the line of battle.

ABACUS, in arelitecture, the uppermost member of the capital of a column. In the Greek Doric, it is a plane square fillet. In the Ionic, and Corinthian, inoulded and enriched.

Anacis, among ancient mathematiciass, was a table strewell over with. dust, or sand, on which they drew theip figures or schicmes.

Asacrs, in aritlmetic, an instrument for facilitating operations by means of counters. Its form is variors: but that

VOL. I.
ABA

chiefly used in Europe is made by dray:ing parallel lines, distant from each other at least twice the diameter of a counter; which, placed on the lawermost line, signifies 1 ; on the second, 10 ; on the third, 100 ; on the fourth, 1000 ; and so on. A. gain, a counter, placed in the spaces be. twcen the lines, signifies only tie half of what it would do on the next superior line.

Asacrs, pythagoricus, a mu!tiplicationtable, or a table of numbers ready cast up, to fucilitate operations in Arithmetic.

Asacts, logisicus, is also a kind of multiplication-table, in form of a right-anglet triangle.

A «sçยs, harmonicus, among musicians, denotes the arrangement of the keys of a musical instrument.

Anacrs, Grecian, an oblong frame, over which are stretched several brass wires, strung with little ivory balls, by tlic variorts arrangements of which all linels of computations are casily male.

A u Aces, Clinese, or Schurapan, consists of several series of bends strung on brass wires, stretched from the top to the bottom of the instrument, and divided in the middle by a cross picce from side to side. In the upper space every string las two beads, which are each counted for five; and in the lowest space cvery striug has five beads, of clifficent values, the first being counted as 1 , the second as 10 , the third as $1 \cup 0$, and so on.

AB.AFT, in sea-language, a term applied to any thing situated towards the sterus of a ressel: thus a thing is said to be abuft the fore-mast, or main-mast, when placed between the fore-mast, or main-mast, and the stern.

A Baft the beam, denotes the relative situation of any object with the ship, when the object is placell in any part of that 
arch of the holizon, which is contained between a line at right angles with the keel and that point of the compass which is directly opposite the ship's course.

ABAS, a weight used in persia for weighing pearis, being one eighth part lighter than the Europeain carat.

ABASED, in heraldry, is said of the wings of eagles, \&c. when the tip looks downwards to the point of the shield, or when the wings are shut; the natural way of bearing them being spread.

ABATE, in law, signifies to break down or destroy, as to abate a nuisance, and to abate a castle. It means to defeat and overthrow, on account of some' error or exception.

ABATEMENT, in heraldry, something added to a coat of arms, in order to lessen its true dignity, and point ont someimperfection or stain in the character of the person who bears it.

Amatruevt, in law, signifies the rejecting a suit, on account of some fault either in the matter or proceeding. Hence, plea in abatement is some cxception alleged, and proved, against the plaintiff's writ, declaration, \&c. and praying that the plaint may abate or cease; which being granted, all writs in the process must begin de novo.

ABATOR, in law, one who enters into a house or lands, void by the death of the last possessor, before the true heir ; and therefore keeps him out, till he brings the writ intrusione.

ABDOMFN, in anatomy; the lower part of tre trunk of the bocly, reacling from the thorax to the bottom of the pelvis. See A varomy.

ABDONINAI.ES, in natural history, an order of fishes, having ventral fins placed behind the pectoral in the abdomen, and the branchia ossiculated. This orcler comprehends sixtecn genera, viz.

$\begin{array}{lll}\text { Amia } & \text { Cobitis } & \text { Atherina } \\ \text { Clupea } & \text { Esox } & \text { Cyprimus } \\ \text { Elops } & \text { Loricaria } & \text { Exocoetus } \\ \text { Fistularia } & \text { Salmo } & \text { Mugil } \\ \text { Polynemas } & \text { Teuthis } & \text { Silurus } \\ \text { Argentina } & & \end{array}$

ABDUCTOR, or.Annecrer, in anatomy, a name given to several muscles, on account of theirserving to withdraw, open, or pull back the parts to which they are affixed. See Avatomr.

ABERRATION, in astronomy, an ap. parent motion of the heavenly bodics, produced by the progressive motion of light and the earth's annual motion in her orbit. Since light proceeds always in right lines, when its motion is perfectly undisturbed, if a fine tube were placed so as to receive a ray of light passing exactly through its axis when at rest, and then, remaining in the same direction, were moved transversely with great velocity, it is evident that the side of the tube would strike against the ray of light in its passage, and that, in order to retain it in the axis, the tube must be inclined, in the same manner as if the light, instead of comingin its actual direction, had also a transverse motion, in a direction contrary to that of the tube. The axis of a telescope, or even of the eye, may be considered as resembling such a tube, the passage of the light through the refiacting substances not alteringthe necessary inclination of the axis. In various parts of the earth's orbit, the aberration of any one star must be different in quantity and in direction; it never exceeds $20^{\prime \prime}$ each way, and therefore insensible in common observations. If $\mathbf{A B}$ and $\mathrm{AC}$ (Plate Acoustics, \&c. fig. 1,) re. present the comparative velocity of light and of the carth, in their respective direc. tions, a telescope mist be placed in the direction $\mathrm{BC}$ in order to see the star $\mathrm{D}$, and the star will appear at $\mathrm{F}$. This discovery was made by Dr. Bradley, in his observations to detcrmine the annual parallax of the fixed stars, or that which arises from the motion of the earth in its orbit round the sun.

Anenritios of the planets, is equal to the geocentric motion of the planet, the space which it appears to move, as seen from the carth, duning the time that light employs in passing from the planet to the earth. Thus, with regard to the sun, the aberration in longitude is constantly $20^{\prime \prime}$, which is the space moved by the earth in the time $8^{\prime} 7^{\prime \prime}$, which is the time that light takes to pass from the sun to the earth. Hence, the distance of the planet from the earth being known, it will be, as the distance of the sun is to the distance of the planet, so is $8^{\prime} 7^{\prime \prime}$ to the lime of light pass. ing from the planet to the carth; then computing the planet's geocentric motion in this time, will give the aberration of the planet, whether it be in longitude, latitude, right ascension, or declination. The aberration will be greatest in longitude, and but very small in latitude, because the planets deviate very little from the plane of the ecliptic. In Mercury it is only $4: \frac{3}{3}{ }^{\prime \prime}$ and much less in the other planets. The aberration in declination and right ascension depends on the situation of the planet in the zocliac. The aberration in longitude, being equal to the geocentric motion, will be more or less, according as 


\section{$\mathbf{A B}()$}

that motion may be. It will be least when the planet is stationary; and greatest in the superior planets, when they are in opposition; but in the inferior planets, the aberration is greatest at the time of their superior coujunction.

A semnatros, ill optics, a deviation of the rays of light, when reflected, whereby they are prevented from meeting in the same point. Aberrations are of two kinds; one arising from the figure of the reflect. ing body, the other from the different re. frangibility of the rays themselres: this last is called the Newtonian aberration, from the name of the discoverer.

ABETTOR, or Aвиетти, in law, the person who promotes or procures a crime to be committed : thus, an abettor of mur. der is one who commands or counsels another to commit it An abettor, accorrl. ing as he is present or absent at the time of committing the fact, is punishable as a principal or accessary. See Accessan r.

An abettor is the same with one who is deemed art and part, by the law of Scotland.

ABEYANCE, in law, is that which is in expectation, remembrance, and intendment of law. By a principle of law, in every laud there is a fee simple in somebody, or it is in abeyance; that is, though at present it be in no man, yet it is in expectancy, belonging to him that is next to enjoy the land. Where no person is seen or known, in whom the inheritance can rest, it may be in abeyance, as in limita. tion to several persons, and the survivor, and the heirs of such survivor, because it is uncertain who will be the survivor, yet the freehold cannot, because there must be a tenant to the pracipe always.

ABJURATION, in law, is used for re. nouncing, disclaiming, and denying the Pretender to have any manucr of right to the throne of these kingdoms : and that upon oath, which is required to be taken upon divers pains and penalties by many statutes, particularly $1 \mathrm{~W}$. and $\mathrm{M}$. I3 W. III. I Anne, 1 Geo. $i$.

ABOLITION, in law, denotes the repealing any law or statute, and prohibiting some custom, ceremony, \&c. Sornetimes also it signifies leave granted by the king, or a judge, to a criminal accuser, to forbear any firther prosecution.

Abolition is also used by ancient civilians and lawyers, for desisting from, or annulling, a legal prosecution; for remitting the punishment of a crime; and for cancelling or discharging a public debt.

AlBOMASUS, A BOMASEm, or Anomasius, in comparative anatomy, names used for the fourth stomach of ruminating beasts; or such as chew the cud. These liave four stomachs, the first of which is called veitier; the second, reticulum; the thirt, omasts; and the fourth, abomasnes. 'This last is the place where the chyle is formed, and from which the food descends inmediately into the intestines.

ABORTION, in medicine, an untimely or premuture birth of a foctus, otherwise called a miscarriage; but if this happen before the second month of pregnancy, it is only called a false conception. Sec Memcixe, Mhumfeix, \& c.

A nontor, in law, if caused by giving a potion to, or striking, a pregnant woman, was murder, but now is said to be a grcat inisprision only, and not murder, unless the child be boin alive, and dic thereof.

ABOUT, in military affairs, a word to express the movement, by which a body of troops clianges its front, by facing according to any given word of command.

ABRA, a silver coin of Polanil, nearly equivalent to the English shilling. See Cors.

ABRELST, a sea term, expressing the situation of two or more ships, that lie with their sides parallel to each other, and their heads advanced. When the line of battle at sea is formed abreast, the whole squadron advances uniformly. Abreast woithin the slip, denotes on a line with the beam, or by the side of any object aboard.

ABRIDGEMENT, in law, the shortening a count, or declarution: thus, in as. size, a man is said to abridge his plaint, and a woman lier demand in action of dower, if any land is put therein, which is not in the tenure of the defendant; for, on a plea of non-tenure, in abatement of the writ, the plaintift may leave out those lands, and pray that the tenant may answer to the remainder. The reason is, that these writs run in general, and there. fore shall be good for the rest.

ABROMA, in botany, a worl signifying not fit for food, is trsed in opposition to 'Theobroma, as a genus of plants belonging to the natura! order of Columnifera, and the eighteenth class of Polyadelphis Dodecandria. There are two species, viz. the maple-leaved abroma, which is a tree with a straight trunk, yielding a grum when cut, and filled with a white pith like the elder; it flowers from Junc to October, and its fruit ripens in September and Oc. tober; it is a native of New South Wales and the Plilippine islands, was introduced into Kew gardens about 1770, and is a lot-liouse plant, requiring great lieat, and rucb water:-and Wheler's Abroma, so 


\section{ABS}

called by Koenig, in compliment to Edward Wheler, Esq. of the Supreme Council in Bengal; this is a shrub with a brown bark, a native of the East Indies, and is not known in Europe. There is but one of the species known in Europe, which is propagated with us by cuttings. The plant requires a strong heat, and abundance of water. The seeds rurcly arrive at a state fit for propagation.

ABRUS, in botany, from a Greek word signifying soft or delicate, so called from the extreme tenderness of the leaves, is a genus of the natural order of Legumino. sa, and the seventeenth class of Diadel. phir Decandria. There is one species, viz, the Abrus precatorius. It grows naturally in both Indics, Guinca, and Egypt. It is a perennial plant, rising to the height of cight or ten feet. Its leaficts have the taste of liquorice, whence it is called, in the IVest Indies, Jamcica wild liquorice, and used for the same purpose. There are two varieties, one with a white, and the other with a yellow seed. The sceds are commonly strung, and worn as ornaments in the countries where the plant grows wild; and they are frequently brought to Europe from Guinea, and the East and West Indies, and wrought into various forms with other hard seeds and shclls. They are also used for weighing precious commodities, and strung as beads for rosaries, whence the epithet precatorius. They are frequently thrown, with other West India seeds, on the coast of Scotland. This plant was cultivated by Bishop Compton, at Fulham, before 1680. It is propagated by seeds, sown on a good hot-bed in spring, and previously soaked for twelve or fourteen hours in water. When the plants are two inches, each of them should be transplanted into a separate pot of light earth, and plunged into hot-beds of tanner's bark, and shaded from the sun. They will flower the second year, and sometimes ripen their seeds in England.

ABSCESS, in medicine and surgery, an inflammatory tumour, containing purulent matter. See Strgenx.

ABSCISSE, in conic sections, the part of the diameter of a curve line intercepted between the vertex of that diameter and the point where any ordinate, or semi-ordinate, to that diameter falls. From this definition it is evident, that there are an infinite number of variable abscisses in the same curve, as well as an infinite number of ordinates.

In the parabola, one ordinate has but one abscisse; in an ellipsis, it has two; in
$\mathrm{AC} \Lambda$

an hyperbola, consisting of two parts, it has also two; and in curves of the second and third orcler, it may have three and four. Sec Coric Sectioss.

$\triangle B S C I S S I O N$, in rhetoric, a figure of specch, whereby the spcaker stops short in the midlle of his discourse: $\mathrm{c} . \mathrm{g}$. one of her agc and beauty, to be seen alone, at such an hour, with a man of his character. I need say no more.

ABSINTHIUM. See Antemisia.

ABSORBENTS, in the materia medica, such medicines as have the power of drying up redundant humours, whether applied to ulcers, or taken inwardly. See Matemia Mroica and Pranmacy.

A bsornevт "vessels, in anatomy, are those which take up any fluid from the surface of the body, or of any cavity in it, and carry it into the blood. They are denominated according to the liquids which they convey, as Licteals, or Lymphatics, the former conveying chyle, a milky fluid, from the intestines; the latter a lymph, a thin pellucid liquor, from the places whence they take their origin. The lymphatics also take up any fluids that are extravasated, and likewise substances rubbed on the skin, as niercury, and convey them into the circulation.

ABS'TRACT iden, among logicians, the idea of some gencral quality or property, considered simply in itself, without any respect to a particular subject : thus, magnitude, equity, \&c. are abstract ideas, when we consider them as detached from any particular body or person. Various controversies have been maintained respecting the existence of abstract ideas; but all these disputes seem to be merely verbal. It is ccrtainly impossible to pos. sess an idea of an animal, which shall have. no precise colour, figure, magnitude, or the like; but it is an useful artifice of the understanding, to lcare these out in our general reasonings. Thus it is that the $a, b, c, \& c$. of the algebraists are usefully applied to denote numbers, though undoubtedly they are only general signs.

ABUCCO, Amocco, or Amoccil, a weight used in the kingdom of Pegu.

ABUNDANT numbers, those whose parts added together make more than the whole number: thus, the aliquot parts of 20 , viz. $1,2,4,5,10$, make 22 .

ACACIA, in botany, a species of mimosa. See Mimosa.

AcAcrs, in the materia medica of the ancients, a gum madc from the Egyptian acacia-tree, and thought to be the same with our gum-arabic.

ACADEMICS, a sect of philosophers, 
$\Lambda \mathbf{C A}$

who followed the doctrine of Socrates and Plato, as to the uncertainty of knowleckge, and the incomprehensibility of trutli.

Academic, in this sense, imounts to much the same with Platonist; the differ ence between them being only in point of time. They who embraced the system of Plato, annong the ancients, were called Academici; whereas those who have done the same, since the restoration of learning, lave assumed the denomination of Platonists. We usually reckon three sects of Academics; though some make five. The ancient Academy was that which was founded by Plato; and consisted of those followers of this eminent philosopher, who taught the doctrine of their master without mixture or corruption. 'The first of these was Speusippus; he was succeeded by Xenocrates. After his death the direction of the academy devolved upon l'ole. mo, and then upon Crates, and terminated with Crantor. After the death of Crates, a new tribe of philosophers arose, who, on account of certain innovations in their manner of philosophising, which in some measure receled from the Platonic system, without entirely deserting it, have been distingtuished by the appellation of the Second, or Middle Acadeny. The first preceptor who appears in this class, and who, in consequence of the innorations which he introduced juto the P'latonic school, has been commonly considered as the founder of this acalemy, is Arcesilaus. Before the time of Arcesilaus, it was never denied, that useful opinions may be leduced from the senses. Two sects arose about this time, which threatencd the destruction of the Platonic system; one was founded by Pyrrho, which held the doctrine of universal scepticism, and the other by Zeno, which maintained the certainty of hunan knowledge, and taught with grest confidence a doctrine essentially different from that of Plato. In this situation, Arccsilaus thought it necessury to exercise a cautious reserve with regarl to the doctrine of his master, and to conceal his opinions from the vulgar, under the appearance of doubt and uncertainty. Professing to derive his doc. trime concerning the uncertainty of knowJelge from Socrates, Plato, and other philosophers, he maintained, that though there is a real certainty in the nature of things, every thing is uncertain to the hu. man understauding, and consequently that all confident assertions are unicasonable. IIe thought it disgracefiul to isscut to any proposition, the truth of which is not fully established, and maintained, that in :IH questions, opposite opinions may be supported by arguments of equal weight. IIe clisputed igrainst the testimony of the senses, and the anthority of reason; ac. knowledging, at the same time, that they furnislı probable opinions sufficient for the conduct of life. However, his secret die. sign scems to hare been to establish the

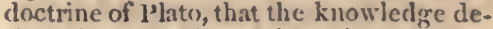
rived from sensible objects is uncertain, and that the only true science is that which is employed upon the immutable objects of intelligence, or icleas.

After the deatl of Arcesilaus, the Pla. tonic school was successirely under the care of Lacydes, who is said to have founded a new school, merely because he changed the place of instruction, and held it in the garden of Attalus, within the limits of the Academic grove, and of Evander and Egesinus. Arcesilaus, however, had opposed the Stoics, and other clogmatical philosophess, with such violence, and extended his doctrine of uncertainty so far, as to alarm not only the general body of philosopliers, who treated him as a common enenyy to philosophy, but even the governors of the state, who apprehended that his opinions would dissolve all the bonds of social virtue and of religion. Ilis successors, thercfore, found it difficult to support the credit of the academy; and Carncarles, one of the disciples of this scliool, relinquished, at least in words, somic of the more obnoxious tenets of $\mathbf{A r}^{-}$ cesilaus.

From this period the Platonic school assumed the appellation of the New Academy, which nuay be reckoned the third in order from its first establishment. It was the doctrine of this academy, that the senses, the understanding, and the imagination, frequently deccive 115 , and therefore camnot be infallible judges of truth ; but that, from the impressions produced on the inind, by means of the senses, call. ed by Carnearles phantasies, or images, we infer appearances of tuth, or prohabilities. These inages do notalways correspond to the real nature of things, and there is no infallible metlod of determining when they are truc or false; and consequently they afforl no certain criterion of truth. 13ut, with respect to the conduct of life, and the pursuit of happiness, probable appearances are a sufficient guicle, bc. causc it is unreasonable not to allow some degree of credit to those witnesses who commonly give a true report.

AC.IDEMY, in Crecian antiquity, a. large villa in one of the suburbs of Athens, where the sect of philosophers called Aca- 
demics held their assemblies. It took its name from one Academus, or Ecademus, a citizen of Athens; as our modern academies takes theirs from it. This term was also used metaphorically, to denote the sect of Academic philosophers. Sce AcADEMICS.

Acanrsy, in a modern sense, signifies a society of learned men, established for the improvement of arts or sciences. See Sucietr.

AC ENA, in botany, a genus of the Tetrandria Monogynia class and order of plants. There is but a single species, which is a Mexican plant.

ACALYPHA, in botany, a genus of plants belonging to the Monoecia Monodelphia class, and the natural order of Tricoccr, called the Tick-fruit. There are fourteen species: the $\mathbf{A}$. virginica; grows naturally in Virginia, and in $\mathrm{Cey}$ Ion: the A. virgata is a native of the warmest countries, and grows plentifully in Ja: maica; its leaves resemble those of the annual nettle, and sting as much. Most of the other species are natives of the West Indies. The plants have no beauty to recommend them, and are preserved in some botanic gardens merely on account of variety.

ACANTHA, among botanists, a name given to the prickles of thorny plants.

Acavtila is also used by zoologists for the spines of certain fishes, as those of the echinus marinus, \&c.

ACANTHACEOUS, among botanists, an epithet given to all the plants of the thistle kind, on account of the prickles with which they are beset.

ACANTHONOTUS, in natural history, a genus of fishes of the order Abdominales: the generic character is, body clongated, without dorsal fin : spines several, on the back and abdomen. There is but one species, the nasus, about 30 inches long, a native of the East Indies. The eyes are large, and the nostrils conspicu. ous: the body, which is of a moderate width for about the third of its length, gradually decreases or tapers towards the extremity : both head and body are covered with small scales, and are of a bluish tinge, with a silvery cast on the abdomen : the pectoral fins are brown, and of a moderate size : the ventral ratlier small, and of a similar colour: the lateral line is straight, and situated nearer to the back than to the abdomen : along the lower part of the back are ten strong but short spines, and beneatl the abdomen twelve or thirteen others, which are followed by a small anal fin. (Sce plate I. Ichthyology, fig. 1.)
ACANTIUURU, in natural history, a genus of fishes, of the order Thoracici, of which the gen. character is, tceth small, in most species lobated : tail aculeated on each side : general habit and appcarance like the genus Chrtodon, which see. This genus consists of such species of the Linnaan genus Chxtodon, as, in contradiction to the principal cliaracter of that genus, have moderately broad and strong teeth, rather than slender and setaccous ones: they are also furnished on each side the tail witl s strong spine. There are twelve species, of which the principal is A. unicornis; this is the largest of the genus, growing to the length of three feet or more. It is a native of the Indian and Arabian seas, in the latter of which it is generally seen in large shoals of two or three hundred each, swinming with great strength, and feeding principally on different kinds of sea-weed. This fish was described by Grew, in his Museum of the Royal Societry, under the name of the Lesser Unicorn fish. Fine specimens are to be found in the British and Leverian museums.

ACANTHUS, Bsan's. BREECH, or Bnavk-Unsive, in botany, a genus of the Didynamia Angiospermia class, and be. longing to the natural order of Personatx. There are ten species: 1 . The smooth acantlus, with white flowers, proceeding from about the middle to the top of the stalk, is the species used in medicine under the name of Branca ursina, or Brank. ursine. It is a native of Italy, about $\mathrm{Na}$ ples, of Sicily, Provence, and the islands of the Archipelago, and is cultivated in our gardens, and flowers in June and July. Turner (in his Herbal in Hort. Kew.) informs us, that it was cultivated in Sion gardens so long ago as the year 1551 . The leaves, and particularly the roots, abound with a soft, insipid mucilage, which may be readily extracted, either by boiling or by infusion. Rectified spirit digested on the leares, extracts from them a fine deep green tincture, which is more durable than that which is communicated to spirit by other herbs. IBrank-ursine is seldom or ever used medicinally in this country. Jut where it is common, it is employed for the same purposes to which the Althra, or marsh-mallow, and other mucilaginous vegetables, are applied anıng us. In foreign countries the cow-parsnip is said to be substituted for it, though it possesses very different properties. The leaves of this species of acanthus accidentally growing round a basket covered with a tile, gave occasion to Callimachus to invent the Corinthian capital in architecture. 2. 'The 


\section{$\mathbf{A C A}$}

thistle-leaved acanthus was found by Sparrman at the Cape of Cood Ilope, and has many leaves, proceceling imnediately from the root, resembling those of the thistle. 3. The prickly ucanthus grows wild in Italy and l'rovence, and flowers froin July to September. Its leaves are divided into segments, terminated with a sharp spine, whicli renders this plant troublesome to those who handle it. 4. The acanthus of Dioscosides, as Linnzus supposes it to be, grows naturally in the East, on Lebanon, \&c. 5. The holly-leaved acanthus is an evergreen shrub, about four feet high, and separating into many branches, with leaves resembling those of the common holly, and bearing white flowers, similar to those of the common acanthus, but smaller. $6,7,8,9$. These species, viz. the entire-leaved, procumbent, forked, and Cape acanthi, are na. tives of the Cape of Good Hope. 10. The Madras acanthus is a native of the East Indies.

The smooth and prickly acanthi are perennial plants, and inay bc propagated either by seeds, which slıould be sown in a light dry soil towarls the end of March, and left to grow, about six inches asunder, till autumn, when they should be transplanted wliere they are to remain : or by ronts, whicl may be planted either in spring or autumn for the third sort; but the others must only be removed in the spring, because, if they arc transplanted in autumn, they may be in danger of being destroyed by a cold winter. These plants take deep root, and when they are once established in a garden, thcy cannot be casily eradicated. The 5 th and 10 th species are too tender to thrive out of a stove in England, and cannot be propagated, except by seeds, which do not ripen in Europe. The other sorts must be treated in the same manner with Cape plants.

Aслгтнеs, in architecture, an ornament representing the leaves of the herb acanthus, and used in the capitals of the Corinthian and Composite orders. See ARCHTECTUR.

ACARNA, in botany, a genus belong. ing to the Syngenesia $¥$ qualis class and order: receptacle chafly, down feathery : calyx imbricatc, invested with sealcs, corol. floscular. There are seven species.

ACARUS, the tick or mite, in natural history, so called, lecause it is decmed so small that it cannot be cut, is a genis of insects belonging to the order of $A$ ptora, in the Iduman system. Gmelin, in the last edition of Limnzus's system, has eighty-two species; of which, some are inhalvitants of the earth, others of wates: some live on trees and plants, others among stones, and others on the bodies of other animals, and even under their. skin. Tle generic character is, legrs eighlit; eves two, situated on cach side the heact: feelers two, jointed; egg-shaped. The most familiar species are, 1. the $\mathrm{A}$. siro, or common cheese-mite, which is a fa. vourite subject for microscopic observations. This insect is corcred with hairs or bristles, which resemble in their stmic. ture the awns of barley, being barbed on each side with numerous sharp-pointed processes. The mite is oviparous : from the eggrs proceed the young aninals, resembling the parents in all respects, except in the number of legs, which at first amount only to six, the pair from the head not making their appcarance till after casting their first skin. The eggs in warm weather hatch in about a week, and the young animal may sometimes be scen for a clay together struggling to get rid of its egg-shell. The mite is a very voracious animal, feasting equally upon animal and regetable substances. It is also extremcly tenacious of life; for, upon the authority of Lecwenhoek, though highly discredi. table to his sense of humanity, we are as. sured that a mite lived elevenwecks glued to a pin, in order for him to make observations on. 2. The A. exculcerans, or itch mite, is a species of considerable curiosity, on account of the structure of its limbs : it is slightly rounded, and of a fiattened shape, with the thighs of the two upper pair of legs extremcly thick and short: the two lower pair of lcgs have thick thighs, proceeding from a very slendev base, and are extended into a long, stont, curved, and sharp-pointed briste. Dr. Bononio, an Italian physician, was the first who contended that the itch was occasioned by this insect, an account of which may be found in the Philosophical Transactions, No. 283. Dr. liaker is inclined to think that it constitutes the psora, a species of itch distinet from others confounded with it. 3. A. autumnalis, or harvest-bug, of a bright red colour, with the abromen beset on its hind part with numerous white bristles. It attaches itself to the skin, and is wirh difficulty disen. gaged. On thic part where it fixes, it causes a tumour, about the size of a small bead, accompanied by a severe itching. The tick is of this species, which is to be found on dogs and other animals. Many of the acari attach theinselves to juscets of a larger kind, and hence they take their nanes, as $\mathbf{\Lambda}$. coleopterous, found on the 
black beetle. (See plate t. kintomology; fig. 1. and 2.)

'These insects, which are often very troublesome on plants, and in hot-liouses, inay be eflectually destroyed by the following mixture. Take tiro ounces of soft green soap, one ounce of common turpentine, and one ounce of flour of sulphur; pour upon these ingredients a gallon of boiling water, work the whole together with a whisk, and let the mixture be used warm. This misture may also be of use for preventing the mildew on the peach and apricot; but it should never be used on fruit-trees near the time when their fruits are ripening. A strong ley made of wood-ashes will likewise destroy the acari; lut plants are greatly injured by this, and by briny and spirituous compositions.

ACAULOSE, or ACaUlots, among botanists, a term used for such plants as bave no caulis or stem. See Cavurs.

ACCEDAS ad curiam, in law, a writ lying where a man hath received, or fears false judgment, in a hundred-court, or court baron. It is issued ont of the Chancery, and directed to the sheriff, but returuable in the King's-bench or Commonpleas. It lies also for justice delayed, and is said to be a species of the writ Recordave.

ACCELERATYON, in mechanics, denotes the augmentation or increase of motion in accelerated bodies.

The term acceleration is chiefly used in speaking of falling bodies, or the tendency of heavy bodies towards the centre of the earth produced by the power of gravity; which, acting constantly and uniformly upon them, they must necessarily acquire every instant a new increase of motion. See Gravitation.

ACCELERATOR. See Avatonix.

ACCENT, among grammarians, is the raising or lowering of the voice in pronouncing certain syllables of words.

We have three kinds of accents, viz. the acute, the grave, and circumflex. The acute accent, marked thus ('), shews that the voice is to be raised in pronouncing the syllables orer which it is placed. The grave accent is marked thus ("), and points out when the voice ought to be lowered. The circumflex accent is compounded of the other two, and marked thus $\left({ }^{\infty}\right.$ or $\left.{ }^{n}\right)$ : it denotes a quavering of the roice between high and low. Some call the long and short quantities of syllahles accents; but crroneously.

Accsin, in music, a term applicable to every modulation of the voice, both in speaking and in singing. It is to the stu- dy of this that the composer and performer should unceasingly apply ; since, without accent, there can be no music, because there can be no expression.

ACCEP'TANCF, in common law, the tacitly agreeing to some act before done by another, which might have been defeated without such acceptance. Thus, if a husband and wife, seized of land in right of the wife, make a joint lease or feoffment, reserving rent, and the husband dies; after which the widow receives, or accepts the rent; such receipt is deemed an acceptance, confirms the lease of feoffment, and bars lier from bringing the writ cui in vita.

Acceptance, among merchants, is the signing or subscribing a bill of exchange, by which the acceptor obliges himself to pay the cuntents of the bill.

Bills payable at sight are not accepted, because they must either be paid on being presented, or else protested for want of payment.

The acceptance of bills payable at a fixed day, at usance, or ' double usance, \&c. need notbe dated : because the time is reckoned from the date of the bill; but it is necessary to date the acceptance of bills payable at a certain number of days after sight, because the time does not begin to run till the next day after that acceptance : this kind of acceptance is made thus, Accepted such a day and year, and signed. See Exciravge.

ACCESSARY, or Accrssony, in common law, is chiefiy used for a person guilty of a felonious offence, not principally, but by participation ; as, by advice, command, or concealment. There are two kinds of accessaries; before the fact, and after it. The first is he who commands, or procures, snother to commit felony, and is not present himself; for if he be present, he is a principal.

The second is he who receives, assists, or comforts any man that has done murder, or felony, where of he has knowlerlge. A man may also be accessary to an accessary, by aiding, receiving, \&c. an accessary in felony. An accessary in felony shall liave julgment of life and member, as well as the principal, who did the felony : but not till the principal be first attainted, and convicted, or outlawed thereon. Where the principal is pardoned without attainder, the accessary cannot be arraigned; it being a maxim in law, Ubi non est principalis, non potest esse accessorius. Jut if the principal be pardoned, or have his clergy after attainder, the accessary shall be arraigned. 4 and $5 \mathrm{~W}$. and $\mathrm{MI}$ 


\section{$\mathrm{ACC}$}

cap. 4 ; and by stat. 1 Anne, cap. 9, it is enacted, that where the principal is convicted of felony, or stands mute, or challenges above twenty of the jury, it shall be lawful to proceed against the accessary in the same manner as if the principal had been attainterl; and notwithstanding such principal shall be almitted to his clergy, pardoned, or delivered, before attainder. In some cases, also, if the principal camnot be taken, then the accessary mily be prosecuted for a misdemeanor, and punished by fine, imprisonment, \&c. stat. ib. see stat. 5 Anne, cap. 31 . In the lowest and highest offences there are no accessaries, but all are principals; as in riots, routs, forcible entries, and other trespasses, which are the lowest offences. So also in the highest offence, which is, according to our law, high treason, there are no accessaries, Cok. Littlet 71 .

ACCIDENl:. See Loric.

ACCIPITRES, or rapacious birds, in the Linnan system of ornithologr, the first order of birds; the characters of which are, that the bill bends downwards, that the upper mandible is dilated a little on both sides towards the point, or armed with a tooth-like process, and that the nostrils are wide; the legs are short and strong; the feet are of the percling kind, having three tocs forwarls and one backwarls; the toes are warty under the joints, with claws hooked, and sharp at the points. 'The body, liead, and neck, are musculous, and the skin very tough. The birds of this order subsist by preving on other animals, and on dead carcases, and they are unfit for food. They live in pairs, and are monogamous; and build their nests in lofty situations. The female is generally larger and stronger than the male, and usually lays four eggs at a time. This order corresponds to that of Ferx, and comprehents fonr generas, viz. Vexreze, Falcu, Stux, and Idavius, which see.

ACCOMP'ANIMINT, in heraklry, denotes any thing added to a shield by way of ornamient, as the belt, mantling, sup)porters, \&ic.

Accompaniment is ulso used for several bearings about a príncipal one, as a salticr, benil, fess, \&c.

ACCOMPLICF, in law, a person who was privy to, or aiding in, the perpetra. tion of some crime. Sce Accrssally.

ACCORD, in law, a verbal agreement. between two or more, where any one is injured by a tresspass, or other offence committed, to make satisfaction to the in. jured party; who, after the accord is per. formed, will be barred in law from brisg ing any new action against the aggressor for the same tresspass. It is safest, liow. ever, in pleading, to allege satisfaction, and not accord alone; because, in this last case, a precise cxecution in every part thereof must be alleged; whereas, in the former, the defendant needs only say, that he paid the plaintiff such a sum in full satisfaction of the accord, which he reccived.

ACCOUNTANT-general in the court. of Chancery, an officer appointed by act " of parliament to receive all monies lodged in court, and convey the sume to the bank of England for better security. The salary of this officer and his clerks is to be paid out of the interest made of part of the money, it not being allowable to take fees in this office. Counterfeiting the hand of the accountant-general is felony, without clergy, by 12 Geo. I. c. 32.

ACCOUTIREMENTS, in a military sense, signify the furniture of a soldier, such as puff's, belts, pouches, cartridgeboxes, \&c.

ACCROCHE', in heraldry, denotes a thing's being hooked into another.

ACER, maple, in botany, a genus of the Monoecia order and Polygamia class of plants, and belonging to the natural order of Trililata. There are 25 species. See MAPLE.

ACETATES, in chemistry, a genus of salts formed by the acetic acid. They may be distinguished by the following properties: they are decomposerl by heat: the acid being partly driven off, partly destroyed :-they are very soluble in water:-when mixed with sulphuric acid, and distilled in a moderate heat, acetic acid is disengaged:-when they are dissolved in water, and exposed to the open air, their acid is gradually decomposerl.

ACF.TIC acid, in chemistry. This acid is employed in lifferent states, which liave been distinguishled from cach other by pe. culiar names. When first preparesl, it is ealled rinegar; when purified by clistill: tion, it assumes the nutune of distilled vi. negar, usually called acetous acid: when concentrated as much as possible by cer. tain processes, it is called in the shops ra. dical rinegar; but by chemists it is deno. minated acetic acicl. One loundred parts of acctic acid are composed of

50.19 oxygen

13.94 livirogen

35.87 carbou

100.00

VOL. 1 
ACETITES, a genus of salts formed by the acetous acid.

ACFiTOUS acid. See Acetic Aem.

ACHANIA, in botany, a genus of the Monadelphia Pulyandria class, and the natural order of Columnifers. There are three species, viz. the $A$. malvaviscus, scurlet achania, or bastard hibiscus, which is a native of Mexico and Jamaica ; cultivated bere in 1714 by the Jutcliess of Beaufort, and flowering through the greatest part of the year: the mollis, or woolly achania, a native of South Amcrica and the West Judia islinds, found in Jamaica by Foustoun, in 1730, and introduced in 1780 by B. Bewick, Esq. and flowering in Au. giist and September: and the pilosa, or hairy achania, a native of Jamajca; introduced in 1780 by Mr. G. Alexander, and flowering in November. Achania is gencrally propagated by cuttings, which are planted in pots of light earth, plunged in. to a gentle hot-bed, and kept from the air till they take root, when they should be gradually inured to the open air. They must be preserred in winter in a moderate stove; and, kept warm in summer, they will flower, and sometimes ripen fruit.

ACHEKNEJ, in astronomy, a star of the first magnitude in the southern extremity of the constellation Eridanus. See the article Erinasis.

ACHII.I.F, A, milfoil, in botany, so called from Achilles, who is supposed to have acquired soine knowledge of botany from his master Chiron, and to have used this plant for the cure of wounds and ulcers; a genus of the Syngenesia Polvgamia Su. perfua class of plants, and of the natural order of Compositx Discoidex. There are 27 species, of which the most remarkable are the ptarmica, or sneezewort, M. growing wild in all the temperate parts of Eu. rope, found in Eritain, not uncommonly in meadows, by the sides of ditches, on the balks of corn fields, in moist woods and shady places. The shoots are put into salads, and the roots, being hot and biting, are used for the tooth-ache, whence the plant has been called bastarl pellitory, and, on account of the form of the leaf, goose-tongue : the powder of the dried leaves, used as snuff, provokes sneezing, whence the name : in Siberia, a decoction of the whole herb is sairl to be successfilly used in internal hemorrhages: of this plant there is a variety with double flowers, called batchelor's buttons; it flowers in July and August, and makes a tolerable appearance; and the millefolium, common M. or yarrow; abundant in pastures and by the sides of roads, flowering from June to September : mired instead of hops by the inhabitants of Dalecallia in their ale, in order to give it an inebriating quality : recommended by Anderson, in his Essays of Agriculture, for cultivation, though thought to be a noxious weed in pastures : the bruised herb, fresh, is recommended by Linnaus as an excellent vulnerary and styptic, and by foreign physicians in he. inorrhages, and thought by Dr. Hill to be excellent in dysenteries, when administered in the form of a strong decoction. An vintment is made of it for the piles, and for the scab in slieep; and an essen. tial oil is extracted from the flowers; but it is not used in the present practice.

ACHRAS, or SAPOTA-PLCM, in botany, a genus of the Hexandria Monogynia class, and of the natural order of I Dumosx. There are four species, viz. The mammosa, or mamme sapota, otherwise called nippled S: or American marmelade; growing in America to the height of thirty or forty feet, with leaves a foot long, and three inches broad in the micldle, cream-coloured flowers, and large oval fruit, containing a thick, luscious pulp, called natural marmelade. This tree is planted for the fruit in Jamaica, Barbadoes, Cuba, and most of the West India islands, and was cultivaterl here by Mr. Miller in 1739. Of this there is a variety call. ed the bully, or nisberry bully-tree, because it is the tallest of all the trees in the woods : it is esteemed one of the best timber trees in Jamaica. 2. The sapota, which grows tn the height of sixty or se. venty feet, without knots or branches, and bears a round, yellow fruit, bigger than a quince, which smells well, and is of an agreeable taste. It is common at Panama and some other places in the Spanish West Inclies, but not to be found in many of the English settlements. It was culti. vated here by Mr. Miller in 1739. 3. The dissecta, or cloven-flowered S. cultirated in Malabar for the fruit, which is of tie form and size of an olive, having a pulp of a swcetish acid flavour. Its leaves are used for cataplasms to tumours, bruised and boiled with the root of curcirma and the leares of ginger; supposed to be a native of the l'hilippine islands, and probably growing in China, and found by Forster flowering in September, in the island of Tongatabu. 4. The salicifolia, or white willow S. called in Jamaica the white-bully-tree, or galimeta wood, which supplies good timber. The bark of the sapota and mammosa is very astringent, and is called cortex Jamaicensis. This wrs once supposed to be the true Jesurts bark, 


\section{ACI}

$\mathrm{ACO}$

but its effects on the negroes has been pernicious. These trees cannot be preserved in England but with great care and much heat.

ACHROMATIC, an epithet expressing a want of colour, introduced into astrunomy by De la Lande.

Acunmatic telescopes, are telescopes eontrived to remedy the aberrations in colouis. They were invented by Mr. Jolın Iolland, optician. Sec Optics, TrLescolr.

ACIYRANTHES, in botany, a genus of the I'cntandria Monogynia class of plants, belonging to the nitusal order of Misccllanex. There are cleven specics, but they have but little beauty, and are only prescrved in lsotanic gaudens.

ACIIYJOONIA, in botany, a genus of the Dialelphia Decandria class and order, calyx five-toothed; the lower tooth elongated and cloven : legume compresserl, many-seeded; one species, viz. $\Lambda$. villosi, a slurub found in New Holland, with long silky hairs : leaves lanccolate, acute, entire, with silky hair round the margin.

ACIA, in bitany, a genus of the Mlonodelphia Jodecamiria class and order: calyx five-parterl, five petals, drupe rlry, coriaceous, fibrous, one-sected. "Two spe. eies, trees sixty fect high, found in Guiana.

ACICARI'II $A$, in botany, agenus of tice Polygamia Necessaria classand orrler: receptacle chaffy, the chaff uniting with the seeds after flowering, seeds naked; florets tubular; calyx five-parterl. One species, found in Buenos Ayres.

AC11, in chemistry, a term originally synonymous with sour, and applied only to bodics distingnisherl by that taste; but it now comprehends under it all substau. ces possessed of the following properties. Acids, when applied to the tongue, excite the sensation of sour, they change the blue colours of vegetables to a red; they unite with water in almost any proportion; they combine with all the alkalies, and most of the metallic oxides and earths, and form with them those compounds called in chemistry salts. Every acid iloes not possess all these propertics, but they all possess a sufficient number to distinguish them from other substances. See Cuzजistur.

ACIDIFLABLE base, or RAnICAI, any substance capable of uniting, without de. composition, with such a quantity of oxy. gen as to become possessed of acid propertics. Almost all the acids agree with each other in containing oxygen, but they differ in their bases, which rletermine the species of the acid. Sulphur rrmbincd with certain portions of oxygen fortms sulphurons or sulphuric acid, accorcling to the quantity of oxygen absorbed.

ACIDOTON, in botany, a genus of the Monoecia Polyandria class and order; it has male and female flowcrs on the same, or a different trce. There is but one species, viz. A. urens, a native of Janaca, which grows to the height of eight or nine feet.

ACIIENSER, a genus of fishes of the order Cartilagenei : the chasacters are, that the head is obtuse, the mouth is under tlic head, retractile, and without tecth; that the four cerri are below the front, and before the month; the aperturc of the gills is at the side, the body is clongated, and angulated with many series of scuta, or scaly protuberances. These may be ranked among the larger fish; are inliabitants of the sea, but ascend rivers an: nually ; the flesh of all of them is delicions; from the roe is made caviar, and from the sounds aud muscular parts is made isin. glass; they feed on wornus, and other fishes; the females are larger than the males. There are fivespecies: A. sturio, or common sturgeon, inhabits Eumopean, Mcditcranean, lied, Black, and Caspian seas, and annually ascends rivers in the spring. (Sce plate I. Icluthyology, fig. 2.) A. scliypa, inlubits the Caspiam sea, and large lakes of Sibcria. A, ruthenus, and A. stellatus, both inhabit the Caspian sea: A. hufo, inhabits the Danube, Wolga, and other liussian rivers, and also the Caspian. The skin of this species is so liard and tough, as to be used for carriage traces, Sec STrunizos.

ACNIDA, Vinginia hemp, in botany, $\alpha$ genus of the Pentandria l'entagrnia class and order. There is but a single species, viz. A. caunabiun, which is a native of Virginia, and some other parts of America ; it is seklom cultivated in Europe.

ACONITUM, aconite, wolf's-bane, or monk's-liood, in botany, a genus of plants of the Trigynia orter and Polyandria class, and pertaining to the natural order of Nultisiliqua. In the last elition of Jiunaus, by Gmelin, this genus comprehends fourteen species; most of the species of aconite have biendecined poisonous. The ancients werc so surprised at their pernicious effects, that they were afiaid to touch the plants; and hence sprung many superstitious precautions alsout the imsnuer of gathering them. Theophrastus relates that there was a mode of preparing the aconite in lis days, so that it should only destroy at the end. of one or twa years. But some have 
questioned whether the aconite of Theo. phrastus, Dioscoricles, Pliny, and other ancient writers, be the same with ours, or sliould be referred to the genus of Ranunculus. It is confidently affirmed that the huntsmen on the Alps, who hunt the wolves and other wild animals, dip their arrows into the juice of these plants, which renders the wounds occasioned by thein mortal. A decoction of the roots has been used to kill bugs; and the powder, disguised in bread, or some other palatable vehicle, has been employed to destroy rats and mice. The $\mathrm{A}$. napellus, or common monk's-hood, has beenlong known as one of the most virulent of all vegetable poisons. Linnxus says that it is fatal to swine and goats, but does no injury to horses, who eat it dry. He also informs us, from the Stockholm Acts, that an ignorant surgeon died in consequence of taking the fresh leares, which he prescribed to a patient. The effluvia of the herb in full flower have produced swooning fits and a temporary loss of sight. The leaves and sloots of this plant, used is salad, instead of celery, have proved fatal in several instances. But the most powerful part of the plant is the root. Matthiolus relates, that it was given by way of experiment to four condemned criminals, two at Rome, in 1524, and two at Prague, in 1561, two of whom soon died, and the other two, with great difficulty, were recovered. The juice applied to the wound of a finger, not only produced pain in the arm and hand, but cardialgia, anxiety, sense of suffocation, syncope, \&c. and the wounded part sphacelated before it came to suppuration. Dodonzus says that five persons at dntwerp died in consequence of eating it by mistake. The effects of this plant are, convulsions, giddiness, insanity, violent evacuations, both up wards and downwards, faintings, cold sweat, and even death itself. Nevertheless it has been used for medical purposes. The Indians are said to use aconite, corrected in cow's urine, with good suc. cess against fevers. There is one species of it which has been deemed an antidote to those that are poisonous, called antho$r a$, and those that are poisonous are called thora. The taste of the root of the species denominated anthora is sweet, with a mixture of bitterness and acrimony, and the smell is pleasant. It purges violently when fresh, but loses its qualities when dricd. This is poisonous as well as the others, though in a slighter degree, and is disused in the present practice. The first person who ventured to introduce the cdinmon monk's-hood into medicine was Dr. Stoerck. Stoerck recommends two grains of the extract to be rubbed into a powder, with two drams of sugar, and to begin with tell grains of this powder two or three times a-day. The extract is often given from one grain to ten for a dose : and some have considerably increased the quantity. Instead of the extract, a tincture has been male of the dried lcaves, maccrated in six times their weight of spirits of wine, and forty drops given for a dose.

ACORN, an ornamental piece of wood, in the shape of a cone, fixed to the top of the spindle of a mast-head, above the vane, to keep it from coming off the spindle.

ACORUS, in botany, the sweet flag, or sweet rush, a genus of the Monogynia order, and Hexandria class of plants, and belonging to the natural order of Piperita. There are two species, viz. the $\Lambda$. calamus, or common swect rush, of which there are two varicties, the vulgaris, or European sweet rush, or calamus aroma. ticus, and the Asiaticus or Indian calamus aromaticus. The common calamus aro. maticus grows naturally on the banks of the rivers, and in shallow standing waters ; and is found in many parts of England, but is much more plentiful in the stand. ing waters of Holland, and is common in many other parts of Europe. The Indian calamus, which grows not only in marsh ditches, but in more elevated and dry places, in Malabar, Ceylon, Amboyna, and other parts of the East Indies, differs but littlc from the European, except that it is more tender and narrow, and of a more hot and pungent taste; and A.gramineus, or Chinese sweet-grass, has the roots in tufts, with a few thready fibres. The whole herb has an aromatic sinell when bruised, resembling the English sweetflag, from which it is distinguished by the shortness of that portion of its stalk which is abore the spadix, as well as by all its parts, except the florets, being five times smaller thian in that plant. It is probably a native of China, and cultivated, for the sake of its smell, in pots near the habitations of the Chinese. The sweet flag will succeed very well in moist garden ground, but never produces its spikes, unless it grows in water. The dried roots of the calamus aromaticus are commonly import . ed from the Levant, though those grown in England are equally good. They have a strong aromatic smell, and a warm pungent taste; the flavour is much improved by drying. The powdered root might 


\section{ACOUSTICS}

perhaps supply the place of foreign spices; and incleed it is the only native aromatic plant of northern climates. It is carminative and stomachic, and often used as an ingredient in bitter infusions.

ACOTYLFUONF, in botany, plants so callerl, becanse their seeds are not furnished with lobes, and of course put forth no seminal leaves. Alt mosses are of this kind. See Cotrumorrs.

ACOUSTICS, in playsics, is that science which instrvets us in the nature of sound. It is livicled by some writérs into diacoustics, which explains the properties of those sumds that come distinctly from the sonorons borly to the ear; and catacoustics, which treats of reflected sounds; but this distinction is not necessary. In the infancy of pliblosophy, sound was held to be a separate existence : it was conceired to be wafted throngh the air to our organs of hearing, which it was supposed to affect in a manner resembling that in which our nostrilsare affected when they give us the sensation of smell. Yet, eren in those early years of science, there were some, and, in particular, the cclebrated founder of the Stoic school, who held that sound, that is, the cause of sound, was only the particular motion of external gross matter, propagated to the ear, and there producing that agitation of the organ, by which the soul is immediately affected witl the sensation of sound. Zeno says, "Ilearing is produced by the air which intervenes between the thing sounding and the ear. The air is agitated in asplserical form, and mores off in wares, and falls on the ear, in the same manner as water undulates in circles when a stone has heen thrown into it." The ancients were not remarkable for precision, either of conception or argument, in their discussions, and they were coutented with a general and vague view of things. Some followed the opinion of 'Zeno, without any farther attempts to give a clistinct conception of the explanation, or to compare it with experiment. 13it, in laster times, cluring the ardent researclies into the phenomena of nature, this became an interesting subject of inquiry. The invention of the air-pump gave the first npportunity of decicling, by experinent, whether the elastic undulations of air were the causes of sound; and the trial fully establislsed the point; for a bell rung in vacuo gave 110 sound, and one rung in condensed air gave a very louk one. It was therefore received as a doctrine in general physics, that air was the velucle of sound. The celebrated falileo, the parent of mathenatical philosoply, discovered the nature of that conriection between the lengths of musical chords and the notes which they produced, which had been observed by Pythagoras, orlearned by him in his travels in the East, and which hic made the foundation of a refined and beautiful science, the theory of music. Galileo shewed, that the real connection subsisted between the tones and the vibrations of these chorda, and that their different degrees of acuteness corresponded to the diflerent frequency of their vibrations. The very elementary and familiar demonstration which he gare of this connection did not satisfy the curious mathematicians of that inquisitive age, and the mechanical theory of musical chords was prosecuted to a great degree of refinement. In the course of this investigation, it appeared that the chord vibrated in a manner precisely sirnilar to a pendulum vibrating in a cycloid. It must therefore agitate the air contiguous to it in the same manner: and thus there is a particulas kind of agitation that the air can receive and maintain, which is very interesting.

Sir lssac Newton took up this question as worthy of his notice; and endeavoured to ascertain with mathematical precision the mechanisin of this particular class of undulations, and gave us the principal theorems conceruing the undulations of elastic fluids, which make the 47 , \&ic. Propositions of Book II. of his Principles of Natural P'hilosophy. They hare been considered as giving the doctrines concerning the propagation of sound. Most sorunds, we all know, are conveyed to us by means of the air. In whatever manner they either float upon it, or are propelled forwarl in it, certain it is, that, without the vehicle of this or some other fluid, we should have no soumls at all. Let the :ir be exhausted from a receiver, and a bcll will emit no sound; for, as the air continues to grow less clense, the sound dies away in proportion, so that at last its strongest vibrations are almost totally silent. Thus air is a velicle for soind. llowever, we must not, with some plilosophers, assert, that it is the only vehicle; that, if there were no air, we should have no sounds whatsoever: for it is found, by experiment, thist sounds are conveyed through water with the stme facility with which they move through air. A belt numg in water returns a tome as distinct as if rung in air. "This was obserred by Dr. Derham, who also remarked, that the tone cance : quarterdecper. It appears from the experiments of naturalis!s, that fishes have a strong perception of sound, even 


\section{ACOUS'TICS.}

at the bottom of decp rivers. From hence it would seem not to be very material in the propagation of sounds, whether the fluid wlich conveys them be elastic or otherwise. Water, which, of all substances that we know, has the least elasticity, yet serves to carry them forward: and if we make allowance for the difference of its density, perhaps the somds move in it with a proportionable rapidity to what they are found to do in the elastic fluid of air. But though air and water are both ve. hicles of sound, yet neither of them, according to some philosopliers, seems to be so by itself, but only as it contains an exceedingly subtle fluid, capable of penetrating the most solid bodies. One thing, lowever, is certain, that whatever sound we hear is produced by a stroke, which the sounding body makes against the fluid, whether air or water. The fluid, being struck upon, carries the impression forward to the ear, and there produces its sensation. Philosophers are so far agreed, that they all allow that sound is nothing more than the impression niade by an clastic body upon the air or water, and this impression carried along by either fluid to the organ of hearing. But the manner in which this conveyance is made is still disputed: whether the sound is diffused into the air, in circle beyond circle, like the waves of water when we dis. turb the smoothness of its surface by dropping in a stone; or whether it travels along, like rays diffused from a centre, somewhat in the swift manner that elcetricity runs along a rod of iron; these are the questions which have divicled the learned. Newton was of the first opinion. He has explained the progression of sound by an undulatory, or rather a vermienlax, motion in the parts of the air. If we have an exact idea of the crawling of some insects, we shall have a tolerable notion of the progression of sound upon this hypothesis. The insect, for instance, in its motion, first carries its contractions from the hinder part, in order to throw its fore part to the proper distance, then it carries its contractions from the fore part to the hinder, to bring that forward. Somcthing similar to this is the motion of the air when struck upon by a sounding body. All who have remarked the tone of a bell, while its sounds are decaving away, must have an idea of the pulses of sound, which, according to Newton, are formed by the air's alternate progression and recession. And it must be observel, that as each of these pulses is formed by a single vibration of the string, they mist be equal to each other; for the vibrations of the string are known to be so. Again, as to the veloci. ty with which sounds travel, this Newton determines, by the most difficult calculation that can be imagined, to be in proportion to the thickness of the parts of the air, and the distance of these parts from each other. From bence he goes on to prove, that each little part moves backward and forward like a pendulum; and from thence he proceeds to demonstrate, that if the atmosphere were of the same density every where as at the surfuce of the earth, in such acase, a pendulum, that reached from its highest surface down to the surface of the earth, would, by its vibrations, discover to us the proportion of the velocity with which sounds travel. The velocity with which each pulse would more, he shows, would be as much greater than the velocity of s! Ich a pendulum swinging with one complete vibration, as the circumference of a circle is greater than the diameter. From hence he calculates that the motion of sound will be 979 feet in one second. 13ut this not being consonant to experience, he takes in another consideration, which destroys entire. ly the rigour of his former demoinstration, namely, vapours in the air, and then finds the motion of sound to be 1142 feet in one second, or near 13 miles in a minute, a proportion which experience had established near]y before. Many other theories on this subject have been advanced by ingenious inen, but our limits do not allow to enter farther into them.

Since by experiments it has been prored that sound trarels at about the rate of 114.2 feet in a second, and that no obstacles hin. der its progress, a contrary wind only a small matter diminishing its velocitv, the method of calculating its progress is easily made known. When a gun is discliarged at a distance, we see the fire long before we hear the sonind. If then we know the distance of the place, and know the time of the interval between our first seeing the fire and hearing the report, this will shew us exactly the time that the sound has been travelling to us. For instance, if the gun is dischargesl a mile oft, the moment the flash is seen rou take a watch, and count the seconds till you hear the sound, the number of seconds is the time the sound lias been trarelling a mile. We are also enabled to find the distance between objects that would be otluerwise immeasureable. For example; suppose you see the flash of a gun in the night at sea, and tell severi seconds before you hear the report, it.follows thereforc that the 


\section{Acoustics:}

distance is seven times 1142 feet. In like manner, if you observe the number of se. conds between the lightning and the re. port of the thunder, you know the distance of the eloud from whence it proceeds. But, accorling to another philosopher, $\mathrm{Dr}$. Thomas loung, the velocity of sound is not quite so great. "It has been demon. strated," he observes, "by M. De La Grange and others, that any impression whatever, communicated to one particle of an elastic fluid, will be transmitted through that fluid with an uniform velocity, depending on the constitution of the fluid, without reference to any supposerl laws of the continuation of that impression. Their theorem for ascertaining this velo. city is the same as Newton has deduced. from the hypothesis of a particular law of continuation: but it must be confessed, that the result differs somewhat too widely from experiment to give us full confidence in the perfection of the theory. Corrected by the experiments of various observers, the velocity of any impression transmitted by the common air mas, at an average, be reekoned 1130 feet in a second." "Phil, Trans, vol. XC.

I)r. I)erlam has pioved by experiment, that all sounds whate ver tuarel at the same ratc. The somud of a goun, and the striking of a liammer, are equally swift in their motions; the anftest wlispej fices as swiftly, es far as it goes, as the lourlest thitnder. To these we may add, that smnoth and clear sounds proceed from bodies that are homogeneous, and of an uniform figure; and harsh or obtuse sounds, from such as are of a mixed matter and irregular figure The velocity of sounds is to that of a brisk wind as fifty to one. The strength of sounds is greatest in cold and dense air, and least in that which is warm and rareficd. - Every point against, which the pulses of sound strike, becomes a centre, from which a new series of pulses are propagated in every direction. Sound describes equal spaces in cqual times.

There is probably no substance which is not in some measure a conductor of sound; but sound is much enfeebled by passing frum one medium to another. if a man, stopping one of his ears with his finger, stops the other also by pressing it agsinst the end of a loug stick, and a watch be applied to the opposite end of the stick, or of a piecc of timber, be it everso lons, the beating of the watch will be distinctly hearl: whereas, in the usual way, it can scarcely be heard at the distance of 15 or 18 feet. The sume effect will take place if he stops both his ears with his hands, and rests his teeth, his temple, or the cartilaginous part of one of his ears, against the end of the stick. Instead of a watel, a gentle seratch may be made at one end of a pole or rod, and the person who keeps the ear in close contact with the other end of the pole will hear it very plainly. Thus, persons who are dull of liearing may, by applying their teeth to some part of an harpsichoril, or other sounding body, hear the sound much better than otherwise.

If a person tie a poker or any nther piece of metal on to the middle of a strip of flan. nel ahout a yard long, then press with his thumbs or fingers the ends of the fannel. into his cars, while he swings the poker agrainst any obstacle, as an iron or steel fender, he will hear a sound very like that of a large church bell.

Sound, like light, after it has been re. flected from several places, may be collected in one point, as into a focus; and it will be there more audible than in any other part, even tliat at the place from whence it proceeded. On this principle it is that a whispering gallery is construct. ed. The form of a whispering gallery nust be that of a concave hemispliere, is ABC, plate Acoustics, fig. 2.; and if a low sound or whisper be uttered at $A$, the vibrations expanding themselves every way will impinge on the points $\mathrm{D}, \mathrm{D}, \mathrm{D}$, \& \& . and from thience be reflected to $F, \mathbf{E}, \mathbf{F}$, and from thence to the points $F$ and $G$, till at last they all meet in $\mathrm{C}$, where the sound will be the most distinctly heart. The augmentation of sound, by mems of speat. ing-trumpets, is usually illustrated in the following manner : I.et ABC, fig. 3. be the tube, BI) the surs, and Is the mouth-piece. for conveying the roice to the tube. Then it is evident, when a person speaks'at $\mathrm{B}$ in the trimpet, the whole force of his voice is spent upon the air contained in the tube, which will be agitated thmugh its whole length, and, by various reflections from the sille of the tube to the axis, the air along the middle part of the tube will be greatly condensed, and its momentum propor. tionably increased, so that when it comes to agitate the air at the orifice of the tube $\mathrm{AC}$, its force will be as much greater than what it would bave been without the tiale, as the surface of a sphere, whose radius is equal to the length of the tube, is great . er thian the surfice of the segment of such sphere, whose base is the orifice of the tube, For a persouspeaking at $\Omega$, without the tube, will nave the force of his roice spent in exciting concentric si.perfiries of air all muad the point $B$; and whem 


\section{ACOUSTICS.}

those superficies or pulses of air are diffused as fur as D every way, it is plain the force of the voice will there be diffused through the whole superficies of a sphere whose radius is BD; but in the trumpet it will be so confined, that at its exit it will be diffised through so much of that spherical surface of air as corresponds to the orifice of the tube. llut since the force is given, its intensity will be always inversely as the number of particles it has to move; and therefore in the tube it will be to that withont, as the superficies of such a sphere to the area of the large end of the tube nearly. But it is obvious, Dr. M. Young observes, that the confinement of the voice can have little cffect in in. creasing the strength of the sound, as this strength depends on the velocity with which the particles move. Were this reasoning conclusive, the voice should issue through the smallest possible orifice; cylindrical tubes would be preferable to any that increased in diameter; and the less the diamcter, the greater would be the effect of the instrument; because the plate or mass of air to be moved would, in that case, be less, and consequently the effect of the voice the greater; all which is contradicted by experience. The cause of the increase of sound in these tubes must therefore be derived from some other principles : and among these we shall probably find, that what the ingenious Kircher has siggested is the most deserving of our attention. Ile tells us, that "the augmentation of the sound depends on its reflection from the tremulous sicles of the tube; which reflections, conspiring in propagating the pulses in the same direction, must increase its intensity." Newton also seems to have considered this as the principal cause, in the scholium of Prop. 50, B. II. Princip. when he says, "We hence see why sounds are so much increased in stcntorophonic tubes, for every reciprocal motion is, in each return, increased by the generating cause." Farther, when we speak in the open air, the cffect on the tympanum of a distant auditor is produced merely by a single pulse. But when we itse a tube, all the pulses propagated from the mouth, except those in the direction of the axis, strike against the sides of the tube, and cvery point of impulse becoming a ncw centre, from whence the pulses are propagated in all clirections, a pulse will arrive at the car from each of those points. Thus, by the use of a tube, a greater number of pulses are propagated to the ear, and consequently the sound increased. 'The confinement too of the voice may hare a little effect, though not such as is ascribed to it by some; for the condensed pulses produced by the naked voice freely expand every way; but in tubes, the late. ral expansion being diminished, the direct expansion will be increased, and consequently the velocity of the particles, and the intensity of the sound. The substance also of the tube has its effect; for it is found, by experiment, that the more elastic the substance of the tube, and consequently the more susceptible it is of these tremulous motions, the stronger is the sound. If the tube be laid on any nonelastic substance, it deadens the sound, because it prevents the vibratory motion of the parts. The sound is increased in speaking-trumpets, if the tube be suspend. ed in the air; because the agitations are then carried on without interruption. These tubes should increase in diameter. from the mouth-piece, because the parts vibrating in directions perpendicular to the surface will conspire in impelling forward the particles of air, and consequently, by increasing their velocity, will increase the intensity of the sound: and the surface also increasing, the number of points of impulse and of new propagation will increase proportionably. The se. veral causes, therefore, of the increase of sound in these tubes, Dr. Young concludes to be, 1 . The diminution of the lateral, and consequently the increase of the di. rect expansion and velocity of the included air. 2. The increase of the number of pulses by increasing the points of new propagation. 3. The reflections of the pulses from the tremulous sides of the tube, which impel the particles of air forward, and thus increase their velocity.

An umbrella, held in a proper position over the head, may serve to collect the force of a distant sound by reflection, in the manner of a liearing-trumpet; but its substance is too slight to reflect any sound perfectly, unless the sound fall on it in a very' oblique direction. The exhibition of the Invisible Girl is said to depend on the reflection of sound ; but the deception is really performed by conveying the sound through pipes artfully concealed, and opening opposite to the mouth of the trumpet, fiom which it seems to proceed.

When a portion of a pulse of a sound is separated by any means from the rest of the spherical or hemispherical surface to which it belongs, and proceeds through a wide space, without being supported on either side, there is a certain degree of divergence, by means of which it sometimes becomes audible in erery part of the 
medium transmirting it: but the sound thus diverging is compantil cly very faint. Ience, in order that a speaking-trumpet unty produce its full etfect, it must be directed in a rigil: line towarts the hearer; and the sound coliceled inte the fiscus of a concave mimor is fir more powerfit than at a little clistance firm it which could not happen, if suund, in all sases, tended to sprewl equally in all directions. It is said that the report of a cannon appeurs many times loncler to a person towarls whom it is fired, than to one placed in a contrary direction. It inust, says J)r. Young, have occurred to every onc's ub. servation, that a sound, such as that of a mill, or a fall of water, his appeared much louder after turuing a corncr, when the house or other obstacle no longer intervened. Indeed, the whole theory of the speaking-irumpet would fall to the ground, if it were demonstrable that sound spreads equally in all directions. In windy wea. ther, it may be often observed, that the sound of a rlistant bell varies almost instantaneously in its strength, so as to appear twice as remote at one time as anotlier. Now, if sound diverged equally in all directions, the variation produced by the wind would not exceed one-tenth of the apparent distance: but on the suppo. sition of a motion nearly rectilinear, it nıy easily happen that a slight change in the direction of the wind shall convey a sound, eitlier directly or after reflection, in very different degrees, to the same spot.

The decay of sound is the natural con. sequence of its distribution throughout a larger and larger quantity of matter, as it proceeds to diverge every way from its centre. The actual velocity of the particles of the melium transmitting it, appears to diminish, simply, in the same proportion as the distance from the centre increases; consequently, their energy, which is to be considered as the measure of the strength of sound, must vary as the square of the distance; so that, at the distance of ten feet from the sounding body, the velocity of the particles of the unclium becounes one-tenth as great as at the distance of one foot, and their energr, or the strength of the sound, only one-jumdredth as great.

An eclio is a reflection of sound striking against some object, ts an inage is reflected in a glass : but it has been disputed, what are the proper qualities in a body for thus reflecting sounds. It is in general known, thut caverns, grottoes, nountains, and ruinad buildings, return this reflection of sound. We hatve heard of a very extmordinary eeho, at a ruined

VOL. I. fortress near I.ouvain, in Flunders. If a person sung, he ouly heard his own voice, withnut any repetition; on the contrary, those who stood at some distance heard the echo, but not the voice; but then they heard it with surprising variations, somc. times louder, sometimes softer, now more near, then more listant. There is an account, in the Memuirs of the French academy, of a similar echo near Rouen. It has been already observed, that every point against which the pulses of sound strike becomes the centre of a new series of pulses, and sound describes equal dis. tances in equal times; therefore, when any sound is propasted from a centre, and its pulses strke against a varicty of olsstacles, if the sum of the right lines diswn from that point to each of the obstacles, and from each obstacle to a second point, be equal, then will the latter be a point in whicls an echo will be heard. Thus, let $\Lambda$, fig. 4 , be the point from which the sound is propagated in all clirections, and let the pulses strike against the obstracles C, D, F, F, $\mathbf{G}, \mathbf{1}], \mathbf{1}$, \&c. each of these points becomes anew centre of pulses by the first principles, and therefore from each of them one series of pulses will pass through the point B. Now, if the scveral sums of the right lines $\overline{A C}+C B$,

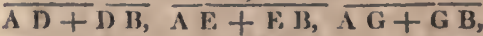

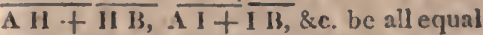
to cach other, it is obvjous that the pulses propugated from $\perp$ to these points, and again from these points to $\mathbf{B}$, will all arrive at $\mathbf{B}$ at the same instant, according to the second principle; and, therefore, if the hearer be in that point, his car will at the same instant be struck by all these pulses. Now it appears, from experiment, that the ear of an exercised musician can alone distinguish such souncls as follow one another at the rate of 9 or 10 in a se. cond, or any slower rate; and therefore, for a distinct perception of the direct and reflected sound, there should intervene the interval of $\frac{1}{9}$ of a second; but in this time sound describes $\frac{1142}{9}$ or 127 feet nearly. And thereforc, unless the sum of the lines drawn from eacl of the obstacles to the points A and $\mathrm{B}$ exeecds the interva] $A B$ by 127 feet, no echo will be heard at 13. Since the several sums of the lines drawn from the obstacles to the points $A$ and $\mathrm{B}$ are of the sane magnitude, it ap. pears that the curve passing through all the points, C, I), F, F, G, H, I, \&c. will be an ellipse. Hence all the points of the obstacles which produce an ccho must 


\section{ACOUSTICs.}

lie in the surface of the oblong spheroid, generated by the revolution of this ellipse round its najor axis. See Conic SEcrouss, As there may be several spheroids of different magnitudes, so there may be sereral different eclioes of the sanie original sound. And as there may happen to bea greater number of reflecting points in the surface of an exterior spheroid than in that of an interior, a second or a third echo may be much more powerful than the first, provided that the superior number of reflecting points, that is, the supcrior number of reflecting pulses propagated to the ear, be more than sufficient to compensate for the decay of sound which arises from its being propagated througl a greater space. This is finely illustrated in the celebrated echoes at the lake of Killarney, in Kerry, where the first return of the sound is much inferior in strength to those which immediately succeed it. From what has been laid down it appears, that, for the most powerful echo, the sounding body should be in one focus of the ellipse, which is the section of the echoing spheroid, and the hearer in the other. However, an echo may be heard in other situations, though not so favourably ; as stıch a number of reflected pulses mar arrive at the same time at the ear, as may be sufficient to excite a distinct perception. I hus a person often hears the ccho of lis own voice; but for this purpose he should stand at least 63 or 64 feet from the reflecting obstacle, according to what has been said before.

If a bell, $a$, fig. 5 , be struck, and the undulations of the air strike the wall $c d$ in a perpendicular durection. they will be reflected back in the same line; and if a per'son be situated between $a$ and $c$, as at $x$, he would hear the sound of the bell by means of the unrlulations as they went to the wall, and he would hear it again as they came back, after the reflection, which would be the echo of the sound. So a person standing at $x$ might, in speaking in the direction of the wall $c d$, hear the echo of lis own voice. But in both cases the distance $c x$ must be 63 or 64 feet. If the undulations strike against the wall obliquely, they will be reflected off obliquely on the other side; if, for instance, a person stand at $m$, and there be any obstacle between that place and the bell, so as to prevent him hearing the direct sound, he may nevertheless hear the ccho from the wall $c d$, provided the direct sound fall in that sort of oblique direction, so as to force the reflected undulations along the lime $c \mathrm{~m}$.

At the common rate of speaking, we do not pronounce above three syllables and $\mathrm{a}$ half, that is, seven half swllables in a se. cond; thicrefore, that the eclio may return just as soon as three syllables are expressed, twice the distance of the speaker from the reflecting object must be equal to 1000 feet; for as sound describes 1142 feet in a second, 6-7 ths of that space, that is, 100 o feet nearly, will be described while six half, or three whole, syllables are pronounced; that is, the speaker must stand near 500 feet from the obstacle. And, in general, the distance of the speaker from the echoing surface, for any number of syllables, must be equal to the serenth part of the product of 1142 feet multiplied by that number. In chirches we never hear a distinct echo of the voice, but a confused sound, when the speaker utters lis words too rapidly ; because the greatest difference of distance between the direct and refiected courses of such a number of pulses as would produce a distinct sound is never in any church equal to 127 feet, the limit of echoes. But though the firstreflected pulses may produce no echo, both on account of their being too few in number, and too rapid in their return to the ear, yet it is evident, that the reflecting surface may be so formed, as that the pulses which come to the ear, after two reflections or more, may, after having described 127 feet or more, arrive at the ear in sufficient numbers, and also so nearly at the same instant, as to produce an echo, though the distance of the reflecting surface from the ear be less than the limit of echoes. This is confirmed by a singular ecloo in a grotto on the banks of the little brook called the Dinan, about two miles from Castlecomber, in the county of Kilkenny. As you enter the cave, and continue speaking loud, no returu of the voice is perceived; but on your amiving at a certain point, which is not above 14 or 15 feet from the reflecting surface, a very distinct echo is heard. Now this echo cannot arise from the first course of pulses that are reflected to the ear, because the breadth of the cave is so small, that they would return too quickly to produce a distinct sensation from that of the original somin: it therefore is produced by those pulses, which, after having been reflected several times from one side of the grotto to the other, and having run over a greater spacc than 127 feet, arrived at the ear in consiclerable numbers, and not more distant from cach other in point of time than the nintli part of a second. ML, De la Grange demonstrated, that all impressions are reflected by an obstacle ter- 


\section{ACOUSTICS.}

minating an elastic fluid, with the sane ve. locity with which they arrived at that obstacle. When the walls of a passage, or of an unfirnished room, are snooth, and perfectly parallel, any explosion, or a stamping with the foot, conimunicates an impression to the air, which is reflected from one wall to the other, and from the second again towards the ear, nearly in the same direction with the primitive impulse: this takes place as frequently in a second, as clouble the breadth of the passage is contained in 1130 feet; and the ear receives a perception of a musical sound, thus determining its pitch by the breadth of the passage. On making the experiment, the result will be found accurately to agree with this explanation. If the sound is predetermined, and the frequency of vibrations such, as that each pulse, when doubly reflected, may coincide with the subsequent impulse, proceceling directly from the sounding body, the intensity of the sound will be much increased by the reflection; and also, in a less degree, if the reflected pulse coincides with the next but one, the next but two, or more of the direet pulses. The appropriate notes of a room may readily be discovered by singing the scale in it; and they will be found to depend on the pro. portion of its length orbreadt] to 1130 fect.

By altering our situation in a room, and expressing a sound, or hearing the sound of another person, in different situations, or when different objects are alternately placed in the room, that somd ma; be hearcl louler or weaker, and more urless distinct. Jlence it is, that blind persons, who are under the necessity of paying great attention to the perceptions of their sense of hearing, acquire the habit of distinguishing, from the sound even of their own roices, whether a room is empty or furnished; whether the windows are open or slut; and sometimes they can even distinguish whether any person be in the room or not. A great deal of furniture in a room checks, in a great measure, the sounds that are produced in it, for they hinder the free communication of the r. brations of the air from one part of the room to the other. The fittest rooms for declamation, or for music, are such as contain few ornaments that obstruct the sound, and at the sune time hare the least echo possible.

$\boldsymbol{A}$ strong and continued somd fatignes the ear. The strokes of heary hammers, of artillery, \&c. are ajt to make people deaf for a time: and it has been known that persons, who hare boen long osposed to the continued and confured noise of certain manufictories, or of water-falls, or other noisy places, can hear what is spoken to them much better in the midst of that noise than elsewhere.

We shall conclude this article with an experiment or two, for tlie anusement of the younger part of our readers.

Fxperiment 1. I'lace a concave mir. ror, $\mathrm{AB}$, fig. 6 , of two fect in cliameter, in a perpendicular direction, and at the distance of about fire or six feet from a partition EF, in which there is an opening equal in size to the mirror; against this opening must be placed a picture, painted in water-colours, on a thin cloth, that the sound may easily pass through it. Rehind the partition, at the distance of a few feet, place another mirror GH, of the same size as the former, and directly opposite to it. At the point $\mathbf{C}$ is to be placel the figure of a man, seated on a peilestal, with his ear exactly in the focus of the first mirror; his lower jaw must be made to open by a wire, and shut by a suring. The wire must pass through the figure, and under the floor, to come up behind the partition. Let a person, properly instructed, be placed behind the partition, near the mirror; any one may now whisper into the ear of the inuage, with the assurance of being answered. The deception is managed by giving a sigual to the person behnd the partition, who, by placing his ear to the focus I of the mirror GH, will hear. distinctly what the other said, and moving the jaw of the statue by the concealed wire, will return the answer directly, which will be heard distinctly by the first speaker.

Ex. 2. Let two heads of plaster of $\mathrm{P}$. ris be placed on pedestals, on opposite sirles of a room. A tin tube of an inch in diameter must pass from the car of one head through the pedestal under the floor, and go up to the mouth of the other. When a person speaks low into the ear of one bust, the sound is reverberated. tlirough the length of the tube, and will be distinctly heard by any one who shall place his ear to the mouth of the other. The end of the tube which is next the ear of the one head shonld be consiclerably larger than that end which comes to the mouth of the other. If there be two tubes, one going to the ear, and the other to the mouth of each bead, two persons may converse together, by applying their mouth and ear reciprocally to the moutb and ear of the busts, while other people, stancling in the middle of the room, between the hearls, will not hcar any part of tho conversation. 


\section{ACR}

Ex. 3. Fig. 7 is a representation of the Eolian harp, which was probably invented by Kircher. T'his instrument may be marle by almost any carpcuter; it consists of a long nartow box of very thin deal, about five or six inches brcad, and two inches deep, with a circle in the middle of the lipper side, of an incl and a half in diameter, in which is drilled small holes. On this sikle seven, ten, or more strings of very fine gut are stretched over bridges at cach end, like the bridge of a fiddle, and screwed up or relaxed with screwpins. The strings are all tuned to one and the same note; and the instrument is placcd in some current of air, wliere the wind call pass over its strings with free. dom. A window, of which the width is cractly equal to the length of the harp, with the sash just raised to give the air admission, is a proper situation. When the air blows upon these strings with ditferent degrees of force, it will excite different tones of sound; sometimes the blast brings out all the tones in full con. cert, and sometimes it sinks them to the softest murmul's.

There are difterent kinds of these instruments; one, invented by the Rev. W. Jones, has the strings fixed to a soundingbosird, or belly, within a rooden cuse, and the wind is admitted to them through an horizontal apcrture. In this form the instrument is portable, and nuy be used any where in the open air. The tension of the strings must not be great, as the air, if gentle, has not sufficient power to make them vibrate, and if it blows fresl, the instrument does not siug, but scream. See Hanuoxics.

ACQUI'T T $\mathrm{L}$, in law, is a deliverance or setting free from the suspicion of guilt; as one who is discharged of a felony is said to be accuitted thereof.

Acquittal is either in fact, or in law ; in fact, it is where a person, on a verdict of the jury, is found not guilty; in law, it is when two persons are inrlicted, one as a principal, \&c. the other as accessary : here, if the forner be discharged, the latter of consequence is acquitted.

ACQUITT ANCE, a discharge in writing for a sum of money, witnessing that the party is paid the same.

A man is obligerl to give an acquitance on recciving money : and a servant's acquittance for money received for the use of his master shall bind him, provided the servant used to receive his master's rents. An acquittance is a full discharge, and bars all actions, \&c.

ACRIDE, in entomology, the name by

\section{ACR}

which linnaus has distinguished the first. family of the gryllus, or the cricket, properily so called : the characters of which arc, that the liead is conical and louger than the thorax, and the antennx ensiform, or sword-sliaped. Of this family there are eight species, none of which are found is Britain. The insects of this family feed on other insects. See Guy

ACROCHOlRDUS, in natural history, a genus of the class Amphibia, and of the order Serpents. There are but three species, viz. A. javanicus, warted snake, brown, beneath paler; the sirles obscurely variegated with whitish. It inlıbits Java, chiefly among the pepper plantations ; grows sometimes to seven feet long. The warts, by means of a magnifying glass, appear to be convex carinate scales, and the smaller ones are furnished with two smaller prominences, one each side the larger. Head somewhat flattened, hardly wider than the neck, boly gradually thicker towards the middle, and suddenly contracting near the tail, which is short, and slightly acuminate. A. dubius, which very nearly resembles the javanicus, except that the head is covered with very minute, rough and warted scales, differing in size alone from those on the other part of the animal. The dubius measures only about three feet in length. A specimen is to be seen in the British Museum. Its native place is not ascertained. A. fasciatus, resembles the dubius so much, that some naturalists suppose them both to be of the same species, and differing only in age and cast of colours. The specimer in the Rritish Museum is abont eighteen inches long. Sec plate Serpentes, fig. 1.

ACRONICHAL, or AcrRovrcak, in astromony, an appellation given to the rising of a star above the liorizon, at sumset; or to its setting when the sun rises. Acronichal is one of the three poetical ris. ings of a star : the other two being called cosmical and helical.

This tem is also applied to the superior plancts, Saiurn, Jupiter, and Mars. when they are come to the meridian of midnight.

ACROS 2 ERMUM, in botany, a genuk of the Cryptogamia Fungi class and order; fumgus quite simple, nearly erect, emitting the seeds exteriorly from the top. Therc are four species.

ACIROS'1CUM, misty-back, woll-me, or forked-fern, in botany, a genus of the Cryptogramia Fices; the character of which is, that the fructifications cover the whole inferior surtice of the leaf There are. 


\section{AC'I}

45 species, distributed into different classes. Few of the species have been introduced into gardens. Those of Europe may be preserved in pots, filled with gravel and line-rubbish, or planted on walls and artificial rocks; but most of them, being natives of very hot climates, must be planted in pots, and plunged into the bark pit.

ACT K.A, in botany, a genus of plants of the l'olyandria Monogynia class and order. Gen. claaucter: calyx perianth, four-leaved; leaflets roundish, obtuse, concave, caducous; cor. petals four, acuminate at both ends, larger than the calyx; filaments about 30 ; germ superior ovate: no style : stigma tlickish, obliquely depressed; jeriearp a berry, ovalglobose, smooth, one-furruwed, one celled; seeds very many, seıni-orbicular, lying over each otlier in two rows. There are four species, viz. the spicat: ; racemoss ; japonica ; and aspera. Of the first there are sarieties, of the black-berried herb Christoplier, or bane-berry, found in the northem parts of England; the Cluristopher, with white berries, a native of America; and that with red berries. The racemosa, or black snake-root, found also in America, of which the root is much used in many disorders, and is supposed to be an antidote against the bite of the rattle-snake, This species is now more properly referred to the genus Cimifuga, and is called by Pursh Cimifuga Serpentaria. See Crmafean. 'The leaves of the A. aspera, being extremely rough, the Chinese use them in polisfing their tin ware.

ACTINLA, in natural history, a genus of the Mollusca order of worms ; the characters of which are, body oblong, cylindrical, fleshy, contractile, fixed by the base; mouth terminal, expansile, surrounded with numerous cirri, and without any aperture. There are 36 species. These marine animals are viviparous, and liave no aperture but the mouth. They feed on shell-fish and other marine animals, which they draw in with their feelers, in a short time rejecting through the same aperture the shells and indigestible parts. They assume various forms, and where the tentacula or feelers are all expanded, hase the appearance of full.blown flowers. Many of them are eatable, and sume of them very sapid.

ACTINOLITE, in mineralogt, a family, oomprehending six species, viz. the actinolite, smaragdite, tremolite, cyanite, syalite, and sclialstone. The actinolite oc. curs chiefly in beils in primitive mountains, and is divided into three sub-species,

\section{$\mathbf{A C} \mathbf{I}^{\prime}$}

viz. the asbestos, common and glassy: The asbestos colours greenish grey, mous: tain green, smelt bluse, olive green, yetlowisli, and biver-brown. Massive, and in capillary cristals. Soft; brittle; specific gravity 2.5 to 2.9 . Melts before the blow: pipe. The usual colour of the common is leek grcen, but its specific gravity is between 3.0 and 3.3 . The principal colour of the glassy is mountain green, passing to the emerald green. Specific gravity 2.9 to 3.9 .

ACIION, in mechanics and physics, is the influence of one body upon another, in gesserating or destroying its motion. It is one of the laws of nuture, that action and reaction are equal, that is, the resistance of the body moved is always equal to the force communicated to it : or, which is the same thing, the moving body loses as much of its forec as it communicates to the body moved.

If a body be urged by equal and contrary actions or pressures, it will remain at rest. But if one of these pressures be greater than its opposite, motion will ensue toward the parts least pressed.

It is to be observed, that the sctions of bodies on each other, in a space that is carried uniformly forward, are the same as if the space were at rest; and any powers or motions that act upon all bodies, so as to produce equal velocities in them in the same, or in parallel right lines, have no effect on their mutual actions, or rela. tive motions. Thus the motion of bodies aboard a ship, that is carried steadily and uniformly forward, are performed in the same manner as if the ship was at rest. The motion of the earth round its aris has no effect on the actions of bodies and agents at its surface, but so far as it is not uniform and rectilineal. In general, the actions of bodies upon each other depend not on their absolvte, but relative motion.

Acriox, in law, denotes either the right of demanding, in a legal manner, what is any man's due, or the process brought for the recovering the same.

Actions are either criminal or civil.

Criminal actions arc to have judgment of death, as appeals of death, robbery, \&c. or only judgment for damage to the injured party, fine to the king, and imprisonment.

Under the head of criminal actions may likewise be ranked penal actions, which lie for some penalty orpunishment on the party sued, whether it be corporal or pecuniary.

Also actions upon the statute, brought on breach of any eatute, or act of partir. 
meut, by which an action is given that did not lie before; as where a person commits perjury to the prejudice of another, the injured party shall have an action upon the statute. And lastly, populur actions, so called, because any person may bring them on bchalf of himself and the crown, by information, \&c. for the breach of some penal statute.

Civil actions are divided into real, per sonal, and mixed.

Real action, is that whereby a man claims a title, lands, tenements, \&c. in fee, or for life, and this action is either possessory, or ancestral; possessory, where the lands are a person's own possession or seisin; ancestral, when they were of the possession or seisin of his ancestors.

Personal action, is one brought by one man against another, upon any contract for money or goods, or on account of trespass, or other offence committed; and thereby the debt, goods, cliattels, \&c. claimed.

Mixt action, one lying as well for the thing demanded as against the person who has it; and on which the thing is recovered, with damages for the wrong sustained; such is an action of waste, sued against a tenant for life, the place wasted being recoverable, with treble damages for the wrong clone.

ACTS of parliament, statutes, acts, edicts, made by the king, with the advice and consent of the lords spiritual and temporal, and commons, in parliament asse mbled. In act of parliament is the highest possible authority, and hath power to bind not only every subject, but the king himself, if particularly named therein, and cannot be altered or repealed but by the same authority. Where the common law and the statute law differ, the common law gives place to the statute, and an old statute gives place to a new one. Penal statutes must be construed strictly; thus a statute of Fdw. I. having enacted, that those convicted of stealing horses should not have the benefit of clergy, the judges conceived that this did not extend to him that should steal but one horse, and a new act for that purpose was passed in the fol. lowing year. Statutes against frauds are to be liberally and beneficially expounded. One part of a statute must be consturied. by another, that the whole may, if possible, stand; - a saving clause totally repugnant to the bocly of the act. If a statute that repeals another is itself repealed afterwards, the first statute is hereby revived. Acts of parliament derogatory from the pow er of subsequent parliaments bind not. Acts of parliament, that are impossible to be performed, are of no validity.

ACULEATE, or Aculeaten, an appellation given to any thing that has aculei, or prickles: thus fishes are divided into those with aculeated and not aculeated fins.

The same term is applied, in botany, to the stems and branclies of those plants that are furnished with prickles, as the rose, the raspberry, and barberry trees. 'The prickle differs from the thorn, which is another species of armature, or defence, agrinst animals, in being only a prolongation of the cortex or outer bark of the plant, and not connected with nor protiuded from the wood. This is apparent, from the ease with which such prickles are detacbed from the stem with the bark, while the other and more rigid species of weapon, being an expansion of the ligneous body, cannot bedetached, without reudering and tearing the substance of the wood. Prickles are either straight, as in the solanum indicum; or bent inwards, as in the mimosa cineraria; or bent outwards; or downy, that is, covered with a sort of wool. See To nextum.

ACUMINATE, in natual history, a term applied to fishes whose tails end in a sharp point.

AD. a Latin preposition, expressing the relation of one thing to another.

It isfrequently prefixed to other words : thus,

In hominem, among logicians, an argument drawn from the professed belief or principles of those with whom we argue.

Av valorem, among the officers of the king's revenue, a term used for such duties, or customs, as are paid according to the value of the goods sworn to by the owner.

ADAGIO, in nusic, signifies the second degree of music from slow to quick. It is applied to music not only meant to be performedinslow time, but also with grace and embellishment.

ADAMANTINE spar, in mineralogy, one of the species of the ruby family, found only in China. Colour dark, hair brown. Massive, crystallized in six-sided prisms, and six-sided pyramids, having their apex truncated. Specific gravity 3.98. See Rсву.

ADAMBFA, in botany, a genus of the Polyandria Monogynia class and order, of which there is but a single species, which grows on the coast of Malabar, in sandy and stony places; rises to about serenfeet, and sends forth branches, which 


\section{ADD}

are terminated by panicles of fine purple Howers, large, and resembling roses.

AD.INSUNI.A, in botany, a genus of the Monarlelphia orrler, and lolyandria class, named after .tichael Adanson, an indefatigable French naturalist. 'The $\mathbf{A}$, digitati, Fitliopean sour-gourd, or monkies' bread, called also absivo, is the on!y species known of this genus.

Al)lir. Sce Colving.

A)DITION, in arithmetic, the first of the four fundamental rules of that art, whereby we find a sum equal to several smaller ones. See Algrara and ArituMETIC.

Anmrioss, in law, denote all manner of lesignations giren to a man, over and above his proper name and surname, to sliew of what estate, degree, mystery, place of aborle, \&c. he is.

Additions of degree are the same with titles of honour or lignity, as knight, lord, carl, lluke, \&.c.

Additions of estate are yeoman, gentle. man, esquire, and the like.

Additions of mystery, or trule, are, car. penter, mason, painter, engtaver, and the like.

Additions of place, or residence, are, London, Edinburgh, Bristol, York, GLasgow, Abericen, \&c.

These additions were ordained, to pre. vent one man's being grieved, or molested, for another; and that every person might be certunly known, so as to bearhis owil burlen.

If a man is of differcnt degrees, as duke, earl, \&c. Jie shall have the most worthy; and the title of knight, or baronet, is part of the party's name, and therefore ought to be riglitly used; whereas that of esquire, or gentleman, being as people please to call then, may be used, or not, or varied at plcasurc.

A Peer of Ireland is no addition of lio. nour here; nay, the law-acdlition to the children of liritish noblemen is only that of escuire, commonly called lord.

Writs without the proper alcitions, if excepted to, shall abate; only, where the process of ontlawry dn:h not lie, aclitions are not necessary. The atdition of a parish, not in any city, mast mention the county, otherwise it is not good.

Anirsos, in heraldry, something added to a coat of aums, as a mark of honour; and therefore directly opposite to abatement.

ADI)CCTOR, in anatomy, a general name for all sich muscles as serve to draw one part of the body towarls another. See Axaтомг

\section{$\triangle \mathrm{DH}$}

ADFLI1, in botany, a genus of the Dioecia Gynandria class and order. Male: calyx threc-parted; no corolla; stamina numerous; unted at the base. Female : calyx five-parted; no corolla; styles threc, lacerated. Capsule three-grained.

ADENANTIIERA, in botany, a genus of the Decaudna Monogynia class of plants, the calyx of which is a sinfric -leaved perianthium, very small, anul eut into five segments: the corollaconsists of fire lanceolated bell-shaped petals; the firuit is a long membranaceous compressed pod, containing several round secils. There are tluree species: $\boldsymbol{A}$. paronina, which is one of the largest trees in the last Indics. Its duration is 200 years, and its cimber is much userl on account of its soliclity : the powder of the leaves is used in their reli. gious ccremonies; the seels are euten, and also valueil as weiglits, being each of them four grains. 'This species must be raised on a hot-bed from seeds. It has never flowered in England : it is of very slow growth. The other species, viz, the A. filcata, and A. scandens, have not been cultivated in this comntry.

A DFNIA, in botany, a genus of the Ilexandria Monogynia elass and order, that grows in Arabia. There is but one species, which is mentionerl by Forskal, in his Flor. Aggyt. He says, that the pow: der of the young branclies mixed in any kind of liquor is a strong poison, and that the capparis spinosa is an antidote to it.

AUFECT F.D equations, in al gelura, those wherein the unknown quantity is found in two or more different powers: such is $x^{3}-a x^{3}+b x=a^{2} b$.

A DII FSION, in philosopliy and chemis. try, is a term generally marle use of to ex. press the property which certain bodies have, of attracting to themselves other bodies, or the furec by which they adhere together: thus, water adheres to the finger, mercury to gold, \&c. Hence arises an important distinction between two words, that in a loose and popular sense are often comfounded. Adhesion, clenotes an imion to a certain point between two dissinilar substances ; and coliesion, that which retains together the component particles of the same mass. Sce Cous. siox.

Adhesion may take place cither be. tween two solids, as two hemispheres of glass, which, according to an experiment of Desaguliers, alhere to each other with a force equal to 19 ounces on a surface of contact one-tenth of an inch in diameter; or between solids and fluids, as the sus- 
pension of water in capillary tubes; or, lustly, between two fluids, as oil and water. About the same time Mr. Haukshee proved, experimentally, the error which. Bernoulli had fallen into, in attributing the adhesion of surfaces and capillary attraction to the pressure of the atmosphere. Nevertheless, in $1772, \mathbf{M} . \mathbf{M}$. Ia frauge und Cigna, taking for granted a natural repulsion between water and oily substances, imagined, if there was an at-

- hesion between water and oll, or tallow, that it must be oecasioned by a cause different from attraction : and having ascertained the reality of the arlhesion, they concluded that it was occasioned by the pressure of the air, and that Lr. 'Taylor's method was not well founded.

Such was the state of opinions on the subject, when, in 1773, Guyton Morveau made his celebrated experiments on adhesion, in presence of the Dijon Academy, demonstrating, as irdeed Hauksbee had. dohe before him, not only that water ascends between two parallel plates of tallow, separated frum each other 1.8 of a line, but also that the atmospheric pressure is not in the least degree the cause of the phenomenon, which is solely attributable to attraction; in proof of this, a polished disk of glass, $3 u$ lines in diameter, was suspended to the arm of a balance, aud brought into contact with the surface of mercury: the counterpoise required to separate it was equivalent to 9 gros and a few grains, and upon moving the apparatt:s into the recciver of an airpump, and forming as perfect a vacuum as pussible, precisely the same counterpoise was required as before.

In the prosecution of his inquiries on this subject, he observed, that the same disk of glass, which, when in contact with pure water, adhered to it with a force equal to 258 grains, required a counterpoise of only 210 , in order to separate it from a solution of potash, notwitlistanding the superior density of this last. This inequality of effects on equal diameters, and in an inverse order to that of the respective specific gravities of the two fluids, appeared not only to be decisive in favour of 1rr. 'Taylor's methoil, but to encourage the hope of applying it to the calculation of chemical affinitics.

In order to verify this proposition, plates of the different metals in their highest state of purity were procurecl, perfectly round, an inch in diameter, of the same thickness, well polislied, and furnished with a small ring in the centre of each, so as to kecp them suspended precisely parallel to the plane of the hori. zon. Fach of these plates was in turu suspended to the arm of an assay balance, and cxactly counterpoised by weights placed in the scale attached to the opposite arn; the plate, thens balanced, was applied to the surface of some mercury in a cup, about two lines beneath it, by sliding the plate orer the mercury, as in the silvering of mirrors, so as to exclude every bubble of air; weights were then sucressively added, till the adlicsion be. tween the plate and the mercury was broken. Fresh mereury was used for each experiment. The following is the table of results :

(iold adberes to inercury with

a force equal to . . 446 grains.

Silver ... . . 429

Tin . . . . 418

Jead . . . . . . . 397

Bisinuth : : : 372

Tinc. . . . . 204

Copper . . . . . 142

Antimony (regulus) : . 126

Irnn . . . 115

Cobalt : $\because \quad 8$

The striking differences in the above tahle shew that the pressure of the at mosphere has no share in them, since in this respect the circumstances of each were precisely similar; nor do they depend on the respective specific gravities ; for if so, silver should rank after lead, cobalt before zinc, and iron hefore tin.The only order which agrees with the above is that of the chemical affinity of these metals, or the respective degrees of their solubility in mercury. It is highly probable, therefore, that at least the principal part of the adiuesive force thus found by experiment is owing to chemical affinity ; and that the above numerical series, $446,429,418,397, \&$. . is an approximation towards the ratio of the relative affinities of gold, silver, tin, lead, \&c. for mercury.

ADIAFTHUM, Maidenhair, in botany; the name of a genus of plants of the Cryptogamia Filices class and order, the characters of which are, that the fructifications are collected in oval spots at the ends of the leaves, which are folded back. There arc forty-four species, of which one only belongs to Great Britain, viz. the A. capillus veneris, which is found rarely in Scotland and Wales, on rocks and moist walls, and which is a native of the south of Europe and the Levant. From this the syrup of capillaire is made. Another species, the Adlianthum pedatum, was formerly esteemed as a valuable article 


\section{ADIPOCIRE.}

of the Materia Medica. It has, however, fallen into disrepute.

ADIPOCIRE, is a term formed of adeps, fat, and cera, wax, and denotes a sub. stance, the nature and origin of which are thus explained. The ehanges which aniinal matter undergoes in its progress towards total decomposition have been, for many obvious reasons, but little attended to. But an opportunity of this kind was offered at Puris in 1786 and 1787 , when the old burial ground of the Innocens was laid out for building upon, in conse. quence of which, the surface soil, and the animal remains contained therein, were removed. This cemetry baving been for ages appropriated to the reecption of the dead, in one of the most populous elistricts of Paris, was eminently well calculated to exhibit the various process. es of animal decomposition; another favourable circumstance was, that it contained several of those large pits (fosses communes) in which the bodies of the poor are deposited by hundreds. These pits are cavities 30 feet deep, with an area of 20 feet square, in which the shells containing the bodies are closely packed in rows over each other, without any intermediate earth, and with only a slight su. perficial covering of soil, not more than a foot thick : ench pit contained from 1200 to 1500 bodies, and may be considered as a mass of animal matter of the dimensions above mentioned. M. M. Fourcroy and Thouret were present at the opening of several of these receptacles; and it is from a memoir by the former of these, that the principal part of this article is composed. The first pit that was examined had been filled and closed up fifteen years before; on opening some of the coffins (for the wood was still quite sound, only tinged of a yellow colour) the bodies were found witlin shrunk, so as to leave a considerable vacant space in the upper part of the coffin, and flattened, as if they had been subject to a strong compression; the linen which corered them adhered hrmily, and upon being removed, presented to view only irregular masses of a soft, ductile, greyish-white matter, apparently intermediate between fat and wax; the bones were enveloped in this, and were found to be very brittle. The bo. dies, thus changed, being but little offensive to the sinell, a great number were dug up and minutely cxamined: in some this alteration had, as yet, only partially taken place, the remains of muscular fibres being still visible: lut where the VOL. 1 . conversion had been complete, the bones throughout the whole body were found co. vered with this grey subsiance, generally soft and ductile, sometimes clry, but al ways readily separating into porous cavernous fragments, without the sliglitest trace of muscles, membranes, vessels, tendons, or nerves: the ligaments of the articulations had been in like manner changed; the connexion between the bones was destroyed, and these last had become so rieldung, that the grave-diggers, in order to remove the bodies more conveniently, rolled each upon itself from head to hee!s, without any difficulty. According to the testimony of these men, to whom the facts just mentioned had been long familiar, this conversion of animal matter is never observed in those bodies that are interred singly, but always takes place in the fosses communes: to efficet this change, nearly three years are required. The sospy matter of latest formation is soft, very ductile, light, and spongy, and contains water; in 30 or 40 years it becomes much drier, more brittle, and assumes the appearance of dense laminze, and where the surrounding earth has been drier than usual, it is sometimes semi. transparent, of a granulated texture, brittle, and bears a considerable resem. blance to wax. Animal matter, having once passed into this stage of decompcrition, appears to resist for a long time any further alteration: some of these pits that had been closed above 40 years were, upon examination, found to be little else than a solid mass of soapy matter; nor is it yet ascertained, how long in common circumstances it would contin uc unchanged, the burial ground of the Innòcens being so sinall, in comparison to the population of the clistrict, as to require each pit in 30 or 40 ycars to be emptied of its contents, in order to receive a new succession of bodies: it appears, however, that the ulterior changes depend in a great measure on the quantity of moisture draining through the mass. From the history of this singular substance, we proceed to an examination of its chemical properties. It was first, however, puri. fied by gently heating in an earthen vessel, till it became of a pasty consistence, and then rubbed through a fine hair sicve, by which means the hair, small bones, and remains of the muscular fibre, were separated with tolerable exactness. In this state, being exposed in an earthen vessel to the naked fire, it readily became soft, but did not liquify without consider. 
able difficulty, rather frying as a piece of soap would do, and disengaging at the same time ammoniacal vapours. Four pounds being put into a glass retort, and submitted to slow distillation in a water bath, afforcled in the space of three weeks eight ounces of a clear watery fluid, with a fectid odour, turning syrup of violets green, and manifestly containing ammonia in solution; the soapy matter remaining in the retort had acquired a greater consistence, was become less fusible, of a deeper brown colour, and, upon cooling, was evidently dirier than before, though not admitting of being broken. Eight ounces of soapy matter, white and purified, were mixed with an equal weight of powdered quick lime; on the addition of a little water, the mass heated, swelled, and disengaged a very strongly ammoniacal vapour, accompanied by a peculiar putrescent smell; a sufficiency of water being then added, to bring the whole to the state of an emulsion, it was heated to ebullition, much ammoniacal vapour escaping at the same time; the liquor being thrown on a filter, passed perfectly clear and colourless, and appeared to be only lime-water, with a very small quantity of soap in solution: the matter remaining on the filter, being well washed, was beaten up with water, but shewed no tendency to unite with it, subsiding after a time in the form of a white mass; this, by drying for a few days in the openair, became grey, and much reduced in volume: it was then mixed with diluted muriatic acid, which immediately rlecomposed it, and a number of white clots rose to the sufface of the liquor. This last being obtained clear by fittration,yielcled erystals of muriat of lime, and a slight trace of phosphoric salt; the white clots being washed and dried, and afterwards melted in a water bath, cooled into a dry; com. bustible, oily matter, brittle, waxy, crystallizable, and perfectly insoluble in water, to which the name of adipocire has been appropriated. From this series of experiments with lime, it appears that the soapy matter is a true ammoniacal soap, with a base of adipocire, to which lime has a stronger affinity than ammonia; but whieh last composition is again in its turn decomposed by all the aeids, learing the adipocire in a state of purity. lotash and soda produce effects perfectly analogous to these of lime. To the foregoing experiments of Fourcroy, a few facts have since been added by Dr. Gib-

bes. The reeptacle at Oxford for those bodies, which have been used by the andtomical professor there for his demonstrations, is a hole dug in the ground to the depth of thirteen or fourteen feet, and a little stream is turned through it, in or. cler to remove all offensive smell: the flesh contained in this was found, on examination, to be quite white, and for the most part changed into the soapy matter above mentioned. From this hint, pieces of lean beef were enclosed in a perforated box, and placed in running water, and at the end of a month were found converted into a mass of fatty matter; this change was observed to take place much sooner, and more completely, in running than is stagnant water: in order to get rid of the fetid smell, nitrous acid was had recourse to, which inmediately had the desired effect; a waxy smell was perceived, and by melting the matter it was obtained nearly pire; the yellow colour, which had been given to it by the nitrous acicl, was wholly discliarged by the oxymuriatic acicl. A similar conversion of muscular fibre takes place by maceration in very diluted nitrous acid. Dr. Gibbes has not mentioned whether the fatty matter produced by running water is pure adipocire, or ammoniacal soap: it appears probable, however, that it is in the former state; where nitrous acid is the men. struum employed, it is obviously impossible that the adipocire should be combined with an alkali.

ADIT of a Mine, the hole or aperture whereby it is entered and dug, and by which the water and ores are carried awav; it is distinguished from the airshaft. The adit is usually made on the side of a hill, towards the bottom, about four or six feet ligh, and eight wide, in form of an arch; sometimes cut into the rock, and sometimes supported with tim. ber, so conclueted, as that the sole or bottom of the adit may answer to the bottrm of the shaft, only somewhat lower, that the water may have a sufficient current to pass away without the use of the pump.

AD.IUTAGE, or AJotage, in hydraulies, the tube fitted to the mouth of a pipe through which a fountain plays. See IIrmuertes.

ADJUTANT, in the military art, an officer whose business is to assist the major, and therefore sometimes called the aid-major.

Anjetast-general, an officer of distinction, who assists the general in his laborious duty: lie forms the several de- 


\section{ADM}

lails of the cluty of the army with the hrigade majors, and keeps an account of the state of each brigarle and regiment. In the day of batte he sees the infuntry drawn up, after which be places himself by the side of the general, to receive orders. In a siege he visits the several posts, gires and signs all orders, and lias a serjeant from each brigade to carry any orders which he mav have to send.

AIME.ASUREMENT, in law, a writ for acljusting the sluares of something to be diriderl. 'Thus, admeasurement of dower takes place, when the widow of the deceased clains more as her dower than what of right belongs to her. And ad. neasurement of pasture may be obtained, when any of the persons who have right in a common pasture puts more cattle to feed on it than he ought.

ADMINISTRATOR, in law, the per. son to whom the goods, effects, or estate of one who died intestate are entrusted; for which lie is to be accountable when required.

The bishop of the diocese, where the party dies, is regularly to grant administration; but if the intestate las goods in several dioceses, alministration must be granted by the archbishop in the prerogative court. The persons to whom admin. istration is granted are, a husband, wife, chilkren, whether sons or daughters, the father or mother, brother or sister, and, in general, to the next of kin, as uncle, aunt, cousin; then to a creditor.

An action lies for and against an administrator, as for and against an executor; only that he is accountable no farther than to the value of the goods.

AI) MIIRAL, in maritime aftairs, a great ufficer, who commands the naval forces of a kingdom or state, and decides all maritime causes. For the latter purposes a commission has been instituted in Finglanel, who, by a statute of $W$. and M. have the same authority as the Lord Iligh Admiral. The admirals of Fingland are merely naval conmanders. Fivery other business relative to the navy at jarge is direeted by the 1.orrls Commissioners of

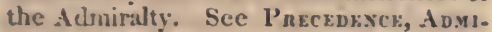
hatty Count, \&.c.

ADMIRAI:TY, properly signifies the office of I.ord II igh Admiral, whether dis. clsarged by one or sereral joint commis. sioners, called I.orls of the Arlmirslry.

Anminatry-Court, or Court of Admiral. $\mathrm{ty}$, in the British polity, a sovereign court lield by the Lord High Admiral, or the Commissioners of the Admiralty.
This court has cognizance in all mari. time aff:irs, eivil as well as criminal. All crines conmitter on the high-seas, or in great rivers, beneath the brilge next the se:, are cognizable only in this court; which, by statute, is obliged to try the same by judge and jury. But in civil causes it is otherwise, these being all de. termined according to the civil law; the reason wheren is, because the sea is without the jurisdiction of the common law.

In ease any person be sued in the admiralty-court, contrary to the statutes, he may have the writ of supersedeas, to stop farther proceedings, and also an action for double damages against the person suing.

Suborlinate to this court, there is ano. ther of equity, called Court-merchant; wherein all causesbetween merchants are decided, agreeable to the rules of the. civil law:

ADOLIA, in botany, a genus of plants found among the trees at Nalabar, which bear a near relation to the rahmnus.There are two species, viz. A. alba, with white flowers, which grows to the height of seven or eight feet, and bears fruit twice a year: the berries, when ripe, are of a purplish black colour : and A. rubra, with red flowers: but the berries, when ripe, are of an orange colour, and of an acid taste.

A1)ONIS, Pheasant's Eye, or Red Mitiths, in botany, a genus of the l'olyandria Polygynia class of plants, the calyx of which is a perianthium, composed of fire obtuse, hollow, somewhat coloured and deciduous leaves"; thic corolla consists of five oblong obtuse beautiful petals, and sometimes there are more than five; there is no pericarpium; the receptacle is olslong, spicated, and holds five series of seeds: the secls are numerous, irregular, and angular, gibbous at the base, and their apex reflex and prominent.There are six species, viz. the $\mathbf{\Lambda}$. restivalis, or tall, which is a native of the southern eountries of Europe, where it grows among corn: the $\hat{\Lambda}$. autumualis, or common, which are found in Kent, near the Medway, in fields sown with wheat: the flowers are brought in great quantities to Lonuton, whice they are solsl under the name of lied Morocco: this is annual, and flowers from May to October: A. vernalis, or spring arlonis, is found in Switzerlaud, l'mussia, and sone parts of Germany : A. apennina is found wild in Siberia: A. vescatoria, or blister adonis, 
and the $\mathbf{\Lambda}$. capensis, are used by the $\boldsymbol{\Lambda}$ ricans for raising blisters. To these lave been added two other species, viz. the miniata and the flammca.

ADOXA, in botany, a genus of the Octandria Tetragynia class of plants, the corolla of which is plain, and consists of a single petal, divided into four oval acute segments, longer than the cup; the fruit is a globose berry, situated between the calyx and corolla; the calyx adheres to its under part; the berry is umbilicated, and contains four cells; the seeds are single and compressed. There is but a single species, viz. the A. moschatellina, bulbous fumitory, which grows naturally in shady places and woods, as in Hampstead and Charlton woods; it is perennial; flowers in April and May. The leaves soon after decay, and the flowers smell like misk, on which account it has sometimes been called musk-crowfoot.

AD QUOD DAMNUM, in law, a writ which ought to be issued before the king grants certain libertics, as a fair, market, or the like; ordering the sberiff to inquire by the country what damage such a grant is like to be attended with.

ADRIFT, in naral affairs, the state of 2 vessel broken loose from her moorings, and driven to and fro by the winds or waves.

ADVERB, adverbium, in grammar, a word joined to verbs, expressing the manner, time, \&cc. of an action; thus, in the phrase, it is conducive to health to rise early; the word early is an adrerb; and so of others.

ADVERSARIA, among the ancients, was a book of accounts, not unlike our journals or day books.

Adversaria is more particularly used, among men of letters, for a kind of common-place book, wherein they enter whatever occurs to them worthy of notice, whether in reading or conversation, in the order in which it occuss: a method which Morbof prefers to that of digesting them under certain heads.

ADVOCATE, Lord, one of the officers of state in Scotland, who pleads in all causes of the crown, or wherein the king is conccrned.

The lord adrocate sometimes happens to be one of the lords of session; in which case, he only pleads in the king's causes.

ADVOWSON, in law, is the right of patronage, or presenting to a vacant benefice.

Advowsons are either appendant, or in 'gross. Appendant acirowsons ars tlose which depend on a manor, or lands, and pass as appurtenances of the same: whereas advowson in gross is a right of presentation subsisting by itself, belonging to a person, and not to lands.

In either case, adrowsons are no less the property of the patrons than their lancled estate : accordingly, they may be granted away by deed or will, and are assets in the hands of exccutors. How: ever, Papists and Jews, seized of any advowsons, are disabled from presenting; the right of presentation being in this case transferred to the chancellors of the universities, or the bishop of the diocese.

Adrowsons are also presentative, collative, or donative. Presentative, wherc the patron hath right of presentation to the bishop or ordinary; collative, where the bishop is patron; and donative, where the king, or any subject. This license founds a church or chapel, and ordains that it shall be merely in the gift of the patron.

ADZE, a cutting tool, of the are kind, having its blade thin and arching, and its edge at right angle to the handle; chiefly used for taking thin chips off timber, \&c. It is used by carpenters, but more frequently by coopers.

ÆCIDIUM, in botany, a genus of the Criptogamia Fungi class and order. Its characters are, that it lias a membranaceous sheath, smooth on both sides, and full of naked separate sides. There are 18 species, of which several are found on the leares of other plants, and one of them is known to agriculturalists by the name of red gum. This species usually grows upon the inside of the glumes of the calyx, and of the exterior valvule of the corolla, under their cpidermes, which, when the plant is ripe, bursts, and emits a powcler of a bright orange colour.Other species grow on decaying wood and mosses, and in the leaves of tussilago, farfara, \&:c.

IEGICERAS, a genus of the Pentandria Monogynia class and order: calyx firecleft; petals five ; capsule curved; onecelled; onc-ralved; one-seeded; two species found in the Moluccas.

IEGILOPS, grat's face, in botany, a genus of the Triandria Digynia class and order, and of the natural order of grasses : the characters are, that the hermaphrodite calyx is a large bivalvular glume, sustaining three flowers; the valves are ovate, and streaked with various awns: the nectary two-leared, with very sman] 
leaflets: the stamina have three capillary filaments with oblong antlers; the pistil. lum is a turbinate germen; no pericardium; the seeds are oblong, conrex on one side, grooved on the other, with the inner valve of the corolla adhering to it, and not opening. There are six species.

EIINET A, in botany, a genus of the Didynamia Angiospermia class and order: calyx one-leafed, spathaceons; corolla campanulate, two-lipped; capsule many celled: one specics, viz. the $\mathbf{X}$. Indicin found at Malabar.

EGIPIIIIA, goat's-fivend, a genus of the Tetrandria Monogynia class and order, and the natural order of Vitices: the calyx is a one-leafed permanent perianthiuni; the corolla is one-petalled, and longer than the calyx; the stamina are capillary filaments, inserted into the mouth of the tube; the pistillum is a roundish su. perior germ, style capillary, decply bifid, and stigmas simple; the pericarpium is a roundish two-celled berry, surrounded with a permanent calyx; and the seed is cither in pairs or solitary. 'There are se. ren species, natives of the W. Indies, chicfly of Jamaica.

IEGLE, in botany, a genus of the Poly. andria Monogynia class and order : calyx five-lobed; petals five; berry globular, many celled, with numerous secds in each. One species, viz. the marmelos, a tree with thorny branches; fruit delicious to the taste, and exquisitely fragrant; seeds imbedded in an extremely tenaccous transparent gluten.

EGOPODUM, in botany, a genus of the Pentandria Digynia class of plants; the general corolla whereof is uniform; the single flowers consist each of five, oval. concare, and nearly equal petals ; the fruit is naked, ovato-oblong, striated, and separable into two parts; the seeds are two, orato-oblong, and striated, convex on one side, and plain on the other. There is but one species, viz. \#: podagraria, gout-wced, which is a perennial, creeping weed, with white flowers, that appear in May or June. It has been used in eases of gout, whence it derives its name. It is voiled for greens, and eaten in Sweden; cows, sheep, and goats, eat it. It is found amongrubbish in shady places, and in hedges.

EGOPRICON, in botany, a genus of the Monandria Trigynia class and order : the male flowers are small, in an ovate ament; their calyx onc-leafed; no coml. $l a$, the stamina of one filament longerthan the calyx, with an ovate anther; the female flowers are on the same plant, and solitary; the caly $\mathbf{x}$ and corolla are the same as the male; the pistillum has au ovate superior germ, three divaricate styles, with simple permanent stigmas; the pericardium is a globular herry; the seeds are solitary, and angular on one side. There is but one species, viz. $£$. betulinum, which is a tree rety much branched, with wrinkled bark and alter. nate leaves resembling those of the myrtlc.

EOLIPILE, a hollow metalline ball, in which is inserted a slender neck or pipe; from whence, after the ressel has been filled with water, and heated, issues a blast of wind with great rehemence.

Great care should be taken, that the aperture of the pipe be not stopped when the instrument is put on the fire, other wise the arolipile will burst with a vast explosion, and may occasion no little mis. chief. Dr. Plot gives an instance, where the rolipile is actually used to blow the fire; the lord of the inamor of Fffington is bound, by his tenure, 20 drive a goose crery New-year's day three times round the hall of the lord of Ililton, while Jack of Hilton (a brazen figure having the structure of an reolipile) blows the fire. In Italy, it is said, that the xlopile is com. monly made use of to cure smoky chim. neys; for being hung over the fire, the blast arising from it camies up the loitering smoke along with it.

An zolipile of great antiquity, made of brass, was lately dug up in the site of the Basingstoke canal, and presented to the Antiquarian Society in London. It is not globular, with a bent tube, but in the form of a grotesque human figure, and the blast proceeds from the mouth.

EOLUS'S harp, or Eolrax harp, a musical instrument, so named from its producing an arrecable harmony merely by the action of the wind. See Acoustrss. ERA, a fixed point of time, from which any number of years is begun to be reckoned. Sce Chasvolugr.

AFROSTATION, in the modemapplication of the term, signifies the art of navigation tlirough the air, both in its prin. ciples and practice. IIence also the ma. clines which are employed for this pur. pose are called acrostats, or acrostatic machines; and oul account of their round figure, air balloons.

The fundamental principles of this art have becii long and generally known; a]. though the application of thein to prac. tice seems to be altogether a modern dis. covery. It will be sufficient, therefore, to observe, in this place, that any body, 


\section{AEROSTA'TION.}

which is specificallv, or bulk for bulk, lighter than the atmospheric air encompassing the earth, will be huoyed up by it, and ascend; but as the density of the atmosphere decreases, on account of the diminished pressure of the superincumbent air, and the elastic property which it possesses at difterent elerations above the earth, this body can rise only to a height, in which the surrounding air will be of the same specific gravity with itself. In this situation it will eitlier float, or be driven in the direction of the wind orcurrent of air, te which it is exposed. An airballoon is a body of this kind, the whole mass of which, including its covering and contents, and the several weights annexed to it, is of less specific gravity than that of the air in which it rises. Heat is well known to rarefy and expand, and consequently to lessen the specific gravity of the air to which it is applied; and the diminution of its weight is proportional to the heat. One degree of heat, accorling to the scale of Fahrenheit's thermometer, seems to expand the air about one fourliundredth part; and abont 400 , or rather 435 , degrees of heat will just double the bulk of a ruantity of air. If, therefore, the air inclosed in any kind of covering be lieated, and consequently dilated to such a degree, as that the excess of the weight of an equal bulk of common air, above the weight of the heated air, is greater than the weight of the covering and its appendages, this whole mass will ascend in the atmosphere, till, by the cooling and condensation of the included air, or the diminished density of the surrounding air, it becomes of the same specific gravity with the air in which it floats; aud without renewed heat it will gradually desccud. If, instead of heating common air incloserl in any covering, and thus diminishing its weight, the covering be filled with an elastic fluid, lighter than atmospheric air, so that the excess of the weight of an equal bulk of the latter, above that of the inclosed elastic fiud, be gteater than the weight of the covering and its appendages, the whole mass will, in this case, ascend in the atmospliere, and continue to rise, till it attains alyeiglit at which the surrounding air is of the sanse specific gravity with itself. Inflammable air, or, as it is called, hydrogen gas, is a fluid of this kind. For the knowledge of many of its properties we are indebted to Mr. Iienry Carendish, who discovered, that if common airis cight hundred times lighter than water, inflammable air is seven times lighter than common air; but if common air is eight lundred and fifty times light. er than water, then inflammable air is 10.8 times lighter than common air. The construction of air-halloons depends upon the principles above stated; and they are of two kinds, as one or the otlicr pf the preceding methods of preparing them is adopted.

In the various schemes that liave been proposed for navigating through the air, some hare had recourse to artificial wings, which, being constructed like those of birds, and anmexed to the human body, might bear itup, and by their motion, produced either by mechanical springs, or muscular exertion, effect its progress in any direction at pleasure. This is one of the methods of artificial flying suggested by Bishop Wilkins, in the seventh chapter of his "Dedalus, or Treatise on Mechanical Motions;" but the success of it is doubtful, and experiments made in this way have been few and unsatisfactory. Borelli, having compared the power of the muscles which act on the wings of a bird with that of the muscles of the breast and arms of a man, finds the latter altogether insufficient to produce, by means of any wings, that motion against the air, which is necessary to raise a man in the atmosphere. Sioon after Mr. Cavendish's discovery of the specific gravity of inflammable air, it occurred to the ingenions Dr. Black, of Edinburgh, that if a bladder, sufficiently light and thin, were filled with this air, it would form a mass lighter than the same bulk of atmosplericair, and rise in it. This thoughtit was suggested in his lectures in 1767 or 1768 ; and hee propos. ed, by means of the alantois of a calf, to try thie experiment. Otheremployment, lowever, prevented the execution of his design. The possibility of constructing a vessel, which, when filled with inflammable air, would ascend in the atmosphere, had occurred also to Mir. Cavallo, about the same time; and to him belongs the honour of having first made experiments on this subject, in the beginning of the year 1782, of which an account was read to the Royal Society, on the 20th of June in that year. He tried bladders; but the thinnest of these, however, scraped and cleaned, were too heavy: In using China paper, he found that the inflammable air passed through its pores, like water through a sieve; and having failed of success by blowing this air into a thick solution of gum, thick varnishes and oil. paint, he was under a necessity of being satisfied with soap-bubbles, which being inflated with inflanmable air, by dipping 


\section{AEROSTATION.}

the end of a small glass tube, connected with a bladeler containing air, into a thick solution of soap, and gently compressing the blackler, ascended rapidly in the atmosphere; and these were the first sort of intlammable air-ballouns that were ever made. For balloons formed on a larger scale, and on the principle of rarefied air, we nutst direct our attention to France, where the two brothers, Steplien and Joseph Moutgolfier, paper-manufacturers at Annonay, about 36 miles from Ly. ons, distinguished themselves, by exhibiting the lirst of those aerostatic machines, which have since excited so much attention and astonishment. The first idea of such a machine was sugrested to them by thic naturul ascent of the smoke and clouds in the atmosplicre; and the first experiment was made at Arignon, by Stephen, the eldest of the two brothers, towards the middle of November 1782. Having prepared a bag of fine silk, in the shape of a parallelopipedon, and in capa. city about 40 cubic feet, he applied to its aperture burning paper, which rarefied the air, and thus formed a kind of cloud in the bag, and when it becamesufficiently expanded, it ascended rapidly to the ceiling. Soonafterwardsthe experiment was repeated by the two brothers at Annonay in the open air, when the machine aseended to the height of about seventy feet. Encouraged by their success, they constructed a machine, the capacity of which was about 650 cubic feet, which, in the experiment, broke the ropes that confined it, and, after ascending rapidly to the height of about 600 feet, fell on the acljoin. ing ground. With another machine, 35 feet in diameter, they repeated the experiment in $A$ pril 1783 , when, breaking loose from its confincment, it rose to the li eight of above 1000 feet, and being carried by the wind, it fell at the distance of about three quarters of a mile from the place where it ascended. The capacity of this machine was equal to about 23,430 cubic fect: and when inflated, it measured 117 English feet in circunference. The covering of it was formed of linen lined with paper, its shape was nearly spherical, and its aperture wasfixed to a wooden frame about 16 feet in surface. When filled with vapour, which wasconjectured to be about half as heavy as common air, it was capable of lifting up about 490 pounls, besides its own weight, which, togither with that of the wooden frame, was cqual to 500 pounds. With this machine the next experiment was performed 2t Amonsy, on the 5th of June 1783, be- fore a great multitude of spectators. The faccic bug was suspended on a pole 35 fect high; straw and chopped wool were burnt under the opening at the bottom; the vapour, or rather smoke, soon infiated the bag, so as to distend it in all its parts; and this immense mass ascended in the air witl sucl a velocity, that in less than ten minutes it resclaed the beight of about 6000 feet. A brecze carried it in an liorizontal direction to the distance of 7668 feet; and it then fell gently on the ground. M. Montgolfier attributed the ascent of the machine, not to the rarefaction of the leatedar, wbich is the true cause, but to a certain gas or aefiform fluid, specifically lighter than common air, which was supposed to be disengaged from burning substances, and which bas been commonly called Montgoltier's gas, as balloons of this kind have been denominated Montgolfiers. As soon 2 the news of this experiment reached Paris, the pbilosophers of the city, concciving that a new sort of gas, lialf as heary as common air, liad been discovered by Messrs. Montgolfier ; and knowing that the weight of inflammable air was not more tlaan the eighth or tentl part of the weiglat of conimon air, justly concluded, that,inflammable air would answer the purpose of this experiment better than the gas of Montgolfier, and resolved to make trial of it. A subscription was opened by MI. Faujas de St. Fond towards defraying the expense of the experiment. A sufficient sum of money having been soon raised, Messrs. Roberts were appointed to construct the machine; and M. Charles, professor of experimental philosophy, to superintend the work. After surmounting many difficul. ties in obtaining a sufficient quantity of inflammable air, and finding a substance light enough for the covering, they at length constructed a globe of lutestring, which was rendered impervious to the inclosed air by a varnish of elastic gum, or caoutchouc, dissolved in some kind of spirit or essential oil. The diancter of this globe, which, from its shape, was de. nominated a balloon, was about thirteen feet, and it had only one aperturc, like a bladder, to which a stop-cock was adapted : its weight, when cmpty, together with that of the stop-cock, was 25 pounds. On the $23 \mathrm{dl}$ of August 1783, they began to fill the globe with inflamniable air ; but this being their first attempt, was attend. ed with many hindrances and disappointments. At bist, however, it was prepared for exhibition; and on the 27th it was carricd to the Champ de Mars, where, 


\section{AEROSTATION.}

being disengaged from the cords that held it down, it rose before a prodigious concuturse of people in less than two minutes to the height of 3123 feet. It then entered a cloud, but soon appeared again; and at last it was lost among other clouds. 'This balloon,' after having floated about threc quarters of an hour, fell in a field about 15 miles distant from the place of ascent; where, as we may naturally imaginc, it occasioned much astonishment to the pcasants. Its fall was owing to a rent, occasioned by the expansion of the inflammable air in that part of the atmosphere to which it ascended. When the balloon went up, its specific gravity was 35 pounds less than that of common air. In consequence of this brilliant experiment, many balloons were made on a small scale; gold-beaters skin was used for the covering; and their size was froin 9 to 18 inches in diameter.

Mr. Montgolfier repeated an experiment with a machine of his construction before the commissaries of the Acarlemy of Sciences, on the 11th and 12th of September. This machine was 74 feethigh, and about 43 feet in diameter. When distended, it appeared spheroidical. It was made of canvass, covered with paper both within and without, and it weighed 1000 pounds. The operation of filling it with rarefied air, produced by means of the combustion of 50 pounds of dry straw, and 12 pounds of ehopped wool, was performed in about nine minutes; and its force of ascension, when inflated, was so great, that it raised eight men who held it some feet from the ground. This machine was so much damaged by the rain, that it was found necessary to prepare another for exhibition before the king and royal family on the 19 th. This new maehine consisted of clotl, made of linen and cotton thread, and was painted with water colours both within and without. Its height was near 60 fect, and its diameter about 43 feet. Having made the necessary preparations for inflating it, the operation was begun about one o'clock, on the 19th of September, before the king and queen, the court, and all the Parisians who could procure a conveyance to Versailles. In eleven minutes it wassufficiently distended, and the ropes being cut, it ascenderl, bearing up with it a wicker eage, in which were a sheep, a cock, and a duck. Its power of ascension, or the weight by which it was lig!ter than an equal bulk of common air, allowing for the cage and animals, w2s 696 pounds. This balloon rose to the beight of about 1440 feet; and being driven by the wind, it descended gradually, and fell gently into a wood, at the distance of 10,200 feet from Versailles. After remaining in the atmosphere eight minutes, the animals in the eage were safely landed. The sheep was found feeding; the cock had received some hurt on one of his wings, probably from a kick of the sheep; the duck was perfectly well. The success of this experiment induced M. Pilatre de Rozier, with a philosophical intrepidity which will be recorded with applause in the history of aerostation, to offer himself as the first adventurer in this aerial navigation. Mr. Montgolfier constructed a new machine for this purpose, in a garden in the Fauxbourg St. Antoine. Its shape was oval; its diameter being about 48 feet, and its height about 74 feet. To.the aperture at the bottom was annexed a wicker gallery, about three feet broad, with a ballustrade about three feet high. From the middle of the aperture was suspended by chains, which came down from the sides of the machine, an iron grate, or brazier, in which a fire was lighted for inflating the machine; and port-holes were opened in the gallery, towards the aperture, through which any person, who sliould venture to ascend, might feed the fire on the grate with fuel, and regulate the dilatation of the inclosed air of the machine at pleasure. The weight of the aerostat was upwards of sixteen hundred pounds. On the fifteenth of October, the fire being lighted, and the unachine inflated, M. P. de Rozier placed himself in the gallery, and ascended, to the astonishment of a multitude of spectators, to the height of 84 feet from the ground, and there kept the machine afloat during $4^{\prime} 25^{\prime \prime}$, by repeatedly throwing straw and wool upon the fire: the machine then descended gradually and gently, through a medium of increasing density, to the ground; and the intrepid adventurer assured the spectators that he had not experienced the least inconvenience in this aerial excursion. This experiment was repeated on the 17th and on the 19th, when M. P. de Rozier, in his descent, and in order to avoid danger by re-ascending, evinced, to a multitude of observers, that the machine may be made to ascend and dcscend, at the pleasure of the aeronaut, by merely iucreasing or diminishing the fire in the grate. The balloon having been hanled down, M. Giraude de Villiette placed himself in the gallery opposite to M. Rozier: and being suffered to ascend; it hovered for about nine minutes over 


\section{AERostation.}

Paris, in the sight of all its inhabitants, at the height of about 330 feet. In another experiment the Marquis of Arlandes as. cended with M. Rozier much in the same manner. In consequence of the report of the preceding experiment, signed by the commissaries of the Academy of Sciences, it was ordered. that the annual prize of 600 livres should be given to Messrs. Muntgolfier for the year 1783 . In the experiments above recited the machine was secured by ropes; but they were soon succeded by unconfined acrial narigation. Accordingly, the balloon of 74 fect in height, above mentioned, was removed to a royal palace in the Bois de Boulogne; and all things being ready, on the 21st of November, M. P. de Rozier and the Marquis d'Arlandes took their respective posts in the gallery, and at 54 minutes after one the machine was absolutcly abandoned to the element, and ascended calmly and majestically in the atmosphere. The aeronauts, having reach. ed the height of about 280 feet, waved their hats to the astonished multitude; but they soon rose too high to be distin. guished, and are thought to have soared to an elevation of above 3000 feet. They were at first driven by a north-west wind horizontally over the river Seine and over Paris, taking care to clear the steeples and high buildings by increasing the firc; and in rising met with a current of air, which carried them southward. Having passed the Boulevard, and desisting from supplying the fire with fucl, they descend. ed very gently in a field beyond the New Boulevard, about 9000 yards distant from the palace, having been in the air about 25 minutes. The weight of the whole apparatus, including that of the travellers, was between 1600 and 1700 pounds. Notwithstanding the rapid progress of acrostation in France, we have no authen. tic account of the aerostatic experiments performed in other countries till about the close of the year 1783. The first experiment of this kind, publicly exhibited in our country, was performed in London, on the 25th of November, by Count Zambeccari, an ingenious Italian, with a balloon of oil silk, 10 feet in diameter, and weighing 11 pounds. It was gilt, in order to render it more beautifil, and more impermeable to the gas. 'This balloon, three-fourths of which were fillcd with inflammable air, was launched from the Artillery-Ground, in presence of $a$ vast concourse of spectators, at one o'clock in the aftermoon, and at half past three was taken up near Petrorth, in VOL. I.
Sussex, 48 miles distant from London: so that it travclled at the ratc of nearly 20 miles an hour. Its descent was occasioned by a rent, which must have been the effect of the rarefaction of the inflammable air, when the balloon ascended to the lighter parts of the atmosphere.

Aerostatic experiments and aerial voyagcs became so frequent in the course of the year 1784, that the limits of this articlc will not allow our particularly recording them. We shall, therefore, mention those which were attended with any peculiar circumstances. Messrs. de Morveau and Bertrand ascended from Dijon, in April, to the height of about 13,000 feet, with an inflammable air balloon: the thermometer was observed to stand at 25 degrees. They were in the air during an hour and 25 minutes, and went to the distance of about eighteen miles. The: clouds flosted beneath them, and secluded them from the earth ; and they jointly repeated the motto inscribed on their. acrostat :- "Surgie nunc gallus ad aethera." In May, four ladies and two gentlemen ascended with a Montgolficr at Paris above the highest buildings: the machine was confined by ropes. It was 74 fect lighl, and 72 in diameter. In a second royage, performed by Mr. Blanchard from Rouen in $\mathrm{May}_{\mathrm{y}}$, it was observed, that his wings and oars could not carry him in any other direction than that of the wind. The mercury in the barometer descended as low as 20.57 inches; but on the earth, before he ascended, it stood at 30.16 inches. On the 23d of June, a large aerostat, on the principle of rarefied air, $91 \frac{1}{2}$ feet high, and 79 feet in diameter, was elevated by Mont. golfier at Versailles, in the presence of the royal family and the King of Sweden. M. Pilatre de Rozier, and M. Proust, ascended with it, and continued for $28 \mathrm{mi}$. nutes at the height of 11,732 feet, and observed the clouds below them, that reflected to the region which they occupied the rays of the sun: the temperature of the air being $5^{\circ}$ below the frcezing point; and in three quarters of an hour they travelled to the distance of 36 miles. In consequence of this experiment, the king granted to M. IRozier a pension of 2000 livres. On the 15th of July the Duke of Chatres, the two brothers Robcrts, and another person, ascended with an inflammable air balloon, of an oblong form, 551 feet lonf, and 34 feet in diameter, fron the l'ark of St. Cloud: the machine remained in the atmosphere about $45 \mathrm{mi}$ nutes. This machine contained an interior small balloon, filled with common air, 


\section{AEROSTATION.}

by which means it was proposed to make it ascend or descend without any loss of inflammable air or ballast. The boat was furnished with a helm and ostrs, intended for griding it. At the place of departure the baronieter stood at 30.12 inches. Three minutes after ascending, the balloon was lost in the clouds, and inrolved in a dense vapour. An agitation of the air, resembling a whirlwind, alarmed the acrial voragers, and occasioned several shocks, which prevented their using any of the instruments and contrivances prepared for the clirection of the balloon. Other circumstances concurred to increase their danger; and when the mercury, standing in the barometer at 24.36 inches, indicated their height to be about 5100 feet, they found it neceasary to make holes in the bottom for discharging the inflammable air : and having made a rent of between seren and eight feet, they descended very rapidly, and at last came safely to the ground. The first aerial voyage in England was performed in Londoil, on the 15th of September, by Vinsent Lunardi, a native of Italy. Ifis balloon was made of oiled silk, painted in altcrnate stripes of blue and red. Its diameter was 33 feet. From a net which went over about two-thirds of the balloon, descended 45 cords to a lioop hang. ing below the balloon, and to which the gallery was attached. The balloon had 110 valve; and its neck, which terminated in the form of a pear, was the aperture through which the inflammable air was introduced, and through which it might be let ont. The air for filling the balloon was produced from zinc, by means of diluted vitriolic acid. M. Lunardi departed from the Artillery Ground at two o'clock; and with him were a dog, a cat, and a pigeon. After throwing out some sand to clear the houses, he ascended to a great height. The direction of his motion was at first north-west by west; but as the balloon rose higher, it fell into another current of air, which carried it ncarly north. About half after three be descended very near the ground, and landed the cat, which was almost dead with cold: then rising, he prosecuted his voyage. He ascribes his descent to the action of an oar; but as he was under the necessity of throwing out ballast in order to reascend, his desecnt was probably occasioned by the loss of inflammable air. At ten minutes past four he descended on a meadow, near Ware, in Hertfordslire. 'The only philosophical instrument which he carried with him was a ther- mometer, which in the course of his voy. age stood as low as $29^{\circ}$, and he obscrved that the drops of water which collected round the balloon were frozen.

The longest and the most interesting voyage, which was performed about this time, was that of Messrs, Roberts and M. Collin. Hullin, at Paris, on the 19th of September. Their aerostat was filled with inflammable air. Its diameter was $27 \frac{3}{4}$ feet, and its length $46 \frac{3}{4}$ feet, and it was made to float with its longest part parallel to the horizon, with a boat nearly 17 feet long, attached to a net that went over it as far as its middle. To the boat were annexed wings, or oars, in the form of an umbrella. At 12 o'clock they ascended with 4.50 pounds of ballast, and, after various manœuvres, descended at 40 minutes past six o'clock near Arras, in Artois, having still 200 pounds of their ballast remaining in the boat. Having risen about 1400 feet, they perceived stormy clouds, which they endeavoured to avoicl; but the current of air was uniform from the height of 600 to 4200 feet. The barometer on the coast of the sea was 29.61 inches, and sunk to 23.94 inches. They found that, by working with their oars, they accelerated their course. In the prosecution of their voyage, which was 150 miles, they heard two claps of thunder ; and the cold occasioned by the approach of stormy clouds made the thermometer fall from $77^{\circ}$ to $59^{\circ}$, and condensed the inflammable air in the bal. loon, so as to make it descend very low: From some experiments they concluded, that they were able by the use of two oars to deviate from the direction of the wind about $22^{\circ}$. Fut this experiment requires repetition, in order to ascertain with accuracy the effect here ascribed to oars. The second aerial voyage in England was performed by Mr. Blanchard and Mr. Sheldon, professor of anatomy to the Royal Academy, the first Englishman who ascended with an aerostatic machine. This experiment was performed at Chelsea, on the 16th of October. The wings used on this occasion seemed to have produced no deviation in the machine's track from the direction of the wind. Mr. Blanchard, having landed bis friend about the distance of 14 miles from Chelsea, proceeded alone, with different currents, and ascended so high as to expe. rience great difficulty of breathing; a pigeon, also, which flew away from the boat, laboured some time with its wings, in order to sustain itself in the rarified air, and after wandering for a good while. 


\section{AEROSTATION.}

returned, and rested on one side of the bost. Mr. Blancharel, pereciving the sca before lim, descended near Rumsey, about 75 miles from London, having travelled at the rate of nearly 20 miles an hour.

On the 12th of October, Mr. Sadler, of Oxforl, inade a voyage of 14 miles from that place in 17 minutes, with an inflammable air balloon of his ow'n contrivance and construction. The fate of M. P'. de lRozier, the first acrial navigator, and of his companion, M. Romain, has been much lamented. They ascended at Boulogne on the 15th of June, with an intention of crossing the channel to England. Their machine consisted of a spherical balloon, 37 feet in diameter, filled with inflam. mable air, and under this balloon was sus. pended a small Montgolfier, or fire balloon, ten feet in diameter. This Mont. golfier was designed for rarefying the atmospheric air, and thus diminishing the specific gravity of the whole apparatus. For the first twenty minutes they seemed to pursue their proper course; but the balloon seemed much inflated, and the aeronauts appeared anxious to desend. Soon, however, when they were at the height of about three quarters of a mile, the whole apparatus was in flames, and the unfortunate adventurers fell to the ground, and were killed on the spot

On the 19th of July, Mr. Crosbie ascenderl at Dublin, with a view of crossing the channel to Fingland. To a wicker basket of a circular form, which he had substituted for the boat, he had affixed a number of bladders for the purpose of rendering his gallerv buoyant, in case of a disaster at sea. The height to which he ascended at one time was such, that by the intense cold his ink was frozen, and the mercury sunk into the ball of the thernioneter. Ile himself was sick, and lie felt a strong impression on the tympanum of his ears. At his utmost elevation lie thought himself stationary; but on discharging some gas, he descended to a very rough current of air blowing to the north. He then entered a dense cloud, and experienced strong blasts of winds, with thunder and lightuing, which brought him with rapidity towards the surfice of the water. The water sonn entered his car; the force of the wind plunged him into the ocean, and it was with difficulty that he put on his cork jacket. The blaulders which he had pre. pared were now found of great use. The water, ardded to his own weight, served as ballast; and the balloon, maintaining its poise, answered the purpose of a sail, by means of which, and a snatch-block to his ear, he moved before the wind as regularly as a sailing-boat. He was at length overtaken by some vessels that were crowding sail after him, and conveyed to Dunleary with the balloon On the $22 \mathrm{~d}$ of July, Major Moner, who ascended at Norwich, was driven out to sea, and afterbeing blown about for abont twoliours, he dropped into the water. After much exertion for preserving his life, and when he was almost despairing of relief, he was taken up by a revenue ctitter, in a state of cxtreme weakness; having been struggling to keep himself above water for about seven hours.

The longest royage, that had been hitherto made, was performed by Mr. Blanchard, towards the end of August. He ascended at Lisle, accompanied by the Chevalierde L'Epinand, and traversed adistance of 300 miles before he descended. On this, as well as on other occasions, Mr. Blanchard made trial of a parachute, in the form of a large umbrella, which he contrived for breaking his fall, in case of any accident. With this machine lie let down a dog, which came to the ground gently, and unhurt. On the 8 th of September, Mr. Baldwin ascended from the city of Chester, and performed an aerial voyage of 25 miles in two hours and a quarter. His greatest elevation was about a mile and a half, and he supposes that the relocity of his motion was sometimes at the rate of 20 miles an hour. He has published a circumstantial account of his voyage, lescribed the appearances of the clouds as he passed through them, and annexed a variety of observations relating to acrostation.

It would be tedious to recount the aerial expeclitions that were peformed in various parts of our own country, as well as on the continent, in the whole course of the year 1785 : more especially as they have afforded us no experiment or disco. very of any peculiar importanee. The most persercring acrial navigator has been Mr. Blancliard. In Augiist, 1788, he ascended at Brunswick for the thirty" second time. Within two years from the first discovery of this art of navigating the atmosplicre, more than forty different persons performed the experiment without any material injury $i$ and it mav be justly questioned, says Mr. Carallo, whicther the first forty persons who trusted themselves to the sea in boats escaped so safely. The catastrophe that befel Rozier, and the unpleasant circumstances that 


\section{AEROSTA'IION.}

have happened to some of the acronauts in our own country, have been owing, not so much to the principle of the art, as to want of judgment, or imprudent management in the conduct of it.

Omitting the various uninteresting, though not very numerous, aerial voyages undertaken in various parts of the world, during the 17 years subsequent to the above-mentioned dreadful accident of $\mathrm{Pi}$ latre de Rozier and Mr. Romain, we sliall only add the account of two aerostatic experiments lately performed in England by Mr. Garnerin, a French aeronaut. The first of these is remarkable for the very great velocity of its motion; the second for the exhibition of a mode of leaving the balloon, and of clescending with safety to the ground. On the 30th of June, 1802 , the wind being strong, though not impetuous, Mr. Garnerin and another gentleman ascended with an inflammable air, or hydrogen gas, balloon, from Ranelagh gardens, on the south-west of London, between four and five o'clock in the afternoon; and in exactly three quarters of an hour they descended near the sea, at the distance of four miles from Colchester. The distance of that place from Ranelagh is. 60 miles; therefore they travelled at the astonishing rate of 80 miles per hour. It seems that the balloon had power enough to keep them up four or five hours longer, in which time they might have gone safely to the continent; but prudence induced them to descend when they discovered the sea not far off. The. singular experiment of ascending into the atmosphere with a balloon, and of descending with a machine called a parachute, was performed by Mr. Garnerin on the 21st of September, 1802. He ascended from St. George's parade, North Audley street, and descended safe into a field near the small-pox hospital, at Pancras. The balloon was of the usual sort, viz. of oiled silk, with a net, from which ropes proceeded, which terminated in, or were joined to a single rope at a few feet below the balloon. To this rope the parachute was fistened in the following manner. The reader may easily form to himself an idea of this parachute, by imagining a large umbrella of canvas, about 30 feet in diameter, but destitute of the ribs and handlc. Several ropes of about 30 feet in length, which proceeded from the edge of the parachute, terminated in a cornmon joining, from which shorter ropes proceeded, to the extremities of which a circular basket was fastened, and in this basket Mr. Garnerin placed him- self. The single rope passed through a hole in the centre of the parachute, also through certain tin tubes, which were placed one after the other, in the place of the handle or stick of an umbrella, and was lastly fastened to the basket; so that, when the balloon was in the air, by cutting the end of the rope next to the basket, the parachute with the basket would be separated from the balloon, and in falling downwards would be naturally opened by the resistance of the air: The use of the tin tubes was, to let the rope slip off with greater certainty, and to prevent its being entangled with any of the other ropes, as also to keep the parachute at a distance from the basket. The balloon began to be filled about two o'clock. There were 36 casks filled with iron filings, and diluted sulphuric acid, for the production of the hydrogen gas. These communicated with three other casks, or general receivers, to each of which was fixed a tube, that emptied itsclf into the main tube attached to the balloon. At six, the balloon being quite full of gas, and the parachute, \&c. being attached to it, Mr. Garnerin placed himself in the basket, and ascended majestically, amiclst the acclamations of innumcrable spectators. The weather was the clearest and pleasantest imaginable; the wind (was gentle, and about west by south ; in consequence of which Mr. Garnerin went in the direction of nearly east by north. In about eight minutes the balloon and para. chute had ascended to an immense height, and Mr. Garnerin, in the basket, could scarcely be perceived. While every spectator was contemplating the grand sight before them, Mr. Garnerin cut the rope, and in an instant he was separated from the balloon, trusting his safety to the parachute. At first, viz. before the parachute opened, he fell with great velocity; but as soon as the parachute was expanded, which took place a few moments after, the descent became very gentle and gradual. A remarkable circumstance was observed; namely, that the parachute, with the appendage of cords and basket, soon began to vibrate like the pendulum of a clock, and the vibrations were so great, that more than once the parachute, and the basket with Mr. Garncrin, seemed to be on the same level, or quite horizontal : however, the extent of the vibrations diminished as he descended. On coming to the earth, Mr. Garnerin experienced some pretty strong shocks; but he soon recovered his spirits, and remained without any material hurt. 


\section{AEROSTATION.}

As soon as the parachute was separated from the balloon, the latter ascended with great rapidity, and, being of an oval form, turned itself with a longer axis into an horizontal position.

We now come to the practice of the art. The shape of the balloon is one of the first objects of consideration. As a sphere ad. mits the greatest capacity under the least surface, the spherical figure, or that which approaches nearest to it, has been generally preferred. However, since bodies of this form oppose a greater surface to the air, and consequently a greater obstruction to the action of the oar or wings than those of some other form, and there. fore cammot be so well guided in a calm, or in a course different from the direction of the wind, it lias been proposed to constinict balloons of a conical or oblong figure, and to make them proceed with their narrow end forward. Nest to the shape, it is necessary to consider the stuff that is most proper for forming the envelope of the inflammable or rarefied air. Silk stuff, especially that which is called lutestring, properly varnished, has been most commonly used for hydrogen gas balloons; and common linen, lined within and without with paper, varnished, for those of rarefied air. Varnished paper, or gold-beaters' skin, will answer the purpose for making small hyclrogen gas balloons; and the small rarefied air balloons may be made of paper, without any varnish or other preparation. The stuff for large balloons of both kinds requires some previous preparation. The best mode of preparing the cloth for a machine, upon Montgolfier's principle, is, first to soak it in a solution of sal-ammoniac and gize, using one pound of each to every gallon of water; and when the cloth is quite dry, to paint it over with some earthy colour, and strong size or glue. It may be also varnished over, when perfectly dry, with some stiff; oily rarnish, or simple drying linseed oil, which would dry before it penetrates quite through the cloth. The pieces of which an hydrogen gas balloon is to be formed must be cut of a proper size, according to the proposed dimensions of it, when the ramish is sufficiently dry. The pieces that compose the surface of the balloon are like those gores that form the superficies of a globe : and the best method of cutting them is, to describe a pattern of wood or stiff cardpaper, and to cut the silk or stuff upon it. 'To the upper part of the balloon there must be adapted a valve, opening inward, to which is annered a string passing through a hole made in a small round piece of wood, which is fastened to the lowest part of the balloon, oppositc to the valve, to the boat below it; so that the aeronaut may open it as occasion requires, and let the hydrogen gas out of the balloon. 'To the lower part of the balloon are fixed two pipes of the same stuff with the covering, six inclies in cliameter for a balloon of 30 feet, and much larger for balloons of greater size, and long enought to reach the boat. These pipes are the apertures through which the hydrogen gas is introluced into the balloon. The boat may be made of wicker work, and covered with leather, well painted or varnished over. The best method of suspending it is by means of ropes, proceeding from the net which goes over the bal. loon. This net should be formed to the shape of the bulloon, and fall down to the middle of it, and lave various cords proceeding from it to the circumference of a circle, about two feet below the balloon; and from that circle other ropes should go to the edge of the boat. This circle may be made of wood, or of several pieces of slen. der cane bound together. The meshes of the net may be small at top, against which part of the balloon the hydrogen gas exerts the greatest force, and increase in size as they recede from the top. A hoop has been sometimes put round the middle of the balloon for fastening the net. This is not absolutely necessary; but when used, it is best made of pieces of cane bound together, and covered with leather. When the balloom and its appendages are constructed, the next object of importance is to procure proper materials for filling it. Hydrogen gas for balloons may be obtained in several ways : but the best methods are by applying acids to certain metals ; by exposing animal, vegetable, and some mineral substances, in a close vessel, to a strong fire; or by transmitting the vapour of certain fluids trrough red hot tubes. In the first of these metliods, iron, zinc, and sulphuric acid, are the materials most commonly used. The acid must be diluted with five or six parts of water. Iron may be expected to yield in the common way about 1700 times its own bulk of gas, or 43 ounces of iron; the like weight of sulphuric acid, and 223 ounces of water, will produce one cubic foot of hydrogen gas ; 6 ounces of zinc, an equal weight of acirt, and 30 ounces of water, aro neccssary for producing the same quantity. It is more proper to lise the turnings or chippings of great picces of iron, as of canuton, \&c. than the filings 
of that metal, because the heat attending the effervescence will be diminished, and the diluted acid will pass more readily through the interstices of the turnings, when they are heaped together, than through the filings, which stick closer to one another. The weight of the hydrogen gas thus obtained by means of sul. phuric acid is, in the common way of procuring it, generally one-seventh part of the weight of common air; and with the necessary precautions for philosophical experiments, less than one-tenth of the weight of common air. We shall conclude this article with a description of some figures explanatory of the subject. Figure 1 (plate Aerostation) represents a balloon, DF, suspended by means of the poles $\mathbf{G}$ and $\mathbf{H}$, and the cord, for the purpose of being filled with gas. It is kept steady and lield down whilst filling by ropes, which are readily disengaged. A, $\mathbf{A}$, are two tubs, about three feet in diam. eter, and two feet deep, inverted in larger tubs, B, B, full of water. At the bottom of each of the inverted tubes there is a hole, in which is inserted a tin tube; to these the silken tubes of the balloon are tied. Each of the tubs, $\mathrm{B}$, is surrounded by several strong casks, so regulated in number and capacity, as to be less than half full when the materials are equally distributed. In the top of these casks there are two holes; to one of which is adapted a tin tube, formed so as to pass over the edge of the tub B, and through the water, and to terminate with its aperture under the inverted tub A. The other hole, which serves for supplying the cask with materials, is stopped with a wooden plug. When the balloon is to be filled, the common air is first to be expelled, then the silken tubes are fastened round the tin ones ; the iron filings arc to be put into the casks, then the water, and lastly the sulphuric acid. The balloon will speedi. Jy be inflated by the gas, and support it. self without the aicl of the rope GII. As the filling advances, a net is adjusted about it, the cords procecding from the net are fastened to the hoop MN ; the boat IK is suspenderl from the hoop, and whatever is wanted for the voyage is dcposited in the boat. When the balloon is sufficiently full, the silken tubes are separated from the tin tubes, their extremities are tied, and they are placed in the boat. When the aeronauts are seated in the boat, the ropes that held the balloon down are slipped off, and the machine ascentis in the air, as in figure 2 . In fig. 3 , is a representation of a part of Mr. Garmerin's balloon in its ascent, to which is attacherl a paracliute, in its contracted state, and below is the car. Figure 4 shews the manuer in which Mr. Garnerin descended in the car by means of the expanded paraclute, after lie liad detached it from the balloon. In figure 5 is represented an ap. paratus, as described by $\mathbf{M r}$. Cavallo, for filling balloons of the size of two or tluree feet in diameter with hydrogen gas, after passing it through watcr. $A$ is a bottle, with the ingredients; $\mathbf{B C D}$ a tube fasten. ed in the neck at $B$, and passing through C, the cork of the other bottle, in which there is a bole made to receive the tube, and to this the balloon is tied. Thus the hydrogen gas, coming out of the tube $\mathbf{D}$, will pass first through the water of the bottle $\mathbf{E}$, and then into the balloon. Two small casks may be used instead of the bottles $\mathbf{A}$ and $\mathbf{E}$.

ÆRVA, in botany, a genus of the Mo. nadelphia Decandria class and order. The flowers are polygamous; the calyx five-leaved and patent: the stamina are five; the pistillum is a globulous ovary, having a filiform style, terminated by a bifid stigma : the fruit is an oblong, single-seeded capsule, encompassed by a calyx: there is but one species, viz. $\mathbb{E}$. reyptiaca, or tomentosa, which grows on the sandy calcareous soil of Arabia.

ISCHYNOMENE, a word from the Greek, signifying to be ashamed, because it retreats from the touch: bastard sensitive plant, in botany, a genus of the Diadelphia Decandria class and order, and of the natural order of Papilio Nacex, of which there are 12 species, found native in the East Indies, and cultivated in other hot countries. One of the species may be treated as hemp, and is used for the same purposes.

AESCULUS, in botany, a genus of the Heptandria Mlonogynia class and order, of the natural order of Trihilatre. There are three species : the first, or common horse-chestnut, was brought from the nortliem parts of $\mathbf{A s i a}$ into Europe about the year 1550, and sent to Vienna about the year 1558. From Vienna it was conreyed to France and Italy; but it came to us from the Levant. It is distinguished by the beautiful parabolic form of its branches, the disposition and structure of its digitate leaves, and by the pyramidal bunclies of its whitc flowers, variegated near the centre with yellow or red. Although this tree is now less in esteem for avemues and walks than it formerly was, on account of the early decay of its leaves, it affords an excellent shade; and the 


\section{AES}

spikes are flowers which appesr in May, with the interuixture of large leaves, exlibit a noble appearance. The inost eligible situation for these trees is in lawns and parks, where they may be planted singly, and where their fruit will be serviccable to the deer, who are fond of it. This trec is of quick growtli; and in a fow years it will afforl a good shade in summer, and yield plenty of flowers. Trees, raised from nuts, have in 12 or 14 years become large enough to shade two or three chairs with their branches, which in the season are covered with flowers. But the trees are of short duration, and the rood is of little value. It serves, however, for water-pipes, turners' ware, and fuel: and for these uses it is worth the charge of planting, and should be felled in November or December. The horse-chestnut lias been employed in France and Switzerland for the purpose of bleaching yarn ; and it is recommended in the Memoirs of the Society of Berue, Vol. II. part 2, as capable of extensive use in whiteniug not only flax and hemp, but silk and wool. It contains an astringent saponaceous juice, which is obtained by peeling the nuts, and grinding or raspin them. They are then mixed with hot min or nunning water, in the proportion of 20 nuts to 10 or 12 quarts of water. Wore caps and stockings were milled in this water, and took the die extremely well; aud successful trials were made of it in fulling stuffs and cloths. Linen washed in this water takes a pleasing light sky-blue colour; and tre filsments of hemp, steeped in it some days, were easily seprarated. The author of the memoir, above referred to, imagines, that if the meal of thic chestnut could be made into eakes or balls, it would answer the purposes of soap, in washing and fulling. The sediment, after infusion, loses its hitter taste, and becomes good food for fowls when mixed with bran. The Edinburgh College have admitted the horse-chestnut into their Plarmacopocia of 1783 , on the recommendation of Dr. Gardiner, who says that three or four grains of the powder, snuffed up the nostrils in the evening, operate next morning as an excellent sternutatory, and thereby proves very beneficial in obstinatc inflammations of the eyes. A patent was granted in 1796 , to Lord W. Murray, for his discovery of a method of extracting starch from horse-chestnuts.

The second species, or yellow-flowered horse-chestnut, is a native of North Carolina, was cultivated with us in 1764, and flowers in May and June.

\section{AET N}

The third species, or scarlet horse chestnut, rises to the height of twenty feet, witlıut much extending its branclics; its bark is smooth, and the learcs, which are opposite, on long, red petioles, are of a light green.

The coinmon liorse-chestnut is propagated by sowing the nuts, after preserving them in sand during the winter: but the scarlet is propagated by grafting it upon stocks of the common horse-chestnut.

The American species are : $£$. paria; 五. flava; Æ. macrostaclıya; and Æ. achinata. Of the last there are two varietics, .1. the grlabra, and $B$, the pallida.

ETHUSA, in botany, a genus of the Pentandria Digynia class and order, and belonging to the natural orcler of Umbel. lat $x$ or Umbelliferx: the caly $x$ is an universal spreading umbel, and the partial is also spreading, but small; having no universal involucre, and the partial one placed on the outside, and consisting only of three very long, linear, pendulous leaflets, and the proper perianthium scarcely observable: the unirersal corolla is nearly uniform, with all the floscules fertilc, and the partial has the petals bent in, heartshaper, and unequal: the stamina are simple filaments, with roundish anthers; the pistillum is an inferior germ, and the styles are reflex, with obtuse stigmas: it has no pericarpium, and the fruit is roundish, streaked, and bipartile: the sceds are two, roundish, streaked, except on a third part of the surface, which is plain. Tluere are four species, the principal is $Æ$. cynapium, common fool's parsley, or lesser hemlock, which is a common weed in fields and kitchen-gardens, and. in a slight degrec poisonous. It is casily distinguished when in flower, in July and August, from true parsley and chervil, by the three narrow pendent leaflets of the involucre, placed on the outer part only of the unbel, and by its being a much humbler plant than either of the others. The leares also, in an carlicr state, are of a different form and a darker hue, and, when bruised, emit in a slight degree a disagreeable renomous smell. The safest way to aroid doubt or tanger is to cultivate the curled parsley. Most cattle eat it, but it is said to be noxious to geese.

ETIOLOGY, that branch of physic which assigns the causes of diseases ; in this sense we say the xetiology of the small pox, dropsy, \&c.

Etiozogr, in rhetoric, is deemed a figure of speech, whereby, in relating an event, we, at the same time, unfold the causes of it. 


\section{AETN}

ETNA, a famous volcanic or burning mountain in Sicily, situated on the eastern coast, not far from Catania. The lieight of this mountain is abore 10,000 feet above the surface of the sea, and its circumference at the base is 180 miles. Over its sides are 77 citics, towns, axd villages, the number of inhabitants of which is about I15,000. From Catania to the summit is the distance of 30 miles, and the traveller must pass through three distinet climates, which may be denominated the torricl, the temperate, and the frigid. Accordingly, the whole mountain is divided into three distinct regions, called the fertile, the woody, and the barren. The first, or lowest region, extends through an interval of ascent from 12 to 18 miles. The city of Catania and several villages are situated in this first zone, and it abounds in pastures, orchards, and various kinds of fruit trees. Its great fertility is aseribed to the decomposition of la$v a$, and of those regetables, which have been introduced by the arts of agriculture, and the exertions of human industry. The figs, and fruit in general, in this region, are reckoned the finest in Sicily. The lava in this region flows from a num. ber of small mountains, which are dispersed over the immense declivity of Etna. The woody region, or temperate zone, extends from 8 to 10 miles in a direct line, towards the top of the mountain; it comprehends a surface of about 40 or 45 square leagues. It forms a zone of the brightest green all round the mountain, which exhibits a pleasing contrast to the white and hoary head of the mountain. It is called the woody region, be. cause it abounds with oaks, beeches, and firs. The soil is similar to that of the lower region. The air here is cool and refreshing, and every breeze is loaded with a thousand perfumes, the whole ground being covered over with the richcst aromatic plants. Many parts of this region are the most hearenly spots upon carth; and if £tna resemble hell within, it may with equal justice be said to resemble paradise without. The upper region, called the frigid zone, is marked out by a circle of snow and ice. The surface of this zone is for the most part flat and cren, and the approach to it is indicated by the decline of vegetation, by uncover. cd rocks of lava and heaps of sand, by near vicws of an expanse of snow and ice, and of torrents of smoke issuing from the crater of the mountain, and by the difficulty and danger of adrancing, amidst streams of melted snow, sheets of ice, and gusts of chilling wind. The curious tra-

\section{AFF}

veller, however, thinks himself amply re. compensed, upon gaining the summit, for the peril which he has encountered. At night the number of stars seem increased, and their light appears brighter than usu. al. The lustre of the milky way is like a pure flame that shoots across the heavens, and with the naked eye we may observe clusters of stars totally invisible in the lower regions. The scorix of which the mountain is composed have the same kind of base, containing shorls and feltspars.

AFFIDAVIT signifies an oath in writing, sworn before some person who is authorised to take the same.

In an affidavit, the time, place of habitation, and addition, of the person who makes it are to be inserted.

Affidavits are chiefly used to certify the serving of processes or other matters conccrning the proceedings in a court; and therefore should set forth the matter of fact to be proved, without taking any no. tice of the merits of the canse. They are read in court upon motions, but are not admitted in evidence at trials.

By statute, the judges of the courts at Westminster may commission persons, in the several counties in England, to take afficiavits relating to any thing depending in their sereral courts.

AFFINITY, among civilians, denotes the relation of each of the parties married to the kindred of the other.

A ffinity is distinguished into three kinds. 1. Direct affinity, or that subsisting between the husband and his wife's relations, by blood; or between the wife and her husband's relations, by blood. 2. Secondary affinity, or that which subsists between the husband and his wife's relations, by marriage. 3. Collateral affinity, or that which subsists between the husband and the relations of his wife's relations. The degrees of affinity are always the same with those of consanguinity. Hence, in whatever degree of consanguinity the kindred of one of the parties married arc, they are in the same degree of affinity to the other.

- By the canon law, direet affinity renders marriage unlawful to the fourth generation, inclusive ; but the case is otherwise, with respect to the secondary and. eollateral kinds. It is likewise to be observed, that the affinity contracted by a criminal commerce is an impediment to marriage so far as the second generation: thus, a man is not allowed to marry the sister of a woman he has lain with. Nay, with regard to contracting marriage, affinity is not dissolved by death; for, though 


\section{AGA}

a woman mav be admitted a witness for the brother of her deccased husband, she is not allowed to marry him.

AFrisiry, in clicmistry, the attraction manifest between the parts of bodies in chemical combination is, by many authors, distinguished by this name. See $\mathrm{C}_{\text {нг }}$ MISTM.

AFFIRMLATION, an indulgence allowed by law to the people called Qıakers, who, in cases where an oath is required from others, may make a solemn aftirmation that what they say is true. But their affirmation is confined to civil cases, and is uot allowed in any criminal cause, nor with regard to places of profit or trust under the government.

AFFRAY, or AFFATMEsT, in law, formerly signitied the crime of affrighting other persons, by appearing in unusual armour, brundishing a weapon, \&c. But, at present, affray denotes a skirmish or fighting between two or more; and there nuist be a stroke given, otherwise it is no affray.

A FFRONTEE, in heraldry, an appellation giren to animals facing one another on an escutcheon, a kind of bearing, which is otherwise called confrontée, and stands opposed to culossée.

$A F T$, in the sea language, the sane with abaft. See Anart.

AF\%kiliA, in botany, a genus of the Didynamia Angiospemia class and orler: the calyx is quinquepartite, the corolla canpanilated, and the capsule rotundated with liemispheric receptacls.s. There is but one species, found in Africa, near the equinoctial.

ATAPANTIIUS, in botany, a genus of the IIexandria Monogynia class and order, of the uatural order of Liliacx: the calvx is a spathe: the coro!la is one pe. talled; the stamina are six filaments, inserted into the throat, shorter than the corolla; the anthers kidney-shaped and incumbent; the pistillum is a superior germ; the style filiform, of the length of three stamens; the stigma simple or trifid; the periciurpium is an oblong capsule; the seeds numerous, oblong, compressed, and enlanged with a membrane. There is one species, viz. A. umbellatus, or African blue lily. This is the African tube-rose hyacinth, with a blue umbellated flower. The root of this plant is composed of thick lleshy fibres; from the same head arises a cluster of icaves, which are thick and strcculent, and of a clark green colour. Between these issues the flower stalk, supporting an umbel of blue flowers in a sbeath, and each flower

VOL. 1.
AGA

standing on a pedicle, about an inch long. The umbel being large, the flowers numerous, and of a light blue colour, make a fine appearance. 'They come out at the end of August, or beginung of Septem. ber, and frequently continue in beauty till spring. It is a native of the Cape of crood Hope, from whence it was brought to Holland, and in 1692 it was cultivated at llampton court.

This plant is propagated by offsets, ta. ken at the latter end of June, planted in separate pots, with light kitchen-garden earth, and placed in a sliady situation. In five weeks the off'sets will put oft' new roots, and the pots should then be re. moved to a more sunny situation, and have more water. In September they will put out their flower-stalks, and toward the end of the month the flowers will begin to upen, and should be removed under shelter in bad weather, but in good wea. ther exposed to the free air. Toward the end of October they should be remored to the green-house, and have the benefit of free air, and be occasionally watered during winter, in mild weather, but in frost they should be kept dry.

AGARIC, in botany, a genus of the order of Fungi, and class of Cryptogamia: the pileus or cap has gills underneath, and the gills differ in substance from the rest of the piant, being composed of two lamina, and the seeds are in the gills. There are nearly 400 species. 10r. Withering distributes them into three general classes, comprehending those which have central stems, those with lateral stems, and those which have no stems; and he again subdivides the two former classes into such as have solich, and such as have hollow stems, with decurrent, fixed, and loose gills, respectively. Under these heads, he arranges the species by the colour of the gills, into those whose gills are white, hrown, red, bufl; yellow, grey, green, and purple. As this ingeni. ous author lias formed a sistem, that serves to facilitate the investigation and description of the several species of $\Lambda \mathrm{gta}$ rics, we shall licre give a brief sketch of the principles upon which it is founcled. Agarics are composed of a cap or pileus, with gills underneath, and are either with or without stems. The stems are either central or lateral. They liave also a root, which is more or less apparent, and soine of them, in their unfolderl state, wholly enclosed in a membranaccous or leather. like case, called a wrapper. Some of them have also a curtain, or thin mem. brane, extending from the stem to the I: 


\section{AGA}

edge of the pileus, which is rent as the pileus expands, and soon vanishes; but the part attached to the stem often re. mains, and forms round it a ring, which is more or less permanent, as its substance is more or lcss tender. Of all the species of Agaric, one only has been selceted for cultiration in our gardens, viz. the $A$. campestris, or common mushroom, or champignon. The gills of this species are loose, pinky red, changing to a liver colour, in contact with the stem, but not united to it ; very thick set, irregularly disposed, some forked next the stem, some next the edge of the pileus, some at both ends, and in that case generally excluding the intermediate smaller gills. The pileus is white, changing to brown when old, and becoming scurfy ; regularly convex, fleshy, flatter with age, from two to four inches, and sometimes nine inclies, in diameter, and liquefying in decay; the flesh white. The stem is solid, white, cylindrical, from two to three inches high, half an inch in diameter; the curtain white and delicate. When this $\mathrm{m}$ shroom first makes its appearan ce, it is smooth and almost globular; and in this state it is called a button. This species is estcemed the best and most savoury of the genus, and is much in request for the table in England. It is eaten fresh, either stewed or boiled, and preserved, either as a pickle or in powder; and it furnishes the sance called Catchup. The field plants are better for eating than those raised on artificial beds, their flesh being more tender; and those who are accustomed to them can distinguish them by their smcll. But the cultivated ones are more sightly, may be more easily collect. ed in the proper state for eating, aurl are firmer and better for pickling. The wild mushrooms are found in parks and other pastures, where the turf has not been ploughed up for many years, and the best time for gathering them is August and September.

AGATE, a fossil compounded of various substances, as chalcedony, cornclian, jasper, hornstone, quartz, \&c. These different fossils do not all occur in every agate, commonly only two or three. There are different kinds of agate, as the fortification, the landscape, the ribbon, the moss, the tube, the clouded, the zoned, the star, the fragment, the punctuated, the petrefaction, the coral, and the jasper agate. No country affords finer agate, or in greater abundance, than Germany: it is found in great quantity at Oberstein, where seyeral thousand persons are em-

\section{AGA}

ployed in quarrying, sorting, cutting, and polishing it. It is also found in France, England, Scotland, and Ireland, and very bcautiful in the East Indies, where, however, it is confouncled with onyx. It is cut into vases, mortar's, snuff-boxes, and sometimes into plates for inlaying in tables. Very handsome specimens are made into seals, and the smaller pieces are used for gun flints. It was lighly valued by the ancients, who executed many fine works in it: these, however, are only to be found in the cabinets of the rich. The collections of Brunswick and Dresdenar are remarkable for beautiful spccimens of this kind.

AGATHOPHYLLUM, a genus of the Dodecandria Monogynia class and order: calyx very minute, truncale; petals six, inserted into the calyx ; drupe somewhat globular; nut half five-celled, onc-seeded; kernel fivc-lobed. One species, viz. A. aromaticum, a tree in Mardagascar, with an aromatic rufous bark.

AGA VE, in botany, a genus of the Hexandria Monogynia class and order, of the natural order of Coronarix: it has no calyx; the corolla is one-petalled and funnel-shaped; the stamina are filifurm; the anthers linear; the pistillum is an oblong germen; the style filiform; the stigma headed and three comered; the pericarpium is oblong, and the seeds are numerous. There are seven species, of which we shall notice the A. Ameticana, or great American aloe, whose stems, when vigorous, rise upwards of twenty feet ligh, (one in the king of Prissia's garden rose to forty fect,) and branch. out on every side, so as to form a kind of pyramid, composed of greenish yellow flowers, which stund erect, and come out in thick clusters at every joiñt. The seeds do not come to maturity in England. When this plant flowers, it makes a beautiful appearance; and if it be protected from the cold in autumn, a succession of new flowers will be produced for nearly three months in favourable seasons. It has been a common error, that this plant does not flower till it is one hundred years old: the truth is, that the flowering depends on its growth; so that in hot countries it will flower in a few years; but in colder climates the growth is slower, and it will be much longer before it shoots up a stem. The first that flowered in England is said to have been Mr. Cowell's at Hoxton, in 1729; but they have occurred so often since that time, that they are now scarcely considered as rarities. Few of the rariety with yellow- 
edged leaves have yet blossomed. There are hedges of the common agrave in Spain, I'ortugal, Sicily, and Calabria; it flourishes also about Naples, and in other parts of Italy. The juice of the leares, strained, and reduced to a thick consistence, by heing exposed to the sun, may be marle up into balls by means of lye-ashes. It will lather with salt water is well as fresh. The leaves, instead of passing between the rollers of a mill, may be pounded in a wooden mortar, ancl the juice brought to a consistence by the sum, or by boiling. A gallon of juice will yield about a pound of sof te stract. The leaves are also used for scouring pewter, or other kitchen utensils, and? floors. In Algarvia, where pasture is scarce, they are cut in thin transverse slices, and given to cattlc. The inward substance of the deoaved stalk will serve for tinder. The fibires of the leaves, separited by buising and stceping in water, and afterwarls beating them, will make a thread forcommon uses. Varicties of the common American agave, with gold and silver striped leaves, are not now uncommon in the English gardens. The Karatto agave is a varicty brought from St. Christo. pher's, and the name is given to other species of this genus, and has leaves from 23 to 3 feet long, and about 3 inches brond, ending in a black spine, and more erect than those of the others. This sort has not flowered in Fingland. Linnaus has separated this genus from the aloe, be. cause the stamina and style are extended much longer than the corolla, and the cornlla rests upon the germ. Besides, all the agaves have their central leaves closely folding over each other. and $\mathrm{cm}$ bracing the flower-stem in the centre; so that these never fower till all the leaves are cxpanded, and when the flower is past, the plants dic. Whereas the flower-stem of the aloc is produced on one side of the centre, annually, from the same plant, and the leaves are more expanded than in this genus.

AGE, in horsemanship, makes a considerable point of knowledge, the horse being an animal that remarkably shew's the progress of his years by coirespondent alterations in lis boly. We lave the chief charncteristics from his tecth. 'The first rear he las only small grinclers and gatherers, of a brightisli colour, which are called fual's tecth. The second year lie changes his four foremost tecth, viz. two above and two below, and ticy appear browner and higger than the rest. The third year he changes the teeth next these, leaving no apparent foal's teeth the fore, but two above, and two bclow, on each side, which are all bright and small. The fourth ycar he changes the teetl next there, and leaves no more foal's tcetls before, but one above and below, on each side. The fifth year his foremost teeth are all changed, and the tushes on each side are complete; and those which succeed the last foal's tecth arc hollow, with a small black speck in the micldle, which is called the mark in the horse's mouth, and continues till he is eight years old. The sixtl year there appear ncw tushes, near which is visible some young flesh, at the bottom of the tush, the tuslies being white, small, short, and sharp. The seventh year his tecth are at their full growth, and the mark in his mouth appears very plain. At eight all his teeth are full, plain, and smooth, and the black mark but just discernible, the tushes looking more yellow than ordinary. The ninth, his foremost teeth shew longer, broader, yellower, and fouler, than before, the mark quite disappearing, and the tushes bluntish. At ten no lioles are felt on the insicle of the upper tushes, which, till then, are easily felt. At eleven his teeth are very long, ycllow, black, and foul, and stand directly opposite each other. At twelve the teeth of his uppes jaw hang over those of his under. At thirteen his tuslies are worm almost close to his cliaps, if he has been much ridden; otherwise they will be long, black, and foul.

AG $\mathrm{E}$ likewise denotes certain periods of the duration of the world. Thus, among christian chronologers, we meet with the age of the law of nature, which comprehends the whole time between Adam and Noses; the age of the Jewish law, which takes in all the time from Mo. ses to Christ; and lastly, the age of grace, or the number of years elapsed since the birth of Christ.

Among ancient historians, the duration of the world is also subdivided into certain periods, called ages; of whicls they reckon three: the first, reaching from the creation to the deluge, which liappened in Grecec, during the reign of Orgyes, is called the obscure or uncertain age : the history of mankind, during that period, beingaltogether uncertain. The second, called the fabulous or lieroic, terminates at the furst olympiad; where the third, or historical, age commences.

The ancient poets also diviled the du. jation of the world into four ages, or periouls; tlie furst of which they called the 
Folden age, the second the silverage, the third the brazen age, the fourth the iron age. Not unlike thiese are the four ages of the world, as computed by the East Indians, who extend them to a monstrous length.

AGE, in law, signifies certain periods of life, when persons of both sexes are enabled to do certain acts, which, for want of yenrs and discretion, they were incapable of before. Thus, a man at twelve years of age ought to take the oath of allegiance to the king, in a lect: at fourteen, which is his age of discretion, he may consent to marriage, choose his guardian, and claim his lands held in socage.

Twenty-one is called full age, a man or woman being then capable of acting for themselves, of managing their affairs, making contracts, disposing of their es. tates, and the like; which before that age they could not do. A woman is dowable at nine year's of age, may consent to marry at twelve, and at fourteen choose her guardian, and at twenty-one may alienate her lands.

A $G E$, in military affairs. A young man must be fourteen years of age, before he can become an officer in the line, or be entered as a cadet at Woolwich. Persons may be enlisted as soldiers from sixteen to forty-five; after the latter age, every inhabitant is exempted from serving in the militia.

A GENT, in law, a person appointed to transact the business of another. It is a principle of law, that whenever a man has a power, as owner, to do a thing, he mav, as consistent with his right, do it by deputy, eitheras agent, factor, or servant. If a person be appointed a general agent, the principal is bound by all his acts. But an agent, specially appointed, cannot bind his principal by an act whereby he exceeds lis authority.

AGERATUM, maidlin, in botany, a genus of the Syngenesia Polygamia \$:qualis class of plants, with a monopetalous personated fower, and an oblong membranaceous fruit, divided into two cells, which contain a number of minute seeds, affixed to a placenta. There arc two species.

IGGREGATE, in botany, is a term userl to express those flower's which are composed of parts or florets, so united or incorporated by means either of the recep. tacle or calyx, that no one of them can be taken away without destroying the form of the whole. They are opposed to simple flowers that have no such common part, which is either the receptacle or the calyx, and are usually divided into seven kinds, viz. the aggregate, properly so calledl, whose receptacle is dilated, and whose florets are supported by foot-stalks; such are the blue daisy, thritt, or sea-pink, \&c.: the compound, which consist of several florets, that are placed, without partial peduncles, on a common dilated receptacle, and within a common perianthium; and where each floret hath its proper calyx; it is also a perianthium: umbellate, when the flower consists of many florets placed on fastigate peduncles, proceeding from the same stem or receptacle; and which, though of different lengths, rise to such a height as to form a regular head or umbel, flat, convex, or concave: cymous, when several fastigate peduncles procecd from the same centre, like the umbel, and rise to nearly an even height; but, unlike the umbel, the secondary or partial peduncles proceed without any regular order, às in sambucus, viburnum, \&c.: amentaceous, which have a long common receptacle; along these are disposed squamæ or scales, which form that sort of calvx called the Amentum: glumose, which proceed from a common husky calyx belonging to grasses, called Gluma, many of which flowers are placed on a common receptacle, called Raclis, collecting the florets into the spikes, as triticum, hordeum, bolium, \&c.: and spadiceous, which have a common receptacle, protruded from within a common calyx, called Spatha, along which are disposed several florets. Such a receptacle is called a Spadix, and is eitherbranched, as in phœnix; or simple, as in narcissus, \&c. In this last case, the florets may be disposed all around it, as in calla, draconitum, \& $c_{\text {. }}$; on the lower part of it, as in arum, \&c.; or on one side, as in zostera, \&c. These flowers have generally no partial calyx.

Afigraate, in the Linnaan system of botany, is one of the natural methods of classing plants, and comprehending those which have aggregate fowers.

AGGREGATION, in chemistry, denotes the adhesion of parts of the same kind. Thus, pieces of sulphur united by fusion form an aggregate.

AGIO, in commerce, a term chiefly used in Holland and at Venice, where it denotes the difference between the value of bank stock and the current coin. Mo. ney in bank is commonly worth more than specic: thus, at Amsteriam, they give 103 or 104 forins for every 100 forins in bank. At Venice, the aggo is fixed at 20 per cent. Sce Exchange. Agio is 


\section{AGR}

atso used for the profit arising from the discounting a note, bill, \&c. Agio of assurasce, is the same with what we call poliey of assurance. Sce Assersices.

ACRFE.MENT, in law, significs the consent of scveral persons to any thing done, or to be donc.

There are three kinds of agreement. First, an agrcement already executed at the beginning, as when noney is paid, or other satisfaction made for the thing agreed to. Secondly; an agreement after an act done by another, to which a person agrces : this is also executed. Thirdly, an agrecment executory, or to be execut. ed in time to come.

An agreement put in writing does not change its nature; but if it be sealed and delivered, it becomes still stronger; nay, any writing under hand and seal, or a proviso amounting to an agreement, is oquivalent to a corenant.

AGRICULTURE, is the science which explains the means of making the earth produce, in plenty and perfection, those vegetables, which are necessary to the sulssistence or convenience of man. Its practice demands a considerable knowlerlge of the relations subsisting letween the most important objects of nature. It is eminently couducive to the adrantage of those actirely engaged in it, hy its tendenes to promote their licalth, and to elrerish in them a manly and ingemuons character; and every inprovement made in the art inust be consiclered as of high utility, as it facilitates the subsistenec of a greater proportion of rational and moral agents; or, if we suppose the number to be uniuercased, furnishes them with greater opportunities than could be possessed before, of obtaining that intellcetual and moral cujoyment, which is the most lonourable characteristic of their uature. The strength of nations is in proportion to their skilful cultivation of the snil; and their inclependenee is secured, and their patrotism animated, by nbtaining from their native spot all the requisites for easy and vigorous subsistence.

Nit only to raise vegetables for the use of matu, but those animals also which are used for food, is obviously therefore part of the occupation of the husbandman; and to assist him in his operations, nther animals are to he reared and fed by him, to relicve lis labnurs by their strensth and endurance of exertion. In rold and comparatively infertile clinnates, tlic services of these creatures are par ticularly important, if not absolutely in- dispensable, and their health and multiplication lecome, conscquently, objects of great and unremitted attention.

The periort of the introduction of agriculture into Britain is unknown. pliny observes that, at the time of the laman invasion, the inhabitants were acquainted with certain manures, particularly marl. During the possession of the island by the Romans, great quantities of grain were exported from it, and it cannot be loubted that, as in various other respects, the rude inhabitants clerived advantage from their enlightened conquerors; they were eminently benefited by their agricultural cxperience. Amidst the series of contests and confusions which followed the final ahandonment of Britain by the Romans, the art and practice of husbandry must be presumed to have become retrograde. From the Norman concyuest, however, it derived fresh vigour, as a considerable number of flemish farmers, by this revolution, became proprietors of British estates, and introduced that knowledge of the means of critivation, for which their own country had been long distiuguished.

Before the sisteenth century few data are afforcled, with respect to the details of agrieultural practice in this island. At this period it derived a valnable inpulse from the cxertions of Fitzherbert, a jitge of the common pleas, whose treatises on the subject were read with avidity, and, while they aboumded in instruction, exciter a taste and cmulation for the pursuits of husbandry. Sir IIugh Platt followed this path of gemuine patriotism with great assiduity, modesty, ancl public advantage, treating particularly on the subject of manuring. Gabricl Plattes held out to his countrymen the light of genius, guided hy experience. Captain Blyth, in 1652, published a judicious treatisc, containing directions for watering lands. And ITartlih, the friend of Millan, in a work called the Legacy, suggested the cstablishment of a national institution for the encouragement of husbandry, and stimulated to the practice of it a number of country gentlemen, whom the violence and clianges of the times liad reduced to a situation, in which they found it requisite to avail themselves of all means and resources to extricate themselves from comparative imporerishment. Evelun and Jethro Tull were, at a somew hat later period, of eminent serrice, in dirceting the attention of their contemporarics firm the grossizess and pollutions of roluptuousness, to this mast valuable 


\section{AGRICULTURE.}

department of art; the former, by his treatise on plants; the latter, by his re. commendation of the practice of drill husbandry. Since their successful and ingenious efforts, a series of valuable ex. perimentalists and writers have performed to their country very essential service, by communicating the most useful information, and exciting a spirit of acute research and unwearied exertion.

In France, the political expedience of guarding against that scarcity, which, in time of war, either necessitated the yielding to harsh terms from the enemy, or exposed to the miseries and horrors of famine, by continued hostilities, induced the government, in the late reigns, to bestow on the subject of agriculture considerable attention, and to hold out numerous encouragements to it. The court was present at various experiments in husbandry. Prize questions were proposed at Lyons, Bourdeaux, and Amiens, for its promotion, and no less than fifteen societies, for the express purpose of advancing agriculture, were established, with the approbation, probably at the suggestion, of the governing powers. But, notwithstanding all those efforts, which, however, can by no means be presumed to have been totally useless, French husbandry continued in a very deplorable state, ascribable, in a great degree, to that tenure of lands, by which, through the greater part of the kingdom, the landlord contributed the stock, and the occupier the labour, dividing the profits in certain proportional shares. This circumstance, with several others, opcrated to keep the cultivation of this country in an extremely low state, and a comparative estimate of the produce of an English and of a French estate, of precisely similar natural advantages, at the period when this practice prevailed, would shew that, in consequence, principally, of so absurd and perverse a regulation, the su. periority of the former to the latter was at least in the ratio of 36 to 25. But the rerolution of France, changing erery thing, has swept away, with many excellent individuals, and some valuable institutions, a practice so impolitic and injurians; and although our intercourse with that country, since this event, has scarce. ly been such as to afford accurate and detailed information of the present state of its husbandry, it cannot easily be doubted, that the repeated transfers of landed property, the annihilation of partial burdens upon cultivation, the researches of ingenious chemists, and the general view of government to the pro. ductiveness of its territory, and to the promotion of its arts and sciences, must be connected with considerable improvement in this most valuable of national concerns.

In Germany, lectures have for many years been given on this subject, in rarious states of it; and several princes in the empire, particularly the present king of Bavaria, have directed to it their particular attention and patronage. In Russia, the late Empress gave it every facility which could be applied in the semibarbarous state of her dominions, and sent gentlemen into this and other countries, with a view to acquire information on mural economy, for the benefit of their own. In the Dutchy of Tuscany, the Archduke Leopold recently diffused the active spirit of improvement by which he was himself animaterl, and an academy was endowed for the promotion of agriculture. A society for the same purpose was instituted about the year 1759, at Berne, in Switzerland, consisting of men of great political influence, and also of great personal experience in mural economics. The Stockholm Memoirs sufficiently evince that Sweden, under the influence of the great Linnzus, applied to this science with extraordinary success and adrantage. Even the indolence and pricle of Spain were roused to exertion on this interesting subject, and the government of that country made overtures to the Swedish philosopher, for the superintendance of a college directed to the advance of natural history, and the art of husbandry.

In our own country, however, from a happy combination of circumstances, the exertions of individuals, societies, and government, have been directed, within the last thirty years, to the subject under consideration, with more energy and effect than have been displayed in any other part of Europe. The gentry and nobility have liberally patronized, and many of them judiciously and successfully practised it. The Royal Society, the Society of Arts, and various others, have been of distinguished service in collecting and diffising information, and in promoting a spirit of emulation, with respect to the management and productions of their native soil. The names of Kaims and Hunter, of Anclerson and Marshall, of Sinclair and Young, are celebrated by publications, exhibiting a union of plilosophical sagacity and patient experiment; the results of which have been of incal-s 


\section{AGRICUL'TURE.}

culable advantage; and to the efforts of these and other individuals it may be ascribed, that a hoard of agriculture was established by the government in 1793, whose exertions in procuring and pub. lishung intelligence on the objects of its establislunent have entitled it to the highest credit. By its agricultural surveys, by its diffusion of rewards for important discoreries, and of premiums for valuable treatises, and by its exertions at critical periols of scarcity, its utility and merit may be considered not only as decided, but distinguished. It has the power of directing public attention to any topics particularly requiring practical research or iflustration, and possesses the means of most adrantageously diffiusing its collections, circumstances of high importance to the utility of the establishment. It inust be regarded as its privilege, as well as duty, to suggest, from time to time, to the legis!ature, means for removing various impediments, still existing, to the perfection of the art, for the promotion of which it is expressly instituted.

\section{On Inclosing and Draining.}

Inclnsing of lands must be considered as the grind foundation of all improvements. When remaining open, litigations between neighbours are perpetually occurring, and the ingenuity of any indisilual proprietor is of littie use to him, as he is obliged to foliow the practice pirsued by the ignorant and obstinate necupicrs of the coinmon property in which he shares. In connection with inclos'tres misy he considered the practice of clraining lands, which is the next step in reudcring them productive. The superalsanlance of water is no lcss injurious to vegctat.on than the abso!nte want of it; :ml, whether arising from rain stagnating on the surface, or from springs in uise intefior of the earth, it is one of tli. moss mportant objce's of the furmer to prevent its pernicio is consequences. For this purpose, open or visible drains are in many cases itlopted; while in others, hollow nies, so called from their being concealed in covered trenches, are preferred. The width and depth of open drains must be regulated by the variety of soil and situation to which they are applied. 'To prevent, however, the sides from falling in. they inust at top be three times the width they have at bottom; while their direction inust obviously, and of necessity, be lescenting, it storik, at the same tinnc, not be steep, as this would form inequalities, and bear down their sides by the rapid rush of the water. All open clrains should be cleared, at least, once in every year; which regular vepairs may, in sone cases, rencler them in the end more expensive than those de. nominated hollow, which will sometimes last for several generations unimpaired, but demand originally a fur greater stum for their completion.

The practice of hollow draining was known by the Roman writers on agriculture, and is particularly mentioned by them. In stift clays it is of little service, and it is practised with desired effect. only where the soil is of that porous sub. stance, which easily admits the passage of the water through it Opinions clitfer with regard to the season for carrying these works into execution; some, with plausible reason, preferring the summer, and others, having nearly as much to state in recommendation of winter for the purpose. The depth of the drain, from the surface of the land, should generally be from twenty-six inches to thirty-two; and the principal rule for their depth is, that they should be secured from receiv. ing injury from the feet of horses o: cat. tle ploughing on the spot umler which they are made. It is desirable to constitute the drain in such a manner that the stoncs may lean towards each other, sn as to form a triangle, of which the bottorn of the drain forms the base: in which case, the width of a foot may be regarded as sufficient for them. The ditches constructed for these drains must be executed with great neatness and care; and with respect to filling them up, which they should be about ten inches deep, if stones are plentifully at hand, they should be applied for this purpose 1 ut in many places, faggot-wood, homs, bones, straw". fern, and even turf, laid in like a wedge. are all used in different situations; and drains constructed of these materials, thirty years ago, are found in several places effectuaily to answer their purjose still. By many persons, straw, twisted into a very large rope, has been successfully laicl in the bottom of the ditch; and by others, after twenty years esperience. the white thoru lwas been recominended as answering better than all other materials.

Injurious moisture in land arises often from springs in the bowels of the earth. The person who first published the method of draining land, in these circumstances, was Dr. Joln Anderson, of Aberdecn, while Mr. Elkington was actualty 


\section{AGRICULTURE.}

practising upon the same principle, in various p:urts of Kingland, witl complete success; and at length obtained from the Britishi parliament a thousand pounds, as the ciscorerer of so raluable an improrement. In Italy and Germany, however, it is stated, upon respectable authority, that the art has been long known and practised. Some of the strata of which the carth is composed will admit the free passage of water through them, while others effectually resist it. Gravel is obviously characterised by the former quality, and clay by the latter. The upper part of mountains is frequently composed of gra. vel, which extends far into their depth, and conveys with it the water received upon their surface from the clouds. Meeting with layers of clay or rock, how ever, the water is unable to permeate them, and flows upon the upper part of tliem obliquely, according to that general direction of the layers or laminx, which form the earth towards the plain or val. ley. After descending for some way, the layer of gravel along which the water liad passed, and from which it could not penctrate the clay, flowing only on its surface, often passes, in consequence of the obliquity just mentioned, under new strata of unaterials, consisting of clay, or some substance equally difficult to be penetrated by moisture. The water is thus confined between impervious beds. If the layer of gravel suddenly stops, in such circumstances, as it often does, the water which it liad conveyed between these two beds, lleriving fresh accumulation perpetually from its original source, will at length permeate the superior layer, ascending through its weaker parts, and arriving at last at the surface, will there stagnate. The art of clraining lands in this situation (the principle of which, in whatever research or casnalty its cliscovery originated, is of such happy application) consists merely of digging or boring with an augerinto tlic earth, so as to reacli the layer of gravel; the water in which, finding an easy and rapicl access upwards by this vent, nolonger pressesin its former diffised manuer, to the injury of the superior clay, which will consequently cease to nourish moss and weeds through redundant moisture, and be fitted for the purposes of useful cultivation. 'The application of this principle to the purposes of improved husbandry may be considered at present as in its infancy. It may be presumed that, in future periods, it may be carried to an extent of incalculable utillty; and be connected with the supply of navigable canals, and the movement of machinery adlapted to various objects of art and commerce. The manner in which the various strata are intermingled with each other must, it is obvious, as nearly as possible, be ascertained, before this practice can be applied with certainty of success; and the surest way of discovering their direction consists in examining the beds of the nearest rivers, and the appearance of their steep and broken banks. The examination of pits, wells, and quarries, in the vicinity, will also contribute information on the subject. Rushes and other plants, which grow only in moisture injurious to other vegretables, will like wise of ten indicate where a collection of water. is impeded in its course below, and consequently presses upward, to the destruction of useful vegetation. In draining a large bog, it will be generally proper to dig a trench from one end of it to the other, with cross trenclies at consiclerable distances, to allow the water a free discharge, by frequently piercing the bottom, at which the springs are to be found, with an auger. A single pertoration will fre. quently, indeed, complete the object. Instances have occurred, in which water thus raised has been made to ascend, by erecting round the perforation a building of brick, lined both sides with clay, above the level of the bog, applicable to a variety of purposes, and conveyed by pipes, or otherwise, to a considerable distance. Detailed regulations for the application of this important principle, so productive a source of improved cultivation, are precluded by the assigned limits of this article.

\section{On Fences.}

Without firm and close fences, the husbandman miglit as well cultivate open fields as inclosures, which in these circumstances, indeed, are only 10 minally such. He is under perpetual and well. founded apprehensions, lest cattle of his own or his neighbours should break into his corn or hay-fields. 'To prevent these painful apprehensions and irreparable niscliefs, every attention must be bestowed on the fences of a farm. Large and rich pastures may most easily be divided into fields of ten acres each, by which the land is less liable to be injured through the restlessness, and wild and perpetual movements of cattle, which occur in extensive grounds, where they are collected in considerable numbers. Dividing banks being raised, they may be 


\section{AGRICULTURE.}

connected with the system of draining by a clitch on cach side, about tlirec feet wide at top and four decp. The bank or border should be about the width of six fect at the bottom, lessening gradually to three at the top, at which the height from the ground should be five or six feet. On each side of the bank should be planted a single row of quick thorn. If the thorn be of the bullace or damson kind, it will be productive and protitable. On the top of the border filbert nuts may be planted at the distance of three feet; and, in the middle, apple trees at thic distance of five feet. 'This fence would occupy abont 13 teet, and in the neighbourhood of London, particularly, would be found not only eff cctual for its main purpose, but a source of income, as well as the means of defence. The lawthorn, the black thorn, and the holly, the willow, the black alder, and the birch, liave all been recommended by observant and experieneed men, as admirably calculated to secure fields from the irruptions of eattle, and will be employed for the purpose, according as particular circumstances of dryness or moisture, or other considerations recommend their application. Where there is an abundance of fiat-stones, fences are frequently composed of them ; and, though not so agreeable to the cye as the others, and requiring frequent repair from the stones being dis. placed by cattle, when kept in orderthey are the inost effectual defence that can be procured. With respect to hedges, (which in this country are more usual as well as more pleasing than walls, and which, perhaps, caunot in general be formed of any thing preferable to the thorn, considering the quickness of its growth in congenial soil, in which it shoots six orseven feet in a single season, and that it is more disposed to lateral shoots than all other trees, and by its prickles is especially calculated for the object in view, in the corrstruction of liedges, ) the proper method of repairing them is unquestionably by plashing. This has been defined a wattling made of living woorl. The old wood must, in the first instance, be all cleared from the hedge, together with brambles and irregularly growing stuff, and along the top of the bank sliould be left standing the straightest and best grown stems of thorn, hazel, clm, oak, or ash, about the number of six in a yard. The next step is to repair the ditch, which, in the driest soils, should ncicr be less than three fect wide at top, by two and a half deep, and six inclies wide at bottom; and in all rery moist

VOL. I. oncs should be at least four feet by three, and one at bottom. The earth removed from the ditch should be thrown upon the bank, after which the repar of the lredge commences, and those of the stems above mentioned, left in cutting the old hedge, which grow in the direction in which the new hedge is to ron, are cut off, to serve as hedge stakes for it, which being cliosen as much as possible of sallow and willow readily grow, and effectually preserve the new part from falling or leaning. I The remainder of the wood leftstanding is then plaslied down. One stroke is given to the stick near the ground, and another about ten or twelve inches ligher, just decp enough to slit out a part of the wood between the two, leaving the stem supported by about a quarter of its original size; it is then laid along the top of the bank, and weaved among the hedgestakes. Dead thorns are somctimes woven among them, where there happens to be a scarcity of living wood. After this operation the hedge is eddered in the usual manner. 'The greatest part of the hedge thus consists of living materials, and the importance of this circumstance cannot be too strongly insisted upon, as a compact and lasting fence is thusformed, while those hedges which are constructed of dead materials speedily decay, and crumble into the ditch." It would be endless to detail all the varieties of fence which peculiar circumstances may have rendered expedient, or human ingenuity may liave inverted. The most usual and most generally applicable are those which havo been mentioned.

\section{Irrigation.}

Watering of meadows was used in Fingland even in the days of Queen Elizabeth, and was carried on upon a large scale by Rowland Vaughan, in the golden valley of Herefordshire. He likewise jublished a treatise on the subject. After this period, and about a century since, it was introduced by Mr. Welladvise into Glou. cestersliire, with abundant proofs of its efficacy and importance. So slow, how ? ever, is the progress of improvement, that it is only of late ycars that this overflowing of grounds in nearly all other situations as well as in level ones, luas been brouglit considerably into use. It is a practice by which, in mild seasons, grass is produced in extreme alsundance, even so early as in March: grass, too, particularly nutritious as well as plen. tiful, on which cattle which have win- 


\section{AGRICULTURE.}

tered hardly thrive with great rapidity, and on which young lambs feed with surprising advantuge. Between March and Mar, the feed of meaclows, in consequence of this practice, is estimated at worth one guinea per acre; after which an acre will yield two tons of lay in June, while the after-math may be valued at twenty shillings. In consequence of this management, moreorer, the land is continually improving in quality, its herbage advancing in fineness, the soil becoming more firm and sound, and the depth of its mould being augmented. It may be estimated that in each county in England and Wales two thousand acres may be increascd in value one pound per acre, by means of irrigation; a national advantage of serious moment, and drawing after it the great improvement of otherlands, and the employment of many honest and industrious poor. The principles on which the practice depends have no portion of difficulty and complexity whatever. Water will always rise to the level of the receptacle from which it is derived. All streams descending in a greater or less degrce, which is indicated by their smooth and slow or their agitated and noisy progress, it is obvious that a main or trench may be taken from a river which will convey water over the land by the side of that river to a considerable distance hclow the head of the main, where the river from which it is taken flows greatly below it. As water, however, if left to stagnate upon land, does it very considerable injury, instead of benefiting it, by cherishing Hags, rushes, and other weeds, it is requisite to ascertain, before it be introduced upon any spot, that it can be easily and effectually drained off.

The muddiness of the water applied is stated by some to be of little consequence, and several writers have even laid it down as a inaxim, that the purer or clearer the water is, the more beneficial are its effects. These opinions, however, appear to be directly contradicted by experience; and it may be affirmed, that the mud of water, particularly in some situations, is nearly of as much consequence in winter watering, as dung is in the improvement of a poor upland field. Every meadow will be found productive, proportionally to the quantity of mud collected from the water. Those meadows which lie next below any rillage or town, are uniformly most rapid and plentiful in their growth. So well known is this truth, that disputes are perpetually arising concerning the first application of water to lands; and when mud is supposed to be collected at the bottom. of a river, or in ditches, many persons will employ labourers with rakes, for several days together, to disturb it, that it may be carried down by the water, and spread upon the meadows. The more turbid and feculent the water, the more beneficially it acts. Hasty and violent rains, producing floods, dissolve the salts of the circumjacent lands, and wash from them considerable portions of the manure, which naturally or factitiously had been deposited on them. Water from a spring dependsin no small degree for the quantity of nutriment it affords to vegetables, on the nature of the strata over which it passes. If these be metallic, or consisting of earth partaking of the sulphuric acid, it may be really injurious. But that which passes over fossil chalks, or any thing of a calcareous nature, will highly promote the process of vegetation. That which has run a long way is, almost always, preferable to what flows over land immediately from the spring.

In mid-winter great attention should be applied to keeping watered land sheltered by the water from the rigour of night frosts; but during the whole winter it should be withdrawn once in every twelve days, to prevent its rotting and destroying the roots of the grass. Every meadow should also be attentively inspected, to preserve the equal distribution of the water over it, and to remove obstacles arising from the influx of weeds and sticks, and other similar causes. In the month of February particular caution is requisite. If the water be suffered to remain many days together upon the land, a white scum, extremely pernicious, is the consequence; and if the land be exposed, without drying during the course of the day, to one severe night frost, the herbage will often be completely cut off. Both these causes of injury must be carefully avoided. About the middle of February half the quantity of water previously used will be better than more, all that is requisite now being to keep the ground moist and warm, and to hasten the progress of vegetation; and in proportion as the weather becomes warner the quantity introduced should proportionally be diminished. An important maxim in the application of water is, to bring it on as plentifully as possible, but to let it pass off by a brisk and nimble course, as not only its stagnation is injurious, but by indolently creeping over the land, it is of much less advantage than when passing off quickly. The spring feeding ought never to be done by heavier 


\section{AGRICUL'TURE.}

cattle than sheep or calres, as others would do extreme injury, by poaching the ground with their feet, and spoiling the trenches. The barce the meadows are fed towards the close of April, the better. After clearing, they should hare a week's watering, with a careful attention to every sluice or drain.

With respect to the application of floods, a gencral uule, of no sliglst importance, is, that the farmer should avail himself of them whenerer the grass cannot be used, as the sand and mud brought down by them increase and enrich the soil; but that he should avoid them when the grass is long, or soon to be cut, as in flat countries it is frequently spoiled by them, and much of the matter which they bring down, sticking to the grass, renders it peculiarly unpleasant to cattle, which have been known in some instances rather to starve than use it.

So great is the importance of irrigation, that governments would be fully justified in giving facility to undertakings for conducting it on an extensive plan. The fertility, or, in other words, the national wealth, capable of being derived from the application of cold water, which is at present allowed to flow uselessly away, to the purposes of agriculture, is well worthy the attention of the enlightened and benevolent statesman. In the neighbourbood of the cities of Milan and Lodi, Mr. Young observes, that the exertions in irrigation are truly great and eren astonishing. "Canals are not only numerous and uninterrupted, but conducted with great skill and expense. Along the public roads, almost every where, there is one canal on the side of the road, and some. cimes the re are two. Crossones are thrown over these on arches, and pass in trunks of brick or stone under the rosd. A very considerable one, after passing for several miles by the side of the highway, sinks under it, and also under two other canals, carried in stone troughs a foot wide. The variety of directions in which the water is carried, the ease with which it is made to flow in opposite directions, and the ob. stacles which are overcome, are objects of admiration. The expense thus employed in the twenty iniles from Milan to Lodi is immense ; and meritorious as many undertakings in England are, they sink to nothing in comparison with these truly great and noble works. So well understood is the value of water in this country, that it is brought by the firmer (who has the power of conducting it through his neighbour's ground, for a stipulated sum, and under certain regulations, to any distance that inay suit him) from a canal of a certain size, at so much an hour per week, and even from an hour down to a quarter, The usual price for an hour per week in perpetuity is fifteen hundred lirres."

\section{Manure, Ëc.}

Ingenious theories have too often, in agricultural treatises, usurperl the place of recitals of attentive and patient expe. rience. To tlie latter, the judicious reacler will erer bend his attention with pleasure and aclvantage, rejoicing that, while the systems of men are seen to vanish, one after another, in rapid succession, like the waves of the occan, the course of nature is constant, and may be depended upon through all gencrations and ages. of all the expenses incurred by the husbandman, none so rarely clisappoints its object as that which he employs in mam nures. The use of lime in this connection has been long decidedly established. It reduces to mould all the dead roots of vegetables, with which the soil abounds. Its useful operation depends upon its intimate mixture with the land; and the proper time therefore to apply it is, when both are in that pulverized state in which this union can be best completed. If left to be slaked by humid air, or casual rain, it is seldom perfectly reduced to powder. The proper method is, to place it in heaps on the ground on which it is intended to be spread, to slake it there with a due quantity of water, and afterwards to cover it with sod, to preserve it from the rain. If long slaked, however, before it is spread, it runs into clots, and becomes less operative for its purpose: besides which, it loses in such circunstances its caustic quality, on which account it should be brought home as short a time as possible before its intended application. Lime should not be permitted to lie all winter on the surface of the ground after being spread, for a similar reason, as also becsuse it is washed down into the furrows; and on the sides of hills the whole is apt to be carried off by the winter torrents. It should be spread, and mired with the soil immedistely before sowing. The quantity to be laid on depends upon the nature of the lands, which, if strong, will easily bear a hundred bolls per acre, while thin and gravelly ones will require only thirty or forty, and upon meadow ones fifty or sixty will be found sufficient.

Marl is valuable as a manure in propor. tion to the quantity of calcareous earth which it contaius, which in some instan- 


\section{AGRICULTURE.}

ces amount to olle lialf.' When of this quality, it may be regarded as the most substantial of all manures, converting the weakest ground nearly into the most productive. It is the best of manure for clay soils, in which all agricultural writers are perfectly agreed. - Before its application, the land sliould be cleared of weeds, and smootled, that it may be evenly spread; after which it should remain all winter on the surface. Its isefulness depends on its pulverization and close union with the soil to which it is applied. Frost, and a frequent alternation of dryness and humidity, contribute greatly to reduce it to poivder, on which account it should, as much and as long as possible, be exposed to their infuence. The proper season for marling land is summer. The best grain for tlie first crop after marl is oats. But, whatever be the crop, the furrow should be always ebbed, as otherwise the marl, which is a heavy body, sinks to the bot: tom of it.

Gypsum, or plaster of Paris, is coinmonly used in Switzerland and North America as a manure, and has been tricd in this country with stated results of a very different description. Experiments, however, respecting its efficacy and advantages, do not appear yet to have been made with sufficient accuracy to justify a final opinion respecting it. In Cornwall and other counties, sea sand is laid upon the land in considerable quantities, and found extremely useful in softening stiff clays, and renclering them pervious to the roots of plants. Chalk, or powdered limestonc, will also answer this important end; and sand, together with lime perfectly extinguished, will, more effectually than any thing else, open its texture, and prepare it for whatever is intended to be sown on it.

The true nourishment of végetables consists of water, coal, salts, and different kinds of earths, which are ascertained. to be the only substances common to vegetables, and the soils in which they grow. In favourable weatlier, grasses and corn absorb and perspire nearly half their weight of water every day. The great problem with respect to manuring or fertilizing a soil appears to bc, how to render coal soluble in water for the purposes of regetation, and to discover that composition of the different earths, which is best adapted to detain the due proportion of moisture. With respect to the former, tlie fermentation of dung appears to be the best method hitlierto discover$\mathrm{ed}$; and as to the different kinds of earths to be applied for the improvement of particular soils, the experiments of $\mathrm{Mr}$. Kirwan, to whom the world is indebted for much elaborate and ingenious analy. sis on the subject, have led him to several conclusions, which will be briefly no. ticed. Clay soils, being defective in constitution and texture, want the calcareous ingredient, and coarse sand. The former is supplied by calcareous marl, and both are furmished by limestone gravel. Marl and dung are still more beneficial, as dung supplies the carbonaceous principle. Sand, clialk, or pow dered limestone, will either of them answer this puxpose, though less advantageously. Coal asthes, chips of wood, bumit clay, brickdust, and even pcbbles, may. be applied with this view. For clayey loam, if deficient in the calcareous ingredient, chalk is an excellent manure; if in the sandy ingredient, sand is the obvious and easy remedy; a deficiency in both will be best supplied by siliceous marl, limestone gravel, or effete lime with sand. The most effectual application for the chalky soils, which want both the argillaceous and the sandy ingredients, is clayey or sandy loams. For chalky loam, the best manure is clay, because this soil is clicfly defectire in the argillaceous ingredient. Calcareous marl is the best manure for sandy soils. For sandy loams, chalk should be followed by clay; and for vitriolic soils, lime, or limestone gravel, or calcareous clay, is peculiarly applicable.

Not only sea-sand, but sea-weeds also, may be employed to considerable advantage as manure. For lands on the coast it may be procured, not only in any quantities, but at a trifling expense. The weeds of rivers are also extremely use. ful for the same purpose. The refuse of slaughter-houses and oil cakes are well adapted to fertilize the soil, but in most situations not easily to be obtained at a reasonable rate.

In almost all circumstances, the indus. try and ingenuity of the occupier must be depended on for raising on the spot an ade. quate quantity of dung for its manure ; and for this purpose it is expedient that, in such circumstances, as little as possible of the hay and straw raised upon the premises should be sold from them. This tenaciousness on the part of the farmer will prove the constant source of improre. ment. With a view to turn his means of manure most advantageously to account, lie should draw into his farm yard, at the most leisurely season of the year, before the time of confining his cattle to fodder, 


\section{AGRICULTURE.}

as much mard, turf, dry mud, loam, and vther applicable articles, as will cover its surface to the depth of twclve inches. If there be many hog-houses, stables, and cow-stalls, that are clcansed into the yard, on such spots these matcrials should be spread more thickly. Bog peats, if near at hand, sliould never be neglected. These peats may be regarded as vegetable dungbills, and their easy accessibility in this connection will be regarded as of extreme utility and consequence. Before foldering is hegun, the whole yard sloukl be well littered, for which stubble, fern, and leaves, are well adapted. No moncy laid out by the furmer is more wisely and successfully expended, than that which he employs in procuring, at a reasonable rate, great quantities of litter, by which his cattle are enabled to lie dry and warm, and the mass of manure which he raises is mucl larger and cheaper tlan he could procure in any other mode. Fern abounds in alkaline salts, and must therefore obviously procluce very valuable dung: it requires, lowever, to be rotted well, and is more difficult to be so tlian straw. In woodlands, leares may be collected at slight expence, and will make adnirable litter and dung. In the neighbourhood of marshes, rushes, flags, and coarse grass, inay all be easily procured, and will be exceedingly serviceable. After these exertions and preparations, the farmer must strictly confine his cattle during the winter, not by tying them, as some have done, but so as completely to prevent their roaming in the adjoining pastures. By thus confining all the eat. tle upon straw, and turnips, and liay, as may be requisite, the necessary quantity of animal manure will be obtained to make the compost of the several ingredients ferment, rot, and turn to rich ma. nure, while without these animal materials, the heap mightit be large, but would be of little value. 'The draining from the yarl should never run to waste, and, unless in extraordinary cases, such as extremely violent rains, this may be easily prevented. An excellent method for this purpose is the sinking a wcll in the lower part of the yard to fix a pump in ; by which the water nay be conveyed along a trough to a large heap of marl, turf, chalk, and other appropriate matcrials, which, by a claily application of this liquor, will be of little less value crentu. ally than a heap of dung of the same size.

If the dung remains under water, putreliation is stopped; this, therefore, should be carefully guarded against. Stirring the dung should also be avoided, as the oils and alkaline salts are thus carried off into the atmosphere, and it is not. merely rottenness that is wanted, and particiularly that dry rottenness thus producel, but suclı as exhibits a fat, oily, mucilaginous appearance. It will be advisable, if pritcticable, to let it remain in the yald unmoved, till the ground it is destincd for is completely ready for its rccep. tion. If, for want of room in the yard, it must be carted off into the field, let the litter and the mar] be well mixed in filling the cart, and let the whole form, under the shade of trees, if an opportu- nity be afforded for it, a heap of about four feet in thickness.

The dung raised even by a few sheep in a standing fold, under a shed constructed expressly for the purpose, (for the trouble and expence of one composed of hurdles will overbalance its profits, unless upon a very large scale) is a considerable object, while the sheep under it are at the same time warm and comfortable, instead of being exposed to driving rains and snow.

Animal substances are very far preferable as manures to fossil or vegetable ones. Woollen rags, log's hair, horn shavings, the offial of butcher's and fishmonger's stalls, may be obtained in large cities, and, whenever reasonably to be procured, should be cagerly cauglit at. With regard to the dung of animals, that of sheep is unquestionably the best. That of horses fed upon corn and hay is justly preferred to that of fatting cattje, which, lowever, is greatly superior to that of lean cattle, and particularly of cows, though they may feed upon turnips.

The practice of paring and burning is pronounced by men of great philosophical sagacity and researcli, and who have justly referred more to practical results than to theoretical reasonings, to be of the most decided advantage in the preparation of land. It may be considered as a practice safe on any soil, as in some it is essentially necessary. 'T'hat which most of all requires it, and which it is impossible by any other means to pulverize, is what consists of moss, rushes, and all kinds of coarse grass. It sliould be exercised on moor and heath-fickls, on account of the roots of the grass remaining in it, which are very stubborn and durable, and which check the growtl of corn, turnips, and other vegetables, by depriving them of a certain portion of wourishment. They serve likewise as a harbour 


\section{AGRICULTURE.}

for worms, the onily effectual way to clear the ground from which is to burn it; the odd and the young, together with their eggs, being thus destroyed or smotliered. The ashes procured by paring and burning will furnish manure for several crops. The Icssening of the soil by this husbandry was long apprehended; such a consequence, however, may be safely and positively denied, unless, perhaps, in cases in which the practice is carried to great excess. In poor soils, peat and sedgy bottoms, the process is universally admitted to be a proper one. With respect even to clay lands, it produces not only the common manure found in vegetable ashes, but a substance which acts mechanucally to the utmost advantage, loosening and opening the stubborn adhesion of the soil. In loam itself, the ploughing of rough pastures to the depth of eight or nine inches, and burning the whole furrow in heaps of about thirty bushels each, has been attended with most decided and durable improvement; and even though this depth be nearly twenty times the depth of common paring, the soil has not been supposed to be wasted eventually by the practice. Its texture has been rendered less stiff; the redundance of water has been expelled; and the immediate fertility attending this method of treatment fills it specdily witl far more vegetable particles than it previously possessed. Sandy grounds are as improveable by this method as those of a different description, and chalk lands, in every part of England, have been so treat$\mathrm{ed}$, and most profitably been brought into cuiture. In Gloucestershire, Yorkshire, and Lincolnshire, in Hampshire, Wiltshire, and Kent, the consequent crops of wheat, barley, oats, and sainfoin, have been of sufficient value to buy the land at more than forty years purchase, at a fairly estimated rent, before these improvements were applied. But whatever difference may exist, with respect to the practice on such lauds as have been just mentioned, and which is rapidly vanishing before olvvious and impressive facts, no one, as already observed, doubts the propriety of it on peat. From the fens of Cambridgeshire to the bogs of Ireland, the moors of the north, or the sedgy bottoms abounding in almost every part of the united kingdom, paring and burning are universally employed, on their being broken up, by men of real experience and observation. The metlod of dloing it by fallow is completely abandoned by all persons of this description, after the most regular and decided experiments of its results. In Cambridgeshire the work is performed by a plough, purposely constructed, and admirably adapted for it, which reduces the expence considerably. With respect to meadow and pasture land, it is performed by what is denominated a breast-plough, which, requiring great strength and labour in its application, much increases the cost. With regard to the general practice, it may be observed, that the heaps should not consist of more than twenty bushels, as, if they are much larger, the turfs will be too much burnt. Their size must be regulated, in a great degree, by the nature of the weather and the thickness of the paring. When the ashes are spread, which should be completed as soon as possible, the land, as is usually the case, should be thinly ploughed. In almost all circumstances, the ashes should be left ploughed in for sowing turnips upon lands burnt in the months of March and April. If potatoes are desired, this preparation is excellently adapted to them, and they should be planted in A pril on lands burut in March.

\section{The Culture of Grasses.}

A close and sound turf may be considered as the best manure yet discovered, on which account it is justly remarked, that those who liave grass can at any time have corn, the reverse of which is by no means true. Excellent grass lands, therefore, are valuable, not only directly, for the food of cattle, but indirectly, as containing ample means of raising grain, never failing, upon being broken up, to produce, for a time, a succession of valuable crops, whether of grain or roots. The small degree of labour and hazard attending the pasture of land recommends it to many ; and also the opportunity it supplies of laying out considerable property to great advantage in stock. Lands are preserved by it in good condition, and large estates may be managed under it with peculiar ease.

Grass lands, designed to be cut for hay, are to be distinguished from those on which the herbage is intended to be consumed by cattle on the spot: In fields of the latter kind, properly called pastures, manure is supplied by the cattle; in the others it must be applied artificially, as large crops of hay exlaaust the land, and always in proportion to the maturity which the licrbage is suffered to attain before cropping, while nothing is 


\section{AGRICULTURE.}

returned to the soil, for all that is thus detached from it. In consequence, moreover, of depasturing lands, the plants, being unable to piopagate theniselves by seed, do it by root, forming a compact and matted turf, incapable of sending forth strong and powerful stems, to form a good crop of hay, but abounding in slender and delicate shoots, such as the closeness of the turf will alone permit to pass, and which constitute a most nourishing and pleasing food for cattle. These two modes of employing land therefore should not be intermixed. What has for some time been applied to either purpose should, by all means, be permitted to remain so ; and to attempt to alternate the application of grass lands between pasture and cropping, is an effectual method of completely defeating both objects.

The difficulty of restoring old, rich, and clean pastures to their original state, after their being broken up, should ever prevent their being so, unless in very extraordinary cases. In common times they can be applied to no better purpose than their actual one: whenever it is expedient to direct them to the raising of grain, they will be certain to produce it in immense abundance.

With respect to the improvement of which grass lands are generally susceptible, those, of course, should in the first instance be applied to them, which are connected with draining and inclosure, which happily coincide with each other, as the ditch serves at once for dividing and defending the land, and for clearing off the redundant moisture. Irrigation also, which, as well indeed as the lastmentioned topics, has been already ad. verted to, from its obvious and admirable utility to pasture, will derive every atten. tion in this conncction. In spring a heary wooden roller should be applied, when the weather is moist, as it will then make the greater impression. The roots of the plants will thus be fixed in the soil. The mould will be cruslied, and the wormcasts levelled by this practice; and the ground is prepared by it for the applica. tion of the scythe, which will, in consequence of this operation, cut deeper, and with more facility.

The stocking of poor pastures with sheep, rather than black cattle, is of particular consequence to their improvement, and the perseverance in this practice for years, the sheep being folded upon the spot, has been more recruiting to poor soils, than any other practice. A habit of matting its roots is given to the grass by the close bite of these animals, and a growth of delicate herbage is promoted. Weeds are likewise cleared by sheep, as every thing young and tender (even heath and broom) is readily eaten by them. By means also of the dung, necessarily arising, an amelioration of the soil as well as produce takes place, of extreme and surprising importance. The sweetness of the feed on the downs of Wiltshire arises, not so much from any natural and characteristic excellence of the grass grown on them, as from its being kept close, and eaten as rapidly as it vegetates. It has been remarked, that, on certain poor soils, it requires much more time to produce the second inch of vege. tation than the first, making allowance for the fuller developement and size accompanying the second; a circumstance indicating that the preference should in such cases be given to the feeding by sheep rather than by cattle. The former remarks, howerer, on this subject, concerning the inapplicability of land thus depastured, for rearing crops of hay, must never be forgotten.

Quicklime, spread in powder over the surface of pasture lands, will scarcely fail to improve, not only the poor, but the more valuable ones. The moss plants, which are so particularly pernicious, arc thus destroyed, and converted into valus. ble manure. Upon impoverished and worn-out lands, about 270 bushels per acre, on the sward, in the summer, will be found of great and durable efficacy in cleaning and improving them. Mixing lime with earth taken from ditches or ponds is superior to using it alone, and, as a general rule, double the quantity of earth should be mixed with that of lime. The requisite proportions vary, however, with the nature of the soils; but are easily ascertained by attentive workmen.

Paring and burning may be applied to pasture with great success in a partial manner, by grubbingup rushes and bush. es with which it may be encumbered, burning them after they are dried, and before the autumnal rains come on spreading their ashes on the surface. In some instances this husbandry may be successfully exercised on pasture over the whole surface, as particularly on a poor worn out lev; which, by such a process, attended with the harrowing in of white clover, and several other grass seeds, at the time of spreading the ashes, has been improved into a very fine meadow. Where suitable, such a practice mav be regarded as one of the cheapest of all improvements. 


\section{AGRICULTURE.}

From whaterer cause land may be overun with moos plants, or covered with fern, rushes, and ant-hills, it should be subjected for some time to the plough, as no other method is equally useful to prepare for permanently ameliorating its pasture.

To prepare arable land for grass, it must be cleancd from weeds, and well manured, just in the samc manner as that which is required for a crop of grain. Hixcepting upon stiff clays, the most eligible preparation for grass is a crop of turnips, consumed by cattle in the field; the ground being thus at once manured and cleaned. Where lands are broken up expressly for "the purpose of improving the pasture, the turnips scarcely fail to succeed, through the manure afforded so abundantly by the fresh turf; and the cattle deriving, from the abundant crop consequent on this circumstance, a plentiful food, are thus enabled, the more extensirely, to improve the soil by dung. On the clay land, the soil should be very liberally manured in spring or autumn, it ought to be ploughed once in autumn, and three or four times more in summer, previously to the period of sowing the seeds, which should take place in August. As to the much agitated question of sowing grass seeds with or without a crop of corn, it may be observed, that it is impossible for lands intended for grass crops, or meadow, to possess too high a state of richness, and that, after the soil is improved with a vicw to its permanent fertility in grass, to weaken it by a crop of corn appears little better than blind or infatuated counteraction. If, however, the practice be persevered in, which has so generally been followed in this respect, barley should be the grain preferred, as springing up with a slight stalk, and not overshadowing and smothering the grass plants, and also as being the incumbrance to those plants more specdily removed than any other.

Whether the grass secds be sown in August after a fallow, or with corn in spring, all trampling by horses or cattle should be effectually prevented. Every thing, therefore, should be kept out from it, both during autumn and winter. Not only is the tender soil, which is extremely susceptible of injury, thus secured from it, but the pasturage in the spring is of proportionally more ralue for wot having been eaten off in autumn, and affords a most valuable early bite for the ewes and lambs.

The proper treatment of leys during: the first year is, to feed them with sheep, unless, after a crop of hay be taken from them, vast quantities of manure be spread over their surface.

The chief food of cattle consisting of grasses, their importance is as obvious as it is great, and the distinguishing and selecting them canuot be too fully attended to. By this care the best grasses, and in the greatest abundance that the land ad. mits of, are secured; while, for want of this attention, pastures are either filled with weeds, or bad and inappropriate grasses. The number of grasses fit, or at least necessary, for the purposes of culture, is but small, scarcely exceeding half a score, and by the careful separation and sowing of the seeds of these, the husbandman would soon be enabled to accommodate the varieties of his soil, each with the herbage best adapted to it, the advantage of which would infinitely exceed the trouble necessary for its accomplishment. Were a great variety of grain to be sown in the same inclosure, the absurdity would be universally ridiculed; and scarcely less absurd and ridiculous is the common practice of indiscriminately sowing grass seeds from the foul hay rack, including a mixture of almost every species of grass seed and rubbish.

The species of grass appropriated to any particular soil or application being determined upon, its seeds cannot be sown too plentifully, and no economy less deserving the name can possibly exist, than the being sparing of grass seeds. The seeds of grain may easily be sown too thickly; but with respect to those of grass, it is scarcely capable of occurring. The smaller the stem, the more acceptable it is to cattle; and when the seeds, particularly of some grasses, are thinly scattered, their stems tend, as it is called, to wood.

The most valuable grass to be cut green, for summer's food, is red clover, which also is an admirable preparation for wheat. To have it in perfection, the weeds must be cleared, and the land harrowed as finely as possible. The surface should also be smoothed with a light roll. er. The seeds should likewise be well covered with earth, as should all small seeds, notwithstanding the common opinion to the contrary. From the middle of A pril to that of May is the proper season for sowing it. Although it will last three years, if cut down green, the safest course is to let it stand but one. It is luxuriant upon a rich soil, whether of clay, loam, or gravel, and will grow even upon a moor. For: a wet soil it is totally unfit. 


\section{AGRICULTURE.}

It may be sown with grain with less impropricty than perhaps any other grass, and particularly with flax. When a land, left unploughed, spontaneously produces this plant, the soil may decidedly be pronounced good.

Those who lay down land permanently to grass may best depend on white, or Dutch, clover, for all rich and dry loams and sands, and for rich clays that have been properly drained.

Rye grass will flourish on any land but stiff clays. It is well adapted for permanent pasture, and, if properly managed, is one of the best spring grasses. There are few so early, or more palatable and mutritive to cattle. It is less subject to injury in critical hay seasons than any other, and the secds of none are collected with greater facility. It should be cut for hay sone time previously to its being ripe, as the stalks will otherwise be converted into a species of straw, aud its nutritive qualities be proportionably weakened.

Sainfoin is preferred by many agriculturists to clover, as less likely to injure eattle when they eat it green, producing larger crops, making betterhay, and continuing four times longer in the ground. It is sereral years in arriving at its full strength. The quantity of milk yielded by means of it from cows is nearly double of what is produced by any other green foot, and the quality also of the milk is proportionally better. It is much cultivated on chalky soils, and succeeds best where its roots min deep. Cold and wet elay is extremely ill adapted for it, and the dryncss of land is of more conse. quence to its growth than even the richness of it. It is best cultivated by the drill husbandry, after rcpeated ploughing, harrowing, and rolling; and while care is taken not to leave the seeds uncorered, they must alsa not be buried deeper than about an inch. They should be sowed in the latter end of March. An acre of very ordinary land will maintain four cows for eight months, and afforl the greatest part of their food in hay for the rest of the year.

Iucerne remains at least above twelve years prociucing very large crops, and yielding the most exccllent hay, to the amount of about seven tons per acre. It has obtained the highest praises from all grricultural writers. With a view to its successful cultivation, the soil must be kept open and free from weeds, which is most effectually done by horse-hoeing. It is transplanted with extreme advantage. VOL. I. if the tap root be cut off, by which it is fitted for a shallow soil, and its roots shoot out laterally and near the surfice. The culture of this plant is a principal distinction of French husbandry, and is in that country a source of alnost uniform profit. The best preparation for it is a turnip or cabbage crop. No mauríre should be allowed after the sowing till the crop is two years old. Its improving effect upon the soil is particularly great.

Burnet is a grass peculiarly adapted to poor land, and is so hardy as to flourish when all other vegetation fails. Its cultivation is not hazardous or expensive. It is best sown in the beginning of July. It affords rich pleasant milk, and in great plenty. For moist loams and clays there cannot be a better grass than the ineadow fox-tail, which is not only early, but remains for nine or ten years, and is little injured by frost.

To these remarks on a few of the grasses it may be added, that, in connection with soils, the principal grass plants have been thus arranged by one of the most distinguished agriculturists of the day.

\section{Clay. Loam. Sand.}

Cow grass White clover white clover Cock's-foot Rye Rye Dog's-tail York white York whitc Fescuc Fescue Yarrow Fox-tail For-tail Burnet Oat grass Dog's-tail Trefoil Trefnil Poa Rib York white 'I"imotliy' Timothy Yarrow Incerne

\begin{tabular}{ll} 
Chulk: & \multicolumn{1}{c}{ Peat. } \\
Yarrow & White clover \\
Burnet & Dog's tail \\
Trefoil & Cock's-foot \\
White clover Rib \\
Sainfoin & York white \\
& Rye \\
& Fox-tail \\
& Fescue \\
& Timothy.
\end{tabular}

\section{Instruments and Operations of Hubandry:}

The instruments used in husbandry are so numerous, and, under the same denomination, often'so differently constructed, with a riew to varieties of the same ope-ration, that it would be inipossible, in a sketch like the present, to detail their structure and application. In the process for which they are respectively intended, every agriculturist will of course arail HF 


\section{AGRICULTURE.}

bimself of those, the utility of which is best deciled by experience.

\section{P'oughing:}

In almost all lands there is a fixed depth for the plough to go to, which is the stratun between the fertile and unfertile monkls. No soil should be ploughed heyond this bottom, or sole, which is the preservative on which the top layer should rest, and by which the manure laid upon the ground is prevented from losing its effect. In fallowing land, thercfore, the plough may go as deep as the fertile soil will allow, as also in breaking up land without paring and buming. When land is pared and burnt, it ought to be ploughed in small furrows, and not so deep, as this depth of furrow would hazard the loss of the ashes for the immediate, and indeed for, the subsequent, crops. Where the soils are burıt in small heaps, and by slow fres, and the land ploughed shallow for the first time, and successively deeper and deeper, poor land will be more effcetually bencfited from itself than by any other mode; and in proportion as land can be made to maintain or improve itself; the benefit to the farmer is obvious.

Instead of ploughing stubble into the land, it is far better to move the stubble, and even to harrow the land before it is fa! iowed. In soil of a poor quality, a certain proportion should be observed betwecn the deptly of ploughing and the quantity of manure usually spread, which on better soils might be safely disregarded. 'There are few, which it is not requisite to plough to the depth of six inclies; and for many, the depth of ten is by no means too great. Once in twelve or eighteen months it is highly desirable to plongh to the full depth, while in the interval shallower tillage will be preferable to deep working, for wheat particuhrly, which is best promoted by a firm bottom. A ploughiug before harrest is of extreme consequence in fallowing, with respect to which seasonableness is of more consequence than the number of earths given. When fallows are called for, they should be attended with an observant cyc, and be kept clean, whatever other business may press upon the husbandman's attentiou. On a well-managed farm, servants and cattle will be kept sufficient for every necessary operation. The practice of fallows, however, is now abandoned in a variety of cascs in which they were formerly deemcd absolutely indispensable, and the well-inforned agriculturist will seldom have recourse to them after his first year.
Harrowing is not only necessary for csvering the seed, but also for preparing the land for its reception. The same instruments, whaterer be their form, cannot answer the different purposes of this operation upon all soils, whether firm or loose, and rough or smooth. For every purpose, however, and of whateversize, they should be so constructed, that no tooth can fol. low the track of another, and that every one should be constantly kept acting. The practice is best performed by harrowing a square piece of land at once, so that the instrument may be lifted at the corner, and the refuse stuff left there. The following harrows will thus have an opportunity of passing over every part of the land, and it will be completely cleaned. from couch grass and all noxious weeds.

Till of late ycars the practice of rolling was but little used, or even known, and it is in many places exercised so slightly, as to be of little service. Its utility, when it is exercised as it ought to be, consists in rendering a loose' soil more compact and solid, which, by making the earth adhere to the roots of plants, cherishes their growth. No roller that can be drawn by two, or even by four, lorses, will carry this effect too far. By rollins, moreover, the moisture of the earth is kept more in, and, in a dry season, this circumstance may reasonably be presumed sometimes to constitute the difference between a good and a bad crop. The common practice of breaking clods by means of mallets may judicionsly be superseded by the roller, precerled for a day or two by harrowing. When firm and tougli clay clods are to be broken, a large and heavy roller will be required for this purpose, with circles of iron of the depth of six or seven inches, which will completely reduce the most stubborn clods, and, from its decided usçulness, must by no means be regarded as a refinementin husbandry, productive of expense, without ample corresponding advantage. With respect to grass lands, the mowing for hay is extremely facilitated by the practice of rolling.

The practice of scarifying grass lands is used by a variety of persons, and is directly opposite to that of rolling them in its principle and effect. For this purpose a plough, consisting only of four coulters, or narrow teeth, is employed; and it is asserted that the crops of liay are consider ably increased by the loosening of the earth occasioned by this process, the ronts acquiring the power of fresh vegetation, while rolling is stated to increase the te- 


\section{AGRICUL'TURE.}

מacity of many pastures, in which it ought rather to be diminished. Previously to the manuring of grass land it is observed to be particularly beneficial, as whate. ver it be that is spread over the ground finds, in consequence of this methocl, more rapid access to the ronts, and a snialler quantity is remarked to answer the end proposed than a considerably larger one withont this practice. The operation may undoubtelly be beneficial in various instances and soils, and experiments indeed have evinced that it is so. The use of the roller, however, upon grass lands of a certain description, will be adnitted to be preferable; and with regard to arable land, this new process by no means interferes with the application of the roller, for all the purposes which have been mentioned.

\section{Drill Musbandry.}

The system of drill husbandry has been long known to be extremely prefera. ble on sandy soils and dry loams, and in Norfolk particularly it made a rapid and extensive progress upon such lands. It has latterly been introdnced on the strong soils of siffolk. The objects of this husbandry are, the promotion of the growth of plants by hoeing, and the saving of seed; objects, it will be universally ad. mitted, of great importance. It was well known, that in gardens the hoeing and transplantation of regetables often doubled their vigour : analogy tlicrefore naturally led to the conclusion, that a similar resilt would occur from the same ma nagement of arable lands, and experience has decicled both the practicability and the alvantage of it. Land sowed with wheat, howerer well prepared and finisherl it may bo in the autumn, sinks in winter", so that in the spring it possesses too great tenacity to aclmit the lirec cxtension of the roots for the collection of nourishment, and stands in extreme need of plnughing and hocing to counteract these effects. Grain sown before winter, therefore, requires the process of hoeing inexpressibly more than what is sown in the spring; the land in the latter case not having had the same time to harden, nor to prorluce many wecals by exposire to the winter snow and rain.

As the vigour of the plants upon the drill system is very considerably increas. el, the land must be sowed much thin. ner thin in the old practice; a circum. stance, which, in unreflecting mincls, has operated is a considerable objection, it appearing at the first view, which on such is not only strong, bit often indelibly im. pressive, that the vacant spots are completcly lost or wasted. In the common practice, howerer, even in the most productive laukls, the seeds, though rery thickly so:vn, produce each but one or 1 wo ears, whereas two or threc are universally produced by each in the latter mode, and somctimes a single one will produce 18 or 20. In the old method, there being by far more plants than nourishment, many must perish without attaining maturity, and many of the remainder can exist on. ly in a languid and drooping state; whereas in the other method all have as much nutriment as they require, and though comparatively few, being fur more vigo. rous in their regetation, they affori a larger produce than the numerous but sickly plants cultivated in the ordinary metliod.

For the application of this new mode, howerer, it is expedient that lanrl shou!d Isave been brought into good tilih hy the old method, which being done, it should be so thinly sown as to leave sufficient room for the plants to extend themselves. It must be divided for this purpose into rows, 30 inches distant from each o:her, which will give an, interval of two fect between the rows, every plant there by liasing ample room to extend its ronts and collect its food. In such con. sidcrable intervals, also, the earth may be hoed round the plants withort the hazard of injury to them. The first hocing should be applied when the wheat is in lcaf, before winter, and is designed to draw off the wet, and dispose the ear:h to be mellowed by frost. 'The second, ufter the harl frosts are passed, is calculated for making the plauts branch freely. The third nay be rery slight, an'? should be given when the ears begin to appear. The last shonld be giren when the wheat is in bloom, and is of the frreatest importance, at it makes the esrs lill at the extremities, and increases the size of the grain. In the midclle of the intervals a deep furrow nust be traced, and the carth be thrown to the right and left on the foot of the plants. By the curcfill application of the earth in this manner the plants are supported, and prevented from being laid, and the ground is prepared for the next sowing, in which the seed is to be prit in the micklle of the ground that formed the intervals.

The practice of hocing may take p'ace at almost any time in light and dry soils. but on strong and clily ones, in which 


\section{A GRICUL'URE.}

the extremes of wet and dry are particularly inimical to vegetation, the seasons for its exercise are often short and critical.

As vigorous plants, sucli as are produced by this system, reguire a longer period for attaining maturity, the corn thus cultivated must be sown earlier than in the usual mode. The intervals are usually prepared for sowing again, by placing some well-rotted dung in the deep furrows made in the middle of them, and this dung must be corered by the earth before thrown towards the rows of wheat. This should be performed immediately after harvest, that, before the rows are sowed, there may be time for slightly stirring the land. "The intervals of the second ycar occupy the place taken up by the stubble of the preceding.

The banishment of the plough in spring, to as great a degree as possible, has taken place, in consequence of this most useful and happy innovation. All peas and beans, barley and oats, not only may be put in on an autumnal ploughing, but actually are so in many parts of the country (especially in Suffolk, ) the stiches in this ploughing being carefully thrown to the precise brearth, suited to the intention of the farmer, whether to use only one morement of the drill, or what is usually denominated a bout of it; on which subject opinions differ. By the winter frosts a friability is given to the surface of the soil, so great, that very early in the spring, after one scarifying and harrowing, the corn may be drilled, and without a horse-foot treading any where but in the stich furrows, where it can do no injury. Instead of losing this admirable gift of the atmosphere (which cannot be renewed,) as was done by the former practice of at least two spring ploughings, it is thus completely preserved, and the delay, expense, and vexation, occasioned to the farmer, by the suc. cession of rains and north-easterly winds, giving the dreadful alternative of mire and clods, are wholly aroided.

From a comparative estimate of the profits attending the different modes of husbandry, that of the new is stated, after various experiments, to be very nearly in the proportion of three to two: and making the utmost allowance for the influence, by which the sanguine temperament of the partizan will interfere with the dispassionate calculations of philosophy, the advantage on the side of profit is indisputably and greatly with the mo. dern system. It is also to be observed, that most of the accidents attending crops of wheat originate in their being late sown, which, on the old plan, is una. roidable; whereas, in the new method, the farmer may plough the furrows for the next crop as soon as ever the first is removed. The ground may be ploughed dry, and may be drilled wet. The seed, moreover, is not planted under the furrows, but at the precisely proper depth. The seed las all the advantage of early sowing, therefore, and the crop is more certain than by any other mode. The land, also, is much less exhausted by this method, the weeds being completely destroyed by the hoe, and none of the plants existing to draw nutriment from the ground but what attain their full maturity; whereas in the usual practice seeds are pernitted inevitably to imporerish, and three-fourths of the plants themselves, after liaving derived a certain and a considerable portion of regetable food from the soil, perish abortively. The state of the land, therefore, must necessarily and obriously be left far better by the new mode than by the old.

The practice of ilrill-husbandry has been justly remarked to be the management of the garden brought into the field; and the grand question relating to it is, whether the extraordinary expense of this finer cultivation be compensated by the superior quality or abundance of its crop? which the most sagacious and experienced judges have determined in the affirmative.

Even admitting, for a moment, after all, that the practice is not, on the whole, superior, or equal, to the old mode, its introduction has at least been highly serviceable in correcting and refining the old method of cultivation, and some of the reputation of the new one may uncoubtedly be allowed to have arisen from a comparison with slovenly and defective methods upon the old plan.

With regard to white crops, there are many practitioners of liberality and sense who reject this practice, although, with respect to potatoes, cabbages, beans, and often turnips also, it is admitted by them to be unexceptionable. On a soil, however, in whicli the drill machine can move with freedom, there appears no reason, and it may be almost said no excuse, for the rejection of the modem system, which, indeed, however recently it may have been introduced into this country, is practised in every part of China, and is used also by the inhabitants of the Carna. tic, and, from the decided arersion of these nations to innovation, may naturally 


\section{AGRICULTURE.}

be supposed to have been their practice for a vist succession of ages. T'obacen, cotton, and the castor-oil plunt, are cultivated by it, as well as every species of grain.

\section{The Culture of Grain and lioots.}

Of the various plants raised for the nousishment of man, wheat is of the clicf imiportanec. To prevent the disease so fatal to this regetable, called the sinut, steeping ity seed from twelve to twentyfour hours in a ley of wood ashes, in line water, and in a solution of arsenic, is completely efficacious, even although it should liave been extremely afficted by the disease. A less time is insuftieient. On cold, wet, and backward soils, the best serson for putting this grain into the earth is September, particularly if the weather be rainy, as wheat should never be sown in a dry season. On dry and warm soils the sowing may be best post. poned till Octuber. In proportion to the eariness of tlie sowing, a less quantity of seed is sufficient. The best preparation for it is by beans. Clover forms also an excellent preparation for it : and on a farm dry enough for turnips, and rich enougli for wheat, the Norfolk practice of turnips, barley, clover, and wheat, is perhaps the most eligible that can be adopted.

By the dibbling of wheat, for a fortnight before which the land must be ploughed, and rolled down with a heavy roller, the seed is deposited in the centre of the flag, and the regular treading which the land receives presses down the furrows, and gives it a most valuable de. gree of firmness. The clief attention required in dibbling is, to make the holes deep enough, and to see that the children drop the seed equally, without scattering. After this dropping is completed, bush. harrowing follows. The quantity of sced should be about six pecks in two rows in a flag. If the drill-machine be used, the preparation of the land by ploughing, lyarowing, and rolling, must be extremely accurate, whether for onc stroke of the machine, or for a bout of it, and the quantity of seed should be the same as that used in dibbling. In February, slight dressings are with great advantage spread over the green clop of this grain ; and if the farmer has his choice for this purpose, he can never hesitate about taking them from dung; as dungs of all sorts are excellent, and no other manures, like these, are universally applicable. In the drill-hitslrandry, the practice of hoeing is of the first importance, and lias been already mentioned. If horse-loveing be not employed, the hand-hoe may be used to great advantage, and should be performed, first, early in Mirch, and the second time in the beginning of $\mathbf{A}$ pril. $\mathbf{\Lambda}$ scarifier is by many employed instead of the loe, with the same object and eflect Whatever the operation, employed with this view, inay be, the bottom should, with respect to wheat, be left firm and untoriched. This is of particular inport. anee.

$A$ mild and open winter is far from being favourable to this grain, pushing it forward with too rapid vegetation, and also cherishing those weeds which become its most injurious encmies. No weather is so injurious to wheat in the ground as wet. If, however, it have a good blooming time, though the rest of the summer, both before and after this periorl, may be unkindly, little apprehension for the crop need be entertained from any statc of the weather.

If wlieat be attacked by mildew, which is most likely to occur in the month of July, the only effectual application is the sickle, whicli ought not to be delayed for a moinent, though the ear be perfectly green.

Barley requires a mellow soil, and when sown upon clay, therefore, extraordinary care is required to stir the land immediately after the removal of the previ. ous crop; and, with this view, the prac: tice of rib-ploughing, which exposes the greatest possible quantity of surface to the air and frost, has been employed by many. This object should, at all events, be gained, whichever method be adopted for it, of the many which have been suggested, and are indeed practised. Scarification, with Mr. Cooke's machine for this purpose, instead of ploughing, is found to be an excellent method. In proportion to the tenaciousness of the soil must be the extent of this operation, which is easily dispatelied, even when repeated, leaving the lands, or stiches, in excellent order for the drill-nachine to advance and perfect its work.

The proper season for getting barley into the ground is March. 'Tle most useful preparation for it is br turnips. To have the land clry for sowing is of more consequence for this grain, than it is for almost any other. It should always follow either an ameliorating crop or a fallow, and in many cases it should be followed by clover. The quantity of seed 
larley slould be increased as the season adrances, as early sown crops have more time to tiller than later ones; and in the same proportion, the importance of the drill liusbandry with regard to this article inereases; as, if sown in the latter end of February, in the broadcast method, it would get the start of weeds, which, if it be sown early in April, would extremely annoy it, according to the old mode, but by the hoeing practice may be easily removed.

Oats should never be sown after other corn crops (as the land is by this practice too much exhausted,) and should receive the same preparation as barley : a circumstance often not sufficiently attended to. Warm, forward sands yield as great a quantity of barley as of oats, and should, therefore, be applied to the culture of the former, as generally yielding a better price. Upon various other soils, however, the produce of oats will be in considerably greater proportion than that of barley, and by superior quántity more than compensate for being sold at the smaller priee. To relieve the business of the succeeding months, oats may sometimes be sown in January; without this riew, however, February is preferable. The land should have been ploughed in October. Six bushels per acre may be sown in broadcast, and on poor soils eren eight, to great advantage : the crop being, by thiek sowing, several days sooner ripe, and the idea of saving seed with respect to this grain not being an object worth any particular attention. In the drill lusbandry five bushels per acre are sufficient, and they should be horse-hoed early in the month of May.

Peas are extremely ameliorating to the soil, and may, therefore, with very great adrantage, be substituted in tillage for white corn, a succession of which is pcculiarly impoverishing. They should, however, not be sown on lands negligently prepared, asis too commonly clone; and indeed the maxim'cannot be too much attended to, with respect to grain, that none should be sown but on lands in real. ly good order, with respect to heart, cleanness from weeds, and well-finished tilth. The uncertainty generally ascribed to this crop is to be attributed in a great degree to a negleet of these circumstances. At the same time, however, it is not meant to be asserted, that for all grain the preparation should be equally high and finished. The earlier peas are sown, the better they will thrive, and the more easily they will be moved off the ground in due time for turnips, a circumstance of particular importance. February is the proper month for their being sown. Ear" ly peas will seldom prove beneficial upon wet soils, and should be cultivated only on dry ones, upon sands, dry sandy loams, gravels, and chalks. The broadcast method should be most clearly rejected in relation to them. The only question is between drilling and dibbling them. On a ley, the latter practice camot be too decidedly adopted. Put in on a layer, they do not want manure, whieh will often make them run to long straw, a circumstance unfavourable to pordding, and likewise encourages weeds, which, in the infunt stage of the growth of peas, cannot be extirpated without danger. If the land be in good heart, therefure, as it ought to be, dung may be applied witl much more advantage to other crops; and being an article for which the farmer has, perhaps in all cases, a greater de. mand than lie can supply, should be used with eeonomy, and only where it is sure to answer best. The proper quantity of seeds to be applied in the drill-husbandiry, in equally distant rows, about one foot asunder, is seven pecks per acre. It is a judicious and valuable observation, the result of long experience, that peas should not be sown above once in about ten years, being not found to succeed, if sown oftener.

Beans, where the land is proper for them, deserve from the farmer every attention, constituting one of the surest funds of profit. He is enabled by them to lessen, if not absolutely explode, the practice of fallowing. When cultivated, howerer, with a view of sulsstituting them in the room of fallow, drilling or dibbling must be uniformly employed, so as to ad. mit the plough between their rows, as no hand-work will sufficiently pulverize the lands for the purpose, without extreme expence. Dibbling, when well performed, with respect to beans, is an admiral)le method. The difficulty, however, of procuring it to be well done, must be considered as no trifling objection to it. Beans are too of ten imperfectly delirered by the various drill-machines employed. On the other hand, however, the practice is less expensire than dibbling, and the seed is more surely put in to the desired depth, so that, on the whole, the drilling method seems preferable to that by dibbling. It is a point on which different circum. stances will safely and judiciously lead to different conclusions; and soil, season, dependance upon servąnts, together witld 
other considerations, will be resorted to, previously to the decision upon either of these methods. The common little liorsebean has the advantage of being more marketable than any other. Beans thrive upon light loams better than has been generally imagined. The soils, however, generally applicd to their culture, are al the strong and heavy ones. Wherever they can be cultivated, the farmer ought to have them. They do not exhaust lic soil. Wheat is prepared for by them, perhaps, better than by any other mode. They preserve their ipright attitude to the latest period, admitting of horsehoeing to the very last. The ground is well sliaded by them from the sun: and, if they are harvested favourably, their straw is valuahle, and, at all events, may be converted into admirable dung. By a bacl crop of peas, the land is often filled with weeds; but though a crop of beans should be extremely bad, the land may nevertheless be in the lighest state of cleanness. The quantity of seed differs according to the variety of the grain. A bout two bushcls of the horse-beans per acre, in rows equi-distant, at eighteen inches, is a proper allowance, and Febru. ary is the month in which they should be put in.

Buck-wheat is known to a vast majority of the farmers of this kingdon only by name. It has, however, numerous excelleucies, is of an enricling nature, and prepares well for wheat or any otliel crop. One buslicl of seed is sufficient to sow an acre, which is only about the fourth part of the expense of seed barley. It is sold at the same price as barley, and is equal to it for the fatting of hogs and poultry" The end of May is the proper season for its being sown, and grass seeds may be sown with it, if the practice should be thouglat in any instance eligible, with more advantage than with any other grain, unless harlcy may he excepted. I3uck-wheat may be sown even so late as the first week in July, a circunstance by which the period of tillage is consideribly protractell, and an a meliorating crop may thus be produced, after the usual period has, from any unavoidable or casual occurrence, been neglected.

Potatoes form a most important article of food, both for the human species and for cattle, and are an inestimable substi. tute for bread formed of grain, the best resource in yeriods of scarcity of wheat: and, happily, when the crops of grain fail, through redundant moisture, the potatoe is far from being equally injured, and sometimes is eren benefited by the wet scason. The clioice of soil for the culture of this root is of prime importanee. Po. tatoes never make palatable nourishment for man, if grown in a clay soil, or in rank, black loan, although in these circun! stancesthey are well fitted for cattle, and relished by them, and also produced in great abundance. 'They grow to perfection for human food in gravelly and sandy soils. The drill should be universally preferred for their cultivation. In September, or October, the field intended for them should have successively a rousing furrow, a cross braking, and the operation of the cleaning harrow; and being formed into three-feet ridges, should remain in that state till A pril, which is the proper season for planting this root. After cross braking them, to raise in a small degree the furrows, well-rotted horsedung should be laid along them, on which the roots should be laid at eiglit inches distance. The plough should then pass once round every row, to cover them. As soon as they appear above ground, the plough should be passed mind tliem a second time, laying on tlie plants about an inch, or somewhat more, of mould, in addition. When they have attained the lieight of six inches, tlic plough should go twice along: the middle of each interval, in opposite directions, laying earth first to one row, and then to another; and, to apply it more closely to the roots, a spade'should afterwards be used to corer four inches of the plants, and bury all the weeds. The weeds which arise afterwards must be extirpated hy the hand, as the loes would go too deep, and clamage the roots of the plants. From ten to fifteen bushels will be sufficient to plant an acre, the produce of which may probably be three hundred bushels. Sets should be cut for some few before they are planted, with at least one eye to each, and not in very small pieces, and the depredations of the grub upon them may be effectually prevented by scattering on the surface of the land about two bushels per acre of lime, fresh slak. ed. The most certain method of taking them up is, to plough once round every row, at the distance of four inches, after which they may easily be raised, by a thrce-clawed fork, rather than by a spade, and scarcely a single one will by this practice be left in the ground. They may with care be prescrved till the ensuing crop, particularly by the allowance ne. cessary till A pri] being closely corered in the barn with ily and presseclidown straw, while the remainder for the ensning part 


\section{AGRICULTURE.}

of the year is buried in a dry eave, nixed with the husks of drici oats, sand, or leaves, especially if a liay or corn-stack is erected orer it.

Potatoes are subject to a disease called the curl, which has drawn the attention of sagacious and experienced men, and suggested, in consequence, a great variety of opinions on its cause and remedy. some kinds of this root, however, it is almost unanimously agreed, are less susceptible of the disease than others, and the old red, the golden dun, and the long dun, are the least of all so. One or more of the following circunistances may be most probably considered as causing it ; frost, insects, the planting from sets of unripe and large potaroes, the planting in old and exhausted grounds, and too near the surface, or the small shoots of the sets being broken off before planting. Where certainty on any interesting subject cannot be obtained, the hints of the judicious are always desirable. The methods most successtully exercised for the prevention of the curl are, to cut the sets from smooth ripe potatoes, of the middle size, which have been kept particularly dry, to guard against the rubbing off the first shoots, and to plant them rather deeply in fresh earth, with a mixture of quick lime.

No plant thrives better even in the coldest part of this island than the turnip, and none are more advantageous to the soil. Its introduction was an improvement of the most valuable nature. There is no soil which will not produce it, when previously prepared for it by art; but the gravelly one is best of all adapted to it. No root requires a finer mould than the turnip, and with a view to this object, the land intended for it slould be exposed to frost by ribbing it after the liturest. The season for sowing must be regulated by the time intended for feeding, the later from the first of June to the end of July, in proportion to the designed protraction of this feeding. The field should be first plouglied by a shallow furrow. Lime, if necessary, should be then harrowed into it. Single furrows, at the interval of three feet, should be drawn, and dung laid in them, which should be then covered by going round it with the plough, and forming the three feet spaces into ridges. Wider row's answer no profitable object, and with straiter ones a horse has not room to walk. Thick sowing is far better than thin, bearing better the depredations of the $\mathrm{fly}$, and forming also a protection against drought. The weeds may, in many cases, be most effectually extirpa- ted by women, without injuring the crop; and the standing turnips should be left at twelve inches distance from each other. On average seasons, with good preparation, the produce from this number per. acre may be considered as amounting to 46 tuns of valuable nourishment. For preservation they may be stacked with straw; and 4.2 tons may be thus secured by one load of straw, or of stubble and old haulm. A method preferred by many is that of sowing late crops, eren in August, by which a succession of them remains on the field to be consumed on the spot, cren so late as the ensuing May, and the advantage of having turnips good till the spring grasses are ready for food, has greatly encouraged this practice. To prevent the devastations of the fly, the most destructive enemy to a crop of turnips, the most effectual method, as little dependance can be placed on steepings, or on fumigations, is to sow the seed at such a season, that they may be well grown before the appearance of the insect; and by well dunging and manuring the ground, to hasten their attainment of the rough leaf, in which the fly does not at all affect them. New seed, it may also be observed, vegetates more rapidly and vigorously than old; and the more healthy and vigorous the plants are, the more likely they are to escape depredation. The sowing of tumips with grain is by many recommended in this connection, and stated to be highly efficacious.

The culture of cabbages for cattle is a subject well meriting the attention of the agriculturist. The cabbage is subject to few diseases, and resists fiost inore easily than the turnip. It is palatable to cattle, and sooner fills them than carrots or potatnes; and, in every respect but one, cabbages are superior to turnips. On all soils they require manure; where. as, on good land, turnips may be raised without it. Fifty-four tons have been raised upon an acre of ground not worth more than twelve shillings per annum. Some lands have produced sixty-eight. The time of setting them depends on their intended use. If for feeding in November, plants, procured from seed sown in the end of July in the former year, must be set in March or April : if for feeding in March, April, and Hay, they must be set in the beginning of the preceding July, from seed sown in the previous February. Repeated transplantation may be applied to them with singular adrantage. When they are of the large species, four feet by two and a 
half are a full distance for them. The best protection for them from the cater. pillar, by which these and greens in general are apt particularly to be injured, is to pull ofr the large under-leaves, (which may be given to cows with great benefit) on which the eggs of those insects are usually deposited. Sowing beans among the cabbages is also considered a most effectual preventive of the nuisance.

Carrots require a deeper soil tlian any other root, and when the soil does not 11a. turally extend to the depth of twelve inches, equally good throughout, it must be artificially made so for their culture, which may be easily effected by trench. ploughing. Loams and sandy soils are the only ones in which they will flourish, and no dinng can be used for them in the year they are sown, as it will inevitably rot them. The ground must be prepared for them by the deepest possible furrow's, and, when they are sown, about the beginning of April, it must be smootlied by a brake. In large plots of ground, where liorse-lioeing is requisite, three feet sliould be the distance between the drills. Where an acre or little more only is employed, the interval should not be greater than a foot, and lund-hoeing will be found more convenieut, and scarcely attended with greater expeuse. From six to nine hun. dred busliels have been produced per acre of this root, where the land has been carefully prepared and attended to. As food for horses, its culture is rapidly spreading. For oxen, milch cows, and pigs, carrots are admirably applicable and nourishing, and, when boiled, turkeys and other poultry are fed on them with great success.

The ease with which pausuips are cultivated, and the great quantity of saccharine and nutritious matter which they contain, in which they are scarcely cxceeded by any regetable whaterer, render them well worthy of the attention of the husbandinan. Tliough little used in Britain, they are highly esteemed in many districts of France, in some parts being thought little inferior to wheat as food for man. Cows which are fed with them are stated to give as much milk as they do in the montlis of sunumer. All animals eat them with avidity, and in preference to potatoes, sind fatten more quickly upon them. In the cultivation of then the seed should be sown in the autumn, immedistely after it is reaped. When the seed is put in at this season, the plants will anticipate the growth of weeds in the following spring. Frost never does them any material injury. The best soil for them is a deep, ricls loam. Sand is next, suitable to them; and in a black, gritty soil they will flourish, but not in gravel or clay. In the deepest earth they are always largest. In an appropriate soil no manure isnecessary for tleen, and a very good crop lias been obtained tor three years in succession, withont using any. "The seed should be sown in drills, at the distance of eighteen inches, for the greatcre convenience of loeing; and by a second hoeing and a cautious carthing, by which the leaves may not be covered, the crop will be luxuriant. In Jersey, the roat has been known and eultivated for seve. ral centuries, and is lighly valued. It is considered as an excellent prepuration for wheat, which, after parsinps, yiclds an abundant crop withont any manure.

The profit of cultirating hemp-seed is by wo means small. It requires, bowever, the best land that can be found on a farm, or which is made such by manuring. A rich, deep, putrid, and friable loam is what it particularly delights in; and in addition to natural richness, forty cubical yards of dung per acre sliould be suppli. ed. Besides this original cost of land in natural richness and preparation, it is to be consiclered that hemp returus nothing: to the farm yard, while cos'n will gire straw, and the dung hill is improved by green crops. The question concerning the propricty of its cultivation by any individual is not to be determined, therefore, only from the circumstance of any price in the market, but is to be inferred from a view of all its bearings and connections. For many crops, tillage should be given with caution. With henıp such caution is unnecessary, as its rank and luxuriant growth proves futel to all those weeds, by which corn would not only be injured, but destroyed. From the autumn preceding to the time of sowing hemp, the land should be three or four times ploughed, and be well harrowed to a fine surface. Thie quantity of dung shonld be proportioned to the deficiency of the soil; and when the culture is continued from yearto year, a plentiful dressing must be cvery time applied. About twelve pecks should be sown per acre : and as the destriction of weeds in the till. age is here no object, the broadeast niethod is universally preferable to the drill. It will be ready for pulling in August, or about thirteen weeks after it is sown.

Flax, with due attention, will repay its cultivation; but, generally speaking, in this country the same land and manure 


\section{AGRICULIURE.}

may be more conveniently and profitably applied. Two bushels an acre is the re. quisite quantity of seed, and the land, if it be not particularly rich by nature, must be rendered so by art, must be worked to a fine surface, and be kept perfectly free from weeds.

The preparation for rape-seed is the same which is necessary for that of turnips. It is a crop subject to great injury, and extremely uncertain. In the conquered countries in the north of France, the practice is to sow it in a seed bed for transplantation, which is begun in October, and if there be no frost in November, is continued through that month, when the plants are about two feet long. Were this operation to take place earlier, they would be more secure from the frost. Dibbling is employed for the purpose, and the plants are set at about the distance of eighteen inches by ten. In a farourable year the profit is considerable, as indeed it ought to be, to compensate for the frequent and inevitable failure attending this cultivation. An indispensable point, in regard to this article, is to catch at opportunities of fine weather, for the purpose of reaping and threshing, which must be done in immediate succession. In reaping, extreme care is requisite, to prevent the shedding of the seed. Both in lifting it from the ground and conreying it to the barn floor, the utmost attention must be applied. As rain, at this critical period, may be considered nearly fatal to this produce, celerity of operation is of the first consequence, and as many assistants as possible slould be procured, and not a moment of fine weather should be suffered to pass unimproved.

The cultivation of hops demands a greater capital than that of any other plant. The cost of the first year's preparation and planting will amount to about eighty pounds per acre, and the subsequent annual expense will be little less than half that sum, and after all the expense, preparation, and attention, which may be employed, no crop is more precarious. The serious consideration of a farmer is demanded, before he resolves to introduce this plant where it has not been usually cultivated. And not only the circumstances already mentioned, but that of the accessibility or distance of manure, (for which the largest quantities are called for by hops, and the fact, that a small solitary hop ground seldom thrives like those which cover a large extent of country, from whatever cause this may proceed, should be fully weighed. Ruin may easily follow the want of adrerting to these and other considerations, and they cannot therefore be too strongly impress. ed on the sanguine adventurer. $\Lambda$ flat deep bog, in a sheltered situation, makes an excellent hop soil, constituting, indeed, a natural dung-lill. For the application of such land to hops, the chances are favourable. The best preparation for this plant, when sucb a spot as this does not occur, is made by two successive crops of turnips or cabbages, fed off by sheep, early cnough for the ploughing and planting in March. The plants should be inserted in rows, at eight feet distance from each other, and about six feet from hill to hill. Four fresh cuttings should be planted in each spot which is to form a hill. In April they should be poled, an operation requiring that critical accuracy, which, depending on changeable and casual circumstances, can be derived only from experience. The binds must next be tied to the poles. Tlic superfluous vines must be pruned about midsummer, and are useful food for cows. September is the month for pulling them. But the nuaragement of hops is a subject most operose and delicate, requiring extreme experience, attention, and dexterity; and the details of which would, if extended only equally to its importance, occupy bulky volumes.

\section{Course of Crops.}

No subject of greater importance has been treated by modern writers on husbandry, than the succession of crops. Before the present reign, although a considerable number of writers on agriculture existed, this topic was little treated, and by many scarcely adverted to. It has at length obtained something approacling to that attention which it merits. The main principles upon which all practices on this subject proceed aje, that some crops are more exliausting than others: that some, although of a very impoverish. ing character, yet, by being consumed on the farm, return to it as much as they de. ducted originally from it, and, perhaps, even more, that some admit profitable tillage and accurate cleaning, during their growth; while by others the land is almost unavoidably rendered foul by weeds, is exhausted witlyout return, and, when they are applied in succession, will be extreme$\mathrm{ly}$ and fatally imporerished. By experience, much is found to depend on a cer. tain arrangement of crops of these different and opposite characters; and in no 


\section{AGRICULTURE.}

one circumstance is the theory or pracriee of husbandry, in the present day, so inaterially advanced as in relation to this subject. Unless this department be well understood, the efforts of the farmer in nthers are cither abortive or injurious. In important diflerence is observable between culmiferous and leguminous plants, or those which are cultuvated for their seed, and such as are raised for their roots. The former bind the soil, while the latter uniformly give it openness and freedom. The former also are decidedly more exhausting, though unquestionably in themselves the most profitable. No soil can bear them in long and uninter. mupted succession. And, on the other hand, without the interposition of them among leguminous crops, the soil in whicl the latter grow would by their loos. ening quality become deficient in the tenacity which is necessary for vegetation. Some crops are rendered valuable chiefly from their preparation for others, that are more valuable, of a different kind. The husbandmen of a former age sowed frequently in succession that species of grain which they wished to possess abundantly; whereas, by this practice their object was often, at length, completely defeated. And if wheat, oats, or barley, were for a certain period sown in the same field, the land would eventually, and that in no long time, scarcely return the seed which was put into it.

That rotation is admitted to be best, which enriches the land with abundant manure, preserves it best from weeds, pul. verizes the soil most effectually when it is too tenacious, and binds it most com. pletely, where it is naturally too open. As a general rule, those who are engaged in agriculture cannot, with a view to these purposes, have the importance of provid. ing food for large quantitics of cattle too repeatedly and emphatically recommended to them. Indeed, by attending to this circumstance, larger quantitics of grain are produced than by any other mode, white that produce of the land, which consists of milk, butter, cheese, butcher's meat, and other articles connected with cattle, is nearly so much clear gain. Grass prepares a turf, which, when broken up, constitutes the most valuable of all known manures. 'Turnips, cabbages, beans, peas, and a variety of other similar food for cattle, supply admirable opportunities for cleaning and pul. verizing the soil by repeated loeings; the close covering which they bestow on ihe land smothers those weeds which the hoe does not destroy, and they leave the land, besicles, in a state of increased and great fertility. Certain exceptions to the necessity of rearing cattlc may undoubtedly occur, as, near towns and cities, the easy accessibjlity of dung will supersede very considerable preparation of it on the premises. Lands also may possibly be so rich as to require neitlier cattle nor sheep, and like some which are said to lie near the river Garonne, in France, might produce even hemp or wheat in perpetuity. Certain crops, moreover, may happen to be in such particular demand, as to make it desirable to cultivate them by fallow, and not for cattle or slieep. These exceptions can never interfere with the general rulc, as such, that that farm will be most productive and profitable, in respect to grain, on which is kept the great. est quantity of sheep and cattle. Two crops of white com ought never to be produced from a field in immediate suc. cession. In reference to several varieties of soil, it may be useful to give a succession of crops, which has been recommended by a gentleman of considerable judgment and experience. It should be observed, that on this plan the crops must be all particularly well hoed, and kept properly clean; and that the turnips, peas, and beans, must be put in double rows, on three fect ridges; the cabbages in single rows of three fect ridges.

$$
\text { Clay. Clayey loams. }
$$

Tumips or cabbages Turnips or cabbages Oats Oats

Beans and clover Clover

Wheat Wheat

Turnips or cabbages Turnips or cabbages

Oats Barley

Beans and retches Beans

Wheat Wheat

Rich loams and sandy loams. Peat earth. Turnips \& po- Beans Turnips Turnips tatoes Barley Barley Barley

Barley Peas Clorer Clover

Clover Wheat Wheat Wheat

Wheat Adlinfin.Potatoes P'otatoes

Beans Barley Barley

Barley Peas l'eas

Peas Wheat Wheat

Wlicat Chalky sub- Grazels. Iighs lands.
stratum.

Turnips Tumips Turnips

Barley Barley Iarley

Clover Clover Clover and rye-grass

Wheat Wheat cloverand ryc-grass 


\section{AGRICULTURE:}

Chalky sub. stratum.

Gravels. Iisht lands.

Potatocs Potatoes Clover and rye-grass Barlcy Barley Peas

Peas l'eas Wheat or rye

Wheat Vilieat

\section{Reaping and Storing.}

In converting artificial grasses into hay; the methorl should be different from that used with natural ones. They sliould for a day or two lie in swath, after whicl, being carefully turned, they should remain for a day or two longer; by which easy and simple process the hay is, in good weather, sufficiently made, After remaining two days in cocks, these should be carted to the stack.

With regard to the mowing of gy'ass, in general, for hay, the workmen sliould be made to cut as low as possible, by which the crop is increased, and the re. mainder thrives better than it would do otherwise. Many hands should be ready to assist, and five makers are not too many for every mower. The grass should be shaken out immediately after the scythe. By the evening it should be ra. ked into rows. The next moming it should be again shaken and spread, and in the erening it should be put up into cocks. These being opened on tlie following morning, after a similar process, may in fine weather be safelv collected into the great hay-cock at night. If successive rains come on to damage it, as it is stacked, a peck of salt should be strew. ed in layers on every load, which will sweeten it, and render it palatalle for cattle, which would not taste it without this preparation. The stack should be covered within a week after it is finished; and a trench should be ding near it, to carry off any wet, if it be placed in a situation subject to damp. 'The hard hay of a pool' soil is litttle subject to firing, which often occurs with respect to that made of suc. culent herbage. The latter, therefore, requires longer time for its making. To preserve as much of the sap of grass as possible, without incurring the dinger of firing, is the grand practical problem of hay-inaking.

When the stems of culmiferous plants are totally dirested of green, they are perfectly ripe. Some farmers recommend that wheat should be cut before this mature stage, not mly to prevent any of the grain fram shaking out, but as being found to make more excellent flour from being cut before perfect ripeness, than after having attained it. The latter observation nay very safelybe controverted. I3ut as it is adnitted that every moment it remains standing, after complete maturity, is critical, it may often be judicious to commence the reaping of it before the period of full ripeness. Wheat has been inmemorially reaped insteal of being nowed, and this method ought always to be adopted, as froin its high growth it becomes untractable to the scythe. When barley ground is purposely smootled by rolling, that crop may be cut down with the scythe, which not only, from the greater rapidity of its operation, relnoves that grain nore effectually from the dan. ger of being sliaken by winds, but brings with it a mucli greater proportion of the straw, for manure, than any other mode, a circumstance well deserving attention. Cutting of corn in wet weatlier ought ever. to be avoided, if possible; and, however obvious this caution, it cannot be regarded as superfluous, as it is unfortunately rery often neglected. Barley is particularly sub. ject to injury by wet, liaving no protecting lusk; and has a strong tendency, when cut in this state, to jun to malting; it should not only be cut dry, but immediately, if possible, be botud up, to prevent its being discoloured, which will otherwise easily occur. Peas grow so irregularly as to make the sickle necessary. For removing the produce from the field, long carts, moveable upon the axle, by which the wliole load is moved at once upon the ground, and lifted to the stack by persons appointed for the purpose, are preferable to other modes. Dispatch is thus obtained, when partičularly required, a circumstance always worthy of regard. Instearl of housing corn, stacking it is a far superior practice, as it not only, by the consequent exposure to the air, carries what is called a finer countenance, but as it is more completely preserved from vermin, than by being deposited in a barn. Every sheaf should be made to in. cline downward from its top to its bot. tom. Where they are laid horizontally, rain will be taken in both above and be. low. The.best form for a stack is that of a cone, (the top of which should be formed with three sheares united in a point) placed upon a cylinder. The moment a stack is finished, the covering of it should, if possible, conmence; materials should therefore be previously collected. If much rain should fall before this operation is performed, it will be difficult, and perhiaps impossible, to render the stack dry while it stands; and, in or- 


\section{AGRICULTURE.}

der to prevent patrefaction, it will be often requisite to pull it down, and, after fully exposing every sheaf to the air, to re-construct it.

The methorl of preserving potatoes has already been suggested, and to go farther into detail on this subject would $\mathrm{cx}$ ceed our limits.

\section{Threshing.}

The usual mode of threshing is attended with the inconvenience of the straw being very often not thoroughly cleared, by which mucly grain is lost; and with that of afforcling the workmen great and perpetual incentives to depredation, which, perhaps, are rurely resisted, or at least are certainly often yielded to. A fixed threshing mill will give compàrative security against these evils; and one worked by two or three horses may be purchased for from sixty to a Inudred guineas, and which, in eiglit lours, will thresh fifteen quarters of wheat. The granary should be over this mill, and the corn may then, immediately after thresh. ing, be drawn up into it, and deposited safe under the key of the farmer. Fresh threshed straw is better than old for feeding cattle, and is best managed for them by being cut into chaff.

\section{Fruit trees.}

The culture of trees, for the purpose of deriving a fermented liquor fiom their juice, employs a great proportion of the land of this, and of other countries, and is, therefore, an important branch of agricul. tural attention. The preparation of the juice of apples is more particularly attended to in the Irritish empire, than that of any other fruit; and the few remarks on the general subject which our limits will permit will be confined to that fruit. The varieties of apples are entirely artificial, nature having produced only one species, which is the common crab. But different culture produces very great differences, which are preserved by artificial propagation. The seeds of the finest flavoured apples among the native species should be sown in seed beds, in an extremely rich soil ; and the assistance of a frame, or even a stove, may be applied. In the first or second winter the plants should be removed to the nursery ; while they remain there, the intervals between them may be occupied with garden stuff, which slould not, however, crowd or svershadow them; and weeds, whenever they appear, should be extirpated. In pruning, particular attention must be given to the leacler; and, where there are two, the weakest of them must be cut off. The undermost boughs should be gradually removed, and not all in one sea. son. The height of the stem should be seven feet, or seven and a half as the crops or a trec of this elevation are less exposed, and, indced, the tree itself is less susceptible of injury. When they have attained five inches in girt, which they will do in scven or eight years, they may be safely planted out. Tillage is favourable, as the ground is thus stirred about them; and, where cattle are permitted to feed among them, they are apt to injure them, and, indeed, also to injure themselves after the trees begin to bear, by the fruit sticking in their throats ; on which account apple grounds, not in til. lage, should be enten bare before the season of gathering. Apple trees sliould be carcfully cleared of a iedundance of wood, which intereepts the free circulation of the air. Tluey should be kept clear also of the misletoe, which is often extremely injurious. Moss likewise should never be permitted to incumber them. The failure of crops, in particular years, is often ascribed to what is called blight; but, to adopt more intelligible language, is probably imputable to the greaticxhaustion of the trees by recent bearings; to prevent or mitigate which exhaustion, the best application is that of care, to bestow upon them all the natural means of healthy and vigorous vege. tation. Excess of hearing, however, will inevitably impair strength. Grafting in the boughs, and when they are fully grown thinning the branches, will prevent excessive produce, and may be considered as a very probable metliod of procuring fruit in moderate quantities every year. As general management, with respect to orcliard grounds, it is a juclicious rule to plant, for such, a broken up worn out sward, keeping it under arable till the trecs have attained tolerable growth, when it may with advantage be laid down to grass, and be permitted to remain in that state till the trees arc final. ly removed. After one set of graft-stocks on the stem have become elfcte, a second has been successfully applicd : and thus, though the efieet of age will at length prove fatal, the bearing of trees has been often very long protracted. The pear tree is of much longer duration than the apple, Both should be extirpated without retuctancs, when their produce no 


\section{AGRICULIURE.}

longer compensates for the ground occupied by them.

\section{Timber trees and copfrices.}

The planting of timber trees is an important aid to general cultivation, particularly in mountainous and moorish situations, where they afford shelter both for coin crops and cattle. Wherever plantations are formed in such situations, the aspect of the sumounding land is always improved, and exhibits a richer verdure. When suddenly removed, the contrary effect takes place; the efforts of human industry are then impaired; the warmth of the soil is dissipated; regetation is pierced and chilled by the unresisted blasts which sweep along its surface; and the cattle arc benumbed and stunted, for want of protection fiom its fury:

In a fiat and rich country, plantations often operate injuriously ; and lofty hedge rows, containing statcly trees, check the free passage of the air and light, prevent the seasonable drying of the ground, and, in a changeful and critical climate, the corn is consequently delayed in its progress to maturity, often cannot be gathered in proper condition, aud, sometimes, is completely ruined. These consirlerations will generally be sufficient to decirle the question of planting timber trees in particular situations. Where the practice is thought judicious, with a view to the melioration of the soil, the larch, which is the quickest grower, and the most valtable of all the resinous trees, will be entitied to a preference. 'The most barren ground will answer all its demands for nourisliment. For oak, better lands are indispensable. Beech trees under the protection of Scotch firs, previously planted for their slielter, will lay hold, eventually, even of a soil which pessesses neither clay nor loam, and thrives so rapidly as to require, in a sliort period, that the firs should be cut down, to afford freer air and ramification.

The use of small plantations of timber on large estates is very considerable. A vast quantity of posts, spars, and rafters, for buildings of every description on the farm, is perpetually called for in such circumstances, and will thus be fully supplied on the spot; whereas the want of it is attended with extreme expense and inconvenience. Planting should commence in October, and may be continued till April, excepting during frost. Injuries from cattle must be effectually guarded against in plantations, in their infant stage, which are as easily ruined as fields of corn. The fences, therefore, should be kept in the best possible repair.

With respect to coppices, the caution about cattle is equally necessary. When coppices have attained the age of fourteen years, they may, generally speaking, be cut down more profitably than at any other age; and the most adiantageous method, after this, is to sort out the wood for appropriate purposes, whether for fuel, hoops, or hop poles; wlich arrangement will, in almost all cases furnishing: such varieties, abundantly compensate for the time taken up in making it. In some situations, as in Surry for stakes and edders, in Gloucestershire for cord wood, in Yorkshire for railing, these articles yield a considerable advantage; and as they are sure of a market within a small distance, which, with respect to the carriage of so bulky a commodity, is a point. of the first consequence, an annual fall of wood applicable to these purposes may be desirable. The giround appropriated for its growth should be divided into that number of sowings or plantations, which will equal the number of years intended for their growth before cuitting. The management will thus be easy as well as profitable, and fall naturally, without agitation and embarrassme isto the regur. lar business of the year. These plantations may be sown either in October or March. The land being in good order, it should be sown with corn or pulse, appropriate to the season and soil, after which the tree seeds should be put across the land in drills. Acorns and nuts must be dibbled, and the key berries scattered in trenches, drawn by the hoe, at four feet clistance. Osiers may often be cultivated to great advantage, yielding a profit in the second, or at least in the third year; while a coppice requires 15 or 20 , and an oak 100 years, to attain to its maturity.

\section{Cattle.}

A considerable part of the stock of a farmer must always consist of cattle; and the maintenance and management of these, therefore, must ever be an object of great consequence; and in proportion to the number of them which he keeps for sale, in addition to those which he employs on account of their immediate service and labour, the importance of the subject is increased to him. Whether, in the latter point of view, oxen or horses are the more advantageours, has been a long agitated question. In situations in which 


\section{AGRICULTURE.}

there is a breed of cattle particularly adapted to work, and such situations do occur, the employment of the ox may probably be most beneficial. And when a farm is of so great extent, that a considerable number of beasts may be annually bought at a small expense, and no inconvenience may be incurred by turning out those to fatten which are ill qualified for labour, the same preference may be wisely inade. Bulls are on some accounts to be preferred to-oxen, bcing procured at a clicaper rate, and more active and persevering in labour. In other cases than those just mentioned, the question will be decided differently. The activity of the horse is extremely superior to that of oxen, and it is more applicable to differcut species of employnent. Its hoof is less susceptible of injury; ancl, with respect to well managed farms, in which dispatch is more required than absolute strength in the operation of ploughing, the quickness with which the horse completes the business, in comparison with the ox, will, it may be presumed, at length generally diffise that preference of the one to the other, which is obriously increasing every day. Yorkshire is the most distinguished part of England for the breed of horses, particularly for the saddle, and the black cart horse of the middle counties has been long celebrated. In the north of England, a very valuable breed from Lanarkshire in Scotland has lately been encouraged, of extreme activity, though not fit for particularly heary draught, passing over a rast surface of land in a short time, and lighly useful, therefore, not only in ploughing, but in the general work of a farm. The Norfolk management of horses, as instruments of agriculture, is considered by many as the cheapest that can be practised. In the winter months their sole rack meat is barley straw. In the most busy season a busbel of corn is thought an ample allowance, and the chaff of oats, which is far preferable to that of barley, is universally mixed with it. They are in summer kept out all night, and their fced is generally clover only. A great saving in the maintenance of horses has been obtained by the substitution of roots for grain. Turnips and potatoes have been given them in a raw state, in which case, if hard labour is required of them, some corn in addition may be expeilient. If these roots are boiled, however, the corn may withont injury be dis. pensed with. Carrots are betterfor horses than potatoes, and both are thought ex. tremely serviceable in preventing various disorders to which they are subject, particularly the grease. Carrots are deemed an effectual cure for what is denominated thick wind in horses; and to broken windecl ones, are of admirable use in palliating the complaint.

The practice of soiling horses, instead of turuing them to grass in summer, is by many experienced inen thought by far the superior method. The produce thus managed goes three times as far as if consuned in the field. The injury done by feeding pastures with horses instead of sheep or oxen, an injury very material and obvious, is avoided; and the dunghill, which, in all situations at a distance from towns and cities, is an in. valuable object, especially if plentiful littering be allowed, is sufficiently benefited to compensate for this expense of their keeping.

Black cattle, intended for feeding, should be chosen for their being short-legged, which quality is almost uniformly con. nected with a general good make. Straightness of back is another important recommendation, and the more per. fectly straight they are, while at the same time thcy are very broad and flat on the loins, the more readily experienced judges will decide on their worth. Smallness of dewlap, and the barrel form of carcase, both in the fore and hind quarters, are also justly insisted upon as points of excellence. A curled hide is indicative of a thriving beast, and worthy of observation in the choice of these animals. A still more favourable symptom is a softness or sleekness of skin. Indeed, the nice touch of the hand is requisite in the judge of cattle, perhaps nearly as much as the keen observation of the eye. Oxen that have been worked are more valuable to graziers than others, as not only fat. tening with greater rapidity, but furmish. ing more excellent beef. After working till the age of fourteen years, which is within two of the usual extent of their natural life, they have often supplied most tender and admirable meat.

It is a considcration of great in portance to the grazier, that he should alway's secure such a stock of winter food for his cattle as will maintain them during that season, reserving them for the spring market, which is always superior to that of autumn. From the beginning of March to that of June, the change of prices will be completely in lis favour ; and in orcler to avail hiniself of this, he must so arrange his aftairs, as to pro. 
ckre an adequate stock of winter maintenance. Whatever food is used for this purpose besides hay, the latter is always to be implicd, and from seven to fourteen pounds a day should always be allowed to each beast. For liastening the process of fattening an ox, liuseed cake has bcen found superior to every other article. Its price, however, of late years has been more than proportional to this advantage. Carrots complete their fattening with a ncarly equal degree of celerity; and an ox will eat a sixth part of his weight of this root every day; at which rate an ox of sixty stone may be supported by the produce of an acre of these roots for upwards of five months. 'Two beasts, of the weight just mentioned, if half fat when put to carrots, might bccome completely so by consuming the produce of an acre. Cabbages are but little inferior for the purpose to carrots and oil cake. An ox will eat of them nearly one fifth of his weight. Turnips are the most common description of winter foorl, but possess not the same fattening quality with the substances enumerated; and, being a crop susceptible of various injuries, are much less to be relied on than many others. Of these the consumption of twenty-fire ton is deemed necessary to fatten a beast of about sixty stone.

In consequence of eating succulent plants, and particularly clover, beasts are apt to swell greatly and very dangerously, in which case driving them about with great rapidity is often practised with success, though a still more effectual method is to stab them between the ribs and hip bone, to the depth of about four inches. A flexible tube has also been frequently passed through the mouth into the gullet, by which the air, which causes this disease, is easily dischwged.

The practice of stall-feeding, or keeping the cattle in the bouse at every season of the ycar, and fecding them, when practicable, with green food. where there is abundant litter, is considered by cxcellent judges as the best method of turning to account the produce of the soil. Double the usual quantity of manure also is thus produced; and the annoyance of the cattle in any great degree by flies and insects is eflectually precluded. This plan has been loug and cxtensively practised in Germany, and is making its way in England, under the encouragement of many judicious agriculturists. Not only may gruss be thus employed for food more protitably than in any other way, but boiled roots may be used with ex* treme adrantage; with a view either to maintais or to fatten cattle; and, ridiculous as the idea of this management for vast number of cattle and horses might at first appear, it is found capable of being performed, with the aid of a steam engine, by one superannuated attendant. The roots may be permitted to retain their original form, or may be mashed and con. verted into thick soup, as is deemed most cligrible.

Cleanness and temperate warmth in the process of fattening beasts for human food are of the utmost importance; and it has been philosophically remarked, that analogy will lead us to conclude, what observation justifies from fact, that whatever tends to form in beasts a state of feeling, unirritated by fear, vexation, or pain, must tend to shorten the period necessary for advancing them to their maturity of size and excellence.

\section{Sheep.}

Towards the end of August, the annual purchase of wether lambs, for an estate on which regular flocks are not kept, generally takes place. These are justly preferred for stock to all others. The new Lcicester have the advantage in competition with all the loug-woolled breeds, and the South Down with all those of short or miduling wools. For severe and mountainous moors, the black-faced and coarsewooled Scotch sheep are by far to be preferred, being able to sustain the most rigorous weather, and to live on the most scanty food. Instead of putting sheep, after the above-mentioned purchases, to the highest feed, and pushing them to perfect fattening, the better way is to keep them tolerably well till March, and to begin then to fatten them, by which method they will be fit for sale at a season of more adranced price; and upon this plan the purchase money is, with good management, generally doubled, and the fleece found an additional clear advantage. Whatever be the nature of the stock, to. wards the middle of May they should be turned into their summergriss, and, in an inclosed farm, the division of the fields into different parcels intended to be fed is an object of great importance. It is justly thought, that in large parcels tliey do not thrive cqually well as in small ones, and the waste of food is considerably greater. It will be found, that in focks of from ten to twenty the same furm will kecp considerably more than in one flock. The number should be appropri- 
ated to each ficld, accorling to what it is cnabled to carry, and suffered to remain, without any other change than what dcpends upon the state of individuals from accident or season. They will thus inevi. tably fourish. I3y adhering to the practice of folding, which, however, in certain cases may be necessary, much loss is often sustained; much food is spoiled; and injury arises from numbers being soclose. ly crowded together: and although the practice may be highly bencficial, as pre. parative for corn, this advantage is often too dearly paid for. A nother point of very considerable consequence with respect to sheep is the practice of close feeding. Fven in pasturage shorn completely to the sround, the herbage is found rapidly to spring up ; and when drought is observed nearly to destroy the produce of fields treated in a different manner, by being permitted to run to bent, such as are ma. naged in this close way are in comparison at least highly productive. In all plants cul. tivated for pasture, the moment the sced stem runs, the grand effort of the system is dirccted to the formation of the seed; and the way to produce the greatest abun. dance of leares, there iore, is to prevent the rising of these stems, which, by close feed. ing, is of course effectually accomplished.

In the whole range of lusbandry, per. liaps, the most perplexing point of management is the providing for focks of sheep in the months of March and April. 'Turnips and hay are generally depended upon; but being frequently inadequate, rye is sometimes sown on purpose, and crops of wheat are also sometimes eaten down by them. All, however, is too frequently found insufficient, and they are permitted to run over the clover and pas. tures of the farm, committing great waste and damage. To prevent these evils, burnet should be cultivated by the farmcr. It is a most hardy plant, and preserves its green leaves through the winter, and under deep snows vegetates with singular luxuriance. This will be an ad. mirable feed for sheep in April, when turnips ought no longer to remain upon the ground. But kept grass on dry meadow and pasture, or what is called rouen, is preferable to every other dependance, and though consisting as it were of hay and grass in the same mouthful, being the autumnal growth at top, sheltering the more recent regetation bencath, the sheep cat both togetlier without the slightest liesitation, and are found to thrive upon it extremely. Ten cwes, with their lambs,

IOI., I may be supported throughout April on one acre of this rouen, and no clicaper mode of keeping a full stock in April can possibly be adopted.

In June the washing of the sheep should generally take place previously to the shearing. The washing may be best performed by a strean of water; and those who are engaged in it, instead of standing in the water, in which their uncomfortable situation leads them to hurry negligently over the business, should, by means of a cask or tub, be frecd from such un. pleasant and dangerous exposure. The shearing, which speedily follows this operation, should he as close as possible, and the circular is by far preferable to the longitudinal method with a view to this object.

Sheep that are kept in inclosures, and particularly in a woodland country, should be examined twice every day, to guard against injury to them from the fiy, which, in twenty-four hours after having struck, sometimes produces incurable diseasc. The most efficacious treatment on this subject is, after parting the wool wherever the maggots are found, and picking them out with a knife, to scrape a small quantity of white lead among the wool, so that it may be carried evenly down to the wound. Regular and minute inspection will prevent such 2 circumstance as 2 broken coat in any of these animals, from a cause so dangerous and fatal, where they are neglected.

When ewes arc about to lamb, their keep should be of the most nourishing kind, consisting of plenty of turnips or cabbage. Till this period they may do without them. But all cattle that have young require as good keeping as those which are fatting. The turnips or cabba. ges should be drawn for them, and giren them on dry ground. A standing rack of hay should be left for them on the field. which will be of great advantage to them.

\section{Sroine.}

The quiek multiplication and growth of swine render them a specics of stock high. ly profitable, and if reared systematically, and upon a large scale, inone will be found to answer the purpose of the farmer better. Though supposed to be filthier than any other animals, they enjoy a clean and comfortable place for laying down in, and their thriving and feeding are at least as much improved by cleanly management as those of any other stock. Their stres should therefore be constructed 


\section{AGRICULTURE.}

sloping, to carry off all moisture. The different sorts of swine should be kept separate in them, and many should never be put together, and particularly if they be of different size. Too much attention cannot easily be paid to the rearing of these animals. The large Chinese breed is generally and justly preferred. When swine are reared on a comprehensive plan, crops must be sown purposely for their support, and the dairy cannot be considered as that resource which it is naturally regarded in small farms. From October till May, potatoes, carrots, cabbages, and the Swedish turnip, which is a most useful vegetable for this particular purpose; must be provided for the swine, and stores from October till the end of May, when they may be received into lucerne, chicory, or clover, on which they will be maintained till the clearing of the stubble ; and thus, with the offal of the barn and the corn fields, and the plants and roots just mentioned, the whole year will be amply provided for. In summer, meal must be mixed with water for the sows as they pig, and in winter boiled roots, peas, and oats, sliould be given to the young ones. Dairy wash is a capital addition to this mixture. The sows should be permitted to pig but twice a year, in April and August. When great with pig, they must be carefully secluded from the boars, and sluut up about a fortnight beforchand in the stye ; and while pigging, it is of extreme consequence that no one approaches them, or is even seen looking at them, as in this case they will often devour their farrow. After a week from this period, they should for a few hours in the day have the freedom of the yard, which will be a great relief from total confinement. Winter pigs, if not kept with great attention, are found less profitable than others. Milk and whey may so usefully be applied to them, that perhaps no other mode of their application is equally advantageous; and the best process for weaning them is by giving these articles to them mixed up with peas-soup, though the latter alone will answer well. When three or four months old, nothing is better for them than clover : turnips alone will not be proper, but corn should be added to them. Carrots and potatoes will keep them well till their full growth. Malt grains, if easily and cheaply to be procured, are highly to be recommended.

With a view to fattening hogs, the corn employed should be ground into meal, and in the proportion of five bushels to 100 gallons of water should be mixed in large cisterns: the mixture should for three weeks be well stirred every day, and at the end of that period will have fermented and become acid, before which it should not be given. A succession of vessels should be filled with this fermented food, that some may be always ready ; and, before it is applied, it should be always stirred. Peas-soup is perhaps equal. ly wholesome food with the above, and especially if made with warm milk. The preparation, however, is more expensive. Fatting hogs should be constantly well littered, and be kept perfectly clean.

\section{Poultry.}

With respect to poultry, constituting as they generally do part of the stock, how. ever small, upon farms, a few observations on them may not be thought superfluous. If kept merely for domestie supply, particular attention is needless. When reared with a view to profit, however, and on a somewhat large scale, they will repay, as they indeed require, considerable attention. A house should be erected for them, containing divisions appropriately for roosting, sitting, fatting, and food. The building should be constructed near the farm-yard, having clear water conti. guous to it. Warmth and smoke are great cherishers of poultry. All, of every species, must have access to gravel and grass. Their cheapest food consists of boiled potatoes, on which it appears that they can be supported and fattened without the aid of any corn. Where numbers of them are kept upon a farm, if permitted to go at large, they will often do considerable injury both in the fields and bamyard; besides which they will be extremely exposed to the attacks of vermin, and will lose a considerable number of their eggs. A full-grown hen continues in her prime for three years, and may be sup. posed in that time to lay 200 eggs, which number, however, by warmth and nourishment, might be greatly exceeded.

The quality and size of the Norfolkturkeys are superior to those of any other part of the kingdom. They are fed almost entirely with buck-wheat, which, perhaps, may account for their excellence, and are bred by almost every little farmer in the county. When young, they demand perpetual attention, and must be fed with alum curds and chopped onions, and the expense attending their management and food can be compensated only where broods are tolerably successful, and the prices high. 


\section{AGRICULTURE.}

\section{The Dairy.}

In the conduct of a dairy, which, in all but the most productive corn countries, is an object of particular consequence to the furmer, it is obviously of the first importance to select cowvs of the best sort, and in judging of the value of this ani$\mathrm{mal}$, the best method of deciding it is by the quantity of cream produced in a given time, rather than of milk. The richest milk known is produced by cows of the Alderney brecd; but, in all countries, cows yielding a very superior quantity of milk to the generality are to be found, and should be sought for by those persons to whom their produce is a particular object of attention; and the breed of such should be particularly cultivated. Rough waste lands, when the soil is wet, will do better for cows than shcep, and should be always appropriated to them, not in. deed because they are the best for cows, but because no stock will so well pay upon them.

The grand object of keeping cows being the procluction of abundance and $\mathrm{ex}$ cellence of milk, they must, for this purpose, be supplied with food of the same description. About a month before they calve they should be taken from the strawyard, and have green food given them twice a day, with the roots, whatever they may happen to be, which have been rais. ed for their winter food. Having calved, they should be kept perfectly separate from the lean stock, whether in the house or in another yard, and their food should be continued as before. Winter feeding cows with hay, even though none be given them before they calve, brcaks in greatly upon the profits of the dairy Cabbages will maintain them in the cheapest manner, and not give any unpleasant flavour to the milk and butter. The heart alone of the cabbage, however, should be given to them, and the refuse leaves be left to be picked up by the lean cattle. In the month of May they should be kept in par. ticular good feed, for which purpose they should be titrned into the fields of clo. ver, which had been early eaten off by slicep. Lucerne is, however, perhaps preferable to clover, as it is equally nourishing, and gives no ill flavour. When mown, and given in racks or cribs, it will go farther than in any other way, and yicld an increased quantity of the most valuable manure, a circumstance which has been often insisted upon, and cannot be two frequently suggested. The feeding place should be kept extrenely well lit. tered. The profit of cows, in these circumstances, will be greater than turning them into luxuriant fields of these artificial grasses, although the quantity of their produce might, by the latter method, probably be increased; but by trampling upon and spoiling considerably more than they would eat, the little su. perior milk in jichness or quantity, which might be produced, would be purchased at a most heavy expense, and one acre so managed would be requisite for every cow, while, by soiling, it would be amply sufficient for three. The clear profit in the comparison of any two modes of management is the grand point of the farmer's consideration, and whatever the farmer finds most profitable, will eventually, it must be remembered, most benefit the public. Whatever green meat be thus used in soiling should be fresh mown every two days, the quantity being, as nearly as may be, adapted to the number so fed, not only of cows, but of other stock. Lucerne, if well maunged, will bear four mowings for this purpose.

Cows should be milked threc times a day, if fully fed, throughout the summer; and great caution should be exercised by the persons employed to draw the milk from them completely, not only to increase the quantity of produce, but to preserve its quality. Any portion which may be left in the udder scems gradually to be absorbed into the system, and no more is formed than enough to supply the loss of what is taken away; and by the continuance of the same mode, a yet farther diminution of the se. cretion takes place, until at length scarcely any is produced. This mode of milk. ing is always practised, when it is intended that a cow should be rendered dry.

The apartments appropriated to dairy purposes should, if possible, possess a moderate temperature throughout the year, and should be kept perfectly clean and dry. The temperature of about fifty five degrees is most farourable for the se. paration of the cream from the milk. The utensils of the dairy are best made of wood; lead and copper are soluble in acid, and highly pernicious; and though iron is not injurious, the taste of it might render the produce of the dairy unpala. table.

Objects of attention, with a viero to the settle. ment and success of a young . Igriculturist.

It is an object of extreme importance and dificulty to awaken due attention, 


\section{AGRICULTURE.}

without exciting useless anxiety. In se. lecting a situation in which to exercise the occupation of a farmer, various circumstances are minutely and deliberately to be regarded, and great consideration is required to form an accurate comparison of advantages and disadvantages. After these have been fully ascertained, a balance is to be drawn, and a decision to be made. Miore attention than time is requisite for this purpose, and hesitating, broken application will often occupy a longer period in arriving at an injudicious determination, than, with persevering and dispassionate examination, is necessary to obtain a correct one. Headlong temerity, which diminishes, or even annihilates to the mind, substantial evils, and minute, apprehensive prudence, by which every ant-hill of difficulty is made to swell into a mountain, are both to be carefully avoided; and a firm confidence in human exertion should unite, on this critical oc. casion, with keen and compreliensive observation. The soil is an object of particular consideration, in reference to a vast variety of circumstances; as to its stiffncss and moisture; levelness or slope; its exposure or its stoniness; the manuring, draining, and fencing that may be required; the state of the roads; the accessibibility of markets; the prices of manufactures, of produce, and labour; the custom of tythes; the amount of poor-rates ; the compactness of the land, and the corenants concerning crops; are only a few of the points which demand, in such circumstances, to be duly ascertained and estimated. To fix on good land is a prudential general direction. For such it is not easy, with ordinary, discretion, to pay too miuch, while for poor soils a small rent very frequently exceeds their worth.

The must advantageous of all soils are, the mellow, putrid, crumbling, sandy loams; those which will admit tillage, soon after rain, and, though finely harrowcd, will not harden, as if baked, in consequence of the hottest sunshine, after violent rains. The stiff loam, which is very nearly approaching to proper brick earth, is, without plenty of mamire, an unfavourable soil. On walking over it, it is found cxtremely adhesive in wet weather, and it requires a long time to dry. It may be considered as forming a medium between the clods of clay and the crumblings of loam. In stubble, a small green moss is frequently seen to cover it. By farmers, poverty and hunger are me. taphorically and most expressively applied to this land, which has a great num. ber of varieties. It requires a large quan: tity of manure, and is wonderfully improved by hollow ditching. The expense of these operations must never be forgotten, in connection with an estimate of their result.

Warm, dry, gravelly loams are, in winter, easily distinguishable. Unless in a particularly wet winter, they may be ploughed during almost any part of it, and will break up in a state of crumbling, running mould. A very bad soil is constantly formed by wet, cold gravel, which, in winter, is always indicated by its wetness, and in spring is known by the binding effects produced upon it by short and violent showers. It can be fertilized only by very extraordinary quantities of manure : and drains, fully and neatly completed in it, will considerably improve it. Some gravels are of so particularly sharp and burning a nature, that, unless the summer be particularly wet, they will produce absolutely nothing. At any season this soil is obviously distinguishable. With respect to sands, the rich, red sand possesses always a dry soundness, and a temperate moisture, and will, in the driest summer, secure a crop. Its excellence and profitableness can scarcely be exceeded. Another admirable soil is formed of the light, sandy loam. It may be ploughed during the whole winter. The degree of its adhesion is precisely that of its perfection. It may be usefully observed, that when stiff land is dry and crumbling, it is a sure indication of its goodness, as the adhesive quality of a sandy soil is, with respect to that species of land, an equally decisive symptom in its favour. That which falls flat in powder is a mere barren sand. The chalk marle runs exceedingly to mortar from violent showers, after being pulverizcd, and is a cold and unprofitable soil. Clay land of great tenacity is usually let for more than it is worth; and though it will yield abundance of wheat, is attended, in its management and preparation, with so great expence, that its profit is often trifling, and fortunes are far mole fre. quently made by lands of a dircetly opposte description, consisting of light and dry sand. The common fault of stiff clays is wetness. Where fields are level, and, even though the furrows are well ploughed, the water stands in the land, the extreme tenacity of the soil is obvious. It is also broken up by the plough only by a very powerful draught of cattle, and in picces of vast size and extreme hardness. In winter, soils approaching to 
this character are most to be distinguished. They will yicld large crops of beans and wheat, but the sight of these should always be blended with the consideration of the immense expense at which they are necessarily raised. There are many variations of peat, bog, and fen, and all may be found exceedingly profitable; and if marl or lime be in the neighbourhood, that circumstance is a most important inducement to undertake the management of them.

With regard to grass lands, tlıey are to be best examined at several seasons, in order to ascertain their character. If they be too wet, this is shewn by walking orer them in winter, and by rushes, flags, and moisture, which, in a greater or less degrec, are always observable upon them. The grass is generally blue at the points, and always coarse. Draining may correct stiff loams, but the stiff tenacious clay is scarcely susecptible of cure. Grass, on gra. velley soils, will inevitably burn in hot summers, but will extremely abound on loams in wet ones. On the banks of brooks and rivers, meadow of almost any soil may be considered good, but the circumstance of their liability to summer inundations ought never to be forgotten.

The herbage on many fields is sometimes composed of weeds and the coarsest and worst of grasses, which are at all times discernible, and indeed glaring. Under a prohibition of arable, which is sometimes and not unfrequently the case, fields of this slescription are worth little or nothing. A river, well restrained within its banks, running through a farm, is a circumstance decidedly favourable. The grass lands may thus be presumed to have water for the accommodation of cattle.

The quantity as well as the nature of the soil, is likewise to be considered, and no larger quantity should be occupied than can conveniently be stocked. The bad management, and the perpetual embarrassment occurring in the contrary situation, are often ruinous to the health and to the fortunes of those who are involvetlinit.

The disjoined situation of the various fields of a farm is a circumstance attended with great vexation and expense. Compactness of estates will always render them far more valuable; and opportunities of producing this compactness, by purchasing at a fair valuation, will never be neglected by vigilant and wealthy landlords.

To estimate the rent correctly, it has becn judiciously recommended to con. nect it with tithes and poor rates. What ever sum be intended to be invested in the farm, its interest may be failly calculated at not less than ten percent. A va. luation of the expense and the procluce should, for the next step, be carefully made : and, after the former is declucted from the latter, what remains will be the sum which can be allowed for the de. mand of rent, in the three different forms above mentioned. If the amount of tithes and rates be deducted from this, what remains will be the sum which the occupier can afford to pay the landlord.

The nature of the covenants required, which are sornetimes only absurd, and therefore admissible without difficulty, but sometimes equally absurd and mischevious, ought ever to be considered in connection not only with general but lo. $\mathrm{cal}$ and peculiar circumstances. The unreasonableness of the conditions propossed will sometimes be a valid objection to that occupancy, which rent and situation, and all other circumstances, might render highly eligible, and compensation in diminished rent will be necessary to indemnify for tying down the farmer from modes of cultivation uninjurious to the land, and inexpressibly the most beneficial to the occupier.

From three to fire pounds per acre was, about forty years since, considered adequate to the stocking of any farm, partly grass and partly tillage, of the average fertility. The increase of rents and of rates, the higher composition for tithes, the advance upon all implements of husbandry, and upon every species of sheep and cattle, may be justly consi. dered as having raised the sum necessary for the above purpose to seven or eight pounds. To form calculations upon this subject as accurately as possible, and ascertain that the requisite capital is possessed, for the due managemeut of the land to be occupied, camnot be tuo emphatically insisted upon. The profit attending an increased expense in stock. ing will, in some cases, more than clouble the ratio of profit before that increasc; and if the farmer be incapable of availing him. self of striking opportunitics for improvement, by the purchase of litter or of manure, and indeed by a variety of circumstances which may easily be suggested, for want of capital, his situation must be highly disalvantageous.

The cloice of servants is a point requiring extreme attention. Where the assistance of a bailiff is required, as in all farms of very considerable extent, he 
should be of a somewhat superior description to those whom he nust be authorized to command. The making of contracts, and receiving money, which af. ford agrents great temptation to dishonesty and to excess, should, whenever practicable, be performed by the principal. of the inferior servants, the ploughmen are of most consequence, and skill and do. cility are their grand reccommendations. It is desirable, that all the servants should be under the master's eye. His constant superintendance will have great effect in promoting their sobriety and regularity, and not only will their permanent happiness be improred by this plan, a circum. stance to a man of humanity of no light consideration, but their greater tractability and obedience will render the practice of this domesticating method, in a selfish point of view, more useful to him, than that, according to which, on many extended estates, the men and boys are all comnitted to the boarding and ma. nagcmeit of the bailiff. It may be considered as in general preferable to keep many scrvants and few day-labourers in the present times. The certainty of commanding hands at all scasons is an object of prime importance, and the difficulty of procuring additionlal ones, when they are most wanted, is often upon the other plan insuperable.

It will be always eligible and expedient 10 pursue a systen of management, comprehending every department of business and expenscs. The carelessness of pro. fusion and the sordidness of penury, must both be aroided with equal caution. A fixerl sum, formed upon calculations, resulting from actual experiment, should be allotted for the expenses of the house, for personal expenses, for family dress, and other necessary demands, to be by no means exceeded, and as casual demands will always occur, a reserve should always be provided for contingencies. This methodical arrangement cannot be too strongly enforced on the young practitioner, who, without it, is in danger of inextricable confusion and min. If the investment on a farm be eight thousand pounds, aftcr clearing all expenses arising from regular or contingent demands, and maintaining the establishment in liberal but accurate economy, if a hundred a year be not annually addled to the occupier's capital, the concern must decidedly be a bad one. The addition of one hundred and fifty is very far from unreasonable. Whatever it be, in general, it - cannot be better employed than in prose- cuting ascertained modes of im rovement upon the farm, if it be the property of the occupier, or if he is in possession of a long lease.

Attendance at markets and fairs is an indispensable part of the farmer's occupation, but in a young man is attended with various temptations such as sanguine and social temperaments find it difficult to resist. Caution therefore to such is perpetually requisite. Moreover, the society of persons in a superior style or rank in life, which, in consequence of establish. ments for agricultural improvement is ea. sily accessible to the young man of vivacity and spirit, cannot be cherished without danger. His mind is thus alienated from his regular, and comparatively very laborious, and as it may weakly be deemed, humble occupation. and fastidiousness, discontent, and neglect, will usurp the place of tranquil and active industry.

Such intercourses are completely be. set with temptation, and have often induced imitation and profusion, neglected business, and eventual, and indeed speedy destruction.

\section{Impediments to agricultural improvements.}

The want of wise laws on this subject has ever been a serious obstacle. The produce of land, and the various manures which are necessary for fertilising it, can be easily and cheaply conveyed only along good roads and navigable canals, and in proportion as a country is destitute of these, it is deficient in a grand source of national and agricultural prosperity. Arrangements on these topics cannot easily occupy too much of the attention, or at least meet with too much of the encouragement, of the wise statesman. And as indefinite advantages might be derived from positive regulation on these and other details, in behalf of husbandry, much might also be done in many countries by the removal as well as by the enaction of laws. Where the husbandman is precluded from the best markets, the art of cultivation cannot possibly be pushed up to that point of maturity which it would otherwise acquire; the attainable perfection of this, as well as every other art, depending on the encouragement it finds or, in no less accurate, though perhaps more harsl and grating language, on the profit it produces. The most effectual mode of procuring the growth of any article in abundance is to insure it a reasonable price, and a rapid sale. Freedom of exportation from one country to another 


\section{AGRICULTURE.}

affords considerable facility for these, and promotes, therefore, the object which the blindness of former times supposed to be countcracted by it. Abundance is ascertained to be securel by the very means which the contracted policy of departed legislators inagined necessarily to defeat it. Sucla narrow views are, liowever, in general explorled. And though in countries, where, as in Great Britain, the subsistence of the population is inadequatcly provided for by the natural produce, even in the best of seasons, there is less reason on this subject for complaint, than would operate in other circumstances, it is still an invariable and invaluable maxim, that no lands can be cultivated to their highest point of perfectibility, where restraints are permitted to operate on the disposal of their produce.

The operation of the tythe system must be considercd as one of the most serious impediments on the subject under consideration. This odious and oppressire mode of providing for a class of persons, whose peculiar duty it is to polish the uncouth. ness of savage man, to inculcate on the world the principles of conciliation and kindness, furnishes a most singular dis. sonancy between the means and the end of those who instituted it ; and its unmitigated continuance to the present day is a reflection on the sagacity, the energy, or the patriotism of the British legislature. Regulations, by which those who have no sliare whatever in the expense of im. provement should participate in its advantages, are not mere topics of theoretical absurlity, but attended with serious detriment in their operation throughout this country, in a moral, a religious, and what is most of all to the present purpose, an agricultural point of view. With all the respect due to the representatives of a mighty empire, and with the most decided detacliment from all points of vague and general innovation, this important subject cannot be too frequently presented to parliamentary attention. Human wisdom and human virtue will, it is hoped, be at length found equal to the correction of an absurdity at once so gla. ring and so prejudicial.

The want of due estimation of the oc. cupation of husbandry, is in many countries a grand impediment to its progress. Where the cultiration of the soil is regarded with contempt, or as beneath the attention of men of rank and education, it will be entrusted to the management of persous of narrow capitals, and still narrower minds. Such prejudices operate in various places. They till lately existed to a great extent in France, and are yet deplorably prevalent in Spain. In England, fortunately, they are exery day rapidly dissipating. Agriculture is ascertained to be the road to wealth and re. spectability; and men of high connections and distinguished fortunes think $\mathrm{ch} \mathrm{cm}$ selves honoured, instead of being degraded, by a regular and assiduous applica. tion to it, and by establishing ther sons in situations, in which they may look to it as the means of maintaining families, ac. cumulating property, and doing service and honour to their country.

Agriculture is very injuriously checked by the occupier of land not possessing in it a requisite interest. Even in this coun. try, large portions of land are held by communities of persons, the individuals of which have no right to any particular spot of it, and are not only thus preduded from personal and active cultivation, but, by the scanty right and profit which they possess in the general property, possess no sufficient motive to enforce correct management and improving cultivation on those persons by whom it is actually occupied. Family entails and short leases are likewise eminently hostile to full cul. tivation, upon the obvious principle, that men will ever apply their capital and ex. ertions only in proportion to their especta. tion of advantage. Even when leases are granted of a reasonable number of years, restrictive clauses are too frequently introduced, by which the progress of improvement is arrested, and a mode of cul. tivation insisted upon contrary to the views and the interest of the occupier, and not by any means more beneficial to the own. er, than what was designed to be adopted, often inexpressibly less so. Prejudice and caprice in the proprietorape often substituted for the judgment of experience ; and a routine of practice compelled upon the cultivator, in consequence of which, curious research and attentive experiment are rendered nearly superfuous. Superior knowledge, which would in these circumstances be almost useless, ceases to be sought for, and stupid acquiescence is substituted for lively observation. It is however of importance, that, towards the close of a term, the series of cropping should be regulated by covenant, as the inducement to exhaust land, to the extreme injury of the owner and the pub. lic, would otherwise be seldom resisted. Beyond this object, it is unwise to enforce restriction or to yicld to it, and whatever discoveries are made by the personal ex- 


\section{AGRICULTURE.}

perience of the farmer himself, or are derived from the experience and practice of others, it is desirable that he should ever be free to avail himself of them. The liberal ideas on this subject, which have been suggested by the best writers, and sclopted by enlightened landlords, will unquestionably, in timc, and it is hop. ed rapidly, prevail, to the almost total exclusion of those narrow and pernicious notiors which have hitherto existed.

It is desirable that the farmer should occury a sufficient tract of land to engage is time, not irregularly and occasionally, but fully and completely, by whicl means his attention is not distract. ed frum this important employment to others which would interfere with it, and necessarily prevent its correct and profitable management; and those idle habits, connected with public injury and individual ruin, are effectually precluded. A large farm, therefore, generally speaking, is far preferable to a small one, in this as in erery other point of view. Some persons, not having employment for themselves in the superintendance of the different departments of husbandry on their land, have recourse to personal exertion, and sub. stitute themsclves for labourers, a plan which is extremely unwise. The true art of farming consists, not in driving the plough, or engaging in other menial offices, but in allotting and superintend. ing latour, in recording its results, and contring how and where to dispose of it to the most perfect advantage. To read, and think, and attend the public markcts, and regulate accounts, and observe what others in the same occupation in tlic neighbourhood, or even at some distance, are engaged in, is of far more importance to the advance of agriculture, and the profit of the individual cultivator, than for him to engage in those manual operations, which, in consequence of more practice, are generally performed with more rapidity and success by common labourers. On urgency of business, or as an example to his men, and to give their cmployment that estimation and dignity, the idea of which will ever render them. at once more happy and more dexterous in it, it will be extuemely proper for him to engage occasionally even in these, and his education ought always to have been such, as to enable him to practise them with some degree of skill and neatness, by which he will of course be better enabled to judge when they are well performed by others. list let him consider himself as the manager of a grand manufac- turing establishment, requiring peculiap and incessant vigilance; of a concern, in which occurring contingencies, often require a change of plan, in which the exercise of judgment is perpetually demand. ed; and through the want of a sagacious and presiding mind, the manual labour of many, convertible to extreme advantage, may easily become productirc only of mischief, or may have substituted for it negligence, indolence and dishonesty: This situation of continued superintendance is the proper situation of the farmer; and in proportion as he does not occupy land sufficient to require it, he engages in the profession witl incorrect views, and misemploys his time.

But whatever this quantity of land may be thought to be, differing certainly in relation to different individuals, the importance of adequately stocking and preparing what is actually occupied is extreme. To unite the portion of land ne. cessary to occupy the time of the experienced farmer, with the complete means of its fertility and improvement, affords the most suspicious foundation for the hope of success. For frequent and fine tillage, and abundant manure, which are essential to the perfection of husbandry, considerable expense is demanded. The most skilful servants, the most correct implements, the most robust cattle, are necessary to produce that iniproved tilth, which is the most productive cultivation, and will amply repay the extraordinary cxpense incurred in obtaining them. The procuring of manure in abunclance, to repair the exhaustion of the soil, and not only keep it in lieart, but carry it towards that point of fertility, beyond which additional expense will be incapable of returning proportional produce, is also a matter often of extreme difficulty and cost. The importance indeed of adequate means is so obvious, that it night perhaps by some be scarcely thought excusable to insist upon the subject. But the frequent and ruinous neglect of this consideration will, by others, be regarded as an ample justification of enforcing most emphatically and repeatedly the idea, that the perfection of agriculture can never be attain. ed without an unembarrassed and abun. dant capital. With an inadequate capital, on a large extent of land, the same consequences will take place, which formed the most strikingand decided objection to those little farms, whicb, however strange it may now appear, were formerly thought the grand foundation for national plenty and perfect lusbandry. The produce 


\section{AGRICULTURE.}

must be carried to market, not at the season most advantageous, but almost immediately after the harvest, in order to enable the farmer to extricate limself from immediate embarrassment, and prepare the soil, inadequately as it must be done in these circumstances, for fresh eultivation. Commercial monopoly is consiclerably favoured by this compulsion upon the farmer for selling at whatever price is offered, and artificial scarcity, though now not much to be dreaded in this country, is more likely to originate from this cireumstance than any other. T'hose grand operations of spreading marl over large distriets, at the rate of one hundred and fifty tons per acre, of conveying immense quantities of dung from towns at the clistance of twenty miles, of floating ineaclows at the cost of five pounds per acre, of clraining lands at the expense of Unree, of paying persons to reside in distant shires, or even countries, to accuire superior practical information, or of improving the breeds of sheep and cattle, by giving for the use of a single animal, for a season, a price at which our aneestors would have been absolutely astonishol and confounded; practices, which, happily, have becn farfrom uncommon in the British empire, and are daily adding, perhaps more than any other cause, to its stability and prosperity, have depended entirely upon abundant capital. Such processes for improvement might as easily be expected in the management of those small farms, formerly so highly extolled, and now so justly in theory exploded, as in the conduet of large tracts occupied vuly by men of embarrassed means. The supply of present exigencies preclude those comprehensive and nemote views, on whicl the success of the art most materially depends, and unthrifty savings and corrnding cares are substituted for the liberid expenses and deliglited hopes, which must attend the skilful application of comparative opulenec.

Finally, as the art of lusbandry is particularly intricate and comprehensive, and those engraged in it are gencrally persons of slight education, secluded in a great degree from unutual intercourse and compa. vative observation, ignorance may very justly be considered as an obstacle to its impirrement, perlaps the most operative of all. Instead of beirg collected, like artists in citics, and possessing opportunities for animating curiosity, and benefiting by communication, they are scattered over the surface of the country, and have cultivated generally the same lapds, and

VOL. I. the same prejudices, as their ancestors, for a series of generations. Unless there be among the number of those engaged in this art, a certain proportion of persons of intelligent and educated minds, capable of turuing the experience of themselves and others to advantage, and deriving assistance to agriculture, from the discoveries of other sciences or arts, it would be vain in any country to expect its rapid approach towards that perfect standard, to whicls every liuman effort should be referred. That the proportion of such characters has considerably increased of late years in this country, is an obscrvation no less tive than pleasing; and in the class of persons engaged in agricultural pursuits, it may be safely aftirmed there exists much less tenacity of prejudice, a far greater disposition to research, and openness to conviction, than were to be found in any former age. Fven though, in some instances, old and absurd rous. tines of practice may lave been maintained with more constancy, through the lias. ty projects and absurd expenses of some innovaters, whose failure has checked the spirit of improvement, and unjustly invol. red in one common riclicule all deviations from ancient custom ; these effects, however much to be regretted, are only partial, and information is still making its way into the most remote recesses, and the most stubbom minds. With a view to lessen the darkness and intricacy yet connected with the subject, to prevent randorn speculations and ruinous projects, with their ill consequences of every kind, it may be observed, that it is of the rery first importance, that persons engaged, particularly on a large scale, in the jrofession of agriculture, should kcep correct accounts of all their transactions, and of all their profits and losses. The advantages of clear accounts are obvious in every other occupation of life. Per sons who are engaged in speculations of merchandize, to any extent, and who are known not to attend to this department, are alway's supposed to be in dangerous circuinstances. Agriculture seems by inany to be considered an exception to all other species of business ; that it may be engaged in without preliminary study, and is capable of being properly conducted, even to a large extent, without any regular accounts, necessary as these are admitted to be in other situations. With respect to experimental agriculture, no correct conclusions are to be drawin lout from correct and minute details. Suppositions duawn from gene- 


\section{AGRICULTURE.}

ral observation are of no utility, or deceive rather than inform. The difficulty of keeping accounts, which, however coinmonly neglected, it is allowed never ought to be so, is certainly not inconsiderable. The mode must often be regulated by the nature of the farm. The possessor of open fields, where scraps of land belonging to others are intcrmingled with his own, can, with extreme difficulty only, keep an account of every part, which, however, it is justly thought of the first importance to do in general, as the knowlerlge of what every field has paid, in certain circumstances, is the only basis for corrcet decision on its application. Small fields are from this, as well as from other causes, extremely inconvenient. They are not only inconvenient in preparation, and attended with much loss in borders and ditches, but they derange the acciracy of accounts, if they are not fully noticed, and occupy a great portion of the time of the farmer, if they are. When all the produce of several fields is thrown together, which is far from an uncommon case, some objects, very interesting to be ascertained, must be left entirely to conjecture; and when a comparison is made by guesses, the conclusion formed must be totally invalidated as authority. The separation of crops is therefore an important object, with a view to accounts, and is essential, indeed, to their beingkept with accuracy. For the rent, tithes, and parochial rates, three separate accounts thould be kcpt, but the amount of all should be divided on every field, for which an account should he kept according to the real contents of it. A distinction must be drawn between the gross and net contents of the ficld; as, otherwise, in the comparison of husbandry, that field might be concluded the most advantageous, which had the least border, and merely for that reason, the cultivation practised in the other being, in fact, more profitable. But detail on this subject is here impracticable, and we must be satisfied with observing that, withont correctness of data for a comparison, the conclusions formed will constitute only a catalogie of errors. The article of sundry expenses must universally have place in a well regulated account, and should include whatever payments concern the farm in general, (and are not included in any distinct article) and not any object or ficld in particular. With respect to the article of wear and tear, the arable lands will swallow up by far the greater proportion of tbese expenses.
As they principally attach to the teari, the proper mode of setting them down is, after ascertaining them at so much per pound on the team account, to charge thus proportionally per acre. The land appropriated for feeding grass will have very little concern' in them, and that for mowing by no means much. To settle the expense of the team work, the green food for the teams in summer, the hay and oats consumed, the shoeing and farriexing, their real decline in value, the pay for attendance, are each to be itemed down separately; and to apportion the whole expense to the work executed by them, a day-book must contain an account of this work every day in the year, with a specification of the ficld or business they were engagred in. At the end of the year a clear result may be obtained, by proportionally dividing the amount of the expense among the work. The article manure should be arranged under the head farm-yard, and is one of the most complex and difficult. This account should be charged with the price of the straw used in tlie yard, at what it could be sold for, deducting the carriage, and it should be credited with the price per week of keeping the cattle. All the labour employed in turning over the dung and cleaning the yard is charged to this acconnt. 'The total expense of the dung, when carted to the land, is divided by the number of loals, giving so much per load: it should be charged the following year on the lands on which it is spread, although the benefit of it is not confined to that single year: but keeping open the account for a longer time would expose to great and inextricable confusion. One of the most complex of all accounts is that of grass lands fed. To reduce the difficulty, one account should be opened for mowing ground, to which all expenses of rent, tithe, taxes, \&c. should be carried for every ficld mown; while its credit consists of the value, at the market price of all the mown produce, as delivered to the cattle of any description. The after grass on these fields must be estimated at a certain sum per acre, and charged to the account of feeding ground. To this account must be carried all the debits of the fields fed, while the credit should consist of all the food of the team, at a certain weekly estimate; and of any cattle taken to joist. The account for sheep, dairy, and fatting beasts, is cach to be charged its peculiar expenses ; wages, hurdles, shepherd, \&c. for the first; fuel and straw, \&c. for the second; and the purchase 
money of lean stock for fatting beasts. Amidst all this minuteness and complexity of account, order must be produced. The cattle, cows, and sheep, have turnips, with respect to which the estimate of them must be made, not at what they cost, but at what they would sell for eaten off the field, as they cost more than the latter price, and were intended to repay in the crops for which they prepare. Tlic books should be every yeir balanced, abourt the scason at which the farm was entered upon; and, to avoid arbitrary valuation, the old year's accounts must be continued open considerably after the new ones lure commenced, till the fatting beasts and the corn are sold, and those points decided, on which the profit or loss of the former year depended. By these ineans conjectures may be, in a great degree, precluded, but not altogether, as these must extend to the estimate of the live stock bought and sold within the year, and to the implements of husbandry. The stock must be estimated every year; and in settling this estimate, their worth at the very time of its being made, that is, the price they would then sell for, must be set down. With respect to fatting beasts, cows, and sheep, this procecding must equally take place. Every year, also, implements should be valued, and the ba. lance must be carried, where alone it is applicable, to the general head of wear and tear.

The minutencss and accuracy necessary for this or any other efficient mode of account may deter many from its adoption, and undoubtedly lias this effect on thousands. The want of attention, however, to this subject has, unquestionably, been the cause to which many individuals may justly ascribe their failure in this art, and has operated extremely to check the progress of it in general. 'The hints suggested will be sufficient to evince its general and particular importance, and induee some, perhaps, to follow up, with care and correctuess, a practice, which can alone enable them to give the fair results of interesting experiments, or qualify them to ascertain the particular causes of success or failure in general mangement: The obscurity and perplexity of conjec. ture can by sucli means alone be changed for the clearness of fact and the beauty of order; and, in short, they can thus only decide with trutl, and act with confidence.

AGHIMONLA, agrimony, in botany, a genus of Dudecandria Dyginia class and order: the calyx is one-leafed, perma- nent, perianthium fenced with an outer calyx; the corolla has five petals; the stamina are capillary filaments, shorter than the corolla; the anthers are small; the pistillum is a germ inferior; the style simple; the stigmas obtuse; no pericardium; there are two roundish seeds. Of this genus there are five species: the $A$. pawifiora grows in the borlers of cornhelds, sharly places, and hedges, in Great Britain, and most parts of Europe, also in similar places in the United States; it is perennial, and flowers in June and July. The root is sweet-scented; an infision of it is used by the Canadians with success in burning fevers. Dr. Hill says, that an infusion of sir ounces of the crown of the root in a quart of boiling water, sweetened with honey, and drank to the quantity of half a pint, thrice a day, is a cure for the jaundice. When the plant comes into flower, it will dye wool of a bright full nankeen colour; if gathered in Soptem. ber, it yields a darker yellow. In Prussia it is used for dressing of leather. The American species are three in number: 1 . A. cupatoria, of which there are two rarieties, the hirsuta and the glabra; 2. 1 . parviflora; 3. A. pumila.

AGROSTEMA, the garland of the field, in butany, a genus of the Decandria Pentagynia class and order: the calyx is one. leafed the corolla has five petals; the stamindare ten awl-shaped flaments; the pistillum an ovate germ, with erect styles and simple stygmas; the pericarpium is one-celled; the sceds are numerous. There are four species, viz. 1. A. githago, corn campion, or cockle: 2. A. coronaria, rose-campion: 3. A. flos jovis : and 4. A. coli rosa, smooth campion. The first species is a common annual weed in com fields, and flowers in June or July; the seeds are bluck, with a suffice like shagreen, and appears in the nicioscope like a hedge-hog rolled up. The second species is biennial, a native of Italy, the Valas, and Siberia; but so long an inlabitant of English garlens, that it is become a kind of weed. Of this plant there are three varictics, one with decp red, another with flesh-colourcd, and a third with white flowers; but they are not much esteem. $\mathrm{cd}$, as the double rose-campion, which is a fine flower, has excluded the others fron most good garlens. The single rose-campions are sufficic ntly proparated by the self-sown seeds. The raricty with donble flowers, having no seeds, is propagated by parting the roots in autumn, and planting them in a border of fresh unclunged earth, at the distance of about 
six inches; they should be watcred gently till they have taken root; afterwards wet, as well as dung, is injurious to them. In spring they should be removed into the borders of the flower-garden, where they will be very ornamental whilst they flowcr in July and August. The third species grows naturally on the Swiss and Piedmontese mountains, and in the Palatinate, and was cultivated in $\mathbf{1 7 3 9}$, by Mr. Miller. It flowers in July, and the seeds ripen in September. It will thrive best in a moist soil, and a shady situation. The fourth species is annual. It is a native of Italy, Sicily, and the Levant, but being a plant of little beauty, it is preserved in botanic gardens merely for variety.

AGROSTIS, bent-grass, in botany, a genus of the 'Triandria Digynia class of plants, the calyx of which is composed of a glume, consisting of two valves, and inclosing a single flower; it is of an acuminated figure; the corolla is also of an acuminated figure, and composed of two valves; it is scarce so long as the cup, and one of the valves is larger than the other, and aristated; the corolla serves in place of a pericarpium; it surrounds and every way incloses the seed, which is single, roundish, and pointed at each end.

There are $42^{\circ}$ species, distributed into two classes; the aristatx, or those with awns; and the muticx, or naked without awns. The $\AA$. spica venti, silky bent grass, with entire petals, the outer one having a stiff, straight, and very long awn, and the panicle spreading; is an annual, and common in sandy corn-fields. It flow. ers in June and July, and is liable to be smutted. Horses and goats eat it, but sheep refuse it. The A. arundicea, furnished with a writhed awn; is a native of many parts of Europe, and is a perennial. The Kalnuc Tartars weave mats of it, and thatch their houses with it. The al$\mathrm{ba}$, or white bent-grass, is perennial, and grows in ditches, marshes, and moist meadows : there are four varieties, some of which are found among potatoes in light sandy soils, and some among wheat, flowering from July to September.

AGUE. See Medicine.

AGYNEIA, in botany, a genus of the Triandria Monogynia class and order: the male flowers are below the female, the calyx is six-leaved; no corolla; in the male, instead of filaments, are three or four an. thers: in the fcmale flowers, the germ of the size of the calys; neither style nor stigma. There are two species, viz. A. impubes, with leaves smooth on both sides; and $\mathbf{\Lambda}$. pubera, with leaves downy underncath: both species are natives of China.

-AID de-camp, in military affairs, an officer employed to reccive and carry the orders of a general. He ought to be alert in comprehending, and punctual and distinct in delivering them. He is seldom under the degree of a captain, and all aids-de-camp have ten shillings a day allowed for their duty.

AIGUisce, Aigursse, Egtisce, in heraldry, denotes a cross with its four ends sharpened, but so as to terminate in obtuse angles.

It differs from the cross fitchée, in as much as the latter goes tapering by degrees to a point, and the former only at the ends.

AILANTHUS, in botany, a genus of plants of the Decandria 'Trigynia class and order; it has male, female, and hermaphrodite flowers: 'The calyx of the male is one-leafed; the corolla has five petals: the stamina have ten filaments, the anthers are oblong and versatile. The calyx and corolla of the female are the same as those of the male; the pistillum has from three to five germs; the styles are lateral, and the stigmas capitate; the pericurdium has as many capsules as there are germs; the seeds are solitary. The calyx and corolla of the hermaphrodite are the same with those of the male and fe. male; the stamina have two or threc filaments; the pistillum, pericarpium, and seed, as in the female. There is one species, viz. A. glandulosa, or tall ailanthus, which is a tree with a straight trunk, forty or fifty feet high, a native of China. It grows fast in our climate, and, as it rises to a considerable height, it is pro. per for ornamental plantations. A resinous juice, which soon hardens, flows from the wounded bark. The wood is hard, heavy, glossy, like satin, and susceptible of a fine polish.

AILE, or Arex, in law, a writ which lies where a person's grandfather, or great grandfather, being seised of lands, \&c. in fee-simple the day that he died, and a stranger abates or enters the same day, and dispossesses the heir of his inheritance.

AJOVEA, in botany, a genus of the Hexandria Monogynia class and order: the calyx is single-leaved, the corolla bas three petals, the stigma is divided into six segments, and the fruit is a roundish, single-celled, monospermous berry.' There is one species that grows in the forests of Guiana. 
Alk, a thin elastic fluid, surrounding the globe of the earth. It is compounded principally of two gasses, viz. oxygen and azote, together with a variety of other substances, suspended or dissolved therein. The mecharical and elienical effects of this extensive fluid mass are discussed under various heads of science. See ATмоврнии, Сивилтrт, and the articles thence referred to.

Arn, in music, generally speaking, is any melody, the passages of which are so constructed as to lie within the province of rocal expression, or which, when sung or played, forms that connected chain of sounds which we call tune. The strict import of the word is confined to rocal music, and signifies a composition written for a single voice, and applied to words.

AI R-gun, a machine for exploding balls by means of condensed air.

Autlıors describe two kinds of this machine, viz. the common onc, and what is called the magrazine air-gun. Sce l'Net. Matics.

An-pifies, a contrivance invented by Mr. Sutton, a brewer of I ondon, for clearing the holds of ships, and other close places of their foul air. The principle upon which this contrivance is founded is well known. It is no other than the rare. fying power of heat, which, by causing a diminution of the density of the air in one place, allows that which is in contact with it to ruslı in, and to be succeeded by a constant supply from remoter parts, till the air becomes every where equally elastic. If a tube, then, be laid in the well. hold, or any other part of a ship, and the upperpart of this tube be sufficiently heat. ed to rarefy the impending column of air, the equilibrium will be maintained by the putrid air from the bottom of the tube, which, being thus drawn out, will be succceded by a supply of fresh air from the other parts of the ship; and by continuing the operation, the air will be changed in all parts of the ship. Upon this principle, Mr. Sutton proposed to purify the bad air of a slip by means of the fire used for the coppers, or boiling places, with which every ship is provided. Under every such copper or boiler there are two holes, separated by a grate, one for the fire and the other for the aslies; and there is also a flue, communicating with the fire place, for the discharge of the sinvke. The fire, after it is lighted, is preserved by the constant draught of air through these two holes and the flue; and if the two holes are closed, the fire is extinguished. But when these are closed, if another hole, communicating with any other airy place, and also with the fire, be opened, the fire will of course continue to burn. In order to clear the holds of the ships of the bad air, Mr. Sutton proposed to close the two holes above mentioned, viz. the fire-place and ash-place, with substantial iron doors, and to lay a copper or leaden pipe, of sufficient size, from the hold into the ashplace, and thus to supply a draught of air for feecling the fire; a constant discharge of air from the hold will be thus obtumed, and fiesh air will be supplied down the hatches, and by such other communications as are open into the hold. If other pipes are connected with this principal pipe, communicating either with the wells or lower decks, the air that serves to feed the fire will be drawn from such places.

AlR-shafts, anong miners, are holes made from the open air to meet the adits, and supply them with fresh air.

These, when the aclits are long, or exceeding thirty or forty fathoms, become highly necessary, as well to give vent to the damps and noxious vapours, as to let in fresh air.

AIR-tmink, a simple contrivance by Dr. Hales, for preventing the stagnation of putrid effluvia, and purifying the air in jails and close rooms; which consists of a square trunk, open at both ends, one of which is fixed in the ceiling, and the other is extended to a considerable height above the roof. The noxious effluvia, as. cending to the top of the room, cscape by this trunk. Some of these have been nine, and others six, inches in the clear ; but, whatever be their diameter, their length should be proportional, in order to promote the ascent of the vapour. As the pressure of fluids, and conserguently of the air, corresponds to their perpendicular altitude, the longer these trunk. are, so much the greater will be the difference between columns of air pressing at the bottom and at the top; and of course so much the greater will be their effect. Sce Ventihiton.

Anteressel, in hydraulics, is a name given to those metalline cylinders, which are placed between the two forcingpumps in the improved fire-engines. The water is injected by the action of the pistons through two pipes, with ralves, into this ressel; the air previously con. tained in it will be compressed by the water, in proportion to the quantity aclmitted, and by its spring force the water into a pipe, which will discharge a con- 
stant and equal stream; whereas, in the common squirting engine, the stream is discontinued between the several strokes. Other water-engines are furnished with vessels of this kind.

Antressels, in botany, are certain canals or elucts, whereby a kind of absorption ancl respiration is effected in vegetable bodies.

Air-vessels have been distinguished from sap-vessels; the former being supposed to correspond to the trachea and lungs of animals ; the latter to their lacteals and blood-vessels.

I)r. Grew, in an inquiry into the motion and cause of the air in vegetables, shews, that it enters them various ways, not only by the trunk, leaves, and other parts above ground, but at the root. For the reception, as well as expulsion of the air, the pores are so very large in the trunks of some plants, as in the better sort of thick walking-canes, that they are visible to a good eye without a glass; but with a glass, the cane seems as if it were stuck full of large pin-holes, resembling the pores of the skin in the ends of the fingers, and ball of the hand. In the leaves of the pine, through a glass, they make an elegant shew, standing almost exactly in rank and file throughout the length of the leaves. But though the air enters in partly at the trunk, and also at other parts, especially in some plants, yet its chief adinission is at the root: much as, in auimals, some part of the air may con. tinually pass into the borly and blood by the pores of the skin; but the clief draught is at the mouth. If the chief en. trance of the air were at the trunk, before it could be mixed with the sap in the root, it must descend; and so move not only contrary to its own nature, but in a contrary course to the sap : whereas, by its reception at the root, and its transition from thence, it has a more natural and easy motion of ascent. The same fact is farther deduced from the fineness and smallness of the diametral apertures in the trunk, in comparison of those in the root, which nature has plainly designed for the separation of the air from the sap, after they are both together received into them.

Air-vessels are found in the leaves of all plants, and are even discoverable in many without the help of glasses; for, upon breaking the stalk or chief fibres of 2 leaf, the likeness of a fine woolly substance, or rather of curious small cob. webs, may be seen to hang at both the broken ends. This is taken notice of, not only in some few plants, as in scabious, where it is most visible : but may also be seen more or less in most others, if the leaves be very tenderly broken. This wool is really a skcin of air-vessels, or rather of the fibres of the air-vessels, loosed from their spiral position, and so drawn out in length.

AIRA, hair-grass, in botany, a genus of the Triandria Digynia class and order, and of the natural order of Grasses. There are twenty-five species, some of which have awns, and others liave none. The A. aquatica, water hair-grass, generally grows in the margin of pools and watery places, running into the water to a considerable distance, and is known by the purple or bluish colour of the pannicles, and sweet taste of the flowers. It is a perennial, and flowers in May and June. T'o this grass has been attributed the swectness of Cottenliam cheese, and the fineness of Cambridge butter. The A. cæpitosa, or tufty-hair grass, grows in moist meadows and woods, is perenniat, it flowers in June and July, sometimes trailing on the ground to the length of several feet, and the panicle exhibiting a beautiful silky appearance : cows, goats, and swine eat it, but horses are not fond of it. It is the roughest and coarsest grass that grows in pastures or meadows, and is called by the common people hassocks, rough-caps, and bull's faces. 'To get rid of it, the land should be first drained, and the tufts of the noxious weeds pared off and burnt The ashes yield a good manure. The A. flexuosi, or waved mountain grass, is the principal grass on Banstead Downs, and the Mendip Hills. It is lifficult of cultivation.

AlTONIA, in botany, so called from Mr. Aiton, his Majesty's late gardener at Kew, a genus of the Monadelphia Octandria class and order, and of the natural order of Columniferz. There is but one species, viz. A. capensis, found at the Cape of Thunberg. It has a shrubby stalk, six feet high, and a fruit resenbling that of the winter clierry. With us it is of slow growth, and seldom exceeds three feet in height. At a sufficient age it produces flowers and fruit through the greatest part of the year.

AJUGA, bugle, in botany, a genus of the Didynamia Gymnospermia class of plants : the flower is monopetalous and ringent ; the upper lip being small and bifid; the lower one large and trifid: there is no pericarpium: the seeds are contained in the cup of the flower, and are four in number. There are 10 species. The species native in the United States are 7 
in number, 1. A. Cerpitosa; 2. A. flexuosa; 3. $\Lambda$ pallens, of which there are two varieties, one with and the other without arons; 3. A. truncata: 5. A. inollis; 6. A. purpurea of Walt: 7. A. przeox. There is an eighth doubtful species, $\boldsymbol{A}$. aegytopoides of Walt.

II\%UON, in botany, a genus of the l'o Jyandria P'entagynia: the calyx is a oneleafed perianthim: no corolla; the stamina have unany capillary filaments; the anthers are sinple, the pistillum has a five-cornered gcrm, the seeds art several: there are ten species, all belonging to the hot climates.

ALA, in botany, is used in different senses; sometimes it denotes the hollow between the stalk of a plant and the leaves; sometimes it is applied to the two side petals of the papilionaceous flowers, the upper petal being called the vexillum, 'and the lower one the earina; others use it for the slender membranaccous parts of some seeds, thence said to be alated; and others, again, for the membranaceous expansions found on the stems of plants, thenee denominated alated stalks.

ALABASTER, a well known deseription of stone used by statuaries and others. It is the sulphate of lime. See CnEMrstry and Miseralogr.

AL.E, in anatomy, is sometimes used for the lobes of the liver, the nymphx of the female pudenclum, the two cartilages which form the nostril, the arm-pits, young stems or branches, \&c.

ALANGIUM, in botany, a genus of the necandira Monogynia class and order: the characters of wluch are, that it lias from 6 to 10 linear petals, from 10 to 12 stanina; the calyx clentated; the fruit a spherical berry, single-celled, containing from one to three seeds: there is only one species, viz. A. pungens.

ALA TH1), in botany, an epithetapplied to the seed, stem, or leaf-stalk; a seed is alated, when it has an ala or menbrane affixed to it, which, by its flying, scrves to elisperse it. The foot stalk of a leaf is alated, when it spreads out the sides. Alated leaves are those madé up of several pinnated oncs.

ALAUDA, lark, in ornithology, a genus of hirds of the order of l'asseres; the characters of which are, that the beak is cylindrical, subulate, and straight, bending towards the point, the mandibles are of equal size, and opening downwards at their base; the tongue is bificl; and the hinder claw is straighter and longer than the toe. P'enaant adds, that the nostrils are covered with feiathers or bristles, and the toes divided to their origin. There are 33 species, but we shall notice only two of them. 1. A. arvensis, or sky-lark, the specific charncters of which are, that the two outermost quills of its tail are white lengthwise externally, and the intermediate ones are ferruginous on the inside : the length is about seven incles. The males of this species are somewhat browner than the females; they have a black collar, and more white on the tail ; their size is larger, and their aspect bold$\mathrm{er}$; and they exelusively possess the faculty of singing. When the fernale is impregnated, she forms her nest between two clods of earth, and lines it with herbs and dry roots, being no less attentive to the concealment than to the structure of it. It sometimes builds its nest among corn and in high grass. Each female lays four or five eggs, which are greyish, with brown spots; and the period of her ineubation is about 15 days. The young may be taken out of the nest when they are a fortnight old, and they are so hardy, thst they may be casily brought up. The parent is very tender of her young; and though she does not always cover them with her wings, she direets their motions, supplies their wants, and guards them from danger. The common food of the young sky-larks is worms, caterpillars, ant's egrs, and even grasshoppers; and in maturity they live chiefly on secds, herbage, and all vegetable substances. Those birds, it is said, that are destined for singing, should be caught in October or November; the males should, as much as possible, be selected: and when they are untractable, they should be pinioned, lest they injure themselves by their violence against the roof of the rage. As they cannot eling by the toes, it is needless to place bars across their cage ; but they should hare elean sand at the bnttom of it, that they may welter in it, and be relieved from the vermin which torment them. In Flanders, the young ones are fed with innistened poppy-seeds and soaked crumbs of bread; and, when they be gin to sing, with sheep'sand calves' hearts, hashed with hard eggs; to which are added, wheat, spilt-oats, millet, linseed, and the seeds of poppy and hemp, steepcd in milk. Their eapacity of learning to sing is well known; and so apt are some cock larks, that, after hearing a tune whistled with the pipe, they have caught the whole, and repeat it niore agrecably than any linnet or eauary bird. In summer the lirek sceks the lighest and driest 


\section{ALAUDA.}

situations; but in minter they descend to the plains, and assemble in numerous flocks. In the former season they are very lean, and in the latter very fat, as they are always on the ground, and constantly fecding. In mounting the air, they ascend almost perpendicularly, by successive springs, and hover at a great height; but in descending, they make an oblique sweep, unless they are pursued by a ravenous bird, or attricted by a mate, in either of which cases they fall like a stone. These small bircls, at the height to which they soar, are liable to be waft- d by the wind; and they have been observed at sea, clinging to the masts and cordage of ships. Sir Hans Sloane observed some of them 40 miles from the coast, and Count Marsigli met with them on the Mediterranean. It is conjectured that those which are found in America have been driven thither by the wind. Some have supposed, that they are birds of passage, at least in the more southern and milder climates of Europe; but they are occasionally concealed under some rock or sheltered cave. The lark is found in all the inhabited parts of both continents, as far as the Cape of Good Hope ; this bird, and the wood-lark, are the only birds which sing whilst they fly. The higher it soars, the more it strains its voice, and lowers it till it quite dies away in descending. When it ascends beyond our sight, its music is distinctly heard; and its song, which is full of swells and falls, aukl thus delightful for its variety, commences before the earliest dawn. In a state of freedom, the lark begins its song early in the spring, which is its season of love and pairing, and continues to warble during the whole of the summer. The honourable Daines Barrington reckons this among the best of the singing larks; and as it copies the warble of every other bird, lie terms it a mocking-bird. These birds, which are esteemed a delicacy for the table, though Linnæus thinks the food improper for gravelly complaints, are taken with us, in the greatest numbers, in the neighbourhood of Dunstable. The season begins about the 14th of September, and ends the 25th of Fehruary; and during this time, about 4000 dozen are caught, for supplying the London markets. Those caught in the day are taken in clap-nets, till the 14th of November. But when the weather becomes gloomy, and also in the night, the larker makes use of a trammel-net, 27 or 28 feet long, and five broad, which is put on two pales 18 feet long, and carried by men under each arm, who pass over the fields, and quarter the grounds, as a setting dog. When they see or feel a lark strike the net; they drop it down, and thus the birds are taken. The darkest nights are the most proper for their sport; and the net will not only take larks, but all other birds that roost on the ground; among which are woodcocks, snipes, partridges, quails, fieldfares, and several others. In the depth of winter, pcople sometimes take great numbers of larks by nooses of horse-hair. The method is this: take 100 or 200 yards of packthread; fasten at every six inches a noose made of double horse-irair; at every 20 yards the line is to be pegged down to the ground, and so left ready to take them. The time to use this is when the ground is corered with snow, and the larks are to be allured to it by some white oats, scattered among the nooses. They will soon fly to them, and, in eating, will be hung by the nooses. They must be taken away, as soon as thrce or four are hung, otherwise the rest will be frightened; but though the others are scared away just where the sportsman comes, some will be fecding at the other end of the line, and the sport may be thus continued for a long time. As the sky-lark is a kind of mocking-bird, and apt to catch the note of any other which hangs near it, even after its own note is fixed, the bird-fanciers often place it next to one which has not been long caught, in order to keep the caged skylark honest. Plate II. Ares, fig. 1.

2. A. arborca, wood-lark of English writels, is specifically characterised by a white annular belt, encircling its head. This bird is. smaller than the sky-lark, and of a shorter thicker form; the colours of the plumage are paler; the first feather of the wing is shorter than the second; the hind claw is very long and somewhat bent; it perches on trees; it haunts the uncultivated tracts near copses, without penetrating the woods, whence its name; its song resembles more the warble of the nightingale, or the whist. ling of the black-bird, than that of the sky-lark, its note being less sonorous and less varied, though not less sweet; and it is heard not only in the day, but in the night, both when it flies and when it sits on a bough. This bird builds on the ground, and forms its nest on the outside with moss, and on the inside with dried bents, lined with a few hairs, and conceals it with a turf; and the situation it selects is ground where the grass is. 


\section{$\mathbf{A} \mathbf{L} \boldsymbol{\Lambda}$}

-ank, or become brown. It lays four or five eggs, which are dusky and blotclied with deep brown; its fecundity is inferior to that of the sky-lark, and its numbers are not so great: it breeds carlier, since its roung are solnetimes flown in the middle of March, and therefore they pair in February, at which time, and not before, they part with their last year's brood; whereas tlie common lark does not hatch before the month of May. This is a very tender and delicate bird; so that it is impossible to rear the young taken out of the nest: but this is the case only in F.ngland and such cold climates, for in Italy they are removed from the nest, and reared at first like the nightingale, and afterwards fed upon panic and millet. The wood-lark feeds on beetles, caterpillars, and sceds: its tongue is forked; its stomach muscular and Heshy; and it has no craw, but a moderate dilatation of the lower part of the osophagus, and its cocea are very small. It lives ten or twelve vears. The males are distinguished from the females by their larger size; the crown of the head is also of a darker colour, and the hind nail longer; its breast is more spotted, and its great wing-quills edged with olive, which in the female is grey. The wood-lark mounts higb, warbling its notes, and hovering in the air; it flies in flocks during the winter colds; it is found in Sweden and Italy, and is probably dispersed through the interve. ning countries, and consequently orer the greatest part of Furope. It is also found in Siberia, as far as Kamtschatka, and likewise in the island of Madeira. The best time for taking this bird for the cage is July, or the preceding or following month. Those that are put into the cage at this time sing presently; but their song-time is not lasting;, for they soon fall to moulting, in which state many die; but if they get over it, they commonly prove very healthful afterwards, becone very tame and familiar, and siug sweetly. Those which are taken in the latter end of September are generally ve. ry strong and sprightly; but they do not sing till after Cluristum: Those taken in January and February finally prove the best of all; they generally begin siuging in two or three days, or at the utmost in a week after they are taken. The cockbird of this kind is known from the hen by the loudness and length of his call, by his tallness as he walks about the cage, and by lis doubling his notes in the erening, as if he were going with lys unate J. I. I.
ALB

to roost. A better rule than all otlress. however, is his singing strong; for the lien wood-lark sings but very weakly. Both the eock and hen of this kind are tender, and subject to many disorders; the principa] of these are, cramps, gicldiness of the heacl, and breeding lice. Cleanliness is the best cure for the first and the last of these complaints: but we know of no cure for the other. A good strong bird will last very well for five or six years, and frequently improve during the whole of this time. The lark is not only a very agreeable bird for the cage, but it will also live upon almost any foorl, so that it have once a week a fresh tuft of three-leaved grass put into the cage with it. The wood-lark is one of the sweetest of our singing-birds, and is indeed very little inferior to the nightingale, when in good health; hut we are not to judge by such as are made feeble by improper fiod, or want of cleanliness in their cages.

ALBINOS, in zoology, a denomination given to the wbitenegroes of Africa, who have light hair, blue eyes, and a white body, resembling that of the Europeans, when viewed at a clistance; but upon a nearer apjroach, the wbiteness is pale and livid, like that of leprous persons, or of a dead body. Their eves are so weak that they can liarlly see any object in the day, or bear the rays of the sun, and yet when the moon shines, they see as well, and run through the deepest shades of their forests with as much case and activity, as other men do in the brightest day-light. Their complexion is clelieate; they are less robust and rigorons than other men; they generally sleep in the day, and go abroad in the night. The negroes regard them as monsters, and will not allow them to propagate their kind. In Africa this variety of the luuman species very frequently occurs. Wafer informs us, that there are white Inclians of the same general cliaracter among the vellow or copper-coloured Indians of the isthmus of Darien. It has been a subject of inçuiry, whether these men form a pe. culiar and distinet race, and a permanent variety of the liuman species, or are merely individuals who have accidently degenerated from their original stock. Builion inclines to the latter opinion, and lie alleges in proof of it, that in the isthunus of Amcrica a husband and wife, both of a couper colour, produced one of these white children; so that the singu. lar colour and constitution of these white 


\section{ALB}

Indians must be a species of disease thich they derive from their parents; and the production of whites by negro parents, which sometimes happens, confirms the same theory. Aecording to this author, white appears to be the primitive colour of nature, which may be varied by climate, food, and manners, to yellow, brown, and black; and which, in certain circumstances, returns, but so much altered, that it has no resemblance to the original whiteness, because it has been adulterated by the causes that are assigned. Nature, he says, in her most perfect exertions, made men white ; and the same nature, after suffering every possible change, still renders them white: but the natural or specific whiteness is very different from the individualor accidental. Of this we hare examples in vegetables, as well as in men and other animals. A white rose is very different, even in the quality of whiteness, from a red rose, which has been rendered whito by the autumnal frosts. He dediuces a farther proof that these white men are merely degeneratedindividuals, from the comparative weakness of their constitution, and from the extreme feebleness of their eyes. This last fact, he says, will appear to be less singular, when it is considered that in Europe very fair men have generally weak eyes; and he has remarked that their organs of hearing are often dull : and it has been alleged by others, that dogs of a perfectly white colour are deaf. This is a subject which demands fartherinvestigation. Buffon's Natural History.

ALBUCA, in botany, a genus of the Hexandria Monogynia class and order: corolla six-petalled; the inner ones connivent; outer ones spreading; style triangular: this genus is distinguished into those species, three of whose stamina are fertile; and into others, in which all the stamina and fertile: of the former there are six species; of the latter eight. They are all found at the Cape.

ACBUMEN, in chemistry, a term to denote the white of egg, and all glary, tasteless substances, which, like it, have the property of coagulating into a white, opaque, tougb, solid substance, when heated a little under the boiling point. This substance forms a constituent of many of the fluids of animal bodies, and when coagulated, it constitutes also an important part of their' solids. Substanees analogous to it have been noticed in the vegretable kingdom. The essential characters of albumen are the following:

\section{ALC}

1. In its natural state it is soluble in water, and forms a glary, limpid liquid, having very little taste: in this state it may be employed as a paste and a varuisls. 2. The solution is coagulated by acids, in the same way as milk is acted upon; and also by heat of the temperature of $170^{\circ}$, and by alcohol. 3. Dissolved in water, it is precipitated by the infusion of tan : and also in the form of white powder by the salts of most of the white metals, as silver, mercury, lead and tin. 4. When burnt it emits ammonia, and when treated with nitric acid, yields azotic gas. The juice of the papaw tree yields albumen; so also does the juice of the fruit of the hibiscus esculentis: that obtained from the latter has been used in the West In. dies as a substitute for white of eggs in clarifying sugar.

ALBURNUM, denotes the white, soft substance that lies between the inner bark and the wood of trees, composed of laycrs of the former, which have not attained the solidity of the latter. Plants, after they have germinated, do not remain stationary, but are continually increasing in size. A tree, for instance, every season adds considerably to its bulk. The roots send forth new slioots, and the old ones become longer and thicker. The same increment takes place in the branches and the trunk. A new layer of wood, or rather of alburnum, is added annually to the tree in every part, just under the bark; and the former layer of alburnum assumes the appearance of perfect wood. The alburnum is found in largest quantities in trces that are vigorous; though in such as languish and are sickly there is a great number of beds. In an oak six inches in diameter the albuinum is said to be nearly equal in bulk to the wood.

ALCA, auk, in ornithology, a genus of the order of Anseres, in the Linnzan system, the characters of which are, that the bill is without teeth, short, compressed, convex, frequently furrowed transversely; the inferior mandible is gibbous before the base; the nostrils are behind the bill; and the feet have generally three toes. This genus comprehends 12 species, of which we shall notice the following: A. torda, with four furrows on the bill, and a white line on cach side, running from the bill to the eyes. This is the alca of Clusins and Brisson; the pinguin of Buffon; and the razor-bill, auk, or murre, of Pennant, Ray, Willoughby, Albinus, Edwards, and Latham. This species weighs about $22 \frac{1}{2}$ ounces; its length 1 is about 18 inchęs, 
ALCA.

and breadth 27. These birds, in company with the guillemot, appear in our seas in the beginning of February, but clo not settle in their breeding-places till they begin to lay, about the beginning of May. When they take possession of the ledges of the highest rocks that hang over the sea, they sit close together, and in row's one above another, and form a very grotesque appearance. They lay only one egg at a time, which is of a large size, in proportion to that of the birl, being three inclies long, either white or of a pale seagreen, irregularly spotted with black: If this egg be destroyed, both the auk and the guillemot will lay another, and if this be taken, a third; as they make no nest, they deposit the egg on the bare rock, poising it in such a manner as no human 2rt can effect, and fixing it by means of the viscous moisture that bedews its surface on its exclusion; and though such multitules of eggs are contiguous to each other, each bird distinguishes its own. These eggs serve as food to the inhabitants of the coasts which the birds fre. quent; and are procured with great hazard by persons let down with mpes, held by their companions, and who, for want of stable footing, are sometimes precipitated down the rocks, and perish together. They are found in the northern parts of America, Europe, and Asia They come to breed on the Ferroc islands, along the west of Fingland, and on the Isle of Wight, where they add to the multitude of sea-fowl that inhabit the great rocks called the Needles. Their winter resielence is not positively ascertained. As they cannot remain on the sca in that sea. soll, and never appear on shore, nor retire to southern climates, Edwards supposes that they pass the winter in the carerns of rocks, which open under water, but rise internally as much above the level of the flood as to admit a recess, and here, as he apprehends, they remain torpid, and live upon their abundant fat. The pace of this bird is heavy and sluggish; and its ordinary posture is that of swimming or floating on the water, or lying stretch. ed on the rocks, or on the ice.

A. impenuis, A. major of Irisson, pengrim of Lay, Martin, Edwards. \&c. and great auk of Pennant and Latham, has its bill conipressed and furrowed on both sides, and has an oval spot on each sicle before the eyes. Its length to the end of its toes is three fert; the bill to the corper of the mouth is $4+$ inches: the wings are so small as to be useless for flight; their length, from the tip of the longest quill-fenthers to the first joint, being only $4 f$ inches: and these birds are therefore observed by seamen never to wander beyond soundings, and by the sight of them they are able to ascertain the nearness of the land. They can scarcely even walk, and of course continue on the water, except in the time of breeding. According to Mr. Martin, they breed on the isle of St. Kilda, appearing there in the beginning of Mav, and retiring in the midclle of June. They lay one egg, six inches long, of a white colour: and if the cgg be taken away, no other is laid in the same season. Mr. Mącaulay, in his history of St. Kilda, observes, that this bird cloes not visit that island annually, but sometimes keeps away for scveral years together, and that it lays its eggs close to the sea-mark, and is incapable, by the shortness of its wings, of mounting higher. Birds of this species are said not to be numerous; they seldom appear on the coasts of Norwav. They are met with near Newforndland and Iceland. They do not resort annually to the Ferroe Isl. ands, and they rarely descend more to the south in the European seas. They feed on the cyc:opterus and such fish, and on the rose-root and other plants. The skins are used by the Esquimaux for garments. These bircls live in flocks at sea, and never approach the land, except in very severe cold; and in this case they are so numerous, that they corer the water like a thick dark fog. The Greenlanders drive them on the const, and catch them with the hand, as they ean neither mn nor fly. At the mouth of the Ball river they afford subsistence to tlic inhabitants in the months of Februa:y and March, and their down serves to line winter gar. ments. Plate II. Aves, fig. 2.

A. psittacula, or perroquet ank of Pen. naut and Latham, is foutud in the sea that lies between the northern parts of Asia and America, sometimes hy clay in flocks swimming on the water, though not very far from land, unless driven out by storms, and in the night harbouring in the crevices of rocks. Aboit the middle of June they lav upon the rocks or sand a single egg, about the size of that of a ben, and of a dirty white or vellowist colour, spotted with brown, which is esteemed good. These birds, like others of the same class, are stupid, and are mostly taken by the natives. who place themselves in the evening among the rocks, dressed in garments of fir with large onen sleeves, into which the birds fly for shelter as the right comes on, and thus they becone 


\section{ALC}

an casy prey. They sometimes at sea mistake a ship for a roosting place, and thus warn navigators of their being near the land, at the access of night, or on the approach of storms.

A. cirhata, tuited auk of Pennant and Latbam, is entirelyblack, nearly 18 inches long, swimining about for whole clays in the sea, where it dives well, and occasionally Hies swiftly, but never departing far from the rocks and islands, and feeding on shrimps, crabs, and other shell-fish, which it forces from the rocks with its strong bill; in the niglit it comes to shore, burrows about a yard deep under ground, and makes a nest will feathers and seaweed, in which it lodges with its mate, being monogamous. It lays one egg in May or June, which is fit to be eaten and used for food but the flesh of the bird is liard and insipid. This species iuhabits the shores of Kamtschatka, the Kurile islands, and those that lie between Kamts. cliatka and America.

A. arctica, or puffin, found on the cousts of England; and particularly in r'restholm isle, where they are seen in flocks almost innumerable. They come in the beginning of April, and depart in August. Fig. 3.

ALCEA, holluhock, in botany, a genus of the Monadelplia Polyandria class of plants, the calyx of which is a clouble perianthium; the exterior one, which is permanent, consists of a single pstent leaf, divicled into six segments; the intc. rior is also permanent, and consists of a single leaf divided into fire segments : the corolla consists of five very large patent and emarginated petals, growing together at the base: the fruit is composed of numerous capsules, each containing a single compressed kidney-shaperl seed. There are five species. The hol. lyhock grows wild in the country of Nice. The colour of the flowers is accidental, and the double flowers are only varieties proceeding from culture. These varic. ties are not constant; but the greatest number of plants, produced from sceds carefully saved from the most double flowers, will arise nearly the same with the plants from which they are taken, provided they are kept separate from sinrle or barl coloured fowers. The A. rosea grows naturally in China; a dwarf sort, with beantiful double variegated flowers, has been some years in great esteem, under tlie name of the Chinese hollyliock. IIollyhocks are propagated from seeds, sown half an inch deep in a bed of light carth, about the midulle of
April. When the plants have put ouf six. or eiglit leaves, they are to be transplanted into nursery beds, and in October they are to be removed to the situation where they are to remain.

ILCEDO, kingsfisher, in ornithology, a genus of the older of Picr. The characters are, that the bill is three-sided, thick, straight, long, and pointed; the tongue is fleshy, very slort, flat, and sharp, and the feet are for the most part gressory. There are 41 species. These birds are dispersed over the whole globe, inhabit. ing chiefly the water, and living upon fish, which thcy catch with surprising alertness, and swallow whole, rejecting afterwards the undigested parts; though their wings are short, they $\mathrm{Ay}$ swiftly; their prevailing colour is sky blue; their nostrils are small, and generally covered. A. ispida, ispida of Gesner and Ray, European kingsfisher of Pennant, and common kingsfisher of Latham, is the only one we shall notice: it is sliort-tailed, skyblue abore, fulvous below, and its straps are rufous. This bird is 7 inches long and 11 broad, of a clumsy shape, the head and bill being very large, and the legs disproportionately sniall. The kingsfisher frequents the banks of rivers, and feeds on fisl.. It takes its prey somewhat in the manner of the osprey, baluncing itself at a certain distance over the water for some time, and then darting below the surface, brings the prey up in its feet. When it remains suspended in the air, in a bright day, the plumage exhibit a most beautiful variety of the most dazzling and brilliant colours. It makes its nest in holes in the sides of the cliffs, which it scoops to the depth of three feet, and lays from three to nine eggs, of a very bcautiful semi-transparent white. The nest is very fortid, on account of the refuse of fish with which the young are fed. It begins to hatcl its young early in the season, and excludes the first brood in the beginning of April. Whilst the fe. male is thus emploved, the male is unremitting in his attention, supplying his mate with fish in such abundance, that she is found at this reason plump and fat. He ceases to twitter at this time, and enters the nest as quietly and privately as possible. The young are hatched in about 20 days; but differ both in size and beauty. Some have even doubted, whether the kingsfisher of the moderns and the alcyon of the ancients are the same bird. But the description of Aristotle sufficient ly identifies them. The aleyon, says that philosoplier, is not mucl larger than a 


\section{$A L C$}

sparrow; its plumage is painted with blue and green, and lightly tinged with purple; these colnurs are not distinct, but melted together, and shining variously over the whole body, the wings, and the neck; its bill is yellowish, long, and slender. 'The habits of thesc birds also resemble one another. The alcyon was solitary and pensive; and the kingsfisher is almost alway's seen alone, and the pairing season is of short dimation. The former was not only an inhabitant of the sea-shore, but haunted the banks of rivers; and the latter has also been found to seck shell-fish and large worms, that abound on the shore of the sea, and in rivilets that flow into it. The alcyon was seldom seen, and rapid in its flight; it whecled swiftly round ships, and instantly retired into its little grot on the shore. 'The same charter belongs also to the kingsfisher. The alcyon and the kingsfistier have the same mode of taking their prey, by diviug vertically upon it. The kingsfislier is the nost beautiful bird in our climates, as to the richness and luxuriance of the colours of its plumage. It lias, says Buffon, all the shades of the rainbow, the brilliancy of enamel, and the glossy softness of silk; and Gesner compares the glowing yellow red, which colours the breast, to the red glare of a burning coal; and yet the kingsfisher has strayed from those climates, where its resplendent and glowing colours would ap. pear to the greatest advantage. There is a species that is common in all the islands of tire South Sea; and Forster, in his observations on Captain Cook's seeond voyage, has remarked, that its plumage is much more brilliant between the tropics than in the regions situated beyond tise temperate zone, in New Zealand. In the language of the Society Islands, the kingstisher is calked Erooro, and at Otaheite it is accounted sacred, and not allowed to be taken or killed. hingfishers were found, not only at Ota. heite, but in Huaheine and Ulietea, and in the islands that are scattered over the South sea, though they are more than 1500 leagues distant from any continent. These kingsfishers are of a clull greerh with a collar of the same about their ncek. The islanders entertain a superstitious veneration for them. The chief at tilietea intreated Capt. Cook's companions, in a very scrious tone, to spare the kingsfishers and lierons of his island, giving jermission to kill all the other birds. There are 20 species in Africa and $A$ sin, ansl eight more that arc known
$A L C$

in the warm parts of America. The European kingsfisher is scattered through Asia and Africa: many of those scut from China and Figypt are found to be the same with ours, and 13 clon has met with them in Greece and in Tlirace. This brid, thongh it derives its origiu from the hottest climates, bears the rigour of our seasons. It is seen in the winter along the brooks, diving under the ice, and emerging with its prey: The Gemnans have called it cissvogel, or ice-bird ; and it has been foumd even among tlic Tartars and Sibcrians. The Tartars and Ostiacs use the feathers of these birds for many superstitions purposes. The former use them as love amulets; pretending that those which flont on water will induce a woman who is touclied with them to fall in love with the person who thus applies it. The Ostiacs take the skin, the bill, and the claws of this bird, and enclose them in a purse; and whilst they preserve this amulet, they think they have no ill to fear. Credulity has admitted and reported many other similar tales concerning the cxtraordinary powers and virtues of this bird; but it is needless to recite them. Its flesh has the orlour of musk, and is unpalatable. Plate II. Ares, fig. 4.

ALCIEMY, that branch of chemistry, which bad for its principal objects the transmutation of all the metals into gold : the panaces, or universal remedy for all diseases; and the alkahest, or universal menstruum. Those who pursued these delusive projects gradually assumed the form of a scet, under the name of Alchemists, a term made up of the word chemist, and the Arabian article al as a prefix. The alclicmists laid it down as a first principle, that all metals are composed of the same ingredients, or that the substances at least which compose gold exist in all metals, and are capable of being obtained from them. The great object of their researches was, to convert the hase metals into gold. The substance wlich produced this property they called lapis philosophomm, "the philosopher's stone;" and many of them boasted that they were in possession of that grand instrument. The alchemists were established in the west of Europe as early as the nintl $\mathrm{cen}_{2}$ tury; but betwcen the eleventh aud fifteenth alchemy was in its most flourishing state. The principal alchemists were, $\mathbf{A i}$. bertus Magnus, Roger Bacon, Arnoldus de Villa Nova, Raymond Lully, and the two Isaacs of Holland.

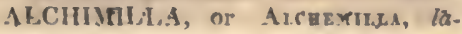


dies' mantle, in botany, a genus of the ' $\mathrm{Te}$ trandria Monogynia class of plants, the calyx of which is a single-leafed perianthium; there is no corolla, nor any pericarpium ; the cup finally becomes a capsule, containing a single elliptical and compressed seed. There are four species, $A$. vulgaris, counmon ladies' mantle, or beanfoot, is frequent in meadows and pastures in Fingland. It is perennial, and flowers in June and Julv. Ilorses, sheep, and goats, eat it. The great richness of the milk in the celebrated dairies of the Alps is attributed to the plenty of this plant, and that of the rib-wort plantain. The plant is astringent, and in Gothland and other places a tincture of its leaves is given in spasmodic and cunvulsive cases. A. alpina, cinquefoil, or alpine ladies' mantle, grows naturally in the North of Eng. land, North Wales, and in the Highlands of Scotland. It is a native of the northern parts of Europe, and is admitterl into the gardens on account of its elegance. The A. pentaphyllea grows naturally on the Alps, and is found in the botanical gardens in this country : it may be propagated by parting the roots in autumn. They should have a moist soil, and a shady situation.

ALCHORNEA, in botany, a genus of the Monadelphia Octandria class and order, of which there is but a single species. Male, calyx three, five-leaved; corolla none: female, calyx five-toothed; corolla none; styles two-parted.

ALCOHOL, a term applied by chemists to the purely spirituous part of liquors that have undergone the vinous fermentation. It is in all cases the product of the saccharine principle, and is formed by the successive processes of vinous fermenta. tion and distillation. Various kinds of ardent spirits arc known in commerce, as brandy, rum, \&ce.; but they differ in colour, taste, smell, \&ic. The spirituous part, however, is the same in each, and may be procured in its purest state by a second distillation, which is termed rectification. See Distillatiox, Fermentatios, and Rectification. Alcohol is procured most largely in this country from a fermented grain-liquor; but in France and otherwine countries, the spirit is obtained from the distillation of wine, hence the term spirit of wine. See BraxIIr. Alcohol is a colourless, transparent liquor, appearing to the eye like pure water. It possegses a peculiar penetrating smell, distinct from the proper odour of the distilled spirit from which it is pro. cured. To the taste it is excessively hot and burning; but without any peculiar favour. From its lightness, the bubbles which are formed by shaking subside almost instantaneously, which is one method of judging of its purity. Alcohol may be volatilized by the heat of the hand. It is converted into vapour at the tempe. rature of $55^{\circ}$ of Fahrenheit, and it boils at $165^{\circ}$. It has never been frozen by any degree of cold, natural or artificial, and on this account it has been much used in the construction of thermometers. Alcohol mixes with water in all proportions, and during the mixture heat is extricated, which is sensible to the hand. At the same time there is a mutual penetration of the parts, so that the bulk of the two liquors when mixed is less than when se. parate; consequently the speeific gravity of the mixture is greater than the mean specific gravity of the two liquors taken apart. Alcohol is supposed to consist of Carbon!: : : 28.53
Hydrogen : 7.87
Water : : 63.6

Its uses are maluy and important : it is employed as a solvent for those resinous gums which form the basis of numerous varnishes: it is employed also as the basis of artificial cordials and liquors, to which a flavour and aclditional taste are given by particular admixtures: it serves as a solvent for the more active parts of vegetables, under the form of tinctures. The antiseptic power of alcohol renders it particularly valuable in preserving particular parts of the body as anatomical preparations. The steady and uniform heat which it gives during the combustion makes it a valuable material for burning in lamps.

ALCORAN, or Alkorav, the name of a book held equally sacred among the Mahometans as the bible is among Christians.

The word alcoran properly signifies reading; a title given it by way of eminence, just as we call the old and New Testament Scriptures.

That Mahomct was the author of the Alcoran is allowed both by Christians and the Jlahometans themselves; only the latter are fully persuaded, that it was revealed to him by the ministry of the angel Gabriel; whereas the former, with more reason, think it all his own invention, assisted by one Sergius, a Claristian monk. The Alcoran is held not only of clivine original, but eternal and uncreated, remaining, as some express it, in the very essence of God. The first transcript has been from everlasting by Grod's throrie, 
written on a table of vast bigness, in which are also reconded the divine decrees, past and future. A copy from this table, in one volume, on paper, was sent down to the lowest heaven, in the month of Ramadan, on the night of power. From whence it was delivered out to Mahomet by parcels, some at Mecea, and some at Medina. Though he had the consolation of sceing the whole once a year, and in the last part of his life twice. 'Ten new cliapters were delivered entire, the greater part only in separate periods, which were written down from time to time by the prophet's amanuensis, in this or thas purt of this or the other chapter, as he directed. The first parcel that was revealed was the five first verses of the ninety-sixth chapter, which the prophet received in a cave of Mount Harah, near Necca.

The general aim of the Alcom was, to unite thic professors of the three different religions then followed in Arabia, Idolaters, Jews, and Christians, in the knowledge and worship of one God, under the sanction of certain laws, and the outward signs of cercinonies, partly of ancient, and partly of novel institution, enforeed by the consideration of rewards and pumishments both temporal and etemal, and to bring all to the obedience of Mahomet, as the prophet and ambassadar of God, who was to establish the true religion on earth, and be acknowledged chief pontiff in spiritusal matters. The chief point therefore inculcated in the Alcotan is the unity of God, to restore which, the prophet confessed, was the chief end of his mission. 'The rest is taken up in prescribing necessary laws and directions, frequent admoni. tions to moral and divine virtues, the wor ship and reverence of the Supreme Being, and resigmation to his will.

As to the book itself, as it now stands, it is divided into 114 Suras, or chapters, which are again divided into smaller por. tions or verses. But, besides these divisions, Mahometan writers farther divide it into 60 equal portions, called $h i=$, or $h a$. sah; each of which they subdivide into four parts.

After the title at the head of each chapter, except the ninth, is prefixed the formula, "In the name of the most merciful God," called by the Muhometans Bismal. lah, wherewith they constantly begin all their books and writings, as the distinguishing mark of their religion.

Twenty-nine of the chapters of the Alcoran have this further peculiarity, that there are certain letters of the alphabet prefired to them. In some a single letter, in others two or more. These letters are supposed, by the true believers, to conceal divers profound mysteries, the understanding whereof has been communicated to no man, their prophet excepted. Yet some have pretended to find their meaning, by supposing the letters to stand for so many words, expressing the names, attributes, and works of God; others explain these letters from the organ made use of in their pronunciation ; others from their value in numbers.

There are seren principal editions of the Koran, two at Medina, one at Mecca, one at Cufa, one at Bassora, one in Syria, and the common or vulgate edition. The first contains 6000 verses; the second and fifth, 6214; the third, 6219; the fourth, 6236 ; the sixth, 6226 ; and the last, 6225 ; but the number of words and letters is the same in all, viz. 77,639 words, and 323,015 letters.

The tleoran is allowed to be written with the utmost elegance and purity of language, in the dialect of the Koreishites, the most noble and polite of all the Arabians, but with some misture of other dialects. It is the standard of the Arabic tongue, and as the orthodox believed, and are taught by the book itself, ininitable by any human pen; and therefore insist. ed on as a permanent miracle, greater than that of raising the dead, and alone sufficient to convince the world of its divine original; and to this mirncle did MLahomet himself chiefly appeal, for the confirmation of his mission, publicly challenging the most eloquent schooluen in Arabia to produce a single chapter comparable to it. A late ingenious and candid writer, who is a very good judge, allows the style of the Alcoran to be generally beautiful and fluent, especially where. it imitates the prophetic manner and scripture phrase ; concise, and often obscure; adorned with bold tigures, after the eastern taste; enlivened with florid and sententious expressions; and, in many places, especially where the inajesty and attributes of God are described, sub. lime and magnificent.

To the pomp and harmony of expression some ascribe all the force and ellect of the Alcoran; which they consider as a sort of music, equally fitted to ravish and amaze, with other species of that art. In this Maliomet sncceeded so well, and so strangely captivated the minds of his audience, that several of his oppoments thanght it the eflect of witcheraft ancl enchantment, as he himself complains. So numerous are the commentartss on 
the Alcoran, that a catalogue of their bare titles would make a volume; we have a rery elegant translation of it into English by Mr. Sale; who has added a preliminary discourse, with other occasional notes, which the curious may consult on this head.

Anong Mahometans this book is held in the greatest reverence and estecm. The IIussulmen dare not touch it without bcing first washed, or legally purified; to prevent which, an inscription is put on the cover or label: "Let none touch it but they who are clean." It is rcad with great care and respect. They swear by it, take omens from it on all weighty occasions, carry it with them to war, write sentences of it on their banners, adorn it with gold and precious stones, and do not suffer it to be in the possession of any who hold a different religion.

ALCYON, in natural history, a name given to the kingsfisher. See Átceno.

ALCYONIUN, in natural history, a genus of Zoophytes, the characters of which are, that the animal grows in the form of a plant; the stem or root is fixed, fleshy, gelatinous, spongy, or coriaceous, with a cellular epidermis, penetrated with stellated pores, and shooting out tentaculated oviparous hydra. There are 28 species. From some experiments made by Mr. Ilatchett, and related by him in the Phil. Trans. on sereral of the species of alcy. onium, he was led to conclude, that they were all composed of a soft, flexible, membranaceous substance, slightly harrlened by carbonate, mixed with a small portion of phosphate of lime.

ALDEBALAN, in astronomy, a star of the first magnitude, called in English the Bull's eye, as making the eye of the con. stellation Taurus.

ALDER-tree, the English name of a genus of trees, called by botanists alnus. Sec Alye's.

ALDERIAN, in the British policy, a magistrate subordinate to the mayor of a city or town corporate.

The number of these magistrates is not limited, but is more or less, according to the matgnitude of the place. In London they are twenty-six; each having one of the wards of the city conmitted to his care. Their office is for life; so $t l_{1 \mathrm{a}} \mathrm{t}$ when one of them dies, or rcsigns, a wardmote is called, who return two persons, one of whom the lord mayor and aldermen choose, to supply the vacancy.

ALIOROVANDA, in botany, a genus of the Pentandria P'entaginia class ancl order, of which there is only one species, viz. the $A$. vesieulosa, found in marshes in Italy and India, with bladders like utricularia, but in buncles.

ALE-conner, an officer in London, who inspects the ineasures of public houses. They are four in number, and chosen by the common-hall of the city

Axw-honises, no licence to be granted to any person, unless he produce a certificate of his good character, under the hands of the clergyman, churchwardens, \&c. Penalties for selling without a licence, unless at fairs, 40 s. for the first offence, $5 l$. for the second; no person can sell wine to be drank at his own house, who has not an ale licence.

Act-silver, a tax paid yearly to the lord mayor of London, by all who sell ale within the city.

Al.ECTRA, in botany, a genus of the Didynamia Angiosperma class and order, of. which there is a single species only, viz. A. capensis, a native of the Cape of Good Hope; fourd in grassy places near rivers; flowering in November and December.

ALEMBERT (JoHx LE RoNd D') an eminent French mathematician and philosopher, and one of the brightest ornaments of the 18th century. He was perpetual secretary to the French Academy of Sciences, and a member of most of the philosophical academies and societies of Europe.

D'Alembert was born at Paris, the 16 th of November, 1717, and derived the name of Jolın le Rond, from that of the church, near which, after his birth, he was exposed as a foundling. But his father, Destouches Canon, informed of this circumstance, listening to the voice of nature and duty, took mcasures for the proper education of his child, and for his future subsistence in a state of case and independence. Ilis mother, it is said, was a lady of rank, the celebrated Mademoiselle Tencin, sister to cardinal Tencin, archbisliop of Lyons.

He receired his first education amoug the Jansenists, in the College of the Four Nations, where he gave early signs of genius and capacity. In the first year of his plilosophical studies, he composed a Commentary on the Epistle of St. Paul to the Romans. The Jansenists considered this production as an omen, that portended to the party of Port-Royal a restoration to some part of tlscir former splendour, and hoped to find one day, in D'Alembert, a second Pascal. To render the resemblance more complete, they engaged their pupil in the study of the ma. 


\section{ALEMBERT.}

thrmatics; but they soon perceived that his growing attachment to this science was likely to disappoint the hopes they had formed with respect to his fiture destination; they therefore endeavoured to divert him from the pursuit; but their endeavours were fruitless.

On his quitting the college, finding limself alone, and unconnccted in the world, he sought an asylum in the house of lis nurse, who was the wife of a glazier. Ile hoped that his fortune, though not ample, would enlarge the subsistence, and better the condition of her family, which was the only one that he could consider as his own. It was here, therefore, that he fixed his residence, resolving to apply himself entirely to the study of geometry. And here he lived, during the space of 30 years, with the greatest simplicity, discovering the augmentation of his means only by increasing displays of his beneficence, concealing his growing reputation and celebrity from these honest people, and making their plain anil uncouth manners the subject of goodnatured pleasantry and philosophic:al observation. IIis good nurse perceived his ardent activity ; hearil him mentioned as the writer of many books; and beheld hin with a kind of compassion: "You will never," sair she to him one day, "bc any thing but a philosopher-and what is a philosopher? $-a$ fool, who toils and plagues limself all his life, that people inay talk of him when he is dead."

As i'Alembert's fortune did not far oxceed the demands of necessity, his friends advised him to think of some profession that might enable him to increase it. II accordingly turned his viev's to the law, and took his degrees in that f?culty, which he soon after abanilnned, and applied limself to the study of medicine. Geometry, howerer, was always drawing him back to his former pursuits : so that, after many ineffectual struggles to resist its attractions, he renounced all views of a lucrative profession, and gave himself up entirely to mathematics and poverty. In the year 1741 he was admitted a member of the Academy of Sciences; for which distinguished literary promotion, at so early an age $(24$, ) lie had prepared the way, by correcting the crrors of the "Analyse Demontrée" of Reyneau, which was highly esteemed in France in the line of analytics. He afterwards set himself to cxamine, with attention and assiduity, what must be the motion and path of a body, which passes from one fluid intn another denser fuid, T(6)1.. I: in a direction oblique to the surface be. tween the two flils. Two rears after his election to a place in the acardeny, he published his "Treatise on Iyruamics." The new principle developed in tinis treatise consisted in establishing an eq a. lity, at each instant, between the changes that the motion of a bodr has indergone, and the forces or powers which have been employed to produce them; or, to express the same thing otherwise, in separating into two parts the action of the moring potrers, and consideling the one as producing alone the motion of the body in the second instant, and the other as employed to destrny that which it bad in the first.

So early as the year 174 , D'Alembert had applied this prineiple to the theory of the equilibrium, and the motion of fuids ; and all the problems before resolved in physics became in some measure its corollaries. The discovery of this new principle was followed by that of a new calculus, the first essays of which were published in a "Discourse on the General Theory of the Winds:" to this the prizemedal was adjuclged by the Academy of Berlin, in the year 1746, which proved a new and brilliant addition to the fame of D'Alembert. This new calculns of " Partial Differences" he applied, the year following, to the problem of vibrating chords, the resolution of which, as well as the theory of the oscillations of the air, and the propagation of sound, had been but imperfectly given by the mathemati. cians who preeeded him; and these were his masters or his rivals. In the year 1749 he furnished a method of apply. ing his principle to the motion of any body of a given figure. IIC also resolved the problem of the precession of the equinoxes: determining its quantity, and explaining the phenomenon of tie nutation of the terrestrial axis discovered. by 1 r. Bradley.

In $1752, D^{\prime}$ Alembert published a trea. tise on the "Resistance of Fluids," to which he garc the modest title of an " Bssav" " though it contains a multitude of original ideas and new observations. About the same time he published, in the Memoirs of the Academy of Ierlin, "Researches concerning the Integral Calculus," which is greatly indebted to him for the rapid progress it has made in the present century.

While the studies of D'Alembert were confined to mere mathematics, he was little known or celehrated in his native country. His connections were limited to a small N 
society of select fricnds. But his cheerful conversation, his smart and lively sal. lícs, a happy method at telling a story, a singular mixture of malice of speech with goodness of heart, and of delicacy of twit with simplicity of manners, rendering lim a pleasing and interesting companion, his company began to be much sought after in the fishionable circles. His reputation at length made its way to the throne, and rendered him the object of roval attention and beneficence. The consequence was, a pension from government, which he owed to the friendship of count D'Argenson.

But the tranquillity of D'Alembert was abated when his fame grew more extensive, and when it was known, beyond the circle of his friends, that a fine and enlightened taste for literature and philosophy accompanied his mathematical genius. Our author's eulogist ascribes to envy, detraction, \&c. all the opposition and censure that D'Alembert met with on account of the famous Encyclopeclie, or Dictionary of Arts and Sciences, in conjunction with Diderot. None surely will refuse the well deserved tribute of applause to the euinent displays of geuius, judgment, and true literary taste, with which D'Alem. bert has enriched that great work. Among others, the Preliminary Discourse he has prefixed to it, concerning the rise, progress, connections, and affinities, of all the branches of human knowledge, is perhaps one of the most capital productions the philosophy of the age can boast of.

Some time after this, D'Alembert published his "Philosophical, Historical, and Philological Miscellanies." These were followed by the "Memoirs of Cliristiana, Queen of Sweden;"'in which D'Alembert shewed that he was acquainted with the natural rights of mankind, and was bold enough to assert them. His "Essay on the Intercourse of Men of Letters with Persons high in Rank and Office" wounded the former to the quick, as it exposed to the eyes of the public the ignominy of those servile chains which they feared to shakc off, or were proud to wear. A lady of the court, hearing one day the author accused of having exaggerated the despotism of the great, and the submission they require, answered slyly, "If he had consulted me, I would have told him still more of the matter."

D'Alembert gave elegant specimens of his literary abilities in his translations of some select pieces of Tacitus. But these occupations diel not divert him from lis mathematical studies; for about the same time he enriched the Encyclopédie with a multitude of excellent articles in that line, and composed his "Researches on several Important Points of the System of the World," in which he carried to a ligher degree of perfection the solution of the problem concerning the perturbations of the planets, that had several years before been presented to the Academy, In 1759 he published his "Elements of Philosophy ;" a work much extolled, as remarkable for its precision and perspicuity. The resentment that was kindled (and the disputes that followed it) by the article Geseva, inserted in the Bncyclopedie, are well known. D'Alembert did not leave this field of controversy with flying colours. Voltaire was an auxiliary in the contest; but as he had no reputation to lose, in point of candour and decency, and as he weakened the blows of his enemies by throwing both them and the spectators into fits of laughter, the issue of the war gave him little uneasiness. It fell more heavily on D'Alembert; and ex. posed him, even at home, to much contradiction and opposition. 'It was on this occasion that the late King of Prussia offercd him an honourable asylum at his court, and the office of president of his academy : and the king was not offended at $D^{\prime}$ Alembert's refusal of these distinctions, but cultivated an intimate friendship with him during the rest of his life. He had refused, some time before this, a proposal made by the Empress of Russia, to entrust him with the education of the Grand Duke;-a proposal accompanied with all the flattering offers that could tempt a man, ambitious of tities, or desirous of making an ample fortune; but the objects of his ambition were tranquillity and study. In the year 1765 , he published his "Dissertation on the Destruction of the Jesuits." This piece drew upon him a swarm of adversaries, who only confirmed the merit and crdit of his work by their manner of attacking it.

Beside the works already mentioned, he published nine volumes of memoirs and treatises, under the title of "Opus. cules ;" in which he has resolved a multitude of problems relating to astronomy, mathematics, and natural philosophy; of which his panegyrist, Condorcet, gives a particular account, more especially of those which exluibit new subjects, or new methorls of investigution. Ife published. also "Elements of Music;" and rendered, at length, the system of Rarreau intelligible; but he did not think the mathe- 
matical theory of the sonorous body suffi. cient to account for the rules of that art. In the year 1772 he was chosen Secretary to the lirench $\mathbf{A}$ cademy of Sciences. Hie formed, soon after this preferment, the design of writing the lives of all the deceased academicians, from 1700 to 1772 ; and in the space of three years he exe. cuted this design, by composing seventy eulogies.

'The correspondence which D' $\Lambda$ lembert leeld with eminent literary characters, and his constant intercourse with learned inen of all nations, together with his great influence in the academy, concurred to give him a distinguished importance above most of his countrymen. By some, who were jealous of his reputation, he was denominated the Mazarin of literature; but there seems now no doubt, but that his influence was obtained by lis great talents and learning, rather than by artful nianagement and supple address. He was a decided and open enemy to superstition and priestcraft. Without inquiring into the merits of Christianity, lie conclu. ded, that the religion taught in France was that which believers in general regarded as the true doctrine, and which he rejected as a fable unworthy the atten. tion of the plilosopher. There is no reason to think that he ever studied the foundations on which natural and revealed religion were built; and it is certain that he adopted a system of deified nature, which bereaves the world of a designing cause and presiding intelligence. He was zealous even in propagating the opinions which he adopted, and might be regarded as an apostle of atheism. The eccentricity of his opinions did not destroy the moral virtues of his heart. A love of truth, and a zeal for the progress of real science and liberty, formed the basis of his character : strict probity, a noble disinterestedness, and an habitual desire of being useful, were its distinguishing features. To the young, who possessed ta. lents and genius, lic was a patron and in. structor : to the poorand oppressed he became a firm and generous friend: to those who had shown him kindness, he never ceased to be grateful; a sure evidence of a great mind. 'To two ministers who had befriended him in their prosperity, he de. dicated works when they were in disgruce with the court. $\mathbf{A} n$ instance of a kind, a grateful disposition, was displayed by D'Alembert in early life. His mother, who had inf:mously disowned and abancloned him, hearing of the greatness of Lis talents, and of the promise which be gave of future celebrity, obtained an in. terview, and laid claim to the character of a parent.- "What do I hear," said the indignant youth, " you are the mother-in. law, the glazier's wite is my true mother:" for the affection and gratitude of a child : and under her roof lie resided, 25 we have seen, many years, till an alarming illness made it necessary for him to remove to a more airy lodging. D' Alembert maintained his high rank and reputation among machematicians and philosophers till his death, in October 1783. His loss was deplored by surviross of every country; but his particular friends and associates exhibited, on the occasion, every mark of grief, which real and unaffected sorrow can alone supply for undissembled worth.

Al.LIBIC, in chemistry, a ressel usu. ally inade of glass or cop'per, formerly used for distillation. The bottom, in which the substance to be distilled is put, is called the cucurbit; the upper part is called the head, the beak of which is fitted into the neck of the receiver. Retorts and the common worm-still are now more generally employed. Sec Curmistar, Distillation, \&c.

ALETRIS, in botany, a genus of the Hexandria Monogynia class and order, of the natural order of Lilia or Liliacea, of which there are nine species; $\boldsymbol{\Lambda}$. farinosa, or American aletris, used by the nistives in coughs, and in the pleurisy. Some of the species are natives of the Cape of Gond Hope, others are found natural in Ccylon and Guinea. The A. zelanica, or Ceylon aloe, is common in gardens where exotic plants are preserved. A. guianensis, or Guinea aloe, when in Hower, seldom continues in beauty more than two or three days, and never produces seeds in England. The Ceylon, Guinea, and sweet-scented species, are too tender to live througli the winterin England, unless in a warm stove; and they will not pro. duce flowers if the plants are not plunged into a tan-bed. The creeping roots of the Ceylon and Guinea sorts send up many heads, which should be cut of in June, and after having been laid in the stove a fortnight, that the wounded part may lieal, they should be planted in small pots of light sandy earth, plunged into a moderate hot bed, and trested like other tender succulent plants, and be never set abroad in sunmer.

\$LLUIRITKS, in botany, a genus of the Monocia Monadelphia class and order, of the natural order of Tricoccx. The flpwers are male and female; the calyx 
af the male is a perianthium; the corol: las five petals ; the nectary has five-cornered scales; the stamens arc numerous filanents; the anthers roundish. 'The feinale flowers are few, the calyx, cololla, and nectariurn, as in the male, but larger. There are two sceds with a double bark. Only one species, a tree in the islands of the South Seas.

ALEXANDRLAN Copy of the Nero Testament, preserved in the British Museum, is referred to as an object of curiosity, as well as of considerable importanec, to persons who study the scriptures critically. It consists of four large quarto, or rather folio volumes, containing the whole bible in Greek, including the old and New Testament, with the Apocrypha, and some smaller pieces, but not quite complete. It was placed in the Britisl, Museum in 1758; and had been a present to Cliarles I. from Cyrillus Lucaris, a native of Crete, and patriarch of Constantinople, by sir Thomas Rowe, annbassador from England to the Grand Seignior in the year 1628. Cyrillus bronght it with him from Alexandria, where it was probably written. It is said to have been written by Thecla, a notie Egvptian ladr, about thirteen hundred years ago. In the New Testament there is waning the beginning, as far as Matt. xxv. 6 ; likewise from John vi. 50 , to viii. 52 ; and from -2 Cor. iv. 19 , to xii. 7 . It has neither accents nor marks of aspiration it is written with capital, or, as they are called, uncial letters, and there are 120 intervals between the worls, but the sense of a passage is sometimes terminated by a point, and sornetimes by a vacant space. Dr. Woride publis'ed this valuable work in 1786, with trpes cast for the purprose, line for line, precistly like the original MS : the copy has been examined with the greatest care, and it is found to be so periect a resemblance of the original, that it may supply its place. The authenticity, antiquity; \&c. of this MS. is briefly, but ably, discussed in Rees's New Cyclopedia, Vol I. p. ii.

ALG.E, in botany, an order or division of the Cryptogamia class of plants. It is one of the seven families or natural tribes into whicli the vegetable kingdom is distributed, in the Philosophia Botanica of Linnxus; the 57 th order of his fragments of a natural method.

The plants bclonging to this order are described as having their root, leaf, and stem, entire, or all one. The whole of the sea-weeds, and various other aquatic plants, are comprehended under this di- vision. From their admitting of little clistinction of root, leaf, or stem, and the parts of their flowers being equally incapable of description ; the genera are distinguished by the situation of what is supposed to be flowers or seeds, or by the resemblance which the whole plant bears to'some other substance. The parts of fructification are either found in saucers and tubercles, as in lichens ; in hollow bladders, as in the fuci; or dispersed through the whole substance of the plants, asin the ulva. The substance of the plants has mucl varicty ; it is Hesh-like or leather-like, membranaceous or fibrous, jelly. like or horm-like, or it has the resemblance of a calcareous earthy matter.

Lamarck distributes the algx into three sections : the first comprehends all those plants, whose fructification is not appa. rent, or seems doubtful. These commonly live in water, ofupon moist bodies, and. are membranous, gelatinous, or filamentous. To this section he refers the byssi, conferva, ulva, tremella, and varec. The plants of the second section are distinguislied by their apparent fructification, though it be little known, and they are formed of parts which have no partictlar and sensible opening or explosion, at any determuned period; their substance is ordinarily crustaceous or coriaceous. They include the tassella, ceratosperma, and lichen. The third section comprehends plants which have their fructificaton very apparent, and distinguished by constituent parts, which open at a certain perod of maturity, for the escape of the fecundating dust or seeds. These plants are more herbaccous, as to both their substance and their colour, than those of the other two sections, and are more near. ly related to the mosses; firom which they do not essentially differ. Their flower's are oftencontained in articulated and re. ry elastic filaments. To this section are referred the riccia, blasiz, anthoceros, targionà, bepatica, and junger-manna. In the Linnæan system the algæ are divided into two classes, viz, the terrestres and aquatica. The former include the anthoceros, blacia, riccia, lichen, and byssus; and the latter are the ulvafucus, and conferva. The fructification of the algx, and particularly of those called aquatic $x$, is denominated, by a judicious botanist, the opprobrium botanicorum.

ALGAROTH. See A A

ALGEBRA, a general method of re. solving mathematical problems by means of equations; or, it is a method of computation by symbols, which have been 
invented for expressing the quantities that are the objects of this science, and also their mutual relation and dependence. These quantities might, probably, in the infancy of the science, be denoted by their names at full length; these, being found inconvenient, were succeeded by abbreviations, or by their mere initials; and, at leugth, certain let. ters of the alphabet were adopted as ge. neral representations of all quantities; other syinbols or signs were introcluced, to prevent circumlocution, and to facilitate the comparison of various quantities witl one another; and, in consequence of the use of letters or species, and other general symbols, or indeterminate quantities, algebra obtained the appellation of specious, literal, and universal arithmetic. The origin of Algebra, like that of other sciences of ancient date aud gradual progress, is not easily ascertained. The most ancient treatise on that part of analytics, which is properly called algebra, now extant, is that of Dioplantus, a Greek author of Alexandria, who flourislsed about the year of our Lord 350 , and who wrote 13 books, though only six of them are preserved, which were printed, together with a single imperfect hook on multangular numbers, in a I atin translation by Xylander, in 1575, and afterwards in Greck and Iatin, with a comment, in 1621 and 1670, by ('aspar Bachet, and M. Fermat, Tolosx, fol. These books do not contain a treatise on the elementary parts of algebra, but merely collections of some diliticult questions relating to square and cube numbers, ant other curious properties of numbers, with their solutions. Algebra, however, seems not to have been wholly unknown to the ancient mathematicians, long before the age of Diophantus. We observe the traces and effects of it in many places, though it scems as if they bad intentionally concealed it. Something of it appears in Euclid, or at least in Theon upon Euclid, who observes that Plato lial begun to teach it. And there are other instances of it in l'appus, and more in Archimedes and Appollonius. lBut it should be observed, that the analysis used by these authors is rather geometrical than algebraical; this appears from the examples that occur in their works; and, therefore, Diophantus is the first and only author among the rreeks who has treated professedly of algebra. Our knowledge of the science was derived, not from Diophantus, but from the Moors or Arabians; but whether the
Greeks or Arabians were the inventors of it has been a subject of dispute. It is probable, however, tbat it is inuch nore ancient than Diopliantus, because his trea. tise seems to refer to works similar and prior to his own.

Algebra is a peculiar kind of arithme. tic, which takes the quantity sought, whether it be a number, or a line, or any other quantity, as if it were granted; and by neans of one or more quantities given, proceeds by a train of deductions, till the quantity at first only supposed to be known, or at least some power of it, is found to be equal to some quantity or quantities which are known, and conse. quently itself is known.

Algebra is of two kinds, numcral and literal.

A LeERrA, numeral or vulgar, is that which is chiefly concerned in the resolution of arithmetical questions. In this, the quantity sought is represented by some letter or character; but all the given quantities are expressed by numbers. Such is the algebra of the more ancient authors, as Diophantus, Paciolus, Stifelius, \&c. This is thought by some to have been an introduction to the art of keep: ing merchants" accouints by double entry.

A LGFBRa, specions or literal, or the new algebra, is that in which nll the quantities, known and unknown, are expressed or represented by thcir sjecies, or letters of the alphabet. There are instances of this method from Cardan, and others about his time; but it was more generally introduced and used by Vieta. Dr. Wallis apprehends that the name of specious arthmetic, applied to algebra, is given to it with a reference to the sense in which the Civilians use the word species. Thus, they use the names Titus, Sempro. nius, Caius, and the like, to represent inlefinitely any person in such circumstances; and cases so propounded, they call species. Vieta, aecustomed to the language of the civil law, gave, as Wallis supposes, the name of species to the letters, A, B, C, \&c. which he used to represent indefinitely uny number or quantity so eircumstanced, as the occasion required. This mode of expression frees the memory and imagination from that stress or effort, which is required to keep scveral matters, necessary for the disce. very of the truth investigited, present to the unind; for which reason Ulis art may be properly denominated metapliysical geometry. Specious algebra is not, like the numeral, confined to certain kinds of 
problems; but serves universally for the investigation or invention of theorems, as well as the solution and demonstration of all kinds of problems, both arithmetical and geometrical. The letters used in algebra do each of them, separately, represent either lines or numbers, as the problem is either arithmetical or geometrical; and, together, they represent planes, solids, and powers, more or less high, as the letters are in a greater or less number. For instance, if there be two letters, $a b$, they represent a rectangle, whose two sides are expressed, one by the letter $a$, and the other by $b$; so that by their mutual multiplication they produce the plane $a b$. Where the same letter is repeated twice, as $a$, they clenote a square. Three letters, $a b c$, represent a solid, or a rectangular parallelopiped, whose three dimensions are expressed by the three letters $a, b c$; the length by $a$, the breadth by $b$, and the depth by $c$; so that by their mutual multiplication they produce the solid $a b c$. As the multiplication of dimensions is expressed by the multiplication of letters, and as the number of these may be so great as to become incommodious, the method is only to write down the root, and on the riglit hand to write the index of the power, that is, the number of letters of which the quantity to be expressed consists; as $a^{2}, a^{3}, a^{4}$, \&c. the last of which signifies as much as $a$ multiplied four times into itself; and so of the rest. But as it is necessary, before any progress can be made in the science of algebra, to understand the method of notation, we shall here give a general view of it. In algebra, as we have already stated, every quantity, whether it be known or given, or unknown or required, is usually represented by some letter of the alphabet; and the given quantities are commonly denoted by the initial letters, $a, b, c, d$, \&cc. and the unknown ones by the final letters, $u, z v, x, y, z$. These quantities are connected together by certain signs or symbols, which serve to shew their mutual relation, and at the same time to simplify the science, and to reduce its operations into a less compass. Accordingly the sign + , plus, or more, signifies that the quantity to which it is prefixed is to be added, and it is called a positive or affirmative quantity. 'Thus, $a+b$, expresses the sum of the two quantities $a$ and $b$, so that if $a$ were 5 , and $b 3$, $a+b$ would be $5+3$, or 8 . If a quantity have no sign, $f$, plus, is understood, and the quantity is affirmative or positive.
The sign —, minus, or less, denotes tluat the quantity which it precedes is to be subtracted, and it is called a negative quantity. Thus $a-b$ expresses the difference of $a$ and $b$; so that $a$ being 5 , and $b 3, a-b$, or $5-3$, would be equal to 2 . If more quantities than two were connected by these signs, the sum of those with the sign - must be subtracted from the sum of those with the sign + . Thus $a+b-c-d$ represents the quantity which would remain, when $c$ and $d$ are taken from $a$ and $b$. So that if $a$ were 7 , $b 6, c 5$, and $d 3, a+b-c-d$, or $7+6$ $-5-3$, or $13-8$, would be equal to 5 . If two quantities are connected by the $\operatorname{sign} u n$, as $a$ in $b$, this mode of expression represents the difference of $a$ and $b$, when it is not known which of them is the greatest. The sign $\times$ signifies that the quantities between which it stands are to be multiplied together, or it represents their product. Thus, $a \times b$ expresses the product of $a$ and $b ; a \times b \times c$ denotes the product of $a, b$, and $c ;(a+b)$ $X c$ denotes the product of the compound quantity $a+b$ by the simple quantity $c$; and $(a+b+c) \times(a-b+c) \times(a+b)$ represents the product of the three compound quantities, multiplied continually into one another; so that if $a$ were $5, b$ 4 , and $c 3$, then would $(a+b+c) \times$ $(a-b+c) \times(a+c)$ be $12 \times 4 \times 8$, or 384. The parenthesis used in the foregoing expressions indicate that the whole compound quantities are affected by the sign, and not simply the single terms between which it is placed. Quantities that are joined together without any intermediote sign form a product; thus $a b$ is the same with $a \times b$, and $a b c$ the same with $a \times b \times c$. When a quantity is multiplied into itself, or raised to any power, the usual mode of expression is to draw a line over the quantity, and to place the number denoting the power at the end of it, which number is called the index or exponent. Thus, $(a+b)^{2}$ denotes the same as $(a+b) \times(a+b)$ or second power, or square, of $a+b$ considered as one quantity; and $(a+b)^{3}$ denotes the same as $(a+b) \times(a+b) \times(a+b)$, or the third power, or cube, of $a+b$. In expressing the powers of quantities represented by single letters, the line over the top is usually omitted: thus, $a^{2}$ is the same as $a c$ or $a \times a$, and $b^{3}$ the same as $b b b$ or $b \times b \times b$, and $a^{2} b^{3}$, the same as $a a \times b b b$ or $a \times a \times b \times b \times b$. The full point and the word into, are sometimes used instead of $x$ as the sign. of multiplication. Thus, $(a+b) \cdot(a+c)$, 


\section{ALGERBA.}

and $a+b$ into $a+c$, signify the same thing as $(a+b) \times(a+c)$, or the product of $a+b$ by $a+c$. The sign $\div$ is the sign of division, as it denotes that the quantity preceding it is to bedivided by the succeeding quantity. Thus, $c \div b$ signifies that $c$ is to be divided by $b$; and $(a+b) \div(a+c)$, that $a+b$ is to be divided by $a+c$. The mark) is sometimes used as a note of division; thus $a+b) a b$ denotes that $a b$ is to be divided by $a+b$. But the division of algebraic quantities is most commonly expressed by placing the divisor under the dividend, with a line between them, like a vulgar fraction. Thus, $\frac{c}{b}$ represents the quantity arising by dividing $c$ by $b$, or the quotient, and $\frac{a+b}{a+c}$ represents the quotient of $a+b$ divided by $a+c$. Ruantities thus expressed are called algebraic fractions.

The sign $\checkmark$ expresses the square root of any quantity to which it is prefixed; thus $\sqrt{ } 25$ signifies the square root of 25 , or 5 , because $5 \times 5$ is 25 ; and $\checkmark(a b)$ denotes the square root of $a b$; and $\int\left(\frac{a b+b c}{d}\right)$ denotes thesquare root of $\frac{a b+b c}{d}$, or of the quantity arising from the division of $a b+b c$ by $d$; but $\frac{V(a b+b c)}{d}$, which has the separating line drawn under $\checkmark$, signifies that the square root of $a b+b c$ is to be first ta. ken, and afterwards divided by $d ;$ tso that if $a$ were $2, b 6, c 4$, and $d 9$, $\frac{\sqrt{ }(a b+b c)}{d}$ would be $\frac{\sqrt{ } 36}{9}$ or $\frac{6}{9}$; but $\sqrt{ }\left(\frac{a b+b c}{d}\right)$ would be $\sqrt{\left(\frac{36}{9}\right)}$ or $\checkmark 4$, which is 2. The sign $\checkmark$ with a figure over it is used to express the cubic or biqualratic root, \&sc. of any quantity; thus $3 / 64$ represents the cube root of 64 , or 4 , because $4 \times 4 \times 4$ is 64 ; and $y$ $(a b+c d)$ the cube root of $a b+c d$. In like manner $\sqrt{ } \overline{16}$ denotes the biquadratic root of $16,0 r^{2}$, because $2 \times 2 \times 2 \times 2$ is 16 , an $14(a b+c d)$ denotes the biquadra ic root of $a b+c d\}$ and so of others. Quantities thus expressed are called radical qu: ntities, or surds; of which those, consisting of one tem only, as $\sqrt{ } a$ and $\checkmark(a b$, are calied simple surds; and those consisting of several terms or numbers, as $\sqrt{ }\left(a^{2}-b^{2}\right)$ and $\sqrt{3}\left(a^{2}-b+b c\right)$ are denominated compound surds. Ano. ther comniodions method of expressing radical quantities is that which denotes the root by a vulgar fraction, placed at the end of a line clraw over the quantity given. In this notation, the square root is expressed by $\frac{1}{2}$, the cube root by $\frac{1}{3}$, the biquadratic root by $\frac{1}{4}$, \&c. Thus $a \frac{1}{2}$ expresses the same quantity with $\checkmark a$, i. e. the square root of $a$, and $\left(a^{3}+a b\right) \frac{1}{3}$ the same as $y^{3}\left(a^{2}+a b\right)$, i. e. the cube root of $a^{2}+a b$; and $a \frac{12}{3}$ denotes the cube root of the square of $\alpha$, or the square of the cube root of $a$; and $(a+\Rightarrow) \frac{7}{4}$ the seventh power of the biquadratic root of $a+z$; and so of others; $\left(a^{2}\right) \frac{1}{2}$ is $a$, a: $\frac{1}{3}$ is $a$, \&c. Ruantities that have no radical $\operatorname{sign}(\checkmark)$ or index annexed to them, are called rational quantities. The sign $=$, called the sign of equality, signifies thit the quantities between which it oc. curs are equal. Thus $2+3=5$, shews that 2 plus 3 is equal to 5 ; and $x=a-b$ shews that $x$ is equal to the difference of $a$ and $b$. The mark : : signifies that the quantities between which it stands are proportional. As $a: b:: c: d$ denotes that $a$ is in the same proportion to $b$ as $c$ is to $d$; or that if $a$ be twice, thrice, or four times, \&c. as great as $b, c$ will be twice, thrice, or four times, \&c. as great as $d$.' When anyquantity is to be taken more than once, the number, which shows how many times it is to be taken, must be prefixed; this $5 a$ denotes that the quantity $a$ is to be taken 5 times, and $3 b c$ represents three times $b c$, and $7 \checkmark\left(a^{3} \times b^{2}\right)$ denotes that $\checkmark\left(a^{3}+b^{2}\right)$ is to be taken 7 times, \&c. The numbers thus prefixed are called co-eficients; and if a quantity have no co-efficient, unit is understood, and it is to be taken only once. Similar or like quantities are those that are expressed by the same letters under the same powers, or which differ only in their co-efficients; thus, $3 b c, 5 b c$, and $8 b c$, are like quantitics, and so are the radicals $2 \sqrt{\left(\frac{b+c}{a}\right) \text { and } 7} \sqrt{\left(\frac{b+c}{a}\right) \text { But un- }}$ like quantities are those which are expressed by different letters, or by the same letters with different powers, as $2 a$ $b, 5 a b^{2}$, and $3 a^{2} b$. When a quantity is expressed by a single letter, or hy several single letters multiplied together, without any intervening sign, as $a$, or $2 a b$, it is called a simple quantity. But the quantity which consists of two or more such simple quantities, connected by the signs + or - , is called a compound quantity: thus, $a-2 a b+5 a b c$ is a compound 


\section{ALGEBRA.}

quantity; und the simple quantities, $a, 2$ $a b, 5 a b c$, are called its terms or mem. bers. If a colstpound quantity consist of two terms, it is called a binomial; of tliree temins, a trinomial; of four terms, a quadrinomial, and of many terms, a multinomial. If one of the terms of a binomial be negative, the quantity is called a residual quantity. The reciprocal of any quantity is that quantity inverted, or unity divided by it ; thus $\frac{a}{b}$ is the reciprocal of $\frac{b}{a}$, and $\frac{1}{a}$ is the reciprocal of a. The letters by which any simple quantity is expressed may be ranged at pleasure, and yet retain the same signification; thus $a b$ and $b \quad a$ are the same quantity, the product of $a$ and $b$ being the same with that of $b$ by $a$. The several terms of which any compound quantity consists may be disposed in ally order at pleasure, provided they retain their proper sigus. Thus $a-2 a b+$ $5 a^{2} b$ may be witten $a+5 a^{3} b-2 a b$, or $-2 a b+a+5 a^{2} b$, for all these repre. sent the same thing or the quantity which remains, when from the sum of $a$ and 5 $a^{2} b$, the quantity $2 a b$ is deducted.

Axious. 1. If equal quantities be add. ed to equal quantities, the sums will be equal.

2. If equal quantities be taken from equal quantities, the remainders will be equal.

3. If equal quantitics be multiplied by the same, or equal quantities, the products will be equal.

4. If equal quantities be divided by the same, or equal quantities, the quotients will be equal.

5. If the same quantity be added to and subtracted from another, the value of the latter will not be altered.

6. If a quantity be both multiplied and divided by another, its value will not be altered.

\section{ADDITION OF ALGEBRAICAL QCAXTI-} TIES.

The addition of algebraical quantities is performed by connecting those that are unlike with their proper signs, and collecting those that are similar into one sum.

Add together the following unlike quantities :

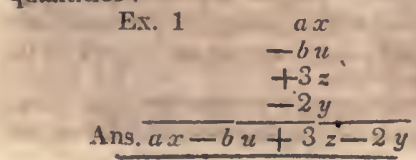

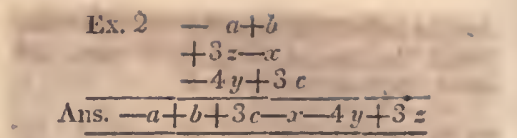

It is immaterialin what order the quan. tities are set down, if we take care to prefix to each its proper sign.

When any terms are sinilar, they may be incorporated, and the general expression for the sum shortened.

1. When similar quantities have the same sign, their sum is found hy taking the sum of the co-efficients with that sign, and annexing the common letters.

$$
\begin{aligned}
& \text { Ex. 3. } 4 . a-5 b \\
& 2 a-6 b \\
& 9 a-3 b \\
& \text { Ex. 4. } 4 a^{2} c-10 b d e \\
& 6 a^{3} c-9 b d e \\
& 11 a^{2} c-3 b d e
\end{aligned}
$$

Ans. $21 a^{2} c-22 b d e$

The reason is evident; $4 a$ to be add. cd, together with $2 a$ and $9 a$ to be adcl. ed, makes $15 a$ to be added; and $5 b$ to be subtracted, together with $6 b$ and $3 a$ to be subtracted, is 14.6 to be subtract. ed.

2. If similar quantities have different signs, their sum is found by taking the difference of the co-efficients with the sign of the greater, and annexing the common letters as before.

$$
\begin{aligned}
& \text { Ex. 5. } 7 a+3 b \\
& -5 a-9 b \\
& \text { Ans. } \overline{2 a-6 b}
\end{aligned}
$$

In the first part of the operation we have 7 times $a$ to add, and 5 times $a$ to take away; therefore, upon the whole, we have $2 a$ to add. In the latter part, we have 3 times $b$ to acld, and 9 times $b$ to take away; $i$. e. we have, upon the whole, 6 times $b$ to take away: and thus the sum of all the quantities is $2 a-6 b$.

If several similar quantities are to be added together, some with positive and some with negative signs, take the difference between the sum of the positive 


\section{ALGEBRA.}

and the sum of the negative co-efficients, prefix the sign of the greater sum, and annex the common letters.

12. 7. $3 a^{3}+4 b c-c^{3}+10 x-25$ $-5 a^{2}+6 b c+2 c^{3}-15 x+44$ $-4 a^{2}-9 b c-10 c^{3}+21 x-90$ Ins. $=6 a^{2}+b c-9 c^{2}+16 x-71$

Ex. 8. $4 a c-15 b d+e x-a x$ $11 a c+7 b^{2}-19 e x+4 a x$ $-41 a^{2}+6 b d-7 d e-2 a x$

A. $15 a c-41 a^{2}-9^{2} d+7 b^{2}-18 e x-7 d e-a x$

Ex. 9. $p x^{3}-q x^{3}-r x$

$a x^{3}-b x^{3}-x$

Ans. $p+a x^{3}-\overline{q+b}-\overline{x^{3}-r+1} x$

In this example, the co-efficients of $x$ and its powers are united; $\overline{p+a} \cdot x^{3}=p$ $x^{3}+a x^{7} ;$ also $-\overline{q+b} \cdot x^{3}=-q x^{2}-b$ $x^{3}$, because the negatire sign affects the whole quantity under the vinculum; and $-\overline{r-1} \cdot x=-r x-x$

\section{SCBTRACTIOУ.}

Silberaction, or the taking away of one quansity froin unother, is performed by changing the sign of the quantity to be subtracted, and then adding it to the other, by the rules laid doron in the last article.

Fx. 1. From $2 b x$ take $c y$, and the difference is properly represented by $2 b x$ $-c y$; because the - prefixed to $c y$ shew's that it is to be subtracted from the other; and $2 b x-c y$ is the sum of $2 b x$ and $-c y$.

Ex. 2. Again, from $2 b x$ take $-c y$, and the difference is $2 b x+c y$; because $2 b x$ $=2 b x+c y-c y$, take away $-c y$ from these equal quantities, and the differences will be equal; i. e. the difference between $2 b x$ and $-c y$ is $2 b x+c y$, the quantity which arises from adding $+c y$ to $2 b x$.

$$
\begin{array}{r}
\text { Ex. 3. From } a+b \\
\text { take } a-b \\
\text { Ans. } \underline{+2 b}
\end{array}
$$

Ex. 4. From $6 a-12 b$

$$
\text { take }-5 a-10 b
$$

Ans. $11 a-2 b$

Ex. 5. From $5 a^{3}+4 a b-6 x y$ take $11 a^{2}+6 a b-4 x y$

VOL. I.
Ex. 6. From $4 a-3 b+6 c-11$

take $10 x+a-15-2 y$

Ans. $\overline{5 a-3 b+6 c-10 x+2 y+4}$

Ex. 7. From $a x^{3}-b x^{3}+x$

take $p x^{3}-q x^{3}+r x$

Ans. $\overline{a-p \cdot x^{3}-\overline{b-q} \cdot x^{2}+\overline{1-r \cdot x}}$

In this example the co-efficients aro united; $\overline{a-p} \cdot x^{3}$ is equal to $b x^{2}-q x^{3}$; $-\overline{b-q} \cdot x^{2}$ is equal to $b x^{2}-q x^{3} ;$ and $\overline{x-r} \cdot x=x-r x$.

\section{MELTIPLICATIOX.}

The multiplication of simple algebraical quantities must be represented according to the notation already pointed out.

Thus, $a \times b$, or $a b$, represents the pro. duct $a$ multiplied by $b ; a b c$, the product of the three quantities, $a, b$, and $c$.

It is also indifferent in what order they are placed, $a \times b$ and $b \times a$ being equal.

To determine the sign of the product, observe the following rule.

If the multiplier and multiplicand have the same sign, the product is positize; if they have diffcrent signs, it is negative.

1. $+a x+b=a b$; because in this case $a$ is to be taken positively $b$ times; therefore the proluct $a b$ must be positive.

2. $-a x+b=-a b$; because $-a$ is to be taken $b$ times; that is, we must take $-a b$.

3. $+a \times-b=-a b$; for a quantity is said to be multiplied by a negative number -6 , if it be subtracted $b$ times; and $a$ subtracted $b$ times is - $a b$.

4. $-a \times-b=+a b$. Here $-a$ is to be subtracted $b$ tinies; that is, $-a b$ is to be subtracted; but subtracting - $a b$ is the same as adding $+a b$; thercfore we have to add $+a b$.

'Tlie $2^{d}$ and $4^{\text {th }}$ cases may be thus pror. ed : $a-a=0$, muitiply both sides by $b$, and $a$ together with $-a \times b$ must be equal to $l: a$, or nothing; therefore, $-a$ multiplied by $b$ must gise $-a^{\prime}$, a quantity wluch wlicu added to $a b$ makes the sum nothing.

Again, $a-a=0$; multiply both sides by $-b$, then $-a b$ together with $-a x$ $-b$ must be $=0$; therefore $-a \times-b$ $=+a b$.

If the quantities to be multiplied bare co-eficients, these must be multiplied to. 


\section{ALGEBRA.}

gether, as in common arithmetic; the sign and the literal product being determined by the preceding rules.

Thus, $3 a \times 5 b=15 a b$; because $3 \times a \times$ $5 \times b=3 \times 5 \times a \times b=15 a b ; 4 x \times-11 y$ $=-44 x y ;-9 b x-5 c=+45 b c$; $6 d \times 4 m=-24 m d$.

The powers of the same quantity are multiplied together by adding the indices; thus $a^{2} \times a^{3}=a^{5}$; for $a a \times a a a=a a a a a$. In the same manner, $a^{m} \times a^{n}=a^{m+n}$; and $-3 a^{2} x^{3} \times 5 a x y^{2}=-15 a^{3} x^{4} y^{2}$.

If the multiplier or multiplicand consist of several terms, each term of the lat. ter must be multiplied by every term of the former, and the sum of all the pro. ducts taken, for the whole product of the two quantities.

\section{Ex. 1. Mult. $a+b+x$} by $c+d$

Ans. $\overline{a c+b c+x c+a d+b} \overline{d+x d}$

Frere $a+b+x$ is to be added to itself $c+d$ times, i. e. $c$ times and $d$ times.

Ex. 2. Mult. $a+b-x$ by $c-d$

Ans. $a c+b c-x c-a d-b \overline{d+x d}$

Here $a+b$ is to be taken $c-d$ times, that is, $c$ times wanting $d$ timcs ; or $c$ times - positively and $d$ times negatively.

Ex. 3. Mult. $a+b$

Ans. $\frac{\frac{b y a+b}{a^{2}+a b}}{+a b+b^{2}}$

Ex. 4. Mult. $x+y$

$$
\text { by } \frac{x-y}{x^{2}+x y}
$$$$
\text { Ans. } \frac{-x y-y^{2}}{x^{2}-a^{2}}
$$

Ex. 5. Mult. $3 a^{2}-5 b d$

$$
\begin{aligned}
\text { by } & -5 a^{2}+4 b d \\
& =15 a^{4}+25 a^{2} b d \\
\text { Ans. } & =15 a^{4}+37 a^{2} b d-20 b^{2} d^{2}
\end{aligned}
$$

Ex. 6. Mult $a^{2}+2 a b+b^{2}$

$$
\begin{aligned}
& \text { by } \begin{array}{l}
\frac{a^{2}-2 a b+b^{2}}{a^{4}+2 a^{3} b+a^{2} b^{2}} \\
-2 a^{3} b-4 a^{2} b^{2}-2 a b^{3} \\
+a^{2} b^{2}+2 a b^{3}+b^{4}
\end{array} \\
& \text { Ans. } \frac{a^{4}-2 a^{2} b^{2}}{+b^{4}}
\end{aligned}
$$

Ex. 7. Mult. $1-x+x^{3}-x^{3}$ by $1+x$

Ans. $\frac{1+x-x^{2}+x^{3}-x^{4}}{*}$

Ex. 8. Mult. $x^{2}-p x+q$

by $x+a$

$$
\overline{x^{3}-p} \overline{x^{2}+q x}
$$

$$
+a x^{2}-a p x+a q
$$

Ans. $\overline{x^{3}-p-a x^{2}+q-a p \cdot x+a q}$

Here the co-efficients of $x^{2}$ and $x$ are collected; $-\overline{p-a} \cdot x^{2}=-p x^{2} a x^{2} z$ and $\overline{q-a p} x=q x-a p x$.

\section{DIVISIOX.}

To divide one quantity by another, is to determine how often the latter is contained in the former, or what quantity multiplied by the latter will produce the former.

Thus, to divide $a b$ by $a$ is to determine how often $a$ must be taken to make up $a b$; that is, what quantity multiplied by $a$ will give $a b$; which we know is $b$. From this consideration are derived all the rules for the division of algebraical quantities.

If the divisor and dividend be affected with like signs, the sign of the quotient is $+:$ but if their signs be unlike, the sign of the quotient is -

If $-a b$ be divided by $-a$, the quotient is $+b$; because $-a \times+b$ gives $-a b$; and a similar proof may be given in the other cases.

In the division of simple quantities, if the co-efficient and literal product of the divisor be found in the dividend, the other part of the diridend, with the sign determined by the last rule, is the quotient.

Thus, $\frac{a b c}{a b}=c$; because $a b$ multiplied by $c$ gives $a b c$.

If we first divide by $a$, and then by $b$, the result will be same; for $\frac{a b c}{a}=b$ $c$, and $\frac{b c}{a}=c$, as before.

Hence, any power of a quantity is divided by any other power of the same quantity, by subtracting the index of the divisor from the index of the dividend. Thus, $\frac{a^{5}}{a^{3}}=a^{2} ; \frac{a^{5}}{a^{3}}=\frac{1}{a^{3}}=a^{-3} ; \frac{a^{m}}{a^{n}}=a^{m-\mathrm{k}}$.

If only a part of the product wlich forms the divisor be contained in the divi- 


\section{ALGEBRA.}

dend, the quantities contained both in the divisor and dividend must be expunged. Thus, $15 a^{3} b^{2} c$ divided by $-3 a^{2} b x_{2}$ or $\frac{15 a^{3} b^{2} c}{-3 a^{2} b y}=\frac{-5 a b c}{y}$.

First, divide by $-3 a^{2} b$, and the quotient is $-5 a b c$; this quantity is still to be divided by $y$, and as $y$ is not contained in it, the division can only be represented in the usual way; that is, $\frac{-5 a b c}{y}$ is the quotient.

If the dividend consist of several terms, and the divisor be a simple quantity, eve. ry term of the dividend must be divided by it.

$$
\text { Thus, } \frac{a^{3} x^{3}-5 a b x^{3}+6 a x^{4}}{a x^{2}}=a^{2}-
$$
$5 b x+6 x^{2}$.

When the divisor also consists of several terms, arrange both the divisor and di. vidend according to the powers of some one letter contained in them; then find how often the first term of the divisor is contained in the first term of the dividend, and write down this quantity for the first term in the quotient : inultiply the whole divisor by it, subtract the product from the dividend, and bring down to the remainder as many other terms of the dividend as the case may require, and repeat the operation till all the terms are brought down.

Ex. 1. If $a^{2}-2 a b+b^{2}$ be divided by $a-b$, the operation will be as follows:

$$
\begin{aligned}
& \frac{a^{2}-a b}{-a b+b^{2}} \\
& -a b+b^{2} \\
& \hline
\end{aligned}
$$$$
a-b) a^{2}-2 a b+b^{2}(a-b
$$

The reason of this, and the foregoing rule, is, that as the whole dividend is made up of all its parts, the divisor is contained in the whole, as often as it is contained in all the parts. In the preceding operation we inquire, first, how often $a$ is contained in $a^{3}$, which gives $a$ for the first term of the quotient, then multiplying the whole divisor by it, we have $a^{2}-a b$ to be subtracted from the dividend, and the re. mainder is $-a b+b^{2}$, with which we are to proceed as beforc.

The whole quantity $a^{2}-2 a b+b^{2}$ is in reality divided into two parts by the process, each of which is divided by $a-b$; therefore the true quotient is obtained.

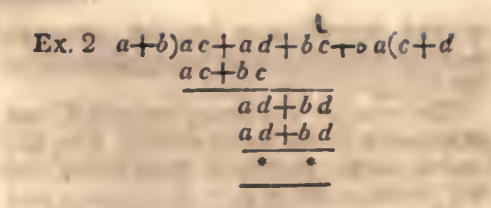

Ex. 3

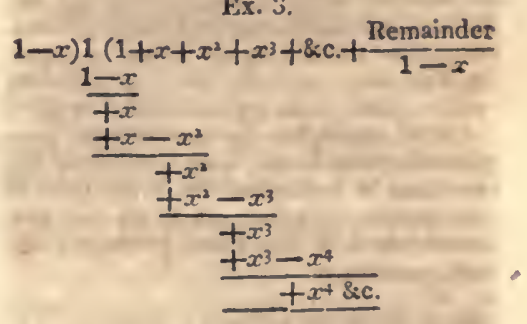

Ex. 4. $y-1) y^{3}-1\left(y^{3}+y+1\right.$

$$
\begin{aligned}
& \frac{y^{3}-y^{2}}{+y^{3}} \\
& \frac{y^{2}-y}{+y-1} \\
& y-1
\end{aligned}
$$

Ex. 5.

$x-a) x^{3}-p x^{2}+q x-r\left(x^{2}+a-p x+a^{2}-\right.$ $p a+q x^{3}-a x^{2}$

$$
\begin{aligned}
& \frac{\frac{a-p \cdot x^{2}}{a-p x}-q x}{x^{3}-a^{4}-p a x} \\
& +\frac{a^{2}-p a+q-x-r}{p a+q \cdot x-a^{3}-p a^{2}+q a} \\
& \frac{a^{2}-p a i n d e r a^{3}-p a^{2}+q a-r}{\text { Remain }}
\end{aligned}
$$

\section{THE TRAXsFonMatiox of FRactIoxs} TO OTHERS OF EQTAL VALUX.

If the signs of all the terms both in the numerator and denominator of a fraction be changed, its value will not be altered. For

$$
\begin{aligned}
& \frac{-a b}{-a}=+b=\frac{+a b}{+a} ; \text { and } \frac{a b}{-a}=-b= \\
& \frac{-a b}{a}
\end{aligned}
$$

If the numerator and denominator of a fraction be both multiplied, or both divided, by the same quantity, its value is not altered. For $\frac{a c}{b c}=\frac{a}{b} ;$ and $\frac{a x y z}{a b c z}=\frac{x y}{b c}$

Hence, a fraction is reduced to its lowest terms, by dividing both the numern. 


\section{ALGEBRA.}

tor and denominator by the greatest quantity that measures them both.

The greatest common measure of two quantities is found by arranging them according to the pozvers of some letter, and then diriding the greater by the less, and the preceding divisor alvoays by the last remainder, till the remainder is notling; the last divisor is the greatest common measure required.

Let $a$ and $b$ be the two $b) a(p$ quantities, and let $b$ be contained in $a, p$ times, with a remainder $c$; again, let $c$ be contained in $b, q$ timcs, with a remainer $d$, and so on, till nothing remains; let $d$ be the last divisor, and it c) $b(q$

d) $c(r$ 0 will be the greatest common measure of $a$ and $b$.

The truth of this rule depends upon these two principles:

1. If one quantity measure another, it will also measure any multiple of that quantity - Let $x$ measure $y$ by the units in $n$, then it will measure $c y$ by the units in $n c$.

2. If a quantity measure two others, it will measure their sum or difference. Let $a$ be contained in $x, m$ times, and in $y, n$ times; then $m a=x$ and $n a=y$; therefore $x \pm y=m a \pm n a=\overline{m \pm n} a$; i. e. $a$ is contained in $x \pm y, m \pm n$ times, or it measures $x \pm y$ by the units in $m \pm n$.

Now it appears from what has been said, that $a-p b=c$, and $b-q c=d$; every quantity therefore, which measures $a$ and $b$, measures $p b$, and $a-p b$, or $c$; hence also it measures $q c$, and $b-q c$, or $d$; that is, every common measure of $a$ and $b$ measures $d$.

Ex. To find the greatest common measure of $a^{4}-x^{4}$ and $a^{3}-a^{2} x-a x^{2}+x^{3}$, and to reduce $\frac{a^{4}-x^{4}}{a^{3}-a^{3}} \frac{x-a x^{2}+x^{3}}{x}$ to its lowest terms.

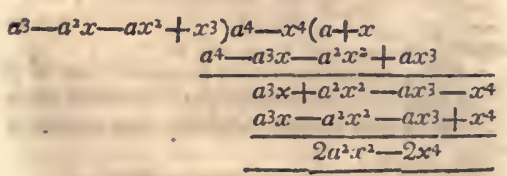

leaving out $2 x^{2}$, which is found in each term of the remainder, the next divisor is $a^{2}-x^{2}$.

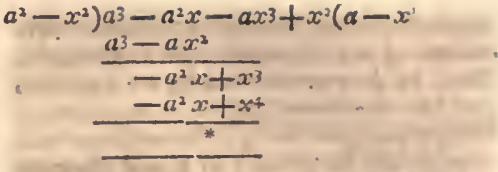

$a^{2}-x^{2}$ is therefore the greatest common measure of the two quantities, and if they be respectively divided by it, the frac. tion is reduced to $\frac{a^{2}+x^{2}}{a-x}$. its Iowest terms.

The quantity $2 x^{2}$, found in every term of one of the divisors, $2 a^{3} x^{3}-2 x^{4}$, but not in every term of the dividend, $a^{3}-a^{2}$ $x-a x^{2}+x^{3}$, must be left out; otberwise the quotient will be fractional, which is contrary to the supposition made in the proof of the rule; and by omitting this part, $2 x^{2}$, no common measure of the divisor and dividend is left out; because, by the supposition, no part of $2 x^{2}$ is found in all the terms of the dividend. .

To find the greatest common measuro of three quantities, $a b c$; take $d$ the greatest common measure of $a$ and $b$, and tho greatest mersure of $d$ and $c$ is the greatest common measure required. In the same manner, the greatest common meam sure of four or more quantities may be found.

If one number be divided by another, and the preceding divisor by the remainder, according to what has been said, the remainder will at length be less than any quantity that can be assigned.

Fractions are changed to others of equal value with a common denominator, by multiplying each numerator by every denominator except its own, for the new numerator; and all the denominators together for the common deszominator.

Let $\frac{a}{b}, \frac{c}{d} \bar{f}$ be the proposed fractions; then $\frac{a d f}{b d f}, \frac{c b f}{b d f}, \frac{e d b}{b d f}$, are fractions of the same value with the former, having the common denominator $b d f$. For $\frac{a d f}{b d f}=\frac{a}{b} ; \frac{c b f}{b d f}=\frac{c}{d} ;$ and $\frac{e d b}{b d f}=\frac{e}{f}$, the numerator and denominator of each frac. tion having been multiplied by the same quantity, viz. the product of the denominators of all the other fractions.

"When the denominators of the propo: sed fractions are not prime to each other, find their greatest common measure; multiply both the numerator and deno: 


\section{ALGEBRA.}

minator of each fraction by the denominators of all the rest, divided respectively by theirgreatest common measure; and the fractions will be reduced to $a$ common denominator, in lower terms than they would have been by proceeding ac. cording to the former rule.

Thus, $\frac{a}{m x}, \frac{b}{m y}, \frac{c}{m z}$, reduced to a com. mon denominator, are $\frac{a y z}{m x y z} ; \frac{b x z}{m x y z}$; $\frac{c x y}{m x y z}$

ON THE $\triangle$ DDITIOF AND BUBTRACTION OF rastroxs.

If the fractions to be adiled have a com: mon denominator, their sum is found by adling the numerators together, and retaining the common denominator. Thus,

$$
\frac{a}{b}+\frac{c}{b}=\frac{a+c}{b}
$$

If the fractions have not a common denominator, they must be transformed to others of the same value, which have a common denominator, and then the addi. tion may take place as before.

Ex. $2 \cdot \frac{a}{b}+\frac{c}{d}=\frac{a d}{b d}+\frac{b c}{b d}=\frac{a d+b c}{b d}$.

Ex. 3. $\frac{1}{a+b}+\frac{1}{a-b}=\frac{a-b}{a^{2}-b^{2}}+\frac{a+b}{a^{2}-b^{2}}$ $=\frac{a-b \pm a+b}{a^{2}-b^{2}}=\frac{2 a}{a^{2}-b^{2}}$.

Ex. 4. $a+\frac{e}{f}=\frac{a f}{f}+\frac{e}{f}=\frac{a f+e}{f}$. Here $a$ is considered as a fraction whose denominator is unity.

If two fractions lave a common densominator, their difference is found by taking the difference of the numerutors, and retaining the common denominator. Thus,

$$
\frac{a}{b}-\frac{c}{b}=\frac{a-c}{b} .
$$

If they have not a common denomina. tor, they must be transformed to others of the same value which have a common denominator, and then the subtraction may take place as abore.
Ex. $2 \cdot \frac{a}{b}-\frac{c}{d}=\frac{a d}{b d} \frac{b c}{b d}=\frac{a d-b c}{b d}$.

Ex. 3. $a-\frac{c d}{b}=\frac{a b}{b}-\frac{c d}{b}=\frac{a b-c d}{b}$.

Ex. 4. $\frac{a}{b}-\frac{c+d}{c-d}=\frac{a c-a d}{b c-b d}-\frac{b c+b d}{b c-b d}$ $=\frac{a c-a d-b c-b d}{b c-b d}$.

The sign of $b d$ is negative, because every part of the latter fraction is to be taken from the former.

\section{ON THE MULTIPLICATION AND DIVIgION} OF FHACTIONS.

To multiply a fraction by any quantity; multiply the numerator by that quantity, and retain the denominator.

Thus, $\frac{a}{b} \times c=\frac{a c}{b}$. For if the quantity to be divided be $c$ times as great as be. fore, and the divisor the same, the quo. tient must be $c$ times as great.

The product of two fractions is fouml by multiplying the numerators together for a nezo vamerator, and the denominators for a new denominator.

Let $\frac{a}{b}$ and $\frac{c}{d}$ be the two fractions; then $\frac{a}{b} \times \frac{c}{d}=\frac{a c}{b d}$. For if $\frac{a}{b}=x$ and $\frac{c}{d}=y, b y$ multiplying the equal quantities $\frac{a}{b}$ and $x$, by $b, a=b x$; in the same manner, $c-r l y$ : therefore $a c=b d x y$; dividing these equal quantities, $a c$ and $b d x y, b y b d$, we have $\frac{a c}{b d}=x y=\frac{a}{b} \times \frac{c}{d}$.

To dizide a fraction by any quantity, multiply the denominator by that quantity, and retain the nunierntor.

The fraction $\frac{a}{b}$ divided by $c$, is $\frac{a}{b c}$. Bccause $\frac{a}{b}=\frac{a c}{b c}$, and a $c^{\text {th }}$ part of this is $\frac{a}{b c}$ : the quantity to be divided, being a $c^{\text {th }}$ part of what it was before, and the divisor the same.

The result is the same, whethertiedenominator is multiplied by the quantity, or the numerator divided by it.

Let the fraction be $\frac{a c}{b 2}$; if the dencmi- 


\section{ALGEBRA.}

nator be multiplied by $c$, it becomes $\frac{a c}{b d c}$ or $\frac{a}{b d}$; the quantity which arises from the division of the numerator by $c$.

To divide one fraction by another, invert the numerator and denominator of the divisor, and proceed as in multiplication.

Let $\frac{a}{b}$ and $\frac{c}{d}$ be the two fractions, then $\frac{a}{b} \div \frac{c}{d}=\frac{a}{b} \times \frac{d}{c}=\frac{a d}{b c}$.

For if $\frac{a}{b}=x$, and $\frac{c}{d}=y$, then $a=b x$, and $c=d y$; also, $a d=b d x$, and $b c=$ $b d y$; therefore $\frac{a d}{b c}=\frac{b d x}{b d y}=\frac{x}{y} \quad \frac{a}{b} \div \frac{c}{d}$.

The rule for multiplying the powers of the same quantity will hold, when one or both of the indices are negative.

Thus, $a^{m} \times a^{-n}=a^{m-n}$; for $a^{m} \times a^{-n}$ $=a^{m} \times \frac{1}{a^{n}}=\frac{a^{m}}{a^{n}}=a^{m-n}$; in the same manner, $x^{3} \times x^{-5}=\frac{x^{3}}{x^{5}}=\frac{1}{x^{2}}=x-2$.

Again, $a^{-m} \times a^{-n}=a^{-\overline{m^{+n}}}$; because $a^{-n} \times a^{-n}=\frac{1}{a^{m}} \times \frac{1}{a^{n}}=\frac{1}{a^{m+n}}=\overline{a^{-m+n}}$

If $m=n, c m \times a-m=a m-m=u^{\circ}$; also, $a^{m} \times a^{-m}=\frac{a^{m}}{a^{m}}=1$; therefore $a^{0}=1$; according to the notation adopted.

The rule for dividing any power of a quantity by any other power of the same quantity holds, whether those powers are positive or negative.

Thus, $a^{m} \div a^{-n}=a^{m} \div \frac{1}{a^{n}}=a^{m} \times a^{n}$ $=u^{m+n}$.

Again, $a-m \div a^{-n}=\frac{1}{n m} \div \frac{1}{a^{n}}=\frac{a^{n}}{a^{m}}=$ $a^{m+n}$.

Hence it appears, that a quantity may be transferred from the numerator of a fraction to the denominator, and the contrary, by changing the sign of its index. Thus, $\frac{a^{m} \times a^{m}}{b p}=\frac{a^{m}}{b p a^{-n}} ;$ and $\frac{a^{m}}{a^{n} b p}=\frac{a^{m} \times a^{-n}}{b p}$

\section{ON IXYOLUTION AXD ETOLCTIOX.}

Ixroutros. If a quantity be continually multiplied by itself, it is said to be involved or raised; and the power to which it is raised is expressed by the number of times the quantity has been employed in the multiplication.
Thus, $a \times a$, or $a^{2}$, is called the second power of $a ; a \times a \times a$, or $a 3$, the third pow. er, $a \times u \ldots(n)$, or $a^{n}$, the $n^{\text {th }}$ power.

If the quantity to be involved be negative, the signs of the even powers will be positive, and the signs of the odd power negative.

For $-a \times-a=a^{2} ;-a \times-a \times$ $-a=-a^{3}, 8 \mathrm{c}$.

A simple quantity is raised to any power, by multiplying the index of every factor in the quantity by the exponent of the power, and prefixing the proper sign determined by the last article.

Thus, am raised to the $n^{\text {th }}$ power is $a m n$, Because $u^{m} \times a^{m} \times a^{m}$....to $n$ factors, by the rule of multiplication, is $\iota^{m n}$; also, $a b n=a b \times a b \times a b \times \& c$. to $n$ factors, or $a \times a+a \ldots .$. to $n$ factors $\times b \times b \times b$....to $n$ factors $=v_{i} n \times b^{n}$; and $a^{2} b^{3} c$ raised to the fifth power is $a^{\text {ro }} b^{15} c^{5}$. Also, - am raised to the $n^{\text {th }}$ power is $\pm a^{m} n$; where the positive or negative sign is to be prefixed; according as $n$ is an even or odd number.

If the quantity to be involved be a frac. tion, both the numerator and denomina. tor must be raised to the proposed power.

If the quantity proposed be a compound one, the involution may either be represented by the proper index, or it may actually take place.

Let $a+b$ be the quantity to be raised to any power.

$$
\begin{aligned}
& \begin{array}{c}
a+b \\
\frac{a+b}{a^{2}+a b} \\
\frac{+a b+b 2}{a^{2}+2 a} \overline{b+b^{2}} \text { or the sq. or } 2^{d} \text { power }
\end{array} \\
& a+b \\
& \overline{a^{3}+2 a^{2}} \overline{b+a b^{2}} \\
& \overline{a+b} \text {; or } \frac{+a^{2} b+2 a b^{2}+b^{3}}{a^{3}+3 a^{2} b+3 a b^{2}+b^{3}} \text { the } 3^{d} \mathrm{pr} \text {. } \\
& a+b \\
& \overline{a 4+3 a^{3} b+3 a^{2}} \overline{b^{2}+} " \overline{b^{3}} \\
& +a^{3} b+3 a^{2} b^{2}+3 a^{3} b^{3}+b_{4}
\end{aligned}
$$

the fourth power.

If $b$ be negative, or the quantity to be involved be $a-b$, wherever an odd power of $b$ enters, the sign of the term must be negative.

Hence, $a-b^{4}=a^{4}-4 a^{3} b+6 a^{2} b^{2}$ $-4 a b_{3}+64$.

Eroutrox, or the extraction of roots, is the method of determining a quantity, which, raised to a proposed power, will produce a given quantity. 
Since the $n^{\text {th }}$ power of $a^{m}$ is $a^{m} n$, the $n^{\text {th }}$ root of $a^{m n}$ must be $a^{m} ; i$. e. to ex. tract any root of a single quantity, we must divide the index of that quantity by the index of the root required.

When the index of the quantity is not exactly divisible by the number which $\mathrm{ex}$. presses the root to be extracted, that root must be represented according to the notation already pointed out.

Thus the square, cube, fourth, $n^{\mathrm{eb}}$ root of $a^{2}+x^{3}$, are respectively represented by $\left(a^{3}+x^{3}\right) \frac{1}{2},\left(a^{2}+x^{3}\right) \frac{3}{3},\left(a^{2}+x^{2}\right) \frac{1}{4}$, $\left(a^{2}+x^{3}\right) n$; the same roots of $\frac{1}{a^{3}+x^{3^{2}}}$ or $\left(a^{3}+x^{2}\right)^{-1}$, arerepresentedby $\left(a^{3}+x^{3}\right)-\frac{1}{2}$ $\left(a^{2}+x^{3}\right)^{-\frac{1}{3}},\left(a^{2}+x^{3}\right)^{-\frac{1}{4}},\left(a^{2}+x^{2}\right)^{-\frac{1}{n}}$.

If the root to be extracted be express. ed by an odd number, the sign of the root will be the same with the sign of the pro. posed quantity.

If the root to be extracted be expressed by an even number, and the quantity pro. posed be positive, the root may be either positive or negative. Because either a positive or negative quantity, raised to such a power, is positive.

If the root proposed to be extracted be expressed by an even number, and the sign of the proposed quantity be negative, the root cannot be extracted; because no quantity, raised to an even power, can produce a negative result. Such roots are called impossible.

Any root of a product may be found by wking that root of each factor, and mul. iplying the roots, so taken, together.

Thus, $(a b)^{\frac{1}{n}}=a^{\frac{1}{n}} \times b^{\frac{1}{n}}$; because each of these quantities, raised to the $n^{\text {th }}$ power, is $a b$.

In $a=b$, then $a^{\frac{1}{n}} \times a^{\frac{1}{n}}=a_{n}^{\frac{2}{n}}$; and in the

$$
\frac{r}{n} \frac{n+s}{n}
$$

same manner $a \times a=a$.

Any root of a fraction may be found by taking that root both of the numerator and denominator. Thus, the cube root of $\frac{a^{2}}{b^{2}}$ is

$$
\frac{a^{\frac{2}{3}}}{b \frac{2}{3}} \text { or } a \frac{2}{3} \times b-\frac{2}{3} ; \text { and }\left(\frac{a}{b}\right)^{\frac{1}{n}}=\frac{a \frac{1}{n}}{b \frac{1}{n}} \text { or } a^{\frac{1}{n}}
$$$$
x b-\frac{1}{n}
$$

To extract the square root of a compound guantity.

$$
\begin{gathered}
\frac{a^{2}+2 a b+b^{2}(a+b}{2 a+b) 2 a b+b^{2}} \\
\frac{2 a b+b^{2}}{2}
\end{gathered}
$$

Since the square root of $a^{2}+2 a b+b^{3}$ is $a+b$, whatever be the values of $a$ and $b$, we may obtain a general rule for the extraction of the square root, by observ. ing in what manner $a$ and $b$ may be derived from $a^{3}+2 a b+b^{3}$.

Having arranged the terms according: to the dimensions of one letter, $a$, the square root of the first term $a^{2}$ is $a$, the first factor in the root; subtract its square from the whole quantity, and bring down the remainder $2 a b+b^{2} ;$ divide $2 a b$ by $2 a$, and the result is $b$, the other factor in the root; then multiply the sum of twice the first factor and the second $(2 a+b)$, by the second $(b ;$, and subtract this pro. duct $\left(2 a b+b^{3}\right)$ from the remainder. If there be no more terms, consider $a+b$ as a new value of $a$; and the square, that is $a^{2}+2 a b+b^{2}$, having, by the first part of the process, been subtracted from the proposed quantity, divide the remainder by the double of this new value of $a$, for a new factor in the root; and for a new subtrahend, multiply this fictor by twice the sum of the former factors increased by this factor. The process must be re. peated till the root, or the neoessary approximation to the root, is obtained.

Ex. 1. To extract the square root of $a^{2}+2 a b+b^{3}+2 a c+2 b c+c^{3}$.

$a^{2}+2 a b+b^{2}+2 a c+2 b c+c^{2}(a+b+c$ $a^{3}$

$$
\begin{array}{r}
2 a+b) 2 a b+b^{3} \\
2 a b+b^{2} \\
2 a+2 b+c)^{2} \\
2 a c+2 b c+c^{2} \\
2 a c+2 b c+c^{2} \\
\end{array}
$$

Ex. 2. To extract the square root of $a \&$ $a x+\frac{x^{2}}{4}$

$$
a^{2}-a x+\frac{x^{2}}{4}\left(a-\frac{x}{2}\right.
$$

$a^{2}$

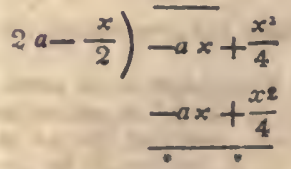

Ex. 3. To Extract the square root of 1 $+x$. 


\section{ALGEBRA.}

$$
\begin{gathered}
\frac{1+x\left(1+\frac{x}{2}-\frac{x^{2}}{8} \& c .\right.}{\left.\frac{1}{2}+\frac{x}{2}\right)} \\
\left.2+x-\frac{x^{2}}{8}\right) \frac{-\frac{x^{2}}{4}}{-\frac{x^{2}}{4}-\frac{x^{3}}{8}+\frac{x^{4}}{64}} \\
\hline
\end{gathered}
$$

It appears from the second example, that a trinomial $a^{2}-a x+\frac{x^{2}}{4}$, in which four times the product of the first and last terms is equal to. the square of the middle term, and a complete square, or $a^{2} \times \frac{x^{2}}{4} \times 4=a^{2} x^{2}$.

The method of extracting the cube root is discovered in the same manner.

$$
\begin{aligned}
& a^{3}+3 a^{2} b+3 a b^{2}+b^{3}(a+b \\
& \left.3 a^{2}\right) \frac{a^{3}}{3 a^{2}} b+3 a b^{2}+b 3 \\
& \frac{3 a^{2} b+3 a^{2} b^{2}+b^{3}}{}
\end{aligned}
$$

The cube root of $a^{3}+3 a^{2} b+3 a^{2} b^{2}+b^{3}$ is $a+b ;$ and to obtain $a+b$ from this compound quantity, arrange the terms as before, and the cube root of the first term, $a 3$, is $a$, the first factor in the root; subtract its cube from the whole quantity, and divide the first term of the remainder by 3 $a^{2}$, the result is $b$, the second factor in the root; then subtract $3 a^{2} b+3 a^{2} b^{2}+b_{3}$ from the remainder, and the whole cube of $a+b$ bas been subtracted. If any quantity be left, proceed with $a+b$ as a new $a$, and divide the last remainder by $3 . \overline{a+b})^{2}$ for a third factor in the root; and thus any number of factors may be obtained.

\section{ON SIMPIE ERUATIONS.}

If one quantity be equal to another, or to nothing, avd this equality be expressed algebraically, it constitutes an equation. Thus, $x-a=b-x$ is an equation, of which $x-a$ forms one side, and $b-x$ the other.

When an equation is cleared of fractions and surds, if it contain the first power only of an unknown quantity, it is call- ed a simple equation, or an equation of one dimension : if the square of the unknown quantity be in any term, it is called a quadratic, or an equation of two dimensions; and in general, if the index of the highest power of the unknown quantity be $n$, it is called an equation of $\mathrm{n}$ dimensions.

In any equation quantities may be transposed from one side to the other, if their signs be changed, and the two sidles will still be equal.

Let $x+10=15$, then by subtracting 10 from each side, $x+10-10=15-10$ or $x=15-10$.

Let $x-4=6$, by adding 4 to each side, $x-4+4=6+4$, or $x=6+4$.

If $x-a+b=y$; adding $a-b$ to each side, $x-a+b+a-b=y+a-b$; or $x=y+a-b$.

Hence, if the signs of all the terms on each side be changed, the two sides will still be equal.

Let $x-a=b-2 x$; by transposition, $-b+2 x=-x+a$; or $a-x=2 x-b$.

If every term, on each side, be inultiplied by the same quantity, the results will be equal.

An equation may be cleared of fractions, by multiplying every term, successively, by the denominators of those fractions, excepting those terms in which the denominators are found.

Let $3 x+\frac{5 x}{4}=34$; multiplying by 4 , $12 x+5 x=136$, or $17 x=136$.

If each side of an equation be divided by the same quantity, the results will be equal.

Let $17 x=136 ;$ then $x=\frac{136}{17}=8$.

If each side of an equation be raised to the same power, the results will be equal.

Let $x^{\frac{1}{2}}=9$; then $x=9 \times 9=81$.

Also, if the same root be extracted on both sides, the results will be equal.

$$
\text { Let } x=81 \text {; then } x^{\frac{1}{2}}=9 \text {. }
$$

To find the value of an unknown quantity in a simple equation.

Let the equation first be cleared of fractions, then transpose all the terms which involve the unknown quantity to one side of the equation, and the known quantities to the other; divide both sides by the coefficient, or sum of the co-efficients, of 
the unknown quantity, and the value required is obtained.

Ex. 1. To find the value of $x$ in the equation $3 x-5=23-x$.

by transp. $3 x+x=23+5$

$$
\text { or } 4 x=28
$$

by Jivision $x=\frac{28}{4}=7$.

Ex.2. Let $x+\frac{x}{2} \frac{x}{3}=4 x-17$.

Mult. by 2 , and $2 x+x-\frac{2 x}{3}=8 x-34$

Mult by 3 , and $6 x+3 x-2 x=24 x-102$ hy transp. $6 x+3 x-2 x-24 x=-102$

$$
\begin{gathered}
\text { or }-17 x=-102 \\
17 x=102 \\
x=\frac{102}{17}=6 \\
\text { Ex. } 3 \frac{1}{a}+\frac{b}{x}=c \\
1+\frac{b a}{x}=c a \\
x+b a=c a x \\
x-c a x=-b d \\
\text { or } a x-x=b a
\end{gathered}
$$

i. e. $\overline{c a-1 .} x=b a$

$$
x=\frac{b a}{c a-1} \text {. }
$$

E.x. $4.5-\frac{x+4}{11}=x-3$.

$55-x-4=11 x-33$.

$55-4+33=11 x+x$

$84=12 x$

$$
x=\frac{84}{12}=7 \text {. }
$$

Ex. $5 . x+\frac{3 x-5}{2}=12-\frac{2 x-4}{3}$.

$2 x+3 x-5=24-\frac{4 x-8}{3}$

$6 x+9 x-15=72-4 x+8$

$6 x+9 x+4 x=72+8+15$

$19 x=95$

$$
x=\frac{95}{19}=5 \text {. }
$$

If there be two independent simple equations involving two unknown quantitics, they may be reduced to one which involves only one of the unknown quantities, by any of the following methorls:

1st Method. In eitlier equation find the value of one of the unknown quantities in terms of the other and known quantities, and for it substiute this value in the other equation, which will then only contain one unknown quantity, whose

VOL. 1. value may be found by the rules before laid down.

Let $\left\{\begin{array}{l}x+y=10 \\ 2 x-3 y=5\end{array}\right\}$ To find $x$ and $y$ From the first cquat. $x=10-y$; hence, $2 x=20-2 y$,

by subst. $20-2 y-3 y=5$

$$
\begin{gathered}
2 u-5=2 y+3 y \\
15=5 y \\
y=\frac{15}{5}=3
\end{gathered}
$$

hence also, $x=10-y=10-3=7$.

2d Method. Find an expression for one of the unknown quantities in each , quation; put these expressions equal to each other, and from the resulting equation the other unknown quantity may be found.

Let $\left\{\begin{array}{l}x+y=a \\ b x+c y=d e\end{array}\right\}$ To find $x$ and $y$.

From the first equat. $x=a-y$

from the second, $b x=d e-c y$, and $x$ $=\frac{d e-c y}{b}$

$$
\begin{aligned}
& \text { therefore } a-y=\frac{d e-c y}{b} \\
& b a-b y=d e-c y \\
& c y-b y=d e-b a \\
& a-b \cdot y=d e-b a \\
& y=\frac{d e-b n}{a-b} .
\end{aligned}
$$

Also, $x=a-y$; that is,

$x=a-\frac{d e-b a}{c-b}=\frac{c a-b a-d e+b a}{c-b}$

$=\frac{c a-d e}{c-b}$.

3d Mcthod If either of the unknown quantities have the same co-efficient in both equations, it may be cxterminated by subtracting, or adding, the equations, accorling as the sign of the unknown quantity, in the two cases, is the same or different.

I.et $\left\{\begin{array}{l}x+y=15 \\ x-y=7\end{array}\right\}$ To find $x$ and $y$.

By subtraction, $2 y=3$, and $y=4$.

By addition, $2 x=22$, and $x=11$.

If the co-cfficients of the unknown quantity to be exterminated be different, multiply the terms of the first equation by the co-efficient of the unknown quantity in the second, and the terms of the second equation by the co-cficient of the same unknown quantity in the first; then add, or subtract, the resulting equations, as in the former case. 


\section{ALGEBRA.}

Ex. 1. Let $\left\{\begin{array}{l}3 x-5 y=13 \\ 2 x+7 y=81\end{array}\right\}$ To find $x$

Multiply the terms of the first equation by 2 , and the terms of the other by 3 , then $6 x-10 y=26$

$$
6 x+21 y=243
$$

By subtraction, $-31 y=-217$

$$
\text { and } y=\frac{217}{31}=7 \text {; }
$$

also, $3 x-5 y=13$, or $3 x-35=13$, therefore $3 x=13+35=48$

$$
\text { and } x=\frac{48}{3}=16
$$

Ex. 2. Let $\left\{\begin{array}{l}a x+b y=c \\ m x-n y=d\end{array}\right\}$ To find $x$

From the first, $n a x+m b y=m c$

froin the other, $m a x-n a y=a d$

by subtraction, $m b y+n a y=m c-a d$,

$$
\begin{array}{r}
\text { therefore, } y=\frac{m c-a d}{m b+\frac{a}{n a}} \\
\text { Again, } n a x+n b y=n c \\
m b x-n b y=b \quad l
\end{array}
$$

by addition, $\overline{n a+m b} \cdot x=n c+b d$,

therefore $x=\frac{n c+b d}{n a+m b}$.

If there be three independent simple equations, and three unknown quantities, reduce two of the equations to one, containing only two of the unknown quantities, by the preceding rules; then reduce the third equation and either of the former to one, containing the same two unknown quantities; and from the two equations thus obtained, the unknown quantities which they involve may be found. The third quantity may be found by substituting their values in any of the proposed equations.

Ex. Let. $\left\{\begin{array}{l}2 x+3 y+4 z=16 \\ 3 x+2 y-5 z=8 \\ 5 x-6 y+3 z=6\end{array}\right\} \begin{gathered}\text { To find } x \text {, } z \text {. } \\ z \text {. }\end{gathered}$

From the 21st equa. $6 x+n y+12 z=48$

$$
6 x+4 y-10 z=16
$$

by subtr. $5 y-22 z=32$

from the $1^{\text {st }}$ and $3^{\text {rd }} 10 x+15 y+20 z=80$

$$
10 x-12 y+6 z=12
$$

by subtr. $27 y+14 z=68$ and $5 y+22 z=32$

hence $135 y+70 z=340$

and $135 y+594 z=864$

by subtr. $524 z=524$

$$
z=1
$$

$$
5 y+22 z=32
$$

that is, $5 y+22=32$

$$
\begin{aligned}
& 5 y=32-22=10 \\
& y=\frac{10}{5}=2
\end{aligned}
$$

$$
\text { that is, } \begin{aligned}
& 2 x+3 y+4 z=16 \\
& 2 x+6+4=16 \\
& 2 x=16-6-4=6 \\
& x=3
\end{aligned}
$$

The same method may be applied to any number of simple equations.

That the unknown quantities may have definite values, there must be as many independent equations as unknown quantities.

Thus, if $x+y=a, x=a-y$; and assuming $y$ at pleasure, we obtain a value of $x$, such that $x+y=a$.

These equations must also be independent, that is, not deducible one from another.

Let $x+y=a$, and $2 x+2 y=2 a$; this latter equation being deducible from the former, it involves no different sup. position, nor requires any thing more for its truth, than that $x+y=a$ should be a just equation.

\section{PROBLENS WHICH PRODCCE SIMPLE ERUATIOXS .}

From certain quantities which are known, to investigate others which have a given relation to them, is the business of Algebra.

Wlien a question is proposed to be re. solved, we must first consider fully its meaning and conditions. Then substituting for such unknown quantities as appear most convenient, we must proceed as if they were already determined, and we wished to try whetherthey would an. swer all the proposed conditions or not, till as many independent equations arise as we hase assumed unknown quantities, which will always be the case, if the ques. tion be properly limited; and by the so. lution of these equations, the quantities sought will be determined.

Prob. 1. To divide a line of 15 inches into two such parts, that one may be threefourths of the other.

Let $4 x=$ one part,

then $3 x=$ the other.

$$
\begin{aligned}
7 x & =15, \text { by the question, } \\
x & =\frac{15}{7} \\
4 x & =\frac{60}{7}=8 \frac{4}{7}, \text { one part, } \\
3 x & =\frac{45}{7}=6 \frac{3}{7} \text {, the other, }
\end{aligned}
$$

I'rob. 2. If $A$ can perform a piece of work in 8 days, and $B$ in 10 days, in what time will they finish it together? 


\section{ALGEIRA.}

Let $x$ be the time required.

In one day, $A$ performs $\frac{1}{8}$ part of the work; therefore, in $x$ days, he performs $\frac{x}{8}$ parts of it; and in the sane time, $B$ performs $\frac{x}{10}$ parts of it; and calling the work 1 ,

$$
\begin{aligned}
& \frac{x}{8}+\frac{x}{10}=1 . \\
& 10 x+8 x=80 \\
& 18 x=80 \\
& x=\frac{80}{18}=4 \frac{8}{18}=4 \frac{4}{9} \text { days. }
\end{aligned}
$$

Prob. 3. $A$ and $B$ play at bowls, and $A$ bets $B$ three shillings to two upon every grame; after a certain number of games, it appears that $q$ has won three shillings; but had lie ventured to bet five shillings to two, and lost one game more out of the same number, he would have lost thirty shillings: low many games did they play?

$$
\text { Let } x\left\{\begin{array}{l}
\text { be the number of games } \\
A \text { won, }
\end{array}\right.
$$$$
y \text { the number } B \text { won, }
$$

then $2 x$ is what .2 won of $B$,

$$
\text { and } 3 y \text { what } B \text { won of } A \text {. }
$$

tion: $2 x-3 y=3$, by the ques. $\overline{x-1.2}, 5.9$ would win on $\underline{x-1.2}\left\{\right.$ the $2^{\mathrm{d}}$ supposition $y+1.5, k$ would win, $5 y+5-2 x+2=30$, by the question;

or $5 y-2 x=30-5-2=23$,

therefore, $5 y-2 x=23$

and $2 x-3 y=3$

by addition, $5 y-3 y=26$

$$
\begin{aligned}
& 2 y=26 \\
& y=13 \\
& 2 x=3+3 y=3+39=42 \\
& x=21 \\
& x+y=34, \text { the number of }
\end{aligned}
$$

games.

\section{ON RCADRATIC EQCATIONS.}

When the temns of an equation involve the square of an unknowr quantity, but the first power does not appear, the value of the square is obtained by the preced. ing rules; and by extracting the square root on both sides, the quantity itself is found.

$$
\begin{gathered}
\text { Ex, 1. I.et } 5 x^{3}-4.5=0 \text {; to find } x \text {. } \\
\text { By traus. } 5 x^{3}=45 \\
x^{3}=9
\end{gathered}
$$

ilierefore, $x=\sqrt{ } \overline{9}= \pm 3$.
The signs + and - are both prefixed to the root, because the square root of a quantity may be either positive or negative. The sign of $x$ may also be negative; but still $x$ will be cither equal to +3 or -3 ,

Ex. 2. Let $a x^{2}=b c d$; to find $x$.

$$
\begin{aligned}
x^{2} & =\frac{b c d}{a} \\
x & = \pm \sqrt{ }\left(\frac{b c d}{a}\right)
\end{aligned}
$$

If both the first and second powers of the unknown quantity be found in an equation : Arrange the terms according to the dimensions of the unknown quanti. ty, beginning with the highest, and trans. pose the known quantities to the other side; then, if the square of the unknown quantity be affected with a co-efficient, divide all the terms by this co-efficient, and if its sign be negative, change the signs. of all the terms, that the equation may be reduced to this form, $x^{2} \pm p x=$ $\pm q$. Then add to both sides the siuare of hialf the co-efficient of the first power of the unknown quantity, by which means the first side of the equation is made a complete square, and the other consists of known quantities; and by extracting the square root on both sides, a simple equation is obtained, from which the value of the unknown quantity may be found.

Ex. 1. Let $x^{2}+p x=q$; now, we know that $x^{2}+p x+\frac{p^{2}}{4}$ is the square of $x+\frac{p}{2}$, add therefore $\frac{p^{3}}{4}$ to both sides, and we have $x^{2}+p x+\frac{p^{2}}{4}=q+\frac{p^{2}}{4}$; tlien by extracting the square root on both sides,

$$
\begin{aligned}
& x+\frac{p}{2} \pm \pm \sqrt{ }\left(q+\frac{p^{2}}{4}\right) \text { and by trans. } \\
& x=-\frac{p}{2} \pm \sqrt{ }\left(q+\frac{p^{2}}{4}\right)
\end{aligned}
$$

In the same manner, if $x_{2}-p x=q, x$ is found to be $\frac{p}{2} \pm \sqrt{\left(q+\frac{p^{2}}{4}\right)}$.

Fx. 2. Let $x^{2}-12 x+35=0$; to find $x$. By transposition, $x^{2}-12 x=-35$, and adding the square of 6 to both sides of the equation, $x^{2}-12 x+36=36-35=1$; then extracting the square root on both sides, 


\section{AlGEBRA.}

$x-6= \pm 1$

$x=6 \pm 1=7$ or 5 ; either of which, substituted for $x$ in the original equation, answers the condition, that is, makes the whole equal to nothing.

Ex. 3. Let $x+\sqrt{ }(5 x+10)=8$; to find $x$.

By transposition, $\sqrt{ }(5 x+10)=8-x$ squar. both sides $5 x+10=64-16 x$ $+x^{2}$

$x^{2}-21 x=10-64=-54$ complete $x_{2}-21 x+\frac{441}{4}=\frac{441}{4}-54$ $=\frac{441-216}{4}$, or $x^{2}-21 x+\frac{441}{4}=\frac{225}{4}$ extracting the sq. root, $x-\frac{21}{2}= \pm \frac{15}{2}$ $x=\frac{21 \pm 15}{2}=3$ or 18 .

By this process two values of $x$ are found, but on trial it appears, that 18 does not answer the condition of the equation, if we suppose that $\checkmark(5 x+10)$ represents the positive square root of $5 x+$ 10. The reason is, that $5 x+10$ is the square of $-\checkmark(5 x+10)$ as well as of $+\sqrt{ }(5 x+10)$; thus by squaring both sides of the equation $\checkmark(5 x+10)$ $=8-x$, a new condition is introduced, and a new value of the unknown quantity corresponding to it, which had no place before. Here, 18 is the value which corresponds to the supposition that $x-$ $\sqrt{ }(5 x+10)=8$.

Every equation, where the unknown quantity is found in two terms, and its index in one is twice as great as in the other, may be resolved in the same manner.

Ex. 4. Let $z+4 z^{\frac{1}{2}}=21$

$$
\begin{aligned}
& z+4 z^{\frac{1}{2}}+4=21+4=25 \\
& z^{\frac{1}{2}}+2= \pm 5 \\
& z^{\frac{1}{2}}= \pm 5-2=3, \text { or }-7
\end{aligned}
$$

therefore $z=9$, or 49 .

Ex. 5. Let $y^{4}-6 y^{2}-27=0$.

$$
\begin{aligned}
& y^{4}-6 y^{2}=27 \\
& y^{4}-6 y^{2}+9=27+9=36 \\
& y^{2}-3 y= \pm 6 \\
& y^{2}-3 \pm 6=9, \text { or }-3 \\
& y= \pm 3, \text { or } \pm \sqrt{ }-3
\end{aligned}
$$

Ex. 6 Let. $y^{6}+r y^{3}+\frac{q^{3}}{27}=0$.

$$
\begin{gathered}
y^{6}+r y^{3}=-\frac{q^{3}}{27} \\
y^{6}+r y^{3}+\frac{r^{3}}{4}-\frac{r^{2}}{4}-\frac{q^{3}}{27} \\
y^{3}+\frac{r}{2}= \pm \sqrt{\left(\frac{r^{2}}{4}-\frac{q^{3}}{27}\right) .} \\
y^{3}=-\frac{r}{2} \pm \sqrt{\left(\frac{r^{3}}{4}-\frac{q^{3}}{27}\right) .} \\
y=\sqrt[3]{\left[-\frac{r^{3}}{2} \pm \sqrt{\left.\left(\frac{r^{3}}{4}-\frac{q^{3}}{27}\right)\right] .}\right.} .
\end{gathered}
$$

When there are more equations and unknown quantities than one, a single equation, involving only one of the unknown quantities, may sometimes be obtained by the rules laid down for the solution of simple equations; and one of the unknown quantities being discovered, the others may be obtained by substituting its value in the preceding equations.

Ex.7. Let $\left\{\begin{array}{l}x^{2}+y^{2}=65 \\ x y=28\end{array}\right\}$ To find $x$ and $y$.

From the second equation, $2 x y=56$

\& adding this to the 1st, $x^{2}+2 x y+y^{3}=121$ sub. it from the same, $x^{2}-2 x y+y^{2}=9$ by extracting the sq. roots, $x+y= \pm 11$ and $x-y= \pm 3$ therefore, $2 x= \pm 14$

$$
\begin{aligned}
x & =7, \text { or }-7 \\
\text { and } y & =4 \text {, or }-4
\end{aligned}
$$

\section{PRORLFMS PRodecivg qAUDRATIC} EQUATroxS.

Prob. 1. To divide a line of 20 inches into two such parts, that the rectangle under the whole and one part may be equal to the square of the other.

Let $x$ be the greater part, then will 20 - $x$ be the less.

and $x^{2}=(20-x) \cdot 20=400-20 x$ by the question.

$x^{2}+20 x=400$

$x^{2}+20 x+100=400+100=500$

$x+10= \pm \sqrt{ } 500$

$x=+\sqrt{ } 500-10$, or $-\sqrt{500}-10$.

Prob. 2. To find two numbers, whose sum, product, and the sum of whose squares, are equal to each other.

Let $x+y$ and $x-y$ be the numbers ; their sum is $2 x$

their product $x^{2}-y^{2}$

the sum of their sqs. $2 x^{3}=2 y^{3}$

and by the question $2 x=2 x^{2}+2 y^{2}$ or $x=x^{2}+y^{2}$ also, $2 x=x^{2}-y^{2}$

therefore, $3 x=2 x^{2}$ 


\section{ALGEBRA.}

$$
\begin{gathered}
x=\frac{3}{2} \\
2 x=x^{2}-y^{2} \\
\text { or } 3=\frac{9}{4}-y^{3} \\
y^{2}=\frac{9}{4}-3=\frac{9-12}{4}=\frac{-3}{4} \\
y= \pm \frac{\sqrt{ }-3}{2} \\
x+y=\frac{3+\sqrt{ }-3}{2} \\
x-y=\frac{3-\sqrt{ }-3}{2}
\end{gathered}
$$

Since the square of every quantity is positive, unegative quantity hras no square ront; the conclusion therefore shews that there are no sucl, numbers as the question supposes. See Bivonial Tirfonex; Eruations, nature of; SFiries, Surow, \&c. \&c.

A lemara, application of to geomerry.The first and principal applications of algebra were to arithmetical questions and computations, as being the first and most useful science in all the concerns of hu. man life. Afterwards algebra was applied to geometry, and all the other sciences in their turn. The application of algebra to geometry is of two kinds; that which regards the plane or common geometry, and that which respects the higher geometry, or the nature of curve lines.

The first of these, or the application of algebra to cominon geometry, is concerned in the algebraical solution of geome. trical problems, and finding out theorems in geometrical figures, by means of algebraical inrestigations or demonstrations. 'Tinis kind of application has been made from the time of the most early writers on algebra, as Diophantus, Cardan, \&c. \&c. down to the present times. Sorne of the best precepts and excreises of this kind of applieation are to be met with in Sir I. Newton's "Universal A rithmetic," and in 'Thomas Simpson's "Algebra and Select Exercises." Geometrical problems are commonly resolved more directly and easily by algebra, than by the geometrical analysis, especially by young beginners; but then the synthesis, or construction and demonstration, is most elegant as dcduced from the latter method. Now it commonly happens, that the algebraical solution succeeds best in such problems as respect the sides and other lines in geometrical figures; and, on the cont rury, those problems in which angles are concerned are best effected by the geometrical analysis. Sir Isaac Newton gives these, among muny other remarks on this brancl. Ilaving any problem proposed, compare together the quantities concerned in it; and making no difference between the known and unknown quantitics, consider low they depend, or are related to, one another; that we may perceive what quantities, if they are assumed, will, by proceeding synthetically, gire the rest, and that in the simplest manner. And in this comparison, the geometrical figure is to be feigned and constructed at random, as if all the parts were actually known or given, and auy other lines drawn, that may appear to conduce to the easier and simpler solution of the problem. Ilaving considered the method of computation, and drawn out the scheme, names are then to be given to the quantities enter. ing into the computation, that is, to some few of them, both known and unknown, from which the rest may most naturallyand simply be derived or expressed, by means of the geometrical properties of figures, till an equation be obtained, by which the value of the unknown quantity may be derived by the ordinary methods of reduction of equations, when only one unknown quantity is in the notation : or till as many equations are obtained as there are unk nown letters in the notation.

For example: suppose it were required to inscribe a square in a given triangle. Let ABC, (Plate Miscellanies. fig. 1.) be the given triangle : and feign DEFC to be the required square : also draw the perpendicular BP of the triangle, which will be givell, as well as all the sicles of it. Then, considering that the triangles BAC, $B E F$ are similar, it will be proper to make the notation as follow's, viz. making the base $\mathbf{A C}=b$, the perpendicular $\mathbf{B P}=p$, and the sicle of the square $\mathrm{DE}$ or $\mathrm{EF}=x$, Hence then $B Q=B I^{2}-E D=p-x$; consequently, by the proportionalityof the parts of those two similar triangles, viz. $\mathrm{HP}^{2}: \mathbf{A C}:: \mathbf{B Q}: \mathbf{E F}$, it is $p: b:: \beta-x: x$; then, multiply extremes and means, \&c. there arises $p x=b p-b x$, or $b x+p x$ $=b p$, and $x=\frac{b p}{b+p}$, the side of the square sought; that is, a fourth proportional to the base and perpendicular, aud the sum of the two, taking this sum for the first term, or $\mathbf{A C}+\mathbf{B} 1^{3}: \mathbf{B} \mathbf{1}^{3}: \mathbf{A C}: \mathbf{E F}$.

The other branch of the application of algebra to geometry was introduced by Descartes, in his Geometry, which is the new, or higher, geometry, and respects the nature and properties of curve lines. In this branch, the nature of the curve is expressed or denoted by an algebraic equation, which is thus derived: $\mathbf{A}$ line is 


\section{ALG}

conceired to be drawn, as the diameter or some other principal line about the curve; and upon any indefinite points of this line other lines are erected perpendicularly, which are called ordinates, whilst the parts of the first line cut off by them are called abscisses. Then, calling any absciss $x$, and its corresponding ordinate $y$, by measis of the known nature, or relations, of the other lines in the curve, an equation is derived, involving $x$ and $y$, with other given quantities in it. Hence, as $x$ and $y$ are common to every point in the primary line, that equation,so derived will belong to every position or value of the absciss and ordinate, and so is properly considered as expressing the nature of the curve in all points of it; and is commonly called the equation of the curve.

In this way it is found, that any curve line has a peculiar form of equation belonging to it, and which is different from that of every other curve, either as to the number of the terms, the powers of the unknown letters $x$ and $y$, or the signs or co-efficients of the terms of the equation. Thus, if the curve line HK, (fig. 2.) be a circle, of which HI is part of the diameter, and IK a perpendicular ordinate; then put $\mathrm{HI}=x, \mathrm{IK}=y$, and $p=$ the diamcter of the circle, the equation of the circle will be $p x-x^{2}=y^{2}$. But if HK be an ellipse, an hyperbola, or parabola, the equation of the curve will be different, and for all the four curves will be respectively as follows: viz.

For the circle . . p $x-x^{2}=y^{2}$, For the ellipse. . $p x-\frac{p}{t} \times 2=y^{2}$,

For the hyperbola $p x+\frac{p}{t} x^{2}=y^{2}$,

For the parabola $. p x \quad \cdots=y^{2}$;

where $t$ is the transverse axis, and $p$ its parameter. And in like manner for other curves.

This way of expressing the nature of curve lines, by algebraic equations, has given occasion to the greatest improvement and extension of the geometry of curve lines; for thus all the properties of algebraic equations, and their roots, are transferred and added to the curve lines, whose abscisses and ordinates have similar properties. Indeed the benefit of this sort of application is mutual and reciprocal, the known properties of equations being transferred to the curves they represent; and, on the contrary, the
ALG

known properties of curves transferred to their representative equations.

Besides the use and application of the higher geometry, namely of curve lines, to detecting the nature and roots of equa. tions, and to the finding the values of those roots by the geometrical construction of curve lines, even common greometry made be made subservient to the purposes of algebra. Thus, to take a very plain and simple instance, if it were required to square the binomial $a+b$ (fig. 3.) by forming a square, as in the figure, whose side is equal to $a+b$, or the two lines or parts added together denoted by the letters $a$ and $b:$ and then drawing two lines parallel to the sides, from the points where the two parts join, it will be immediately evident that the whole square of the compound quantity $a+b^{2}$ is equal to the squares of botl the parts, together with two rectangles under the two parts, or $a^{2}$ and $b^{2}$ and $2 a b$, that is, the square of $a+b$ is equal to $a^{2}+b^{2}+2 a b$, as derived from a geo. metrical figure or construction. And in this very manner it was, that the Arabians, and the early European writers on algebra, derived and demonstrated the common rule for. resolving compound quadratic equations. And thus also, in a similar way, it was, that Tartalea and Cardan derived and demonstrated all the rules for the resolution of cubic equa. tions, using cubes and parallelopipedons instead of squares and rectangles. Many other instances might be given of the use and application of geometry in algebra.

ALGOL, the name of a fixed star of the third magnitude in the constellation Perseus, otherwise called .Medhsa's Head. This star has been subject to singular rariations, appearing at different times of different magnitudes, from the fourth to the second, which is its usual appearance. These rariations have been noticed with great accuracy, and the period of their return is determined to be $2^{d} 20^{k}$ $48^{\prime} 56^{\prime \prime}$. The cause of this variation, Mr. Goodricke, who has attended closely to the subject, conjectures, may be either owing to the interposition of a large body revolving round Algol, or to some motion of its own, in consequence of which, part of its body, covered with spots or some such like matter, is periodically turned towards the earth.

ALGORITHM, an Arabic term, not unfrequently used to denote the practical rules of algebra, and sometimes for the practice of common arithmetic; in which last sense it coincides with logistica nume- 


\section{ALI}

ralis, of the art of numbering truly and readily.

ALikN, in law, a person born in a strange country, not within the king's allegiance, in contradistinction from a denizen or natural subject.

In alien is incapable of inheriting lands in England, till naturalized by an act of parliament. No alien is entitled to vote in the clioice of members of parliament, has a right to enjoy offices, or can be returned on any jury, unless where an alien is party in a cause; and then the inquest of jurors shall be one half denizens and the other aliens.

Every alien neglecting the king's proclamation, directing him to depart from the realm within a limited time, shall, on conviction, for the first offence, be imprisoned for any time not exceeding one month, and not exceeding twelve months for the sccond; at the expiration of which, he shall depart within a time to be limited : and if such alien be found thercin aftersuch time so limited, he or she shall be tramsported for life.

AIIMENTARY duct, a name which some call the intestines, on account of the fool's passing through them. See Avaтоn

ALIMONT, alimonia, in law, denotes the maintenance sued for by a wife, in ease of a separation from her husband, whercin she is neither chargeable with elopement nor adultery.

ALIQUANT parts, in arithmetic, those which will not diride or measure the whole number exactly. Thus, 7 is an aliquant part of 16 , for twice 7 wants 2 of 16 , and three times 7 excecds 16 by 5 .

ALIQUOT pare, is such part of a number as will divide and measure it exactly, without any rcmainder. For instance, 2 is an aliquot part of 4,3 of 9 , and 4 of 16 .

To find all the aliquot parts of a num. ber, divide it by its least divisor, and the quotient by its least divisor, until you get a quotient not farther divisible, and you will have all the prime divisors or aliquot parts of that number. T'hus, 60 , dirided by 2 , gives the quotient 30 , which divided by 2 gires 15 , and 15 divided by 3 gives the indivisible quotient 5 . Hence, the prime aliquot parts are $1,2,2,3,5$; and by multiplying any two or three of these together, you will find the compound aliquot parts, viz. $4,6,10,12,15$, 20,30 .

Aliquot parts must nat be confoundel with commensurable ones; for though the former be all commensurable, yet these are not always aliquot parts: thus
4 is commensurable with 6 , but is not an aliqunt part of it.

ALISML, great zorter plantain, in bota. ny, a genus of the Hexandria Polvginia class of plants, the calyx of which is a perianthium composed of three oval, hollow, permanent leaves; the corolla consists of thrce large, roundish, plane, and very patent petals; the fruit consists of capsules, arranged together in a round. ish or trigonal form : the seeds are single and small. There are nine, species.

AIKAIEST, or Alcahest, among chemists, denotes a universal menstruum, capable of resolving all bodies into their ens primum, or first matter ; and that without suffering any change, or diminution of force, by so doing. See Alсnемr.

AIKALI, in chemistry, a word applied to all bodies that possess the following properties: they change vegetable bluc colours, as that of an infusion of violets, to grecn : they have an acrid and peculiar taste: they serve as intermedia between oils and water: they are capable of com. bining witl acids, and of destroying their acidity : they corrode woollen cloth, and, if the solution be sufficiently strong, reduce it to jelly; and they are soluble in water. The alkalies at present known are three; viz. ammonia, potash, and so$\mathrm{da}$ : the two last are called fixed alkalies, because they require a red heat to volatilize them; the other is denominated volatile alkali, because it readily assumes a gaseous form, and is dissipated by a very moderate degree of heat. Barytes, strontian, lime, and magnesia, have been denominated alkalies by Fourcroy ; but as they possess the striking character of earths in their fixity, this innovation does not seem entitled to general adoption.

Since writing the abore, some discoreries of great importance, on the subject of alkalies, have been made known to the philosophical world by Mr. Davy, Professor of Chemistry at the Royal Institution. We shall in this place give a sketch of the two papers which he has just laid. before the Royal Society, referring to some subsequent articles for further par. ticulars. In a former discourse, read before this learned body, Mr. Dary, in speaking of the agencics of electricity, suggested the probability, that other bodies not then enumerated might be decomposed by the electric fluid. In the course of the last summer, this celebrated philosopher was employed in making a nunber of experiments with this particular view, and by means of very powerful galranic troughs, consisting of a 
hundred pair of plates, six inches square, and onc hundred and fifty pair, four inches square, he has succeeded in decomposing potash and soda. A more brilliant discovery has not been made since those which liave immortalized the names of Priestley and Carendish. This was effected by placing moistened potash, or soda, on a plate of platina, and exposing it to the galvanic circle. Oxygen was disengaged, and the alkalies reduced to their primitive base, which is found to be a peculiar and highly inflammable matter, and which assumes the form and appearance of small globules of mercury. These globules are, however, ligliter than water, and when potash is used, they are in the proportion of 6 to 10 . At the freezing point they are hard and brittle ; and when broken and examined by a microscope, they present a number of facettes with the appearance of crystallization: at $40^{\circ}$ Fahrenheit they are soft, and can scarcely be diseriminated but by their gravity from globules of mercury; at $60^{\circ}$ they are fluid, and at the small heat of $100^{\circ}$ volatile. When exposed to the atmosphere, they rapidly imbibe oxygen, and reassume the alkaline character. In distilled naptha they may be preserved four or five days, but if exposed to the atmosphere, they almost instantly become incrusted with a coat of alkali : the incrustation may be removed, and the reduced globule will remain, either in naptha, or otherwise scparated from all contact with oxygen. See Bitumes.

One part of the base of alkali and two of mercury, estimated by bulk, form an amalgam, which when applied in the circle of a galvanic battery, producing an intense heat to iron, silver, gold, or pla. tina, immediately dissolved them, and converted them into oxides, in which process alkali was regenerated. Glass, as well as all other metallic bodies, was also dissolved by the application of this substance : the base of the alkali seizing the oxygen of the manganese and of the minium, potash was regenerated. One of these globules placed on a piece of ice dissolved it, and burnt with a bright flame, giving out an intense heat. Potash was found in the product of the dissolved ice. Nearly the same effects followed, when a globule was thrown into water: in both cases a great quantity of hydro. gen was rapidly liberated. When laid on a piece of moistened turneric paper, the globule seemed instantly to acquire an ir. tense heat; but so rapid was its movement in quest of the moisture, that no part of the paper was burnt, only an in. tense deep red stain marked the course it followed, and showed a reproduction of alkali. The specific gravity of the base of soda is as seven to ten of water : it is fixed in a temperature of about $150^{\circ}$, and fluid at $180^{\circ}$. Mr Dary next tried its effects on the pliosplates, phosphurets, and many other salts of the first and second degree of oxydizement, all of wbich it decomposed, seizing their oxygen, and reassuming its alkaline qualities. From many experiments it appears, that 100 parts of potaslı contain 15 of oxygen, and 85 of an inflammable base, and that the same quantity of soda contains 20 of oxygen, and 80 base This ingenious chemist, after a great number of complex experiments, in which he was assisted by Messrs. Pepys and Allen, ascertained that oxygen is also an essential ingredient in ammonia; of which 100 grains appeared to yield 20 of oxygen. Mr. Davy has also found that oxygen is onc of the constituent principles of the earths barytes and strontites. See Cummstri, Potasu, and SopA.

ALLAMANDA, in botany, a genus of the Pentandria Monogynia class and or. der : corolla twisted; capsule lens-form, erect, echinate, one-celled, two-valved, many-seeded. One species, viz. cathartica, a climbing plant, found in Guiana, near rivers. The infusion of its leaves is used in the cholic.

ALLANTOIS, or Ar.cantoines, in comparative anatomv, a vesicle investing the foctus of several animals, as cows, sheep, goats, \&c. and filled with a urinous liquor conveyed thither from the urachus.

ALLEGIANCE, is the lawful duty from the subject to the sovereign; and is either natural, as every subject born ought to pay ; acquired, whére a man is naturalized; local, which a man ought to pay who comes under the dominion of the king.

ALLEGORY, in matters of literature, a mode or species of writing, wherein something else is signified than the words in their literal meaning express. An allegory may be considered as a series or chain of metaphors, continued throngh a whole discourse For example, when the propliets represent the Jews under the allegory of a vine planted, cultivated, and watered, by the hand of God, which, instead of producing good fruit, brings forth verjuice and sour grapes.

ALLEGRO, in music, an Italian word, denoting that the part is to be played in a sprightly, brisk, lively, and gay manner. Allegros move swifter in triple than in 


\section{ALI}

common time. Sometimes in conjunction with anotber word, placed at the beginning of compositions, it is intended to rouse and stimulate the more violent passions.

ALLEMANDE, in music, a slow air or melody in common time, of four erotchets in a bar. A species of cornposition, sup. posed from its name to be of German origin. It is found in Handel's harpsichord lessons, and other works of about that date ; but as a sonata movement it is now obsolete. The dance known by this name is still used in Germany and Switzerland, and is written in common time of two crotchets in a bar.

ALLFN, ('Inомas,) a celebrated mathematician of the 16 th century. He was born at Uttoxeter in Staffordshire, in 1542; was admitted a scholar of Trinity College, Oxford, in 1561; where he took his degree of naster of arts in 1567. In 1570 he quitted his college and fellowship, and retired to Gloucester $\mathbf{H a l l}$, where he stıdied very closely, and became famous for his knowledge in antiquities, philosophy, and mathematics. He received an invitation from Henry, Earl of Northumberland, a great friend and patron of the mathematicians, and he spent some time at the Earl's louse, where he became acquainted witl those celebrated mathematicians, Tlıomas Ilarriot, John Dee, Walter Warner, and Nathanicl Torporley. Robert, Farl of Leicester, too, had a great estcem for Allen, and would have conferred a bishopric upon him; but his love for solitude and retirement made him decline the offer. His great skill in the mathematics, gave occasion to the ignorant and vulgar to look upon him as a inagician or conjurer. Allen was very curious and indefatigable in collecting scattered manuscripts relating to history, antiquity, astronomy, philosopliy, and mathematics ; which collections have been quoted by several learned authors, and mentioned as in the Bibliotheca Alleniana. He prublished in Latin the second and thirl books of Pto. leny, "Concerning the Judgment of the Stars," or, as it is usually called, of the quadripartite construction, with an exposition. He wrote also notes on many of Lilly's books, and some on Jolin Hale's work, "De Scriptoribus Mag. Brittauniz." He died at Gloucestcr Hall in 1632, being 90 years of age.

Mr. Hurton, the author of his funcral uration, culls him " the very soul and sin of all the inathematicians of his age." And Selden mentions him as a person of the most extensive learuing and cousummate judgment, the brightest omameat of VOL. I. the University of Oxford. Also Camden says, he was skilled in most of the best. arts and sciences. A. Wood has also transcribed part of his character from a manuscript in the lihrary of Trinity Col. lege, in these worls : "He studicel polite literature with great application; he was strictly tenacious of academic discipline, always highly esteemed both by foreigners and those of the university, and by all of the highest stations of the cliurch of England, and the University of Oxford. He was a sagacious observer, an agrecable companion," \&:c.

AlLIGATION, in arithmetic, is the rule of mixture, which teaches to compound several species of ingredients or commodities together, according to any intent or design proposed; and is either medial or alternate.

Alcugatsox, meclial, shews the rate or price of any nixtures, when the several quantities of the mixture, and their rates, are known.

Rule : multiply each quantity given by the price ; and then, by direct proportion, say, as the sum of the quantities given to the sum of the products; so is any part of the mixture to the value of that part. Example : a goldsmith melts 3 ounces of gold, at $4 l .6 s .8 d$. per ounce, with twelve ounces at $4 l$. per ounce; and 8 ounces at $4 l .58$. per ounce : when they are all melted together, one ounce will be found to be worth $4 l .2 s \cdot \frac{7}{23} d$. Thus,

$$
\begin{aligned}
& 0=1.8 . d
\end{aligned}
$$

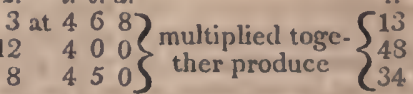

$$
\begin{aligned}
& 23 \text { Sum } \\
& \text { oz. l. oz. l. s. d. } \\
& \text { Sum } 95
\end{aligned}
$$$$
\text { Then as } 23: 95:: 1: 427 \frac{7}{3} \text { Ans. }
$$

Alugation, alternate, teaches to mix goods, of different prices, in such proportion, that the mixture may be sold for any price proposed.

Rule: set down the names of the things to be mixed, together with their prices; then, finding the difference between each of these, and the proposed price of the mixture, place these difficrences in an altemate order, and they will sliow the proportion of the ingredients.

ALLIONIA, in botany, so called in lno. noúr of Cliarles Allioni, professor of botany at Turin, a genus of the Tetrundria Monogyia class and orter, of the natural order of I gyregatx; the calyx is a perianthium common to threc flowers; and the perianthium proper is obsolete supe- 


\section{ALL}

rior; the corolla proper, one-petalled, funnel-shaped, and erect; the stamina liave setaceous filaments; antliers roundish ; the pistillum has a germ inferior, oblong, style setaceous, longer than the stamens, stigma multifid and linear, no pericarpiun; seeds solitary, the receptacle naked. There are two foreign species, describerl by Willdenow, viz. the $\mathrm{A}$. violacea, and A. incarnata. The American species described by Pursh are three in number, viz. A.nyctaginea, $\mathbf{A}$. albicla, and A. ovata.' The first is found on the banks of the river Tenessee; the second in lower Carolina; the third found by Meriwether Lewis on the plains of the Missouri.

ALLIOTII, a star in the tail of the Greater Bear, much used for finding the latitude at sea.

ALLITERATION, in rhetoric, is a figure, or decoration in language, chicfly used in poetry, and consisting in the repetition of the same letter or letters at certain intervals, whence the name is derived.

ALLIUM, garlic, in botany, a genus of the Fexandria Mohogynia class and order ; the calyx is a common sheath, and many-flowcred; the corolla consists of six oblong petals; the stanina bave six filaments, generally of the length of the corolla; the anthers are oblong and upright; tte pistillum has a germ, superior, short, bluntly three-cornered; the pericarpium is a capsule, short, broad, three-celled and three-valved; the seeds are many and round. There are 53 species, according to Willdenow, distributed into several divisions. The common garlic has a large round white bulbous root, of an irregular form, with numerous fibres at the bottom, composed of many smaller bulbs denomi. nated cloves, which are included in a common membranous covering, each of which being planted, grows, and in one season attains the size and structure of the parent bulb; the leaves are cauline, or form a kind of stalk, which seldom spindles, except when the same roots remain in the ground two or three years, when they run up and bear a flower and small bulbs at the top. It deserves to be cultivated in the garden for the sake of its root, which is in great estimation for culinary and other domestic purposes. Indeed, the roots, as well as all the other parts of the plant, have a very acricl taste, with an highly offensive smell, which has rendered its cultivation in gardens less desirable. It is a hardy plant, capable of growing in most sorts of soils and situa- tions, and readily propagated cither by roots or seeds.

Rocambole has very small compound bulbs, which grow in clusters; tlic stalk generally spindling two or three feet ligh, with many bulbs at its summit, which, as well as the root bulbs, are useful for the same purposes as garlic, though much in. ferior. 'The latter, or the flowery kinds, have the flowcr-stems rising immediately from the root, growing erect, and attaining difl'erent heights, from twelve to thirty inclies; in some the leaves arc radical, in others cauline, or elevated with the stalk; some are broad like tliose of a tulip, others long and narrow like a daffodil, and some taper and rush-like; but in all the sorts the stems are terminated by a sort of sheatl, from which is protrucled an aggregate of many small flowers, forming: a kind of umbel. The flowers singly are composed each of six petals, which, though separately small, from many being collected into large heads, are very conspicuous. Of the second division, or the onion kind, the characters, \&c. of which are the same as those of girlic, the species are these: 1 . Cepa, or common onion; the best garden rarieties of which arc, the Strasburgh or common round onion, the oval or long-keeping common onion, the Spanish large flat onion, the Spanish silken-skinncd onion, the Spanish red-skinned onion, and the Portugal great roundish oval onion. 2. Fistulosum, or the ciboule or Welsh onion. 3. Schinoprasum, cives or chives. 4. Ascalonicum, eschalot or schallot. 5. Canadense, or Canada-tree onion. All the first species and varieties liave large bulbous roots, and the plants are biennial, or, being sown in the spring, arive at perfection in the root the same year, and next ycar shoot up into stalk, flower, and ripen seed, when the stalks quickly die, and the individuals are annililated. But the second and third species never form any bulbs at bottom ; they are, how: ever, hardy and peremnial, and may be continued many years. And the fourth and fifth species are bulbous rooted perennials, multiplying greatly by off-sets, as is evident from their culture.

Ciboule or Welsh onion. This is a perennial plant, which never forms any bulb at bottom; therefore deserves to be cul. tivated only to be drawn as young green onions for salads, \&c. in spring; but, on account of its strong taste, it is greatly inferior to those of the common onion. From the plants being so extremely hardy as to survive the severest winter, in 


\section{ALL}

which, though their blades be cut off, the roots remain sound, and slyoot forth with great vigour early in spring, furnishing seasonable supplies till May, when they generally run to seed. From this singular hardiness they may be cultivated more or less as a winter standing crop, 'with advantage, for spring use.

Cives, or chives. This is the smallest of all the onion kind, rising but a few inches high; but its roots are perennial, and increase considerably into clusters, from which large tufts of slender awl. shaped leares issue, which are the principal part used, the roots never forming any bulb, at least not bigger than small peas. This is a hardy plant, which merits a place in every garden. Its clusters of leares rise early in spring, and are use. fill both in salads and for culinary purposes, in default of onions. The method of gathering it is, to cut the leaves off near the ground, by which a fresh supply is soon produced from the bottom; or oc. casionally the plants in clusters may be slipped quite to the root in separate litrle plants, resembling young onions, and used as substitutes for them. It is easily increased by dividing the roots in spring, and planting eight or ten of them together in holes, at six inches distance; in this way, by autumn, they will multiply into bunches of a large size.

Eschalot, orschallot. This is a species of onion which is bulbous-rooted, and which increases greatly by off-sets, the largest of which are the proper parts of the plant for use. The bulbs are oblong, irregular, and seldom grow large; as they gene. rally increase into clusters, they do not swell like roots that grow singly. From the roots are produced many long, narrow, infirm leaves in the spring, and which wither in July or August, when the roots are full grown : they are then taken up, made dry, and housed, when they kecp in good perfection till the following spring.

Canada or tree-onion. This deserves to be cultirated, both as a curiosity in producing the onion at the top of the stalk, and for the use of the onions, es. jecially for pickling, in which they are excellent, and superior in flavour to the coinmon onion. It is perenuial, and propagated by planting the bulbs in spring or nutunn. Either the root.lulbs, or those prociuced on the top of the stalk, being planted in a bed or beds of any good eartl, in rows a foot asunder, six inches distance in cach row, and two or three inches deep, they shoot up leares and stalks in the

\section{ALL}

spring and summer, and produce the bulbs for use in .uly or August; and the root-lulbs remaining furnish a produc. tion of top-bulbs, anumally, in that season; the root-bulb increasing by off-sets, may be taken up occasionally at the time the stem decays in autumn; or once in two or three years, in order to separate the off-sets, and replant them whenneecssary.

The leek is the third division of the genus, the general characters of which are the same as those before described, and the species and varieties are, the pormun, or common leek, which may be said to be an annual-biennial plant; for although the roots often survive after perfecting seeds, yet the plants al ways attain perfection the same year they are sown, and the year afterwards run up to stalk, and become unfit for use. The seerl-stalk of this plant does not belly like that of the onion. The best of the varieties of this plant for general culture is the binadleaved or London leek, which attains a large growth, the neck acquiring a thick substance, in length from six to nine or ten inches, dividing upwards into many large, long, thick leaves, arranging themselves in some what of a fan-shape. There are seren species indigenous in America, and described by Pursh, viz: 1. A. vineale, common in old fields. 2. $\Lambda$. fra. grans, (which is $\mathbf{A}$. inodorum of Botanical Mragazine 1129, and $\Lambda$. mutabile of Micliaux's f. Ame. 1 p. 195) found on the mountains of Virginia and Carolina. 3. A. striatum (which is A. ornithogaloides of Halt's f. Car. 121, and ornitliogalum bivalve of Lin.) natire in Virginia and Carolina. 4. $\AA$. angulosum, found on the banks of the Mlissouri by Lewis and Nut. tall. 5. A. triflorum, found on shady woods and high mountains of Penisy/vania. 6. A. canadense, found in fields and woods from Canada to Carolina, 7.'A. tricoccon, found in shadly woods, Pennsylvania to Virginia.

ALI.ODIAL, an epithet given to an inheritance held without any acknowledgment to a lord or superior, in opposition to feudal.

ALIODIUN, or Arrexp, denotes lands which are the absolute property of their owiser, willout being obliged to pay any service or acknowledginent whaterer to a superior lord; in which sense they stand opposed to feudal lands, which pay a fec to some superior.

ALLOPIILUS, in botany, a gemus of the Octandria Monogynia class of plants, the caly, of which is a perianthium composed of fourleaves of an orbicular figure, 
and two opposite ones smaller than the others; the corolla consists of four petals, less than tlie cup, of an orbicular figure, and equal one to another, with large ungues of the same length with the smaller leares of the cup. There are three species: A. zeylanicus is a tree having the appearance of persea, and a native of Ceylon. A. cominia rises 30 feet in height, with a stem as thick as a man's thigh, with numerous flowers, to which succeed berries the 'size of a pin's head, with shell and kernel : grows plentifully in Jamaica. A. ternatus is a native of Cochin China.

AlLOY, or Allar, a proportion of a baser metal mixed with a finer one. Thus, all gold coin has an alloy of silver and copper, as silver coin has of copper alone ; the proportion in the former case, for standard gold, being two carats of alloy in a pound troy of gold; and in the latter, 18 penny-weights of alloy for a pound troy of silver.

According as gold or silver has more or less alloy than that mentioned above, it is said to be coarser or finer than the standard. However, it ought to be remarked, that the coin of different nations varies greatly in this respect; some using a larger, and others a less proportion of alloy, the original intention of which was to give the coin a due degree of hardness.

Arrox, in a chemical sense, may be defined a combination of two or more metals into one homogeneous mass, not separable from each other by mere heat. The most valuable and useful of these are, brass, type-metal, tutenag, bronze, speculum metal, for which see the different articles. If two metals being fuscd together produce a mass, whose specific gravity is either greater or less than the mean specific gravity of its elements, the result is an alloy, or proper chemical combina. tion. One of the most striking proofs of actual combination between the parts of an alloy is, a remarkable increase of fusibility. This, in almost all cases, is much gTeater than could be inferred from the mean fusibility of its component parts. Thus, equal parts of tin and iron will melt at the same temperature as is required for equal parts of tin and copper, notwithstanding the great difference between the fusing heat of copper and iron, when they are each of them purc. So also an alloy of tin, bismuth, and lead, in the proportion of 3,8 , and 5 , will melt in boiling water, which is a less heat than is neces. sary for the liquefaction of bismuth, the most fusible of the three. The oxyda. bility of an alloy is generally cither great. er or less than that of the unmixed netals. Tin and lead mixed will, at a low red heat, take fire, and oxydate immediately.

ALLUSION, in rhetoric, a figure by which something is applied to, or understood of another, on account of some similitude between them.

ALLUVIAL, by alluvial depositions is meant the soil which has been formed by the destruction of mountains, and the washing down of their particles by torrents of water. The alluvial formations constitute the great mass of the earth's surface. They have been formed by the gradual action of rain or river water up. on the other formations. They may be divided into two kinds, viz. those deposited in the vallies and mountainous districts, or upon elevated plains, which often occur in mountains; and those deposited upon flat land. The first kind consists of sand, igravel, \&c. which constituted the more solid parts of the neighbouring mountains, and which remained when the less solid parts have been washed away. They sometimes contain ores, particularly gold and tin, which existed in the neighbouring mountains. The second kind consists of loam, clay, sand, turf, and calctuff. Here are also earth and brown coal, in which amber is found, wood coal, bituminous wood, and bog-iron ore. The sand contains some metals. The calctuff contains plants, roots, moss, bones, \&c. which it has incrusted. The clay and sand often contain petrified wood, and skeletons of quadrupeds.

ALLUVION, among civilians, denotes the gradual increase of land along the sea-shore, or on the banks of rivers. 'This, when slow and imperceptible, is deemed a lawful means of acquisition : but when a considerable portion of land is torn away at once by the violence of the current, and joined to a neighbouring estate, it may be claimed again by the forner owner.

ALMAGEST, the name of a celebrated book composed by Ptolemy; being a col. lection of a great number of the observations and problems of the ancients, relat. ing to geometry' and astronomy, but especially the latter; and being the first work of this kind which has come down to us, and containing a catalogue of the fixed stars, with their places, besides numerous records and observations of eclipses, the motions of the planets, \&c. it will ever be beld dear and valuable to the cultiva. tors of astronomy. See Prolemx.

In the original Greek it is called

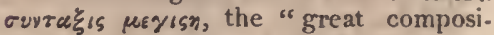
tion" or "collection." And to the word 
$\mu \varepsilon \%$ sgn the Arabians joined the particle "aj," and thence called it "Almaghesti," or, as we call it from them, the Almagest.

AI.MAMON, Calipli of Hagdat, a philosopher and astronomer in the beginning of the nimth century, he having ascended the throne in the vear 814. He was son of Ilarun Al-raschid, and grandson of Almansor. Having been educated with great carc, and with a love for the liberal sciences, lic applied himself to cultivate and encourage them in his own country. For this purpose he requested, the Greek enperors to supply him with such books of philosophy as they had among them; and he collected skilful interpreters to translate them into the $A$ rabic language. He atso encouraged his subjects to study them; frequenting the meetings of the learned, and assisting at their exercises and deliberations. He formed a college at Khorasan, and selected to preside orer it Mesul of Damascus, a famous Cliristian pliysician. When lis father, who was still living, remonstrated against the appointment, on account of the president's religion, he replied, that he had chosen him, not as a teacher of theology, but for the instruction of his subjects in science and the'uscful arts, and that his father well knew, that the most learned men and skilful artists in his dominions were Jews and Christians. Ile caused Ptolemy's Almagest to be translated in 827, by Isaac Ben-honain, and Thabet Ben-korah, ac. cording to Ilerbelot, but according to others, by Sergius, and Alhazen, the son of Joseph. In his reign, and doubtless by his encouragement, an astronomer of liagdat, named Habash, composed three sets of astronomical tables.

Almamon himself made many astrono. mical observations, and determined the obliquity of the celiptic to be then $23^{\circ}$ $35^{\prime}$, or $23^{\circ} 33^{\prime}$ in some manuscripts, but Vossius says $23^{\circ} 51^{\prime}$, or $23^{\circ} 34^{\prime}$. IIe also caused skilful observers to procure proper instruments to be made, and to cxercise themselves in astronomical observations; which they did accordingly at Shemasi in the province of Bagdat, and upon Mount Casius, near Damás.

Under the auspices of Mamon, also, a degree of the meridian was measured on the plains of Sinjar, or Sindgiar, upon the borders of the Red Sea; by which the degree was found to contain $562-3$ miles, of 4000 coudecs each, the coudee being a foot and a half: but it is not known what foot is here meant, whether the Roman, the Alexandrian, or some other. Albufeda says that this cubit con- tained 27 inclies, each incl being dieter. mined by six grains of barley placed side. ways; but Therenot says, that 144 grains of barley, placed in this manner, wonld give a length equal to $1 \frac{1}{2}$ P'aris foot: four cubits would be equal 10 one tnise and nine inches, and therefore $4.000 \mathrm{cu}$ bits, that is, $562-3$ miles, would give 63,730 toises. But if the orclinary cubit of 24 inches was the measure to which the calculation is to be referred, the degree, in this estimate of it, would contain 56,666 toises. According to another valuation of a cubit, this measure would consist of 53,123 French toises.

Almamon was a liberal and zealous encourager of science, in consequence of which the Saracens began to acquire a degree of civilization and refinement, to which they had formerly been strangers. The liberality of lis mind obtained for Almamon the reputation of ínficlelity. But, whatever opinions he might hold re. specting the Koran, he seems to have had a confidence and trust in the Supreme Being. In this work we slsall not follow the Caliph into the field of battle, nor record his victories, which were brilliant and important. We must look to him in the character of a philosopher and man of science, and, in addition to what has already been noticed, we may remark, that he built a new nilometer, for measuring the increase of the Nile, and repaired one that was gone to decay. In the year 833 , as he was returning from one of his expeditions, he unwarily quenched his thirst, while very much, heated by exercise, with cold watcr, which brought on a disorder that termi. nated his life. During his last illness, he settled the affairs of the state, and then exclaining, in the spirit of picty, "O thou who never diest, have mercy on me, a dying man." Ile expired at the age of 49 , after a reign of 20 ycars. Ile was interred at 'Tarsus. To the principles of science, and not to those of the Molianmedan religion, have been ascribed the liberality and beniguity of temper, which he displayed in certain trying circumstances. When his uncle and rival Ibra. him was taken, brought to trial, and condemned, the caliph, instead of sanctioning the sentence, tenderly cinbraced his relation, saying, "Uncle, be of good cheer, I will do rou no injury:" and he not only pardoned him, but granted him a rank and fortune suitable to his birth. l3eing compliniented on account of this generous deed, he exclaimed, "Did but men know the pleasure that I feel in par. 
doning, all who have offended me trould come and confess their faults." Almamon, in the course of his reign, employed the most skilful astronomers that he could find, to compose a body of astrono. mical science, which still subsists among oriental MSS. entitled "Astrononia elaborata à compluribus $\mathbf{D}$. D. jussu regis Maimon."

ALMANAC, in matters of literature, a table containing the calendar of days and months, the rising and setting of the sun, the age of the moon, \&sc.

Authors are ne:cher agreed about the inventor of almanacs, nor the etymology of the word; some deriving it from the Arabic particle al, and manah, to count; whilst others think it comesfrom almanah, $i$.e. handsels, or new year's gifts, because the astrologers of Arabia used, at the beginning of the year, to make presents of their ephemerides for the year ensuing.

As to the antiquity of Almanacs, Ducange informs us, that the Egyptian as. trologers, long before the Arabians, used the term almenuch, and almenaclica descripito, for their monthly predictions. Be this as it will, Regiomontanus is allowed to have becn the first wlio reduced almanacs to their present form.

Almaxacs, construction of. The first thing to be done is, to compute the sun's and moon's place for each day in the year, or it may be taken from some ephemericles and entered in the almanac; next, find the dominical letter, and, by means thereof, distribute the calendar into weeks: then, having computed the time of Easter, by it fix the other moveable feasts; adding the immoveable ones, with the names of the martyrs, the rising and setting of eacli liminary, the length of day and night, the aspects of the pla. nets, the phases of the moon, and the sun's entrance into the cardinal points of the elliptic, i.e. the two equinoxes and solstices.

These are the principal contents of almanacs; besides whicl there are others of a political nature, and consequently different in different countries, as the birtl-days and coronation of princes, tables of interest, \&c.

On the whole, there appears to be no mystery, or even difficulty, in almanac making, provicled tables of the heavenly motions be not wanting. For the duties upon almanacs, see STiMP-DUTtes.

Asmavac, nautical and astronomical ephemeris, is a kind of national almanac, published annually by anticipation, under the direction of the commissioners of lon- gituic. Besides every thing cssential to general use that is to be found in other almanacs, it contains, among other payticulars, the distances of the moon from the sun and fixed stars for every thrce hours of apparent time, adapted to the meridian of Greenwich, by comparing which with the distances carefully observed at sea, the mariner may readily infer his longitude, to a degree of exactness that may be thought sufficient for most nautical purposes. The publication of it is chiefly designed to facilitate the use of Mayer's lunar tables, by superseding the necessity of intricate calculations in determining the longitude at sea.

Almanac, is part of the law of Fingland, of which the courts must take notice in the returning of writs; but the almanac to go by is that annexed to the Book of Common Prayer. An almanac, in which the father had written the day of the nativity of his son,, was allowed as evidence to prove the nonage of his son.

ALMOND-tree, in botany. See AmraDaLES.

ALMUCANTARS, in astronomy, an Arabic word denoting circles of the sphere passing through the centre of the sun, or a star, parallel to the horizon, being the same as parallels of altitude.

Almucantars are the same, with respect to the azimuths and horizon, that the parallels of latitude are, with regard to the meridians and equator. They serve to shew the height of the sun and stars, and are described on many quadrants, \&c.

ALNAGE, or Aulvagk, in the English polity, the measuring of woollen ma. nufactures with an ell, and the other functions of the alnager. See the next article. Alnage was at first intended as a proof of the goodness of the commodity, and therefore a seal was invented; as a signal that the commodity was made according to the statute.

ALNAGER, in the English polity, a public sworn officer, whose business is to examine into the assize of all woollen clotli made throughout the kingdom, and to fix seals upon them. Another brancl of his office is, to collect an alnage duty to the king. See the last article.

There are now three officers relating to the alnage, namely, a searcher, measurer, and alnager; all which were formerly comprized in the alnager, until, by his own neglect, it was thought proper to separate these offices.

AlsNUS, the alder-tree, in botany. Sce lietcia.

ALOL, in botany, a genus of the Hex- 


\section{ALO}

andria Monogynia class of plants, with a liliacenus flower, consisting of only one " tubular leaf, divided into six deep segnic.nts at tlie edge; its fruit is an oblong capsule, divided into three cells, and containing a number of angulated seeds. There are 16 species.

Several species of this exotic plant are cultivatedin the garclens of the curious, where they afforl a very pleasing variety; as well by the odd shape of their leaves, as by the different spots with which they are iariegated.

Some aloes arc arborescent, or divided into a number of branclies, like trees; ouliers are very small, growing close to the ground 'The two most considerable species arc the aloc of America, and that of Asia; the former on account of its bcautiful flowers, and the latter for the drug prepared f:om it.

All the alocs are natives of hot climates; and the place of growth of most of them is the Cape of Good Hope. The Hotten. rots hollow ont the trunk of the first species, or $\mathrm{A}$. dichotoma, to make quivers for their arrows; and several of them are used for liedges. Among tlue Mahometans, and particularly in Fgypt, the aloe is a kind of symbolic plast, and dedicated to the offices of religion : for pilgrims, on their return from Mecea, stispend it over their doors as an evidence of their having performed that holy journey. The superstitious Egyptians inugine, that it bas the virtue of kecping off apparitions and evil spirits from their houses, and it is hung over the doors of Christians and Jews in Cairo for this purpose. They also distil from it a water, whicl is sold in the shops, and recommended in coughs, astlimas and hysteries. Ilasselquist mentions a person who was cured of the jaundice in four days by taking about half a pint of it. The Arabians call it sabbara. Tlie negroes, as we arc informed by Arlanson, in his royage to Senegal, make very good ropes of the leaves of the Guinc: aloes, which are not apt to rot in water. M. Fubroni, as we learn from the Annales de Chimie, procured from the leaves of tlie aloe suc. cotrina angustifolia, a violet dye, which resists the action of oxygen, acids, and al kalies. This juice, he says, produces a superb transparcnt colour, which is high. ly proper tor works in nuniature, and wlich, when dissolved in water, may serve, cither cold or warm, for dyin gsilk from the lightest to the darkest sliade: and he reckons it one of the most durable colours known in nature. Aloes was used among the ancients in embalming, to preserve bodies from putrefaction. Of this species of a'oes, int-rpreters understand that to lave been which Nicociemus brouglit to embalm the body of Clirist, John xix. 3. Aloes, whose résinous part is not soluble in water, las been used as a preservative to ship's bottons against the worms, to which those that trade to the East and West Indies are particularly subject. One ounce of aloes is sufficient. for two superficial feet of plank; about 12lb. for a vessel of 50 tons burthen, and $300 \mathrm{lb}$. for a first rate man of war. It may be incorporated with six pounds of pitch, one of Spanish brown, or whiting, and a quart of oil; or with the same proportion of turpentine, Spanish brown and tallow. Such a coat, it has been said, will prescrve a ship's bottom eiglit inonths, and the expense for a first rite slup will be about 18 . The same composition may be used in lot countries for preserving rafters, \&c. from the wood-ant. The cf. ficacy of alocs, as a defence against worms, has been controverted.

Aloz, or Alors, in plarmacy, the inspissated juice of the aloc perfoliata, asiatic aloe, prepared in the following manner: from the leaves, fresh pulled, is pressed a juice, the thinner and purer part of which is poured off, and set in the sun to evaporate to a hard yellowish sub. stance, which is called succotrine aloc, as being chiefly made at Succotra. - The thicker part, being put into another vessel, hardens into av substance of a livercolour, and thence called aloe hepatica. The tlickest part, or sediment, harlens into a coarse-substance, called aloeca. balina, or the horse-aloc, as being chicfly used as a purge for horses.

Fabroni has discovered that the recent juice of the leaves of the aloe lias the property of absorbing oxygen, of assuming a tine reddish purple, and of yielding a pig. ment which he strongly recommends to the artist.

ALOPECURUS, fox-tailgrass, in botany, a genus of the Triandria Digtrnia class of plants, and of the natural urrler of Grasses, the calyx of which is a bivalyce glume, containing a single finwer; the valres are hollow, of an orate lanceolated figure, equal in size, and compressed; the corolla is univalve; the valve is concave, and of the length of the cup, and has a very long arista inserted into its back near the base. There is no pericarpium: the corolla itself remains, and contains the seed, which is single and of a roundish figure. Thereare 12 species. The A.pratensis, meadow foxtail, is a na. 
tive of most parts of Europe, and is found with us rery common in pastures and mcadows. It is perennial, and flowers in May. This is the best grass to be sown in low meadow grounds, or in boggy places which hare been drained. It is grateful to cattle, and possesses the three great requisities of quantity, quality, and earliness, in a degree superior to any other, and is therefore highly deserving of cultivation in lands that are proper for it. The seed may be casily collected, as it does not quit thie chaff; and the spikes are very prolific; but the larva of a species of inuscre, which are themselves the prey of the cimex campestris, devour the seeds so inuch, that in many spikes scarcely one is found perfect. A. agrestis is a very troublesome weed in cultivated ground, and anong wheat it is execrated by farmers, under the name of blackbent; it is also common by way sides, as well as in com fields, and in pastures in the Isle of Wight. It has acquired the name of mouse-tail grass in English, from the great length and slenderness of the spike, which resembles the tail of a mouse. It is aunial, and flowers in July, continues flowering till autumn, and comes into bloom very soon after being sown.

ALPIABET, in matters of literature, the natural or accustomed series of the several letters of a langtage.

As alphabets were not contrived with design, or according to the just rules of analogy and reason, but have been successively framed and altered, as occasion required, it is not surprising that many grievous complaints have been heard of their deficiencies, and clivers attempts made to establish new andmore adequate ones in their place

All the alphabets extant are charged by Bishop Wilkins with great irregularities, with respect both to order, number, power, figure, \&c.

As to the order, it appears (says he) inartificial, precarious, and confused, as the vowels and consonants are not reduced into classes, with such order of precedence and subsequence as their natures will bcar. Of this imperfection, the Greek alphabet, which is one of the least defective, is far from being free : for instance, the Greeks should have separated the consonants from the vowels; after the vowels they should have placed the diphthongs, and then the consonants; whereas, in fact the order is so perverted that we find the opisgor, the fifteenth letter in order of the alphabet, and the wus?u or long 0 , the twenty fourth and last, the $\varepsilon$ the fifth, and the $\eta$ the seventh.

With respect to the number, they are both redundant and deficient ; redundant by allotting the same sound to several letters, as in the Latin $c$ and $k, f$ and $p h$; or by reckoning double letters among the simple elements of speech, as in the Greek $\xi$ and $\psi$, the Latin $q$ or $c u, x$ or $e x$, and the $j$ consonant; deficient in many respects, particularly with regard to vowels, of which seven or eiglit kinds are commonly used, though the Latin alphabet takes notice only of five. Add to this, that the difference among them, with regard to long and short, is not sufficiently provided against.

The powers, again, are not more exempt from confusion; the vowcls, for instance, are gencrally acknowledged to have each of them several different sounds; and among the consonants we need only bring, as evidence of their different pronunciation, tlie letter $c$ in the word circa, and $g$ in the word negligence. Hence it happens, that some words are differently written, though pronounced in the same manner, as cessio and sessio; and others are different in pronunciation, which are the same in writing, as give, dare, and gire, rinculum.

Finally, the figures are but ill-concert$\mathrm{ed}$, there being nothing in the characters of the vowels answerable to the different manner of pronunciation ; nor in the consonants analagous to their agreements or disagreements.

Alphabets of different nations vary in the number of their constituent letters. The English alphabet contains twentyfour letters, to which if $j$ and $v$ consonants are added, the sum will be twenty-six; the French twenty-three; the Hebrew, Chaldec, Syriac, and Samaritan, twentytwo each; the Arabic, twenty eight; the Persian, thirty-one ; the Turkish, thirtythree; the Georgian thirty-six; the Coptic thirty-two; the Muscovite, fortythree ; the Greek, twenty-four; the Latin, twenty-two; the Sclavonic, twentyseven ; the Dutch, twenty-six; the Spanish, twenty seven; the Italian, twenty; the Ethiopic, as well as Tartarian, two hundred and two; the Indians of Bengal, twenty-one; the Baramos, nineteen; the Chinese, properly speaking; have no alphabet, except we call their whole language their alphabet; their letters are words, or rather hieroglyplics, and amount to about 80,000 .

If alpliabets had been constructed by 
alile persons, after a fuil examination of thr: subject, they would not liave been fillecl with such contradietions between the manner of writin: have shown above, nol with those imperfections that evidently ajpear in the alphabets of every nation. Mr. L.udowick, however, and Bishop Wilkins, have endeavoured to obviate all these, in their universal alphabets or characters. See Cinallacieul.

It is no wonder that the number of let. ters in nost langruages should be so small, and that of words so great, since it appears, that, allowing only 24. letters to an alphabet, the different works or combinations that may be made out of them, taking them first one by one, then two by two, \&c. \&c. would amount to the following number:-1391, 724288, 887252, $999425,128493,4022000$. See СомвгNatuos. It must be admitted, neverthe. less, that the condition, that every sylla. ble must contain, at least, one vowel, would modify this number in the way of denomination; but on the other hand, the combinations in polly syllabic words would operate the contrary way.

Many learned authors have composed inquiries into the origin of alphabetic writing, and not a few hare referred the inveution to the inmediate inspiration of God. Nevertheless, it appears to be a very simple and direct improvernent of the hieroglyphic art. Sensible objects are depicted in outlines by children, and most rude nations; and, as in the construction of languages, so in this writing by figures, substantives will come to be used adjectively, to denote relations or qualitics. As words beconse more com. plex and less perfect by the use of abstractions, so likewise must the hieroglypic picturesbecome combined and im. perfect, and at length must have denoted things very difierent from any object capable of being delineated; and, among other consequences, there is one very striking; numely, that the picture, after degenerating into a sign or character, will be assnciated by memory with the oral character, or name, or correspondent word. An immediate step after this must be, that characters associated with monosyllabic words will be lrequently put to. gether to form pollysyllabic words, in which the picture is left out of the consideration, and the sound alone forms the subject of the record, (as if the ch:urcters for man and eye were united to form the word inany, or multitudinous.) And lastly, habit must in fact have given a VOL. 1.
8

preference, in the composition of the se polysyllabic words, to such simple sounds and their characters as wer found to be most extensively useful. That is to say, an unintentional process of analysis must have thus given rjse to the alphabet.

The sounds of language are modified by articulation, which ilepends on certain gross, and in general obvious, changes in the figurc of the organs; and by accent or mere intensity ; and by intonation or music. The first of these, as used in discourse, is much more capable of having its variations marked by characters than the others; and from this circumstance, it is found that the alpliabet cin deliver with correctness the words of such lan. guages as communicate chiefly by articu. lation; but in languages where the same articulated monosyllable denotes a great varicty of things, accorling to the accent or intonation, there will be comparatively few instances of depicted sound, and the system of writing will continue to be hieroglyphic, or rathersymbolic, in all its improvements. This system is, for the reason here mentioned, in use in China, and does not seem inferior to the alphabet, but in some respects more advan. geous.

Alpianft is also used for a cypher, or table of the usual letters of the alpha. bet, with the corresponding secret cha. racters, and otherblank symbols, intend. ed to render the writing more difficult to he decyphered. See the article DEcr. pHERING.

ALPIA BET, among merchants, a kind of index, with the twenty-four letters in their natural order, in which are set down the names of those who have ope ned ac. counts, referring to the folios of the ledger.

ALPHONSINE tubles, astronomical ta. bles, calculated by orler of Alphonsus, King of Castile, in the construction of which that prince is supposed to have comributed his own labour.

ALPINA, in botany, a genus of the Monandria Monogvuia class of plants, the corolla whereof is monopetalous, 11 . equal, and as it were louble; the exterior one is trifid; the upper segment is hollow, the two side ones Hat, and it has a tube; the interior is short, its edge is trifid, and the lower segment of the three hangs out beyonil the lateral parts of the exterior corolla, the otber two are emar. ginated, aml the base is ventricose; the fuit is a fleshy capsule, of an ovated figure, composed of three valves, and containing three cells; the secds are numerous, of an ovated figure, with a pro. 
minent but truncated apex, and a caudated base. There are sevell species.

ALSINE, chick-reed, in botany, a ge. nus of the Pentandria Trigy nia class and order, and the natural order of Caryo. phyllei : its charactersare, that the calyx is a five-leaved perianthium, leaflets concave, oblong and acuminate : the corolla has five equal petals, longer than the calyx; the stamina consist of capillary filaments, the anthers roundish; the pis. tillum has a subovate germ, styles filiform, and stigmas obtuse; the pericarpium is an ovate: onc-celled, threc-valved, capsule, covered with the calyx; the seeds are very many and roundish. There are five specics, of which the following is the principal. A. media, common chickweed, with petals bipartite, and leaves ovate cordate. The number of stamens in the flowcr of the common chick-weed is uncertain, from three to ten. This species in different soils and situations as. sumes different appearances; but it is distinguished from the ccrastiums, which it most resembles, by the number of pistils, and by having the petals shorter than the leaves of the calyx, and from all the plants related to it, and particularly the stellaria nemorim, by loaving the stalk alternately hairy on one side only. Dr. Withering refers it to the stellaria, with which genus it agrees in various respects, and especially in the capsules opening with six valves. He observes, that it grows almost in all situations, from danıp and almost boggy woods, to the driest gravel walks in gardens; but in these various states its appearances are very different, so that those whohave only taken notice of it as garden chick-weed would hardly know it in woods, where it sometimcs exceeds half a yard in heiglit, and has.leaves near two inches long, and more than one inch broad. In its truly wild state, he says, in damp woods, and hedge bottoms, with a northern aspect, it has almost always ten stamens; but in drier soils aud more sunny exposures, the stamens are usually five or three. When the flowers first open, the peduncles are upright; as the flowers go off, they hang down; and when the secds ripen, they again become upright. Dr. Withering obscrves, that the fiowers are upright, and open from nine in the morning till noon; but if it rains, they do not open. After rain tley become pendent; but in the course of a few days rise again. In gardens or dunghills, chick-weed sheds abundance of seeds, which are round, compressed, yellow, and rough, with lit- tie tubercles; and thus becomes a trou. blesome weed; but if it be not suffered to sced, it may be destroyed, as it is annual, without much trouble. This species is a renurkable instance of the sleep of plants; for every night the leaves approach in pairs, including with their upper surfices the tender rudiments of the new shoots; and the uppermost pair but one, at the end of the stalk, is furnished with longer leaf-stalks than the others, so that they can close upon the terminating pair, and protect the end of the branch. The young shoots and leaves, wlien boiled, can scarcely be distinguished from spring spinach, and are equally wholesome. Swine are very fond of it; cows and horses eat it; sheep are indifferent to it; and goats refuse it. This plant is found wild in most parts of the world. It is annual, and flowers almost through the whole year.

ALSTONIA, in botany, a genus of the Polyandria Monogynia class and order. Essen. char. corol. ore-petalled, eight or ten cleft: clefts alternated. There isbut one species, a slirub found in South America. It is rery smooth, and has the air of the bohea-tea, in the leaves, calyxes, and situations of the flowers. The dricd leaves taste like tliose of Chinese tea.

ALSTROEMERIA, in botany, a genus of the Hexundria Monogynia class and orcler: cor. six-petalled, somewliat twolipped; the lower petals tubular at the base: stamina declined. There are six species, all found in South America.

ALT, in music, a term applied to that part of the great scale of sounds, which lies between $F$ above the treble-cleft note and $\mathbf{G}$ in altissimo.

ALT AR, a place upon which sacrifices were anciently offered to some deity.

The hcathens at first made their altars only of turf; in following times they were made of stone, of marble, of wood, and even of horn, as that of Apollo in Delos. Altars differed in figure as wcll as in matcrials. Some were round, others square, and others oval. All of tliem were turned towards tlie east, and stood lower than the statues of the gods, and wcre generally adorncd with sculpture, inscriptions, and the leaves and flowers of the particular tree consecrated to the deity. 'Thus, the altars of Jupiter were decked with oak, those of A pollo with laurel, those of Venus with myrtle, and those of Mincrva with olive.

The heiglit of altars also differed according to the different gods to whom they sacrificed. Those of the celestial 


\section{ALT}

gods were raised to a great height above the ground; those appointed for the terrestrial were almost on a level with the surface of the earth; and on the contrary, they ding a hole for the altars of the infernal gods. According to Scrvius, the first were called altaria, the second are, and the last crobiculi; but this distinction is not every where observed, for we find in the best authors, the word ara, as a general word, including the altars of celcstial, infernal, and terrestrial gods.

Hefore temples were in use, altars were erected sometimes in groves, sometimes in the high ways, and sometimes on the tops of mountains; and it was a custom to engrave upon them the name, proper ensign, or character of the deity to whom they were consecrated. Thus, St. Paul abserved an altar at Athens, with an inscription To the unknozon God.

In the great temples of ancient Rome, there were ordinarily three altars; the first was placed in the sanctuary, at the foot of the statue of the divinity, upon which incense was burnt, and libations offered : the second was before the gate of the temple, and upon it they sacrificed the rictims: and the third was a portable al. tar, upon which were placed the offerings and the sacred ressels.

Besides these uses of the altars, the ancients swore upon thein, and swore by them, in making alliances, confirming treaties of peace, and on other solemn occasions. Altars also served as a place of refuge and sanctuary to all those who fled to them, whatever crime they had eommitted.

Altar is also used, among Christians, for the communion-table.

AITEIRNATE, in heraldry, is said in respect of the situntion of the quarters.

Thus the first and fourth quarters, and the second and third, are usually of the same nature, and are called alternate quarters.

ALTERNATION is used for the different ways which any number of quanti. ties may be changed, or combined. Sce Commitioy.

ALTII $Æ A$, marghomallow, in botany, a genus of plants, with a double calyx, the exterior one being divided into nine segmests; the fruit consists of numerous capsules, each containing a single seed. It belongs to the Monodelphia l'olyandria class and order. There are nine species. The A. officinalis is perennial, and flowers from luly to September. It grows plentifully in salt marshes, and on the banks of rivers anel ditchs's, in many parts of England, Ilolland, France, Italy, Silie. ria, \&c. It has been in great reruest in every country where medicine has been regularly cultivated. All its parts abound with a glutinous juice, with scarcely any smell or peculiar tiste.

ALTIMF:TRY, denotes the ast of mea. suring altitudes or heights. See MrsstRATION.

AL.TITUDF, in geometry, one of the three dimensions of body; being the same with what is otherwise called height.

Altitule of a figure is the distance of its vertex from its base, or the length of a perpendicular let fall from the vertex to the base.

Thales is supposed to have been the first person who applied the principles of geometry to the mensuration of altitude: by means of the staft he measured the height of the pyramids of Egypt, muking the altitude of the staff and pyramid proportional to the length of the shadows.

Altrtude, in optics, is the lieight of an object above a line, drawn parallel to the horizon from the eye of the oliserver.

Altitude of the eye, in perspective, is its perpendicular height above the geometrical plane.

Altituve of a star, Éc. in astronomy, is an arch of a vertical circle, intercepted between the stars and the horizon.

This altitude is either true or apparent, according as it is reckoned from the rittional or sensible horizon, and the cliffe. rence between these is what is culled by astronomers the parallax of altitucle. Near the horizon, this altitude is always increased by uneans of refraction.

Altimine of the mercury, in the baro. meter and thernometer, is marked by degrees, or equal divisions, placed by the side of the tube of those instruments. The altitude of the mercury in the barometer, in and about the metropolis, is usually comprised between 28.4 and 30.6 inches : in the course of the last seren years it has not varied from these limits more than twice. During the sane pepiod, the thermometer in the shade has been rarely higher than $82^{\circ}$ or $83^{\circ}$, and this seldom more than three or four times in a whole summer, nor often lower than about $8^{\circ}$ or $10^{\circ}$ below the freezing point. This degree of cold is not common.

\section{ALTO.RELIEVO. See ReLEVo.}

ALUM, in chemistry and the arts, is denominated the sulphate of alumina, though it is not inerely a combintion of alumina with the sulphuric acid. It possesses the following claracters: 1. It las a sweetish astringent taste. 2. It is solu: 
ble in warm water, and the solution reddens regretable colours, wlich proves the acicl to be in excess. 3. When mixed with a solution of carbonate of potash, an effervescence is produced by the uncombined acid, which prevents the first portions of alkali that are added to the solution of sulphate of alumina from occasioning any precipitate. 4 . When sulphate of alumina is heated, it swclls up, loses its regular form, and becomes a dry spongy mass ; but, according to the experiments of Vauquelin, the whole of its acid cannot be thus expelled. 5. The combination of sulphuric acid with alumina is incapable of crystallizing without an addition of potash, which makes a constituent part of all the alum of commerce. 6 . It is decomposed by charcoal, which combines with the oxygen of the acid, and leaves the sulphur attached to the alumina.

Dr. Thomson says there are four varieties of alum, all of which are triple salts; two neutral, and two he calls supcr-salts. These are this denominated:

1. Sulphate of alumina and potash.

2. Sulphate of alumina and ammonia.

3. Super-sulphate of alımina and potash.

4. Super-sulphate of alumina and ammonia.

The discovery of alum was made in Asia, from whence it continued to be imported till the end of the fifteenth centu. ry, when a number of alum works were established in Italy. In the sixteenth century it was manufactured in Germany and Spain; and during Quecn Elizabeth's reign an alum manufactory was established in England. The alum of commerce is usually obtained from native mixtures of pyrites and clay, or sulphuric acid and clay. Bergman has published a very complete dissertation on the process usually followed. The earth from which it is procured is usually called aluminous shistus, because it is slaty. Its colour is blackish, because it contains some bitumen. In most cases it is necessary to burn it before it can be employed: this is done by means of a slow smothered fire. Sometimes long exposure to the weather is sufficient to produce an efflorescence of alum on the surface. It is then lixiviated, and the water concentrated by evaporation, and mixed with putrid urine, or muriate of potash; crystals of alum and of sulphate of iron usually form together. The composition of alim has been but lately understood with accuracy. It has been long known, indeed, that one of its ingredients is sulphuric acid; and the experiments of Pott and Margraff proved in- contestibly that alumina is another ingredient. But sulphuric acid and alumina are incapable of forming alum. Manufacturers knew that tlie addition of a quan. tity of potash or of ammonia, or of some substance containing these alkalies, is almost always necessary, and it was proved, that in every case in which such additions are unnecessary, the earth from which the alum is obtained contains already a quantity of potash. Various conjectures were made about the part which potash acts in this case; but Vauquelin and Cliaptal ap. pear to have been the first chemists that ascertained, by decisive experiments, that alum is a triple salt, composed of sulphuric acid, alumina, and potash or ammonia united together. Alum crystallizes in re. gular octahedrons, consisting of two foursided pyramids applied base to base. The sides are equilateral triangles. The form of its integrant particles, according to Hany, is the regular tetrahedron. Its taste is, as we liave observed, astringent. It always reddens vegetable blues. Its specific gravity is 1.7109 . At the tempe. rature of $60^{\circ}$ it is soluble in from 15 to 20 parts of water, and in $\frac{3}{4}$ ths of its weight of boiling water. When exposed to the air it effloresces slightly. When exposed to a gentle heat it undergoes the watery fusion A strong heat causes it to swell and foam, and to lose about 44 per cent. of its weight, consisting chiefly of water of crystallization. What remains is call. ed calcined or burnt alum, and is sometimes used as a corrosive. I3y a violent heat, the greater part of the acid may bc driren off. Though the properties of alum are in all cases pretty nearly the same, it has been demonstrated by Vauquelin that three varieties of it occur in commerce. The first is, super-sulphate of alumina and potash ; the second, supersulphate of alumina and ammonia; the third, is a mixture or combination of these two, and contains both potash and ammonia. It is the most common of all; doubtless, because the alum-makers use both urinc and the muriate of potash to crystallize their alum. Vauquelin has lately analysed a number of specimens of alum manufactured in different countries. The result was, that they all contain very near. ly the same proportion of ingredients. The mean of all his trials was as follows -

Acid ....... . 30.52

Alumina . . . . 10.50

Potash ...... 10.40

Water . . . . 4 48.58 


\section{ALU ALU}

When an umusual quantity of potash is added to slum liqquor, the salt loses its ustual form, and crystallizes in cubes. This constitutes a fourth variety of alum, usually distinguished by the name of cu. bic alum. It contuins an excess of alkali. Wlien the potash is still further increased, Chaptal has observed, the salt loses the property of erystallizing altogether, and falls down in tlakes. This constitutes a fifth variety of alum, consisting of sulphate of jotasl combined with a small proportion of alumina. If three parts of alum and one of flour or sugar be melted together in an iron ladle, and the mixture dried till it becomes blackish and reases to swell; if it be then pounded small, put into a glass phial, and placed in a sanclbath till a blue flame issues from the month of the phial, and after burning for a minute or two be allowed to cool, a substance is obtained, known by the name of Ilomberg's pyroplorus, which has the property of catching fire whenever it is exposed to the open air, especially if the air be moist. This substance was accidentally discovered by llomberk about the beginning of the eighteenth century, while he was engaged in his experiments on the human fieces. He had clistilled a mixture of human freces and alum till he could obtain nothing more from it by means of heat; and four or five days after, while he was taking the residutum out of the retort, he was surprised to sce it take fire spontancously. Soon after, Lemery the younger discovered that honey, sugar, Hour, or almost any animal or vegetable matter, conld be substituted for human faces; and afterwards MIr. Lejoy de Suvigny shewed that several other salts con. taining sulphuric acid may be substituted for alum. Schecle proved that alum deprived of potash is incapable of forming pyrophorus, und that sulphate of potash may be substituted for alum. And Mr. Proust has shewn that a number of neutral salts, composed of vegetable acids and earths, when distilled by a strong fire in a retort. leave a residumm which takes firc spontancously on exposure to the air. These facts have thrown a great deal of light on the nature of IIomberg's pyroplioms, and enabled us in some measure to account for its spontaneous inflarnmation. It has been ascertained, that part of the sulphuric acid is decomposed dnring the formation of the pyrophoris, and of course a part of the alkaline base becomes uncombined with acid; and the charcoal, whiclı gives it its black coloul, is evidently divided into rery minnte par- ticles. It has been ascertained, that during the combustion of the pyroplirms a gutantity of oxygen is absorbed. The inflanimation is probably occasioned by the charcoal; the sulphiret of potash alse acts an essential part. Perlıaps it preduces a sudden increase of temperature, by the absorption and solidification of water from the atmosphere.

A new process for making alum is used at some works, for which we are indebt. ed to $\mathrm{Mr}$ Sadler, which is as follows : The boilers are filled with prepared licju or of 10 pennyweights, to which sulpliate of potash is added, and boiled together, un. til it weighs 16 pennyweights, by which time the whole of the superfluous alumins and the oxyde of iron is precipitated. The fluid is then run into a settler, where it remains until clear, after which it is pumped into a second boiler, and evaporated up to 26 pennoweights, let into the coolers, and left to crystallize. By this process, it is saicl, he gains the whole of the alum at one evaporation, and from the mother liquor remaining there is a pro. duct, the sulphate of iron.

ALUMIN $A$, in chemistry, one of the five proper earths. It was cliscorered by the alchemists that alum was composed of sulphuric acid and an earth, the nature of which was long unknown; but Geoffroy, and afterwarils Margtraft, found that the earth of alum is an essential ingredient in clays, and gives them their properties, hence it was called argil; but Morveau gave it the name of alumina, because it it obtained in a state of the greatest purity from alum by the following process. Dissolve alum in water, and add to the solution ammonia as long as any precipitate is formed. Decant off the fuid part, and wash the precipitate in a Iarge quantity of water, and then allow it to dry. Tlie substance thus obtained is alumina : not however in a state of absolute purity, for it still retains a portion of the sulphuric acidwith which it wis combined in the alum. Int it may be rendered tolerably pure, by dissolving the newly precipitated earth in muriatic acicl, eraporatiug the solution till a drop of it in cooling de. posits small crystals, setting it by to crys. tallize, separating the crystals, concentrating the liquid a scconil time, and se. parating the crystals which arc again deposited. $13 y$ this process, most of the alum which tlie eartl retained will be se. parated in crystals. If the liquid be now: mixed with unmonia as long as any precipitate appears, this precipitate, washed and dried, will be alumina nearly pure. 
Alumina has little taste: when pure, it kas 110 smell; but if it contains oxyde of iron, which it of ten does, it onits a peculiar smell when breathed upon, known by the name of earthy smell. This sinell is very preceptible in common clays. The specific gravity of alumina is 2.00 . When heat is applied to alumina, it sradually loses weight, in consequence of the evaporation of a quantity of water, with which, in its usual state, it is combined; at the same time its bulk is considerably diminished. The spongy alumina parts with its moisture very readily; but the gelatinous retains it very strongly. Spongy alumina, when exposed to a red heat, loses 0.58 parts of its weight; grelatinous, only 0,43 : spongy alumina loses no more than 0.58 when exposed to a heat of $130^{\circ}$ Wedge. wood; gelatinous in the same temperature loses but 0.4825. Yet Saussure has slown that both species, after being dried in the temperature of $60^{\circ}$, contain equal proportions of water. Alumina undergoes a diminution of bulk proportional to the heat to which it is exposed. This contraction seems owing, in low temperatures, to the loss of moisture; butin high temperatures it must be owing to a more intimate com. bination of the earthy particles with each other; for it loses on perceptible weight in any temperature, however high, after being exposed to a heat of $130^{\circ}$ Wedge. wood.

Mr. Wedgewood took advantage of this property of alumina, and by means of it constructed an instrument for measuring ligh degrees of lieat. It consists of pieccs of clay of a determinate size, and an apparatus for measuring their bulk with accuracy; one of these picces is put into the fire, and the tcmperature is estimated by the contraction of the piece. The contraction of the clay pieces is measured by means of two brass rules, fixed upon a plate, the distance between which at one oxtremity is 0.5 inch, and the other extremity $0.3 \mathrm{inch}$; and the rules are exact. ly 24.0 inches in length, and divided into 240 equal parts, called degrees. 'These degrees commence at the widest end of the scale. The first of them indicates a red heat, or $947^{\circ}$ Fahrenheit. The claypieces are small cylinders, baked in a red heat, and madeso as to fit $1^{\circ}$ of the scale. They are not composed of pure alumina, but of a fine white clay. Alumina is scarcely soluble in water; but may be diffused through that liquid with great fa. cility. Its affinity for watcr, however, is very considerable. In its usual state it is combined with more than its own weight of water, and tie have seen with what ob. stinacy it retains it. Even this combina. tion of alumina and water is capable, in its usual state of dryness, of absorbing $2 \frac{1}{2}$ times its weight of water, without suffering any to drop out. It retains this water more obstinately than any of the earths hitherto described. In a freezing cold it contracts more, and parts with more of its water, thin any other earth; a circum. stance which is of some importance in agriculture. Alumina has no effect upon vegetable blues. It cannot be christal. lized artificially ; but it is found native in beautiful transparent crystals, exceeding ly hard, and having a specific gravity of 4 . It is distinguisedin this state by the name of sapphyr. It does not combine with metals; but it has a strong affinity for metallic oxydes, especially for those oxydes which contain a maximum of oxygen. Some of these compounds are found native. Thus, the combination of alumina and red oxyde of iron often occurs in the form of a yellow powder, which is em. ployed as a paint, and distinguished by the name of oclure. There is a strong affinity between the fixed alkalies. and alumina. When heated together, they combine, and form a loose mass, without any transparency. Liquid fixed alkali dis. solves alumina by the assistance of heat, and retains it in solution. The alumina is precipitated again, unaltered, by ciropping an acid into the solution. This is 2 method employed by chemists to procure alumina in a state of complete purity ; for alumina, unless it be dissolved in alkali, almost always retains a little oxyde of iron and some acid, which disguise its properties. Liquid ammonia is also capable of dissolving a very minute proportion of newly precipitated alumina. Bar rytes and strontian also combine with alu. mina, both when heated with it in a cru. cible, and when boiled with it in water. The result, in the first case, is a greenish or bluish-coloured mass, coliering but imperfectly: in the second, two compounds are forned; the first, containing an excess of alumina, remains in the state of an insoluble powder; the other, containing an excess of barytes or strontian, is held in solution by the water. Alumina has a strong affinity for lime, and readily enter's with it into fusion. None of the earths is of more importance to mankind than alumina; it forms the basis of china and stone-ware of all kinds, and of the crucibles and pots employed in all those manufactures which require a strong heat. It is absolutely necessary to the dyer and 


\section{AMA}

calico printer, and is employed too, with the greatest aclvantuge, by the fuller and cleaner of cloth.

ALURNUS, in natural history, a genus of insects of the order Coleoptera. Essen. character: antenne filiform, short; feelers four to six, very short: jaw horney, arched. There are three speciesA. grossus, an inhabitant of South America and India : A. femoratus, found in In. dia: and $\mathrm{A}$. clentipes, found at the Cape of Good Hope.

ALYSSO, or Acrssur, mad wart, in botany, a genus of the Tetradynamia ks. sculosa class of plants; the flower is of the cruciform kind, and consists of four leaves; the fruit is a small roundish capsule, divided into two cells, in which are contained a number of small roundish seeds.

The alyssum is arranged in three divisions, viz. into $A$. in which the stem is somewhat shrubby: 13. stems herbace. ous : C. silules infiated, or calyx oblong, closed. There are 33 species; but according Martyn only 17. All the species may be propagated by seed, and most of them by slips and cuttings. In rich ground they seldom live through the winter in Fngland; but in dry, poor, rubbishy soil, or on old walls, they will abide the cold, and last much longer.

AMALG.AM, in the arts. The metals in general unite very readily with one another, and form compounds; thus pewter is a compound of lead and tin, brass is a compound of copper and zinc, \&c. These are all called alloys, except when one of the combining metals is mercury ; in that case the compound is called an amalgran : thus mercury and gold form a compound ealled the amalgatm of gold.

The amalgan of gold is formed very readily, becuse there is a very strong affinity between the two metals: If a bit of gold be dipped into mercury, its surface, by combining with mercur; , becomes as white as silver. The easiest way of forming this amalgam is, to throw snall pieces of red lot gold into inercury heated till it begins to smoke. The proportions of the ingredients are not determinable, because they combine in any proportion. This amalgam is of a silvery whiteness. By squeezing it through leather, the excess of mercury may be separated, and a soft white amajgam obtained, which gra. dually becones solid, and consists of about one part of mercury to two of gold. It melts at a moderate temperature; and in a heat below redness the mercury evaporates, and leares the gold in a state of purity. It is much used in gilding. The amalgam is spread upon the metal which is to be gilt; and theu, by the upplica. tion of a gentle and equal heat, the mercury is driven ofl, and the gold left adhering to the metallic surface: this surface is then rubbed with a brass wire brush under water, and afterwards burnished. The amalgam of silver is made in the same manner as that of gold, and with equal ease. It forms dentrical crystals, which contain eight parts of mercury and one of silver. It is of a white colour, and is always of a soft consistence. Its spe. cific gravity is greater than the mean of the two metals. Gillert has even re. marked, that when thrown into pure mer. cury, it sinks to the bottom of that liquid. When heated sufficiently, the mercury is volatilized, and the silver remains behind pure. 'This amalgam is sometimes employed, like that of gold, to cover the sur. faces of the inferior metals with a thin coat of silver. 'The amalyam of tin and mercury is much used in electricity. See Gicmsvo.

AMARANTHUS, in botany, a genus of the Monoccia Pentandria class and order, of the 'Triandria Tryginia of Gmelin's Linnaus; its characters are, that those species which have male flowers on the same plants with the females have a ca. lyx, which is a five or three-leaved perianthium, upright, coloured, and permanent; the leaflets lanceolate and acute; no corolla ; the stamina have five or three capillary filanents, from upright, patulous, of the length of the calyx, the anthers oblong and versatile: of those which have female flowers in the same receme with the males, the calyx is a perianthium the same with the former; no corol$\mathrm{la}$; the pistillum has an ovate germ, styles three, short and subulate; stigmas simple and permanent; the pericarpium is an ovate capsule, somenliat compressed, as is also the calyx on which it is placed, coloured, and of the same size, three. beaked, one-celled, cut open transverse$\mathrm{Iy}$; the seed is single, globular, compressed, and large. There are 22 species, of which we notice A.melancolicus, two-coloured $A$, with glomerules, axilla$r y$, peduncled, roundish, and leaves ovatelanceolate, and coloured. This species varies in the colour of the leaves; being in the open air of a dingy purple on their upper surface, and the younger ones green; in a stove the whole plant is pur ple-coloured; but it is easily distinguish. ed in all states by its colour, leaves, and the lateness of its flowering, after all the 
others are past: it is joined by I a Marck with a tri-colvur; a native of Guiana and the Fast-lndies, and cultirated in 1731 by Miller. The obscure purple and bright crimson of the leaves are so blended as to set off each other, and, in the vigorous state of the plants, make a fine 2ppearance. A. tri-color, three-coloured A. with glomerules sessile, roundish; stem clasping, and leaves lanceolate-ovate, coloured. This has been long cultivated, being in the gavden of Gerard in 1596, for the beauty of its variegated leaves, in which the colours are elegantly mixed; these, when the plants are vigorous, are large and closely set from the botton to the top of the stalks, and the branches forn a kind of pyramid, and therefore there is not a more handsome plant when in full lustre : a native of Guiana, Persia, Ceylon, China, Japan, the Society Isles, \&.e. A. lividus, livid $\mathrm{A}$. These are the most worthy of a place in the pleasure. garden; but they are tender, and require attention. They are usually disposed in pots, with cocks-combs and other showy plants, for adorning court-yards, and the environs of the house. 'The seeds of these should be sown in a moderate hot-bed, about the end of March ; and when the plants come up, they should have much air in mild weather. When they are fit for transplanting, they should be removed to another moderate hot-bed, and placed at six inches distance, watering and shading them till they have taken new root; afterwards they should have free air, and frequent but gentle waterings. In the be. ginning of June they should be taken up, with large balls of earth to their roots, and planted either in pots or the horders of the pleasure-garden, shaded till they have taken root, and afterwards frequently watered in diy weather. The tree amaranth must be planted in a rich light soil, and if it be allowed room, and well watcred in dry weather, it will grow to a large size, and make a fine appearance. The other sorts are sufficiently hardy to bear the open air, and may be sown on a bed of light earth, in the spring, and when the plants are fit to remove, transplanted into any part of the garden, where they will thrive, and produce plenty of sceds.

AMARLLLIS, in botany, a genus of the Ilexandria Monogynia class and or. der, of the natural order of Lilix or Liliacex; its characters are, that the calyx is 2 spathe, oblong, obtuse, compressed, emarginate, gaping on the flat side, and withering; the corolla has six petals, lanceolate, the nectary has six very short scales winthout the base of the filaments; the stamina have six awl-shaped filaments, with oblong, incumbent, rising anthers; the pistillum has a roundish, furrowed. inferior germ, the style filiform, almost of the length and in the situation of the sta. mens, the stigma trifid and slender; the pericarpium is a subovate, three-celled, three-ralved capsule; and the seeds are several. The inflection of the petals, stamens, and pistil, is very various in the different species of this genus; and the corolla in most of the species is rather hexapetaloid than six-petalled. Gmelin reckons 27 species. A lutea, yellow, A. or autumnal narcissus, with an undivided obtuse spathe, sessile; flower bell shaped; corolla erect, shortly tubular at the base, and erect stamens, alternately shorter; the flowers seldom rise above three or four inches high; the green leaves come up at the same time, and when the flowers are past, the leaves increase througl the winter. This species recedes a little from the genus. It is 2 native of the south of France, Spain, Italy, and Thrace: was cultivated by Gerard, in 1596, and flowers in September. A. formosissima, jacobea lily, so called, because some imagined that they disco. vered in it a likencss to the badge of the order of the knights of the order of St. James, in Spain, the lilio-narcissus and narcissus of others, with a spathe undivided, flower pedicelled, corolla two-lipped, nodding, deeply six-parted stamens, and pistil bent down. The flowers are produced from the sides of the bulbs, are large, of a deep red, and make a beautiful appearance : it is a native of America, first known in Europe in 1593, some roots of it having been found on board a ship which had returned from South America, by Simon de Jovar, a physician at Seville, who sent a description of the flowers to Clusius, who published a drawing of it in 1601 , called, by Parkinson, who figured it in 1629, the Indian daffodil, with a red flower: cultivated in the Oxford Garden in 1658. A. reginx, Mexican lily, with spathe, having about two fiowers, pedicels divarieating, corollas bell-shaped, shortly tubular, nodding, throat of the tube hir. sute, and leaves lanccolate, patulous ; the bulb is green, corolla scarlet, and at the bottom whitish green, the style red, the flowers large, of a bright copper colour, inclined to red : it flowered in Frirehild's garden, at Hoxton, in 1728; and Dr. Douglas wrote a folio pamphlet upon it, . giving it the title of lilium reginx, because it was in full beauty on the first of March, 


\section{AMA}

the queen's birthelay: the mots were brought from Mexico, and therefore Mr. Fairchild ealled it Mexican lily, the name which it has retained. It flowers in the spring in a very warm stove; is in beauty in February; and in a moderate temperature of air will Hower in March or A pril. A. samiensis, lilium sarniense of Donglas, who published a description of it in 1725; narcissus of others; Guernsey lily, so called by Mr. Ray in 1665; with petals linear, flat, stamens and pistil straightish, longer than the corolla, stigmas, parted and revolute. The bulb is an oblong spheroid; the leaves are dark willow green; the number of flowers is commonly from cight to twelve, and circumfer. ence of each about seven inches; the co. rolla, in its prime, has the colour of a fine gold tissue, wrought on a rose-coloured ground, and when it begins to farle, it is a pink: in full sunshine, it seems to be studded witl diamonds, but by candle. light the specks or spangles appear more like fine gold dust; when the petals be. gin to wither, they assume a deep crimson colour. The Howers begin to come out at the end of August, and the heral is usually three weeks in gradually expanding. This beautiful plant is a native of Japan, and has been long naturalized in Guemsey. It is said to have been brought from Japan to l'aris, and cul ivated in Morin's garden before 1634. It was cul. tivated at Wimbledon, in England, by fieneral Lambert, in 1659, and in 1664 becane more common : it does not seem to have been in llolland before 1695 . The plants are reputed to owe their origin in Guernsey to the shipwreck of a vessel re. tuming from Japan, probably befure the midlle of the screnteenth century. The bulbs, it is saich, being cast on sliore, took root in that sandy soil, and produced beautiful flowers, which engaged the attention of Mr. Ifatton, the gorernor's son, who sent roots to several uf his friends. A va. jiety of this, found at the Cipse of Good Hope, is described by Jac quin with a nua. ny-lowered spathe, ecrollas very patent 2nd reflex at the apex, stamens aud pistil somewhat straight, longer than the corol. las and leaves unsiform-linear. Most of these species liave very beautiful flowers, and merit the attention of the botanist and florist. The first, or yellow antumnal $\mathbf{A}$. is very harly, and increases by offsets. The season for transplanting these rnots is from May to the end of July, when the leaves are decaved. They will grow in any soil or situation; but they will thrive best in a fresh, light, dry suil, and open

VOL. 1. situation, and will keep flowering from the loginning of September to the middle of November, provided that they escape severe frosis; and a succession of flow ers will spring from the same root. The Guernsey lily has been cultivated for many years in the gardens of Guernsey and Jersey, whence the roo s are sent to most parts of Europe. The bulbs are common. ly brought over in June and July, and they should then be planted in pots filled with fresh, light, sandy earth, mixed with a small quantity of very rotten dung, placed in a warm situation, and occasion. ally refreshed with water. About the midule of September the stronger roots will shew their red-coloured flower-stem ; and then the pots should be removed int 0 a situation where they may have the full benefit of the sun, and be sheltered from strong winds; but not placed under glasses, or too near a wall, which would draw them up, and render them less beautiful. When the flowers begin to open, the pots should be put uncler shelter, so as to be secure from too much wet, but not kept too close or too warm. The flowers wilicontinue in beauty for a month; and, though without scent, their rich colour entitles them to the first rank in the flowery tribe.

AMASONIA, in botany, a genius of the Didynamia Angiospermia class and urder: calyx five cleft : corolla tubular, with a small five-cleft border : berry four-seeded. There are two species.

AMATFUR, in the arts, denotes a person understanding, loving, or practising the fine arts, without any regard to pecuniary advantage.

AMBASSADOR, a person appointed by onc sovereign power to another, to super. intend his affairs at some foreign court, and supposed to represent the power from which he is sent. The person of an ant. bassador is inviolable.

A.1BER, in nineralogy, a resinous sub. stance, called by the ancients electrum, found in lifferent countries; but nost abundantly in l'russia, either on the sea. shore, or under ground, at the depth of 100 feet, reposing on wood coal. It is obtained in lumps of different sizes. There are the white and the yellow amber. 1. The white amber is in colour straw-ycl. low, inclining to yellowish white; but 2 . The yellow amber is a wax-yellow pass. ing to a honey-ycllow, yellowish brown, and hracinth-red. It is found in blunt pieces, with a rough surface. It is rather brittle, and its specific gTavity is from 1.07 to 1.08 . Amber burns with a yellow-co- 


\section{A.11 13}

loured flame, and, if the heat be strong enough, melts, and emiss a peculiar agreeable orlour, and leaves little ashes. When rubbed, it acquires a strong negative electrical virtue. From this property is derived the word electricity. It is composed of carbon, hydrogen, and oxygen. Amber is often found in the alluvial deposit (usually called Marle) of New-Jersey. According to Sir J. Hill, it is said that amber has been found in digging into the alluvial land in the vicinity of London. It is fourd sometimes on the seashores of several parts of England. Being susceptible of a fine polish, it is cut into necklaces, bracclets, snuff-boxes, and other articles of dress. Before the discove. ry of the diamond and other precious stones of India, it was considered to be the most precious of jewels, and was employed in all kinds of ornamental dress : altars were likewise ornamented with it. The greatest quantity at present consumed in commerce is purchased by Armenian and Grecian merchants, for the use, it is conjectured, of pilgrims, previously to their journey to Mecca, and that on their arrival there it is burnt in honour of the prophet Nahomet. The acid and oil obtained from it are used as medicines.

If often contains insects of various species, in a state of complete preservation, also leares, and other parts of regetables. Varions conjectures have been made respecting its origin and formation. $\mathbf{B y}$ some it is, as we have already seen, considered as a regetable gum or resin; otliers regard it as a mineral oil, thickened by the absorption of oxygen; and Mr. Parkinson is of opinion, that it is inspissa ted mineral oil. There was lately found in Prussia a mass of amber which weighed upwards of 13 pounds, the contents of which amounted to 3183 cubic inches. Fire thousand dollars are said to have been offered for it; and the Armenian merchants assert, that in Constantinople it would sell for six times that pricc at least. Pitch-coal is sometimes found with amber, and is called black, and is sold to thc ignorant at a great price. Specimens inclosing insects, \&c. are highly valued, and the amber-dealers are said to be possessed of means of softening it, in order to introducc insects and other foreign bodies into it. Two parts of the empyreumatic oil obtained by distilling mineral pitch boiled several times, with three parts of turpentine, form a compound, which bears a great resemblance to amber, and which is often cut into necklaces and other ornaments, and sold as true amber.
AMB

AMBERGRIS, in chemistry, is a substance found floating on the sea, near the coasts of India, Africa, and Brazil, usually in small pieces, but sometimes in mass. es of 50 or 103 pounds in weight. Varions opinions hase been entertained concerning its origin. Some affirmed that it was the concrete juice of a tree; others thought it a bitumen; but it is now established, that it is a concretion, formed in the stomach or intestines of the physeter maciocephalus, or spermaceti whale. Ambergris, when pure, is a light soft substance which swims on water. Its specific gravity varies from 0.78 to 0.844 . Its colour is ash-grey, with brownish yellow and white streaks. It has an agreeable smell, which improves by kceping. Its taste is insipid. When heated to $122^{\circ}$, it melts without frothing; if the heat be increased to $212^{\circ}$, it is volatilized completely in a white smoke, leaving only a trace of charcoal. When distilled, we obtain a whitish acid liquid and a light volatile oil; a bulky charcoal remains behind. It is insoluble in water. Acids hare little action on it. Weak sulphuric acid occasions no change; but, when concentrated, it developes a little charcoal. Nitric acid dissolves it, giving out at the same time nitrous gas, carbonic acid, and azotic gas. A'brownish liquid is formed, which leares, when evaporated to dryness, a brittle brown substance, possessing the properties of a resin. The alkalies dissolre jt by the assistance of heat, and form a soap soluble in water. Both the fixed and rolatile oils dissolve ambergris. It is soluble also in ether and alcohol. It possesses the properties of the salty matter into which the muscles are converted by nitric acid, and which makes its appearance when dead bodjes are allowed to putrefy in great numbers together. This substance has been distinguished by the name of adipocire, from its resemblance both to fat and wax. The quantity of it in ambergris anounts to 52.8 parts. According to the analysis of ambergris made by Jouillon La Grange, it is composed of

52.7 adipocire

30.8 resin

11.1 benzoic acid

5.4 charcoal

1.000

AMBIDEXTER, a peson who can use both hands with the sume facility, and for the same purposes, that the generality of people do their right hands.

Were it not for education, some think 


\section{AME}

that all mankind would be ambidexters; and, in fact, we frequently find nurses obliged to be at a good deal of pains be. fore they can bring clildren to forego the use of their left hands. It is to be regretted, that any of the gifts of nature should be thus rendered in a great measure useless, as there are many occasions in life which require the equal use of both hands: strcls as the operations of bleetling in the left :rrm, left aucle, \&:c.

AMBRROSIA, in botany, the name of a distinct genus of plants, witl flosculous flowers, composed of several small infun. clibuliform foscules, dividled into five seg. ments; these, however, are barren; the fruit, which in some measure resembles a club, growing on other parts of the plant.

This genus belongs to the Monoccia Pentundria class and order. There are five species.

A MBROSINIA, in botany, a genus of the Monoceia Monarlelphia class and order; of which there is a species found in the island of Sicily : spathe one-leafed, separated by a meinbranaccous partition, containing the stamina in the hinder cell and upper part of the partition, pistils in the outer cell, anel lower part of the partition : the ront is tubcrous; leaves radical, ovate, and slining.

AMBUSCADE, or AMBrsu, in the military art, properly rlenotes a place where soldiers may lic concealed, till they find an opportunity to surprise the enemy.

AMEI.L.US, in botany, a genus of the syngenesia Superflua : receptacle chaffy' down simple : calyx imbricate : florets of the ray divided. There are three species.

AMEI.IOR.ATING crops, in husbandry, are such as are supposed to improve thie lands on which they are cultivated. Most of those plants which have nlarge stem and slady leaf are thouglit to renders the soils on which they grow more fertile, by producing a confined or stug. nant state of the air. The improvement of lands, by whiat are called ameliorating crops, probably depends upon the culture which the groind reccires while they are growing, and the returns which they inake to it in the wity of manure, after they are consumed by animals.

AME:N, in the scripture language, a solemn formula, or conclusion to all pray. $\mathrm{cr}$, signifying, so be it.

The termamen is Ifehrew, being degived from the verb, $a m a n, i . e$. to be true, faithful, \&:c. so that, strictly speaking, it signifies truth ; ant, used adverbially, as is frequently ilome in the gospels, trily or verily. Sometimes it is repeated twice together, and then it stands for the super lative, as men, amen, dico vobis.

The worl, in music, forms the usual conclusion of anthems, hymns, and other sacred compositions; and las so long been one of the principal themes of choral liarmony, as to liave given birth to a distinct apjellation for music adapted to its expression: as when, using the worl ad. jectively, we say, such an oratorio or an. them concludes with an . Amen chorus.

AMFND, or Avesur, in the French customs, a pecuniary punishment imposed by a judge for any crime, false prosecution, or groundless appeal.

A vesne honorable, an infamous kind of punishment inflicted in France upon traitors, parricicles, or sacrilegious persons, in the following manner: the offender being delivered into the hands of the hangman, his shirt is stripped off; and a rope put about his neck, and a taper in his hand; then he is led into court, where he must beg pardon of God, the King, the Court, and his Country. Sometimes the punislament ends here, but sometimes it is only a prelude to death, or banishment to the gallies.

Amencle honorable is a term also used for making recautation in open court, or in presence of the person injured.

AMENDMENT, in law, the correction of an error committed in a process, which may be amended after judgrnent, unless the error lies in giving judgment, for in that case it is not amendable, but the party must bring a writ of error.

A bill may be fumended on the file at any time before the plea is pleaded; but not afterwards, without motion and leare of the court.

AMERCEMENT, Or AMEICIAMEST, in Jaw, a pecuniary punishment imposed upon offender's at the mercy of the court. Ainercements differ fron fines, the litter being certain punislıments growing expressly from some statute, whereas the former are imposed arbitrarily, in proportion to the fault.

Besides, fines are asse'ssed by the court, but amercements by the eountry.

$\Lambda$ court of recorl only call fine, alt others can only amerce.

Sheriffs are amerceable for the faults of their oflicers, and clerks of the peace may be anerced in the King's-bench for gross faults in inclictments removed to thit court.

$A$ town is subject to amercement for the escape of a murlerer in the day-time, and if the torn is walled, it is sulject to 
amercement, whether the escape hap. pens hy day or night.

The statute of Magna Charta ordains, that a freeman is not to be amerced for a small fault, but in proportion to the offence, by his pecrs and equals.

A VERIMNUM, or Amfmuxos, in botanr, a genus of the Diadelphia Decandria class and order; of the natural order of Papilionacez or Leguminosx; the characters of which are, that the calyx is a nne-leafed periantlium; tube bell shaped, five tootlied, the teeth sharp; the corolla papilionaceous, standard with an oblong claw, roundish, heart-shaped, expanding and convex, wings lanceolate, shorter than the standard, and keel short; the stamina have ten filaments conjoined, anthers roundish; the pistillum has a gum pedicelled, oblong, compressed, leafv, varicose, with lateral veins, svithin woody, not gaping; cells disposed longitudinally within: the seeds solitary, kidney-shaped, thicker at the base, appendicted at the top. There are two species, viz. 1. A. Brownei : this shrub, rises commonly to the height of ten feet, and supports itself on other shrubs. It is a native of Carthagena, Jamaica, and Domingo. 2. A. ebenus, Tamaica ehonv, which is common in Jiknaica and several other parts of the West Indies. where the wood is cut, and sent into England under the name of ebouy, though the true ebony is a native of thie eastern country, and of a different genus. This wood is of a fine greenish brown colour, admits of polishing well, so that it is much valued by the instru. ment makers, and it is of a very hard du. rable nature. 10r. Browne says, that the trunk selelom exceeds three or four inches in diameter; that the slender branches, being very tough and flexible, are used for riding switches, and kept at all the wharfs about Kingston, to scourge the le. fractory slares.

AMFTHYST, in mineralogy, is one of the Quartz family; it occurs massive and in rolled pieces, but most frequently crys. tallized. The crystals are six-sided pyramids : colour violet blue, passing on the one hand to plum blue, brown, brownish black; on the other to pearl and ash grey, greyish white, greenish white, olive green, and in some rare cases pistachió green. In massive varieties several colours appear together in stripes : in this state they are composed of thick prismatic distinct concretions, often shooting into crystals at their cxtremities. Specific gravity 2.75. It is found in veins, and in the hollow ca. vities of agate. It is composed of

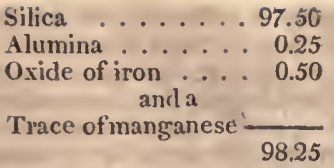

Silica

Alumina ..... 0.25

Oxide of iron ... 0.50

and a

Trace of manganese $\frac{}{98.25}$

It is found abundantly in different parts of Saxony : also in the Hartz, in the Uralian mountains, and in the East Indies. The most beautiful varieties are found at Catharinaburg in Russia. It is cut into rings, seals, and boxes, but it is not very highly valued. The green is the chryso. lite of some authors: the orjental amethyst is the sapphire : it is sometimes covered with capillary crystals of iron mica, and when viewed in certain positions appears red; this variety is named the bair amethyst.

A мстниsт, in heraldry, a term for the purple colour in the coat of a nobleman, in use with those who blazon by precious stones instead of metals and colours. This in a gentleman's escutcheon is called purpure, and in those of sovereign princes mercury.

AMETHYSTEA, amethyst, so called from the ametliystine colours of the flowers, in botany, a genus of the Diandria Monogynia class; the characters are, that the calyx is a perianthium one-leafed, tube bell-shaped, angular, semiquinque. fid, subequal, acuminate, and permanent; the corolla is one-petalled, ringent, little longer than the calyx; border five-parted and subequal ; upper lip erect, roundish, concave, two-parted, gaping; lower three. parted; the sicles rounded, erect, shorter: the middle quite entire, concave, the length of the upper lip; the stamina have filaments, filifurm, approximating, under the upper lip, and longer than it; anthers simple and roundish; the pistillum is a quadrifid germ, style size of the stamens, stigmas two, and acute ; no pericarpium, but the calyx becomes more bell-shaped and spreading; the seels are four, sliorter than the calyx; obtuse, and angular within. There is one species, viz. A. corvlia, mountain upright A. which is * native of the mountains in Siberia, from whence the sceds were sent to the Imperial garden at Petersburgh, and in $\mathbf{1 7 5 9}$ to Chelsea garden, where the plants annually produce seeds. It is annual, and hath an upright stalk, which lises abouta foothigh, and towards the top puts out two or three small lateral branches; these are garnished with small trifid leaves, sawed on their edges, and of a very dark green colour; at the extremity of the 
branches the flowers are produced in small umbels; these are of a fine blue co. lour, as are also the upper part of the branches, and the leaves immediately under the umbel; so that though the flowers are small, yet, from their colour, with Ulat of the upper part of the stalks, the plants make a pretty appearance during their continuance in flower.

A.MIA, in natural history, a genus of fishes of the order Abdominales. Generic character: head bony, waked, rough, with visible sutures. Teeth, both in jaws and palate, close-set, sharp, numerous. Cirri ol beards two, near the nostrils. Gill-membrane twelve-rayed : body sca1y. There is a single species, Calva, a small fresh water tisl, inhabiting some parts of Carolina, of which the tail is round. ed, and with a black spot; it is seldom eaten.

AMIABLE, or amicnble numbers, such as are mutually equal to the sum of one another's aliquot parts, as the numbers 284 and 220.

Van Schouten was the first who gave this name to sucl numbers, of which there are but very few at least to be set down and manageable by us. For 284 and 220 are the two least. 'The aliquot parts of 220 are $1,2,4,5,10,11,20,22,44,55,110$, and the sum of these is equal 284. The aliquot parts of 284 are $1,2,4,71,142$, and the sum of these is 220 . 'The second pair of applicable numbers are 17296 and 18416. The third pair are 9363584 and 9437056.

AMIANTHUS. See Asarstos.

AMICUS murie, in law, if a judge be doubtful or mistaken, in a matter of law, a bystander may inform the cout as amieus curice.

AMMANNIA, named by Houstoun in honour of J. Anman, in botany, a genus of the Tetrandria Monogvinia class and order. Its characters arc, that the calyx is a perianthium, bell-shaped, oblong, erect, with eight streaks and folds, qund. rangular, eight-toothed, teeth alteruate, bent in, and permaneut; corolla none, or four-petalled, petals rertically ovate, spreading, inserted into the calyx; the stamina have filaments, (four or eight) bristly, the length of the calyx into which they are inserted, anthers twin; the pistil. lum is a germ subovate, large and supe. rior, style simple, very short, and stigma headed the pericarpium is a roundish, four-celled capsule (buiry) covered with the calyx; the seeds are nuncrous and small.

A.III, bishop's zeed, in botany, a dis- tinct genus of umbelliferous plants, belonging to the Pentandria Digynia class of Linuzets; the flower of which is rusa. ceous, and composed of heart-like petals ; aud its fruit is a small roundish and striated capsule, containing two striated seeds, convex on one side, and plane on the other. There are four species.

AMMODYTES, in natural history, the launce, a genus of fishes, of the order A podes : liead coinpressed, narrower than the body : upper lip doubled : lower jaw narrow, pointed: tecth small and sharp. Gill-niembrane seven-rayed : body long, roundish, with very small scales : tail distinct. $\mathbf{A}$. tobianus, or sand launce, so named from its shape. It inhabits the northern seas; and is from 9 to 12 inches long. It buries itself on the recess of the tides a foot deep in the sand, and in fine weather rolls itself up and lifts its nose just above the sand; it is the prey of other rapacious fish ; the flesh is tolerably good, but it is used in most cases as baits. The launce lives on worms, water-insects, and small fishes, and even occasionally on those of its own species. The mackarel is very partial to this fish as its own foorl. The launce spawns in May, depositing its eggs in the mud, near the edges of the cosst.

AMMIONIA, in chemistry. Volatile al$\mathrm{kali}$, in its purest form, subsists in a state of gas, and was thought, till the late experiments of Mr. Davy, to be composed of azote and hydrogen. It may be obtained in the following inanner : put into a retort a mixture of three parts of quick -lime and one part of sal ammoniac in powder. Plunge the beak of the retort below the mouth of a glass jar filled with mercury, and standing inverted in a basin of mercury. Apply the heat of a lamp to the retort : a gas comes over, which displaces the mercury and fills the jar. This gas is ammonia. It was known by the name of volatile alkali; it was also called hartshorn, because it was often obtained by distilling the hom of the hart; spirit of urine, becanse it may be obtained by the same process from urine; and spirit of sal ammoniac, because it may be obtained from that salt. Ir. Black first pointed out the difference between ammonia and car. bonate of ammonia, or ammonia combined with carbonic acid ; ant 1)r. Priestley dis. covered the method of obtaining it, in a state of purity, by the process already described. Ammonia, in the state of gas, is transparent and eolourless like air; its taste is acrid and caustic like that of the fixed alkalies, but not nearly sn strong, nor 
rlocs it like them corrode those animal bodies to which it is applied; its smell is remarkably pungent, though not unpleasant when sufficiently diluted. Its use as a stimulant to prevent fainting is well known. Animals cannot breathe it with. out death. When a lighted candle is let down into this gas, it goes out three or four times successively; but at cach time the flame is considcrably enlarged by the addition of another flame of a pale yellow colour, and at last this flame descends from the top of the vessel to the bottom. Its specific gravity, according to the experiments of Kirwan, is 0.60 , that of air being 1.00; while Mr. Davy, whose gas was probably purer, found it 0.55 . At the temperature of $60^{\circ}$, a hundred cubic inches of this gas weigh, according to Kirwan, 18.16 grains, according to Davy, 17.068. Hence it is to common air nearly as 3 to 5 . When exposed to a cold of $-45^{\circ} \mathrm{it}$ is condensed into a liquid, which again assumes the gaseous form, when the temperature is raised. When passed through a red lot tube of porcelain or glass, it is totally decomposed, and converted into hydjogen and azotic gas. It combines very rapidly with water. "When a bit of ice is brought into contact with this gas, it melts, and absorbs the ammonia, while at the same time its temperature is diminished. Cold water absorbs this gas almost instantancously, and at the same time heat is evolved, and the specific gravity of the water is diminishcd. Water is capable of absorbing and condensing more than a third of its weight of ammoniacal gas. It is in this state that ammonia is usually employed by chemists. The term ammonia almost always means this liquid solution of ammonia in water. When heated to the temperature of about $130^{\circ}$, the ammonia separates under the form of gas. When exposed to the temperature of $-46^{\circ}$, it crystallizes; and when surdenly cooled down to $-68^{\circ}$, it assumes the appearance of a thick jelly, and has scarcely any smell. It follows, from the experiments of Mr. Davy, that a saturased solution of ammonia is composed of

74.63 water.

25.37 ammonia.

100.00

Charcoal absorbs ammoniacal gas, but does not alter its properties whilc cold. But when the gas is made to pass through red hot charcoal, part of the charconl combines with it, and forms a substance known by the name of prussic acid. Ammonia is not acted on by azote; but it combines rapidly with muriatic acid; the two gases concreting into the solid salt called muriate of ammonia Ammonia does not combine with the metals; but it changes some of them into oxydes, and then dissolves them. Liquid ammonia is capable of dissolving the oxydes of silver, copper, iron, tin, nickel, zinc, bismutl, and cobalt. When digested upon the oxydes of mercury, lead, or manganese, it is decomposed, water is formed by the union of the hydrogen of the ammonia with the oxygen of the oxydes, and azotic gas is emitted. If a considerable heat be applied, nitric acid is formed at the same time with water. Several other oxydes are also partly deoxidized, when animonia is poured into their solutions in acids. See AlKal, Cırmistay, \&c.

AMMONIAC, in chemistry, a gum re. sin brought from the East Indies. It is supposed to be a species of the Fervila. It is in small pieces agglutinated together, and has a yellowish white colour. Its smell is like that of the galbanum, but more pleasant. Its taste is a nauseous swcet mixed with bitter. It does not melt. Water dissolves a portion of it; the solution is milky, but gradually lets fall a resinous portion. One-half is soluble in alcohol. Its specific gravity is 1.2. Neither alcohol nor water, distilled off it, brings over any thing.

\section{AMMONITRUM. See Grass.}

AMMOPHILA, in natural history, the sand-wasp, a genus of insects of the order Hymenoptera : gen. char. snout conic, inflected, concealing a bifid retractile tuburlar tongue : jaws forcipated, three-toothed at the tip; antenna filiform in each sex, with about 14 articulations : eyes oval: wings plain: sting pungent, concealed in the abdomen. This genus is separated from that of the sphex, on the authority of the Rev. Mr. Kirby : in their nnanners and economy they resemble each other: and it is probable that many more of the spheges might with propriety be removed into this genus. Tliere are four species: A. vulgaris inhabits Europe, in sandy, sunny banks, where it digs a hole with its fore-feet, and buries the carcase of the larra of a moth or half dead spider, in the body of which it has deposited its eggs, and then covers up the orificc.

AMMUNITION, a general term for all warlike provisions, but more especially powder, ball, \&ic.

Ammunition, arms, utensils of war, 
gun-powder, imported without licence
\end{abstract} froun his Mlajesty, are, by the laws of Eingland, forfeited, and triple the value.

And again, such licence obtained, ex. cept for fumbishing his majesty's public stores, is to he roid, and the oflender to incur a premunire, and to be disabled to hold any office from the crown.

A MNESTY, in matters of policy, an act, by which two parties at variance promise to pardon and bury in oblivion all that is past.

Amnesty is either general and unlimited, or particular and restrained, though most commonly universal, without conditions or exceptions; such as that which passed in Germany at the peace of Osna. burg in the year 1648.

Amnesty, in a nore limited sense, rlenotes a pardon granted by a prince to his rebellious sulpjects, usually with some exceptions: such was that granted by Charles 11 . at his restoration.

AMNIOS, in anatomy, a thin pellucid membrane, which surrounls the fotus.

The fartus in the uterus is enveloped in a peculiar membranaceous covering, to which anatomists have given the name of amnios. Within this there is a liquid, distinguished by the name of the liquor of the amnios, which surmounds the foctus on every part. This liquid, as might have been expected, is very different in different animals; at least the liquor amnii in women and in cows, which alone have hitherto been analysed, liave not the smallest resemblance to cacli other. The liquor of the amujos of women is a fluid of a slightly milky colour, a weak pleasant odour, and a saltish taste. The white colour is owing to a curdy matter suspended in it, for it may be obtained quite transparent by fileration. Its spe. cific gravity is 1.005 . It gives a green colour to the tincture of violets, and yet it redklens very decidedly the tincture of turnsole. These two properties would in. dicate at once the presence of an acid and of an alkali. It froths considerably when agitated. On the application of lieat it becomes opaque, and has then a great re. scmblance to milk diluted with a large quantity of water. At the same tine it exhales the odour of boiled white of egg. Acids render it more transparent. Alkalies precipitate an animal matter in small flakes. Alcolıol likewise produces a flaky precipitate, which, when collected and dried, becomes transparent ankl very like glue. The infusion of nut galls produces a very copious brown coloured precipitate. Nitrate of silver ncensions a white precipitate, which is insoluble in uitric acid, and cousequently is muriatc of silver. "The liquor of the ammios of the cow las a visciclity similar to mucilage of gum arabic, a binwnish red colour, an acid and bitter taste, and a peculiar odnur, not unlike that of sounc vegetable extracts. Its specific gravity is 1.028 . It reddens the tincture of turinsole, and therefore contains an acid. Muriate of barytes causes a very abundant precipitate, which renders it probable that it contains sulphuric acid. Alcohol separates from it a great quantity of a reddish coloured matter. The animal matter possesses the following properties : it has a reddish brown colour and a peculi. ar taste; it is rery soluble in water, but insoluble in alcohol, which has the property of separating it from water. When exposed to a strong heat, it swells, exlates first the odour of burning gum, then of empyreunatic oil, and of ammonia, and at last the peculiar odlour of prussic acid becomes very conspicuous. It differs from gelatine in the viscidity which it communicates to water, in not foruing a jelly when concentrated, and in not being precipitated by tannin. It nust be therefore ranked among the very undefined and inaccurate class of animal muci. lages. When burnt, it leaves a lawre portion of coal, which is readily incineraterl, and leaves a little white ashes, composed of phosphate of magnesia, and a small proportion of phospliate of lime.

AMOMU., in botany, a genus of the Monandria Monogy nia class and order, the characters of which are, that tbe calyx is a perianthim, one-leafed, cy lindraceous, and unequally trifid; the co. rolla is monopetalous and funncl-shaped, tube cylindracenus, borter three-parted, parts oblong and spreading: the nectary two-leaved or two-lipped, lower lip inserted under the upper segment of the corolla, spreading almost erect, entire or three-lobed; the stamina lave no filament, except the upper lip of the necta. ry smaller than the lower, and opposite to it, accuminate or three-lobed at the tip; along the middle or at the end of which grows lougitudinaliy a larre oblong anther, germinate, or clivided by a longitudinal furrow into two, which are one-valved ; the pistillum has an inferior, oblong germ, style filiform, clrawn through the suture of the anther, stigna turbinate, obtuse and ciliate; the pericarptum a fleshy capsule, orate, three-corneret), three-celled, and three-valved; the sceds are several, corered with a sort of 
berried aril. Gmelin, in his edition of Limmeus, enumerates twenty species. A. zinziber, narow.leaved ginger, cultiva. ted by Miller, and flowering in Septem. ber, is a native of the East Indies, and other countries of $\mathbf{A}$ sia, and is much used there and in the West Indies. The dried roots furnish a considcrable article of commerce from our West India islands ; they are of great use in the kitchen and in medicine, and when preserved green as a sweet.meat are preferable to every other sort. A. zerumbet, cultivated at Hampton-court, in 1690, and flowering with us from September to November, when the stalks perish like those of the truc ginger; a native of the East Indies, Cochinchina, \&c. and also in Otaheite, and the other Society Isles. This is used externally in the East, in cataplasms and fomentations; but not internally, as spice or medicine; though Garcias says, that it makes a better preserve with sugar than the other. As to the propagation and culture of these plants, it may be observed, that they are tender, and require a warm stove to preserve them in this country. They are easily propagated by parting their roots, which should he done in the spring, before they put out new shoots, in parting the roots, they must not be divided into small pieces, especially if they are designed to have flow ers; nor should they be planted in very large pots. They thrive best in a light rich earth, such as that of the kitchen garden; and with this the pots should be filled within two inches of the top, and the roots should be placed in the middle of the pots, with their crowns upwards, and the pots should then be filled with the same earth; they should be plunged into a hot-bed of tanner's bark, and sparingly watered, till their stalks appear above ground, when they will admit of more moisture, especially in the summer months; but in autumn, the waterings must not be frequent nor plentifil, and during winter very sparing. The pots must constantly remain plunged in the tan-bed; for if they are taken out and placed on shelves in the stove, their fibres often shrink, and thus their roots decay. By this management these plants have greatly multiplied, and the common ginger has produced roots, weighing five or six ounces; but the others have been nearly a pound weight. In the West Indies the ginger thrives best in a rich cool soil; in a more clayey soil the root shrinks less in scalding. The land laid out for the culture of it is furst well cleared and hoed, and then slightly trenched, and planted. in March or April; it flowers about September; and when the stalks are wholly withered, the roots are fit to be taken up, which is generally done in January and February.

AMONTONS (WrLLIAM), in biography, an ingenious French experimental philosopher, was born in Normandy the 31st of August, 1663. While at the grammar school, he by sickness contracted a deafness that almost exclided him from the conversation of mankind. In this situation he applied himself to the study of geometry and meclianics, with which he was so delighted, that it is said he refused to try any remedy for his dis. order, either because he deemed it incurable, or because it increased his attention to his studies. Among other objects of his study were, the arts of drawing, of land-surveying, and of building; and shortly after lie acquired some knowledge of those more sublime laws by which the universe is regulated. He studied with great care the nature of barometers and thermometers; and wrote his treatise of "Observations and experiments concerning a new Hour-glass, and concerning Barometers, Thermometers, and Hygroscopes;" as also some pieces in the Jour12al des Savans. In 1687, he presented a new hygroscope to the Academy of Sciences, which was much approved. He found out a method of conveying intelligence to a great distance in a short space of time; this was by making signals from one person to another, placed at as great distances from each other as they could see the signals by means of telescopes: this was unquestionably done upon the principle of modern telegraphs, which were brought into general use in 1794, almost a century after the death of Amontons. Amontons was chosen a member of the Royal Academy in 1699, as an eleve under the third astronomer; and lie read there his "New Theory of Friction," in which he happily cleared up an important object in mechanics. He had a particular genius for making experiments; his notions were just and delicate: he knew how to prevent the inconveniences of his new inventions, and had a wonderful skill in executing them. He died of an inflummation in his bowels, the 11th of October, 1705, being only 42 years of age. His picces are contained in the different volumes of the memoirs of the Academy of Sciences; these are numerous, and upon various subjects, as the air, action of fire, barometers, 
theimometers, hygrometers, friction, machises, lieat, cold, rarefactions, pumps, \&c. They may be seen in the volunes for the years 1696, 1699, 1702, 1703, 1704 , and 1705. The character of Amontons for integrity, inodesty, and candour, was no less distiuguished than his talents and genius in philosophical pursuits. Upon his death in 1705, M. Fontenelle delivered an elegant and impressive culogium on his merits. See Merorns of the Acadenuy for that year.

AMIORPHA, in botany, bastard indign, a genus of plants belonging to the Iiadelphia Decandria class of Linnaus; the flower of which consists of one petal, vertically ovated, hollow, and erect; and the fruit is a lumulated pod, of a compressed form, and covered with tubercles, in whichare contained two sceds, of an oblong kidney-like shape. There are two specics.

This shrub grows naturally in Carolina, where formerly the inluabitants made a coarsc sort of indigo, which occasioned its name of the bastard indigo. It rises with many irregular stems to the height of twelve or fourtecn feet, with very long winged leares. It was observed by "Thunberg in the island of Niphon, belonging to Japan, but is now become very common in the gardens and nurseries near I.ondon, where it is propigated as a flowering slurub. It is propugated by sceds sent from America.

A.IPELIS, in natural history, the chat. terer, a genus of birds of the orler Y'asseres, bill straight, convex, subineurred, each mandible notched: nostrils covered with bristles : tongue sharp, cartilaginous, bifid : middle toe connected at the base to the outside. There are, according to Gmelin, fourteen species : we sluall notice the following: A. garrulus, or waxen chatterer; a beautiful bird ahout eight inclies long. Its bill is black, and has a small notch at the end; its cy cs are placed in a band of black, which passes from the base of the bill to the hinder part of the head. Its throat is black; its feathers on the head are long, forming a crest; all the upper parts of the body are of a redulish ash colour; the breast and belly inclining to purple; the tail feathers are black, tipped with prale gellow; the quills are black, the third and fourth tipped on their outer edges with white : the five following with straw colour, hut in some bright yellow; the secondaries are tipped with white, each being pointed with a flat horny sub. stance of a bright vermilion colour. VOL. 1.
These appendages vary in different sub. jects. This rare bird risits our islausl only at uncertain intervals. Their summer residence is supposed to be in the nortliern parts of Europe, within the aretic circle, whence they spread themselves into other countries, where they renuain during the winter, and return in the spring to their usilal hames. The fuod of this bird is herries of various kinds; in some countries it is said to be extremely fond of grapes. Only this sjecies of the cliaterer is found in Euroje, the others are natives of America. Sce plate $\mathbf{I}$. Aves, fig. 5. A. caruncul:tia, Tas a black bill, with a pendulous, exjansile, moveable caruncle at the base, inhabits Cayenne and Brazil, and is about twelve inches long. The bill is an inclı and a lialf long, and black; at the base is a flesliy carbuncle hanging over it, like that of a turkey cock. The female is furushed with one as well as the male. These birds are said to have a very loud voice, to be heard half a leaguc off, which is composed of merely two syllables in, an, uttered in a drawling tone; but some have compared it to the sound of a bell. A. Americana, cedar bird : this has been consilered by the European vaturalists is a mere variety of their chatterer; but Mr. Wilson has shewn it to be a distinct species.

AMPELITES, cunnel-coal, a liard, opaque, fossil, inflammable substance, of a black colour. The ampelites, examined by a microscope, appears composed of innumerable very small thin plates, laid closely and firmily upon one another, and full of rery small specks, of a blacker and more shining matter than the rest. There is a large quarry of it in Alençou, in France. It is dug also in many parts of England; but the most beautiful is found in Lancashire and cheshire: it lics usually at considerable depth. It is capable of a very fine polish, ard is made into trinkets, and will pass for jet. Ilusbandmen dress their vines with it, as it kills the vermin which infest'tliem: it is likewise used for dying the hair black.

AMPHIBIA, in natural history, a class of aninals that live either on land or in water. The title Amplibia, applied to this class of aninals by Liminus, may perliaps be considered as not absolutely unexceptionable, the power of living with equal facility both in land and water being not granted to all the animals which coinpose it ; yct, since it is certain that the major piu't are found to possess that faculty in a considerable degree, the title mav be allowed to continue. The Am. 


\section{AMI}

phibia, from the peculiar structure of tlicir organs, and the power which they possess of suspending respiration at pleasure, can not only support a change ol element uninjured, but can also occasionally cndure an abstinence, which would infallibly prove fatal to the higher order of animals. It has been a general doctrine among anatomists, that the hearts of the Amphibia were, in the technical phrase, unilocular, or furnished with only one ventricle or cavity; a doctrine maintained by many eminent anatomists, and, in general, assented to by the greatest plyysiologists, as Boerhaave, Haller, \&c. \&c. and only occasionally called in question, on viewing in some animals of this tribe a seemingly different structure. 'Thus the French academicians of the seventeenth century pronounce the heart of an Indian land tortoise, which they examined, to have in reality three ventricles instead of one. Linnzus, in his Sys. tema Naturæ, acquiesces in the general doctrine, and accordingly makes it a cha. racter of this class of animals. Among later physiologists, lıwerer, there are not wanting some who think it more correct to say, that the hearts of the Amphibia are in reality double, or furnished with two ventricles, with a free or immediate communication between them. The lungs of the Amplibia differ videly in their appearance from those of other animals; consisting, in general, of a pair of large bladders or membranaceous receptacles, parted, in the difficrent species, into more or fewer cancelli, or subdivisions, among which are beautifully distributed the pulmonary blood-vessels, which bear but a small proportion to the vesicular part through which they ramify; whereas, in the lungs of the Mammalia, so great is the proportion of the blood-vessels, and so very small are the vesicles, or air-cells, that the lungs have a fleshy rather than a membranaccous appearance. In the Amphibia, therefore, the vesicular system may be said greatly to prevail over the vascular; and in the Mammalia, or warm-blooded animals, the vascular system to prevail over the vesicular. Many of the Amphibia are possessed of a high degree of reproductive power, and will be furnished with new feet, tails, \&c. when those parts have by any accident been destroyed. Many are highly beautiful in their colours, as well as clegant in their forms; while others, on the contrary, are, in the common acceptation of the words, extremelydeformed, and of unpleasing colours. Their bo. dies are sometimes defended by a hard, horney shield, or covering; sometimes rather by a coriaceous integument; sometimes by scales; and sometimes have no particular defence orcoating, the skin being merely marked by soft, pustular warts, or protuberances, more or less visible in the different species. The bones of the Amphibia, except in a very few instances, are of a more cartilaginous nature than in either the Mammalia or Birds: many species are destitute of ribs, while others hare those parts very numerous: some are furnished with formidable teeth; others are toothless: some are fierce and pre. dacious; others inoffensive. Few, except among the serpent tribe, are of a poisonous nature, the general prejudice against them having arisen rather on account of their form, than from any real poisonous quality; but among the serpents, we meet with some species possessed of the most dreadful poison, as well as with the power of applying it with fatal force to the animals which they attack. The number of poisonous serpents is, however, not so great as was formerly imagined; perhaps not more than a sixth part of the whole number of known species being of that character. Among no animals do we meet with beings of a more singular form than the Amphibia; some of which present appearances so unusual, so grotesque, and so formidable, that eren the imagination of the poet or painter can hardly be supposed to exceed the realities of nature. The amphibia in gencral are extremcly tenacious of life, and will continue to move, and exert many of their animal functions, even when deprived of the head itself. The experiments which have been occasionally made on these subjects can hardly be recited without horror. The natural life of some of the Amplibia, more particularly of the tortoise tribe, is extremely long; and even to the smaller tribes of frogs and lizards, a considerable space seems allotted. The same is also highly probable with respect. to the serpent tribe. By far the major part of the Amphibia are oviparous, some excluding eggs covered with a hard or calcareous shell, like those of birds; others, such as are covered only with a tough skin, rescmbling parchment; and in many, they are perfectly gelatinous, without any kind of cxternal covering, as it the spawn of the common frog. Some few are viviparous; the eggs first hatching internally, and the young being afterwards excluded in their perfect form, as in the viper, \&c. \& $c$. In cold and tempe- 


\section{AMP}

rate climates, most of the Amphibia pass the winter in a torpid state; and that sometimes in a degree of cold which would seem but ill calculated for the pre. servation of animal life. The common large water-newt, in particular, is said to liave been occasioually found completely embedded in large masses of ice, in which it must have remained inclosedfor a very considerable period; and yet, on the dissolution of the ice, lias been restored to life. The Amphibia may be divided into four distributions, viz. Testudines, Ranx, Lacertz, and Serpentes; or Tortoises, Frogs, Lizards, and Serpents. The animals belonging to the three former of these divisions constitute the order entitled Reptilia, containing the Amplibia Pedata, or Fonted Amplibia. The last division, or that of Serpents, constitutes the order Serpeutes; containing the Am. phibia Apoda, or Footless Amphibia.

AMPHITRITE, a genus of worms, of the order Molusca; body projecting from a tube, and annulate; peduncles or feet small, numerous; feelers two, approximate, feathered; nocyes. There are seven spccies : of which the $\mathbf{A}$. reniformis, with a rounded body and simple feelers, is three inclies long, and inliabits the seas about Iceland. The body is of a most beautiful red; head defended by two semicircular arches ; plumes fourteen, and alternately red and white; annulations of the body from 80 to 90 , with each a minute tubercle on eacl side; tail pointed, and not jointed; tube red, tough, coriaccous, simple, and four inches long.

A MPHISB ENA, in natural history, a genus of Serpents, of which the gencric character is, body cylindric, equal; annular divisions on body and tail. Accord. ing to Gmelin there are five species; but Dr. Shaw inentions two only, viz. the Alba and the Fuliginosa. The whole genus is allicd to that of the Anguis, and in some degree to the Lacerta: it is, however, readily distinguished by the manner in which the exterior surface of its skin is marked in well-lefined numerous circles or rings, completely surrounding the body, and divided in a longritudinal direction by still more numerous straight lines, thus forming so many square or parallelogramic scales. The alba is about 18 or 20 inches loug, and of a proportional thickness. Tlie head, which is covered with large scales, being but little larger in diameter than the bolly; the tail is short, terminating in a rounded extremity. The colour is, as the nane inports, white, though in some instances it is tinged with
ANP

a pale rose colour. The usual number of circles in this snake is about 223 on the body, and 16 on the tail. It is a native of South-America, where it is found in woods, preying on insects and worms. It is a harmless animal, but on being handled, it excites a slight itching on the skin, accompanied by small pustules, owing to an acrimonious moisture exuding from the animal. A. fuliginosa is at all times readily distinguished by its colours. There are about 230 rings on its body and tail. It is white, variegrated with black or deep brown spots. The head is without spots. It is found in many parts of South-America, resembling the alba in its manners, and being equally innoxious. The skin of the amphisbxna is rcmarkably strong and tenacious, and of a smooth or glossy surface : it is supposed to be able to performte the ground with great facility, in the manner of carth worms, to obtain its foot. The other species are found in America. See plate Serpentes, fig 2.

AMPLIIUDE, in astronomy, an arch of the horizon intercepted between the east or west point thereof, and the centre of the sum, star, or planet, at its rising and setting, and so is either north or south.

If the amplitude be taken from the rising sun, or star, it is called its rising or ortive amplitude ; if, when it sets, its setting or occasive amplitude. The sun's amplitude, either rising or setting, is found by the glohes, by bringing the sun's place to the horizon, either on the east or west side, and the degrees from the east point, either north or south, are the amplitude required. To find the amplitude trigonometrically, say, as the cosine of the latitude: radius: : sine of the present declination : sine of the amplitude. This problem is useful in navigation, to find the variation of the compass. Thus in latitude $51^{\circ} 31^{\prime}$, when the sun's declination is $23^{\circ} 28^{\prime}$, then we say,

As 60 . S. $51^{\circ} 31^{\prime},: 10$. \&c. :: S. $28^{\circ} 28^{\prime}$ : S. Amp. or, as $9.793990: 10$. \&c: : : 9.600118: $9.806127=$ sine of $39^{\circ} 47^{\prime}=$ the amplitude sought: that is, the sum then rises or sets $39^{\circ} 47^{\prime}$ from the east or west point to the north or south, as the declination is either north or sonth.

Avpltuder, magnefical, the different rising or setting of the sun, from the east or west points of the compass. It is found by observing the sun, at his rising and setting, by an amplitude compass. The diflierence between the magnetical ampli. tucle and the true amplitude is the varia. 
tion of the compass. If the magnetical amplitude be fixind to be . . . $61^{\circ} 55^{\prime}$ at the time it is computed as above to be . . $39^{\circ} 47^{\prime}$

then the difference $\overline{22^{\circ} \quad 8^{\prime}}$ is the variation westward.

Ampromene of the range of a projectile, the horizontal line subtending the path in which the projectile moved. See PnoJeCTILE.

AMPUTATION, in surgery, the cutting off a linul, or other part of the body, with an instrument.

AMULET, a charm, or preservative against mischief, witcheraft or diseases. Amulets were made of stone, metal, simples, animals, and, in a word, of every thing which fancy or caprice suggested; and sometimes they consisted of words, characters, and sentences, ranged in a particular order, and engraved upon wood, \&c. and worn about the neck, or some other part of the body. At other times they were neither written nor engraved, but prepared with many superstitions ceremonies, great regard being visually pail to the influence of the stars. The Arabians have given to this species of anulet the name of talisman.

All nations have been fond of amulets ; the Jews were extremely superstitious in the use of them, to drive away diseases : and the Misna forbids them, unless received from an approved man, who had cured at least three persons before, by the same means.

Even among the Christians of the early times, amulets were made of the wood of the cross, or ribbands with a text of scripture written in them, as preservatives against diseases; and therefore the council of Laodice a forbicls ecclesiastics to make such amulets, and orders all such as wore them to be cast out of the clusrcli.

amygDaloid. Sec Traps Transtrios.

AMYGDALUS, in botany, a genus of the Polyandria Munogynia class and order; its characters are, that the caly $\mathrm{x}$ is a perianthinm, one-leaved, tubulons, inferior, quinquefid, decirluous, divisions spreariing and obtuse; the corolla of five petals, oblong-ovatc, obtuse, concave, inserted into the calyx; the stamina have filanients aboust 30 , filiform, erect, shorter by half than the corolla, inserted into the calyx; anthers simple; the pistillum lias a roundish, villose germ, simple style, of the length of the stamens, and liearled stigma; the pericarpium is a roundish, villose, large drupe, with a longitudinal furrow; the seed is a mut, ovate, compressed, acute, with prominent sutures on each side, reticulated with furrows, and dotted with small holes. The nut of the almond is covered with a dry skin ; that of the peach with a simall pulp. There are seren species, of which we shall notice, 1. A persica, with all the serratures of the leares acute, and the flowers sessile and solitary. 'There are two varieties, viz, the peach-tree, with downy fruit, and the nectarine, with smooth fiuit. 2. A. communis, the almond tree, with the lower serratures of the leaves glandulous, and the flowers sessile and in couplets. The common almond has leaves which re. semble those of the peacil, but the lower serratures are glandular; they proceed from buds, both above' and below the flowers, and not, as in the peach, from the ends of the shoots above and not helow the flowcrs. The form of ine flower is not very different ; but the \& ially come out in pairs, and vary mose ns l eir colour from the fine blush ot $t$. . Ipleblossom to a snowy whiteness. ' 1 'b. hief obvious distinction is in the frutis pheln is flatter, with a coriaceous cover.ng. in. stead of the rich pulp of the peach and nectarine, opening spontaneously when the kernel is ripe. The sheli is not so hard as in the first species, and is sometimes tender and very brittle; it is flatter, smoother, and the furrows or holes are more superficial. , This tree is a great object in some parts of Italy, and in the south of France ; and there are large plantations of it in Provence and Dall. phine. It is common in China, and most of the eastern countries ; and also in Barbary, where it is a native. In the time of Cato it seems not to have been cultivated in Italy ; for he calls the fruit nuces Gracæe, or Greek nuts. With us it is valuable as an ornamental tree in clumps, slurubberies, \&c. within view of the mansion; for it displays its delicate red-purple bloom in the month of March, when few other trees liave either leaves or flowers. An almond tree, covered with its beauti. ful blossoms, is one of the most elegant objects in nature. In a forward spring they often appear in February; but in this case the frost generally destroys them, and they bear little or no fruit ; but when they flower in March, they seldom fail to bear plenty of fruit, very sweet, and fit for the table when green; but they will not keep long. The amygdalus, or almond-tree is cultivated both for the advantage of the fruit, and as being highly 


\begin{abstract}
A.IIY
ornamental in shrubleries, plantations,
\end{abstract} and other descriptions of pleasure ground, from its coming into bloom early in the spring. It is, lowever less important in the former than the latter point of view, as the fivut is often liable to miscarry in this climate. All the species and varie. ties of this tree are deciduons, and of a hardy mature, thriving well in most common garlen soils. Those of the tree kind frequently rise to fiftecin or twenty feet in heighth, dividing into many spreading branches, which ultimately form besutiful hearls, that are generally well adorned in the beginning of March with innumerable Howers, which continue in full bloom for a fortnight or three weeks, and are followed by the leaves, which are loug and narrow, and the fruit takes its growth. This is clow'ny, rather largec, anid of an oval form; consisting of a thick, tough, leathery substance, that cmulraces an oblong nut or stone, in which the kernel or almond is inclosed, which is the only part of the fruit that is capable of locing made use of. The dwarf, shrubby sorts of this tree do not, however, in general exceed three or four feet in lieight, laving slender stems, which send forth a great number of small branches near to the ground; and in the single-flowered kind various suckers are frequentiy'sent up from the ront. And in both the double and single-flowered almond-tree, all the young branches are thickly beset with flowers in the spring, which, from their having a fine pale red colour, and continuing some time in blow, are highly ornamental. The single sort have thicir flowers coming out about the end of March, and the double kiml in the beginning of April, each re. maining about a fortniglit in blow. The sorts chiefly cultivated for use in this country arc, according to Mr. Forsyth, the teister-shelled almond, the sweet almond, the common or bitter almond, the sweet Jordan almond, and the hard-slrellid almond. Those propagated only for crnament are, the dwart and the cloubleHowering almonds.-Ainygdalus P'ersica, or peach-tree. Its native country is not known. It came to the Romans from l'ersia, as its Latin name, malus l'ersica, indicates: : and it has been cultivaterl from time immemorial in most parts of Asia; it has been adopted by almost every nation of Europe, and now flourishes abun. dantly in America, where it has been introclucesl by the Eturopeans. Of this tree we have oily oné rlistinct species; but there are a great many varieties, and by producing them from the seed or kemel, they may be almost indefinitely increascd. But though they are capalle of being greatly augmented in this manner, it is probable that but very few possess the necessary qualities, as nursery-men seldom cultivate more than twenty or thirty sorts. As in the cultivation of this sort of tree much expense is constintly requires iu walls or other suitable buildings, none but sucli as produce fine finit should be attencled to. This sort of trees will grow to a considerable height as standards; but, in order to produce and ripen fruit, requires the shelier of warm walls. They flower early in the spring in common, the flower's appearing before the leaves, mostly on the shouts of the preceding year, and either singly or in pairs along their sides. They are formed each of five sunall petals, with many stamina in the middle, and a small round germen, that becones tlic peach. The fruit is clistinguislied into two sorts, the peach ani pavie, froin the circurnstance of thic flesly or pulp quitting or allhering to the stone, as in the former it easily separates, while in the latter it adheres firmly. There are various sorts of peaches that may be cultivated; but for small gardens Mr. Forsyth recommends the following as the most suitable: the early avant, small mignonne, the Anne peach, royal Gicorge, roy al Kensington, noblesse, early Newington, Galland, early purple, chancellor, ứvette, the Catharine, the late Newington, Amygdalus nucipersica, or the nectarine trec. This is now generally considered as a varicty of the peach; but the two trees cannot by any circumstances in their growth, wood, leaves, or flowers, be distinguished from each other with any degree of certainty. The fivits are, however, readily discriminated in all their different stages of growth, that of the nectarine haviug a smooth, firm cuticle, or rind, while in the peach it is covered with a soft, downy substance. 13esides, the pulp or flesh of the former is much more firm than that of the latter. There are many varieties of the nectarine that may be cultivated; but those that chiefly deserve attention are, the l'airchild's, thie violet, the elrouge, the Newington, the Roman, the temple, and the vermash. The white nectarine may also be cultivated, both for the goodness of its fruit, and as being a curious variety.

AnI inIS, a genus of the Octandria Monoginia class and order; its charac. ters are, that the caly's is a perianthium, one-leafed, four-toothed, acute, crect, sinall, and permanent; thic corolla con- 


\section{AMY}

sists of four oblong, concave, and spreading petals; the stamina have awl-shaped, erect filaments; anthers oblong, erect, of the length of the corolla; the pistillum has a germ, superior, ovate, style thickish, of the length of the stamens, and stigma four-cornered; the jericarpium is a drupaccous and roundish berry; and the seed is a round, shining nut. There are thirtcen species, of which we shall notice A. sylvatica, with leaves ternate, crinate, and acute. This is an erect, leafy shrub, from two to fifteen feet ligh, according to the soil and situation, abounding with a turpentine of a strong disagreeable smell; it is found plentifully about Carthagena, in woods near the sea, and flowers in Au. gust. A. maritima, small, shrubby, sweet wood, with leaves ternate, crenulated and obtuse. This is a dwaf shrub, yielding a juice like that of the former, but more agreeable, and smelling like rue : the berry is of the size of black pepper, black when ripe, inclosing a globular, brittle nut, in which is a white kernel. Swartz doubts whether the preceding be a distinct species firom thiis. It grows in very barren coppices, in a calcareous rocky soil, both near the sea, and on the interior mountains of Jamaica, Hispaniola, and Cubs, and flower's from June to September. A. gileadensis, balsam of Gilead tree, with leaves ternate, quite entire, and peduncles one-flowered and lateral. This species is a shrub with purplish branches, having protuberant buds loaded with balsamic rosin: the fiowers proceed from the same buds by threes; the bracte minute, and slightly bifid. It lias been douhted whether this be a distinct species in itself. A. ambrosiaca, with leaves pinnate and petiolate, and panicles crowded and axillary. This is a tree, with a trunk thirty feet high, branching at the top, with branchlets leafy and flowery : leaves alternate, with two or three opposite, ovate leaflets on eacli side, ending in long points, smooth, entire, on short petioles, gibbous at the base; flowers yellowish white, axillary, and corymbed; perianth very small and four-toothed; petals lanceolate, spreading at the tip; filaments filiform, half as long as the calyx, inserted into the tube; germ superior, subglobose, style cylindrical; stigma capitated, depressed, and four-cornered; fruit oyate, oblique, four-celled, resembling that of the laurel, the nucleus involved in a brittle covering, four-cellcd, with four stones wrapped up in a viscicl red pulp, laving a balsamic smell and taste, hardening into a grey rosin, and used for buming as a perfune
The whole tree is sweet-scented, and yields a very odoriferous balsam from the wounded trunk or branches, which is used in the dysentery; the dose is one dram in red wine; it is also used in hou. ses and churclies for burning as a per. fume. It grows in the woods of Guiana, and by the sea-shore; flowering and fruiting in September A. balsamifera, sweet amyris, white candle-wood, or rose-wood, with leaves two-paired. This grows to a considerable size, and is one of the most valuable trees in the island of Jamaica; the wood is white, and of a curled grain when young, but grows of a dirty clouded ash colour with age, bearing a fine polish, and having a pleasant smell ; it is heavy, and much esteemed among cabinet-maker's. All the parts of this tree are full of warm aromatic particles, and may be used in baths and fomentations : the berries are oblong, and have the taste of the balsam copaiba. An infusion of the leaves lias a pleasant fiavour, is highly cephalic, strengthens the nerves, and is particularly restorative to weak eyes. In Jamaica there are several species of amy. ris, the leaves and bark of which yield a fine balsamic juice; and if the body were tapped at the proper season, a thick liquor would transude, resembling that of the Gilead balsam, to which the taste of the bark and wood of the smaller branch. es bears a very exact relation. Dr. Wright appreliends that this wood, by distillation, would yield a perfume equal to the oleum rhodii.

ANA, among physicians, denotes an equal quantity of the ingredients which immediately precede it in prescriptions: it is written by abbreviation $\bar{a}$ or $\bar{a} \bar{a}$; thus, $B_{0}$ thur. myrth. alum. $\overline{\mathrm{a}} \overline{\mathrm{a}}, \vartheta_{\mathrm{j}}$ : that is, take frankincense, myrrh, and alum, each a scruple.

Asa, in matter's of literature, a Latin termination added to the titles of several books in other languages.

They are collections of the conversation and memorable sayings of men of wit and learning; the Scaligeriana was the first book that appeared with a title in ana, and was afterwards followed by the Perroniana, Thuana, Nudzana, Menagiana, and even by Arlequiniana, in ridicule of all books in ana. The Menagiana are accounted the best.

Axs, among occult philosophers; a term used to clenote the liuman mind; from whence some will have anasapta, a dæmon invoked by sick persons, to be derived. 


\section{ANA}

ANABASIS, in botany, a genus of the Peutandria Digynia class and order: essen. char.; calyx, three-leaved ; cor. five. petalled: ibersy, one-seeded, surrounded by a calyx : there are four species.

ANACARDIUM, in botany, acajou, a genus of the Enneandria Monogynia class and order; its characters are, that it has hermaphrodite flowers, and male flowers, either mixed with the hermaphrodites, or on a distinct tree. The calyx of the former is a perianthium, five-leaved, leaflets orate, concave, coloured, erect, and deciduous; the corolla has five petals, lanceolate, acute, three times as long as the calyx, upriglit at bottom, reflex at the end; the stamiua have ten filaments, united at the base and upright, nine of them capillary, shorter than the calyx; the pistilum has a germ, kidney-sh aped, obliquely emarginate in front, style subulate, bent in, the length of the corolla; stigma small, roundish, depressed and concave: no pericarpium; receptacle fleshy, very large and obovate; the seed a nut, kidney-shaped, large at the top of the receptacle, with a thick shell, cellular within, and abounding in oil. The calyx, corolla, and stamina, of the male flowers, as in the hermaphrodites; the pistillum lias either no germ, or one that is abortive. There is one species, viz. A. occidentale, cashew-nut, cassu or acajou. The cashew is an elegant tree, 12 or 16 feet ligh, spreading much as it rises, and beginning to branch at the height of five feet, accorcling to Browne; but Long affirms that in good soil it spreads to the size of a walnut tree, which it resembles in the shape and smell of the leaves; the trunk seldom exceeds half a foot in diameter; the leaves are coriaceous, subovate, shining, entire, petioled, and scattered alternately ; and terminating, containing many small, sweet-smelling flowers, on oblong receptacles, scarcely distinguishable from the perluncle; the corolla red, with commonly 10 stamens, one of which has no anther, but it has fie. quently eight, or only seven, all fertile; and there are sometines female flowers, entirely destitute of stamens. The fruit has an agreeable subacid Alavour, in sonie degree restringent; in some of a yellow, and in others of a red colour, which difference may be probably owing to the soil or culture. The juice of the frnit, fermented, affords a pleasant wine; and distilled, yields a spirit exceedung arrack or rum, and serves to make punch, and also to promote urine. The ripe fruit is sometimes roasted and sliced, and thus used for giving an agreeable flavour to punch. The restringency of the juice has recommended it as a remedy in drop. sical habits. From one end of the apple proceeds the nut, which is kidneyshaped, inclosed in two shells, the outer of an ash colour, and smooth, and the inner covers the kernel. Between these shells is lodged a thick, inflammable, and very caustic oil, which, incautiously ap. plied to the lips and mouth, inflames and excoriates them. This oil has been successfully used for eating off ring-worms, cancerous ulcers, and corns; but it sliould be very cautiously applied. Some fomales have used it as a cosmetic, in order to remove the freckles and tan occasioned by the scorching rays of the sun, but it proves so corrosive as to peel of the skin, and cause the face' to inflame and swell; but after enduring the pain of this operation for about a fortnight, thin new skin, as it may be called, ap. pears, fair like that of a new born infant. This oil also tinges linen of a rusty iron colour, that can hardly be got out; and when smeared on wood it prevents decay, and might, therefore, serve for preserv. ing house timber and ships' bottoms. 'The fresh kernel has a delicious taste, and abounds with a sweet milky juice; it is an ingredient in puddings, ac. and is caten raw, roasted, and pickled. The negroes of Irazil, who arc compelled by their masters, the Portuguese, to eat this nut, for want of othersustenance, obtain relief from this involuntary use of it in various disorders of the stomach. When the kernel is ground with cacao, it improves the chocolate; but if it be kept too long, it becomes shrivelled, and loses its flavour and best qualities. The milky juice of the trec, obtained by tapping or incision, will stain linen of a deep black, which cannot be washed out; but whe. ther this has the same property with that of the castern anacardium, lias not yet been ascertained; for the inspissated juice of that tree is the best sort of lac which is used for staining black in China or Japan.

ANACHRONISM, in matters of literature, an error with respect to chronology, whereby an event is placed earlier than it really happened, in which scuse it stands opposite to paraclironism.

ANACREONTIC verse, in ancient poctry, a kind of verse so called from its being much used by the poet Anacreon. It consists of three feet and a half, usually spondecs and iambics, and sometimes anapests; such is that of Horace, 


\section{Lydia dic per omnes.}

The word anacreontic is sometimes placed at the begimning of convivial songs, glees, \&c. denotes a gay liilarity of movement, and a free and easy stylc of performance.

ANACYCLUS, in botany, a genus of plants of the Syngenesia Polygamia Superflua. Esse i. char. receptacle chaffy, seeds crowned with an emarginate margin, those at the ray membranaceous at the sides. There are five species: of which the creticus and orientalis grow naturally in the islands of the Archipelago. They are low plants, whose branches tmil on the ground. The first sort lias fine cut leaves, like tliose of chamomile; the flowcrs are small, white, and grow single, with their heads declining; these are like tliose of common may-weed. 'The sccond has leaves like those of the ox-eye; the flowers are white, and like those of chamomile.

AN.GALIIS, in botany, a genus of plants, belonging to the Pentandria Monogynia class of Linnxus; the flower of which is monopetalous, multifid, and orbicular; the fruit is a globose capsule, containing only one cell, and dividing horizontally into two hemispheres; the sceds are numerous and angular. - There are six species.

ANAGIRAM, in matters of literature, a transposition of the letters of some nane, whereby a new word is formed, either to the advantage or disadvantage of the person or thing to whiclı the name belongs; thus, from Galenus is formed Angelus : from James, Simea ; and so of others.

'Those who adhere strictly to the definition of an anagram, take no other liberty than that of omitting or retaining the letter $h$, at pleasure; whereas others make no scruple to use $e$ for $a, v$ for $w$, $s$ for $z$, and $c$ fol $k$; and vice versa.

ANAGYRIS, bean-trefoil, in botany, a genus of plants with papilionaceous Howers, the vixillum of which is shorter than any of the other petals, and its fruit an obloug pod, containing kidney-like seeds : to this it is to be added, that three leares stand on every petal. It belongs to the Diadelphia Decandria class of Linnzus.

According to Martyn, there are three species : viz. the foctida, cretica, and inodorata. The first grows wild in the South of France, in Spain, Italy, and Sicily; also about Smyma. It is a slurub that rises 8 or ten feet high, and produces its flowers in April and M:yy, which are of a bight yellow colour, growing on spikes, somewhat like those of the laburnum : the seeds are never perfected in this country. The second is a native of Camada, and some of the islands of the Arclipelago, and is very rare in English garclens. The third is an upright shrub, equal to a micldle-sized tree: branches langing down, frequently scandent: a native of the woods of Cochinchina.

These may be propagated by laying down their tencler branclies in tlse spring, observing to tongue them in the same manner as the layers of camations.

ANAI,CIME, in mineralogy, a species of Zeolite, found crystallized in the cavities of basalt. The primitive form of its crystals is a cube. It is sometimes found crystallized in cubes, whose solid angles are wanting, and three small triangular fices in place of each; sometimes in po. lyhedrons with twenty-four faces. Spe. cific gravity 2. Colour white, sometimes red. When rubbed, it acquires only a small degree of electricity, and with difficulty. Before the blow-pipe it melts without frothing into a white transparent glass.

ANALEMMA, in geometry, a projec. tion of the sphere on the plane of the meridian, orthographically made by straight lines and ellipses, the eye being supposed at an infinite distance; and in the east or west points of the holizon. See Mups.

Axalfarra denotes likewise an instivment of brass or wood, upon which this kind of projection is drawn, with an horizon and cursor fitted to it, wlierein tlie solstitial colure, and all circles parallel to it, will be concentric circles; all circles oblique to the eve will be ellipses: and all circles whose planes pass through the eye, will be right lines. The use of this instrument is to shew the common astronomical problems.

ANALOGY, in matters of literature, a certain relation and agreement between two or more things; which in other respects are entirely different; thus the foot of a mountain bcars an analogy to the foot of an animal, although they are two very different things.

There is likewise an analogy between beings that have some conformity of resemblance to one another; for example, between animals and plants, and between metals and regetables; but the analogy is still stronger between two different spe. cies of certain animals.

Axalogr, among grammarians, is the correspondence which a word or phrase 


\section{ANALYSIS.}

bears to the genius and received forms of a language.

ANALYSIS, in a general sense, is the resolution of something compounded into its constituent parts. Hence,

Avalrsis, in chemistry, is the separation of any substance into its constituent parts, with a view of ascertaining their nature, relative proportion, and mode of union. An instance of this kind is to be bad in the decomposition of water, by which it is found that the constituent parts are hydrogen and oxygen, in the proportion of fifteen parts of the former, and ciglity-five parts of the latter. As every operation in chemistry is attended witl a disunion of parts, the formation of new compounds is almost an invariable consequence; hence, the business of analysis is intimately connected with the whole of cbemical science, and can be only thoroughly understood by one that is well versed in every branch of chemistry. On so extensive a subject, it is in vain to attempt laying down precise rules for the mode of operation generally. We may, however, observe that a compound, once formed, perpetually acquires the powers of an element, in being able to unite, undecomposed, with other bodies, simple or compounded, in various proportions ; and thus to produce new substances, in which the constituent parts often retain their original affinities, and in analysis again separate into their elementary substances. We may refer to nitrate of ammonia, which is a salt composed of nitric acid, ammonia, and water, each of which is itself a compound, but in this particular. combination, it acts as an elementary body : thus, nitric acid consists of azote and oxygen : ammonia, of azote and hydrogen: and water, as we have seen, of oxygen and hydrogen : so that, in truth, there are only azote, hydrogen, and oxygen, that enter into the combination of nitrate of ammonia; but in their simple state, they cannot be made to form the salt; it is requisite that the acid, the al. kali, and the water, should be first formed, in order to get the neutral salt.

The business of chemical analysis is to resolve a body into its constituent parts; but the first question is, to determine, in every instance of andysis, whether the resolution should proceed to entire sepor ration into real elements, or only into those compounds which act as elements; as in the case referred to, whetler the nitratc of anmonia should bo resolved into azote, laydrogen, and oxygen; or whether it should not first be reduecd in. VOL. I. to nitric acid, ammonia, and water. The former mode is best calculated for research, the latter for utility; but a mixture of the two methods is commonly adopted, where tlie proportion and nature of the compound produced has already becn fully ascertained by previous experiment. The most rigid pro of of the accuracy of analysis is, to be able to produce the same compound, by uniting the identical parts which we have given as its constituents. Tlis can rarely be performed in a manner perfectly satisfactory; but it frequently happens that a sibstance may be produced that resembles the onc analysed, by employing similar constituents, if not the idlentical substances. This proof even is almost totally wanting in the analysis of organised bodies, whether vegetable or animal, especially when reduced to their ultimate elements, and generally when only separated into their immediate constituents. The agents made use of in analysis are, heat, the electric and galvanic fluids, if they are two fluids, and the application of re-agents or substances, wlich indicate the parts of the body to be examined.

Axul.rsis, among logicians, is a method of tracing things backward to their source, and of resolving knowledge into its original principles. It is also called the method of resolution, and stands opposed to the synthetic method, or method of composition. The art of this method consists chiefly in combining our perceptions, and classing them together with ad. dress ; and in contriving o proper expression of our thoughts, so as to represent their several divisions classes, and relations. 'This is elearly seen in the manner of computing by figares in arithmetic, but more particularly in the symbols applicd in resolving algesraical problems.

Arsursis, avong mathematicians, the art of discoveing the truth. or falsehood of a proposition, or its possibility and impossibility This is done by supposing the propssition, suclı as it is, true; and examining what follows from thence, until we arrive at some evident truth; or some impossibility, of which the first proprition is a necessary consequence; and from thence establish the truth or impos. sibility of that proposition.

The analysis of the ancient geometricians consisted in the application of the propositions of Euclid, A pollonius, \&c. till they arrived, procceding step by step, at the truth required. That of the moderns, though not so elegant, must however, be allowed more ready and general. By this U 
last, geometrical clemonstrations are wonderfilly abridged, a number of truths are frequently expressed by a single line, and whole sciences may sometimes be learn. ed in a few minutes, which otherwise would be scarcely attained in many years.

Analysis is divicled, with regard to its object, into that of finites and infinites. Analysis of infinitc quantities, that whicls is called specious arithmetic. Analysis of infinites, the same with fluxions. Sce Fudxoss.

AvALYṡis, in mineralogy, includes the examination of metallic ores, and of the other products of the mineral kingdom. See Miverals, analysis of.

Axalysis of soils, the means of ascertaining the nature, properties, and proportions of the different materials of which they are composed. The proper execution of this business enables the farmer to form a just estimate of the value of the different parts of his lands, to make the application of ameliorating substances with plopriety, and to understand the effeets that may be produced by the combinations of different matters. The apparatus necessary for this business are, scales and weights of different sizes; some porcelain, glass, or stone-ware ressels, unglazed; some muriatic and sulphuric acid, alkali, galls, and pure distilled water.

ANAMORPHOSIS, in perspective and painting, a monstrous projection, or representation of an image, on a plane or curve surface, which, belield at a proper distance, shal! appear regular and in proportion.

To delineate an anamorphosis upon a plane : 1. Draw the square A B C D, (Plate 1. Miscel. fig. 4, ) of a bigness at pleasure, and subdivide into a number of little squares. 2. In this rquare, called the craticula prototype, let the image to be represented deformed, bedrawn. 3 . Then draw the line $a b$ (ibid. fig.5.) equal to $\mathrm{A}$ $\mathbf{B}$, and divide it into the sam number of equal parts as the side of the prototype A B. 4. Erect the perpendicilar E V, in the middle of $a b$, so much tlre longer as the deformity of the image is to be greater. 5. Draw V S perpendicuinr to E V, so much the shorter as you would have the image appear more deformed. From each point of division draw straight lines to $V$, and join the points $a$ and $S$ by the right line $a \mathrm{~S}$. 6 . Through the points $d$ e $f g$ draw right lines parallel to $a b$, then will $a b c d$ be the space in which the monstrous projection is to be delineated; this space is called the craticular ectype. Lastly, in every areola, or small trapezium of the space $a, b, c, d$, draw what appears delineated in the correspondent areola of the square A B C D ; and thus you will obtain a deformed image, which will appear in just proportion to an eye distant from it the length of $F \mathrm{~V}$, and raised abore its height $\mathrm{V} \mathbf{S}$.

An image may be deformed mechanically, if you place it, having little holes made here and there in it with a needle, against a candle, and observe where the rays going through these holes fall on a plane or curve surface; for they will give the corresponding points of the image to be cleformed.

The practical methods of drawing these images is described in the Leipsic Act, for the year 1712, where we have an account of two machines, one for images viewed with a cylindrical, and the other with a conical mirror. The person who has this instrument may take any point. at pleasure, and while he goes over the outlines of it with one pen, another traces the anamorphosis.

In the cloister of the Minims at Paris, there are two anamorphoses traced upon two of the sides of the cloister, one representing a Magdalen, and the other st. John writing his gospel. They are so managed, that when viewed directly they appear like a kind of landscape, butfrom a particular point of sight they appear very distinctly like human figures.

\section{ANANAS. See Bhovelia.}

ANAPEST, in ancient poetry, a foot consisting of two short syllables and one long: such is the word scǒpurlos. It is just the reverse of the dactyl.

ANAPHORA, in rhetoric, a verbal figure, whereby one or more words are repeated in the begining of several sentences. This is a lively and elegant figure, and serves very much to engage the attention; for, by the frequent return of the same word, the mind of the hearer is held in an agreeable suspense till the whole is finished. Such is that in the Psalms: "The voice of the Lord is pow. erful : the voice of the Lord is full of majesty: the voice of the Lord shaketh in the wilderness." Another from Cicero's fine oration against Cataline: "You do nothing, you attempt nothing, you think nothing, but what I not only hear, but also ree and plainly perceive."

ANARHICHAS, in natural history, zoolf$f i s h$ a genus of fishes of the order of Apodes : head rounded, blunt ; fore-teeth in each $\mathrm{j} 2 \mathrm{w}$ conic, large, divergent, six or more; grinders in the lower jaw and palate rounded; gill-membrane seven-12y- 


\section{ANA}

el ; body roundish, caudal-fin distinct. There are three species. A. lupus, or ravenous wolf-fish, inhabits the northern seas ; grows to 15 feet long; it is a most fierce and ravenous fish, and will fasten on any thing within its reach. It feeds on shell-fish, which it grinds to pieces with its teeth, and swallows shells and all: mores slowly with something of a serpentine motion; the grinders are often found fossile, and are called toad-stones; the flesh is good, but not aften eaten. The fossile tecth were formerly much esteem. ed for imaginary virtues, and were set in gold and worn as rings. Notwitlistanding the ferocity of this fish, which is as dreadful to the small inhabitants of the water, as the wolf is to those on land, it is sometimes attacked and destroyed by an enemy of far inferior size anil strength, viz. the cyclopterus, or lump-fish, which, fastening itself on its neck, adheres immoveably, toruenting it in such a manner as to cause its death. The wolf-fish fre. quents the deep part of the sea, and in the spring approaclies the coast, in order to deposit its spawn among marime plants : the ova are about the size of peas; and the young are of a greenish cast, like that of sea-wrick, among which they reside for some time after their birth. See Plate I. Pisces, fig. 3. A. minor is found in the Greenland seas; and the $\mathbf{A}$. pantherinus inhabits the Northern and Frozen Ocean.

ANARRIILNUM, in botany, a genus of the Didynamia Angiospermia class and order: calys five-leaved; corol with a nectariferous prominence at its base pointing downwards; the upper-lip flat, without palate, and the oritice pervious; cap. sule two-celled, many-valved. There are five species.

ANAS, in natural history, a genus of hirds of the order Anseres. The bill in this genus is strong, broad, flat or depressed, and commonly furnished at thic end with an additional piece termed a nail, the edges of the mandibles marked with sharp teeth; nostrils sinall, oval; tongue broad, edges near the bise fringed; toes four, three before and one be. hind, the middle one the longrest. Accorling to Latham, there are 98 species, besides varicties ; but Gmelin gives about 120 species.

From the swan downward to the teal, they are all a clean-plumaged beautiful race of birds, and some of them exquisitely so. Tluse which have been reclaimed from a state of nature, and live depen. dant on unan, are extremely useful to him: under his protection they breed in

\section{ANA}

great abundance, and, without requiring much of his time and care, lead their young to the pool, almost as soon as hatched, where they instantly, witl instinctive perception, begin to search for their food, which at first consists chiefly of weeds, worms, and insects ; those they sift, as it were from the mud, and for that purpose their bills are admirably adapt. edl. When they are farther advanced in life, they pick up the sorlden scattered grain of the farm-yard, which, but for their assiduous searchings, would be lost. To them also are allotted the larger quantities of corn which are shaken by the winds from the erer-ripened ears in the fields. On this clean and simple foort they soon become fat, and their fleshys accounted delicious and nourishing. In a wild state, birds of various kinds préserve their original plumage; but when tamed, they soon begin to vary, and slsew the effects of domestication: this is the case with the tame goose and the duck, which differ as much fiom the wild of their respective kinds, as they do from each other. We shall notice the following, as among the most interesting of the species:

Anas Cygnus, the wild swan, measures five fect in length, and above seven in breadth, and weighs from thirteen to six. teen pounds. The bill is three inches long, of a ycllowish white; from the base to the middle, and thence to the tip, black; the bare space from the bill over the eye and cye-lids is yellow : the whole plumage in adult birds is of a pure white, and next to the skin they are clothed with a thick fine down: the legs are black. This species generally keeps to. gether in small flocks, or families, except in the pairing season, and at the setting in of winter. At the latter period they assemble in immense multitudes. parti. cularly on the large rivers and lakes of the thinly-inhabited northern parts of Europe, Asia, and America : but when the extremity of the weather threatens to become insupportable, in order to shun the grathering storm, they shape their course high in the air, in divided and diminished numbers, in search of milder climates. In sucli seasons they are most commonly seen in rarious parts of the British isles, and in other more southern countries of Europe. The same is ob. served of them in the North Anerican states. 'Tley do not, however, remain longer than till the approsch of the spring, when they again retire northward to the auctic regions to brecl. $\mathrm{A} \mathrm{few}$, 
indeed, drop short, and perform that office by the way, for they are known to breed in some of the Hebrides, the Orkney, shetland, and òther solitary isles; but these are hardly worth notice : the great boclics of them are met with in the large rircrs and lakes near Iludson's Bay, and those of Kampschatka, Lapland, and Iceland. They are said to return to the latter place in flocks of ahout a hundred at a time in the spring, and also to pour in upon that island from the north, in nearly the same manner, on their way soutliward, in the autumn. The young which are bred there remain throughout the furst year; and in August, when they are in noult, and unable to fly, the natives, laking aclvantage of this, kill them with clubs, shoot, and hunt them down with dogs, by which they are casily caught. 'the flesh is highly esteemed by them as a delicious food, as are also the eggs, which are gathered in the spring. The Icelanders, Kamschatrlales, and other natives of the northem world, dress their skins with the down on, sew them together, and make them into gamnents of various kinds : the northern American Indians do the same, and sometimes weave the down as barbers weave the cauls for wigs, and then manufaeture it into ornamental dresses for the women of rank, wlile the larger feathers are formed into caps and plumes, to decorate the heads of their chicts and warriors. They also gather the feathers and down in large quantities, and barter or sell them to the inlabitants of more civilized nations. Much has been said of the singing of the swan, in ancient times, and many beautiful and poetical descriptions have been given of its dying song. No fiction of natural history, no fable of antiquity, was ever more celebrated, often repeated, or befter received; it occupied the soft and lively imagination of the Greeks ; poets, orators, and even philosophers, adopted it as a truth too pleasing to be doubted. The dull insipid truth, however, is very different from such amiahle and affecting fables; for the voicc of the swan, singly, is shrill, piercing, and harsh, not unlike the sound of a clarionet when blown by a novice in music. It is, nevertheless, asserted by those who have heard the mited and varied voiees of a numerous assemblage of them, that they produce a more harmonious effeet, particularly when softened by the murmur of the waters. At the seting in of frosty weather, the wild swans are said to associate in prodigious multitudes, and, thus united, to use every effort to prevent the water from freezing : this they accomplisis by the continual stir kept up amongst. them; and by constantly dashing it with their extended wings, they are enabled to remain as long as it suits their convenience, in some favourite part of a lake or river which abounds with their food. The swan is very properly entitled the peaceful monarch of the lake: conscious of his superior strength, he fears no enemy, nor suffers any bird, however powerful, to molest him; neither does he prey upon any one. Hlis vigorous wing is as a shield against the attacks even of the eagle, and the blows from it are said to be so powerful as to stun or kill the fiercest of his foes. The wolf or the fox may surprise him in the dark, but their efforts are vain in the day. His food consists of the grasses and weeds, and the seeds and roots of plants which grow on the margins of the water, and of the myriads of insects which skim over, or float on its surface; also occasionally of the slimy inhabitants within its bosom. The female makes her nest of the withered leaves and stalks of reeds and mushes, and lays commonly six or seven thickshelled white eggs : she is said to sit upon them six weeks before they are hatched. Both male and female are very attentive to their young, and will suffer no enemy to approach them.

Anas olor, or mute swan. The plumage of this species is of the same snowy whiteness as that of the wild swan, and the bird is covered next the body with the same kind of fine close down; but it greatly exceeds the wild swan in size, weighing about twenty-five pounds, and measuring more in the length of the body and extent of the wings. This also differs, in being furnished with a projecting, callous, black, tubercle, or knob, on the base of the upper mandible, and in the colour of the bill, which in this is red, with black edges and tip; the naked skin between the bill and the eyes is also of the latter colour: in the wild swan this bare space is yellow. The swan, although possessed of the power to rule, yet molests none of the other water-birds, and is singularly social and attentive to those of his own family, which he protects from every insult. While they are employed with the cares of the young brood, it is not safe to approach near them, for they will fly upon any stranger, whom they often beat to the ground by repeated blows; and they have been known by a stroke of the wing to break a man's leg. But, however powerful they are witht heir wings, yet a slight blow on the head will 


\section{ANAS.}

kill them. The swan, for ages past, has been protected on the river 'Thames, England, as royal property ; and it continues at this day to be accounted felony to steal their eggs. "13y this means their increase is sccured, and they prove a de. lightful ornament to that noble river." Iatham says, "In the reign of F.dward IV. the estimation they were held in was such, that $n 0$ one who possessed a freehold of less than the clear yearly value of five marks was permitted even to keep any." In those times, hardly a piece of water was left unoccupied by these birds, as well on account of the gratification they gave to the eye of their lordly owners, as that which they also afforded when they graced the sumptuous board, at the splendid feasts of that period : but the fashion of those days is passed away, and swans are not nearly so common now as they were formerly, being by most people accounted $a$ coarse kind of food, and consequently held in little estimation: but the cygnets (so the young swans are called) are still fattened for the table, and are sold very high, commonly for a guinea each, and sometimes for more : hence it may be presumed, they are better food than is generally imagined. This species is'said to be found in great numbers in lussia and Siberia, as well as further sonthward, in a wild state. They are, without an owner, common on the river Trent, and on the salt-water inlet of the sea near Abbotsbury, in Dorsetshire : they are also met on other rivers and lakes in different parts of the British isles. The femaje makes her nest, concealed among the rough herbage, near the water's edge: she lays from six to eight large white eggs, and sits on them about six weeks (some say eight weeks) before they are hatched. The young do not acquire their full plumage till the second year. It is found by experience that the swan will not thrive if kept out of the water: confined in a court yard, he makes an awkward figure, and soon becomes dirty, taw. dry, dull, and spiritless.

Anas Canadensis, or Canada goose, is another useful species, which has been reclaimed frum a state of nature, and domestieated and multiplied in many parts of Europe, particularly in France and Germany; and it is not very uncommon in England. It is as familiar, breeds as frecly, and is in every respect as raluable as the common goose : it is also accounted a great ornament on ponds near gentlemen's seats. MIr. Pennant, in his Arc. tic Zoology, gives the following intercsting account of the mode of taking the Canada goose in Hudson's bay: "The Fnglish of" Iludson's bay depend greatly on geese, of these and other kinds, for thicir support; and, in favourable years, kill three or four thousand, which they salt and barrel. Their arrival is impatiently attended ${ }_{i}$ it is the harbinger of the spring, and the month named by the Indians the Goose Moon. They appear usually at our settlements in numbers, about St. George's Day, O.S., and fly northward to nestle in security. They prefer islands to the continents, as further from the haunts of men. Thus, Marble Island was found, in August, to swarm with swans, geese, and ducks; the old ones moulting, and the young at that time incapable of flying." "The English send out their servants, as well as Indians, to shoot these birls on their passage. It is in vain to pursue them; they therefore form a row of huts made of bows, at musket-shot distance from each other, and place them in a line across the rast marshes of the country. Each hovel, or, as they are called, stand, is oceupied by only a single person. These attend the flight of the birds, and, on their approach, mimic their cackle so well, that the geese will answer, and wheel and come nearer the stand. The sportsman keeps motionless, and on his knees, with his gun cocked, the whole time, and never fires till he has seen the eyes of the geese. Me fires as they are going from him, then picks up another gun that lies by him, and discharges that. The geese which he has killed he sets up on sticks, as if alive, to decoy others; he also makes artificial birds for the same purpose. In a good day (for they fly in very uncertain and unequal numbers) a single Indian will kill two hundred. Notwithstanding every species of goose has a different call, yet the Indians are admirable in their initation of every one."- "The vernal flight of the geese lasts from the niddlle of A pril until the middle of May. Their first appearance coincides with the thawing of the swamps, when they are very lean. The autumnal, or the season of their return with their young, is from the middle of August to the niddle of October. Those which are taken in this latter season, when the frosts usually begin, are preserved in their feathers, and left to be frozen, for the fresh provisions of the winter stock. The feathers constitute an article of commerce, and are sent into England." "This is the common wild goose of the United States; cinereous : head and neck black; cliceks and chin 


\section{ANAS}

white, also the vent and tail-coverts : it is often tamed, and will breed with the common goose, producing a larger offspring

Anas Anser, or tame goose. To describe the varied plumage and the economy of this well known and valuable do. mestic fowl, may- seem to many a needless task; but to others, unacquainted with piral aftairs, it may be interesting. Their predominant colours are white and grey, with shades of ash, blue, and brown : some of them are yellowish, others dusky, and many are found to differ very little in appearance from the wild kind last described-tle original stock, whence, in early times, they were all derived. The only permanent mark, which all the grey ones still retain, like those of the wild kind, is the white ring which surrounds the root of the tail. They are generally furnished with a small tuft on the head, and the most usual colour of the males (gander or stig) is pure white : the bills and feet in both males and females are of an orange red. By studied attention in the breeding, two sorts of these geese have been obtained: the less are by many esteemed as being more delicate eating: the larger are by others preferred, on account of the bountifiul appearance they make upon the festive board. The average weight of the latter kind is between nine and fifteen pounds; but instances are not wanting, where they liave been fed to upwards of twenty pounds ; this is, lowever, to sacrifice the flavour of the food to the size and appearance of the bird, for they become disgustingly fat and surfeiting, and the methods used to cram them up are unnatural and cruel. It is not, however, altogether on account of their use as food that they are valuable; their feathers, their down, and their quills, have long been considered as articles of more importance, and from which their owners reap more advantages. In this respect the poor creatures have not been spared: urged by avarice, their inhuman masters appear to have ascertained the exact quantity of plumage of which they can bear to be robbed, withoutbeingdeprived of life. Mr. Pennant, in describing the methods used in Lincolushire, in breeding; rearing, and plucking geese, says, "they are plucked five times in the year; first at Lady-day for the feathers and quills : this business is renewed, for the feathers only, four times more between that and Michaelmas:" he adds, tliat he saw the operation performed even upon goslings of six weeks old, from which the feathers of the tails were plucked; and that num: bers of the geese die when the season afterwards proves cold. But this unfeeling greedy business is not peculiar to one country, for much the same is practised in others. The care and attention bestowed upon the brood geese, while they are engaged in the business of incubation, in the month of April, is nearly the same every where; wicker pens are provided for them, placed in rows, and tier above tier, not uncommonly under the same roof as their owner. Some place water and corn near the nests; others drive them to the water twice a day, and replace each female upon her own nest as soon'as she returns. 'This business requires the attendance of the gozzard (goose-herd) a month at least, in which time the young are brought forth : as soon afterwards as the brood are able to waddle along, they are, together with their dams, driven to the coutiguous loughs and fens, or marshes, on whose grassy margined pools they feed and thrive, without requiring any further attendance until the autumn. To these marshes, which otherwise would be unoccupied, (excest. by wild birds, ) and be only useless watery wastes, we are principally indebted for so great a supply of the goose; for in almost every country, where lakes and marsbes abound, the neighbouring inhabitants keep as many as suit their convenience; and in this way immense numbers annually attain to full growth and perfection; but in no part of the world are such numbers reared, as in the fens of Lincolnshire, where it is said to be no uncommon thing for a single person to keep a thousand old geese, each of which, on an average, will bring up seven young ones. So far those only are no. ticed which may properly be called the larger flocks, by which particular watery districts are peopled; and, although their aggregate numbers are great, yet they form only a part of the large family : those of the farm-yard, taken separately, appear as small specks on a great map; but when they are gathered together, and added to those kept by almost every cottager throughout the kingdom, the immense wlole will appear multiplied in a ratio almost incalculable. A great part of those which are left to provide for themserves during the summer, in the solitary distant waters, as well as those which enliven the village green, are put into the stubble fields after harvest, to fatten upon the scattered grain : and some are penned up for this purpose, by which they attain to greater bulk; and it is hardly necessa- 


\section{ANAS.}

sy to observe, that they are then poured in weekly upon the tables of the luxurious citizens of every town in the kingdom. IBut these distant and divided supplies seem trifling, when compared with the multitudes, which, in the scason, are driven in all directions, into the metropolis ; the former appeas only like the scanty waterings of the petty streamlet; the latter like the copious overflowing torrent of a large river. To the country market towns they are carried in bags and pannicrs; to the great centre of trade they are sent in droves of many thousands. To a strarger it is a most curious spectacle to view these hissing, cackling, gabbling, but peaceful armies, with grave deportment, waddling along, (like other armies) to certain destruction. The drivers are each provided with a long stick, at one end of which a red rag is tied as a lash, and a hook is fixed at the other: with the former, of which the gecse seem much afraid, they are excited forwand ; and with the latter, such as attempt to stray are caught by the neck and kept in order; or if lame, ticy are put into an hospital-cart, which usually follows each large drove. In this manner they perform their journies from distant parts, and are said to get forward at the rate of eight or ten miles in a day, from tliree in the morning till nine at night: those which become fatigued are fed with oats, and the rest with barley. The tame goose lays from seven to twelve eggs, and sometimes more : these the careful housewife divides equally among her brood geese, when they begin to sit. Those of her geese which lay a second time in the course of the summer, are seldom, if ever, permitted to have a second hatching; but the eggs are used for house. hold purposes. In some countries the do. mestic geese require much less care and attendance than those of this country. The goose has for manyages been celeb rated on account of its vigilance. The story of the saving Rome by the alarm they gave, when the Gauls were attempting the Capitol, is well known, and was probably the first time of their watchfulness being recorded, and, on that account, they were af terwards held in the lighest estimation by the Ro. man people. It is certain that nothing can stir in the night, nor the least or most distant noise be made, but the geese are roused, and immediately begin to hold their cackling converse; and on the nearer approach of apjechended danger, they set up their more slurill and clamorous crics. It is on account of this property that they are estcemed by many persons as the most rigilant of all sentincls, when placed in particular situations.

Anas Erythropus, or barnacle of Europe. The barnacle weighs about five pounds, and measures more than two feet in length, and nearly four and a half in brcadtl. The bill, from the tip to the corners of the mouth, is scarcely an inch and a half long, black, and crossed with a pale reddish streak on each side: a narrow black line passes from the bill to the eyes, the irides of which are brown : the head is small, and as far as the crown, together with the checks and throat, white: the rest of the head and neck, to the breast and shoulders, is black. The upper part of the plumage is prcttily marbled or barred with bluse-grey, black, and white : the feathers of the back are black, edged with white, and those of the wing. coverts and scapulars blue-grey, bordered with black near their margins, and edged with white: the quills black, edged a little way from the tips with blue-grey: the under parts and tail coverts white: the thighs are marked with dusky lines or spots, and are black near the knces; the tail is black, and five inches and a half long: the legs and feet dusky, very thick and short, and have a stumpy appearance. In severe winters, these binds are not uncommon in England, particularly in the northern and western parts, where, how. ever, they remain only a short time, but depart early in the spring to their northern wilds, to breed and spend the summer.

Anas Bernicla, Brent Goose. Brown: head, breast and neck black, the latter with a lateral white spot : tail-coverts and vent white: plentiful on the sea coast of North America in autumn. It is considered by Mr. Wilson as the same with the Barnacle Goose (A. Erythropus.)

Anas molissima, or eider duck. This wild, but valuable, species is of a size be. tween the goose and the domestic duck, and appears to be one of the graduated links of the chain which connects the two kinds. The full-grown old males generally measure about two fect two inclies in length, and two fcet eighte enin breadth, and weigh from six to above seven pounds. The female is nearly of the same shape, though less than the malc, weighing only between five and six pounds; but her plumage is quite different, the ground $\mathrm{co}$ lour being of a reddish brown, prettily crossed with wared black lines; and in some specimens the neck, breast, and belly, are tinged with ash: the wings are crossed vith two bars of white: quills 


\section{ANA}

lark : the neck is marked with longitudinal dusky streaks, and the belly is deep brown, spotted obscurely with black. The eider duck lays from three to five large, smooth, pale, olive-coloured eggs ; these she deposits and conceals in a nest, or bed, made of a great quantity of the soft, warm, elastic down, plucked from her own breast, and sometimes from that of her mate. The ground-work or foundation of the nest is formed of bent-grass, sea-weeds, or such like coarse materials, and it is placed in as sheltered a spot as the bleak and solitary place can afford. In Greenland, Iceland, Spitabergen, Lapland, and some parts of the const of Nor. way, the eiders flock together, in particular breeding places, in such numbers, and their nests are so close together, that a person in walking along can hardly avoid treading upon them. The natives of these cold climates eagerly watch the time when the first hatchings of the egrss are laid : of these they rob the nest, and also of the nore important article, the down with which it is lined, which they carcfully gather and carry off. These birds will after'wards strip themselves of their remaining down, and lay a second hatching, of which also they are sometimes robbed: but it is said, that when this cruel treatment is too often repeated, they leare the place, and return to it no more. The quantity of this valuable commodity, which is thus annually collected in various parts, is uncertain. Buffon mentions one particular year, in wlich the Icelandic company-sold as much as amounted to upwards of eight hundred and fifty pounds sterling. This, however, must be only a small portion of the produce, which is all sold by the hardy natives, to stuff the couches of the pampered citizens of more polished nations. The great body of these birls constantly resides in the remote northern, frozen climates, the rigours of which their thick clothing well enables them to bear. They are said to keep together in flocks in the open parts of the sea, fishing and diving very deep in quest of shell-fish and other food, with which the bottom is co. vered; and when they have satisfied them. selves, they retire to the shore, whither they at all times repair for shelter, on the approach of a storm. Other less numerous flocks of the eiders branch out, colonize, and breed further southward, in both Eu. rope and America: they are found on the promontories and numerous isles of the coast of Norway, and on those of the northern, and the Hebrides or western isles of Scotland, and also on the Fern isles, on

\section{ANA}

the Northumberland coast, which latter is the only place where they are known to breed in England, and may be said to be their utmost southern limit in that quarter, although a few solitary instances of single birds' being shot further southward along the coast have sometimes happened.

Anas Marilla, scaup duck, or Blue-bill. This species measures, when stretched out, nearly twenty inclies in length, and thirty-two in breadth. The bill is broad and flat, more than two inches long, from the corners of the mouth to the tip, and of a fine pale blue or lead colour, with the nail black : irides bright deep yellow : the head and upper half of the neck are black, glossed with green : the lower part of the latter, and the breast, are of a sleek plain black: the throat, rump, upper and under coverts of the tail, and part of the thighs, are of the same colour, but dull and more inclining to brown. The tail, when spread out, is fan-shaped, and consists of fourteen short, brown feathers. The legs are short, toes long, and as well as the outer or lateral webs of the inner toes, are of a dirty pale blue colour; all the joints and the rest of the webs are dusky. These birds are said to vary greatly in their plumage, as well as size; but those which have come under the author's observation were all nearly alike. The scaup duck, like others of the same genus, quits the rigours of the dreary north in the winter months, and in that season only is met with on various parts of the American shores. It is well known in England.

Anas Clangula, the golden-eye. The weight of this species varies from twenty. six ounces to two pounds. The length is nineteen inches, and the breadth thirty. one. These birds do not congregate in large flocks, they are varied with black and white; head tumid, violet; at each corner of the mouth a white spot. They are frequent in the waters of the United States during the winter, and take their departure northward in the spring. In their flight they make the air whistle with the vigorous quick strokes of their wings; they are excellent divers,' and seldom set foot on the shore, upon which, it is said, they walk with great apparent difficulty, and, except in the breeding season, only repair to it for the purpose of taking their repose. The attempts which were made by $M$. Baillon to domesticate these birds, he informs the Count de Buffon, quite failed of success. See Plate 11I. Ares, fig. 1 to 5 .

ANASARCA, in medicine, a species of dropsy, wherein the skin appears puffed 


\section{ANA}

up and swelled, and yiclds to the impres. sion of the fingers, like dough Sec $\mathbf{I E}$ Dicisis.

ANASTATICA, the rose of Jericho, in botany, a genus of the Tetradynamia Siliculosa class of plants, the calyx of which is a deciduous jerianthium, consisting of four oval, oblong, coneare, ercet, and de. ciduous leaves ; its flowers consist of four roumlish petals, disposecl in the form of : cross; and its fruit is a short bilocular pod, containing in each cell a single roundish seed. There are two species; one is found growing uaturally on the coast of the Red sea, in l'alestine, and near Cairo, in sandy places. The stalks are ligneous, though the plant is aninual. It is prescrred ins botanic gardens for the variety, and in sone curious gardens for the odd. ness of the plant, which, if taken up before it is withered, and kept entire in a dry room, may be long preserved, and after being many years in this situation, if the root is placed in a glass of water a few hours, the buds of the flowers will swell, open, and appearas if newly taken out of the ground. The second species, called the A. syriaca, is a native of Austria, Steria, Carniola, Syria, and Sumatra. These plants, being annual, can be propagated only by seeds, which rarely ripen in Eng. lant.

ANATOMY is the art of examining animal bodies by dissection. It teaches the structure and functions of these bodies, and shews nearly on what life and health depend. When these are well understood, a great step is made towards the knowledge and cure of diseases.

It is derived from the Greck verb,

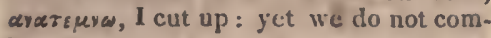
hend under it the mere cutting of dead bodies; but every opcration, by which we endeavour to cliscover the structure and use of any part of the lindy.

As every animal body is the subject of anatomy, we divide it into the human and comparative. The lirst of these, which is confined to the human body, forms the subject of the present article; the last, which is extencled to the whole animal creation, will be considered umeler the head of Compantive Avatonx. The offices or functions of the various parts of the body are the objects of the science of Pursioconr: to which article the reader is reforred for those subjects.

The limits to which we are confined, by the nature of the present work, will prevent us from entering much into the details of the structure and composition of the human body. We shall present the VOL.I.

\section{ANA}

reader with a general sketch of the sub. ject, as being more suited to the space which this article is allowed to occupy. After a cursory view of the origin and progress of anatomical science, we sliall give a general description of the component parts of the human body, and their functions; and proceed in the last place to the more particular enumeration and description of the various organs.

\section{HISTOII OF ANATUMY.}

The want of recorls leaves us in the dark, with regard to the origin of tlis art; yet it is reasonable to conclude, that, like most other arts, it had no precise beginning. The nature of the thing would not aduit of its lying for a time altogetlier concealed, and of being suddenly brouglit to liglit, either by chance, or genius, or industry.

All the studies and arts which are ne. cessary in human life are so interusting and obvious, that man in every situation has always by instinct and common sense tumed his thoughts to them and male some progress in the cultivation of them. To talk seriously of the invention of agriculture, architecture, astronomy, navigation, mechanics, physic, surgery, or anatomy, by some particular man, or in one particular country, or at a time subsequent to some prior are, would be to discover great ignorance of human nature. We might just as well suppose, that, till a certain period of time, man was without instinctive appetites, and without observation and reflection, and that in a happy hour be found out the art of supporting lifc by taking food. All sucl arts, in a less or niore cultivated state, were, from the beginning, and ever will be, found in all parts of the inhabited world.

The first men who lived must soon have acquired some notions of the structure of their own bodies, particularly of the extemal parts, and of some cren of the internal, sticly as bones, joints, and sinews; which are exposed to the examination of the senses in the living boly.

This rurle knowledge was indecl gradually improved by the accillents to which the body is exposed, by the necessities of life, and by the various custons, ceremo. nies, and superstitions of different nations. Thus, the observance of bodics killed by violence, attention to wounded men, and to many cliseases, the various ways of putting criminals to death, the funeral cere. monies, and a variety of such things, must have shewn men, every day; more and 
more of themselves; especially as curiosity and self-love would urge them powerfully to observation and reflection.

The brute creation having such an affinity to man, in outward form, motions, senses, and ways of life, the generation of the species, and the effect of death upon the body, being observed to be so nearly the same in both, the conclusion was not only obvious, but unaroidable that their bodies were formed nearly upon the same model. The opportunities of examining the bodie's of brutes were so easily procured, indeed so necessarily occured in the common business of life, that the luuntsman in making use of his prey, the priest in sacrificing, the augur in divination, and, above all, the butcher, or those who might out of curiosity attend his operations, would have been daily adding to the little stock of anatomical knowleclge. Accordingly we find, in fact, that the South-sea islanders, who have been left to their own observation and reasoniug, without the assistance of letters, have yet a considerable share of rude or wild anatomical and physiological knowledge. When Omai was in Dr. Hunter's museum, although he could not explain himself intelligibly, it appeared plainly that he kuew the principal parts of the body, and something like wise of their uses, and manifested a great curiosity, or desire, of having the functions of the internal parts of the body explained to lim; particularIy the relative functions of the two sexes, which, with him, seemed to be the most interesting object of the human mind. The poems of Homer likewise shew us that many facts were popularly known in his time; he probably possessed the general information on the subject. The following passages display a knowledge of some of the internal parts of the body:

"Antilochus, as Thoon turn'd him round,

Transpierc'd his back with a dishonest wounkl.

The hollow vein that to the ncek extends,

Along the chine, his eager jav'lin rends." Iliad, b. 13 .

The stonc, which Dinmed threw at Encas, is srid to have broken the acetabulium, and to have torn both the ligaments which connect the thigh in its situation. These particulars are not mentioned in Mr. P'ope's translation, we thercfore cite the original:

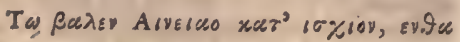
TE unpos

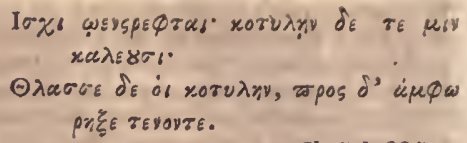

Il. 5. 1. 305 .

From the sources which have been just enumerated was derived the anatomical knowlege of early times. This knowledge was general or popular. . Inatomy, properly so called, viz. the knowledge of the structure of the body, obtained by dissections expressly instituted for that purpose, is of much inore recent origin.

Civilization and improvement of every kiud would nafurally hegin in fertile conntrics and healthful climates, where there would he leistre for reflection, and an ap: petite for amusement. It seems now to be clearly made out, that writing, and ma. ny otheruseful and ornamental inventions and arts, were cultivated in the eastern parts of $\mathrm{Asia}$, long before the earliest times that are treated of by the Greek or other European writers; and that the arts and learning of those eastern people were, in subsequent times, gradually communicated to adjacent countries, especially by the medium of traffic. The customs, superstitions, and climates of eastern countries, appear, however, to have been as unfavourable to practical anatomy, as they were inviting to the study of astionomy, geometry, poetry, and all the softer arts of peace. In those war'm climates, animal bodies run so quickly into nauseous putrefaction, that the early inhabitants must have aroided such offensive employments as anatomical inquiries, like their posterity at this day. And, in fact, it does not appear, by the writings of the Grecians, Jcws, or Plicnicians, that anatomy was particularly cultivated by any of those nations.

The progress of anatomy in the early ages of the world was more particularly prevented by a very generally prevalent opinion, that the touch of a dead body communicated a moral pollution. When we consider the extent and inveteracy of this prejudice, we shall cease to wonder at the imperfect state of anatomical know. ledge in the periods now under review. The practice of embalming the bodies of the dead did not at all reconcile the Egyp. tians to dissections. The person who made the incision, through which the viscera were removed, immediately ran away, followed by the imprecations and even vio. le nce of the bye-standers, who considered him to have violated the body of a friend. The ceremonial law of the Jews was very rigorous in this respect. To tauch seve- 
ral animals which they accounted unelean, subjected the person to the necessity of purifications, \&.c. To touch a clead body made a person uncleau for seren days. "Whosoever (says the Jewish lawgiver) toucheth the body of any man that is clead and purifietls not limself, defileth the tabernacle of the I.ord; and that soul shall be cut off from Istzel."

fu tracing it bnckwarls in its infancy, we cannot go fartleer into antiquity tloan the times of the Grecian philosophers. As an art in the state of some cultivation, it may be said to have been brought forth and bred up among them, as a branch of natumal knowledge. We discover in the writings of Plato, that he had paid atten. tion to the organization and functions of the human body.

Hippocrates, who lived about four lunn. dred years before Christ and was reckoned the cigluteenth in descent from Nisculapius, was the first who separated the protessions of philosoplyy and physic, and derotel himself exclusively to the latter pursuit. He is generally supposed to be the first who wrote upon anatomy. After the restoration of Greek learning, in the fifteenth century, it was so fishionable for two hundred years together, to extol the knowleclge of the ancients in anatomy, as in other things, that anatomists seem to have made it a point of emulation, who sliould be most lavish in their praise; some from a difficlence in themselves; others tlrough the love of detracting from the merit of contemporaries; many from having laboriously studied ancient learn. ing, and laving become enthusiasts in Greck liternture ; but more, perliaps, because it was the fashionable turn of the times, and was held up as the mark of good eclucation and fine taste. If, how: ever, we read the works' of Ilippocrates with impartiality, and apply his accounts of the parts to what we now know of the human body, we must allow his descrip. tions tobe imperfect, incorrect, sometimes extravagant, and of ten unintelligible, that of the bones only excepted.

From Hippocrates to Galen, who flou. rished towards the end of the second century, in the clecline of the Roman empire, that is, in the space of six lundred years, anatomy was greatly improved; the phi. losophers still considering it as a most curions and interesting bruncls of natural knowledge, and the plyysicians, as a prineipal foundation of their art. Both of them in that interval of time, contributed daily to the common stock, by more accurate and extended observations, and by the lights of improving philosoplyy.
Aristotle, a disciple of Plato, and preceptor of Alexander the Great, is no less entitled to immortality for lis inmense Jabours in uatumal history and comparutive anatomy, than as the founder of the Peri. patetic philosoplyy, which for two thou. sand yeirsheld undisputed sway over the whole learned world. He harl formed the most enlarged desigu which perhaps was ever conceived by any man; no less than tliat of a general and detailed history of all natıre, a plan by far too rast for the sliort life of an individual. The love of science which distinguished Alexander no less than lis ambition and thirst for glory, Jed lim to encourage and assist the plans of A ristotlc in a manmer worthy of so great a prince, of so exalted a genius, and of such magnificent designs. The sum of money which he was thereby enabled to devote to his works on natural history would be almost incredible, did we noto consider the traits of greatness which mark every action of Alexander, and were not the circumstance stated ly writers of urexceptionable authority. Athenzeus, Pliny, and Elian, concur in representing it at between one and two hundred thol:sand pounds.

Slrortly after the foundation of Alexandria, a celebrated school was established there, to which the fireeks and other for. eigners resorted for instruction, and where physic and erery branch of natural know. leclge were taught in the grentest perfee. tion. II rophilus and Erasistratus, two anatomists of this school, are particulas. ly celebrated in the history of anatomy. They secm to be the first who dissected the humanbody. At least in the time of A sistotle, who preceded these anatonists by a very sliort interval, brutes only had been anatomised. It might have been expected that the practice of $\mathrm{cm}$ balming would afford favourable opportunities of anatomical investigation, but the rude manner in which the body was prepared, and the dreacl of pollution, prevented all instructive exannination. 'The progress of the science required that anatomists should have subjects, on which careful and deliberate dissection might be prosecuted without fear of interruption. This benefit was obtained througl the taste which the prinecs of that time displayed for the arts and sciences. The I'tolomies inherited, with their shar of the empire of Alexder, the love of science, which shone so conspicuously in that monarcls. Ptolemy Philadelphus inited to his capital the greatest inen of the age ; and by cullecting books from all parts, at an inmense expense, laid the foundation of the magnif- 
cent Alcxandrian library. This king and his predecessor seem to have overcome the religious scruples which forbade the touch of the dead body, and gave up to the physicians the bodies of those who had forfeited their lives to the law. Nay, if the testimony of severul anthors may be believed, Herophilus and Erasistratus dissected several unfortunate criminals alive. There is, however, something in this practice so repugnant to every fe eling of huma. nity, that we ought probably to considerit only as an exaggerated report of the novel practice of dissecting the human subject. The writings of these anatomists hare not. descended to us : our knoweledge of their progress in anatomy is derived only fiom a few extracts and notices which occur in the works of Galen; but these prove them to have made great advancesin the knowledge of the structure of the human body.

The Romans, in prosecuting their schemes of unirersal conquest and dominion, soon became acquainted with the Greeks, and the intercourse of the two nations was constantly increasing. Thus the arts, the philosophy, and the mamers of the Greeks were introduced into Italy. Military glory and patriotism, which liad formerly been the ruling passion of the Roman people, now gave way in somc degree to the soft arts of peacc. The leading men of the Roman rcpublic sought the company and conversation of the learned Greeks; thus literature and philosophy were transported from the Greeks to the Romans, and gave rise to the taste and elegance of the Augustan age. In this way dicl conquered Greece triumph over the unpolished roughness of her conquerors.

Gracia capta ferum victorem cepit, et artes Intulit agresti Latio.

Although Rome produced orators, poets, philosophers, and historians which mav be brought into competition with those of the Greeks, to the eternal disgrace of their empire it must be allowed that their his. tory is hardly embellished with the name of a single Roman who was great in science or art, in painting or sculpture, in physic, or in any branch of natural knowledge. We cannot therefore introduce one Roman into the history of anatomy. Pliny and Celsus were mere compilers from the Grecks. We may account for this apparent neglect of anatomy among the Romans, as well indeed as for its slow progress among the Greeks, from some of their religious tencts, as well as from the notion already mentioned, of pollution be. ing communicated by'touching a dead bo. dy. It was believed, that the souls of the unburied were not admitted into the 2 bodes of the dead, or, at least, that they wandered for a bundred years along the river Styx, before they were allowed to cross it. Whoever saw a dead body was obliged to throw some earth upon it, and if he neglected to do so, he was obliged to expiate his crime by sacrificing to Ceres. It was unlawful for the pontifex maximus not only to touch a dead body, but even to look at it; and the flamen of Jupiter might not even go where there was 2 grave. Persons who had attended a funeral were purified by a sprinkling of water from the hands of the priest, and the house was purified in the same manner. If any one (says Euripides, in Iphigenia) pollutes his hands by a murder, by touching a corpse, or a woman who has lain in, the altars of God are interdicted to him.

There was no anatomist or physiologist, of sufficient reputation to attract our notice, from the times of Herophilus and Erasistratus to the age of Galen. 'This illustrious character was born at Pergamus, in Asia Minor, about the 130th year of the Christian xra. No expense was spared in his education; after the completion of which, he risited all the most famous schools of philosophy which then existed; and afterwards resided chiefly at Rome, in the service of the emperors of that time,

To all the knowledge which could be clerived from the writings of Ilippocrates, and the philosophical schools of the time, Galen addecl the results of his own labours and observations, and compiled from these sources a roluminous system of medicine. It is generally considered that the subjects of his anatomical labours were chiefly brutes; and it is manifest from several passages, that his descriptions are drawn from monkeys. Indeed, he never expressly states that he has dissected the human subject, although he says he has seen human skeletons. IIe must be accounted the first whoplaced anatomical science on a respectable footing; and deserves our gratitude for this, that he was the only source of anatomical knowledge for about ten centuries. The science declined with Galen; his successors were contented with copying him; and there is no proof of a dissection of any human body from Galen to the emperor Frederick iI. We may observe, that when any man arrives at the reputation of having carried his art far beyond all others, it seems to throw the rest of the world into a kind of despair. Hopeless of being able to improre their art still further, they do nothing. The great man, who was at first only respectable, grows 
every day into higher credit, till at Jength he is deified, and every page of his writings becomes sacred and infallible. This visas actually the fortune of Aristotle in philosopliy, and of Galen in anatomy, for many ages; aud such respect shewn to auy man in any age must always be a mark of declining science.

Anatomy experienced the same fate as learuing in general on the decline and fall of the Ronun empire. The moral and intellectual character of the Romans had bcen much debassd in the later ages of the empire. Philosophy and science were manifestly degenerating, and their place was supplierl by adebased and corrupted theology. The successive irmuptions of the northern barbarians accelerated the approaching ruin. The great inundation of the Goths into Italy, in the fifth century, extinguished, witli the Roman empire, its laws, manners, and learning, and plun. ged the world into the depths of iguorance and superstition. The succeeding ten centuries, which have received the appel. lation of the dark ages of the world, pre. sent a melancholy picture to the philosophic observer of human nature; a harren and dreary waste, not eulivened by a single trace of cultivation.

The followers of the Arabian prophet dissipated the little remains of learning that were left in Asia and Kgypt. A contempt of all human knowledge, and the religious obligation of extending the Mahonetan faith by means of the sword, made these ignorant barbarians the most dangerous and lestructive foes to science and the arts. The city of Alexandria, the school of which hal becn the resort of the learned for centuries, was taken in the year 640 , hy Amrou, the general of the Caliph Omar; the celebrated library was buint, with the exception of those bnoks which related to merlicine, whicli the love of life induced the Arabians to spare.

When the Saracens were establislied in their new conquests they began to discern the utility of learning in the arts and sciences, and particularlyin physic. Maloonet had made it death for any Nussulman to learn the liberal arts : this prolijbition was gradually neglected, and many of the calipliss distinguislied themselves by their love of letters, and the munificent institutions which they founded for the propazation of learning. The freck authors were collected, translated, and commented on; but there was no improvement nor extension of science marle. In anatomy, the Arabians went no further than Galen, the perusal of whose works supplied the placc of dissection. Theywere prevented from touching the dead by their tenets respecting uncleanness and pollution, which they had derived from the Jews

The Irabian enpirt in the east was arerturned by the Turks, who, still more barbarous ani illiterate tlan the Sar:tcens, carricol ignorance and oppression wherever they directed their footsteps. They soon destroyed all the institutions which the Saracens had formed for the propagation of science, and threatened Constantinople itself, which still retained the faint and almost dying embers of Greek knowledge. This city was taken and sacked in the midclle of the fifteenth century ; and the learned Greeks fled for safety to the western nations of Europe, bringing with them the Grecian authors on medicine, and translating them : which works, the invention of printing, that happened about the same time, greatly contributed to disperse throughont Europe. Peoplelad now an opportunity of becoming acquainted with the writings of Galen and the ancients, and, by these means, of arriving at the source of that knowledge which they had hitherto obtained only through the clianel of the Arabian plyssicians. The superiority of the former was soon discovered, and the opinions of the Grecian writers were considered, even in anatomy, as unimpeacliable.

For the restoration of anatoniy, as well as tlat of science in general, we are indebied to the Italians. I3ut the first men who signalized themselves in this path partook of that blind reverence for the words of Galen, which had reigned uni. versally in medieine since his death, and which concurred with the universally prevailing prejudices of those times, concerning the violation of the dead, to obstruct alladvancement of the science. As an instance of the latter circumstance, we may mention a decree of Pope Boniface VIII. prohibiting the boiling and pre paring of bones, whicli put a stop to the researches of Mundinus.

Among the circumstances which contributed to the restoration of anatomy is to be reckoned, the assistance which it derived firm the great painters and sculptors of this age. A knowledge of the anatomy of the surface of the body, at least, is essential to the prosecution of these arts. Michael Angelo dissected nuen and animals, in orcler to learn the muscles which lie under the skin. A collection of anato. mical drawings ntade hy Leunardo da Vinei at this period, is still extant, and, with subjoined explanations, are found in the library of the king. Dr. Ifunter hears witness to the minute and accurate know- 
ledge which these sketches discover, and doe's not hesitate in considering Leonardo as the best anatomist of that time.

Abont the midldle of the sixteenth century the great Vesalius appeared, He was born at Brussels, and studied successive. ly at the different miversities of France and Italy. Thus he acquired all the knowledge of antiquity. Not contented with this, he took every npportunity of examinins the human body, and followed the army of the emperor Charles $V$. into France for that purpose. Vesalius was the first who maintained that dissection was the proper way of learning anatomy, in opposition to the study of the works of Galen. His extcnsive researches into the structure of man and animals led him to retect the errors of Galen, which he freely exposed, shewing from many parts of his works, that this great man had clescribed the human body from the dissection of brutes. This conduct, which should have excited the admiration and estcem of his contemporaries, served only to rouse in their minds the base and sordid passions of jealousy and envy. Galen had held an. undisputed sway over the minds of men for many centuries. I His works were regarded as the only source of anatomical know:ledge, and his opinion on medical subjects, like that of Aristotle in philosophy, wasresorted to in all disputes as final and decisive proof. The first man who penetrated this intellectual mist, and erected the standard of reason and truth, ip opposition to that of prejudice and anthority, unight naturally expect to encounter the opposition of those who had been contented to go on in the beaten track. The anatomists, who had always held up Galen in their lectures as the source of all information, were indignant that his faults should be discovered and laid open by so roung a man as Vesalius. The con. troversies which arose from this cause were favourable to the progress of anato$\mathrm{my}$, as the several disputants were obliged to confirm their own opinions, or invalidate those of their opponents, by arguments drawn from dissection.

Vesalius published, at the age of 25 , lis grand work on the structure of the liuman body, with numerous elegant figures, supposed to have beendrawn by the celebrated Titian. This work contains such a mass of new information, that it may justly be considered as forming an ara in the history of anatomy We cannot help being surprised that so young a man could have investigated the subject so deeply, at a time when dissection was esteemed sacrilegious, and was therefore carricd on sc- cretly, with great danger and difficulty. The great reputation of Vesalius procured for lum the esteem and confidence of Charles V. who made him his physician, and kept him about his person in all his expeditions. 1 lis zeal for science proved. the cause of his death : for having opened. a person too soon, the heart was seen to palpitate. He was condenned to perform a pilgrimage to Jerusalein; and as he was returning to take the placc of anatomical professor at Venice, he was slipwrecked on the island of Zante, and perished of hunger. It would be unjust to pass over unnoticed the names of Fallopius and of Eustachius, who were contemporary with Vesalius, and contributed greatly to the advancement of anatomy. The anatomical plates drawn and engraved by the latter are executed with an accuracy which cannot fail to excite surprise, even in an anatomist of the present day.

From the time of Vesalins, the study of anatomy gradually diffused itself over Europe ; insomuch, that for the last hundred and fifty years it has been daily improving by the lahour of many professed a natomists in almost every country of Europe.

. In the year 1628 , our immortal countryman, Harvey, published his discovery of the circulation of the blood. It was by far the most important step that has been made in the knowledge of animal bodies in any age. It not only reflected useful lights upon what had been already found out in anatomy, but also pointed out the means of further investigation; and accord. ingly we see that, from Harvey to the present time, anatomy has been so much impioved, that we may reasonably question if the ancients have been further outdone by the moderns in any other branch of knowledge. From one day to another there has been a constant siccession of discoreries, relating either to the structure or functions of our body ; and new anatomical processes, both of investigation and demonstration, have been daily invented. Many parts of the body, which were not known in Harvey's time, have since then been brought to light; and of those which were known, the internal composition and functions remained unerplained ; and indeed must have remained inexplicable, without the knowledge of the circulation.

The principal facts relating to this subject were known before the time of Harvey : it remained for lim to reject thespecious conjectures then maintained conccrning the blood's motion, and to examine the truth of those facts which were then known, and by experiments to discover those which remained to be detected. 


\section{ANA'OMY.}

This he did, and thereby rendered his name ímmortal.

It secms proper in this place to review the several steps which were made in the investigation of this important subject. Hippocrates belicved that all the vessels communicated with each other, and that the blood underwent a kind of flux and re. flux from and to the heart, like the ebbing and flowing of the sea. The anatomists at A lexundria adopted a w mng but ingenious opinion; as they fo.md the arteries empty, and the veins containing blood, in their dissections, they imagined that the former were tubes for the distribution of air, and gave them that name, which they have re. tained ever since; and that the veins were the only chamels for the bloor. Galen iscertained that the blood flowed both by the arteries and reins, though he knew not then its natural course. On the reviral of anatomy in Europe,tlie pulmonary circulation was known to many eminent men. This was certainly the case with Servetus, who fell a sacrilice, on account of his religious opinions, to the savage bigotry and intolerance of Calvin. Fubricius ab Aquapendente, the preceptor of our famous Harvey, particularly deseribed the valves of the veins, the mechanism of which would absolutely prevent the blowd finin flowing in those vesscls towards the-extremities. When Ilarvey returned from his sudies in Italy, his attention being excited to the subject, he began those experiments, by which he learned and demonstrated the fact of the circulation. Harvey's first proposition of the subject im. presses conviction so strongly on the mind that we are left in perfect astonishment, how a circumstance so luminuusly evident slould have remained so long unobserved. It must be granted, that the heart projects about two ounces of blood into the arteries at every pulse; what then, it may be asked, becomes of this large quantity of blood, umless it circulates? It must be granted that the heart reccires that quantity prior to every pulse. From whence is it received, unless the blood circulates? Harvey tied an artery, and the corresponding vein received no blood; he tied a vein, and all its branches, and those of the cor. responding artery were choaked with blood, even to the entire obstruction of circulation and motion. But Ilarvey was not acquainted with the direct communication that exists between thiese ve'ssels. He imagined that the blool transuded from the arteries into the veinstlimugh a spongy substance. Mnch yet remained to bc ascertained by microscopical observa- tions, and subtile anatomical injections and Iissections.

As opportunities of dissection lsecame more numerous, the defects of the old writers in anatomy were discoverel. Ingeni. ous men, having gone through their education, determined to consult nature for theniscives. It is not to be wondered at that errors and deficiencies in auatomy were found in every page of the works of Galen, tu say notling of Ilippocrates, since the hmman body, in his time, conld not be consulted for information. The authority of the Greck writers on these subjects was quiekly demolished, and amatomy began to be taught from the subject itself. IVe must not omit the infurence, which the writugs of our inmortal countryman, 13a. con, had on the proscecution of natural knowledge, and in cvery species of reasoning. The philosophy of Aristotle was driven from the pre-eminent station which it had so long occupied, to make room for the only solid and secure method of observation, experiment, and induction. At this time the Acarlemy del Cimento arose in Italy, the Royal Society in I.ondon, and the Royal Academy in Paris. From this period, the important doctrine of rejecting all hypothesis, or general knowledge, till a sufficient number of fiets shall liave been ascertained, by curefiul observation and ju. dicious experiments, has been crery day growing into more crelit. The anatomists and plisiologists of these times distinguished theinselves by a patient observa. tion of nature itsclf, and an accurate account of the phanomena which they obsęrved.

After the discovery and knowledge of the circulation of the blood, the next yuestion would naturally be about the passage and route of the nutritious part of the food, or cliyle, from the bowels to the blood. vessels. The name of Asclli, an Italian plysician, is rendered illustrious by the diseovery of the ressels which carry the chyle from the intestines. He observed them full of a white lipuor on the nysentery of living animals, and from th is circumstance called them nilky or lacteal vessels. For many years the anatomists in all parts of Curope were daily opening living animals, either to see the lacteals, or to observe the phxnomena of the circulation. In making an experiment of this kinil, l'eequet, in l'ranee, was fortunate enough to discover the thoracie duct, or common tunk of all the lacteals, which convers the cliyle into the subclavian rein. And now the lacteals having been traced from the intestines to the thoracic cluct, and that 


\section{ANA'IOMY.}

duct having been traced to its termination in ablood-vessel, the passage of the chyle was completely made out. "The discovery of the absorbent vesscls in other parts of the body, where they are known by the name of lymphatics, from the transparent colour of their contents, very soon follow. ed that of the lacteal and thoracic duct. Rudbeck, a Swede, is generally allowed to have been the first who discovered these vesse!s; but this honour was disputed with him by Bartholin, a learned Dane. By these vesscls the old particles of our bodies, which are no longer fit to remain in it, are removed and conveyed into the blood, to be elimina ed by the excretory organs

Leeuenhoeck took up the subject of anatomical inquiry, where others had left it. He investigated the minute structure of the body by the help of magnifying glasses; and was thereby enabled to de. monstrate the circulation of the blood in the pellucid parts of living animals; the red globules of the blood, and the animalcula of the sement vere first observed by this anatomist. Malpighi also directed his attention chiefly to the developement of minute structure; as that of the glands or secretory organs of the body.

About this time anatomy made two great steps, by the invention of injections, and the method of making anatomical preparations. For tliese we are indebted to the Dutch, particularly Swammerdam and Ruysch. The anatomists of former ages bad no other knowledge of the blood-ves. sels, than what they could collect from laborious dissections, and from examiuing the smaller branches of them upon some lucky occasion, when they were found more than commonly loaded with red blood. But filling the vascular system with a bright coloured wax, enables us to trace the large vesscls with great ease, renders the smaller much more conspicuous, and makes thousands of the very minute ones visible, which, from their delicacy, and the transparency of their natural contents, are otherwise impcrceptible. The modern art of corroding the Heshy parts with a menstruum, and of leaving the moulded wax entire, is so exceedingly useful, and at the same time so ornamental, that it does great honour to the ingenious inventor, Dr.Nichols. The method of casting figures in wax, plaister, or lead, is also a great ac. quisition to anatomy, as it enahles us to preserve a very perfect likeness of such subjects as we but seldom meet with, or cannot well preserve in a natural state. The modem improved methods of preserving animal bodies, or parts of them, in spirits, has been of the greatest service to anatomy; especially in saving the time and labour of the anatomist, in the nicer dissections of the small parts of the body. For now, whatever he has prepared with care, he can preserve, and the object is ready, to be seen at any time. And, in the same manner, be can preserve anatomical curiosities and rarities of every kind; such as parts that are uncommonly formed; parts that are diseased; the parts of the pregnant uterus, and its contents. Large collections of such curiosities, which modern anatomists are stuiving every where to procure, are of infinite service to the art; especially in the hands of teachers. They give students clear ideas about many things, which it is very essential to know, and yet, which it is impossible that a teacher should be able to shew otherwise, were he ever so well supplied with fresh subjects.

When anatomy had thus become a clear and distinct science, it wasinculcated and taught, in the different nations of Europe, by numerous professors, with a zeal and industry highly honourable to themselves, and useful to mankind. As the prejudices of mankind respecting dissection have in a great measure subsided, the difficulties, which formerly obstructed anatomical researches, have mostly disappeared, and a sufficient quantity of subjects for anatomical purposes can generally be procured. In most, perhaps in all, the countries of the continent of Europe, the government has provided for the want of anatomists in this particular. In England, however, it still remaius a matter of considerable difficulty and expense to procure tlie means of instruction in practical anatomy ; and, accordingly, while foreigners have been enriching science with many splendid works, the name of one Englishman cannot for many years past be recorded in the annals of anatomy. We wish we could announce to our readers any prospect of a change in this respect; but here literature and science are left to themselves, and must advance unaided by the patronage of government, or not. adrance at all.

It would occupy us too long to detail the labours and discoreries of all the eminent men, who have immortalized themselves in anatomy during the last century. We may'state, generally, that every part of the buman body has been most thoroughly and minutely examined and described; and accurate and elegant engravings have appeared of every part. So that a student, in these days, possesses every facility for the prosecution of his anatomical labours. The bones and muscles have been most 


\section{ANATOMY.}

elegantly represented and described by Albinus, Cheselden, Suc, and Cowper. The vascular system has been illustrated by a splendid work of the immortal Haller. Walker and Meckel of Berlin, and Scarpa at Pavia, have bestowed equal, or even superior, diligence in tracing the distribution of the most important nerves, and representing them in faithful engravings. Mr. Cruikshank distinguished himself by an excellent book on the absorbing system; and Mascagni has lately given to the public a most elaborate account of the absorbing vessels, with very splendid plates. Dr. Hunter, to whom anatomy owes more in this country than to any individual, has published a complete history, with beantiful explanatory engravings, of the growth of the human ovum, and of the changes which the uterus undergoes after the orum bas been received into its cavity. His brother, Mr. John Hunter, also demands mention in this place, as an accurate and minute dissector, and a patient experimentalist. He surveyed, in his rescarches, the whole field of animated nature, and greatly promoted the science of phisiology. He formed also the grandest and most beautiful anatomical cabinet in Europe; and this precious treasure has now passed into the hands of the Royal College of Surgeons in London. The structure of the brain has been represented with unrivalled elegance by Vicq D'Azyr, a French anstomist, in a folio volume of coloured plates, which we hesitate not to applaud as a chef d'ourre of anatomical science, and a most splendid monument of the arts. Some parts of this most important organ hare also been illustrated by the labours of Soemmering, who still prosecutes the study of anatomy with unwearied industry. We have lately, from his hands, two most finished productions, in every respect, on the anatomy of the eye and ear. It would be unjust not to enumerate, with a due tribute of applause, the labours of 'Zinn, Cassebohm, and Scarpa, on the same subjects.

Morgagni, who taught anatomy in P'adua, published a work of great utility on morbid anatomy. Dr. Baillie has of late in this country prosecuted the same subject, though in a difierent manncr. Ife has published a book on the morbid anatomy of the body, and hasillustrated hisclescriptions by a collection of the most elegant, expressive, and accurate plates.

Winslow, Sabatier, and Bichat, are the authors of the most approved anatosnical systems in l'rauce, and Soemmering and Gildebrant in Germany. We-regret that it is not in our power to mention any cor-

VOL. $\mathbf{F}$. rect and complete system by an Fnglish writer. The imperfect and contemptible ephemeral productions, published under the auspiccs of booksellers, cannot have a place in this enumeration.

\section{CTILITY OF ANATOMX.}

Astronomy and anatomy, as Fonterelle observes, are the studies which present us with the most striking view of the two grcatest attributes of the Supreme Being. The first of these fills the mind with the idea of his immensity, in the largeness, distances, and number of the heavenly hodies; the last astonishes, with his intel. ligence and art in the variety and delicacy of animal mechanism.

The human body has been commonly enough known by the name of microcos. mus; as if it did not differ so much from the universal system of nature, in the symmetry and number of its parts, as in their size.

Galen's excellent treatise on the use of the parts was composed as a prose hymn to the Creator, and abounds with as irresistible proofs of a Supreme Cause, and gorerning Providence, as we find in modern phisico-theology. And Cicero dwells more on the structure and economy of animals, thian on all the productions of nature besides, when he wants to prove the existence of the Gods, from the order and beauty of the universe. He there takes a surrey of the body of man, in a most elegant synopsis of anatomy, and coricludes thus; "Quibus rebus expositis, satis docuisse rideor, hominis natura quanto omnes antcirct animales. kx quo debet intelligi, nec figuranı situmque membrorum, nec ingeni mentisque, vim talem effici potuisse fortuna." "The sutisfaction of mind which arises from the study of anatomy, and the influence which it nust naturally bave on our minds as philosophers, cannot be better conveyed than by the following passage from the same author; "Qua contuens animus, accepit ab his cognitionern deorum, ex qua oritur pietas : cui conjuncta justitia est, reliquacque virtutes; ex quibus vita beata exsistit, par et simili deorum, nulla alia re nisi immortalitate, qua nilil ad bene vivendum pertinet, cedens colestibus."

It would be endless to quote the animated passages of this sort, which sre to be found in the physicians, philosophere, and theologists, who have considered the structure and functions of animals, with a view towarls the Creator. It is a view that must strike us with the most awful conviction. Who ean know and consider 
the thousand evident proofs of the astonishing art of the Creator, in forming and sustaining an aninal body such as ours, without feeling the most pleasing enthusiasm? Can we seriously reflect upon this awful subject, without being almost lost in adoration! Without longing for another life after this, in which we may be gratified with the highest enjoyment which our faculties and nature seem capable of, the seeing and compreliending the wholejplan of the Creator, in forming the universe, and directing its operations.

In the excellent work of Archdeacon Palcy, on natural theology, this view of the subject is most ably explained and illustrated; and the subject is pursued through all its details. We strongly recommend this work, as exhibiting, in a popular form, a very interesting view of the structure and functions of animal bodies; and we subjoin the following extract, as a very successful application of the argument.

"It has been said, that a man cannot lift his hand to his head, without finding crough to convincé him of the existence of a God. And it is well said ; for he has only to reflect, familiar as this action is, and simple as it seems to be, how many things are requisite for the performing of it: how many things which we understand, to say notling of many more, probably, which we do not; viz. first, a long, laril, strong cylinder, to give to the arm its firmness and tension; but which, being rigid, and, in its substance, inflexible, can only turn upon joints: secondly, therefore, joints for this purpose, one at the slıoulder to raise the arm, another at the elbow to bend it; these joints continually fed with a soft mucilage, to make the parts slicle ensily upon one another, and holden together by strong braces, to keep them in their position : then, thirdly, strings and wires, i.e. muscles and tendons, artificially inserted, for the purpose of drawing the - bones in the directions in which the joints allow them to move. Hitherto, we scem to understand the mechanism pretty well; and,understanding this, we possess enough for our conclusion : nevertheless, we have hitherto only a machine standing still; a dead organization - an apparatus. To put the system in a state of activity ; to set it at work ; a further provision is necessary, viz. a communication with the brain by means of nerves. We know the existence of this communication, because we can see the communicating threads, and can trace them to the brain; its necessity we also know, because, if the thread be cut, if the conmunication be intercepted, the muscle becomes paralytic: but beyond this we know little; the organization being too minute and subtle for our inspection.

"To what has been enumerated;; as officiating in the single act of a man's raising his hand to his head, must be added, likewise, all that is necessary, and all that contributes to the growth, nourishment, and sustentation of the limb, the repair of its waste, the preservation of its health ; such as the circulation of the blood through every part of it ; its lymphatics, exhalants, absorbents; its excretions and integuments. All these share in the result; join in the effect: and how all these, or any of them, come together, without a design. ing, disposing intelligence, it is impossible to conceive."

But the more immediate purposes of anatomy concern those who are to be the guardians of health, as this study is necessary to lay a foundation for all the branclies of medicine.

The more we know of our fabric, the more reason we have to believe, that, if our sense's were more acute, and our judgment more enlarged, we should be able to trace many springs of life, which are now hidden from us; by the same sagacity we should discover the true causes and nature of diseases, and thereby be enabled. to restore the health of many, who are now, from our more confined knowledge, said to labour under incurable disorders. By such an intimate acquaintance with the economy of our bodies, we should discover even the seeds of discases, and detroy them, before they had taken root in 'the constitution.

This, indeed, is a pitcl of knowledge which we must not expect to attain. But, surely, we may go some way; and, therefore, let us endeavour to go as far as we can. And if we consider that health and disease are the opposites of each other, there can be no doubt, that the study of the natural state of the body, which constitutes the one, must be the direct road to the knowledge of the other. What lias been said, of the usefulness of anatomy in physic, will ouly be called in question by the more illiterate empirics among physi. cians. They would discourage others from the pursuit of knowledge which they have not themselves, and which, therefore, they cannot know the value of, and tell us that a little of anatomy is enough for a pliysician.

That anatomy is the rery basis of sur. gery cvery body allows. It is dissection alone that can teach us where we may cut the living body with freedom and dis. patch; where wc may renture with grcat' 


\section{ANATOMY。}

circumspection aud slelicacy ; and where we must not, upon any account, attempt it. This informs the lead, gives clexterity to the hand, and familiarizes the heart with a sort of necessary inlumanity, the use of cutting instruments upon our fellow-creatures.

Were it possible to doubt of the advantages which arise in surgery, from a knowledge of anatomy, we might liave ample conviction, by comparing the present practice with that of the ancients: and upon tracing the improvements which have been made in later times, they would be found, generally, to have sprung from a more accurate knowledge of the parts concerned. In the hands of a good anatomist, surgery is a salutary, a dirine art; but when practised by men who know not the structure of the human body, it of ten becomes barbarous and criminal.

The comparison of a pliysician to a ge. neral is both rational and instructive. The human body, under a disease, is the country which labours under a civil war or an invasion. The physician is, or should be, the dictator or general, who is to take the command, and to direct all the necessary operations. To do his duty with full ad. vantage, a general, besides other acquirements, useful in his profession, must unake himself master of the anatomy and jhysiology, as we may call it, of the country. He may be said to be master of the anatamy of the country, when he knows the figure, dimension, situation, and connection, of all the principal constituent parts ; such as the lakes, rivers, marshes, mountaius, precipices, plains, woods, roauls, passes, fords, towns, fortifications, \&.c. I3y the physiology of the country, which he ought likewise to understand, is meant all the varicty of active influence which is produced by the inhabitants. If the general be well instructed in all these points, le will find a hundred occasions of drawiug advantages from them; and without such knowledge, he will be for ever exposed losome fatid blunder.

GEXERAL ACCOUXT OF TIN CUMPOSITION OF THE BQDY.

After having considered the rise and progress of anatomy ; the various disco. veries that lave been made in it from time to tine; the great number of diligent observers who have applied then. selves to this art; and the importance of the study, not only for the prevention and cure of diseases, but in furnishing the liveliest proots of divine wistom; the following questions seem naturally to arise. For what purpose is there such 2 variety of parts in the human body? Why such a complication of nice and tender machincry? Why was there not rather a more siniple, less delicate; and less expensive frame?

That beginners in the study of anatomy mat acquire a satisfactory, general, idea of these subjects, we shall furnish them vith clear answers to all such questions. Let us then, in onr imagination, make a man : in other words, let us suppose that the mind, or immaterial purt, is to be pla. ced in a corporeal fabric, to hold a corres. ponklence with other matcrial beings, by the intervention of the body; and then consider, a priori, what will be wanted for her accominodation. In this inquiry we shall plainly see the mecessity, or advantage, and therefore the final cause, of most of the parts, which we actually find in the luuman body. And if we consider, that, in order to answersome of the requisites, human art and invention would be very insufficient, we need not be surprised if we meet with some parts of the bocty, the use of which we cannot yet make out; and with some operations or functions which we cannot explain. We can sce and comprehend that the whole bears the stiongest marks of excelling wisdom and ingenuity; but the imperfect senses and capacity of man cannot pretend to reach every part of a machine, which nothing less than the intelligence and power of the Supreme being could contrive aud execute.

To procoed then; in the first place, the mind, the thinking immaterial agent, must be provided with a place of imme. diate residence, which shall have all the requisites for the union of spirit and body; accordingly, she is provided with the brin, where she dwells as governor and superintendant of the whole fabric.

In the second place, as she is to hold a correspondence with all the matcrial beings which surround her, slie must be sup. plied with organs fitted to receive the dif. ferent kinds of impressions that they will make. In fact, therefore, we see that she is provided with the organs of scnse, as we call them; the eye is adapted to light, the ear to sound, the nose to smell, the mouth to taste, and the skin to touch.

In the third place, she must be provi. decl with organs of communication be. tween herself, in the brain, and those orgaus of sense, to give her information of all the impressions that are made upon them : and she must have organs betwe''n herself; in the brain, and every other pait of the body, fitted to convey her commands and influence over the whole. For these purposes the nerves are actually given. 


\section{ANATOMY.}

They ave chords, which rise from the brain, the immediate residence of the mind, and disperse themselres in branches through all parts of the body. They are intended to be occasional monitors against all such impressions as might endanger the well-being of the whole, or of any particular part, which vindicates the Creator of all things in having actually subjected us to those many disagrecable and painful sensations, which we are exposed to from a thousand accidents in life.

Furher, the mind, in this corporeal system, must be endued with the power of moving fiom place to place, that she may have intercourse with a variety of objects; that she may fly from such as are disagreeable, dangerous, or hurtful, and pursue such as are pleasant or useful to her. And accordingly she is furnished with limbs, and with muscles and tendons, the instruments of motion, which are found in every part of the fabric where motion is necessary.

But to support, to give firmaness and shape to the fabric, to keep the softer parts in their proper places, to give fixed points and the proper direction to its mo. tions, as well as to protect some of the more important and tender organs from external injuries, there must be some firm prop-work interwoven through the whole. And, in fact, for such purposes the bones are given.

The prop-work must not be made into one rigid fabric, for that would prevent motion. Therefore there are a number of bones. These pieces must all be firmly bound together, to prevent their dislocation, and this end is perfectly well answered by the ligaments. The extremities of these bony picecs, where they move and rub upon one another, must have smooth and slippery surfaces, for easy motion. 'This is most happily provided for by the cartilages and mucus of the joints.

The interstices of all these parts must be filled up with some soft and ductile matter, which shall keep them in their places, unite them, and at the same time allow them to move a little upon one an. other. This end is accordingly answered by the cellular membrane, or adipous substance.

There must be an outward covering aver the whole apparatus, both to give it a firm compactness, and to defend it from a thousand injuries, which, in fact, are the very purposes of the skin, and other in. teguments.

As she is made for society and intercourse with beings of her own kind, she must be endued with powers of expres- sing and communicating her thoughts by some sensible marks or signs, which shall be both easy to herself, and admit of great variety. Hence she is provided with the organs and faculty of speech, by which she can throw out signs with amazing facility, and vary them without end.

Thus we have built up an animal body, which would seem to be pretty complete; but we have not yet made any provision for its duration: and, as it is the nature of matter to be altered and worked upon by matter, so in a very little time such a living creature must be destroyed, if there is no provision for repairing the injuries which she must commit upon herself, and tlie injuries which she must be exposed to from without. Therefore a treasure of blood is actually provided in the heart and vascular system, full of nutritious and healing particles, fluid enough to penetrate into the minutest parts of the animal. Impelled by the heart, and conveyed by the arteries, it washes every part, builds up what was broken down, and sweeps away the old and useless materials.

Hence we see the necessity or advan. tage of the heart and arterial system : the overplus of this blood, beyond what was required to repair the present damages of the machine, must not be lost, but should be returned again to the heart; and for this purpose the venal system is actually provided. These requisites in the animal explain, a priori, the circulation of the blood.

The old materials, which are become useless, and are swept off by the current of blood, must be separated and thrown out of the system. Therefore glands, the organs of secretion, are given, for straining whatever is redundant, vapid, or noxious, from the mass of blood: and, when strained, it is thrown out by excretories.

Now, as the fabric must be constantly wearing, the reparation must be carried on without intermission, and the strainers must always be employed: therefore there is actually a perpetual circulation of the blood, and the secretions are al. ways going on.

But even all this provision would not be sufficient; for that store of blood would soon be consumed, and the fabric would breakdown, if there were not a provision made for fresh supplies. These we ob. serve, in fact, are profusely scattered round her in the animal and regetable kingdoms; and she is prorided with hands, the finest instruments that could have been contrived for gathering them, and for preparing them in a variety of different ways for the mouth. These supplies, 


\section{ANATOMY.}

which we call food, must be considerably changed; they must be converted into blood: therefore she is provided with teeth for cutting and bruising the food, and with a stomach for melting it down; in short, with all the organs subservient to digestion. The finer parts of the aliments only can be useful in the constitation: these must be taken up, and conveyed into the blood, and the dregs must be thrown off. With this view the intestinal canal is constructed. It separates the nutritious part, which we call chyle, to be conreyed into the blood by the system of absorbent vessels; and the feces pass downwards, to be conducted out of the body.

Now we have got our animal, not only furnished with what is wanted for its im. mediate existence, but also witl the power of spinning out that existence to an indefinite length of time. But its duration, we may presume, must necessarily be limited : for as it is nourished, grows, and is raised up to its full strength and perfection, so it must, in time, in common with all material things, begin to decay, and then hurry an to final ruin. Hence we see the necessity of a scheme for renovation. Accordingly, a wise Providence, to perpetuate as well as to preserve his work, besides giving a strong appetite for life and self-preservation, has made animals male and female, and given them such organs and passions as will secure the propagation of the species to the end of the world.

Thus we sec, that by the very imperfect survey which human reason is able to take of this subject, the animal man must necessarily be complex in his corporeal system, and in its operations, He must have one great and general system, the vascular, branching through the whole for circulation : another, the nervous, with its appendages, the organs of sense, for every kind of feeling: and a third, for the union and connection of all those parts.

Besides these primary and general systems, be requires others, which may be more local or confined : one for strength, support, and protection; the bony compages: another for the requisite rotions of the parts among themsclves, as well as for moving from place to place; the muscular part of the body : another to pre. pare nourishment for the daily recruit of the body; the digestive organs : and one for propagating the species; the organs of generation.

In taking this general survey of what would appear, a priori, to be necessary for adapting an animal to the situations of humanity, we observe, with great satis. faction, that man is in fact made of such srstems, and for such purposes. He has them all, and he has nothing more, except the organs of respiration. Breathing we cannot account for a priori, we only know that it is in fact essential to life. Notwithstanding this, when we see all the other parts of the body, and their functions, so well accounted for, and so wisely adapted to their several purposes, we cannot doubt that respiration is so likewise. We find, in fact, that the blood in its circulation beconses altered in its properties, and that these are renewed by the ab. sorption of the oxygenous or pure part of the atmospliere in the lungs; we find also, that this function is the means of supporting the temperature of the animal.

The use and neecssity of all the different systems in a man's body is not more apparent, than the wisdom and contrivance which has been exerted in putting them all into the most compact and convenient form, and in disposing them so, that they shall mutually receive and give helps to one annther, and that all, or many of the parts, shall not only answer their principal end or purpose, but operate success. fully and usefully in many secondary ways.

If we understand and consider the whole animal machine in this light, and compare it with any machine, in which human art has done its utmost, suppose the best constructed ship that ever was' built, we slaall be convinced, beyond the possibility of doubt, that there is intelligence and power far surpassing what humanity can boast of.

In making such a comparison, there is a peculiarity and superiority in the natu. ral machine, which cannot escape observation. It is this; in machines of human contrivance or art, there is uo internal power, no principle in the machine itself, by which it can alter or accommodate jtself to any injury which it may sufier, or make up any injury which is reparable: But in the natural machine, the animal body, this is most wonderfully provided for by internal powers in the machinc it. self, many of whicls are not more certain or obvious in their effects, than they are above all human comprehension as to the manner and means of their operation. Thus, a wound heals up of itself; a broken bone is made firm again by callus; a dead part is separated and thrown off; noxious juices are driven out by some of the emunctories; a redundancy is remo. ved by some spontareous blceding; a 


\section{ANATOMY.}

bleeding naturally stops of itself; and a great loss of blood, from any cause, is in some measure compensated by a contracting power in the vascular system, which accommodates the capacity of the vessels to the quantity contained. The stomach gives information when the supplies have been expended, represents with great exactness the quantity and quality of what is wanted in the present state of the machine, and in proportion as she meets with neglect, rises in her demand, urges her petition in a loucler voice, and with more forcible arguments. For its protection, an animal body resists heat and cold in a very wonderful manner, and preserves an equal temperature in a burning and in a freezing atmosphere.

'There is a farther excellence or st. periority in the natural machine, if possible, still more astonishing, more beyond all human comprehension, than what we lrave been speaking of. Besides those internal powers of self-preservation in each individual, when two of them cooperate, or act in concert, they are endued with powers of making other animals or machines like themselves, which again are possessed of the same powers of producing others, and so of multiplying the species without end. These are powers which mock all human invention or imitation, they are characteristics of the Divine Architect.

As the bolly is a compound of solids and fluids, anątomy is divided into,

1. The anatomy of the solicls, and

2. The anatomy of the fluids.

The solids of the human body consist of,

1. Bones, which give support to the other parts of the body;

2. Cartilages, or gristles, which are much softer than the bones, and also flexible and elastic;

3. Ligamcrits, which are more flexible still, and connect the ends of the bones to each other;

4. Membranes, or planes of minutely interwoven and condensed cellular sub. stance;

5. Cellular substance, which is formed of fibres and plates of animal matter more loosely connectell, and which forms the general uniting medium of all the structures of the body ;

6. Fat, or adipous substance, an animal oil contained in the cells of the cellular membrane;

7. Muscles, which are bundles of fibres, endued with a power of contraction ; in popular language they form the flesh of an animal;
8. Tendons, hard inelastic cords, which connect the muscles or moving powers to the bones or instruments of motion;

9. Viscera, which are various parts, adapted for different purposes in the animal economy, and contained in the cavities of the body, as the head, chest, abdomen, and pelvis;

10. Glands, organs which seciete or separate various fluids from the blood;

11. Vessels, which are membranous canals, dividing into branches, and transmitting blood and other fluids ;

12. Cerebral substance, or that which composes the brain and spinal marrow, which is a peculiar soft kind of animal matter:

13. Nerves, which are bundles of white fibrous cords, connected by one end to the brain, or spinal marrow, and thence expanded orer every part of the body, in order to reccive impressions from external objects, or to convey the commands of the will, and thereby produce muscular motion.

The fluids of the human body are,

1. Blood, which circulates through the vessels, and nonrishes the whole fabric;

2. Persipirable matter, excreted by the vessels of the skin;

3. Sebaceous matter, by the glands of the skin;

4. Urine, by the kidneys;

5 Ceruminous matter, secreted by the glands of the external ear;

6. Tears, by the lachrymal glands;

7. Saliva, by the salivary glands;

8. Mucus, by glands in various parts of the body, and by various membranes;

9. Serous fluid, by membranes lining circumscribed cavities;

10. Pancreatic juice, by the pancreas;

11. Bile, by the liver;

12. Gastric juice, by the stomach;

13. Oil, by the vessels of the adipose membrane ;

14. Synovia, by the internal surfaces of the joints, for the purpose of lubricating them ;

15. Seminal fluids, by the testes;

16. Milk, by the mammary glands.

The account of these animal fluids will be found chiefly under the article Pursio. LOGX.

'The anatomical deecription of the body is technically arranged under the following lieads :

1. Osteolngy, or the description of the structure, shape, and uses of the bones.

2. Syndesmology, or a description of the connection of bones by ligaments, and of the structure of the joints. 


\section{ANATOMY.}

3. Myology, or doetrine of the moving powers or muscles.

4. Angeiology, or description of the vessels engaged in nourishing the body, in absorption, and in the remoral of super. fluous parts.

5. Adenology, or account of the glands, in which various licquors are separated or prepared from the blond.

6. Splanchnology, or a description of the diflerent bowels which serve various and dissimilar purposes in the animal econoiny.

7. Neurology, under which title the brain, the nerves, and the organs of sense must be compreliended,

The functions carricd on in animals, in the explanation of which physiology consists, and for the detailed account of which we refer the reader to the article PurssoLog $\mathbf{Y}$, may be thus arranged.

1. Digestion, or the conversion of extraneous matter into a substance fit for the nourislıment of their own bodies.

2. Absorption, by which the nutritive fluid is taken up and conreyed into the vascular system, and by which the old parts of our body are removed.

3. Respiration, or the exposure of the nutritive fluid to the action of the atmosphere.

4. Circulation, or the distribution of the converted matter to every part of the animal, for its repair and augmentation. 'The process is naned circulation, from the mode in which it is carried on in the ge. nerality of animals.

5. Secretion, or the separation and deposition of the particles composing the structure of animals and vegetables, as well as the formation of various substan. ees which they produce from the circulating fuids.

6. Irritability, or the principle by which living fibres contract, by means of which absorption and circulation are carried on, and which is more strikingly manifested by the occasional exertions of the muscular powers.

7. Sensation, by which animals become conscious of their own existence, and of that of exterual bodies.

8. Generation, by which new beings, similar to the parents, are formed and pro. duced.

PARTICLLAH AXATONIFAL DESCRIFTIOX OF THE ULNAY HODY.

After a cursory notice of the cellular sub. stance, which formus the grand uniting roe. dium of the varions structuresin the body, and of membranes, which are formed of that substance, we shall proceed to de. scribe the other parts, chiefly according to the tecbnical arrangement above mentioned.

Cellular substance, or,cellular membrane, tela cellulasa or mucosa of Latin writers, is the medium which connects and supports all the varions parts and structures of the body. Any person may gain a gene. ral notion of this substance, by observings it in joints of veal, where it is always inflated by the hutchers. It consists of an assemblage of fibres and laminx of animal matter, connected to each other so as to form inuumerable cells or sinall.cavities, from which its name of cellular is derived. It pervades every part of the animal strue. ture, By joining togetler the ininute fibrils of muscle, tendon, or nerve, it forms obvious and visible fibres; it collects these fibres into large fasciculi ; and by joining such fasciculi or bundles to each other, constitutes an entire musele, tendon, or nerve. It joins together the individual muscles, and is collected in their intervals. It surrounds each ressel and nerve in the body ; often connecting these parts together by a firm kind of capsule, and in a looser form joining them to the neighbouring muscles, \&c. When condensed into a firm and compact structure, it con. stitutes the various membranes of the bo$\mathrm{dy}$, which, by long maceration in water, may be resolved into a loose cellular tex. ture. In the bones it forms the basis or ground-work of their fabric, a receptacle, in the interstices of which the earth of bone is deposited. As cellular substance is entirely soluble in boiling water, it is ascribed by chemists to that peculiar modification of animal matter termed gelatine. In consequence of its solution by the united agencies of heat and moisture, the muscular fibres separate from each other, and form the other structures of the body. This effect is seen in meat which is subjected to long boiling or stewing for the table, or incleed in a joint which is mere. ly over-boiled.

Its watery solution assumes, when cold, the appearance of jelly ; and, after a particular mode of preparation, constitutes glue.

The interstices of the cellular substance are lubricated and moistened by a serous or watery Huid, poured out by the exha. lant arteries. and again taken in by the lynphatics. It thus acquires a pliancy and sofiness, which adapt it particularly to serve as aconnecting medium for parts which have motion on each other. The importance of this property will be best understood by observing the eflects of 
its loss. Inflanmation or absecss often causes an induration or consolidation of the cellular texture, by which the integutments are fired to the muscles, the muscles are firmly united to each other, and to the surrounding parts, and the motions of the. whole are considerably impaired.

From the universal extent of this cellular texture, two conclusions may be drawn; $1 \mathrm{st}$, it forms the basis of the whole animal fabric, in such a way, that if we conceive every part removed but this, the form of the whole would still be expressed in ccl. lular substance; $2 \mathrm{dly}$, it forms a connection and passage between all parts of the body, however remote in situation, or dissimilar in structure. For the cells of this substance every where communicate; as we may collect from facts of the most common and familiar occurrence. In $\mathrm{em}$ physema, where air escapes from the lung wounded by a broken rib into the cellular substance, it spreads rapidly from the chest into the most remote parts of the body ; and has even been known to gain admission into the eye-ball. A similar diffusion of this fluid may be effected by artificial inflation, which is commonly practised by butchers on the carcases of calves. In anasarca, or preternatural ac: cumulation of fluid in the cellular substance, the most depending parts are the most loaded; and punctures in these drain the water off from the whole body.

Adipons subsance, or fat.-The cells of the cellular substance, in many parts of the body, are destined for the reception of a fluid, termed fat. This is of an unctuons nature, inflammable, lighter than water, usually inodorous, and, generally speaking, similar to the regetable oils. It is white in young animals, and becomes yellower as they advance in age: this difference may be seen in the curcases of a calf and cow. It is alwayg more or less fluid in the living şubject; in carnivorous animals, and in man, it retains much of its oily appearance after death ; but in lierbivorous animals it constantly assumes a concrete form. Dr. Hunter called those parts of the cellular substance which contain fat, adipones cellular substance; and distingtushed the other by the epithet recticular.

As the fat is deposited in cells, it assumes in general a kind of granular form. It $v$ aries considerably in consistence. That of the orbit is the softest in the body, and forms a well-known epicurean bonne bonche, in a boiled calf's head. The fat about the kidneys becomes particularly hard after death, and is called suet. The globules or portions of this aie very large, and it contains on the whole less cellulay" substance than any fat in the body. There is generally a layer of fat under the skin; whence a membrana adiposa has been sometimes enumerated as one of the com. mon integuments of the body.

Some parts of the body never contain fat, even iu subjects who have the greatest accunulation of this fluid. This is the case with the scrotum, the integuments of the penis, and the eve-lids: it is obvious that the functions of these parts would be completely destroyed, if they were subject to the enormous accumulations of fat, which occur in other parts of the body. Several of the viscera also never contain any fat, probably for the same reason; this is the case with the brain ard lungs.

The quantity of fat varies according to the age, the state of health, and the peculiar habit or disposition of the individual. It is not found in the early periods of foetal existence; and cannot be distinguished with any certainty sooner than the fifth month after conception.

In the fotus, and for some time after birth, the fat is confined to the surface of the body, and is only found in a stratum under the skin. It begins, however, gradually to be deposited in the intervals of the muscles, and on the surface of some viscera. In old subjects, however thin they may seem on an external view, there is always much fat, penetrating even the substance of the muscles: the bones are greasy throughout; the heart is more or less loaded, as are also the parts in the abdomen.

There is a considerable difference in the quantity of fat in different individuals : and in some there is a propensity or disposition to its accumulation; a sedentary life, copious food, and tranquil state of the mind, are particularly favourable to the increase of fat, which sometimes proceeds to such a pitch, from the coutinuance of these causes, that it must be cunsidered as a disease, and is attended with the greatestinconvenience to the individual. General diseases of the frame are commonly attended with an absorption of the fat from the cellular substance: acute disorders canse a very rapid emaciation. In no case is the adipous substance more completely removed from the whole body than in anssarca, where its place is supplied by a serous fluid.

The uses of the fat seem to be, in part, common to it with the cellular substance: it connects contiguous parts, and at the same time prevents their coalition. It ad. 


\section{ANATOMY.}

mits of their moving on eacls other with fire edom and facility. Its deposition under the iuteguments gives a roundness and convexity to the surface, on which the beauty of the human form principally de. pends. Indeed, its accumulation in particular situations immediately influences the outline of the part; as in the orbit, the cheek, and the buttocks. 'The effeets of its loss is most disagreeably manifested in the lank cheek and hollow eye of an emaciated patient.

It lias bcen supposed that the fat absorbed under certain circumstances is applied to the nutrition of the bodly; as in hyberuating animals.

Hembranes. - In the foregoing observations on cellular substance, we have stated. that membranes are formed by a condensation of that substance. They consist of thin sheets of compacted and close cellular texture. This is proved by long maceration in water. The fluid gradually penetrates the interstices, and resolves the mernbraue into a loose and Hocculent substance. They are found in every variety of density and softness.

A grand use of membranes is, to line what anatomists call the circumscribed $\mathrm{ca}$ vities of the body. These are hollow spaces, containing the different viscera, and in every instance completely and accurately filled by such viscera; so that the term eavity, when used by anatomists, does not, as in common language, denote a roid or empty space.

Nembranes lave a smooth internal polished surface, turned towards the contained viscera. 'This is constantly moistened by a lubricating fluid exlialed by the minute arteries of the part, and bestow's on the surface of the membrane the greatest sofucss and smoothness. IIence the motions of the viscera are perforned with perfect facility, and they are prevented from adhering to each other, or to the sides of the containing cavity. The extent of such cavities is bounded and defined by the lining membranes, and henee arises the epithet circumscribed. To increase the facility of motion, the surfuce of the contaned viscera is covered by a continustion of the same menbrane, and alwins therctione possesses the same smoothness and polısh with the sides of the cavity. The membrane lining a cir. cunscribed cavity is a complete and entire sae, which is reflected over all the viscera contained in the cavity. In the eurease of an animal just ṡlaughtered, the lubricating secretion flies off in the form of a fine vapour when the eavity of the belly or VOL. 1. chest is laid open. It is nothing more than an increase of this natural secretion, combined jerhaps with a dcticient ab. surption, that gires rise to dropsies of the difierent cavities.

Thie oppositc or external surface of the membrane is rough and cellular; and ad. heres to the rarious parts which form the sides of the cavity.

Another use of membranes is, to form blood-ressels or tubes for conreying the notritious fluid to all parts of the body. The bore or hollow of the tube is per. fectly smooth and polished, so that the blood experiences no obstruction in its course; and the external surface is rough, to connect it with the surrounding parts. In a similar nanner are formed the sto. mach and intestines, which receire the food; the urinary bladder, which holds the urine, \&:c.

It must be obvious, that for all the pur. poses which we have enumerated, whether for lining circuniscribed cavities, for conveying the blood, for receiving the food, or holding any' other liquors, it is essentially necessary that membranes should be impermeable to fluids in the living state.

\section{OSTEOLOG T.}

The bones are the most solid parts of the body. They are composed of a ras. cular substance, not differing materially in structure from that of the rest of the body, except that there is denosited in its interstices an earthy matter, which gives to the whole mass rigidity, strength, and a perinanent figure. The nutrient vessels of arteries, membranes, and ligaments, occasionally deposit lime, and cause the ossitication of those parts.

'The account of the original formation of the bones in the fotus, is technically termed ustoogeny. The parts of the young fotus, which are afterwards to becone bones, are at first cartilaginous; and their substunce is rendered white and firm, in proportion to the quantity of linse depo. sited in it. 'The quantity at the time of birth is only sufficient to give firmuess to the whole mass, not to prevent its flexibility.

The extremities of all the long bones consist of large portions of cartilage, and these by degrees become bony. Tlie for. mation of bone begins in the centre of the cartiluge, and griddually extcuds fion thence to the remote parts, so that the separate piece of bonk, tomned at the extremity, remains till near the time of pu. berty, conjoined to the body of the bone 


\section{ANATOMY.}

by a crust of cartilage. In this state it is technically termed an epiphysis. The body, or middle part of the bone, is called the diuphysis. The projecting parts, or processes of bones, arc also in many instances nriginally epiphyses. The time by which these epipliyses are consolidatcd by a bony union with the diaphysis, varies iu different bones, but it is not pro. longed in any much beyond the age of puberty.

We perceive an cvident advantage in the bones of the foctus being formed as they are. Their flexibility admits of the form of the limbs becoming adapted to the varying figure of the pelvis, through which they must pass ; and their elasticity, which is powerful, restores them afterwards to their natural shape.

The animal substance contained in bones is demonstrated by immersion in weak acids, which dissolve the earth, and lcare a kind of cartilage similar to that in which the bone was originally formed. Long boiling in a close vessel remores the gelatinous substance, which is dissolved in the water. The earth of bones is demonstrated by calcination, which drives off the animal matter, and leaves the carth alone behind. This earth consists chiefly of phosphate of lime; but there is also a small proportion of carbonate of lime. In young subjects the animal substance predominates, and the bone appears redder, in consequence of the artcries being larger and more numerous. The bones of old persons contain more earth, and are consequently whiter and less vascular.

Some recent cxperiments have shewn the quantity of jelly contained in bones to be much larger than was supposed, and as it forms a very good soup when dis. solved in water, the circumstance is of considcrable importance, as furnishing an articlc capable of supplying much wholesome nutriment. The quantity of soup furushed from a given bulk of bruised or pounded bones, boiled in a vessel with a closed lid, considerably excecds that which can be extracted firm the same quantity of meat. Of course the articular heads of bones, and the reticular texture, in general furnish the greatest quantity.

It has been generally taught, that bones are composed of fibres and laminx: the fact is, that they consist of a reticulated texture, very similar to ccllular substance in other parts of the bodly.

According to the obvious differences in their forms, bones are divided into the long and flat.
Two kinds of structure may be obserr. ed in all bones : in the one, the bony substance is condensed, and leaves no interstices; in the other, there is a mere net-work of bony fibres and plates, leav. ing numerous intervals. The latter is termed the cancellous substance of bones.

The cylinder of a long bone is composed entirely of the firmer substance, and in its centre is hollowed out to con. tain the marrow. In those extremities of the bones, which form the joints, which are greatly expanded, in order to increase the extent of surface, there is a thin layer of the compact substance, but all the in. terior is cancellous. In broad or flat bones, the firmer substance is formed into two plates or tables, and the interval be. tween these is occupied by cancelli.

Many advantages arise from this arrangement of the earth of bones. The long bones are made slender in the middle, to allow of the convenient collocation of the large muscles around them; they become expanded at their extremities, to afford an extent of surface for the formation of joints, and the support of the weight of the body. A cavity is left in the middle; for if all the earthy matter had been compacted into the smallest possible space, the bones would have been such slender stems, as to be very unsuitable to their offices; and if they had been of their present dimensions, and solid throughout, they would have been unnecessarily strong and weighty.

The phenomena, which result from fecding an animal with madder; sufficiently demonstrate the existence of blood. vessels and absorbents in the bones. There is a strong attraction between the earth of bone and the colouring matter; by means of which they unite and form a beautiful red substance. The wbole of the bones of an animal assumc this colour soon after an animal has been taking the madder. If it be left off, the bones in a slıort time resume their natural white appcarance, from the absolption of the red colouring substance. Tlie short time in which growing bones become thoroughly dyed, and in whicl again the pretermatural tint is lost, prove that even in these, the hardest parts of our frames, there is a process of remoral of old purts, and deposition of new ones constantly going on.

That bones possess nerves, as well as arteries, reins, and absorbents, cannot be doubted. Althougls in.the naturil state. they seem to be insensible, they become extremely painful when diseased; and again, a fungus, which is sensible, some. 


\section{ANA'TOMY.}

times grows out of a bone, though it may have no connexion whatever with the surrounding suft parts; of course it must have derived its nerves, by means of which it possesses sensation, from the bone out of which it arose.

Bones are covered by a strong and firm membrane, termed periostenun, on which the ressels are first distributed; from this they descend into the substance of the bone. The vessels enter through holes which are evident on the surface, and which are larger and more numerous in the extremities of the long bones than in the middle.

\section{OF TIE MARROW}

This is of an oily nature. It hardens when cold, in herbaceous animals; but it remains fluid in those which are carnivorous. It has a reddish and bloody appearance in young animals; but this soon goes off. It is contained in fine membranous cells, which do not communicate with each other. The marrow occupies the tube left in the middle of the long iones, and also fills the cancelli of their extremities.

'The cellular substance, which contains the marrow, being condensed upon the insicie of the walls of the bone, and adhe. ring to them, has been termed the periosteum internum.

We observe in the principal bones arteries, much larger than those which nourish the bone, penetrating these bodies obliquely, and spreading their branches upon the medullary cells.

Various unsatisfactory opinions have been proposed concerning the use of the manzow. The utility of the bones being formed as they are, small and tubular in the middle, expanded and spongy at their extremities, has been already explained. If then spaces are necessarily left in their interior parts, those spaces must be filled with something; for they cannot be left void, or the immense pres. sure of the atmosphere would crush their sides, and destroy the racuum. There is no matter in the animal body more suitable to fill their spaces than Ule marrow; and it is to be regarded as a part of the adipous system of the animal.

From the circumstances which have been detailed in the foregoing account, ziz. the great and general vascularity of bones; the quantity of soft substance existing in every part of them; their growth and mutation of form in disesse, \&c. it is natural to conclude, that there cxist in the composition of every bony filsre, arte. ries for its formation, absorbents for its removal, cellular substance for the connexion of its parts, and nerves to give animation to the whole. In this riew of the subject, we see no essential difference of stricture between bones and other parts of the body; nor do we expect any essential difference in the functions of their nutrient and other vessels. We naturally conclude that bony fibres are formed and repaired, and that they undergo mutation and remoral in the same manner, and from the same causes, that soft parts do.

\section{CARTILAGE.}

Is a semipellucid substance, of a milkwhite or pearly colour, entering into the composition of several parts of the body. It holds a middle rank, in point of firmness, between bones, or hard parts, and the softer constituents of the human frame. It appears, on a superficial examination, to be homogeneous in its texture; for, when cut, the surface is uniform, and contains no visible cells, caritics, nor porcs; but resembles the section of a piece of glue. It possesses a very high degree of elasticity; which property distinguishes it from all other parts of the body. IIence it enters into the compo. sition of parts, whose functions require the combination of firmness with pliancy and flexibility: the preservation of a certain external form, with the power of yielding to external force or pressure.

Cartilages are covered by a membrane, resembling, in texture and appearance, as well as in its office, the periosteum of bones; this is termed the perichondrium. They receive arteries and veins from this membrane: these vessels, however, have never been clemonstrated in the cartilaginous crusts of articular surfaces. $\mathrm{Ab}$. sorbent vessels cannot be actually shewn, but their existence is abundantly proved by many phenomena. The conversion of cartilage into bone is alone sufficient for this purpose. The cartilaginous sub. stance is gradually remored, as the formation of the bone atrances. In affiections of the joints, their cartilaginous coverings are often both entirely destroyed, or partially remored : which appearances can only be ascribed to the action of ab. sorbent ressels

It does not scem to possess nerres, as it is entirely destitute of sensibility.

The thinner cartilages of the body are resolved by maceration into a kind of fibrous substance : e.g. those of the or- 


\section{ANATOMY.}

gans of sense. Those of the ribs are found by long maceration to consist of concentric oval lamina. In some there are tenclinous fibres intermixed; as in those of the vertebrz.

Anatomists divide cartilages into two kincls : the temporary and the permanent. 'The former are confined to the earlier stages of existence : the latter commonly retain their cartilaginous structure throughout every period of life.

The temporary cartilages, are those in which the bolves of the body are formed. They are hence called by the Latin writers ossescentes. All the bones of the borly, except the teeth, are formed in a nidus of cartilage. The form of the bone, with its various processes, is accurately represented in these cartilaginous primordia; and $j$ is the substance alone which changes.

The permanent cartilages are of various kinds. We find them composing the cxternal ear, external aperture of the nostrils, and eye-lids. The larynx is entirely composed of this substance; and the tra. chea, with its branches, is furnished with cartilaginous hoops, by which these tubes are kept permanently open, for tlie ready passage of air to and from the lungs.

The bodies of the vertebra are joined by large masses of a peculiar substiunce ; partaking of the properties and appearance of cartilage and ligament, which allow of the motions of these parts on each other, without weakening the support that is aftorded to tlie upper parts of the body in general, and to the head in particular, by the vertebral column. Tliese cartilages impart a great clasticity to the spine; by which the eflects of concussion from jumping, from falls, \&c. are weakened, and clestroyed, before they can be propagatcd to the hearl. When the body has been long in an erect position, the compression of tlicse cartilages, by the superior parts, diminishes the height of the person. 'They recover tlieir former lengtl, when freed fiom this pressure: hence a person is taller when he rises in the moming, than after stistaining the fatigues of the day, and the difference luas sometimes anininted to an incls.

C:utilagesare snnctimes interposed between the a:ticular surfaces of bones, wilere they fill wp imegularities, that might otherwise impede the motions of the part; ard increase the security of the joint, by ailapting the articular surfaces to rarh otlier.

The articular surfinces of bones are, in crery instarce, corercuby a thin crust of cartilage, having its surface most exquisitcly polished, by which all friction in the motions of the joint is avoided, and the ends of the bones glide over each other with the most perfect facility.

Nimnenclature of bones. - The processes or apopliyses of bones bear different names, according to their figures. Hence we find them described under the terms of head (roundish ball); condyle (a Aattened head); neck; tuberosity; spine; \&c. others have particular names from supposed resemblances.

The cavities or depressions of bones are called cotyloid, when deep; glenoid, when shallow. Again, we have pits, furrows, notches, sinuosities, foss $x$, sinuses, foramina, and canals.

Connection of bones. - Anatomists have divided these into three classes; Symphysis, Synarthrosis, and Diarthrosis.

The term symphysis merely denotes the union of the conjoined bones, without any reference to peculiar form or motion; hence it is clivicled, according to the means by which it is effected, into

1. Synchondrosis, where cartilage is the connecting medium : this is exemplified in the junction of the rihs and sternum; of the bodies of the vertebre; and of the ossa pubis :

2. Synneurosis or syndesmosis; where ligaments are the conirecting bodies, as in all the moreable articulations :

3. Syssarcosis; where muscles are stretclied from one bone to another.

The synarthrosis, or immorable conjunction of bones, consists of,

1. Suture; where the bones are mutually indented, as if sewn togetier:

2 . Irarmonia; where the conjunction is effected by plare surfaces :

3. Gomphosis; where one bone is fixed in another, as a nail is in a board. The teeth afford the only specimen :

4. Schindylesis; where the edge of ore bone is received into a groove in another: as the nasal plate of tiie ethmoid, in the vomer.

Diarthrosis, or moveable conjunction of bones. Tlie conjoined parts of the bones are covercd with a smooth cartilage, and connected by one or more ligaments. It has three subdivisions; vi:.

1. Enarthrosis, or ball and socket; where a round head of one bone is re. ceived into a cavity of anotlier, and consequently is capable of motions in all di. rections :

2. Arthrodia; whcre the cavity is more superficia!, and much motion not allowed ;

3. Ginglymus; where the motions are 


\section{ANATONY.}

restricted to two directions, as in the hinge of a door.

The skelcton consists of an assemblage of all the bones in the body, excepting the os hyoides. It is said to be a natural ske. leton when the bones are connected by means of their own ligaments or cartilages; an artificial one, when wire or other extraneous substances are employ. ed.

It is divicled into the head, trunk, and extremities.

The head consists of the cranium and the face. The former of these partsconsists of 1 or 2 ossa frontis ; 2 ossa parietalia; 1 os sphenobasilare; 2 ossa temporum; 2 mallei ; 2 incudes; 2 orbicularia ; 2 stapedes; and 1 os xthmoideum: on the whole, of 15 or 16 bones.

The face las 2 ossa maxillaria superiora; 2 ossa palati; 2 ossa malr ; 2 ossa nasi ; 2 ossa lacrymalia or uncuis ; 2 ossa turbinata inferiora; 1 os vomer; 1 maxilla inferior; 32 teeth; on the whole, 46 bones.

The os hyoides consists of a body, 2 lateral portions called comua, and 2 sural processes called appendices.

The bones of the head are therefore 61 or 62 ; with the os hyoides 66 or 67.

In the neck therc are 7 cervical vertebra; in the chest 12 dorsal vertebrx ; 24 ribs; 2 or 3 bones of the sternum; in the loins 5 lumbar vertebre; in the pelvis 1 sacrum, 4 ossa coccygis, 2 ossa innomi. nata.

Therefore the whole trunk has 57 or 58 bones.

The shoulders have two clavicles, and 2 scapalae; the arms 2 humeri; the fore. arms 2 ulna and 2 radii ; the wrists 2 ossa scaphoidea; 2 ossa lunaria; 2 ossa cunciformia; 2 ossa pisiformia; 2 ossat trapezia; 2 ossa trapezioidea; 2 ossa magna; 2 ossa unciformia; the metacarpi 10 metacarpal bones; the fingers 10 posterior phalanges, 8 middle phalanges, 10 anterior phalanges, and 8 sesamoid boncs.

The bones of the upperextremitics are in the whole 72 .

The thighs have 2 femora; the legs 2 tibix, 2 patellax, and 2 fibula ; the tarsi 2 astragali, 2 ossa calcis, 2 ossa navicularia, 6 cuneiform bones, 2 ossa cuboidea ; the metatarsi 10 metatarsal bones; the toes 10 posterior phalanges, 8 middle phalanges, 10 anterior plialanges, and 6 sesamoid boures.

The bones of the lower extremities are 66 .

The whole skcleton contains 259 or 261 bones.
Of the bones just enumerated, the os frontis, spheno-occipitale, ethmoideum, vomer, inferior maxilla, the vertebrx, sacrum, and os coccygis, the bones of the sternum, and the os linguale mediun, or body of the os hyoides, are single bones; and being placed in the middle of the bo$\mathrm{dy}$, are consequently symmetrical. Of all the other bones, there is a pair, consisting of a bone for the right, and another fur the left side.

The structure of the whole skeleton is therefore symmetrical; since an imaginary perpendicular line drawn throngli the whole would divide even the single bones into a right and a left half, exactly resembling each other. This observation must however be taken with some allowance; since the corresponding bones of one side are not always perfectly similar to those of the opposite; nor rlo the two halves of the single boucs always exactly agree in form, \&c.

The entire natural skeleton of a man of middle stature, in a dried state, weighs from 150 to 200 ounces ; that of a woman from 100 to 160 ounces.

Bones of the head.-The cranium is the oral bony cavity containing the limin; the face is placed at the anterior and lower part of this cavity, and holds some of the organs of sense, and the instruments of mastication.

The bones of the head are joined by sutures, a mode of union nearly peculiar to themselves; hence, when all the soft parts are destroyed by maceration, they still remain most firmly connected to each other, excepting the front teeth and the lower jaw. The sutures are formed by numerous sliap and ranified processes of the opposed edges of the different bones, shooting into corresponding vacuities of eacli other. In some instances, however, the bones seem to be joined by the opposition of plane sunfaces, and here the union appears externally like a mere line, instead of the irregular zigzag conrse which it takes in the former case The last mentioned junction is called harmonia.

In the fatal state, the hones of the cranium do not touch each otlier, but are separated by considerable intervals of membrane, and have thin extunuated margins, which allow them to ride over each other when subjected to pressure. The larger and more conspicuous of these intervals are called fontanelles, and allow of the pulsation of the brain being felt in a young subject. The importance of this strucinre, in allowing the head to accom- 
modate itself to the varying figure of the parts through which it passes, in the act of parturition, and to sustain the violent pressure which it experiencesin the same act, is sufficiently obvious. In the progress of ossification the edges of the bones meet each other, and become united by the sutures. 'The use of these in the adult cranium cannot be satisfactorily assigned, nor do we see any difference that would arise, if the head had been composed of one piece only, without any suture. In old persons the sutures often become morc or less generally obliterated.

The individual bones are very firmly connected by this mode of union. The edges of the different bones overlap cach other at different parts, so that they are mechanically locked together, and cannot be driven in by any force $a b$ externo.

The bones of the cranium are composed of two plates of compact bony substance, called the extemal, and internal or vitreous tables; and an intervening more or less obvious reticular texture, termed diploc. The proportion of these constituent parts varies very considerably; the diploe is in no case of a very loose or open texture. The thickness of indiviclual skulls is subject to great variety; and there is much difference in the ra. rious parts of the same skull. For the internal surface is every where exactly moulded to the form of its contents, instead of influencing them, as we might lave expected $a$ priori. Hence the convolutions of the brain, the ressels which ramify on its surfuce, \&c. all leave prints on the innor table. The ordinary thickness varies from about the fifth of an inch to almost a mere line.

The common number of the bones of the cranium is, as we have already stated, 7 : but this is often increased by small partions formed between the others, and surrounded by distinct sutures. These are called ossa, triquetra, or wormiana.

The form of the cranium is elliptical, and pretty regularly so, particularly on the front, tapper and back part, and sides. The smaller circle of the ellipse is in front, and the larger behind. It is tolera. bly smooth, externally, except its basis, and it is almost entire or unperforated, except at the same part. In this situation, however, it possesses numerous holes, or, as they are teclinically named, foramina, which transmit blood-ressels to the brain, and the nine pairs of nerves which arise fiom that organ.

The upper and lateral parts of the cranium constitute a bony vault or arch, for protecting the brain : this part is distir. guished by the name of the scull cap.

Individual bones of the liead.-The os frontis forms the upper and anterior part of the skull, the eyebrow, and the roof of the orbit.

The ossa parictalia are called also ossa bregmatis, since the fontanelles or bregmata are formed between their edges. They compose the whole upper and most of the lateral parts of the skull, and possess an irregularly quadrangular figure.

The ossa temporum compose the lower part of the sides, and the middle of the basis of the cranium. They are divided into a squamous portion, a mamillary, and a petrous portion. The former of these has a process contributing to the zygoma, or bony arch, at the side of the cranium, under which the temporal muscle passes. The second is also remarkable, by forming a large nipple-like protuberance towards the basis cranii. The third, which projects into the cavity of the skull, contains the organ of hearing.

The os spheno-occipitale has generally been described as two bones. The occipital portion forms the posterior portion of the basis cranii, and a part also of the back of the bony case.

The sphenoid portion is situated in the middle of the base of the skull, and ex. tends across it from one temple to another. It is extremely irregular in its figure, and divided into a body placed in the middle, two alre on the sides, and two pterygoid processes projecting downwards.

The os ethmoides occupies the middle of the forepart of the basis cranii. It lies in the interval between the two orbits, and contributes to the cavity of the nose. It consists of an irregular assemblage of bony cclls and processes, of a very thin and delicate formation. It has a cribriform or horizontal plate towrards the brain : a nasal or perpendicular plate; 2 turbinated bones; cells; and two orbital plates.

The sutures joining these are the coronal, between the os frontis and the two ossa parictalia; the sagittal, between the two ossa parietalia; the lamb. doidal, joining the ossa parietalia to the os occipitis; the squamous, between the temporal and parietal bones.

The foramina occurring in the cranium, for the transmission of nerves, are; 1 , those of the cribriform plate of the ethmoid bone : 2 , f. optica : 3 , f. lacera or bitalia : 4 , f. rotunda: 5 , f. ovalia : 6 , meatus auditorii interni: $7, \mathrm{f}$. lacera in basi cranii : $8, f$. conclyloidea anteriora : 9 , foramen magrum. 


\section{ANATOMY.}

Those which transmit blood ressels are; 1 , canales caroctici : $2, \mathrm{f}$. spinosa : 3 , f. lacera in basi cranii : 4, f. magnum.

Bones of the face-The ossa nasi constitute tlie arch of the nose. The ossa lacrymalia or unguis are placed at the forepart of the inner edge of the orbits, and contain an excavation which holds the lacrymal bag.

The ossa malarum form the prominen. ces of the cheeks.

The ossa maxillaria superiora form the largest portion of the upper jaw, and most of the bony palate, or roof of the mouth; they contain also the upper tecth.

The ossa palati form the back part of the bony palate.

The ossa turbinata inferioraare situat. ed in the cavity of the nose.

The former completes, with the nasal portion of the cthmoid, the scptum that divides the two nostrils.

The maxilla inferior is articulated to the basis cranii, and holds the lower teeth.

The bones of the cranium and face compose the two orbits, or pyramiclal bony cavities, holding the organs of vision; to each of these, seren bones contribute. They also form the carity of the nose, which is very extensive, and includes portions of nearly all the bones of the face, and some of the skull. It has various cells, formed in the bones of the skuil and face, opening into it.

'The teeth.-These organs are composed internally of a very hard hony substance; and are covered externally by a still hard. er matter, called the cortex or enamel. Each tooth has a body or crown, which is the part seen in the mouth; a neck, round which the gum adheres; and one or more fangs or roots, which are sunk in a process of the jaw, called the alreolar. These hodies are not formedin a nidus of cartilage, like bones, hut on a soft vascular body, called a pulp, which may be compared to the core, on which a horm is formed. This is sumounded by a delicate membrane, called the capsule of the tooth. When the teeth are being formed, these pulps and capsules, with the rudi. ments of the teeth, a re lodged in cavities hollowed out of the jaw bone. They as. terwards rise, and, piercing the gum, ap. pear in the mouth.

'Ieeth differ from other bones in possessing no vessels nor nerres in their sub. stance. As they are destined for the merely mechanical function of triturating the food, such parts would not have been suitable to this office. The pain of tooth. ach arises from a nerve, whict, with a vessel, resides in a hollow, formed in the centre of the fang and body of each tooth. These parts are exposed by the decay. The tecth, in consequence of possessing ro vessels, are only affected by chemical and mechanical causes. Thicy do not repair the effects of trituration, nor of accidental injury; nor do they suffer from any of the diseases which affect other bones.

There are two sets of teeth; the first are fewer in number, and smaller in size; as they fall out at a certain age, to make room for other larger ones, they are called deciduous or temporary. The second set lasts throughout life, and are called the adult or permanent sct.

The latter consists of 32 teeth; 16 in each jaw. There are four incisores or cutting teeth in front; 2 eanini or cuspidati, or dog tecth, placed one on each side of the former; 4 bicuspides bchind the last; and 6 molares behind these. From the late period at which the last molaris appears, it is called the dens s.pientix, or wise tooth.

The temporary set consists of twenty tecth; ten in each jaw. There are 4 incisores ; 2 cuspidati ; and 4 molares.

The permanent tecth are lodged at first in cavities of the jaw, near the roots of the temporary ones; and, as these last are shed, rive up to supply their placcs.

The bone of the tongue is called os hyoides, from its very accurate resem. biance to the Greek $v$. It consists of a bodr, two cornua, and two appendices, which are in fact so many separate bits of bone.

The bones of the trunk consist of those of the spine, thorax, and pelvis.

The spine consists of twenty-four true or moveable vertebric; an os sacrum, and an os coccrgis (which indeed is composed of four pices); thicse last bones, bearing considerable resemblance to the vertebra, are called sometimes the false vertebrix.

Each vertebra has a body, which in situated anteriorly, and consists of a cy. lindrical piece of bone: a perfuration be. hind this, in which the spinal marrow runs; two superior and two inferior articulating processes, by which it is joined to the bone immediately above and below it; two transverse processes, and one spinous process, which, projecting behind, forms a sliarp ridge, from wlich the name of spine has becil applied to thic whole column.

The vertebre are divided into three classes, according to their situation: the seven upper ones are called cervical: of 


\section{ANATOMY.}

these, the firsi, that immediately supports the head, is called the atliss; and the second, from a remarkable bony process which it possesses, the vertebra dentata. The twelve next are called dorsal vertebre, and are distinguished by having the ribs articulated to them. The five last are called lumbar. These all difl'er from each other in some circumstances. The most obrions distinction arises from the. size: the upper ones are the smallest, and there is a gradual increase as we descend.

The column of the spine, when viewed altogether, is not perpendicular; it stands forward in the neck, recedes in the upper part of the back, and projects again in the loins. Holes are left between the bones, for the transmission of the nerves which arise from the spinal marrow.

The sacrum forms the back of the pelvis, and is followed out in front. In form it is triangular, and the base is joined to the last vertebra. It is perforater by a canal, in which the termination of the meclulla spinalis is lodged. Its apex has connected to it the os coccygis.

The thorax is formed by the twelve dorsal vertebra, the ribs, and sternum. The ribs are long, curved, flattened, and narrow bones, attached behind to the dorsal vertebrax, both in their bodies and transverse processes, and joined in front to a piece of cartilage. They are twelve in number, and the seven upper ones, whose cartilages are affixed to the sides of the stcrnum, are called true ribs; the five lowerones, the cartiliges of which do not reach so far, are called the false ribs.

The sternum is a broad and flat bone, placed in the front of the chest. It consists of two pieces of bone, and of a cartilage called the ensiform. The clavicles are aticulated towards its upper parts, snd the cartilages of the ribs are joined to its sides.

Tlie pelvis is formed by the two ossa innominati, or haunch bones, the sacrum, and os coccygis. The former are very large and that bones, expanded into a broal surface above for the support of the abdominal viscera, and the attaclunent of the abdoninal muscles, and furnished witl large tuberosities below, for the support of the bouly in the sitting position. Each os innominatum is divided into the ilium, ischium, and pubes. It is firmly joined to the sacrum belind, arid to the opposite bone in front, by the symphisis pubis. The conjomed portions form an arch, called the arch of the pulses. The cavity of the pelvis is much linger in the female than in the male, as it holds the uterus and vagina, in addition to what it contains in the male, and as the fortus. passes through it in parturition.

The bones of the upper extremity are distributed into those of the shoulder, arm, fore-arm, and hand.

The shoulder contains two; the scapula and clavicle. The former is situated at the upper and onter part of the cliest, and is joined to the end of the clavicle.

The humerus is a long and nearly cylindrical bone, joined by a round head to the scapula above, and articulated with the radius and ulna below.

The fore-ar'm lras two bones; the ulna, which is joined by a linge or ginglymus to the humerus ; and the radius, which has a cavity playing upon a rounded head of that bone. The prominent extremity, of the ulna, which forms the elbow, is called the olecranon. The hand is dided into the carpus, or wrist, the metacarpus, and the fingers and thumb.

The carpus contains eight bones, disposed in two phalanges, of which the first forms, with the radius, the joint of the wrist, and the second is articulated to the metacarpus.

The bones of the first phalanx are the os scaphoides, lunare, cuneiforme, and pisiforme: those of the second, os trapezium, trapezioides magıum, and unciforme.

The metacarpus has five bones, and each of the fingers three; the thumb only two.

In the lower extremity we have the femur, the largest of the cylindrical bones in the body. This has a round head, con. tained in a socket of the os innominatum : the great trochanter forms a conspicuous process at the upper and outer part of the bone. Below it has two condyles, which form part of the knee.

'Ilic leg las two bones; the tibia and fibula. A large flat portion of the former, covered only by skin, is called the slin. The foot is composed of the tarsus, metatarsus, and toes. 'The tarsus lias seren bones:-1. Astragalus, composing the ankle, with the lower portion of the tibia and fibula. 2. Os calcis. 3. Os naviculare. 4. Os cuboides. 5, 6, 7. Ossa cuneiformia. The metatarsal bones are five in number, and the bones of eacli toe are three, except the great toe, which has only two.

SXNHESHOLOGT, OR DUCTRYE OF THE JUIXTS.

Construction of a joint.-The opposed surfuces of bones, which form joints, are 


\section{ANATOMY.}

covered by a thin crust of cartilage, most exquisitely smooth and polished. Hence they move on cach otluer, in whatever di. rection their structure admits, without any hindrance from friction. They are tied togetler by strong and unyielding cords, resembling tendons, and known by the name of ligaments. These keep the surfaces of the bones together, and re. strict their motions to certain directions. In ortcr still further to promote the fa. cility of motion, and to obviate every pos. sibility of friction, the cartilaginous surfices are smeared with an unctuous fluid, called synovia, which makes them perfectly slippery. This fluid is confined to the surface of the joint by means of a thin and delicate membrane, called the cap. sular ligament, which envelopes the joint. It is secreted from portions of a fatty sub. stance, called the synovial glands. The ligments are usually situated on the out. side of the capsula; but in many instances they are contained in the carity of the joint, passing from the centre of onc bone to another. 'These are called interarticu. lar ligaments.

Particular joints.-Joint of the lower jaw. This is formed between the con. dyle of the jaw and a hollow in the tem. poral bone. It contains a moreable cartilage, which renders the articulation more secure, when the jaw is brought forwards on the bone under certain circumstances.

The connection of the head to the rer. tebre is effected by means of two prominences of the occiput, whicls are received into corresponding carities of the atlas. By this joint the nodding motions of the head are performed. But the atlas itself turns lorizontally round the tooth-like process of the vertebra dentata, and as the head is closely connected to the atlas, it is carried round at the same time. Therefore, the latcral or rotatory motions of the head are perfomed by a different joint from that which performs the nod. ding motions. Neither of these articula. Lions admits of very extensive motion; but the deficiency is compensated by the mobility of the vertebre, which enable us to carry the licad freely in any direc. tion we may' wish. 'I'le head rests near. ly in equilibrio on the spinal column; yet, if lcft to itself, it would fall forwarts, as the joint is not precisely in the centre of the basis cranii. To counteract this tendency, there is a ligamentous substance extended from the spinous processes of the ccrvical rertebrix to the occiput, and IOL. 1. called the ligamentum mucha. In quad. rupeds this can be best seen, as the weight of the liead is there supported to a much greater disadvantage. The inus. cles also contribute to keep the head up. right; and lience, when a man drops asleep sitting, the relaxation of the extensor muscles causes the head to nod forwards.

Joints of the spine.-The spine, or back. bone, is a chain of joints of very wonderful construction. Various, difficult, and almost inconsistent, offices were to be executed by the same instrument. It was to be firm, yet flexible; firm, to support the erect position of the body; flexible, to allow of the bending of the trunk in all clegrees of curvature. It was further, also, to become a pipe or conduit for the safe conreyance of a most important part of the animal fiame, the spinal marrow ; a substance, not only of the first necessity to action, if not to life, but of a nature so delicate and tender, so susceptible, and so impatient of injury, as that any unusual pressure upon it, or any considerable ob. struction of its course, is followed by paralysis or death. It was also to afford a fulcrum, stay, or basis, for the insertion of the muscles which are spread over the trunk of the body, in which trunk there are not, as in the limbs, cylindrical bones, to which they can be fastened; and like. wise, which is a similar use, to furnish a support for the ends of the ribs to rest upon.

The breadth of the bases, upon which the parts severally rest, and tlic closeness of the junction, give to the chain its firmness and stability; the number of parts, and consequent frequency of joints, its flexibility; which ftexibility, we may also observe, varies in different parts of the chain; is lcast in the back, where strength more than flesure is wanted; greater in the loins, which it was necessary should be more supple than the back; and greatest of all in the neck, for the free motion of the head. Then, secondly, in order to afford a prssage for the descent of the medullarr substance, each of these bones is bored through in the middle in such a mannes, as that, when put together, the hole in one bone falls into a line and corresponds with the holes in the two bones contiguous to it; by which means the perforated pieces, when joined, form an entire, close, unninterrupted clıannel. But, as a settled posture is inconsistent with its use, a great difficulty still remained, which was, to prevent the vertebre from

I a 


\section{ANA'I'OMY.}

shifting upon one another, so as to break the line of the canal as often as the body moves or twists, or the joints gaping extermally, whenever the body is bent forwards, and the spine chereupon made to take the form of a bow. These dangers, which are mechanical, are mechanically provided against. The vertebra, by means of their processes and projections, and of the articulations whicli some of tlese form with one another at their extremitics, are so locked in and confined, as to maintain, in what are called the bodies $01^{\circ}$ broad surfaces of the bones, the relative position nearly unaltered; and to throw the change and the pressure produced by flexion almost entirely upon the intervening cartilages, the springiness and yielding nature of whose substance admits of all the motion which is necessary to be performed upon them, without any chasm being produced by a separation of the parts. I say of all the motion which is necessary; for, although we bend our backs to every degree almost of inclination, the motion of each vertebre is very small: sucli is the advantage which we receive from the chain beirg composed of so many links. Had it been composed of three or four bones only, in bending the body the spinal marrow must have been bruised at every angle.

The substances which connect the bodies of the vertebræ to eaclı otlier, called the intervertebral cartilages, are thick, firn, and elastic. They are similar in shape, and nearly so in size, to the bones which they join. They are thicker before than behind, so that, when we stoop forwards, the compressible cartilage, yield. ing to the force, brings tlie surfaces of the adjoining vertebra nearer to a state of parallelism than they were before, instead of iucreasing the inclination of their planes, which must liave occasioned a fissure or opening between them: and their clasticity restores the body to its former state, when the compressing force ceases.

In order still further to irerease the strength of the compages, and to add a greater security against luration, the ver. tebra are articulated to each other by means of the processes before mentioned. And these processes so lock in with and overwrap one another, as to secure the body of the vertebra, not only from accidentally slipping, but even from being pushed out of its place by any violence short of that which would break the bone. The roots of the spinous processes are also joined to each other by very strong and highly elastic ligamentous substances, which will tend powerfully to restore the column after it lias been bent forwards.

The general result is, that not only the motions of the human body, necessary for the ordinary offices of life, are performed with safety, but that it is an accident hardly ever beard of, that even the gesticulations of a harlequin distort his spine.

The ribs are articulated by their pos. terior extremities to the bodies and to the transvel'se processes of the vertebra, and the true ribs are also joined by means of their cartilages to the sternum. Two great advantages are derived from the ribs having this cartilaginous portion. The effect of blows, or of any acciclental violence, is eluder, by the flexibility which they thus obtain; and the elastic power of the cartilages restores the ribs to tlı eir former position, after they have been raised by the intercostal muscles in breathing.

Joints of the upper extremity. - The clavicle is articulated to the sternum at one end, and to the scapula at the other.

The shoulder is formed by a round liead of the humerns, which plays in a cup of the scapula; and the ends of the bones are inclosed by a thick and strong ligamentous membrane, called the orbicular ligament. 'There is here, therefore, evcry latitude of motion allowed.

In the elbow, on the contrary, the joint is a mere hinge: lateral motion is restrain. ed by strong ligaments placed at the sides of the joint, and the fore-arm can therefore be moved only forwards and backwards. This joint is formed between the ulna and the humerus.

. The wrist is formed by the junction of the radius with the first phalanx of carpal bones. Its motion is very little more than that of a ginglymus. The rotation of the hand and wrist, or what anatomists call the pronation and supination, are performed by the radius revolving round the ulna, and carrying the hand with it. In this case the elbow joint is fixed; neither does the joint of the wrist move; but the 'radius moves freely round the ulna, and the hand is included in the motion. The pronation and supination of the hand are well exemplified in the use of the broadsword, and in cudgel-playing.

The carpal and metacarpal bones are united by joints and ligaments, but have no obvious 'motion on each other. The phalanges of the fingers are also articulated by ginglymi.

The bones of the pelvis are inseparably 


\section{ANATOMY}

connected by adhering cartilaginous surfaces and immense ligaments. Such is the strength of this union, that it will yield to no force but one that would destroy and crush the whole fabric.

Joints of the loroer extremity. - In the hip, which supports the whole body, and which is the centre of motion of the whole in moving from place to place, we find an apparatus, admitting of extensive motion, but at the same time most carefully guarded and strengthened. There is a rery large roundecl head of the thigh reecived into a leep cup of the os innominatum. Here it can revolve freely, and is prevented from escaping by thick and strong rising edges, that guart the brim of the cavity. From these edges there springs a very tough and stout orbicular ligament, which is firmly stretched over the head of the bone, and implanted into a contracted part called the neck. In order to provide still further for the security of so impor. tant a joint as the hip, there is a short, strong ligament arising from the head of the ball, and implanted in the bottom of the cup. 'This affords a very great obsta. cle to any force tending to displace the bone; but at the same time lies in the bottom of the cavity, so as not to interfere with any of the ordinary motions.

The knee-joint is formed by three bones : the head of the tibia, the condyles of the femur, and the patella. It is a ginglymus, and its motions are accordingly restrained by two strong lateral ligaments, and it is secured still further by two immense ligamentous ropes within tlic cavity of the joint, called the crucial ligaments.

The ankle is a ginglymoid joint, formed by the tibia and fibula, togcther with the astragalus. This joint, which is an important one, as bearing the weight of the whole body; is strengthened at its sides by two bony processes, called the internal and external malleoli or ankles.

The bones of the tarsus, metatasus, and toes, are articulated, like those of the hant.

\section{MroLogr.}

Muscles consist of bundles of red fibres; but the colour is not essential, since it can be removed by repeated washings and maceration.

The threals composing a muscle are enveloped by cellular substance, which connects it to the surrounding parts. Liach bundle consists of numcrous fibres, so small, that our instruments of research cannot arrive at the ultimate or original fibre: hence, any perceivable fibre, how:ever small, is formed by the juxts-position of numerous fibrilla; and, as we employ magnifying instruments of greater power, a fibre, which before seemed simple, resolves itself into a congeries of still more minute tlureads. We pass over in silence the dreams of various investigators, who lave busied themselves in looking for the ultimate muscular fibre; these researches do not assist us in explaining the plenomena of muscular action. The cohesion of the constituent particles of the moving fibre is maintained by the vital power: hence, a dead muscle will be torn by a weight of a few ounces, which in the living body would have supported many pounds. The muscular fibre receives a copious supply of vessels and nerves.

Tendons are formed by an assemblage of longitudinal parallel fibres. They are extremely dense and tough, of a splendid white colour, which is beautifully contrasted with the florid red of a healthy muscle. The muscular fibres terminate in these bodies, and they are connected to the bones. They possess no apparent nerres, and very few and small blood. ressels.

There is always an exart relation between the joint and the riuscles that move it. Wlatever motion the joint, by its me. chanical construction, is capable of performing, that motion the annexed muscles, by the ix position, are capable of producins. For example, if there be, as at the $k$ nee and elbow, a hinge joint, capable of motion only in the same plane, the muscles and tendons are placed in directions parallel to the bone, so as by their construc. tion to produce that motion, and no other. If these joints were capable of freer motion, there are no muscles to produce it. Whereas, at the shoulder and the hip, where the ball and socket joint allows by its construction a rotatory or sweeping motion, tendons are placed in such a position, and pull in such a direction, as to pro. luce the motion of which the joint adnits. In the head and hand, there is a specific mechanism in the bones for rotatory mo. tion; and there is accordingly, in the oblique direction of the museles belonging to them, a specific provision for putting this mechanism of the bones into action. The oblique muscles would have been inefficient without that particular articulation, and that particulararticulation would have been useless without the innscles.

As the muscles act only by contraction, it is evident that the reciprocal eaergetic 


\section{ANATOMY.}

motion of the limbs, or their motion with force in opposite directions, can only be produced by the instrumentality of opposite or antagonist muscles, of flexors and extensors answering to each other. For instance, the biceps and brachialis inter. nus, placed in the front of the arm, by their contraction, bend the elbow, and with such degree of force as the case re. quires, or the strength admits of. The relaration of these muscles after the effort would merely let the fore-arm drop down: for the back stroke, therefore, and that the arm may not only bend at the elbow, but also extend and straigthen itself with force, other muscles, as the triceps and anconeus, placed on the hinder part of the arm, fetch back the fore-arm into a straight line with the humerus, with no less force than that with which it was bent out of it. It is evident, therefore, that the animal functions require that particular disposition of the muscles which we call antagonist muscles.

It of ten happens that the action of muscles is wanted, where their situation would be inconvenient. In which case, the bo. $\mathrm{dy}$ of the musele is placed in some commodious position at a distance, and it communicates with the point of action by slender tendone. If the muscles which move the fingers had been placed in the palm or back of the kand, they would have swelled that part to an awkward and clumsy thickness. The ieanty, the proportions of the part, would havo been destroyed. They are therefore disposerl in the arm, and even up to the elhow, and act by long tendons strapped down at the wrist, and passing under the ligament to the fingers, and to the joints of the fingers, which they are severally to move. In the same manner the muscles, which move the toes and many of the joints of the foot, are gracefully disposed in the calf of the leg, instead of forming an unwieldy tumefaction in the font itself.

The great mechanical variety in the figure of the museles inay be thus stated. It appears to be a fixed law, that the conraction of a muscle shall be towards its centre. Therefore the subject for mechanism on each occasion is, so to modify the figure, and adjust the position of the muscle, as to produce the motion requircd, agreeably with this law. This can only be done by giving to different mus. cles a diversity of configuration, suited to their several offices, and to their situation with respect to the work which they have to perform. On which account we find them under a multiplicity of forms and attitudes; sometimes with double, sometimes with treble tendons, sometimes with none; sometimes one tendon to several muscles, at other times one muscle to several teuclons. The shape of the organ is susceptible of an incalculable variety, whilst the original property of the muscle, the law and line of its contraction, remains the same, and is simple. Herein the muscular system may be said to bear a perfect resemblance to our works of art. An artist does not alter the native quality of his materials, or their laws of action. He takes these as he finds them. His skill and ingenuity are employed in turning them, such as they are, to his account, by giving to the parts of his machine a form and relation, in which these unalterable properties may operate to the production of the effects intended.

The muscular system would afford us. numerous examples of what may be called mechanical structure: $i$. $e$. of such contrivances, employed to attain certain objects, as a human artist would adopt on similar occasions. One of the muscles of the eye-ball presents us with a very perfect pulley; by means of which the globe of the eye is moved in a direction exactly contrary to the original application of the force. This muscle, which is called the trochlearis, arises from. the very back part of the orbit: it has a long and slender tendon, running through a pulley in the inner part of the front inargin of the orbit, and then going back to be fixed in the hind portion of the eye-ball. Thus it draws the globe obliquely upwards and forwards, although the line of the contraction of the muscle is directly loack. ward.

In the toes and fingers, the long tendon, which benrls the first joint, passes through the short tendon, whicl bends the second joint.

The foot is placed at a considerable angle with the leg. It is manifest, therefore, that flexible strings, passing along the interior of the angle, if left to themselves, would, when stretched, start from it. The obvious preventive is to tie them down, and this is done in fact. Across the instep, or rather just above it, the anatomist finds a strong ligament, under which the tendons pass to the foot. The effect of the ligament, as a bandage, can be made evident to the senses; for if it be cut, the tendons start up. The sim. plicity, yet the clearness of this contrivance, its exact resemblance to established resources of art, place it among the 


\section{ANATOMY.}

most indubitable manifestations of design with which we are acquainted.

The number of the muscles of the luman bocly is so great, and the circum. stances which demand attention in every muscle are likewise so numerous, that a particular description of cach would ex:tend this article beyond its prescribed limits. We shall therefore merely give a catalogue of the muscles; which, together with the references to the annexed plate's, will give the rcader' a sufficiently clcar notion of the subject.

. Wuscles of the scalp.-1. Fronto-occipita. lis, or epicranius.

. Muscles of the ear.-1. Attollens auricu. lam; 2. anterior auris; 3,4 . retrahentes auriculam; 5 . major lielicis; 6 . minor helicis; 7. tragicus; 8 . antitragicus; 9. transversus auricula; 10. laxator tym. pani major; 11. laxator tympani minor; 12. tensor tympani; 13. stapedeus.

Muscles of the eye.-1. Orbicularis palpebrarum; 2. corrugator supercilii; 3 . fevator pal]scbrx superioris; 4. attollens oculi; 5. abdluctor oculi; 6. depressor oculi; 7 . adductor oculi: these are also called rectis $v i z$. rectus supcrior, exterwus, inferior, and internus; 8 . obliquus supcrior oculi, or trochlearis; 9 . obliquus inferior oculi.

- Yuscles of the nose. - 1. Compressor narium; 2. levator labii superioris et ala nasi ; 3. nasalis labii superioris; 4. depressor als nasi.

Muscles of the hips.-1. Levator labii supcrioris; 2 . zygomaticus major; 3 . zygomaticus minor; 4 . levator anguli oris; 5 . n̉epressor anguli oris; 6 . depressor labii inferioris; 7 , buccinator; 8 . orbicularis oris; 9 . anomalus maxillx superioris; 10 . levator menti.

Imwer gary.-1. Biventer maxilla, or digastricus; 2 massetcr; 3 . temporalis; 4. pterygoideus externus; 5 . pterygoideus interiuus.

Nick.-1. Latissimus colli, or platysma myoides; 2. sterno-cleido-mastoideus.

Tongre and thyroid cartilage.-1. Omohyoideus; 2. sternoliyoideus; 3. sterno. thyreoideus; 4 . lyyothyreoideus; 5 . musculis glandula thyreoidex; 6 . stylohyoideus ; 7 . styloglossus; 8 . mylohyoideus; 9. geniohyoideus; 10 . hyoglossus; 11 . ge. nioglossus; 12 . lingualis.

Muscles of the pharymx and palate.-1. Stylopharyngeus; 2 constrictor pharyngis superior: 3. constrictor medius; 4 . constrictor inferior; 5. sal pingo-pharyngeus; 6 . palato-pharyngeus : 7 . constric. tor isthmi faucium; 8. levator palati mol. lis; 9. circumflexıs palati; 10. azygus uvulax.

Muscles of the larynx.-1. Cricotliyreoideus; 2. crico-ary tenoideus posticus; 3. crico-arytenoidcus lateralis; 4 . ary tenoideus obliquus; 5 . arytenoideus transversns; 6 . thyreo-arytenoidcus; 7 . thyreoepiglotticus.

The whole number of muscles sbout the head, neck, and tliroat, is the refore 72 . . Inscles of the abdomen.-1. Obliquus externus abclominis ; 2 obliquus internus abdominis ; 3 . transversalis abdominis ; 4. rectus abdominis; 5 . py ranidalis ; 6 . diaphragma or septuma transversum.

. Wuscles of the thorax.-1. Sterno costalis, or tijangularis sterni; 2 . serratus pos-。 ticus supcrior; 3 . serratus posticus inferior; 4,5,6. scalenus anterior, medius, and posterior; 7 to 18 . levatores brevio. res costarum; 19 to 21 . levatores longiores costarum; 22 . intercostales externi ; 23. intercostales interni; 24. quadratus lumborum.

. Wuscles moring the head and sprine.-1. Splenius capitis ; 2 . splenius cervicis; 3. biventer cervicis; 4 . complexus; 5 . trachelomastoideus ; 6 . transversus cervicis ; 7. cervicis descendens; 8 . longissimus dorsi; 9. sacrolumbalis; 10 . spinalis cervicis; 11. spinalis dorsi; 12 . multifidus spina; 13 to 22 . interspinales cervicis; 23 to 28. interspinales lumborum; 29. rectus capitis posticus major; 30 . rectus capitis posticus minor: 31. obliquus capitis superior; 32 . obliquus capitis inferior; 33 . rectus lateralis; 34 . rectus ca. pitis anticus major; 35 . rectus anticus minor; 36 . longus colli; 37 to 43 . intertransversi colli priores; 44 to 49 . intertransversi colli posteriores; 50 to 57 . intertransversi clorsi ; 58 to 62 . intertrans. versi lumborum.

Nuscles of the anus and perineum.-1. transversus perinei; 2. transversus perinei alter; 3 . sphincter ani ; 4. levator ani ; 5. musculus coccygeus; 6 , currator coccygis.

Wiscles peculiar to the male organs of $\mathrm{gc}$. neration.-1. Cremaster; 2. crector penis ; 3. accelerator; 4. compressor prostatx.

- Yuscles peculiar to the female organs of generution.-1.' Erector clitoridis; 2. splincter vagina; 3 . depressor urethrx.

the whole number of muscles of tise trusk 105.

. Wuscles of the upper extrcmity.-Shoulder. 1. Pecturalis major; 2. pectoralis minor: 3. subclavius: 4. serratus magnus; 5 . trepazius; 6 . latissimus dorsi : 7 . rhomboidcus minor; 8. rhomboidcus major; 9. levator anguli scapulx; 10. 


\section{ANA'TOMY.}

deltoides; 11 . supraspinatus; 12 . infraspinatus; 13 . teres major; 14 teres minor ; 15. subscapularis.;

Arm.-1. Biceps flexor cubiti; 2. brachialis internus; 3 . coracolurachialis; 4 . triceps extensor cubiti ; 5 . anconeus.

Fore-arm.-1. supinator radii longus; 2, 3. extensor carpi radialis longior et brevior ; 4 . extensol carpi ulnaris; 5 . extensor communis digit?rum manus; 6 . cxtensor proprius auricularis; 7 . abductor lougus pollicis manus; 8. extensor major pollicis manus; 9 . extensor minor pollicis; 10 . indicator; 11 . flexor carpi ulnaris; 12. palmaris longus; 13. flexor carpi radialis; 14. pronator radii teres; 15. flexor digitorum sublinis, or perforatus ; 16 . flexor profundus, or perforans ; 17 to 20 . musculi lumbricales; 21 . flexor longus pollicis manus; 22. supinator 1adii brevis; 23. pronator radii quadratus.

Miscles of the hand.-1. abductor brevis pollicis manus; 2. opponens pollicis manus; 3 . Acxor brevis pollicis; 4 . abductor pollicis; 5 . palmaris brevis; 6 . abductor digiti minimi ; 7. flexor proprius digiti minimi ; 8 . abductor ossis metacarpi digiti minimi; 9 to 11 . interossci interni manus; 12 to 15 . interossei exterri manus.

The muscles of the upper extremity are 58.

Arucles of the thigh.-1. Tensor fascix latx; 2. glutens maximus; 3 . gluteus medius; 4. gluteus minimus ; 5 . pyriformis : 6,7 . geminus superior and inferior ; 8. obturator internus; 9 . quadratus femoris; 10 . biceps flexnr cruris; 11 . semitendinosus; 12 . semimembranosus; 13. psoas minor; 14. psoas major; 15 . iliacus internus ; 16 . sartorius; 17 . gracilis ; 18. rectus extensor cluris; 19 . vastus exteruus; 20 . vastus internus; 21 . cruralis; 22. pectincus; 23. triceps adductor femoris; 24. obturator externus.

Muscles of the leg.-1. Gastrocnemius or gemellus; 2. soleıs; 3. plantaris; 4. popliteus ; 5 . flexor longus digitorum pedis; 6 to 9. lumbricales peclis; 10 . fiexor longus hallucis; 11. tibialis posticus; 12. peroneus longus; 13 . peroneus brevis; 14. tibialis anticus; 15. extensor longus digitorum pedis; 16 . peronens tertius.

Muscles of the foot.-1. Extensor proprius hallucis ; 2. extensor brevis digitorum pedis; 3 . flexor hrevis digitorum pedis; 4. abductor hallucis; 5 . transvelsus pedis; 6. abductor digiti minimi pedis ; 7. flexor brevis digiti minimi pedis; 8 to 10 . interossei interni pedis; 11 to 14 , interossei extemi pedis.
The muscles of the lower extremity are 54 ; and the whole number of the body 289. But as they are the same on both sides, this must be doubled, which will give 578 ; an enumeration which is pretty nearly correct.

\section{Congang coNcenxed IN TIE REDUCTION AND ASSIMILATION OF TIIE FOOD.}

Organs of mastication and deglutition.The two jaws, with their teeth, and the tongue, are the principal agents in the business of mastication.

The articulation of the condylc of the lower jaw with the glenoid cavity of the temporal bone admits of the former part being moved in various directions. Its depression and elevation cause the opening and shutting of the mouth. It can be brought fomwards, and carricd backwards ; and admits also of being moved to one side or the other. It is by a combination of these various motions that the food is masticated, or reduced into a soft and pulpy form. The different teeth which are placed in various parts of the cavity of the mouth are adapted, by their form and situation, for various parts of the pro. cess of mastication. The anterior ones, which have a thin cutting edge, and in which the superior overlap the inferior, act like the blades of a pair of sclssors, These cut the food into snuller morsels; and serve us also in biting off a portion from any mass of food which we may be eating. The back teeth have broad bases, furnished with obtuse prominences; and they shut perpendicularly on each other. These are therefore well adapted for the grinding and trituration of the food. As their office requires a greater muscular force, they are placed in the back of the mouth, near to the centre of motion, and where, consequently, the action of the muscles is felt with the greatest effect. Ihe cutting teeth are placed in front, at a grcater distance from the attachment of the muscles, because their office does not require so great a muscular exertion.

The tongue is of considerable utility in contributing to mastication, as it serves to move the food about in the cavity of the mouth, and to subject it agrain to the ac. tion of the grinding teeth, wlien it lias escaped from between their surfaces. 'the muscles of this organ, whicl, we have enumcrated in the myological division of the article, give it a power of motion in every direction.

But the simple act of mastication would 


\section{ANATOMY.}

wily reduce the food into a powder, or at all events into a dry mass, that could not be swallowed without great difficulty. To obviate this inconvenience, it is plentifully moistened with a watery fluirl called saliva, and is the reby converted into a soft paste, which ean be couveyed into the stomach with perfect facility. The source of this fluil is, in several glandularbodies, situated near the mouth, and sending excretory ducts, which convey the secret. ed fluid into that carity. As the jaw's move, the muscles compress these glands; and squeeze the secreted fluid into the mouth. The tongue is constantly $\mathrm{cm}$ pluved in bringing again uncler the action of itue tecth those portions of the food which escape from between them; and the closure of the lips prevents it from falling out of the mouth.

The true salivary glands are three in number, on each side of the hearl. The largest is placed in the space left between the ear and the lower-jaw-bone; and is called, from its situation, the paroticl. Its duct pierces the midclle of the cheek. The two others are placed under the tongue, and are called the subnavillary and sublingual. Their ducts join to open by a common orifice, at the side of the niembrane called the frenum of the tongue, which ties the under surface of that organ to the inside of the lower jaw. Besides these large salivary glands, therc are other sinall granular bodies, which pour a mucous fluid into the mouth ; these are named, according to their situation, glandula labiales, buccales, \&c.

The cavity of the mouth in which the process of mastication grocs on is not a very extensive one. There is a small space left between the cheeks and the teeth externally; but within the teeth the tongue occupies nearly the whole room. The upper boundary is formed by the palate or roof of the mouth, and the lower by the surface of the tongue. The mouth opens belind, by a tolerable free communication, into a membranous bag, called the pharynx. The surface of the mouth is every where covered by a soft and smootli membrane. This is of course kept constautly in a moist state, as the glauds abov c enumerated contiuually pour move or less of their secretion into the cavity. The membrase of the mouth is continuous with the external surface of the body; but the skin assumes a more delicate urganization, as must be apparent to every hody, from the cliange of colour at the lips.

Bag of the pharynx.-The masticated aliment is collected on the back of the tongue, which is then carried npwards, and backwards, to discharge it into the phary inx. This bag is covered by muscular fibres (forming the muscles called constrictores pharyngis) which contract, successively, in order to propel the food towarls the stomach. But as there are several organs communicating with the pharynx, the food might pass in a wrong direction, if the parts were not so contrived as to prevent such occurrences.

In the upper and anterior part of the phaynx, the nostrils open by two large and free apertures. Between these and the entrance from the mouth is found a fleshy and morcable curtain, called the soft palate, or velum pendulum palati. There is a small body, of a pointed figure, projecting from the middle of this organ, and known by the name of the uvula. This curtain and the urula can be easily seen in the throat of a living person. It admits of being elevated so as to shut the opening of the nostrils ; and its action is exemplified in the act of vomiting: the food is forcibly thrown into the pliarynx, and would pass mostly into the nose, were it not prevented by the soft palate. From the urula the membrane is continued on either side, in an arched form, towards the root of the tongue, and it contains a glandular body, called the tonsil, which secretes a mucous fluid, to lubricate the parts, and facilitate the passage of the aliment. The larynx opens into the pharynx, just at the root of the tongue; orer this part, which is termed the glottis, every morsel of the fool must necessarily pass ; yet, so exquisitely tender is the membrane of the wind pipe, that the contact of the smallest extraneous body excites a conrulsive paroxysm of cougling, that does not cease until the offending matter be removed. Here then are two objects to be effected; the function of respiration recluires that tle winclpipe should have a free communication with the external air, while the irritable nature of its membrane clemands that no extraneous body should find admission. These points are both attained br mealss of a strictly mechanical contrivance; by a structure which produces the required. effect, independently of the will of thic animal, and merely in consequence of those motions which the organs perform in the office of deglutition. At the back of the tongue, and just in front of the glottis, is a cartilaginous valve, called tle epiglottis. When the parts are at rest, this valve stands perpendicular, and con- 
sequently does notinterfere with the passage of the air into the wind-jpipe. In the act of swallowing, the tongue is carried backwards, and the wind-pipe is drawn up : hence the epiglottis becomes mechanically applied orer the opening; and at this moment the food enters the pharynx over it, and by its pressure closes the aperture still more completely. As soon as the food has passed, the tongue and wind-pipc resume their former position, the elasticity of the cartilage restores it to the erect state, and the glottis is again free for the continuance of respiration. So completely does this simple mechanism answer the proposed end, that, al. though every morsel of food passes over the glottis, the accident of any portion going the wrong way, as it is termed, is comparatively'rare, and can only arise from our being imprudent enough to laugh or talk while we are swallowing. In either of these cases air must pass out of the trachea, and, by so doing, it lifts up the epiglottis.

The pharynx opens below in the csophagus, a muscular tube, which conveys the food into the stomach. The aliment, in its farther progress, goes through different viscera contained in the abdomen ; and we shall therefore proceed with a description of that cavity.

The tern abdomen includes a large portion of the body. It is bounded above by the cartilages of the ribs, and by the diaphragm, which separates it from the chest, at the back part, by the bodies of the lumbar vertebra ; in front and at the sides, by the abdominal muscles; and below, by the bones of the pelvis.

It is every where lined by a membrane called the peritoneum. The surface of this is perfectly smooth and polished, and moistened by a serous exhalation produ. ced by the minute arteries of the part. This membrane not only lines the cavity of the abdomen, but also covers all the viscera contained in that cavity, so that the exterior surface of each part consists of what anatomists call its peritoncal coat. IIence the motions of these parts upon cach other, and upon the surface of the cavity, are performed with perfect facility. The productions of the membrane, which gives these exterior investments to the viscera, serve also to confine them in their relative positions.

Tle cavity is subdivided into three re. gions, the epigastric, which includes all the space above an imaginary line drawn across the belly, from the greatest convexities of the cartilages of the seventh true rib; the umbilical, which is the division between this line and another drawn from the anterior superior spines of the ilia; and the hypogastric, which is the space left below the last line.

The sides of the cpigastric region, which are the spaces covered by the eartilages of the ribs, are called hypochondria : the sides of the umbilical region are named the loins : and those of the hypo. gastric the groins.

The stomach is a large membraneous reservoir, receiving the food from the $\propto$ so. phagus, and retaining it until a certain change, called digestion, is produced. Its figure is conical, as it is largest at the left end, and gradually decreases in size towards the right: these are called the greater and smailer extremities of the stomach. It is also bent in its course, so that we describe a greater and smaller curvature or arch. It has two openings, one close to the diaphragm, called the cardiac, superior, or asophageal ; the other, just at the smaller end, is called the pyloric, or lower orifice. The capacity of the stomach varies from about 5 to 11 pints.

Its structure is muscular; and this is necessary in order to propel the food when digested. Under the muscular coat is found the internal, or villous, tunic; the arteries of which pour out the gastric juice, the chief agent in the digestion of the food.

The pylorus, which word is derived from two Greek terms, signifying the keeper of the gate, is a contracted ring, by which the stomach commuricates with the small intestine. It prevents the food from passing out of the stomach before it has been sufficiently acted on by the gastric juice,

The stomach receives a portion of peritoneum as the æsophagus passes the dia. phragm. There is also a process coming from the liver, called the lesser omentum, or mesogaster. This is attached to the lesser arch of the stomach. The great omentum, or the caul, is affixed to the greater arch of the stomach, and hangs from thence over the surface of the intes. tines, being interposed between them and the parietes. It is also attached to a part of the colon : its use is unknown.

The smallintestine is divided into three parts; the duodenum, jejunum, and ileum; but this distinction is an arbitrary one, and not founded on any difference in struc. ture. It consists of a membranous tube, about an inch, or an inch and a lialf in diameter, and four times the length of the subject. Notwithstanding this great length, it is collected, by means of numcrous turzl. 
ings and convolutions, into a comparative. ly small space. These conrolutions of the small intestine occupy the chief part of the umbilical and hypogastric regions of the abelomen. They are connected in their situation by means of a broad folded nembrane, called the mesentery. This production of the peritoneum is about six inches broad at its commencement, but it expands gradually, something after the manner of a fan, so that it becomes broad enough, ultimately, to cover the whole length of the small intestine. It scrves to keep the different convolutions of the ca. nal in a certain relative position, and allows, at the same time, a considerable freedom of motion, without any danger of intangling. In tracing the course of the small intestine, we follow the duodenum from the lesser extremity of the stomach, in the rightlyy pocliondrium, making three turns close on the backbone, and then coming out just over the left kidney. The general direction of the canal from this point, independently of its various turnings and wndings, is towards the right groin, where the ilium terminates by en. tering the cocum.

The small intestine possesses three coats similar to those of the stomach, viz. an external or peritoneal; a midc’le or muscular; and an internal, or villous, tu. nic. The latter forms a great many transverse, loose, and floating processes, called valvula conniventes; by ineans of which the extent of surface of the villous eoat is very much augmented. Numerous -landular bodies are found in parts of the canal, collected into small parcels, and hence called glandula agminatx.

The food which is reduced by the acmon of the stomach into an homogeneous mass, called cluyme, enters the small in. testine, where it undergoes a further change, and becomes cliyle. It is propelled along the canal by the muscular -oat of the intestine, and the villous tunic absorbs from it the nutritious particles. It passes along every turn and winting of this long cana, continually subjected to the action of the absorbing vesscls. The residue of the alimentary matter is sent into the lange intestine, from which it is expelled in the form of frees.

The large intestine is a canal of about two or three inches incliameter, and seven feet in length. It is divided into the caecum, colon, and rectum. The cocum is a bag situated in the right groin, and receiving the termination of the ilium. The latter interstice enters in such a manner, that the passage of the aliment is allowed VOLL. I. from it into the coecum, but prevented from returning. The part which effects this is called the valvula coli. A sinall process, about equal in size to an earth. worm, is connected to the coecum. Il is called appendix cocei vermiformis, and its use is unknown.

From the right groin the intestine ascends on the right side of the abdomen over the kidney, under the name of colon: it turns completely over the abdomen at the upper part, and descends along the left side to the left groin; here it makes a large tum over the brim of the pelvis, and enters that cavity, where it takes the name of rectum, which terninates at the anus. We distinguish in the colon the right or ascending portion; the midule or trans. verse arch; the left or descending; and the sigmoid flexure. The right and left portions of this gut are closely bound down in their situations by two portions of peritoneum, called ligamenti coli. The transverse arch has a broad process connected to it, by which it is loosely attached : this is calied the mesocolon.

The large intestines have a peritoneal, a muscular, and a villous coat; but they have no valvula conniventes. The longitudinal muscular fibres are collected into three bands, which, being shorter than the rest of the intestine, occasion the other coats to be gathered up in folds between them, and thereby give the intestine a sac. culated appearanice.

The residue of the alimentary matter, which the large ipcestine receives from the small, in cosiverted in the former canal into a substance of peculiar odour, colour, and consistence, called frecs; in whion form it is expelled from the body.

Parts subservient to the functions of the alimentary canul, and costained in the carity of the abclomen.

The liver is the largest glandular mass in the body, and is placed towards the right side of the epigastric region. Its thickest portion fills the right bypochondrium; a thinner part of the gland extends across tlre middle of the epigastric region to the left hypochondrium. Its size is greater in proportion as the animal is younger. In the adult it is contained within the cartilages of the ribs; but in the futus it extends to the navel, and fills half the belly. Its upper surface is con$v e x$, and in close contact with the concare under surfice of the diaphragm. Its under or concave surface rests chicfly on the stomach. It is divided into $\mathrm{a}$ right and left lobe, and lobulus spigelii. It bas a $13 \mathrm{~h}$ 
posterior and thick, an anterior and thin, margin. Its colour, in the most healthy state, is of a reddish brown; but it often deviates from this. Its wcight, in an adult man of middling stature, is about 3 pounds. It is connected to the diaphragm by four ligaments, viz. 1. ligamentum latum, or suspensorium, whicli divirles the light and left lobes from each other. The front edge of this part contains the fibrous remains of the umbilical cord of the foetus, which, assuming the appearance of a round rope, is called the round ligament. 2,3. Ligamenta lateralia, or dextrum, et sinistrun. 4. ligamentun coronarium.

The liver is covered exteriorly by peritoneum, and there are certain fissures and excavations on its surface. 1. Fossa, for the gall-bladder, in the under surface of the right lobe. 2. Fissure on the anterior thin margin, for the entrance of the umbilical vein. 3. Portx, or large transverse notch, at which the blood-ressels enter, and from which the he patic duct proceeds. 4. Notch for the inferior vena cava. 5. Excavation for the bodies of the vertebrx.

The liver is composed of a tolerably firm and close substance, consisting of a closely united congeries of different ressels. These vessels are the vena portarum, the hepatic artery, the hepatic veins, and the biliary ducts. The former vessel carries to the liver the blood which has circulated through the different abdominal viscera. It ramifies in the liver like an artery, and the secretion of the bile is supposed to take place from the blood which it conreys to the liver. The blood of this vein, as well as that brought by the hepatic artery, for the nourishnient of the liver, is returned by the large lopatic veins to the inferior vena cava. The small branches of the hepatic duct, which conveys the secreted bile from the liver, appear like small yellow pores, when a section of the liver is made, and hence they are called pori biliarii.

The mesogaster, or little omentum, is attached to the port $x$ of the liver. The vena portarum, the biliary ducts, the hepatic artery, and the hepatic plexus of nerves, pass along the right side of this process; and the part in which they are situated is called the capsula Glissoni. Under the edge of this part is an opening, leading to the bag of the great omentum, and called the foramen epiploicum.

GALL-BLADDER AND BILTARY DLCTS.

The gall-bladder is a membranous bag, serving as a reservoir for the bile. Its shape is that of a pear, being broader at one end, and diminishing conically to- wards the opposite extremity. 'The broad end is called the fundus; and the smaller part of the neck the viscus. Its ave1age capacity may be about one ounce. It is firmly bound to the surface of the liver by peritoneum. Its inner surface is elegantly reticulated, and furnishes 2 viscid mucus that mingles with the bile.

The hepatic duct is continued in 2 straight course from the liver to the duodenum, in which it opens. It passes, how. ever, in an oblique manner, between the coats of the intestine, before opening into its carity. Hence the contents of the intestine cannot enter the duct; and the more fully the intestine is distended, the more completely is this prerented by the compression of the duct between the intestinal tunics. The neck of the gallbladder is gradually contracted into a small tube, called the cystic duct, which joins the hepatic at an acute angle, after first running parallel with it. The remainder of the hepatic duct, after the junction with the cystic, is often called the ductus communis choledochus. The surface of the cystic duct, as well as that of the ncck of the gall-bladder, has numerous small folds of the internal membrane, which must retard and obstruct the course of the bile.

Pancreas. -Is a gland of the conglomerate kind; that is, composed of numerous minute portions, united by cellular substance. It is connected by one cnd to the coinmenceinent of the duodenum, and extends across the vertebra, behind the lesser arch of the stomach, to the spleen. Its length is about six inches; its breadth one and a half; and its thickness half an inch.

Each of the small molecules which com. pose this gland has an excretory duct; these unite together into larger and larger trunks, and the main tube of all runs along the sentre of the gland, and joins the ductus communis choledochus just before that duct opens into the duodenum.

Spleen.-This part, which in common language is called the milt, is a soft and livid mass, interposed between the great end of the stomach and the diapliragm. It weighs about six or seven ounces. It consists of a congeries of cells filled with blood, as the arteries and reins of the organ communicate with them. It is closely connected to the great end of the stomach by vascular ramifications, which the splenic vessels send to the stomach. It has a concave and convex surface; an anterior and posterior extremity; and an cxterual peritoneal covering. 


\section{ANATOMY.}

ORGIXS OF RESPIRATIOY.

As these are containcd in the cavity of the thorax, we shall consider the subject in the form of a description of that cavity and its contents.

The cavity of the thorax is the space included by the dorsal vertebra belind, by the ribs with their cartilages, the sternipm, and intercostal muscles, at the sides and fore part; and by the diaphragm be. low. This cavity is lined by a mesubrane called the pleura, which has a smoorh interual surface, constantly moistened by a serons exlualation.

The cavity of the chest contrins two distinct membranous bags, called the right and left bags of the pleura; each of these holds the lung of its own side, and is entirely separated from the oppo. site one. The pleura not only forms a bag which holks the lung, but is also reflected over the surface of the viscus, be. stowing on it a sinooth exterior investment. This is ealled the pleura pulmonalis, to distinguish it from the other, which is named pleura costalis.

If the cartilages of the ribs be divided on one side of the chest, the correspond. ing bag of the pleura will be opened; and it will then appear, that this is separated from the opposite one by a partition, which extends from the sternum in front to the rertebre behind, and is known by the name of mediastimum. The pleura may be compared to two bladders placed laterally with respect to each other, but adhering only partially, and separated by vari. ous intervening bodies. Thus, the heart and adjoining large blood-ressels, the ceophagus, and the division of the trachea into the two bronchi, are placed between the two pleurr. The mediastinum then is the space included between the opposed surfaces of the two bags of the pleurx, and containing the parts above mentioned. The name of anterior mediastimum is applied to a small interral left between the two pleurre, just behind the stemum, and occupied only by a loose cellular texture. The posterior meiliastinum is a larger space in front of the bodies of the vertebra; it contains the descending aorta, the rena azygos, thoracic duct, csopliagus, and the par vagum.

The eapacity of the chest taken altogether varies, accorling as we estimate it in a state of inspiration or expiration; being largest in the former, and smallest in the latter state. The right bag of the pleura is considerably larger than the left, as in also the right lung.
In the living state, the lung is in close contact with the surface of the earity, and follows all the motions of the sides of the cbest. It is distended by the intux of air, when the chest is enlarged; and the air is expelled from the lung, when the chest is diminished. As soon as the thorax is opened in the dead subject, the lung falls down from the sides of the chest, or, in. technical language, collapses, and then a large empty space is seen between it and the ribs. From this representation it should appear, that the lungs are quite passive in the business of respiration.

The lungs are two in number: one being contained in each bag of the pleura. They are loose and unconnected in these bags, exceptat one point, towards theup. per and posterior portion of each viscus, where the great vessels enter them, and where the bag of the pleura is continu. ous with the reflected portion of the mem. brane. These are called the ligaments of the lungs.

Their colour varies considerably. It is always rerging more to a red, in proportion as the subject is younger : in the adult, it has more of a spotted and livid cast. Towards the back of the lungs it i i always much decper, from the gravitation of', lood in the ressels in consequence of the position of the subject. It is lighter, when the lungs contain much air.

The lungs are subdivided into lobes; of which the right contains three, and the left two. Their substance is composed of a congerics of minute membranous cells, about equal in size to a pin's head, and as these are more or less filled with air, they gire the lung a peculiar spongy feel. These cells communicate with the ultimate ranuifactions of the air ressels, and receive air from that source. The pulmonary ressels ranify minutely in them, and therr:by expose the blood to the ef. fects of the contained air ; and in this exposure the object of respiration is effected.

The windpife. The tubc, which conreys the external air into the lungs, may be divided into three parts; the larynx, the trachea, and the bronclii.

The larynx is a hollow cartilaginous or. gan, placed at the top of the trachea. The air which passes through this from the lungs, in expiration, produces the voice.

The cavity of the lary $n x$ opens above at the root of the tonguc, and below into the trachea. The nrgan is composed of five pieces of cartilage : viz. the thyroid and cricoid cartilages and epiglottis, and two arytenoid cartilages.

The thyroid carulage is the largest, and 
consists of two irregularly quadrangular pieces, united in front at an obtuse angle. This part projects in the front of the neck, and much more conspicuously in the male than in the female sex: it is called po. mum Adani.

The cricoid cartilage may be compared to a ring with a seal, of which the broad or seal part is placed behind, and the narrower portion in front. It is directly under the thyroid cartilage.

The arytenoid are two pyramidal por. tions of cartilage, connected by regular moveable articulations to the back of the cricoid.

The epiglottis is the softest cartilage of the larynx. It has a basis firmly tied to the thyroid cartilage, while its opposite extremity, which is very thin, is of a rounded figure, and stands directly upwards, except during deglutition, when it descends so as to cover the opening of the larynx.

The thyroid cartilage is tied by three ligaments to the os hyoides above, and by as many to the cricoid cartilage below; but the most important ligaments of these parts are the ligamenta glottidis; which arise from the front of the arytenoid cartilages, and are attached to the posterior surface of the front portion of the thy roid: A longitudinal slit, called the rima glottidis, is left between these, and it is by the passage of the air through that slit that the voice is formed. Hence, from the great share which these ligaments have in forming the voice, the name of chordx vocales has been given to them.

The larynx is lined by a vascular and very sensible membrane, copiously moistened with mncus, in order to defend it from the external air. It admits of free motion in the neck, and its parts are also moved on each other; particularly the arytenoid cartilages, whose morements, by altering the size of the ruina glottidis,. and the state of tension of the chorla vo. cales, contribute most immediately to the variations in the tone of the voice.

The trachea is that portion of the aerial tube; which is placed between the cricoid cartilages and the origin of the bronchi. It is a cylindrical membranous tube, of from 5 to 7-8ths of an incl in diameter. It runs along the middle of the fore-part of the neck, having the large blood-ressels of the head on eacl side, and being con. necter belind to the asophagus. Soon after it lias entered the chest, it divides into the two bronchi.

The tube of the trachea is furnished with hoops of cartilage, by which it is kept permanently open for the passage of the air; these ale not, however, complete circles, being deficient behind. The lining of the tube is highly vascular and sensible, and covered with a copious mu. cons secretion, which is rendered necessary by the constant current of ais to which it is exposed.

'The bronchi are merely the two bran. ches into which the trachea divides for the two lungs; and of these the right is the largest and shortest. They ramify throughthelunges dividing into smaller and smaller branches; and the ultimate ramifications communicate with the aircells.

\section{ORGATS OF CIRCULATION.}

The heart is the centre of the circulating system; being the source of the arteries, and the termination of the veins. The younger the subject, the larger is the heart in proportion to the body. It is often smaller in tall and strong men, than under different circumstances.

It is connected at its posterior part, behind the sternum, by the large blood vessels, being unattached erery where else, and merely confined in its situation by the pericardium.

The pericardium is placed in the carity of the chest, behind the second, third, fourth, and fifth ribs of the left side. It is covered to the right and left by the bags of the pleura, which adhere by a loose cellular membrane It is not actually connected by any part of its surface to the sternum. Below, it rests on the diaphragm, and adheres very firmly to the superior surface of the tendon of that muscle.

The cavity of the pericardium is larger then the heart, so that this viscus can move freely in it.

The bag of the pericardium in shape resembles the figurc of the heartitself, being conical. Its substance is thick and compact, and it is much more dense and strong than the peritoncum or pleura. Where the great vessels are connected to the heart, this membrase becomes re. flected over its surface; and hence the substance of the heart has a close investment from this membrane, besides being contained loosely in the bag-like portion. A small portion of the large blood-ves. sels is included within the cavity of the pericardium; particularly of the aorta and pulmonary artery; which are consequently covered by the reflected portions.

The internal surface of the pericurdir 
$4 \mathrm{~m}$ is moistened by a serous secretion from the exhalant arteries; which is collected after death into a few drops of a clear light ycllow liquor. It is an unnatural increase of this that constitutes dropsy of the pericardium. This fluid in the living state lubricates the opposed surfaces of the heart and pericardium; and thercly facilitates their motion on each other, and prevents their accretion.

The heart, which is contained almost entirely in the left side of the chest, resembles a half cone; hence we distinguish in it a basis or broad part; and an apex or narrower portion; a convex and a Hat surface. The basis is placed towards the right, and backwards; the apex points obliquely to the left, forwards and downwards. The basis is opposite to the seventh or eighth rertebra of the back, and the apex points to the cartilage of the fifth or sirth left rib. The position however varies by the motion of the dia. pliragm in respiration, as it is drawn dow $n$ in a strong inspiration, and again rises in expiration. Its position also seems to vary slightly, according to the situation of the body in lying.

A small portion of the left lung seems, as it were, removed just at the apex of the lieart; so that that part of the viscus is not corered by the lung like the rest, but touches the front of the chest.

Those cavities of the heart which are called the riglit are placed in front; and the left cavities are towards the back part; so that the epithets anterior and posterior would correspond more nearly with the true position of these parts, than those of right and left.

The flat surface of the heart looks directly downwards, and rests on the ten. don of the diaphragm; this, therefore, in point of position, is inferior; the convex surface is turned upwards, forwards, and obliquely towarls the left, so that it may be called the superior surface.

The weight of the human heart, when removed from the body, with its pericardium, is from 10 to 15 ounces.

Like the heart of all warm-blooded animals, this organ consists of two hearts, closely and intimately connected. One of these is concerned with the circulation through the body, or the greater circulation; the other with the circula. tion through the lungs, or the minor circulation. These might perform their offices, if separate and even distant from each other. Each of these hearts consists of two cavities ; an auricle, or membranous bag, placed at the mouths of the veins; a ventricle, or strong muscular organ, placed at the orifice of the artery, and constructed for the purpose of driving the blood into that ressel and its branches.

The two auricles are placed at the bas sis or broulest part of the heart; and the two ventricles, composing the chicf bulk of the organ, are found in front of the former cavitics.

In the following description of the structure of the lieart, we shall trace tlio parts in the same order in which the blood pases through them. This fluid, then, after circulating through the blood. ressels of the body, after scrving the various purposes of nutrition, secretion, \& c. is returned into the right auricle of the heart by three large veins, viz. the superior and inferior vena cava, and the great coronary vein. The properlies of this blood have been so altered in its course, that it is necessary for it to be subjected to the action of the atmosphere in the lungs, before it is again fit to be sent into the arteries of the body. The right auricle derives its name of auricle from a small fringed process, which is found at its anterior part; the rest of the cavity is called the sinus of the vena cava. The lining of this bag, as indeed that of all the other parts of the heart, consists of a smooth and polished surface. The muscular fibres of the auricle are not numerous nor large; they are arranged in parallel fasciculi, which lave been com. pared to the teeth of a comb ; and hence the epithet of musculs pectinati has been given to them.

The right auricle transmits the blood into the riglit, anterior, or pulmonary ventricle, through a large circular orifice, called the annulus venosus, or the auricular orifice of the rentricle. When this latter cavity contracts, the blood would be driven back towards the auricle, were not this prevented by a valve, called the tricuspidal or triglochine. This valve is formed by a production of the lining of the heart, divided into three pointed portions. These are tied by tenclinous strings to certain projecting packets of the muscular fibres, called the fleshy co. lumns of the ventricle. The structure of the ventricle is very difierent from that of the auricle. It is a strong mus. cular cavity, adapted to the office of forcibly projecting the blood through the arterial ramifications; whereas the auricle is a mere reservoir, holding the blond until the ventrical has cmptied ixself by its contraction. 


\section{ANATOMY.}

The pulmonary artery, which arises from the upper and anteriol part of this ventricle, conveys the blood into the lungs. The opcning of this artery, which is called the arterial orifice of the ventricle. is furnished with tliree valves, called sigmoid or semilunar, which prevent any retrograde motion of the blood from the artery towards the heirt.

The venous blood, by being exposed to the atmospheric air in the lungs, is alter. ed in its properties, and becomes arterial blood, in which state it is returned to the left auricle of the leart by four pulmonary veins, two of which belong to each lung. This left or posterior auricle consists of a large carity, called the sinus of the pulmonary veins; and of a smaller process or auricula. It is situated quite at the upper and back part of the lieart, and transmits the blood through the auricular orifice of the left ventricle into that cavity. This opening is perfectly similar in all essential circumstances to the eorresponding part on the right side of the heart. But its valve, being divided into two portions only, is called mitralis, from a comparison with a bishop's mitre.

The left ventricle is much thicker and stronger than the right. It feels externally almost like a solid mass of flesh ; while the right is comparatively thin and habby. The reason of this difference is obvious. The left ventricle has to drive the blood to the most remote parts of the body, whereas the right only sends it through the lungs. The aorta arises from the left ventricle, and its mouth is graarded by three semilunar valves. This is the trunk from which the arteries of the whole body arise.

\section{STRCCTURE OF THE ARTERIES.}

Those vessels, through which the blood flows from the heart into every part of the body, are called arteries. The term, which is derived from $\alpha x \rho$, air, and $\tau \eta \rho \varepsilon \omega$, I hold, was first adopted by the anato. mists of the Alexandrian school, in consequence of the erroneous opinion which they entertained, that these vessels werc designed for the distribution of air throughout the body.

The larger arteries have thick and elastic sides, so that they remain open when divided, and present a regularly circular aperture. The sides may be separated into thrce strata of dissimilar substances, which are technically called coats. The innermost, which is generally termed the cuticular coat, is thin, strong, and highly elastic. The intemal surface of this coat is perfectly smooth, so that the blood glides along it without impediment; the external surface is connected to that coat which surrounds it. The middle, or, as it is called, the muscular coat, is composed of a congeries of circular fibres, separable into numerous strata, but not much resembling muscular fibres as found in other situations. The external coat of the artery is made of condensed cellular substance, which unites these vessels to the neighbouring parts.

It appears that the larger vessels have the greatest elastic power, with the smallest muscular force; while these properties exist in reversed proportions in the smaller vessels. In the large arteries muscular power is unnecessary, for the force of the heart is fully adequate to the propulsion of the blood; but in the smaller arteries, where the effect of the heart's action de. clines, a proportionate muscular power is allotted to the vessels, to urge on the circulating fluids.

The arteries have their nutrient arteries and veins, their absorbents, and their nerves.

All the arteries proceed from one great vessel, as the branches spring from the trunk of a tree; and we proceed to notice certain circumstances observable in their ramifications.

1. When an artery gives off a branch, the conjoined areas of the two vessels make a greater space for the blood to move in, than the area of the original vessel. The increase of dimensions in the branches of a large artery is slight; but in those of a small one it is so considerable, that Haller lias estimated it as surpassing by one third that of the trunk from which they sprung. The conjoined areas of all the small arterics so greatly exceed that of the aorta, that the same anatomist, in opposition to former opinions, affirms that these vessels are conical, the basis of the cone being in the extreme arteries, and the apex in the heart.

2. When a large artery sends off a branch, its course does not, in general, deviate further from that of the trunk than an ang!e of 45 degrees. Sometimes a branch, which has gone off at an acute angle, returns, and proceeds in a contrary direction to that of the trunk. Sometimes indeed a large artery does proceed from the trunk at nearly a right angle, as the renal arteries. Though the large arteries generally ramify at acute angles, there is great diversity in the branching of the smaller ones. 
3. Arteries in general do not pursue a straiglat, but a serpentine course ; this is reniarkably the case in some instances; as in the spernatics, those of the face and occiput, and in most of the smaller arteries.

4. Though the ramification of arteries may be compared to the branching of trees, yet it differs materially in this par. ticular, that the different branches frequently conjoin. This conjunction is technically termed, if we borrow the term from the Greek language, their anustomosis ; if from the Latin, their inosculation. This union of arteries rarely happens among the larger ones, but frequently among the smaller; and increases in number in pro. portion to the minuteness of the ressels. The utility of the inosculations of arteries is evident; were it not for this circum. stance, if any arterial trumk were accidentally compressed, so that the current of blood in it should be fer some time obstructed, the parts which it supplied must perish. But in consequence of the frequent communications of these tubes with each other, the blood can pass from the adjacent arteries into all the branches of any one accidentally obstructed.

When arteries inosculate, two currents of blood, moring in opposite directions, must come together, and retard each other's motion. This probably is the rea. son, why larger arteries, in which the blood flows with rapidity, so scldom conjoin; whilst the smaller ones, in which the blood's motion is more tardy, commu. nicate in surprising numbers, and with a frequency proportionate to their minuteness. The very frequent communications of the minute arteries prevent the prejudicial consequences of obstruction of the trunks almost as effectually, as if those arteries themselves communicated by more direct and larger channels.

All these minute arterial tubes are capable of enlargement ; and it is an ascertain. ed fact, that even the aorta itself may be gradually obstructed at some distance from the heart, without the parts which it supplies being deprived of nourishment. From an attentive consideration of all these circumstances, it has been conclud. ed, that the moderate increase of the area of the branches of large arteries; the acute angles at which they divide; their uearly rectilincar course; and the rare oc. currence of inosculation between them ; are designed to facilitate the rapid motion of the blood in them, so that it may arrive unchanged, and in the same state that it was in when projected fiom the heart, at that part of the body, for the nourishment of which it was intended: whilst, on the contrary, the great increase of the area of the smaller vessels, the variety of their an. gles, their tortuous course, and their frequent communications, were designed to chick the velocity of the blood's motion, when it has arrived at that part, where secretion is to be performed, and nutrition is to take place. Contrary opinions have indeed been maintained; and for the further discussion of this subject, we must refer the reader to the remarks on the circulation in the article Pursıoner.

Termination of the arteries. - When these vessels have become very minute, they terminate in two ways: they either turn back again, and become veins, and return the blood to the heart, or they send off fine ressels, which abstract something from the circulating blood, and are therefore called secerning arteries. Though none bit minute arteries are ever reflect. ed to become veins, yet rany of them are of sufficient magnitude to admit common waxen injection; and when this experiment succeeds, the continuity of the arte. ries and reins is very manifest. It seems therefore to follow from this facility of communication, that the mass of the blood is constantly and freely circulating, in order to undergo that change which is effected in the lungs, whilst but a small part of it proceeds into the very minute arteries, for the purpose of having secretions made from it. For these arteries, however minute, must be considered large, in com. parison with the exility of others, which cannot be injected with wax, and even reject the red globules of the blood, or admit them in such small proportion, that they do not impart the red colour to the fluid which moves in those vessels. Now, we may venture to affirm that these globules do not much exceed in diameter. the 150,000th part of an inch, which circumstance sufficiently shows the minute. ness of the lesser arteries.

The seceming arteries are in general too minute to admit of demonstration; they are however evident in some glands; in the kidney, for instance, they may be seen contimied into the excretory vessels. Subtile injections, when thrown into the lasger arterial trunks, ooze out on the surfaces of membranes, and into the cellular substance, and they are generally supposed to be poured forth from the open orifices of secerning arteries. Analogy, therefore, rather than actual demonstration, leads us to believe, that the secerning arteries abstract the particles of nutrition, or the materials which compose the fabric of the body, from the circulating fluids, and de- 
posit them from their open mouths, so as by this means to build up and keep in repair the structure of the body.

Distribution of the arteries. - The great artery, whose branches supply the whole of the body, is named the aorta. It arises from the upper part of the left ventricle ; and emerges from the heart, between the pulmonary artery and the right auricle. It first ascends in the chest; opposite the upper edge of the second rib it bends backwards till it reaches the left side of the spine, in which situation it descends from the fourth or fifth dorsal to the last Jumbar vertebra.

By the arch of the aorta is meant that part of the vessel which arises from the heart, and bends across the chest. It sends off the following branches : the two first arising at right angles close to the heart; the three following from the convexity of the arch :

1. Righit coronary artery of the heart.

2. Left coronary artery of the heart.

3. Arteria innominata, a common trunk, lividing into

1. Right subclavian.

2. Right common carotid.

3. 2 Left common carotid.

4. Left subclavian.

The common carotid artery is destined for the supply of the head. It emerges from the chest by the side of the trachea: mounts upwards in front of the vertebra, and parallel with the trachea, till it reach. es the upper margin of the thyroid cartilage, without sending off a single branch. At this part it divides into the external and internal carotid arteries, the former of which is distributed to the outside of the head; the latter to the brain.

The external carotid continues its course upwards between the jaw and the ear, being imbedded in the substance of the parotid gland.

\section{Branches of the external carotid artery.}

1. Superior thyroideal. a. Laryngeal branch.

2. Lingual artery. $a$. Ilyoideal branch.

b. Artery to the back of the tongue. c. Raminal artery. lary.

3. Facial or labial, or external maxil.

a. Ascending palatine branch.

$b$. Arteries to the surrounding glands.

c. Inferior labial artery.

$d$. Coronary artery of the lower lip.

e. Coronary artery of the upper lip. f. Nasal arteries:

4. Ascending pharyngeal artery.

5. Occipital artery.

6. Posterior artery of the ear.

7 Superficial temporal artery.

$a$. Branches to the parotid gland.

b. Anterior auricular arteries.

c. Transverse artery of the face.

d. Middle temporal artery.

e. Anterior temporal branch.

f. Posterior temporal branch.

8. Internal maxillary artery.

a. Middle artery of the dura $\mathrm{ma}$ ter, or spinous artery.

b. Inferior maxillary artery.

c. Pterygoid branches.

d. Deep temporal branches.

e. Artery of the cheek.

$f$. Alveolar artery of the upper jaw.

g. Infra-orbital artery.

$h$. Superior palatine branch.

$i$. Nasal branch.

The internal carotid artery enters into the skull, through the canal formed in the substance of the temporal bone. And its branclies ramify through the substance of the brain. All the arteries of the brain have thinner coats than these vessels possess in any other part of the body.

\section{Branches of the internal carotid artery.}

1. Ophthalmic artery, supplying all the parts contained in the orbit.

a. Lacrymal branch.

b. Ethmoidal arteries.

c. Superior and inferior muscular branches.

d. Central artery of the retina.

e. Ciliary arteries.

$f$. Superior and inferior palpebral branches.

g. Nasal artery.

$h$. Frontal artery.

2. Communicating branch.

3. Anterior artery of the brain.

4. Middle artery of the brain.

The subclavian artery passes over the first rib, and behind the clavicle, into the cavity of the axilla. There it takes the name of axillary, and is covered by the pectoral muscles. Emerging from the armpit, its name is again changed for that of brachial. This part of the trunk runs along the inside of the arm, close to the edge of the biceps muscle, until it reaches the elbow joint, where it divides int the branches that belong to the fore arm.

\section{Branches of the subclavian artery.}

\section{Internal mammary.}




\section{ANATOMY.}

2. Inferior thymideal.

a. 'Thy'roit br:usch.

b. Ascending thyoid artery.

c. "l'inusverse artery of the neek.

d. Transverse artery of tlie slioulder, or supra scapulary.

3. Vertchral, a large trunk passing blirough perfor:ations in the transwerse prucesses of thc cervical veitchrx, and througli tie formen inaguun of tie skull tu the brain, where it unites with its fellow of the upprosite side, to form the ba. silar artery.

a. Inferior artery of the cerebellum.

b. Arteries to the spinal marrow.

c. Supucrior artery of the cerebel. Iisn.

d. Posterior or deep scated artery of the brain.

N. 13. 'The Emerial circle of Willis is a large anastomosis: by which the two carotids are joined to gruticr, and united al. so to the basilar artery.

4. Superior intercostal.

5. Diep-suatcel cervical artery:

6. Superficial cervical artery.

\section{Branches of the axilury artery.}

1. Superior or short thoracic.

2. Inferior or long thoracic.

3. 'I"horicic artery of the shoulder.

4. )eep thoracic artery.

5. Intra-scapular artery.

6. Posterior circumflex.

․ Anterior circuntlex.

\section{Brunches of the bruchial antery.}

1. Various muscular branclies.

2. Profunda liunieri inajor, or greater deep-seated artery of the arm.

3. Medullary artery of the lumerus.

4. I.esserdeep-scated artery of the arm.

5. Cireat anastomizing brancli.

6. Radial artery.

7. Ulnar artery.

The two last branches are those into which the trunk of the brachicl diviles at the elbow. 'They run along the foreartm to the wrist.

\section{Branches of the radial artery.}

1. Recurrent branch.

2. Superficial artery of the palm.

3. Branch to the back of the wrist.

4. Branches to the back of the thumb and fore-finger.

The artery then enters the palm, and fornis the deep-seated arterial arch of the paln.

VOL. I.
Branches of the ulnar artery.

This ressel, when it has amved at the wrist, passes forwards into the paln of the hand, more superficially this the ra. clial, and forms the superticial arch of the pain.

1. Recurrent artery.

2. Interosseous artery.

n. I'osteror branch.

«. Interosseous recurrent.

b. Anterior branch.

3. Branch to the back of the Irand.

4. Deep palnar branch.

5. Thee large digital arteries.

Branches of the descending portion of the uorta in the chest.

1. Common bronchial artery.

2. Right and left bronchial arteries.

3. Esopliagcal arteries.

4. Lower intercostal arteries.

Whe aorta passes llirough the dia. phragm at the lover part of the chest, and takes the namc of abdominal aorta. It is still situated on the left side of the bodies of the vertebrx, and at the fourth lumbar vertehra it terminates by dividing into the two common iliac trinks.

Branches of the ubdominal uorta.

1. Right and left phrenic arteries.

2. Caliac artery.

a. Coronary artery of the stomaclı.

b. Hepatic artery. "

๔ Duodeno-gastric, or gastro. epiploic artery.

$\beta$ Superior pyloric artery.

\% Cystic artery.

c. Splenic artery.

a l'ancreatic arterics.

$\beta$ Short arteries to the stoinacl.

$\%$. Left gastro-epiploic artery.

3. Superior mesenteric artery.

a. From 12 to 20 large bixinches to the small intestine.

b. Middle colic artery.

c. Ilencolic artery.

4. Renal or emulgent arterics.

5. Spermatic arteries.

6. Inferior mesenteric artery.

a. Left colic branch.

b. Internal henoryoidal hranch.

7. Five pairs of lumbar arteries.

8. Two coumon iliac arteries.

9. Mirldle sacral artery.

The conmon ilisc quickly divides into the exterual and internal ifiac hranclies, of which the former goes to the thigh, the latier enters the cavity of the pelvis, C $c$ 


\section{ANATOMY.}

\section{Eranches of the intermal iliac artery.}

1. Ilco-lumbar artery.

2. Lateral sacral arteries.

3. Vesical arteries.

4. Middle hemoirrhoidal.

5. Uterine branch.

6. Obturator artery.

7. Gluteal artery.

8. Ischiatic artery:

9. Pudendal artery.

a. External hemorrhoidal branches.

b. Artery of the perineum.

c. Dorsal artery of the penis.

d. Deep artery of the penis.

The external iliac artery having chang. ed its name for that of femoral, runs along the front of the thigh, and then bends inwards to the han, where it takes the nane of popliteal. It passes through the latter space to the leg, when it terminates by dividing into two, of which one runs along the front, and the other the back of the leg.

\section{Branches of the external iliac artery.}

1. Epigastric artery.

2. Circumflex artery of the ilium.

\section{Branches of the femoral artery.}

1. Branches to the lymphatic glands, and integuments.

2. External pudic arteries.

3. Deep-seated artery of the thigh.

a. External circumflex artery.

b. Internal circumflex artery.

c. First and second perforating branches.

4. Branches to the ncighbouring muscles.

5. Great anastomosing branch.

\section{Branches of the popliteal artery.}

1. Superior internal articular artery.

2. Superior external articular artery.

3. Middle articular artery.

4. Inferior internal articular artery.

5. Inferior external articular artery.

6. Anterior tibial artery.

7. Posterior tibial artery.

\section{Branches of the anterior tibial artery.}

1. Recurrent branch.

2. Various small muscular branches.

3. External and internal malleolar arteries.

4. Tarsal and metatarsal arteries.

5. Dorsalis hallicis.
Branches of the posterior tibial artery.

1. Large muscular branclies to the soleus.

2. Medullary artery of the tibia.

3. Peroneal or fibular artery.

a. Anterior branch.

b. Posterior branch.

4. External plantar artery.

a. Four digital arteries.

5. Internal plantar artery.

There is another large arterial tiunk in the body, besides the aorta, called the pulmonary artery; this rises from the right rentricle, and conveys the venous bloorl to the lungs, for the purposes of respiration.

OF THE VEIXS.

The blood is constantly moving in the arteries from the trunks into the branches; in the reins it follows a directly opposite course, and flows from the branches to the trunks.

There are seven large venous trunks in the body, to which all the blood is returned; three of these, viz. the superior and inferior vena cara, and the coronary vein of the heart, return the bloorl, which has circulated through the body into the right auricle of the lieart; the other four are the pulmonary veins, and bring the blood back from the lungs to the left auricle.

The coats of the veins are thin when compared with those of the arteries; hence the blood can generally be plainly seen through them; and hence when divided they collapse, instead of presenting a circular section, as arteries do. It is difficult to separate them into coats, yet they are said to consist of two; viz. a smooth and lighly polished internal one, which lines the canal; and a rough, cellular external tunic, in which no muscular power resides. Hence the circulation proceeds through these vessels merely by the impulse of the arterial blood, and is not aided by any action of the containing tubes.

The veins are much more numerous, and also large. than the arteries. In most parts of the body each artery has two veins lying by its side; and in many instances there is another numerous set of veins besides these. Hence the venous system is much more capacious than the arterial; and this difference is so great, that the veins are supposed to contain nine parts out of thirteen of the whole mass of blood. This great capacity of the venous system obviates the effects of any 


\section{ANATOMY.}

c2sual obstruction to the ready transmission of blood through the lungs; for the whole of the veins are not distended in a natural state, but serve as an occasional reservoir, in which the blood, constantly urged forwards by the heart, may be held till the cause of obstruction has ceased. But as such retardation in the course of the venous blond would tend to drive back the whole mass on the minute veins, which are the least able to bear it, such retromarle motion is prevented by valves, whicl exist in great numbers in the venous system. These are thin membranes, having a semilunar edge attached to the side of the rein, and a straight eclge floating in the cavity of the vessel: they are placed in pairs. When the blood is going on in its natural dircetion, thev lie elose to the sides of the tube; but, when it attempts to return, the blond raises the loose edge, and that meets in the centre of the vessel with the corresponding part of the opposite valve, and thus closes the canal. Thus, when an obstmetion takes place, cach portion of a vein has to sup. port that column of blood only which is contained between its own valves. Still, as these vessels possess no powers of their own, and are too far removed from the heart to feel its influence on the passage of bloorl through them, we find that the circulation is allected in them by external causes, as position, \&ce. Hence the legs swell after long standing; and henee also the veins of thesc parts are apt to become enlargerl and raricose.

Tlistribution of the veins. - This is for the most part similar to that of the arteries, as each of the latter ressels have genemally two accmpanving veins, (which bear the same names as the concomitant arteries) named venæ sodales arteriarum. But in some situations there is a class of reins not corresponding to the arteries, but running under the skin, and terned cutameous or superficial veins. These are found par. ticularly in the extremities, and rary much in size at different times.

The vena cava superior is formed by three large trunks.

1. Vena azygos, which returns the blood from the sides of the chest, and runs along the middlle of the spine.

2. Right subclavian, which is also made up by three venous trunks, viz. the internal jugular, the exterıal jugular, and the axillary.

3. I.eft subclarian, formed in the same manner as the right.

The external jugular vein returns the blood from the outsicle of the head, and runs along the neck; just under the skith
We sometimes bleed from this in affec. tions of the head.

The internal jugular is a very large ves. sel, lying deeperin the neck, and close to the carotid artery. It brings back the blood fiom the brain. The danger in attempts at suicide consists in dividiug this vessel or the carotid artery, and not the external jugular vein. The axillary vein is made up of the vessels wlich bring the blood back from the arm. Besides the deep-seated veins, we have liere a large superficial vessol, running along the outside of the fore-alm anci arm, and called the cephalic vein; arother on theinside, named the basilic. lietween tirese in the fore-arm are found some veins called the median. At the bend of the elbow these last make up two large trunks, of which one opens into the basilic, and the other into the cephalic vein. 'These are cilled vena mediana basilica, and rena mediana cephalica. It is the latter veins that we gencrally bleed, when that operation is performed in the arin; and as they run clireetly over the artery, the latter vessel is entangered by the lancet.

The inferior vena cava is a very large trunk, rumningalong the spine at the right side of the aorta, It returns the blood from all the lower parts of the body. It is made up by the junction of the two common iliac veins; and as it ascends through the abdomen, it receives the following venous trunks; the lumbar, spermatic, renal, and the inmense venx cava bepaticx.

'The common iliac vein is formed by the junction of the external and internal iliacs. The latter brings back the blood from the eavity of the pelvis; the former returns it from the lower cxtremity.

We have two large cutaneous veins to notice in the le and thigh; viz. the saphena major, which runs up along the inner side both of the leg and thigh, and can be distinetly seen in the living person when in the ercet posture; the sajuliena minor, which runs over the calf of the leg. The former termiuates in the femoral vein near the abdomen, the latter in the popliteal vein.

The rena portarim is a large vessel, formed by the union of those veins which belong to the stomach and intestines, the spleen and paserens. It conveys the blood, which has circulated through those organs to the liver, and it branchics out in that gland as arteries do, in other parts. Its blood is returned from the liver by the hepatic reins, which have been already noticed. 


\section{ANATOMY.}

ORGAYS OF ABSORTTIOX.

The absorbents are a minute kind of resse's found in animal bodies, which attract and imbibe any fluid that is brought near their mouths. They are so minute and transparent, as not to be discovered in ordinary dissection; but by great labour they hare at length been cletected in great numbers in every tribe of animals. As these ressels are transparent, their contents are visible, which circumstance ocrasioned them to reccive the different denominations of lacteals and lymphatics. The former were so called, because they imbibed the chyle, a milky fluid, from the bowels; whilst the latter, containing much lymph, which they had taken up from all the interstices of the body, were therefore named lvmphaties. The discovery of this system of vessels is referred to the seven. teenth century. But at first their number did not appear sufficient to perform the whole function of absorption ; neither had they been discovered in birds or fishes, whence anatomists still retained the idea that the veins participated in this important office. The merit of first demonstrating the absorbing ressels in those animals belongs to $\mathrm{Mr}$ IIewson, who assisted in the labours of the first eminent anatomical school in London, where anatomy was most ably taught by Dr. Hunter. And it is to the immortal Hunter that we are indebted for fully proving the important doctrine, that the whole business of ab. sorption is performed by the vessels which we are now considering. They have of Iate been injected in such great abundance, that they appear fully adcquate to perform their office.

If, as we firmly believe, these vessels be the only ones which peiform the office of absorption, they must exist in every part of the body. For there is no spot on the surface of the skin from which ointment may not be taken up, nor any interral part from which blood, when accidentally effused, may not be absorbed; nay, the very matter composing the texture of our bodies is undergoing coutinual removal and renovation. These vessels must therefore be supposed to begin by open orifices generally throughout the bidy, although the fact can be demonstrated in the intestines only. On the inner surfaces of tivese organs they appear to the unaicled cyc fine and pointed tubs: but by the microscope their mouths are discerned to be patulous, and like a cup. The beginning ahsorbents soon join together, and after some time form minute vessels, capable of being injected by anatomists : these again conjoin, and form larger vessels, which are still discorerable with gueat difficulty.

In structure and arrangements these vessels have great similitude to veins : they have in consequence been named by some anatomists the lymphatic reins. J.ike the veins, their sides are thin and transparent, though of considerable strength : like the veins, they frequently communicate together, or, as it is technically termed, anastomose. The adrantage derived from these communications is obvious : for by these means, the dissimilar matters which they take up from various parts are mix. ed together, and blenderl with the lympl, which they imbibe from the interstices of the body, and which serves as the rehicle for such heterogeneous particles; they also prevent accidental pressure made on a few ressels from obstructing the progress of the absorbed fluids, which are in that case conveyed forwards by collateral channels. Like the reins also. these tubes, by conjoining, form a tube of smaller area than the united areas of the vessels before their junction. The effect of this construction is the same as in the veins; that is, an acceleration in the current of the lymph, in proportion as it comes nearer to the trunk of the absorb. ing resscls. The diameter of the thoracic disct bears but a small proportion to the united diameter's of all the minute $a b$. sorbents in the body, and when this duct has been opened, the lymph has flowed from it with a force and jet like that with which the blood issues from a large vein. Like the veins, the absorbents are furnish. ed with numerous valves, which prevent any retrograde motion of their fluids, and also prevent any portion of the vessel from sustaining the weight of more fluid than is contained between its valves. The aissorbents, how ever, differ from the veins in one very material circumstance, viz. that they have a power of contraction, and are able of themselves to propel their contents. Whoever reflects on the phenomena of absorption can scarcely cloubt that these vessels have a contractile power, by which they refisse almission to noxious substances, whilst they readily imbibe those that are salutary. If these vessels are observed in the mesentery, when turgid with absorbed chyle, their contents will disappear in a certain tract, and again become visible; a phenome non that can only be explained by supposing the vessel to contract at that part, and urge forwards its contents. Haller found that the thoracic duct contracted when stimulated, so that there can be little 


\section{ANATOMY.}

lloubt of these vessels being muscular thronghout their whole extent.

'The absorbents are found in consider. sble numbers under the skin of the extremities; and when they arrire at the groin and armpit, they pass turough little bodies about the size of small beans, which are ealled lymuphatic glands. The absorbent vesscls, as they approach the ghankl, gene. rally separate into several branclies, which terninate in that body : and again, about an equal number of alssorbents emerge froun the gland, conjoin, and form one or more principal absorbing vessels. The absorbents, which enter the gland, are usually denominated vasa inferentia, and those which go out of it, vass efferentia. If quicksilver be poured into the former vesscls, the gland swells, and a great deal of quicksilver appears to be deposited in it; snd afterwards, if the power propelling the injection be continued, it is seen coming out of the glank by the vasa efferentia. It scems therefore to follow, that the progress of the absorbed fluid is checked a little in these glands, and it is probable, that some clange is effect cd in its progress through them. This opinion is confirned by observing, that these glands abound with blood-vessels, which probably pour some fresh auimal juices unto those which are contained in the lymphatic vessels.

The lymplatic glands are found in great numbers in the groin, armpit, and sicle of the neck, apparently serving like barriers to the absorbents of the head and extremities, as they approach to the large veins of the tmink. "The absorl-ents of the intestines, which contain the clyyle, a scarcely animalized fluid, sometimes pass through three or four sets of glands, before they arrive at the thoracic duct; hence they are called lacteal vessels primi, secundi, tertii, or quarti generis. The place wliere the lacteals conjoin, and meet with the Irmplatics from the lower parts of the boily, to form the thoracic duct. appears in animals like a reservoir, and has been named the reeepta. culum chyli. The vessel thus formed, penetrates the cliaphragm, in conjunction with the aorta, and is called the thoracic duct. In this situation it lics close on tie back bone, hetween the vena azygos and the aorta. 'Towarls the neck, it leares the bone in reach the left subclavian vein, intu which its contents are poured; the alssorbents of the left arm and side of the head having previously joined it. The pasiage of blood from thie vein into the duct is effectually precluded by means of valyes.

'Tlie absorbents of the right arm and side of the head form a smaller trunk on the right side, which opens into the corresponding part of the right subclavian vein.

Thus, all the old materials of the body; which the absorbents are continually removing, all the new matter inbibed from the surface, all the redundant lymph taken up from the interstices of the body, and all the clyyle occasionally obtained from the bowels, are conveyed into the large veins near the heart. It is, in short, chic Ay by this system of vessels, that the blnod is augmented in quantity, or alter. ed in quality; they replenish the body with nutriment, and occasionally taint it with infection.

It is sufficient to inform the reader, that these vessels exist in great numbers in all parts of the body, without entering into any cletailed description of their particular distribution. We may just observe, that the course of these vessels, and their entrance iuto glandls, become occasionally demonstrated in clisease. When irritated by any local mischief, they form red streaks, manifest on the surface of the body: and the irritating or poisonous nature of the matters whicls they imbibe causes swelling and inflammation of the glands in which this matter is deposited. Thus the glands in the groin swell from the absorption of venereal matter ; those in the axilla become affected in cancer, and in the inoculation for the small pox.

\section{OF THE COMIXART ORGANS.}

The urine is secreted in two large glanis, called the kidnics. These are situated behind the peritoneum, in that part of the abdomen termed the lumbar region, where they are surrounded by a çuantity of loose cellular and adipous substance. Their form resembles pretty exactly that of the kidney bean. There scems to be a small part as it were scooped out, opposite to the bodies of the vertebra; at this, which is called the notch of the kidney, the hlood-vessels cnter.

When we make a cut through the suisstance of this organ, it is found to be made up of two substances, differing in appearance. The exterior is called the cortical or arterial part, the interior, which consists of scyeral conical portions, is named the urinifcrous. The latter remains perfectly white, if a kidney be injected. 


\section{ANATOMY.}

Several very minute converging tubes are seen running through the uriniferous portion, and terminating by open mouths on their conical points; these, whicl can be filled with minute injection from the ar. teries, and the open moutlis of which can be seen with the aid of a small magnify. ing power, are the excretory tubes, or tubuli uriniferi, of the kidney. The uriniferous portion of the gland forms about fifteen conical projections, termed papil$1 x$; on each side of which the excretory tubes open in great numbers. The papillx project into short membranous canals, called infundibula; and these terminate in a common receptacle, situated at the notch of the kidney, and known by the name of the pelvis. From this, a canal about equal in size to a writing quill, the ureter, conveys the secreted fluid into the bladder.

The bladder is a membranous and muscular reservoir, receiving the urine as it is found in the kidnies, retaining it until it has accumulated in some quantity, and then expelling it through a canal called the urethra.

The internal surface of the bladder is former by a smooth membrane, constantly covered with a mucous secretion, which defends it from the irritating effects of the contained fluid. It has a muscular coat; sometimes described as a muscle, under the name of detrusor urinæ; and that part of the fibres, which is situated round the opening of the urethra, is called the sphincter vesicx, as it keeps the aperture constantly closed, until we make an effort for the expulsion of the contained fluid. The ureters open into the lower part of the bladder; and open in suclı a manner, that, although the urine flows readily from them into the receptacle, none can return. They pass between the museular and internal,tunics, before they penetrate the latter.

The bladder is situated just behind the ossa pubis; and is partly covered by the peritoneum. The urethra proceeds from its lower and anterior surface, and this part is called the neck of the bladder; it then goes under the arch of the pubis. It forms in the female a canal about an inch and a half, or two inches long, which opens in the cavity left between the labia pudendi. In the male it is about nine inches in length, and mins along the under part of the penis to the extremity of that organ, where it opens.

ORGANS OF GEYERATION.

The parts whicb the two sexes per- form, in the important business of pro. pagating the species, are so entirely different, that we shall not be surprised at finding that the male and female organs of generation are wholly dissimilar to each other.

The germs or rudiments of the future beings are produced by the female, in organs called the ovaria. But these remain inert and useless, unless called into action by the fecundating influence of the male. The fecundating fluid is prepared in two glands, called the testes. When the germ has been acted on by this fluid, it passes through a canal called the fallopian tube, into the uterus, where it is re. tained until it has acquired a considcrable magnitude ; and from which it is expell$\mathrm{ed}$ at the end of nine months. The se. minal liquor of the male is poured into the urethra, and is introduced by means of the penis into a membranous cavity of the female, called the vagina.

External parts of generution in the female. Over the surface of the pubis, there is a greater accumulation of fat and cellular substance than in the male; and the prominence caused-by this structure is called mons veneris. A longitudinal cavity extends from this eminence in front to the anus behind; and the sides of it are bounded by two folds of the skin, called labia pudendi, or alæ majores. 'The whole of these parts taken together constitute the pudendum, or sinus pudoris. The mons veneris, and tbe outer surface of the labia, are covered with hair to a greater or less extent.

The parts contained within this longitudinal cavity are corered by a more delicate kind of integuments, than that which composes the general surface of the body. A change takes place in the organization of the skin, somewhat similar to that which is observed at the lips. Hence the surface of the parts contained within the labia has a red, smooth, and soft covering; which is besmeared with a cebaceous secretion of peculiar odour, furnislied by numerous small glands, lying just under the surface. This unctious matter is required in order to defend tlie parts from the urine; and also to obviate the effects of that rubhing on each other, which must be occasioned by the motions of the body.

Towards the upper part of the longitudinal slit, left between the labia, a small prominent organ is discerned, call. ed the clitoris. This exactly resembles the male penis in structure. It only projects, however, about a quarter of an 


\section{ANATOMY.}

inch. We distinguish in it a glans and preputium, which resemble, on a snall scale, the parts of the same nane in the male.

Below the clitoris are two small folds, called the nympliz. These are cronnected ubove to the preputium clitoridis; they dircrge from esch other, as they extend below. They vary much in size; in a natural state they may measure about half an incli at the brosidest part. They are of a much greater magnitude in the Hottentot fumale, and have given rise to the reports of travellers, that the sinus pudoris is covered in those persons by a curtain, or aprou of skin. About three yuarters of un inch below the clitoris, we neet with a round aperture, which is the termination of the female urethra: and just below this is the opening of the vagina; which opening is technically called os externum uteri. This has a very dilferent appearance in a young girl, and in a marnied woman. In the latter it is a large and fiec aperture, fully adcquate in size to the admission of the penis; in the fotmner it is shut up in a great measure by a thin membrane, called the hymen. This closes the lower portion of the os cxternum, to various extents in different subjects; and is torn and destroyed by the consummation of mar. riage. Some little excrescences, supposeil to be the remains of the ruptured hy. men, are called caruncula myrtiformes. The anus is found about one inch behind the commencement of the vagina.

The vagina, or canalis uteri, is a mem. branous cinal, about five inches in length, extending almost directly backwards from the os extcrnum. Its sides are dense and tough; and the surface is corered with nuncrous wrinkles and prominences, which are less conspicuous in women who have had clildren than in virgins.

'The utcrus is a hollow organ; but its cavity is so small in the impreguated state, and its sides are so thick and dense, that it fecls like a solicl fleshy mass. Its broadcst and largest part, which is called the fundus, is situated directly upwards. The smaller and narrower portion, term. ed the neck, is downwarls. 'The length of the organ, from the fundus to the end of the neck, is about three inches; its breadth at the fundus about one inch, and at the cervix considerably less. It is situated within the cavity included by the bones of the pelvis. 'the peritoneum passes from the bladder to the anterior surface of the uteris, and completely co. vers the organ. It is extended from the two sides of the uteris to the bones of the pelvis, forming two broad duplicatures, called the broad liganents of the uterus; each of which includes thrce parts, named the appendages of the uterus: viz. the ovarium, fallopian tube, and round ligament.

The cavity of the uterus opens into the posterior part of the vagina by an orifice, named the os tince or os internum uteri.

The round ligament of the uterus is a fibrous chord, passing from the fundus uteri through the abdominal ring, and serving to confine this organ in its proper situtation.

The ovurium is an oval fleshy body, si. tuated towards the posterior surface of the broad ligament. It contains some small watcry vesicles, called ovula graafiana, which are supposed to be the germs of the future beings, that are to be called into action by the stimulus of the male semen.

The fallopian tube is a convoluted canal, commencing by a very minute orifice from the corner of the uterus, running along the ripper margin of the broad ligaments, and gradually increasing in size, till it encls near the ovarium by a broad trumpet-shaped mouth, open to the cavity of the abdomen, and having an ele. gant arrangement of plaits and fringes surrounding the aperture, whence it is often called the fimbriated extremity of the tube.

-Male organs of generation.-The testes, or glinds, which produce the semen, are contained in the scrotum, a bag formed of common integuments, and hanging from the front of the pelvis between the thighs. A prominent line, called the raphe, runs along the middle of this, and divides it. into two equal portions. The testes are surrounded and comnected in their situa. tion by a loose cellular substance. They are of an oval shape, and about equal in size to a pigeon's egg. 'They hang from the abdomen by the spermatic chords, which consist of the arteries, reins, lymphatics, and excretory tubes of the testes, united by a cellular substunce, and cover. ed by a inuscle, called the cremaster, by the action of which the testis is occasionally drawn up towards the belly.

The substance of the testis is corered by two membranous tunics, one, which inmediately iurcsts it, ancl is called tunica albuginea; another, which surrounds this more closely, and forms a bag, in which the testis hangs, the tunica vaginalis. 


\section{ANA'TOMY.}

There is a small body partly distinct from the testis, and placed behind it, called the epididymis.

The substance of the testis is found by dissection to be soft; and it is composed of a congerics of very minute tubes, named tubuli seminiteri, which may be unravelled and separated by maceraung in water, although they were previously comnected into the appearance of a fleshy mass. The diameter of these tubes is estimated at 1-2uUth of an inch; and the number of them at about 60,000 . It they were joined together, they would form a tube of about 50u0 feet long. 'These tubes terminate ultimately in a single small canal, which, by its innumerable turns and windings, makes up the whole epididymis. If this could be completely drawn out, it would be about 30 feet long. It increases rather in size towards the end of the epididymis, and leaves that body in the form of a simple and unconvoluted tube, assuming the name of vas deferens, and ascending along the back of the spermatic chord to the abdomen. It can be readily distinguished in that situation in the living person : it feels like a hard chord, about the size of a crow quill.

When the spermatic chord has entered the abdomen, the vas deferens leaves it, runs along the back of the bladder, and opens into the commencement of the urethra.

Vesicule seminales.-Before the vas de. ferens terminates in the uretlira, it is joined at an acute angle by the canal of the resicula seminalis.

These vesicles are two soft bodies, lying in contact with the under-surface of the bladder, and formed, eacli of them, by the conrolutions of a single ncmbranous tube. An injected liquor thrown into the vas dcferens will pass into the vesicula seminalis, rather than into the urethra; for the opening into that canal is extremely smal, while the communication with the vesicula is large and free. Hence it lias been suppossd that these vesicles are reservoirs for retaining the fuid formed in the testicles until it is wanted.

Mr. John Hunter has however pretty clearly demonstrated that the vesicula are not intended to contain semen, but thrat they secrete a peculiar fluid, to subserve the purpose of gencration. See lis "Observations on certain parts of the Animal Economy."

Prostate gland.-The origin of the urethra is surrounded by the substance of this gland, which in size and form much resembles the chesnut. Numerous openings are lound in the commencement of the urethra, which discharge on pressure a whitish viscid fluid, secreted in the sub. substarice of the prostate. A portion of the gland projects into the lower part of the commencement of the urethrib, and lias received the name of caput gallinaginis : it is on this that the openings of the canals, forned by the junction of the vasa deferentia and vesiculæ seminales are found.

The urethra is subservient to two purposes; the expulsion of the semen in the act of copulation, and the conveyance of the urine from the bladder. Its surface is perfectly smooth, and is corered and protected by a mucous secretion. The diameter of this canal varies shightly at different parts, but may be stated generally at about one-eighth of an inch. At its first departure from the bladcler, it is survounded for one inch by the prostate; it is then continued as a simple membranous tube, but surrounded by muscula $\mathrm{r}_{\mathrm{r}}$ fibres for another inch; this is called the mentbianous portion of the urethra. In the rest of its passage it is surrounded by a vascular substance, called corpus spongiosum; this is accumulated in a considerable mass at its cominencement, where indeed the urethra is broader than in any other situation, and this is called the bulb. The seminal and prostatic liquors are poured into the bulb of the urethra, and are forcibly expelled from thence by a sort of convulsive contraction of a muscle, whose fibres surround this part of the canal; the ejaculator seminis. The glans penis is nothing more than a portion of the same rascular mass, which surrounds the rest of the urethra, corered by a very delicate, sensible, and finely organized integument.

The bulb, corpus spongiosum, and glans, are susceptible of the same erection as the body of the penis; which is indeed essential to the performance of their functions, in conveying the fecundating liquor into the body of the female. 'The penis consists of two bodies, call. ed crura, or corpora cavenosa, which arise separately from the bones of the pelvis; but join so as to form afterwards a single organ. Eacli crus consists of a very strong and dense ligamentous tube, filled internally with cellular substance, into the cells of which the arteries open, and from which the reins commence. The arteries pour the blood into these organs with great energy, in obedience 


\section{ANATOMY.}

to the passions of the mind, and thereby distend the ligamentous tubes until they feel perfectly hard and rigid, in which state the whole organ is fitted for the function which it has to perform in the act of copulation. The urethra, surrounded by its spongy substance, runs along the under surface of the corpora cavernosa, and the glans penis is situated at the anterior extremity of these parts.

The body of the penis is covered by common integuments, which, being adapted to cover the organ in its extended state, fall into wrinkles when it is collapsed. These are continued beyond the end of the glands, and are inHected, so as to form a hool or covering to the glans, called the prepuce. The latter part is connected to the mouth of the urethra by a sinall fold named the frenum. The surface of the glans, and the lining of the prepuce, are smeared with an unctuous matter of peculiar odour, furnished by some small glands.

\section{OF THE BRAIY ASD NERTES.}

The brin is a soft and somewhat white substance, situated in the cavity of the skull, and corresponding in form to that cavity. Its parts are supported by a firm membrane, called the dura mater, and its substance is more immediately invested by a delicate membrane, called the pia mater.

The structure of the brain is remarkably constant and uniform; very seldom deviating from the accustomed standard. Varieties of formation occur, not unfre. quently, in most other parts of the body ; but the parts of the hrain preserve an almost invariable relation of form, position, magnitude, and connection; which seems to prove, that the right performance of the functions of this organ requires an exactness in the structure of individual parts.

According to Sormmerring, the weight of the brain varies from $2 l b .5 \frac{1}{2} 0 z$. to $3 l b$. $3 \frac{3}{10}=$. Of two hundred brains, which this anatomist examined, none weighed four pounds, whereas Haller states its weight as amounting in general to five pounds. The weight of the brain, compared to that of the body, is an inverse ratio to the age of the subject. In young foctuses it is soft and almost fluid: it becomes of a more solid consistence in increasing age, and is firmest in old persons.

The dura mater is a very firm and compact membrane, adhering closely by ressels and fibres to the internal surface VOL. 1. of the cranium. It is therefore to be regarded as the periosteum of the internal table of the cranium, as well as a mein. branc for supporting and iuvesting the brain. It is described by anatomisis as consisting of two layers, intimately connected in general, but separated from each other at particular parts, so as to leave vacancies between them, called sinuses, into which the veins of the brain pour their blood. The chief of these are, the superior longitudinal, the two lateral, and the torcular herophili. There are besides some smaller ones, as the inferior longitudinal, the cavernous, the circular, the superior, and the anterior petrosal. They all terminate ultimately in the lateral sinus, which, quitting the cranium, takes the name of internal jugular vein.

On the upper part of the dura mater. some small eminences are observed, aris. ing from clusters of white granular bodies, situated between this membrane and the pia mater; they are the glandulac Pacchioni, and fill the pits which may be observed in-the skull-cap. The runifications of the spinous artery, which is the clicf nutrient vessel of the dura mater, are very conspicuous on each side of the head. The inner surface of the dura mater is smooth and shining, and has 110 connection with the pia mater, except where veins pass from the latter membrane to the sinuses.

The processes which the dura mater forms, for separating and supporting the different parts of the brain, are, 1 . the falx cerebri; 2. tentorium cerebelli; 3 . falx cerebelli.

The two membranes which iminediately invest the brain were considered as one, and called the pia mater, until a more minute investigation lıad shewr that it could be divided into two layers. The outer one is called tunica arachnoidea. This is spread over the visible surface of the brain, is of a pale white colour, yet in in some degree transparent, very thin, and devoid of evident vessels. It is seen most evidently, where it passes between the two lobes of the cerebellum, and about the middle of the basis cerebri : in other parts it adheres so intimately to the pia mater, that the distinction can scarcely be demonstrated.

The pia mater every where covers the external surface of the brain, and therefore sends processes into all the convolu. tions of this organ. It is extremely vascular, and a great portion of the blood, which the brain reccives, is spresd out 'Dd 


\section{ANA'TOMY.}

upon its surface in minute ressels. The outer surface is tolerably smooth; the inner universally villous, from the torn orifices of inuumerable ressels, which entered the substance of the brain.

The surface of the brain appears convoluted, so as to resemble the windings of the small intestines. These convolutions do not in general penetrate more than one inch, or an inch and a balf, into the substance.

The contents of the cranium are divided into ccrebıum, cerebellum, and medulla oblongata.

The cerebrum is the upper, and by far the largest, portion : it occupies all the superior part of the vaulted cavity of the skull, and rests below on the tentorium, the petrous portions of the temporal bones, the sphenoid alre, and the orbits. Its upper surface presents a regularly convex oval, narrower in front than behind. It is divided into a right and left hemisphere by a deep longitudinal fissure, into which the falx cerebridescends. Fach hemisphere is divided into two lobes by means of the fissura magna Sylvii. This fissure commences at the basis of the brain, opposite to the lesser ala of the sphenoid bone; the anterior lobe is that portion of the hemisplyere situated in front of the fissure ; and the posterior lobe is the division placed behind.

The hemispheres of the cerebrum are uniterl together at about two inches and a half from the surface of the brain, by means of a medullary body, called corpus callosum. This is about three inches in length, and three quarters of an inch in breadth.

As there are no distinguishable parts in the upper portions of the hemispheres of the cerebrum, it is customary to pare all these away in dissection, nearly to the level of the corpus callosum, in order that we may be able more easily to open, and more particularly to examine, certain cavities, which are situated at the sides of that body, and are called the lateral ventricles.

On making a section of the brain, we perceive that it is composed of two sub. stances; an exterior one, which is of a grey colour, and an interior one, which is white. These are simply termed the cineritious and white substances, or substantia cinerea et alba; or, from the former surrounding the latter, as the bark does the wood of a tree, they are named, in contradistinction, the cortical and me. dullary substances of the brain.

The two lateral ventricles are situated in the substance of the brain, by the side of the corpus callosum, (one in either hemisphere). The cavity begins in the front lobe of the brain, as far forwards as the commencement of the corpus callosum ; it runs from before backwards, in a direction parallel to that body, and at its posterior end bends downwards, and returns obliquely from behind forwards, to terminate almost under its superior extremity. At the place where the ventricle bends, in order to run downwards, there is a parti. cular elongation passing into the posterior lobe, forming a triangular-pointed cavity, and terminating in a cul de sac. This is the digital cavity, or cornu posterius, of the lateral ventricle. These and the other ventricles of the brain contain a small quantity of a watery fluid. The disease of liydrocephalus is a morbid increase of: quantity in this fluid, which accumulates sometimes to the amount of some pounds, distending and dilating the ventricles enormously. The learned Sœmmerring, who may justly be esteemed the first of modern anatomists, places the censorium commune in this fluid. He has traced all the nerves of the brain to the sides of the ventricles; and concludes, that impres. sions made on these nerves will be trans. mitted to the water of the ventricles, which be considers as the organ of the soul.

The two lateral ventricles are separated by a perpendicular partition, called the septum lucidum, which passes from the corpus callosum to the fornix. It contains a small triangular cavity, called by some the fifth ventricle of the brain. It has no communication with the other cavities of the brain.

The fornix is a roundish medullary body, lying between the two ventricles at the lower part. It arises by two anterior crurafrom the front of the brain ; these unite, to form the body or pillar of the fornix, which separates behind into two posterior crura, that run into the reflected portion of the ventricles. Under the anterior part of the fornix is a small slit-like opening, by which the two lateral ventricles communicate.

The clioroid plexus is a production of the pia mater, containing a vast number of arterial and venous ramifications, floating almost loosely in the cavity of the ventricles. It is first observed in the reflected portion of the ventricle, where it is the broadest and largest : it diminishes in size as it ascends, and terminates just at the opening of communication between the two cavities. The choroid plexuses of the two ventricles are united by a middle ex. 


\section{ANATOMY.}

pansion, passing under the fornix, and called the velum.

The lateral ventricle contains certain eninences, whicls form its sides; the corpus striatum is the anterior and supcrior cminence, grey on its external surfuce, and striated internally. The posterior eminence in each ventricle is called the thata. mus nervi optici; it is hemispherical, and white, and joined to its opposite onc by sul union of substance, callecl the soft contmissure. The hippocampus major is a large elongated emincnce, lying in the descending portion of the lateral ventricle: and the hippocampus uninor is a smuller one, in the digital cavity.

The pincal gland, or conarium, is found bchind the optic thalani. Its size is about that of a small horse-bean; its colour grey, and figure conical. Two small medullary chords connect it to the optic thalumi. In the substance of this body is found a small quantity of a gritty matter, nearly jesembling sand. It consists of a number of semi-transparent and light yel. low grains. Soemmerring, who first discovered that this belonged to the healthy structure of the brain, calls it the acervulus of the pincal gland. This little body has been more attended to ancl noticed than it would otherwise have been, in conse. quence of the chimerical dream of Des. cartes, who represented it us the seat of the soul.

Below the pineal gland is a square portion of the brain, divided into four super. ficial emincuces, called corpora quadrigemina, and from these a thin production extencls to the cerebellum, under the nanne of valvula cerebri.

By drawing asunder the optic thalani, and separating their soft commissure, we expose the third ventricle of the brain. This appears as an oblong cavity, about an incls and a quarter in length. A round medullary rope is seen in fiont of it, and a similar one bchind; these are called the anterior and posterior cornmissures. A round aperture is observed under the anterior commissure, beyond which the ven. tricle terminates by a pointed and conical extremity, from which a short process is continued to the pituitary gland, under the name of infundibulum. Tlie foramen commune anterius is an opening observed between the optic thalami before they are clisturbed, and leading from the aperture of communication, which connects the two lateral ventricles under the fornix, into the third ventricle. Just before the posterior commissure a round opening is found, leading through a short canad, in front of the tubercula quadrigemina, to the fourtli ventricle. It is named canalis medius, iter ad quartum ventriculum, or aquaductus Sylvii. 'Tlus the four first ventricles of the brain have a free conumunication with each otlier.

Under the posterior lobes of the cerebrum there is found a transverse prodluction of dura mater, called tent orium, which is attached to the internal transverse ridge of the occiput behind, and to the petrous portions of the temporal bone in front. Unter this membrane lie the two lobes of the cercbellum, separated by a small perpendicular production, called the falx cerebelli.

The fourth ventricle is a cavity, leftbetween the upper and posterior surface of the medulla oblongata, and the front of the cercbellum. It extends laterally to a considerable distance in the crura cerebelli: a groove runs along the middle of the medulla oblongata, which constitutes the front of the ventricle, and terminates at the end of the carity in a point. From the lateral productions, and the pointed termination of the cavity, it has been named the calamus seriptorius.

The pituitary gland is a firm substance, differing in texture from the brain, and lodged in the sella turcica. Its name is derived from a supposition that it secreted the mucus of the nose, which in ancient times was supposed to flow from the head. It is connected by the infundibulum to the basis of the brain. Behind the last mentioned part, at the basis cerebri, are secn two small rounded eminences, called corpora subrotunda. The crura cercbri are two large medullary processes going from the cerebrun to the medulla oblongata.

The cercbellum is situated in the lower fossz of the occipital bone, under the tentorium. It consists of an intermisture of cortical and medullary substance, arranged differently from the order observed in the cerebrum. A perpendicular seetion of this part discovers a very olegant structure in this respect. A thick trunk of meslullary matter sends ofl processes, in cvery direction; from these other lranches procced, all of which are surromuled by cortex. This is called tlse arbor vita. The arbor vitze constitutes the crus cerebclli on each side, and these processes join the meclulla oblongata.

The medulla oblongata is a large medullary protuberance, resting on the basilar process of the occiput. Its connection with the crura cerebri and cerebelli have been already noticed. A inedullary chord is continued from its posterior end, under the nane of medulla spinalis.

- Medulla spinalis. This is a roundish 


\section{ANATOMY.}

medullary chord, about the size of the fore-finger, arising within the cranium from the inedulla oblongata ; leaving that cavity at the foramen magnum occipitale, and continued along the canal left in the spine to the upper lumbar vertebræ, where it terminates by forming the cauda equina.

It sends off a pair of nerves at each interval between two vertebra. It is co. vered immediately by pia mater and tunica araclinoidea, and more loosely by a sheath of dura mater, which lines the whole spinal canal. It is plentifully supplied with blood ressels. The nerves come off from this body in numerous threads, quite separate from each other at first, but uniting afterwards. The cauda equina consists of the medulla spinalis, entirely resolved into a bundle of such threads.

Structure of the Nerves.-The nerres are soft, white, and fibrous chords, nearly of a cylindrical shape, arising from the brain, or medulla spinalis. When they leave the brain, the pia mater collects the fibres into larger or smaller fasciculi:

The medullary filaments of the nerves are covered by a vascular membrane, calledl by Reil neurilema, which detaches pro. cesses from its inner surface, to surround and invest the smaller divisions and fibres of the medullary substance. By immersing a nerve in alkali, its medulla is dissolv$\mathrm{ed}$, and the containing membranous tubes, formed of neurilema, are left. Acids dissolve the neurilema, and leavo the medullary fibres. These organs receive a collsidcrable supply of blood from vessels ramifying on their neurilema.

By maceration in water, and careful dissection, a nervous trunk may be separated into numerous threads; and each of these, when examined in a microscope, scems to be an assemblage of proportionably smaller fibres. Grcater magnifying powers shew those fibres, which before appeared simple, to be composed of still smaller threads; and it is doubtful, whether the ultimate nervous fibre can be discovered. All that is said, therefore, of the form, course, \&ic. of these ultimate fibres is wholly conjectural. The fibres do not proceed in a straight uninterrupted course, but join frequently with each other.

A ncrve clivided in the living subject retracts: the medulla is expressed from its extremities, by the cortraction of its membranes, in the form of globules. If the animal be killed at some distance of time from the operation of dividing a nerve, the divided extremities are rather swoln, and are connected by a newly formed matter. Anatomists have disputed greatly, whether or not this be a real nerve. As this question can hardly be decided by merely anatomical testimony, it appears most philosophical to inquire, whether the new matter will perform the functions of a nerve ; and this lias been completely proved by the experiments of Dr. Haighton, in the first part of the Philosophical Transactions for the year 1795 .

In some parts of the nervous system, little tubercles, or knots, called ganglia, are found in the course of the nerve, and are usually formed by the concurrence of several branclies. These bodies are of various figures, but generally flattened. They partake more of the red colour than the trunks of the nerves on which they are formed, as they possess more numerous blood-vessels. They contain nervous fibres, surrounded by a firm vascular sub. stance.

By the term, origin of a nerve, we understand its connection with the brain or spinal marrow. This end is called its sensorial extremity, being considered as the point to which it conveys the impressions made on it by external objects, and from which it receives the commands of the will, to be transmitted to the organs which it supplies.

There is con siderable difference in form, structure, and consistence, between the individual nerves.

The nerves are arranged in pairs, as they are exactly similar on both sides of the body. Hence any pair of nerves consists of the right and left nerve.

They are sometimes divided into those of the brain; and those of the medulla spinalis; or into the nerves of the organs of sense, the nerves of motion, and the nixed nerves; or, according to the nature of the parts which they supply, into voluntary and involuntary nerves.

The quantity of nerves distributed to the different structures in the body varies greatly. The organs of sense receive the most copious supply-riz. the eye, the nose, labyrinth of the ear, ends of the fingers, glans penis et clitoridis, and the rest of the skin. Muscles have also a large share of nerves : the blood-vessels are much more sparingly furnished. The nerves of the viscera are very small in proportion to the size of the organs. Bones, cartilages, tendons, ligaments, membranes, marrow, fat, have no discernible nerves.

Nerves ramify through the body something like arteries : thus, a nervous trunk 


\section{ANATOMY.}

sculs off branches : these, again divided, form ramifications: and in their further progress form twigs, filamențs, \&c. and this division goes on, until the nerve, from its smaltuess, can be no longer traced. Yet we can manifestly discern the nerves in some instanccs, as in the organs of sense, terminating in a pulpy expansion.

like the arteries, nerves communicate vitlı each other; and it is conjectured that these communications, like those of the blood-ressels, are designed to obviate the effects of the injury of conjpression of any particular nervous trunk. In some parts these communications are very uumerons, so as to constitute a minute network of nervous filaments, called a plexus.

Description of the particular nerves.There are in the whole borly thirty-nine pairs of nerves; of which nine arise from the brain, and thirty from the spinal marrow. There is another pair, called the great sympatletic, which can harlly be ascribed to either of these classes.

\section{Nierves of the brain.}

1st. pair. Olfactory nerves; arise from the corpora striata, and go through the cribriform lamella of the ethmoid bone to the pituitary membrane of the nose.

$2 d$ pair. Optic nerves; arise from the thalami nervorum opticorum, and proceed to the eye-ball, where they are expanded to form the retinx.

3d pair. Nervi motores oculorum; arise from the crura cerebri, and are distributed to some of the muscles of the eye-ball.

4th pair. Nervi trochleares; come from the valve of the brain, and supply the trochlearis muscle of the eye.

5th pair. Nervi trigemini; arise from the side of the medulla oblongata. 'This nerve divides into three branches, of which the first, or ophthalmic, goes into the orbit, and after giving a few branches there passes out on the forchead. The second, or superior maxillary, supplies the parts about the upper jaw; a remark. able branch of it is the infra-orbital, which comes through the large hole under the orbit to the face. The third, or inferior maxillary, is distributed to the lower jaw and adjacent parts.

6th pair. Nervi motores externi; from the medulla oblongata to the exteraal straight muscle of the eyc.

Fth pair. Nervi auditorii. This pair consists of two nerves lying in contact, but completely distinct from each other, both in their origin, course, and distribution. The portio mollis of this nerve is distributed to the labyrinti of the ear. The portio dura goes through the tempo. $\mathrm{ral}$ bone, and is very widely spread over the face. These nerves are more cor. rectly termed nervis auditorius, and nervus facialis. The cliorda tympani is a branch of communication between the facial nerve and the lingual branch of the inferior maxillary.

8th pair. Par vagum; arises from the meclulla spiualis, before it quits the cra. nium. It receives an accessory branch, that originates from the upper portion of the medulla spinalis, contained in the cervical vertebra. The par ragum passes along the neck, in company with the carotid artery and the internal jugular vein. It sends off in the upper part of the neck, 1. the glossopharyngeal nerve; 2 . superior laryngeal; and 3. the accessory brancl. The trunk that enters the chest, and gives rise to the inferior laryngeal or recurrent nerve. It afterwards becomes connected to the asophagus, and passes the diapliragm in conjunction with that tube, to be distributed finally to the stomach; sending in its passage several brauclies which supply the lungs.

9 th pair. Nervi linguales; arise near the former, gotlirough the foramen condyloideum, and supply the muscles of the tongue.

Nerves of the medulla spinalis.-The cervical nerves, soon after they come out from between the vertebra, communicate with each other. They supply all the muscles which are situated about the vertebre of the neck. The second sends 2 large branch, which ramifies extensively over the occiput.

The nerve of the diaphragm, called the phrenic or diaphragmatic, arises principally from the fourth cervical nerve. It lies close on the anterior scalenus muscle, then goes over the pericardium to the diaphragm.

The four lower cervical nerves, and the first dorsal, concur in forming the axillary plexus, from which the upper extremity derives its supply. 'These are large nerrous trunks, coming out at the side of the neck, and variously united to each other. They go behind the clavicle with the axil. lary artery. This plexus sends of the following branches:

1. Nervi thoracici, accompanying the thoracic arteries.

2. Nervis supra-scapularis, clistributed with the artery of the same name.

3. Nervus axillaris, following the course of the posterior circunflex artery.

4. Cutancus internus, ruuning orer the 


\section{ANATOMY.}

brachial artery to the elbow, and then ramifying under the skin of the inner side of the fore-arm.

5. Cutaneus externus, distributed along the outer side of the fore-arm.

6. Median nerve, a large trunk accompanying the brachial artery, then proceeding to the hand, and supplying the thumb, with the two neighbouring fingers, and the radial side of the ring finger.

7. Radial nerve, bends round the os humeri, from the inner to the outer side - of the bone; it is distributed superficially to the back of the hand and fingers.

8. Ulnar nerve, accompanying the nerve of the same name to the hand, where it supplies the little finger, and the ulnar side of the ring finger.

The twelve pairs of dorsal nerves supply the muscles in their neighbourhood. They give also numerous branches of communication to the great sympathetic.

The five pairs of lumbar nerves send branches to the ncighbouring muscles, and give communicating filaments to the great sympathetic. They also produce two nerves distributed to the front of the thigh; viz. the anterior crural, which goes out of the pelvis near the external iliac artery, and has an extensive distribution to the thigh and leg; and the obturator nerve, which belongs also to muscles on the front of the thigh.

The sacral nerves give communicating hranches to the great sympathetic; and several filaments to the organs of generation in both sexes, to the bladder, rectum, \&c. They mostly, however, unite to form the great sciatic nerve, which is the largest trunk in the body. It goes out of the pelvis at the back part, and passes to the thigh. Here it sometimes is pressed by the weiglit of the body in sitting, and causes the effect of the foot going to sleep, as it is expressed in common language. This nerve is distributed to the back of the thigh, and over the whole leg and foot.

Great sympathetic or intercostal nerve.It is first formed by a small filament of the 6th pair, or nervus motor extermus, together with another derived from the pterygoid branch of the superior maxillary. In the upper part of the neck this nerve his a very large ganglion lying on the vertebrx, called the superior cervical ganglion. This ganglion receives branches of communication from the five upper pairs of cervical nerves, and sends off a branch to the heart. The trunk descends along the neck, and forms an inferior cervical ganglion, which has communicating filaments frum the neighbouring spinal nerves, and sends several branches to the heart, forming the carcliac plexus. The sympathetic nerve then passes through the chest, over the heads of the ribs, receiving branches from each dorsal nerve, and forming a dorsal ganglion between every two vertebrx. In its course it sends off the splanchnic nerves, which go through the diaphragm, and form a vast and most intimate plexus about the root of the caliac artery, called the cxliac plexus, from which the liver, pancreas, spleen, large and small intestines, and kidnies, derive their nerves. All these organs receive several filaments, united so as to form plexuses, and surrounding their arterial trunks.

The trunk of the great sympathetic enters the abdomen, and goes over the lumbar vertebra, receiving branches of communication, and forming lumbar ganglia; it is then continued along the front of the sacrum, where the sacral nerves supply communicating filaments, and where five sacral ganglia are formed.

\section{ORGAXS OF SENSE.}

Organ of vision.-The globe of the eye is contained in a bony socket, formed by the bones of the cranium and of the face. It is furnished with muscles which can move it in every direction, and surround. ed by a very soft and delicate kind of fat, which yields to it in all its motions. It is composed of certain membranes, called its tunics or coats, and of other parts termed liumours.

Its figure is vely nearly spherical; but the transparent portion in front is the section of a smaller sphere than the globe. The optic nerve, to which the eye-ball is attached posteriorly, enter's considerably on the inside of the axis of the eye.

The coats of the eye are disposed concentrically; and the exterior, which is very dense, firm, and tough, is called the sclerotica. This does not cover the whole globe, but leaves a circular opening in front, filled by the transparent comea, which, althougl, pellucid, is a very firm and strong inembrane. Hence, the sclerotica and cornea together form a very complete exterior case, which defends and supports the more clelicate parts within. The necessity of having the front of the globe transparent, for the purpose of admitting the rays of light, is obvious.

Under the sclerotica a soft and rascular membrane surrounds the eye-ball, and is called the choroid coat. It is connected 


\section{ANATOMY.}

to the sclerotica by a loose adhesion, which can be destroyed by blowing air between the membranes; but in front this adliesion is stronger, and forms a white circle naned. orbiculus or Jiganentum ciliare. The colour of the clioroid coat is a deep brown, approaching to a black, and this colour is derived from a substance called pigmen. tuin nigruin, which separates from the choroid by maceration, and dissolves in water so as to render it turbid.

The inner surface of the choroid coat, which is universally coloured by pigmentum nigrum in the human subject, is sometimes called tunica ruyschiana, as Ruysch endeavoured to prove that it formed a distinct membrane from the external part. It is this inner surface that possess. es the brilliant colours observable in animals, whence the appellation of tapetum. This surface lies in contact with the retina, but does not adhere to that nembrane. On the front of the eye, however, and be. yond the anterior margin of the retina, the choroid is closcly attached by means of numerous and very delicate folds, called the ciliary processes, to the surface of the vitreous humour, round the margin of the crystalline lens.

The iris is a membrane continued transversely across the eye-ball, behind the cornea, and appearing as a continuation of the choroid from the orbiculus ciliaris. The round opening in the front of this membrane is called the pupil; it allows the passage of the rays of light into the interior of the eye. This aperture varies in its dimensions according to the quantity of light to which the organ is cxposed : a strong light causes the pupil to become contracted, in order to exclude a portion of the ray's of light which offend the organ. The aperture is dilated in a weak light, to let in as many rays as possible. Some anatoinists have tlought proper to employ theinselves in debating at length, whether these motions arise from a really muscular structure or no: but we believe that they have not yet settled the point completely.

The name of iris was applied to this part, from the diversity of colours obser. vable in it in different individuals; and it is the colonr of this that produces the colour of the eye, in the popular sense of the phrase. - There is a remarkable correspondence in this point between the skin and hair and the iris. A light complexion and hair is accompanied with blue, grey, or the lighter colours of the iris; while a dark skin and black hair are at. tencled with the dark brown iris.

In that curious variety of the human race called the Albinos, where the skin and hair are of a clead milk-white hue, in consequence of a total absence of the rete mucosum or colouring principle, the colouring matter of the iris and choroid is also deficient, and these parts appear red, from the numerous blood-vessels which they contain.

The posterior surface of the iris is co. vered by pigmentum nigrum, and is called the uvea.

Under the choroid coat is found a thirl membrane of the cye-ball, called the retina, which is formed by the expansion of the medullary substance of the optic nerve, and forms the immediate organ of rision. It is of a yellowish grey colour, and so ex. tremely soft as almost to be lacerated by the slightest touch. Its outer surface is entirely unconnected with the choroid coat; and the inner surface is expanded on the vitreous humour, but not connected to it. It terminates in front by a distinctly defined edge, where the ciliary processes begin to adhere to the vitreous humour. On the inside of the retina are scen the branches of an artery and vein, which enter through the centre of the optic nerve, (arteria et vena centralis oculi). The part at which it enters the eye is termed the porus opticus, and is of conrse insensible : and hence physiologists have explained the reason why the optic nerve is inserted out of the axis of the eye; as otherwise the axis of vision would lave fallen on an insensible part of the retina.

On the outcr, or temporal side of the retina, there is a fold of the membrane of a bright yellow colour, in the recent state, and there is also said to be an aperture. These eircumstances were first pointed out by Soemmerring, and have been named after him.

The vitreous humouroccupies the greatest share of the globe of the eye. It consists of a clear water contained in a cellular substance, which is so perfectly transparent as to resemble pure glass, whence its name is derived. The cellular substance is condensed on the surface into a smooth membrane, called the membrana lyaloidea. This is marked in front bra circular scries of black radiated lines, caused by the adhesion of the ciliary processes. which, like other parts of the choroid, are covered with pigmentum nigrum. Under these a circular canal runs, named the canal of Petit.

The crystalline humour or lens is im. bedded in the front of the vitreous humour. Its size is about that of a pes, but it is much more flattened in form. It is of a waxy consistence, softer externally, and groving gradually firmer towards the cen- 


\section{ANATOMY.}

tre. The lens is contained in its proper capsule, the posterior surface of which acheres firmly to the tunica hyaloidea; but its separation can sometimcs be effected without fupturing it. It has no appa. rent connection to this capsule. It is an opaque state of this body that constitutes the disease called cataract.

The aqueous humour is a small quantity of transparent water, placed immediately behind the cornea, and occupying the space betwcen that membrane and the crystalline lens : it is easily reproduced when let out.

In the midst of the space occupied by this lumour the iris is found, and it di. vides the space into two portions, called the anterior and posterior chambers of the eye; which communicate by means of the pupil. The anterior is much the largest of these.

The clioroid coat, ciliary processes, and iris, are very vascular, and derive their supply from the ciliary branches of the ophthalmic artery.

The iris is very largely supplied with nerves from a small ganglion, named len. ticular, formed on a branch of the nervus motor, or nerve of the third pair. These are called the ciliary nerves.

of the eye-lids and lacrymal apparatus.The eye-ball is covered by two moveable curtains, formed by a folding of the common integument, and called the eye-lids. In order to keep these uniformly expanded, and to prevent them from forming wrinkles, each of them contains a thin portion of cartilage, adapted in figure to the convexity of the globe, and called the tarsus. In order to provide still further for the grcatest possible facility of motion, the eye-lids are lined by a smooth and polished membrane, and the globe of the eye is covered by the same membrane, on its anterior part : this is called conjunctiva, as it serves to connect the front of the eyeball to the ere-lids.

The junctions of the eyc-lids are called the internal and externalcanthus, or angle of the eye.

They are opened by the levator palpebre lifting up the upper lid; and this muscle is in a state of constant action so long ss we keep our eyes open. They are closed by the circular orbicularis palpe. brarum.

The cilia, or eyc-lashes, are two rows of strong curved hairs implanted in the opposed edges of the two eye-lids, and admirably calculated for protecting the eye from dust or other foreign bodies

The hairy prominences above the eye. lids are the supercilia, or eye-brows; these are very moveable; they scrie as a pro. tection to the eyes, and are much concerned in expressing the passions.

In order to facilitate the motions of the eye-lids and eye-balls on each other, the surface of the conjunctiva is constantly moistened by a watery and mucilaginous fluid, poured out by the arteries of the part. The incrustations of the mucilage in the night would glue the eye-lids together : but this effect is obviated by a natural ointment, formed in a very elegant grandular apparatus on the inner surface of the tarsi. We there find about 16 or 17 longitudinal parallel rows of very minute glandular bodies; and these pour out their sebaceous secretion from a series of apcrtures on the edges of the eye-lids. They are called. the meibomian glands, and ciliary ducts.

The fluid just described is constantly formed on the surface of the conjunctiva ; but on extraordinary occasions, as when an irritating foreign body is in the eye, or in consequence of affections of the mind, a fluid is poured out in greater abundance, which has the name of tears, and is secre. ted by the lacrymal gland. This is a small conglomerate gland, situated in the orbit, near the upper eye-lid, and having ducts which terminate on the surface of the con. junctiva; but which, on account of their minuteness,are hardly demonstrable in the human subject. The utility of this secretion in washing away any forcign substance must be sufficiently obvious.

The'superfluous part of the lacrymal secretion is conveyed through two very fine tubes to a small bag, situated at the internal angle of the eye. These tubes com. mence by open moutlis, called the puncta lacrymalia, from the inner extremitics of the eye-lids, and are about equal in size to admit a log's bristle.

There is a little fleshy projection at the corner of the eye, and between the two puncta, called caruncula lacrymalis.

The lacrymal sac is a small membranous bag, placed in the hollow formed at the inner edge of the orbit. The tendon of the orbicularis palpebrarum, which generally forms a slight eminence visible through the skin, crosses the middle of this bag.

A canal, called the ductus nasalis, and lodged in a groove of the superior maxillary bone, conveys the tears into the nose; where it terminates by an open orifice within the inferior turbinated bone.

ORGAN OF HEARING.

The organ is divided into two parts, the external and internal ear, by the membra- 


\section{ANATOMY.}

ar tympani. The situation of the former on the out side of the head is well known; the latter is contained in the petrous portion of the temporal bone.

The external ear consists of two parts, viz. the pinna, or ear, popularly so called, and a tube called meatus auditorins externus leading form the pinna to the mem. brana tympani. These parts serve for collecting sounds, and conveying them to the membrana tympani.

The pinna consists of a convoluted cartilage inclosed by common integuments. The lower part, which is pierced for ear. riugs, has no cartilage, and is called the lobulus. The helix is the fold forming the extemal circumference of the ear; the next eminence to this, which forms the margin of the great cavity of the external ear, is called anthelix; it separates at its upperand anterior end into two processes named crura. The projection immediately in fiont of the meatus is the tragus, and that immediatcly opposite, the antitragus. The great cavity within the anthelix, and leading to the meatus, is called the concha. Several sebaceous glands are situated in the folds of the car.

The meatus externus is formed first by a portion of cartilage, continued from the pinua, and more interiorly it consists of a canal in the substance of the bone. This bony jart-does not exist in the foctus, where the meatus is wholly cartilaginous. The common integuments continued from the pinna line the meatus externus, and the cuticle is produced over the membrana tympani.

The surface of the meatus, at its commencement, is furnished with numerous fine hairs, and the canal is moistened by a secretion of an oily and inflammable na. ture, called cerumen. This is produced by numerous small glands, visible on the crternal surface of the meatus, and distingnishable hy their yellowish colour. The ccrumen crincretes, and is collected sometimes in such quantity as to induce a slight degree of deafness, which is easily removed by syringing with warm water.

The membrana tympani, which is a circular membrane aliove a quarter of an inch in climeter, is stietched across the inner extremity of the meatus, and clerives its nane from a comparison with a drism liead, to which it bears some analogy in its use. In the fortus it is stretched on a distinct bony ring, called the annulns suditorius. This ring is deficient at its upper part, and has no bony union to the rest of the tem. poral bone, but it becomes united soon after birkl.

VOL. I.
This membrane is concave on its exterior surfice, and convex towards the tinpanum. Its position is inclined, the upper margin being more towards the outside of the head, and the under part farther inwards; so that the superior part of the meatus forms an obtuse angle, and the inferior part an acute angle, with the mein. brane.

The internal ear consists of two divisions, viz. the tympanum and the labyrinth.

The tympanum is an irregular bony carity, which will about admit the end of $a$ finger, hollowed out of the temporal bone, just with in the membrana tympani. It has sereral communications with the neighbouring parts.

Opposite to the membrana tympani are two openings, which lead to the labyrinth of the ear. The upper one is named the fenestra ovalis, the lower one the fenestra rotunda, and the projection between them is called the promontory. The fenestra ovalis is filled, as we shall presently see, by one of the little bones of the tympanum, and the fenestra rotunda is closed by a membrane.

The eustachian tube, or iter a palato ad aurem, opens in front of the tympanum. It commences by an expanded cartilaginous orifice at the back of the nostrils, passes through the substance of the temporal bone, and terminates by a contracted orifice in the tympanum. Its office is to convey air into the cavity of the tympanum. The membrana tympani is thrown into vibrations by the impulse of the sonorous undulations of the air, and that vibration could not take place unless there was air in the inside as well as on the outside of the membrane. Water, or any other fluid, would not have answercil the purpose. Ience an obstruction of this tube. causes deafness, which surgeons have at. tempted to remedy by puncturing the membrana tympani. An opening in the latter membrane of asmall extent doesby no means injure liearing : for many persons have the power of impelling tobacca smoke, or agitating the flame of a candle, through the ear, and yet seem to have a perfect use of the organ. In these cascs the air or smoke enters the eustachian tube from the throat, and passes through the unnatural aperture in the membrane.

The mastoid process of the temporal bone is composed internally of numerous cells, cominunicating with each other, and finally opening into the back part of the trmpanum. These do not exist ia the foctus.

I. $\mathrm{C}$ 
The cavity of the tympanum contains a chain of small bones called ossicula auditus, connected by one end to the nembrana tympani, and by the other to the fenestra ovalis. Of these the first, which is compared to a hammer, is called the inalleus; the second is named the incus, the third the orbiculare, and the fourth the stapes.

The malleus possesses a manubrium or handle, a loug and short process, and a head which forms an articular surface.

The incus resembles a grinding tooth, with its two fangs diverging. We remark in it a body, the surface of which is hollowed out to receive the head of the mal. leus: a long and a short leg.

The orbiculare is of the size of a small grain of sand. It is attached to the extremity of the long crus of the incus and the stapes.

The stapes has an exact resemblance to the iron part of a stirrup; it has a head, two crura, and a basis.

The handle of the malleus is firmly con. nected to the membrana tympani; and hence arises the external concarity and internal convexity of the membrane. The head of that bone is joined to the body of the incus, whose long leg is articulated to the head of the stapes The basis of the stapes fills up the fenestra ovalis. The ends of the bones forming these articulations are covered with cartilage, and furnished with capsules like other joints.

The boncs of the tympanum have some small muscles connected to them by which they are moved outwards, or towards the membrana tympani, and inwards, or towards the fenestra ovalis. The first of these motions rclaxes, the latter stretches the membrane. The names of these inus. cles are, tensor tympani, laxator tympani, and stapedeus.

The nerve called chorda tympani passes across the tympanum between the handle of the malleus and the long leg of the incus.

The use of the ossicula auditus seems to be that of transmitting the vibrations of the air from the membrana tympani to the labyrinth. The final use of the muscles which moves these bones is unknown.

The labyrinth of the ear consists of three parts :-1. A spiral bony canal, twisted like a snail-shell, and thence called the cochlea. 2. Three semicircular bony canals : and 3. A small cavity, called the vestibulum, into which the cochlea and the semicircular canals open. These parts arc formed of the hardest bone in the body, almost equal in solidity to ivory, and the petrous portion of the temporal bone, which incloses them, is of a similar structure. In the foctus the labyrintli is surrounded by a softer and looser kind of bone, so that it can be most easily dissected at that age.

The vestibulum is about equal in size to a large pea, and the fenestra ovalis opens into the middle of the cavity. It has also five openings from the semicircular canals; the superior and exterior joining by one of their extremities, and opening by a common hole.

The cochlea has two turns and a half. Its canal turns round a bony centre, called the modiolus, to which is attached a thin plate of bone, projecting into the carity of the coclilea, and named lamina spiralis. This projecting plate divides the canal of the cochlea into two parts: one opening into the restibulum, the other at the fenestra rotunda. The latter is called the scala tympani, the former scala vestibuli.

The vestibulum, cochlea, and semicircular canals, are lined by a delicate vascu. larmembrane, on which the portio mollis of the scventh pair of nerves is distribu. ted. This membrane contains a clear water.

The filaments of the auditory nerve pass from the meatus auditorius internus through a number of very small apertures which lead to the labyrinth, and they terminate on the vascular membrane of the laby rinth, so that the nervous pulp is exposed almost bare to the contained fluid. The distribution of the nerve on the coclllea is particularly bcautiful. The aque. ducts of the ear are two very fine tubes, passing from the restibulum and cochlea to opeu on the surface of the dura mater.

\section{ONGAX OF SMELLIIYG.}

The nose is a cavity of very irregular figure, formed chicfly by the bones of the face, and communicating with the various sinuses or bony cells formed in the head.

It is separated by the brain above by the cribriform lamella of the ethmoid bone. This separation is a perfect one, and the two cavities of the cranium and nose are wholly distinct from each other, although they are supposed, by the uninformed in anatomy, to communicate togetlier.

The bottom of the cavity is formed by the upper surface of the pallet.

The general cavity is clivided into two equal haves, called nostrils, by the sep. tum narium, a thin and flat bony partition, descending from the cribriform la- 
mella to the palate. The flat surface of the septum may the refore be said to forin the inner side of the nostril ; and its outer side presents three bony eminences, called the $\operatorname{couch} x$ narium, or turbinated boncs.

Moreover, the following excarations or sinuses open into the cavity at various parts. Two frontal sinuses; uunierous cells of the ethunoid bone; two sphenoi. dal sinuses; and two great hollows in the upper jaw-bone, called the antra, or maxilliury sinuses.

The front openings of the nostrils are well known. This aperture is heart-shaped in the skeleton, the broadest part be. ing towards the mouth ; but it is much altered in the recent subject by the apposition of pieces of cartilage, the broadest of which are the lixteral portions, termed alx nasi. Behind, the nostrils open by largo apertures into the upper and anterior part of the pliary nx, above the velum pendulum palati.

The sides of the bony cavity just de. scribed are covered by a thick, soft, and very vascular membrane, called mem. brana schneideriana, or pituitaria. Its surface is constantly moistened by a se. cretion of mucus from the arterics, with which it is very copiously supplied. This prevents the effects which the current of air in respiration would otherwise produce, of drying the menbrane. It is only an increased quantity of this secretion, altered too somewhat in its quality, that is discliarged from the nose in colds, and which is popularly supposed to come from the brain. This membrane extends into the cells which communicate witls the nose, but is thinner and less vascular there.

The ethmoidal cells open into the cavity of the nose, partly above, and partly under, the loose edge of the superior turbinated bone. The frontal sinuses open into the front of these cells; and the splienoidal sinuses into the hack part of them. The antrum maxillare lias a round opening between the two turbinated bones. The nasal duet opens under the inferior of these bones : and the expanded orifice of the eustachian tube is just at the communication between the back of the nose and the pharynx.

The filaments of the olfactory nerres, having penetrated the cribriform lamella, are distributed to the pituitary membrane that covers the septum nasi and superior turbinated bone.

Several small branches from the fifth pair are also distributed on the nose, at dificrent parts.
ORGAX OF TASTE.

It would be a waste of worls to describe the situration and form of the tongue. This orgau presents a most interesting subject to the phisiologist, from the conl. cern which it has in the functions of mas. tication, deglutition, and articulation, besides that it constitutes the organ of the scuse of taste.

Its bulk is macle up of numerous mus. cles, which are distinct at their origin, but hecome mised and confused at their in. sertion into the tongue. The union of these fibres with each other, and with the fatty substance which connects them, constitutes the peculiar substince of the tongue. It is covered exterially by a continustion of the coinmon membrane of the mouth. This membrane, however, on the edges, tip, and upper surface of the organ, is covered with small projecting processes, called papilla, in which the sense of taste resicles.

Towards the back of the tongue several mucous glauds are found, with openings that would admit a bristle. These secrete a fluid, to facilitate the passage of the food through the isthmus faucium.

Next to these openings, and still at the posterior part of the organ, are found eight or ten large papill $x$, arranged in the form of the letter $V$, with the pointed part towards the throat. These are the pipilla magne or capitatx. They consist of a round body, surrounded by a circu. lar fold of membrane. These also are mucous glands.

The most numerous class of papillie are those which occupy the sides and tip of the tongue. Thiese are the smallest in size, so as to have been compared to the villi of the skin; and conical in shape. They are called papill $x$ conic $x$ or villos $x$. Anong these a few larger ones are scattered, the papillx semilenticulares.

The tongue recejves three large nerves on each side; 1st, the glossoplatryngeal branch of the eighth pair, distributed to the back of the tongue and upper part of the pharynx: 2ndly, the lingual nerve, or nerve of the 9 th pair, which supplies the muscles: and 3rdly, the lingual branch of the inferior maxillary, which goes to the papillac cliefly.

ORGAN OF TUE SEXSE OF TOTCh.

This sense may be considered, in the most enlarged acceptation of the term, as residing in the surface of the body in general : in a more limited vicw, we regard 


\section{AN A'TOMY.}

the ends of the fingers as more particu. larly adapted, by their organization, for exploring the tangible properties of bodies.

The skin, or exterior covering of the bo$\mathrm{dy}$, is divided into three layers, riz. the cuticle, the rete mucosum, and the cutis. These parts are called the common integuments of the body. To them a fourth is sometimes added, viz. the adipous membrane. But although there is generally : layer of fat under the skin, this is not invariably the case.'

The cutis vera, or true skin, is a very dense and compact membrane, formed, as it were, by a general condensation of the cellular substance on the surface of the body. It is this that forms leather, when subjected to the operation of tanning. Its thickness varies in different parts of the body. It possesses considerable elasticity, oy virtue of which it yields to any distending power, and on the cessation of such force recovers its former state. It lias also a species of contractility, which is evinced by its corrugation from cold. Its colour in the inhabitants of all countries is whitc. It possesses great vascularity, and has also an abundant supply of nerves, which bestow on it acute sensibility. It is thrown into folds in different parts of the body, in consequence of their motions on each other; this may be particularly observed in the hands and fingers. Its surface is also marked by lines, crossing and intersecting each other variously, and intercepting spaces of all shapes and descriptions.

Such parts of the cutis as are the most highly organised have numerous fine hair-like processes, called villi. These are more vascular than other parts, and receive also a more copious supply of nerves. Such parts enjoy a ligher and more acute sensibility. This is the case with the ends of the fingers, which, both by their form and organization, are more especially fitted to act as organs of touch. It is also observed in the lips, and in the glans peris.

The rete mucosum is a soft mucous substance, readily demonstrable in the negto, where it is thick and of a black co. lour, but hardly discernible in the European. This is the seat of the colouring matter of the skin.

The cuticle is a thin semi-transparent corering, possessing no particular arrangement of parts, no vessels nor nerves. It adheres, however, closely to the subjacent parts, and is exactly moulded to the sur- face of the eutis. It is best seen after the action of a blister, when it is elevated by an effusion of fluid under it. In the dead body it may be separated from the cutis by putrefaction, or by immersion in hot water. In this way it may be remove ed, entire, from tlie hand and fingers, so as to resemble a glove.

It forms an insensible medinm, interposed between the nerves of the organ of touch and external objects; and as it covers the whole exterior of the body, our surface is actually dead. When removed from any part, it is speedily renewed by the cutis. Its thickness varies in different parts; being greatest where it is exposed to friction, as in the palms and soles. Its thickness is here also inereased by friction, as we may observe, by contrasting the hand of a labourer with that of a person who does not use his hands in the same rough manner.

It appears that the cuticle is impervious to fluids, as the serum contained in a blistered part does not transude; neither does a dead body become dried while covered by this expansion; but when that is removed, it is speedily reduced by evapora. tion to a state of dryness. Yet it must be penetrated by the vessels in a living body, as is proved by the immense discharge both of sensible and insensible perspiration. I'robably, also, the absorbents open on it by patulous orifices ; for mercurial ointment, rubbed on the skin, affects tlie system.

Sebaceous glands are formed under the skin, in a few situations only, as about the nose and external ear.

IIairs consist of an insensible excre. scence produced fiom the cutis. Fach hair grows from a small bulb, and is lengthened by means of additions made to it in the bulb. These bodies perforate the cuticle.

Nails are portions of a horny substance, connected to the ends of the toes and fingers. Their surface, corresponding to the back of the finger, is convex, and tolerably smooth; the opposite part is laminated and concave. These laminx adhere to corresponding ones of the cutis. The integuments advance for some length over the root of the nail, so as to cover a considerable portion of it ; and the cuticle adheres closely to its surface. The nail grows like the hair, by additions from below.

The account of the progress of the embryo after conception, or the description of the gravid uterus and its contents, together with the enumeration of those circium. 


\section{ANATOMY.}

stances of anatomical stricture, which arc peculiar to the foctus, will be giren under the article Fortes.

EXPLAXATIOY OT THE AYATOMICAL PLATES. l'LATE. I.

Fig. 1. A front viers of the skoleton.

1. The cranium.

2. Os frontis.

3. 3. The orbits.

4. Upper jaw-bone.

5. Teeth.

6. Lower jaw-bone.

7. The seven true ribs.

8. The five false ribs. -

9. First bone of the sternum.

10. Second bone of the sternum.

11. Fnsiform cartilage.

12. The five lumbar vertebrx.

13. Ilium, or haunch-bone.

14. Os ischii.

15. Os pubis.

16. Os sacrum, or bone of the rump.

17. Symphisis pubis.

18. Thigh-bone.

19. Head of the thigh-bone.

20. Troclsanter major.

21. Patella, or knee-pan.

22, 23. Fiternal and internal condyles of the thigh.

24. Tibia.

25. Fibula.

26. Bones of the tarsus.

27. Bones of the metatarsus.

28. Bones of the toes.

a. The clavicle, or collar-bone.

b. Scapula, or shoulder-blade.

c. Humerus, or bone of the arm.

d. Ulna.

e. Radius.

$f$. First row or phalanx of carpal bones. $g$. Second row or phalanx of carpal bones.

$h$. Bones of the metacarpus.

i. First phalanges of the fingers.

$k$. Second phalanges of the fingers.

l. Third phalanges.

$m$. Three phalanges of the tlumb.

Fig. 2. View of the right ventricle and pulmo. nary artery laid open.

These parts are marked $\mathbf{\Lambda} \boldsymbol{s}$ in Plate VI. Fig. 1.

a. A triangular flap of the fleshy side of the ventricle, turned back, to expose the cavity.

b. Columnx earnex of the heart.

e. Tricuspidal valve.

๗. The three semilunar ralres in the mouth of the pulmonary artery, which is slit open.

c. $e$ Cut edges of the ventricle.

Fig. 3. Tiew of the cavity of the left rentricle, and mouth of the aorta.

a. a. Cut edges of the ventricle.

b. Columnz carnex.

c. Chorlx tendinie.

d. Mitral valve.

e. Semilunar valves of the aorta.

\section{Plate II.}

Fig. 1. Back view of the skeleton.

1. 2. Ossa parietalia.

3. Os occipitis.

4. Os temporis.

5. Mastoid process of the temporal bone.

6 . The seren cervical vertebrx.

7. The twelve dorsal vertebra.

8. The five lumbar vertebrx.

11. Os sacrum, or rump-bone.

12. Os coccygis, or crupper bone.

13. Ilium.

9. Ischium.

14. Neck of the thigh-bone.

15. Trochanter major.

16. Trochanter minor.

17. Condyles of the thigh.

18. Nalleolus externus.

19. Malleolus internus.

20, Os calcis.

Fig. 2. The small bones contained in the tymfranum of the ear.

1. Malleus.

2. Incus.

3. Os orbiculare.

4. Stapes.

Fig. 3. A ziero of the same bones, as joined to each other, and as connected to the mem. urana tympani.

e. Membrana tympani with the handle of the malleus connected.

$f$. Head of the malleus joined to

$\xi$, which is the body of the incus.

$h$. Base of the stapes.

Fig. 4. A viero of the labyrinth of the car.

a. Three semicircular canals unopened.

6. Section of the cochlea.

c. Auditory nerve.

d. Branches of the nerre going to the vestibulum and semicircular canals.

e. Trunk of the nerre most beautifully 


\section{ANATOMY.}

ramified on the solid axis, and projecting bony plate of the cochlea.

Fig. 5. Second view of the labyrinth; representing the vestibulum and semicircular canals laid open, and the branches of the auditory nerve terminating on those parts.

a. Cavity of the vestibulum.

\section{Prate ill.}

Fig. 1. A front view of the muscles.

The right side of the figure represents the first or most superficial stratum : on the left side the second layer is exhibited. It would be impossible to refer to all the muscles exhibited in this and the follow. ing muscular plates: we must therefore confine ourselves to the more obvious and important ones.

a. Orbicularis palpebrarum.

b. Orbicularis oris.

c. Zygomatici.

d. Sterno-cleidomastoideus.

1. Platysma myoides.

2. Pectoralis major.

e. Latissimus dorsi.

3. Obliquus externus abdominis.

4. Rectus abdominis.

+ Pectoralis minor.

$f$. Serratus anticus.

5. Obliquus externus abdominis.

5. Deltoid muscle.

6. Biceps flexor cubiti.

$h$. Supinator radii longus.

$i$. Pronator radii teres.

k. Flexor carpi radialis.

l. Extensors of the thumb.

$m, n$. Two heads of the biceps flexor cubiti.
o. Opponens pollicis.
p. Muscles of the little finger.
$q$. Flexor tendons of the fingers.
$r$. Flexor digitorum profundus.
8. Flexor longus pollicis.
7. Tensor vaginz femoris.
8. Sartorius.
9. Vastus externus.
10. Rectus extensor femoris.
11. Vastus internus.
12. 'Iibialis anticus.
13. Extensor muscles of the tocs.
14. Extensor tendons of the toes.

Fig. 2. Posterior surface of the eye-lids, with the lacrymal gland.

$a, b$. Posterior surface of the eye-lids. The perpendicular parallel lines are formed by rows of the sebaceous or meibomian. glands. c.c. c. c. Cut edge of the tunica conjunctiva, where that membrane was reflected from the eye-lids to the eye-ball.

d. Lacrymal gland.

e. Openings of its ducts on the surface of the conjunctiva.

f. Pueta lacrymalia.

g. Caruncula lacrymalis.

Fig. 3. Front view of the eye-brow and eyelids; designed to shcro the margins of the latter, and their union with each other.

b. Fold of the skin between the upper eye-lid and the eye-brow.

c. Orifices in which the hairs of the eye-lash were implanted.

$f$. Openings of the ducts of the sebaceous glands along the margin of the eye-lid.

$d . m$. Superior and inferior punctum la. crymale, or external openings of the canals, by which the tears are conveyed to the lacrymal bag.

$h$. Carunçula lacrymalis.

s. External canthus or angle of the eye ; the opposite part is the internal can. thus.

Fig. 4. View of the lacrymal passages.

a. a. Puncta lacrymalia.

b. b. Lacrymal ducts, commencing from the puncta, and terminating in

c. The lacrymal bag.

d. Nasal duct.

e. Its termination at the nose.

$f$. Lacrymal gland.

\section{Plate IV.}

Fig. 1. A posterior view of the muscles; in which the right side exhibits the superficia?, and the lefi a deeper-sected stratum.

a. Temporal muscle.

b. Supraspinatıs.

c. Infraspinatus.

d. Teres minor.

e. Teres major.

$f$. Pyriformis.

g. Vastus externus.

h. Biceps flexor cruris.

$i$. Semitendinosus.

k. Peronei muscles, \&.

$l$. Their tendons.

m. Levator scapulz.

1. Trapezius.

2. Rhomboideus.

3. Latissimus dorsi.

4. Splenius capitis.

5. Complesus. 
6. Serratus inferior posticus.

7. 7. Sacrolumbalis and longissimus dorsi.

8. Deltoid.

9. 9. Triceps extensor cubiti.

11. Gilutcus maximus.

12. Gluteus inedius.

13. Flexors of the knee-joint.

14. Gastro-cnemius.

15. Soleus.

16. Tendo achillis.

Fig. 2. I view of the surfuce of the brain, exposed by remoring the skill-cap.

On the right side the brain is covered by its dur'a inater: that membrane is cut through, and turned aside, so as to ex. pose the left henispliere.

Fig. 3. The skull and lrain cut through horizontally in about the midtle.

It shews the difference of the cortical and medullary substances, and the union of the $t w 0$ hemispheres by the corpus callosum.

d. The dura mater, which covered the brain, and formed the falx, thrown back.

$e . e$. Cineritious substance.

g. Medullary substance.

$h$. Corpus callosum.

Fig. 4. The basis of the brain, with the origin of the nerves.

a. a. Anterior lobes of the brain.

b. b. Middle lobes.

c c. P'osterior lobes.

d. $d$. Two lobes of the cerebellum.

$f$. Pons varioli, or medulla oblongata.

e. Medulla spinalis.

\section{PLATE V.}

Fig. 1. Sitperficial viezo of the contents of the abdomen

d. d. Omentun.

c. c. Liver.

$f . f . f . f$. Various convolutions of small intestine.

a. a. a. Transverse arch of the colon covered by the omentum.

Fig. 2. is a scheme to represent the whole tract of the intestinal canul, as the stomach and some other parts do not come into view in the precedling fisure. 'The arrows represent the course of the uliment.

a. End of the esophagus.

B. The stomach. h. Pylorus.

g.i.k. l. Various convolutions of small intestine.

e. Caput coli.

m. Appendix vermiformis.

$f$. Ascending colon.

a. a. a. Tyansverse arch of the colon.

$b$. Sigmoicl flexure of the colon.

c. Rectum.

\section{Plate Vi.}

Fig. 1. A view of the licart and lings, zuith the adjacent large bloorlwessels of the thos. rax and ablomen.

A. Right ventricle of the heart.

e. Right auricle.

1. 2.3. The three lobes of the riglit lung.

4. 5. Two lobes of the left lung.

a. Origin of the pulmonary artery.

b. Arch of the aorta.

$x$. Arteria innorninata.

$y . y$. Right and left carotid arteries.

$u$. u. Jugular reins.

k. E. Left subclavian vein.

c. Superior rena cavit.

$k$. Descending aorta, sending off different branches to the abdominal viscera; as, $l$, the caliac; $m$. superior mesenteric; $n$. inferior mesenteric; $0 . p$. renal arteries.

$h$. Trunk of the inferior vena cara.

r.q. Renal veins.

$v$. Trunk of the absorbing systcm, called the thoracic duct.

d. Termination of that duct in the angle formed by the junction of the left subclavian and jugular vcins.

1.ig. 2. $A$ vierv of the thorax and abdoment, representing some parts not seen in Plate $\boldsymbol{V}$. anul now axposed by lifting up the liver.

1. Thyroid gland.

2. Trachea. The large blood ressels correspond to those of the preceding figure.

3. The heart.

4. I.eft lung.

5. Right lung.

6. Under surface of the left lobe of the liver.

7. Under surface of the right lobe.

8. The stomach.

9. Great onentum.

10. Small intestines.

11. 11. The coveriugs of the abdomen cut through and turned asidc.

12. Fladder of urine. 
13. Jesser omentum.

14. Gall-bladder.

Fig. 2. Gall-bludder and biliary ducts, and pancreas.

K. Hepatic duct, formed by various branches coming from the liver.

l. Cystic duct.

I. Gall-bladder.

N. Ductus communis.

P. Pancreas with its duct.

Q. A portion of the intestines, with a longitudinal slit, the opening of the united ducts.

ANAXAGORAS, in biography, a celebrated philosopher among the ancients. He was born in Ionia about the 70th olympiad, became the disciple of Anaximenes, and was afterwards a lecturer himself at Athens. In this city he was cruelly persecuted, and at length banished. He went to Lampsacus, where he was greatly honoured during his life, and still more respected after his death. Statues have been erected to his memory.

Anaxagoras was a mathematician, and wrote, during his imprisonment at $\mathrm{Athens,}$ upon the quadrature of the circle. As a philosopher, he introduced some important innovations, as they were then called, but which redound much to his honour: he maintained, in opposition to the common systems of a plurality of Gods, that an infinite mind is the author of all motion and life. Plato asserts, that Anaxagoras taught that "mind was the cause of the world, and of all orler," and that, "while all things else are compounded, this alone is pure and unmixed:" he ascribes to this principle two powers, viz. to know, and to move. Testimonies to this purpose in fa. vour of Anaxagoras are numerous; Plutarch, speaking of the Ionian philosophers who flourished before this great man, says, that they made fortune, or blind necessity, the first principle in nature; but Anaxagoras affirmed, that a pure mind governs the universe. By Diogenes Laertius he is represented as the first person, "who superadded mind to matter." He died in the year 428 before Christ, and throughout his life he supported the character of a true plilosopher. Superior to the motives of avarice and ambition, he resigned in early life a patrimony, that would have secured liin distinction and independence, in order that he might give himself up wholly to the pursuits of science, and in the midst of the vicissitudes of fortune preserved an equal mind. Being asked, just before lis death, whether he wished to be carried for interment to his native city, he replied, "it is unne. cessary: the way to the regions below is ev. ery where alike open :" and in answer to $\mathbf{a}$ message sent him at the same time by the senate of Lampsacus, requesting to be informedin what manner they might honour his memory after his decease, he said, "By ordaining the day of my death to be annually kept as a holiday in all the schools of Lampsacus." This request was complied with, and a festival called Anaxagoria was instituted on the occasion.

ANAXIMANDER, in biography, a very celebrated Greek philosopher, was born at Miletus on the $42 \mathrm{~d}$ olympiad; for, ac cording to Apollodorus, he was 64 years of age in the second year of the 58th olym. piad. He was one of the first who pub. licly taught philosophy, and wrote upon philosophical subjects. He was the kinsman, companion, and disciple of Thales. He wrote also upon the sphere and geo. metry, and framed a connected series of geometrical trutlis : he also wrote a summary of his doctrine, and carried his researches into nature very far, for the time in which he lived. It is said that he dis. covered the obliquity of the zodiac; that he first published a geographical table; that he invented the gnomon, and set up the first sun-dial in an open place at Lace. dxmon. Iic is said to have been tho first who delineated the surface of the earth, and marked the divisions of land and water upon an artificial globe. He taught, that an infinity of things was the principal and universal element; that this infinite always preserved its unity, but that its parts underwent changes; that all things came from it; and that all were about to return to it. He held that the worlds are infinite; that the stars are composed of air and fire, which are carried about in their splieres, and that these spheres are gods; that the sun has the lighest place in the heavens, the moon the next, and the planets and fixed stars the lowest; that the earth is a globe, placed in the middle of the universe, and remains in its place, and that the sun is 28 times larger than the earth.

ANCHOR, in maritime affairs, an extremely useful instrument, serving to retain a ship or boat in its place.

It is a very large and heavy iron instrument, with a double hook at one encl, and a riing at the other, by which it is fastened to a cable.

It is cast into the bottom of the sea, or rivers, where, taking its hold, it keeps ships from being drawn away by the wind, tide, or currents.

The parts of an ancher are: 1 . The 


\section{ANC}

ring to which the cable is fastened: 2 . the beam, or shank, which is the longest part of the anchor: 3. the arm, which is that which runs into the ground: 4. the flouke or lluke, by some called the palm, the broad and peaked part, with its barbs, like the head of an ariow, which fastens into the ground : 5. the stock, a piece of wood fastened to the beam near the ring, serving to guicle the fluke, so that it may fall right, and fix in the ground.

'The following are the dimensions of the several purts of an anchor, as given by $\mathbf{M}$. Bougier. The two arms generally form the arch of a circle, the centre of which is 3-8ths of the shank from the vertex, or point where it is fixed to the shank; each arm is equal to the same length or radius, so that the two arms together make an arch of 120 degrees : the fukes are half the length of the arms, and their breadths two fifths of the stid length. Wirh respect to the thickness, the circunference of the throat or vertex of the shank is generally inade about 1-5th part of its length, and the small end two thirds of the throat: the small end of the arms of the flukes three fourths of the circumference of the shank of the throat.

Cast iron anchors have been proposed, and indeed, fiom the improvements in this metil, it is probable they would be cheap and serviceable But when we consider the great importance of anchors to the lives and property intrusted in shipping, it wonld not be an act of prudence to make an anchor of any material but the very best. It appears reasonable, that a cast iron anchor, made broad in the flukes, and strong in the shank, and fortificd with a kind of edge-bar, knee, or bracket, in each angle, between the arm and the shius, might prove as trust-worthy as a forged anchor, and be more than equal to the strain of any cable which is marle.

There are several kinds of anchors: 1 . the sheet anchor, which is the largest, and is never used but in violent storms, to hinder the ship from being driven ashore: 2. the two bowers, which are used for ships to ride in a harbour: 4 . the stream anchor: 5 . the grapnel. The iron of which anchors are made ought ne:ther to be too soft nor too brittle; for, if the iron be brittle, the anchor is apt to break, and if it be tro soft, the anchor will bend. In order to give them a proper temper, it is the practice to join brittle with soft iron, and for this reason the Spanish and swedish iron ought to be preferrecl.

'The sliank of an anclior is to be three times the length of one of its Hukes, and

VOL. I. a ship of 500 tons hath her sheet anchor of 2000 weight; and so proportionably for others smaller or greater, although Aubin observes, that the anchors of a large veasel are made smaller in proportion than those of a small one.

The anchor is saicl to be a-peak, when the cable is perpendicular between the hawse and the auchor.

An anchor is said to comc home, when it cannot hold the ship. An anchor is foul, when, by the turning of the ship, the cable is hitched about the fluke. To shoe an anchor, is to fit boards upon the flukes, that it may hold the better in soft ground. Whell the anchor hangs right up and down by the ship's side, it is said to be : cock bell, upon the ship's coming to an anchior.

The inhaljitants of Ceylon use large stones instead of ancliors; and in some other places of the Indies, the anchors are a kind of wooden machines loaded with stones.

ANCliOliage, in law, is a duty taken of ships for the use of the port or harbour where they cast anchor: for the ground. there belonging to the king, no man can let fall anchor thereon, without paying the king's officers for so doing.

ANCIIUSA, in botany, the alkonet, a genus of the l'entandria Monogynia class of plants, the calyx of which is an oblong, cylindric, acute perianthium, divicled into five segments, and permanent; the corolla consists of a single petal; the tube is cylindric, and of the length of the cup; the limb is lightly clivided into five segments, erecto-patent and obtusc; the opening is clnsed by five oblong, convex, prominent, and connivent squamula: there is nopericarpiun : the cup becomes larger, and serves as a fruit, containing in its cavity four oblong, obtuse, and gib. bous seeds. There are thirteen species: though according to Martyn only ten. They are mostly biennial, except when they grow in rubbish, or out of a wall. They may all be casily propagated by secds, sown in the autumn.

ANCISTIUU, in botany, a genus of the Diandria Monngynia class and order: calyx four leared: no corolla : stigma many-parted : clrupedry, hispid, one cellcd. There are three species. A. decumbens resembles burnet in the herb and mal ier of flowering: it is remarka. ble for the yellow awns to the calyx, re. scinbling fox's nails. A native of New \%ealand. A. lucidum is a native of the Falk. laud islands, introduced here in 1777 by 1)r. Fotlier'rill; it flowers in May and June.

ANDAI.USIT F, or harkpar, in mineralogy, a species of the. Felspar family, disIf 


\section{AND}

covered by Boumon in a primitive granitic mountain in Forez. Colour flesh red, sometimes approaching to rose red. Massive, and crystallized in rectangular foursided prisus. Specific gravity 3.16. Infusible by the blow-pipe witlout addition. It is distiuguished from felspar by its great bardness, and higher specific gravity, and from corundum, by its inferior specific gravity and its form. It is now found in the primitive mountains in Spain and France, with quartz and mica, and sometimes in a mica state at Braunsdorf, near Freyberg in Saxony.

ANDRACHNE, in botany, a genus of the Monocia Gynandria class of plants; the corolla of the male flower is formed of five emarginated slender petals, shorter than the cup; the female flower has no corolla; the fruit is a capsule containing three cells, with two obtuse trigonal seeds, roundish on one side, and angular on the other. There are three species.

ANDIREA, in botany, a genus of the Cryptogramia Musci class and order. Essen. char. capsule very short, turbinate: fringe simple, of four incurved concave teetl, united at their tips, and bearing the lid and veil. There are two species.

ANDROIDES, in mechanics, an automaton, in the figure of a man, which, by virtue of certain springs, \&c. duly contrived, wàlks and performs other external functions of a man. Albertus Magnus is recorded as having made a famous androides, which is said not only to have moved, but to have spoken. Thomas Aquinas is said to have been so frightened when he saw this head, that he broke it to pieces; upon which Albert exclaimed, " Perit opus triginta annorum." Artificial puppets, which, by internal springs, run upon a table, and, as they advance, move their heads, eyes, or hands, were common among the Greeks, and from thence they were brought to the Romans. Figures, or puppets, which appear to move of themselves, were formerly employed to work miracles; but this use is now superseded, and they serve only to display ingenuity, and to answer the purposes of amrisement. One of the most celebrated figures of this kind was constructed and exhibited at Paris, in 1738; and a particular account of it was published in the Memoirs of the Acudemy for tliat year. This figure represents a fute-player, which was capable of performing various pieces of music, by wind issuing from its mouth into a German flute, the holes of which it opened and shut with its fingers: it was about $5 \frac{1}{2}$ feet high, placed upon a square pedestal $4 \frac{1}{2}$ feet high, and $3 \frac{1}{2}$ broad. The air entered the body by three separate pipes, into which it was conveyed by nine pairs of bellows, that expanded and contracted, in regular succession, by means of an axis of steel turned by clock-work. These bellows performed their functions without any noise, which might have dis. covered the manner by which the air was conveyed to the machine.

The three tubes which received the air from the bellows passed into three small reservoirs in the trunk of the figure. Here they united, and ascending towards the throat, formed the cavity of the mouth, which terminated in two small lips, adapted in some measure to perform their proper functions. Within this cavity was a small moveable tongue, which, by its motion at proper intervals, admitted the air, or intercepted it in its passage to the flute. The fingers, lips, and tongue, derived their proper movements from a steel cy. linder, turned by clock.work. This was divided into fifteen equal parts, which, by means of pegs pressing upon the ends of fifteen different levers, caused the other extremities to ascend. Seven of these levers directed the fingers, having wires and chains fixed to their ascending extremities, which, being attached to the fingers, made them to ascend, in proportion as the other extremity was pressed down by the motion of the cylinder, and vice versa; then the ascent or descent of one end of a lever produced a similar ascent or descent in the corresponding fingers, by which one of the holes of the flute was occasionally opened or stopped, as it might have been by a living performer. Three of the levers served to regulate the ingress of the air, being so contrived as to open and shut, by means of valves, the three reservoirs abore mentioned, so that more or less strength might be given, and a higher or lower note produced, as occasion required. The lips were, by a similar mechanism, directed by four levers, one of which opened them to give the air a freer passage, the other contracted them, the third drew them backward, and the fourth pushed them forward. The lips were projected upon that part of the flute wluch receives the air, and, by the difterent motions already mentioned, modified the tune in a proper manner. The remaining lever was employed in the direc. tion of the tongue, which it easily moves, so as to shut or open the mouth of the flute. The just succession of the several motions, performed by the various parts of this macline, was regulated by the following simple contrivance. The extremi. ty of the axis of the cylinder tcrminated 


\section{ANDROIDES.}

on the right side by an endless screw, consisting of twelve threads, each placed at the distance of a line and au halffrom the other. Above this screw was fixed a piece of copper, and in it a steel pivot, which, falling in between the threads of the screw, obliged the cylinder to follow the threads, and, instead of turning directly round, it was continually pushed to one side. Hence, if a lever was moved, by a peg placed on the cylinder, in any one revolution, it could not be moved by the same peg in the succeeding revolution, because the peg would be moved a line and a half beyond it by the lateral motion of the cylinder.

Thus, by an artificial disposition of these pegs in different parts of the cylinder, the statue was made, by the successive cle. vation of the proper levers, to exhibit all the different motions of a flute-player, to the admiration of every one who saw it. Another figure, constructed by the same artist, Vaucanson, played on the Provencal shepherd's pipe: held in its left hand, and with the right beat upon a drum.

The performances of Vaucanson were imitated, and even exceeded, by M. de Kempelin, of Presburg, in Ilungary. 'Tlie androides constructed by this gentleman, in 1760 , was capable of playing chess. It was brought over to kngland in 1783, and remained here for more than a year. It is thus described: The figure is as large as life, in a Turkish dress, seated behind a table, with doors $3 \frac{1}{2}$ feet long, 2 deep, and $2 \frac{1}{2}$ high. The chair on which it sits is fired to the table, which is made to run on four wheels. It leans its right arm on the table, and in its left hand holds a pipe; with this hand it plays after the pipe is removed. A chess-board of 18 inches is fixed before it. The table, or rather chest, contains wheels, levers, cylinders, and other pieces of mechanism, all of which are publicly displayed. The vestments of the figure were then lifted over its head, and the body seen full of similar wheels and levers. There is a little door in its thigh, which is likewisc opened: and with this, and the table also open, and the figure uncovered, the whole is wheeled about the room. The doors are then shut, and the automaton is ready to play; and it al. ways takes the first move. At every motion the wheels are heard, the image moves its head, and looks over every part of the chess-boand. When it checks the queen it shakes its head twice, and thrice in giving check to the king. It likewise shakes its head when a false move is made, replaces the piece, and makes its own move, by which means the adversary loses one. M. de Kempelin exhibited his autn. maton at Petersburg, V"ienna, Paris, and London, before thousands, many of whom were mathematicians, and chess-players, and yet the secret by which he governed the motion of its arm was never cliscover. ed. Ile valued himself upon the construc. tion of a meclanism, by which the arm could perform ten or twelre inoves. It then nceded to be wound up like a watch, after which it was capable of continuing: the same number of notions. 'This auto. maton could not play unless M. de Kem. pelin, or lis assistant, was near it, to direct its movements. A small square box was frequently consulted by the exluibitor during the game, and in this consisted the secret, which the inveritor declared lie could communicate in a moment. Any person who could beat M. de Kempelin at chess, was sure of conquering the automaton.

Remark by the British Editor.- When this picce of mechanism was exhibited in London, it played a great number of mores without requiring to be wound up, and it was worked by a M. Anthon, who walked about the room, without any apparent com. munication, during the performance. The chess-board was part of the top of the square counter, or table, to which the figure was attached in a leaning posture. When the back of the figure was opened, an upright iron axis was scen, with two strong springs, whicl apparently were intended to restore the quiescent position after any more; and when the doors of the counter were opened, two compartments were seen, formed by an upriglit partition in the interior space. In one of them was seen a brass barrel, resembling that of a barrel organ, having sixteen verticle bars or levers, so placed as if to be tripped by the barrel; and there was also some wheel-work: and in the other com. partment there was little, except a brass horizontal arc, or quadrant, with a brass radius, most probably capsble of being set to different angular situations. The liand of the figure lay upon a cushion, and every approaching move was announced by the discharge of a click, and the buzzing noize of a fly was heard until the move was com. pleted. The forearm was first raised about two inches by a vertical motion at the elbow : it was then carried horizontally, until the hand was immediately over the piece to be taken up, at which time the fingers suddenly opened, the hand dropped, seized the picce, rose again, made the move, and dropped the piece on the square to which it had arrived. But in case the adversary's picce were to be 


\section{AND}

taken, it was first séized in the mannerhere described, and carried clear off the board and dropped, and the subsequent more then made into the einpty squarc. After the game was played, the Baron Kempelin gave the figure a knight, and it moved the piece in succession, without any pause, by the proper course, till it had passed every square in the board, as was sliewn by an assistant placing a counter on each square, as the knight quitted it.

What can be deduced from so slight and transient a public view of this apparatus? -very little. It seems as if the greatest skill bad been exerted in producing the mechanical effects, and that the communication of the player (Anthon) with the apparatus may be a riddlc of no great depth. 'The sixteen pulls from the barrel may bear some relation to the eight rows of squares, twice taken for the two sides, the white and the black; and as the moves are all reducible to those of the castle of the bishop, from which they differ in extent of shift only, (cxcept that of the knight, which is an immediate combination of both) we may guess that the pull might determine the line to be played in, and the quadrant the distance from the back row. But it is useless to extend our con. jectures, with such scanty means.

The same Baron Kempelin exhibited, in his private parlour, a small speaking instrument or organ, which he said was not then in a finished state. It was a kind of box, which he brought out and placed upon a table. Speaking withont notes from the recollection of four and twenty years now elapsed, I judge its dimensions were about two feet in length, one foot wide, and eight or nine inches deep. It was open; but we were prevented from seeing the inside by a eloth put over it. The Baron put his hands under the cloth, so that his right arm was disposed longitudinally in the box, and seemed to press a pair of bellows : the other hand was put in crosswise at the end, near the place of the right hand, and secmed to be employ. ed with kcys, or some apparatus, or perhaps both hands may have been so employed. When he made the instrument speak, he raised his right elbow, and gra. dually pressing it down, the sound was heard. It was monotonous, as if from a single pipe, about the pitch of $\mathrm{D}$, above the middle $\mathbf{C}$, concert pitch; and the words papa and mama were uttered very distinctly, in a slow drawling manner; that is to say, there was a want of the usual inflections of tone, and the sound fell off in intensity towands the end. After several other words had been spoken, a

\section{ANE}

lady asked in French, if it could not speak sentences, and the Baron asked what it should sav. She answered "Que je suis mechante," and the instrument said " Tous etes mechante, nuis vouts ete's aussi bonne."

Kratzenstein has given some account of the principles of an engine of this kind, in a work extracted in the Journal de I'lyysique: and Dr. Young has eursorily mentioned this subject in his lectures, with some diagrams.

ANDROIIEDA, in astronomy, a small northern constellation, consisting of twenty-seren stars, visible to the naked eye, behind Pegasus, Cassiopiea, and Pcrseus. The number of stars placed in this con. stellation by Ptoleny is 27 ; by Tycho Brahe 23; by Hevelius 47 ; and by Flamstead 66 . The constellation has been thought to resemble a woman almost na. ked, with her fect at a distance from each other, and her arms extended and chained.

Axunosens, in botany, a genus of the Decandria Monogynia class of plants; the calyix of which is a very small acute coloured and permanent perianthum, cut into fire segments; the corolla consists of a single petal, of an oval form, inflated and quinquefid; the fruit is a roundish capsule, containing five cells, in which are several roundish shining seeds. There are 25 species.

ANDROI'GON, in botany, a genus of the Polygamia Monoecia elass of plants, the calyx of which is a bivalve, oblong, obtuse glume; the corolla is also a bivalve glime, smaller and thinner than the cup; there is no pericarpium; the seed, which is single, oblong, covered and armed with the arista of the flower, is includ. ed in the glumes of the calyx and corolla. 'I'here are 32 species.

ANEMOMETER, among mechanical philosopliers, an instrument contrived for measuring the strength of the wind. There are various kinds of anemometers; that of which Wolfius gives the structure is mored by sails like those of a windmill. II experienced, he says, the goodness of it, and affirms that the inward structure may be preserved to measure even the force of running water, or that of men and horses when they draw. In the inemoirs of the academy of sciences is described a new anemometer, which expresses on paper, not only the several winds that have blown during the space of the last 24 hours, but also the strength and velocity of each. In the philosophical Transactions for the year 1766, Mr. Brice has 'described a method of measuring the velocity of the wind, by means of 


\section{ANE}

that of the shadow of clouds passing verer the surface of the earth. This, however, in general exceeds that near the ground. M. d'Ons en Brav invented an ancmometer, which of itself expresses on paper, not only the several winds that liave blown during the space of twenty-four hours, and at what lour each began and ended, but also the strength and velocity of each. See Memoirs Acad. Scien. Anno 1734.

ANFMONF, in botany, a genus of the Polyandria Polygynia class and order. Its characters are, that it lias no calyx; that the corolla has petals in two or three rows, three in a row, somewhat oblong; the stamina have numierous filanents, capillary, half the length of the corolla: anthers, twin and erect: the pistillum has numerous gcrms on a head, styles acuminate, and stigmas obtuse : no pericarpium; receptacle globular or oblong; seeds very many; acuminate, retaining the style: there are about 30 species. The garden anemones are natives of the east, from whence their roots were originally brought; but culture has so improved them, that they are become the chief ornaments to our gardens in the spring. To prepare the soil for these plants, take a quantity of fresh, light, sandy loam, or hazel-earth, from a common or dry pasture, not dug above ten inches deep; $\mathrm{mix}$ this with a third part of its quantity of rotten cow-rlung, and lay it up in a heap; turn this over at least once a month, for eight or ten months, and every time pick out the stones, and break the clods. After this mixture has been twelve months made, it will be fit for use. The beds of this earth must be prepared in September, and sbould be made six or eight inches deep, in a wet soil : but in a dry one, three inclses will be sufficient; lay this compost at least $2 \frac{1}{2}$ feet thick, with about four or five inches of rotien neat's dung, or the rotten duwg of an old melon or cucumber bed, at the bottom; in a wet soil let the beds be rounded, so that the water may run off; but in a dry soil let them be nearer to a level: tliree weeks after the compost has been lairl in, stir it about six inches deep with a spade, and then with a stick draw lines each way of the bed, at six inches distance, so that the whole may be in squares; then make a hole three inches deep in the centre of cach square, and plant a root in each; and when all are planted, rake the earth of the whole bed smooth, so as to cover the roots two inches thick. The season of planting these roots for forward flow - ers is the latter end of September; and for those of a middle season is (letober : this is best done at a time when tlicre are gentle rains. Some roots should also be saved, to be planted after Christmas, for fear of accidents to the forner from very hard weather. 'These usually flower three weeks after those planted in autumn. They are propagated two ways, either by dividing the roots or by sowing. 'The roots are to be divided as soon as they are taken up out of the ground; they will suc. ceed, if broken into as many parts as there are eyes or buds in them; but they flower most strongly, if not parted too small. The way by sowing is this; cloose first some good kinds of single anemones, called the gardeners poppy anemones; plant these early, and they will produce ripe seeds three weeks after the Hower first blows. This must be carefully gathered, and in August it should be sowed in pots or tubs, or a well prepared bed of light earth, rubbing it between the hands with a little diry sand, to prevent several of the seeds from clinging together, and spread. ing them as even as possible all over the bed; after this a light hair brush should be drawn many times over the surface of the bed, to pull asunder any lumps of seed that may yet have fallen together; observing not to brush off the seed, and as unuch as possible not to brush it into lumps. When this is done, some light earth, alsout a quarter of an incli deep, should be sifted over the bed. If the weather be hot, the bed unst be at times covered with mats laid hollow, and gently watered. In about ten weeks after sow. ing the plants will appent, if the season bas been favourable, and they are to be carefully defended from the hard frósts by proper covering, and from the heat of the sun afterwards, by a moveable reed fence. As the spring alvances, if the weather be dry, they must be gently watered, and when their green leaves decay, there must be a quarter of an inch more earth sifted over them, and the like "sain at Michaelmas; and the bed niust be kept clear from weeds, and dle following spring they will fower. Tle single or poppy anemones will fiower most part of the winter and spring, when the seasons are favourable, and in a warm situation and they require little eulture, for it will be sufficient to take up the roots every other year; and when they are taken up, they should be planted again very early in the autumn, or clse they will not fow: er till the sping. There are some fine blue colours among these single ane. 


\section{ANE}

mones, which, with the scarlets and reds, form a beautiful mixture of colours; and as these begin to flower in January or February, when the weather is cold, they will continue for a long time in beauty, provided that the frost is not too severe. 'The seeds of these are ripe by the middle or end of May, and must be gathered daily as they ripen, because they will soon be blown away by the winds. The roots of wood ariemone may be taken up when the leaves decay, and transplanted into wildernesses, where they will thrive, and in the spring have a good effect in covering the ground with their leaves and flowers. The blue anemone flowers at the same time with the foregoing, and intermixed with it, makes a fine variety. Double flowers of both these sorts have been obtained from seeds. This, and most of the other wild anemones, may be propagated by offsets from the root, which they put out plentifully; and they will grow in most soils and situations. Virginian anemone, and some others, producc plenty of seeds, and may bc readily in. creased also that way.

ANE.MOSCOPE, a macline invented to tell the changes of the wind. It should consist of an index moving about a circular plate, like the dial of a clock, on which the 32 points of the compass are drawn, instead of hours. The index, pointing to the divisions in the dial, is turned by an horizontal axis, having an handle-head at its outward extremity. This handle-head is moved by a cogwheel on a perpendicular axis, on the top of which is fixed a vane, that moves with the course of the wind, and gives motion to the whole machine. The contrivance is simple, the number of cogs in the wheel and rounds in the trundle-head must be equal, because it is necessary, that when the vane moves entirely round, the index of the dial should also make a complete revolution. A different anemoscope is described in the Phil. Trans. vol. xliii. part ii. and one is described in Martin's 'hlil. Brit. vol. ii.

ANE'THUM, in botany, dill, a genus of the Pentandria Digynia class and order. Essen. char. fivit ovate, somewhat com. pressed, striate : petals involute, entire. There are three species. The common dill differs from fennel, in having an an. nual root, a smaller and lower stem; the leares more glaucous, and of a less pleasant smell; the seeds broader and fi atter. This plant grows wild among the corn in Spain and Portugal, and also near the coast in Italy, and near Constantinople: it is an

\section{ANG}

annual, and has been cultivated here more than 200 years. The seeds are directed for use by the London and Edinburgh Pharmacopeias. Common fennel, another species of ancthum, is much used for culinary purposes, and likewise in medicine.

INEURISM, or ArEURYsi, in surgery, a throbbing tumour, distended with blood, and formed by a dilatation or rupture of an artery.

ANGEL, in commerce, the name of an ancient gold coin in England, of which some are still to be seen in the cabinets of the curious. It had its name from the figure of an angel represented upon it. It was $23 \frac{3}{4}$ carats fine, and weighed four pen. ny-weights. Its value differed in different reigns.

ANGELICA, in botany, a genus of the Pentandria Digynia class of plants, the general umbel of which is roundish and multiple; the partial umbel, while in flower, is perfectly globose; the general involucrum is composed of either three or five leaves; the partial involucrum is small, and composed of eight leaves; the proper perianthium is small and quinquedentate; the general corolla is uniform; the single flowers consist each of five deciduous, lanceolated, and slightly crooked petals; the fruit is naked, roundish, angular, and separable into two parts : the seeds are two, of an oval figure, plain on one side, and convex or striated on the other.

All the sorts may be increased by seeds. The common angelica delights in a moist soil, in which the seeds should be sown soon after they are ripe; and when the plants are about six inches high, they should be transplanted ata large distance, about three feet asunder, on the sides of ditches or pools of water. In the second year they will fower, and their stems may be cut down in May, and heads will be put out from the sides of the roots, and thus they nuay be continued for three or four years; but if they have been permitted to seed, their roots would perish soon after.- The stalks of garden angelica were formerly blanched, and eaten as celery. The young shoots are in great esteem among the Laplanders. In Norway, bread is sometimes inade of the roots. The gardencrs near London, who have ditches of of water in their gardens, propagate great quantities of this plant, which they sell to the confectioners, who make a sweet. meat with the tender stalks cut in May. Bohemia and Spain are supposed to produce the best: the College of London, formerly directed the roots brought from Spain only to be kept in the shops. Lin. 


\section{ANG}

neus, however, assures us, that the plant proves most vigorous on its native northern inountains, and gives a decided preference to the root dug here, either early in the spring or late in the autumn. The roots of angelica arc one of the principal aromatics of Furope an growth, though not much regarled in the present practice. They have a fragrant agreeable smell, and a bitterish pungent taste ; on being chewed they are first sweetish, afterwards acrid, and leave a glowing heat in the mouth and fauces, which continue for some time. The stalk, leaves, and seeds, appear to possess the same qualities, though in an inferior degree. Dr. Lewis says, that on wounding the fresh root early in thespring, it yields, from the inner part of the bark, an unctuous, yellowish, odorous juice, which, gently exsiccated, retains its fragrance, and proves an elegant, aromatic, gummy, resill. Rectified spirit extracts the whole of the virtues of the root; wa. ter but very little; and, in distillation with the latter, a small portion of very pungent essential oil. may be obtained. The Lap. landers extol the utility of angelica, not only as food but as medicine. For coughs, hoarseness, and other disorders of the breast, they eat the stalks, roasted in bot ashes; they also boil the tender flowers in dairy milk, till it attains the consistence of an extract; and they use this to pro. mote perspiration in catarrhal fevers, and to strengthen the stomach in diarrhxa, \&c. According to the explanations of Sir Jolin Pringle, the herb is antiseptic, but the efficacy of the leaves is soon lost by drying them. The seeds also, which come nearest to the roots, can scarce be kept till the spring after they are gathered, without the loss of their vegetative power, as well as a diminution of their medicinal virtue. These are the only parts of the plant which are ordered by the London College, and that only in compound spirit of aniseed. The aromatic quality of the root is more considerable than that of any other part; but many other simples surpass angelica in aromatic and carminative powers; it is sel. dom employed in the present practice. All the parts of the wild angelica are simi. lar in quality to those of the former species, but rather weaker, and the former may be more easily procured. Cows, goats, and swine, eat it, but horses refuse it.

ANGIOP'TERIS, in botany, a genus of the Cryptogamia Filices. Fssen. char. fructification oval, sessile, in a line near the margin of the fiond, approximate in a doul?le row, one celled.

A NGIOSIFRMA, in botany, a term used, by Limnxus, to express the second order of the Didynamiz plants, which have seeds not lodged naked within the cup, as in Gymnospermia, but inclosed in a cipsule, and adhering to a receptacle in the middle of a pericarp. The class of Didynamia contains the labiated and personated plants. 'The Angiosperinia are the personated; the others the labiated kind. In this order many of the corollas are personate, or labiate, with lips closed; some, however, have bell-shaped, wheclshaped, or triangular corollas. To liave seeds inclosed in a pericarp is common to all; and hence the name of the order $\mathrm{An}$ giospermia. This order contains 87 genera.

ANGLE, in geometry, the inclination of two lines meeting one another in a point, and called the legs of the angle. See Grometr.

ANGLING, may be defined the art of catching fish by a rod and line, furnished with a hook and bait, or artificial fly. It is divided into two species principally, fly fishing and bait fishing: the first is perform. ed by the use of artificial flies, which are made to imitate natural flies so exactly, that fish take them with equal eagerness. The second species of angling is cffected by the application to the hook of a variety of worms, grubs, small fish, parts of fish, and a number of other matters, which sball be detailed more particularly:

Fly fishing requires more skill and ad. dress than bait fishing; and the formation of the artificial flies, for it is an art in itselt of so much nicety, that to give any just idea of it, we must devote an article to it particularly. See Fısuise Fuss.

To constitute a good angler, a knowledge of the natural history of the fisli he desires to take is cssentially necessary: without this, he cannot perfectly know the bait most suitable to them at different seasons, and in different situations; which is so far from being obvious, that there are many small rivers which are considered as totally exhausted of their fish, by the generality of anglers, where, however, alew of extraorlinary skill will find good sport, and take many fish of the best kinls.

The tish cauglit by angling in this part of the world are, the salmon, salmon-trout, cod, bull-head, founder, wcak-fisl, seabasse, black-fish, perch, rock, drum, catfisli, ecl, red drum, \&c.

Several of these only inhabit the salt waters, others migrate regularly froin the sea up the rivers tudeposit their eggs, and some are found in the fres! waters only. In the lakes, rivers, and other streams of the interior, are crught rock, perch of dificrent kinds, a salmon trout, gudgeon, carp, chub, roach, redfin, sucker, minnow 


\section{ANGLING.}

(called minny), white and yellow-bellied catfish, cel, sunfish, or old wife, pike, \&.c. \&c. The common and silver minuow, on account of their diminutive size, are used only as bait.

To this list a very large addition might be made, but it would consist of names, like several of the above, often local, and confined exclusirely to a particular state or district, or applied, in different parts of the country, to fish in every respect unlike each other. This vague nomenclature is a source of constant error, and obviously in. dicates the conrenience, and even neces. sity, of an universal language, such as scientific natural history presents us with.

Baits for fish are principally natural; a few artificial ones are used, chiefly in fishing for pike and perch, made to imitate small fish, frogs, \&c. The natural baits are whatever is commonly eaten by fish, as worms, maggots, grubs, caterpillars, snails, small fish, frogs, roe of fish, beetles, butterflies, moths, wasps, grasshoppers. Vegetable baits are sometimes used, as beans, wheat, barlcy, and peas, which last are best when green, and slightly boiled; paste made of dough, bread, or flour, mixed with oil, and a little cotton to unite it together, also forms bait. It is generally best to colour it red, particularly for smelts.

Maggots are best procured by hanging up a bullock's liver, scarified pretty deeply all over, covered loosely, so as to admit flies. In two or three days, living maggots will appear on it, when it should be taken down and put into a pan, till the gentles attain their full size; a sufficient quantity of fine sand and bran is then to be put over the liver in the pan ; and the maggots will in a few days come into it and scour themselves, which renders them tough, clean, and fit to be halldled. Those produeed in autumn will continue in that state all the winter, if they can get just under the surface of the earth. In the spring, as the weather becomes warm, they change into flies.

The cadbate is a very excellent bait. This is an imperfect insect, resembling a worm, inclosed in a tube formed of agglutinated pebbles, out of which the head and six feet arc protruded when in motion; it is the larva of the genus Pliryga nea, and is to be found in great plenty in gravelly and stony rivulets; and by the sicle of streams in large rivers among stones; when you want them, turn up the stones, and you will find the best sticking to theri. When a sufficient quantity of them are procired, hang them up in a linen bag, and dip them, in the bag, once. a day into water, for four or five days. They will then turn yellow, and become tough and fit for use, being much better than when they first came out of the water.

The lob, or dew worm, is found in gardens anrl pastures, late in summer evenings, by using a lanthorn and candle. They are also dug up in fields, and by the sides of drains and ditches. To scour and preserve them for use, take some moss, dip it into clean water, wring it dry, put half of it into an earthen pot, then put in the worms, and the rest of the moss at top; cover it close, that they may not get out, and keep it in a cool place in summer, and in a warmer in winter; the moss should. be changed every fifth or sixth day. In a week the worms will be fit for use. These directions will also answer for other species of worms.

Brandlings, red-worms, and gilt-heads, are found in the same dunghills together, which consists of hogs' dung, horses' dung, and rotten earth. But the worms which are found in tanner's bark, after it has been used and become quite rotten, are the best of all; but they are generally better for angling without any scouring.

Long white worms, found chiefly in turnip fields, are good bait, especially in muddy water. They are preserved best in some of their own earth, kept damp, with some moss over it.

Marsh worms, found in marshy grounds and rich banks of rivers.

The red worms, found in cow dung, and dock worms, found about the roots of docks, flags, and sedges, are all good bait. As are likewise the grubs found in cow dung, called cow-dung bobs, which are of a yellowish white, with red heads, and the short bobs, or grubs, found in mellow sandy land, which have pale red heads, yellowish tails, and bodies of the colour of the earth wherein they are found, but which when scoured are of a pale white. These last are an excellent winter bait ; the best way to render them tough is, to put them into boiling milk, for about two minutes, on the morning which they are to be used.

Caterpillars, found by beating the branches of oaks, and other trees, that grow over highways, paths, and open places, and the cabbage grubs found on and in the hearts of cabbages, are also excel. lent bait; these last are to be fed, and preserred, with the same kind of leaves on which they are found. Shad-roe is likewise a good bait; but the numerous pastes 


\section{ANGLING.}

and oils, which many have preseribed for enticing fish to bite, are, in the opinion of the most experienced anglers, only idle climaras.

Worms are best put on hooks, by running the hooks in at the head of one worm, and out about his middle, drawing it up over the shank, and putting on a second worm benesth the first, in the micl. dle of whose body the point of the hook is to be concealed; the tails of both worms hanging loose will entice the fish.

Ground bait is often used with good effect, particularly for barbel and for perch. It should be a general rule, that the ground bait should be always inferior to that which is used on the hook ; greaves therefore should not be used, as is cus. tomary with some; but for this purpose, malt grains, bran, blood, parts of lobworms, and clay, all worked up together and made into small balls, is the most proper composition; and two or three of these balls, thrown into the place where you desire to fish, is sufficient at a time. This may be repeated now and then, but much should not be used, for if this should be done, the fish will glut themselves, and become less eager for the bait on the hook.

A good ground bait is made for perch, by taking three or four balls of the stiffest clay that can be procured, making lioles in them, putting one end of a lob-worm into cach hole, and closing the clay fast on them. These balls should then be thrown into the water, about a yaurl from each other, when the worms, being alive in the balls, will more and twist about, which tempts the fish to feed upon them. But by angling with worms of a superior kind, the fish will on sight of them leave those in the clay, and seize the others with the greatest avidity.

The tackle necessary for angling consists of fishing rods, lines, links of huir, and of other materials usual; hooks, floats, spare-caps, split shot, bait of different sorts, including ground bait, shoemakers' wax, twine, silk, a cleamng ring, which being passed over the rod, when the hook is entangled, and drawn down the line by a strong twine attached to it for the purpose, to the look or below it, if the obstruction is caused by weeds, will either free the hook or break the line near it, and prevent its being strained in any other place, by pulling the twine witl sufficient force. A landing net is also useful to land large fish: and a gaff, when fishing for salmon, to be used for the same pur-

VOL. I. pose; which instrument consists of a large hook attached to the end of a pliable stick; by passing the hook into the nose or gills of the fish, it may be casily lifted out of the water, for which purpose a landing net is too small. A disgorger is also neccssary, to put down the throat of a fish, when he has gorged the look, till you touch it, when on pulling the line it will be free. The disgorger is formed by a piece of flat wood, about six inches long, and half an inch wide, forked at the encls. T" these articles a fish-basket should be added, to carry the fish in.

Fishing rods are made of various lengths, according to the sort of fish they are intended for; those for salmon are abont 18 feet long, those for trout 14 or 15 feet, those for pike the same as for salmon; and for other fish, either the trout or the salmon, rods may be used accorling to their size and strength. All rods should be made to taper evenly from the buts; and when not formed of pieces of the natural growth, which should al. ways consist of ground shoots, they should be macle of cleft timber, as sawed pieces can never be depended on. Ash, or hickory are best for the lower joints, yew for the next, and the extremity of the top should always consist of whalebone; the fewer joints used in the rod the more equal will be its elasticity in every part : some have the joints formed with screw ferules, and some with sliding connections retained by plain ferules; but none are better for the elasticity of the rod, and for security, than simple spliced joints, secured by well waxed twine; some recommend those latter joints to be previously glued together, before the waxed twine is applied, with give prepared with strong lime water: but it is obvious that the wet to which rods are exposed must render glue of little nse : thick white paint, or some of the varnish hereafter mentioned, wulld probably cement the pieces togecher more durably. Whaterer may be the number of permanent joints, the loig rorls need not be made to separatc into more than three long pieces, and 2 sliort top; and the short rods into two pieces, and a short top; the lower joint of trout rods should be bored hollow, to contain a second top; for every trout rod should have two tops male for it; one very pliable for fly fishing, and the other stiffer for bait; the top not in use will be conveniently and safely kept in the hol. low but. The rod should be furnished with rings for the line to pass through, from the top to within two feet of tae 


\section{ANGLING.}

reel ; and when it is completed, it should be well rarnished over with a varnish form. ed by boiling a little scraped Indian rub. ber, or coutchouc, in half a pint of drying linseed oil till it dissolves: the varnish should be skimmed, and be used warm. The rod, after being varnished, should be laid aside till quite dry ; the varnish will then appear on it like a fine thin bark, will be very durable, and will preserve it from being worm eaten, and from other injuries. The hollow part of the rod should be rubbed inside with linseed oil, three or four times each year, which may be done by a rag dipped in the oil, and tied to the end of a stick.

Hair lines should be long, round, clear, and free from knots, frets, or scales. For fly fishing, a line should be prepared from nine to twelve yards long, gradually tapering to the extremity. It is formed of a number of links of hair, twisted first, and then knotted to each other. The four lowest links consist of three hairs each, with the weak tops cut off all of a length; the next four links have four hairs each; the third four links five hairs; and so on till the line is completed. The links are to be knotted together with the fisherinan's or water-knot; the short ends of the hairs are to be cut off pretty close to the knots, and the knots to be whipped over with well-waxed silk. A loop should be made at each end of this line : the upper loop to fasten it to the end of the running line at the top of the rod, and the lower loop to fasten the lower links to, which should never consist of more than two or three, of either gut or hair, for fly or bottom fishing.

The best culours for lines are pale bluish, green, or watery grey, and light bay.

Running hair lines, or those all of one thickness, are made on engines prepared and sold at the fishing-tackleshops. They may likewise be made by passing bairs through three short tubes made of quills or reeds, secured by pegs at the lower ends. The hairs are to be knotted together at the top, and the quills being then turned round all together between the fingers, will form an equal twist above them ; which being drawn out, according as the quills are tumed round, make the line, fresh bairs being still put into the quills at the lower ends as the upper hairs are worked into the line.

The most excellent hooks are those made of the best tempered fine steel wire, longish in the shanks, and strong and rather deepish in the bend; the barbs well formed, and the point fine and straight, and as true as it can be set to be level with the shank, which last for fly fishing should be tapered off to the end of it, that the fly may be finished the neater. Hooks made in this manner, so as tolie all in one plane, are much better than twisted so as to project at one side: they do not make so large an orifice when the fish is hooked, nor are they so liable to break the hold as the others. The two kinds being fairly tried against each other for several sea. sons, considerably more fish were missed in the rising, and in biting at the bottom, and much more lost after being hooked witl the crooked hooks, than with those above recommended. The best hooks of the kind are made in limerick.

Floats for angling are made of many kinds, as of swan quills, goose quills, Muscory duck quills, and porcupine quills. The first is the best, when light baits are used in rivers or deep waters, and the others for slow water, or ponds not very deep. For beavy fishing, with worms or minnows, a cork float is best, made of a pyramidical form, with a quill placed in it lengthways for the line to pass through. Quill floats must carry shot enough to sink them, so as that the top may appear abore water, that the slightest nibble may be better perceived. The cork floats should have sufficient shot placed beneath them on the line, to make them stand upright when the shot is off the bottom, by which it may be known when the shot is on the ground; for then the float will fall on one side, and no longer stand upright.

Angling has been divided, by those who have written on the subject, into many other kinds besides those mentioned. Of these, float angling and ground angling may be easily understood from what has been mentioned already. Nightangling is performed nearly in the same way as day angling; but in it the larger and more conspicuous bait, such as garden worms, snails, and minnows, are best. Some lay long lines in rivers at night, with short lines, furnished with hooks attached to them at certain intervals; and some use lines fastened to floats of various sorts; but these modes of fishing can scarcely be called angling, properly speaking. The largest and finest fish are often caught by these methods.

Sea angling has nothing particular in it, but that small parts of fish, clams or crabs, are mostly used in it for bait. The same fish may be caught at the heads of piers and the mouths of rivers, and by the same bait as at sea, therefore fishing in such placess is classed with sea angling:

Lastly, trimmer angling is a species of 


\section{ANG}

float angling. The float consists of a round piece of cork, six inches in diameter, with a groove cut at itsedge, in which the line is coiled, except so much next the hook as to allow it to hang in mid-water, and so much at the other end as will reach to the bank. When a fish takes the bait, and runs with it, the line unwinds off the trimmer without giving any check ; but it will be prudent to give a slight jerk, to secure the fish when you come to take up the line. This method is very successful in canals, large ponds, or other still water.

Before concluding this article it will be proper to notice, that the weather has much influence on fish. When the wind is in some points few fish will bite; the most unfavourable is the eastern quarter. A warm lowering day, with flying showers, and a slight ripple on the water, is the most favourable. Water slightly disturbed prerents fisl from seeing the tackle, and in it they take the bait most readily. Hence, whaterer tends to disturb it so is to hide the line, witlout totally obscuring the bait, is of advantage. In waters affected by the tide, the flood is the best time for angling; but the ebb should not be neglected. Whirlpools, eddies, mill-tails, sides of bridges, and beneath their arches, are places where fish more readily bite, chiefly for the above reason; and in general a certain degrec of darkness in the water, whether occasioned by the shade of buildings, rocks, or other bodies, or calsed by the agitation of its surface, or by mudily streans fowing into it, is far ourable to angling.

The proper season for fishing is in general from the beginning of spring to the end of autumin; but this deperids much on the nature of the fish angled for: some may be cainght at all times; others, as those of passuge, are only to be met with at particular seasony ; and others, though always confined to one piece of water, are nearly torpial during the winter, and are found only in deep places.-See Tay. lor's Angling.

ANGUIS, in natural history, the 8loroworm, a genus of serpents : the generic character is, scales both on the abdomen and beneath the tail. There are, accorring to Gmelin, 26 species. This genus is easily distinguishec, by having the abdomen and under part of the tail corered with scales of a sinilar appearance to those on the rest of the animal, except that in some few instances they are rather larger. The body is of a sliorter and more uniformly cylindric form than in the genus Coluber: the eyes are in general small, and the tail rather obtuse. No poi-
ANG

sonous species of anguis has yet been discovered. Afragilis, or common slow-worm, is found in almost all parts of Europe, in similar situations with the common snake, and is a perfectly innoxious animal, living on worms and insects. It is about 10 or 12 inches long : the tail measures more than half the length of the animal, and terminates pretty suddenly in a slightly acuminated tip. The slow-worm is a viviparous animal, and produces occasionally a numerous offspring: like other serpents, it varies in intensity of colours at different periods, and the young are commonly of a deeper cast than the parent animal. The general motions of the slow-worm are tardy, except when endearouring to make its escape : it can, howerér, occasionally exert a considerable degree of swiftness, and can readily penetrate the loose soil in order to conceal itgelf from pursuit. They are often found in considerable numbers during winter, at soine depth beneath the surface, and lying in a sate of torpiditr, and again emerging from their concealmeists on the apprasch of spring, when they cast their skin, and recorer their fornier liveliness. If strick with riolence, the body of this animatl will break into pieces. A. corallina, or coral slow-worm, is a very elegant species, sbout 18 inches long, and of a considerable thickness : the scales are moderatcly large, and the head and tailare remarkably obtuse. It is a native of South-Amcrica, where it is found in woods, and to prey on the larger insects, as the scolopendrie, \&c.: in colour it sometimes varies, a mixture of black being blended with the red on the sides. (See Plate I. Serpentes, fig. 3.) A.ventralis, or glass slow-worm, is a handsome species, about two feet long : it is a native of North-America ; body ashy-green, striate ; lateral band black; belly short, apparently joined by a hollow suture; tail verticiliate, three timos as long as the bo. $d y$; it takes its name from the circum. stance of breaking to pieces in two or three places with a small blow of a stick, the muscles being articulated quite through the vertebrz. A. Jamaicens's, or Jamaica slow-worm, found in Jamaica about the roots of decayed trees, near ants' nests, \&c. and though it has generully been deemed poisonous, vet it is really innocuous; its colour is an uniform pale brown, with a kind of silvery gloss on the scales, which are rery sinooth.

ANGUI.AR motion, in mechanics and astronomy, is a motion of a body which describes an angle, or which moves circularly round a point. 'Tlus a pendulum has an angular motion about its centre of 
motion, and the planets have an angular motion about the sun. The angular motions of revolving bodies, as of the planets about the sun, are reciprocally proportional to their periodic times; and they arc also as thcir real or absolute motions directly, and as their radii of motion inversely.

Angular motion is also composed of a right-lined and circular motion, or in which the moveable body slides and revolves at the same time : such is the motion of a coach-wheel.

ANGURLA, in botany, a genus of the Monoecia Diandria class and order; calyx five-cleft ; corolla five-petalled; pome inferior, two-culled, many-seeded.

ANHYDRILE, in mineralogy, one of the sulphate family, found at Salz on the Neckar, in Wirtemberg. Colour smalt blue, which passes into a milk white. Massive : not very britlle. Specific gravity 2.94. It differs from cube spar in colour, fracture, shape of fragments, and in having a higher specific gravity.

ANIGOZANTHUS, in botany, a genus of the Hexandria Moringynia class and order : corolla six parted, with unequal incurved segments : staminainserted in the throat of the corolla: capsule three-celled, many-seeded. There is only a single species; a nativé of New Holland. The stem is leafy, covered at the top with reddish hairs, leaves linear: flowers umbelled: corolla clothed with reddish hairs.

ANLMAL, in natural history, an organised and living body, endowed with the powers of sensation, and of spontane. ous loco-motion. Some have defined animals, from their loco-motion, as being capable of shifting from place to place, whereas plants adhere to the same subject. This property they assume, as the great characteristic by which animals may be distinguished from the other orders of beings. On this principle, howerer, oysters, barnacles, and many zoophytes, would be almost excluded from the class of animals, inasmuch as they usually adhere or grow to rocks, \&c. and yet it is certain that these creatures are real animals. But loco-motion alone is not sufficient to constitute the generic difference of animals ; nor, indeed, does it sufficiently distinguish an animal from a plant. Many instances are produced in which plants manifest loco-motive power. This is the case with those denominated sensitive plants, many of which, upon the slightest touch, shrink back and fold up their leaves; as the snail in the slightest couch retires into its shell. There are some, on which if a fly perches, instantiy close and crush the insect to death. Plants also change their position and form in different circumstances and seasons: they take advantage of good weather, and guard themselves against bad weather; they open their leaves and flowers in the day, and close them at night; some close before sun-set, and some after; some open to receive rain, and some close to avoid it; some follow the sun, and some turn fromit; the leaves of some plants are in constant motion during the day, and at night they sink to a kind of rest or sleep. It has also been observed, that a plant has a power of direeting its roots for procuring food; and that it has a faculty of recovering its natural position after it has been forced from it. A hopplant, for instance, in twisting round a pole, directs its course from south to west, as the sun does; if it be tied in the opposite direction it dies; but if it be left loose in this direction, it will regain its natural course in a single night. $\mathbf{A}$ honeysuckle proceeds in a certain direction, till it be too long to sustain itself; it then acquires strength by shooting into a spiral form; and if it meet with another plant of the same kind, both these coalesce for mutual support, one twisting to the right and the other to the left. There are other instances in which plants manifest a ficulty of loco-motion; and, perbaps, in alinost as eminent a degree as some animals. Oysters, $e . g$. are fixed to one place as much as plants, nor have they any power of motion, besides that of opening and sluutting their shells; nor do they seem, in this respect, to have any superiority, with regard to the powers of motion, to the sensitive plant, and others of a similar kind. In order, therefore, to form a complete and satisfactory distinction between animals and vegetables, as well as minerals, it is necessary to com. bine with spontaneous locp-motion, which they unquestionably possess in a more perfect degree than plants, the powers of sensation. These seem to be unexceptionably distinguishing and characteristic. Howerer, M. Buffon, after allowing that, although progressive motion constitute a perceptible difference between an animal and a vegetable, this distinction is neither general nor essential, proceeds to state, that sensation morc essentially distinguish. es animals from vegetables. But he adds, that this distinction is neither sufficiently general nor decided. If sensation, he says, implied no more than motion consequent upon a stroke or impulse, the sensitive 


\section{ANIMAL.}

plant enjoys this power; whereas, if by sensation we mean the faculty of perceiving, and of comparing ideas, it is uncertain whether brute animals are endowed with this faculty. If itshould be allowed to dogs, elcphants, \&c. whose actions secm to proceed from motives similar to those by which men are actuated, it must be denied to many species of animals, particularly to those that appear not to possess the faculty of progressive motion. If the sensation of an oyster, e. g. differ in degree only from that of a dog; why do we not ascribe the same sensation to vegetables, though in a degree still inferior? In examining the distinction which arises from the manner of feeding, he observes, that animals have organs of apprehension, by which they lay hold of their food: they scarch for pasture, and have a choice in their aliment. But, it is alleged, that plants are under the necessity of receiving such nourishment as the soil affords them, without exerting any choice in the species of their food, or in the manner of acquiring it. However, if we attend to the organization and action of the roots and leaves, we shall soon be convinced that these are the external organs, by which vegetables are enabled to extract their food; that the roots turn aside from a rein of bad earth, or from any obstacle which they meet with in search of a better soil; and that they split and separate their fibres in different directions, and even change their form, in onder to procure nourishment to the plant. From this investigation, he concludes that there is no absolute and es. sential distinction between the animal and vegetable kingdoms; but that naturc proceeds by imperceptible degrees, from the most perfect to the most imperfect animal, and from that to the vegetable ; and that the fresh water polypus may be re. garcled as the last of animals, and the first of plants. After examining the distinc. tions, this anthor proceeds to state the resemblances which take place between aninals and vegetables. The power of reproduction, lie says, is common to the two kingdoms, and is an analogy both universal and essential. A second resemblance may be derived from the expansion of their parts, which is likewise a common property, for vegetables grow as well as animals; and though some difference in the manner of expansion may be remarked, it is neither gencral nor essential. $A$ thirrl resemblance results from the manner of their propagation. Sume animals, be says, are propagated in the same manner, and by the same means, as vegetables. The multiplication of the sacceron or vine-fritter, (see Aphis) which is, he observes, effected without copulation, is similar to that of plants by seed; and the multiplication of the polypus by cuttings resembles that of plants by slips. Hence it is inferred that animals and vegetables are beings of the same order, and that nature passes from the one to the other by imperceptible degrees ; since the propertics in which they resemble one another are universal and essential; while those by which they are distinguished are limited and partial. Dr. Watson, Bishop of Landaff, has examined, with his usual judgment, the distinguishing marks between animals and regetables. He rejects, as insufficient, both figure and spontaneous motion; and if perecption be substituted in their stead, it will be found to be a criterion that is, in many respects, liable to exceptions. However, the ingenious and learned prelate produces many chemical, physical, and me. taphysical reasons, which serve to render the supposition not altogether indefensible, that vegetables are endowed with the faculty of perception. Dr. Percival, likewisc, in a paper read before thic Literary and Philosophical Society of Manchester, produces several arguments to evince the perceptive power of vegetables. From the reasoning adduced by both these ingenious writers, of which 2 more particular account will be given in the sequel of this work (see PLAXTs and Vergtakiss); those who duly advert to it will, we conceive, incline to the opinion, that plants are not altogether cestitute of perception. But on a question that has perplexed and divicled the most ingenious and inquisitive naturalists, it is very difficult to decide. If we extend to the vegetable kingdom tliat kind of vitality with which sensstion and enjoyment are connected, there will remain no dis. cernible boundary between this and the animal kingdom; and that which has been considered as the distinctive charac. teristic of animals, and by whicl they are separated from vegetables, will be abolish. ed. We shall now add, that the principle of self-preservation belongs to all animals; and it has been argued, that this principle is the tme cliaracteristic of anjinal life, and that it is unquestionably a consequence of sensation. There is $n$ animal, when apprehensive of danger, that does not put itsclf into a posture of defence. - A muscle, when it is touched, immediatcly shuts its shell; and as this 


\section{ANIMAL.}

action puts it into a state of defence, it is ascribed to a principle of self-preservation. Those who adopt this reasoning allege that vegetables do not manifest this principle. When the sensitive plant, for instance, contracts from a touch, it is no more in a state of defence than before, for whatever would have destroyed it in its expanded state, will also destroy it in its contracted state. They add, that the motion of the sensitive plant proceeds only from a certain property called irritability; and which, though possessed by our bodies in an eminent de rec, is a characterisic neither of animal or vegetable life, but belongs to us in common with brute matter. The scnsitive plant, after it has contracted, will suffer itself to be cut in pieces, without making the least effort to escape. This is not the case with the meanest animal. An hedgehog, when alarmed, draws its body together, and expands its prickles, thus putting itself in a posture of defence : when thrown into the water, the same principle of self-preservation prompts it to expand its body and swim. A snail, when touched, withclraws itself into its shell; but if a little quick-lime be sprinkled upon it so that its shell is no longer a place of safety, it is thrown into agonies, and endeavours to avail itself of its loco-nuotive power, in order to escape that danger. Muscles and oysters, also, though they have not the power of progressive motion, constantly use the means which nature has given them for self-preservation. We, ourselics, possess both the animal and vegetable life, and ought to know whether there be any connection between vegetation and sensation, or not. We are conscious that we exist, that we hear, sce, \&c. but of our vegetation we are absolutely unconscious. We feel a pleasure in gratifying the demands of hunger and thirst ; but we are totally ignorant of the process by which our aliment is formed into chyle, the cliyle mixed with the blood, the circulation of that fluid, and the separation of all the humours from it. If we, then, who are more perfect than other vegetables, are utterly insensible of our own vegetable life, why should we ima. gine that the less perfect vegetables are sensible of it ? We have witlin ourselves a demonstration, that vegetable life acts without knowing what it does; and if ve. getables are ignorant of their most sagacious actions, why should we suppose that they have any sensation of their inferior ones; such as contracting from a touch, turning towards the sun, or advancing to a pole? As to that power of irritability which is observed in some plants, our solids liave it, when deprived both of animal and vegetable life; tor a muscle, cut out of a living body, will continue to contract, if it be irritated by pricking, after it has neither sensation nor vegetation. Encycl. Brit. On the other hand, those who are of opinion that plants possess powers of perception, allege that tireir liypothe. sis reconmends itself by its consonance to those higher analogies of nature, which lead us to conclude that the greatest possible sum of happiness exists in the uni. verse. The bottom of the ocean is overspread with plants of the most luxuriant magnitude; and immense regions of the earth are overspread with perennial fo. rests. Nor are the Alps or the Andes destitute of herbage, tlough buried in depths of snow ; and can it be imagined that such profusion of life subsists without the least seusation or enjoyment? Let us rather, with humble reverence, suppose that regetables participate, in some low degree, of the common allotment of vitality ; and that one great Creator hath appointed good to all living things, in number, weight, and measure.

Aximal flower, a name given to a variety of creatures of the Vermes tribe, that bear some resemblance to a flower. These, for the most part, belong to the order Molluscr ; the name is, however, frequently given to a different order, viz. the Zoophytes.

Aximal mamere, in agriculture, are all substances that are formed from the decomposition of animal substances of any kind; as the muscles, blood, hair, wool, bones, fit, \&c. 'These are generally esteemed as more powerful, in promoting vegetation, than such as are derived from vegetable matters. On account, however, of their being but seldom procured in large quantities, they are generaliy made use of in the state of mixture or combination with other materials. By the action of ammonia, which is constantly formed during the decomposition of animal substances, the mould is made more suitable for plants.

Axisal, parts of, substances which compose the bodies of animals may be arranged under the following heads:

1. Bones and Shells

2. Horns and Nails

3. Muscles

4. Skin

5. Membranes

6. Tendons and ligaments 


\section{ANI}

\section{Glands}

8. Irain and nerves

9. Hair and feathers

10. Silk and similar bodies.

Besides these substances, which constitute the solid part of the bodies of animals, there are a number of fluids, the most important of wlich is the blood, which pervades every part of the system in all the larger animals: the rest are known by the name of secretions, because they are formed, or secreted, as the anatonists term it, from the blood. The principal animal secretions are the following :
1. Milk
2. Eggs
3. Salive
4. Pancreatic juice
5. Bile
6. Cerumen
7. Tears
8. Liquor of the pericardium
9. Humours of the eye
10. Mucus of the nose, \&c.
11. Sinovia
12. Semen
13. Liquor of the amnios
14. Poisonous secretions.

Various substances are separated cither from the blood or the food, on purpose to be afferwards thrown out of the body as useless or lurtful. These are called excretions. The most important of them arc,

\section{Urine \\ 2. Frecs.}

Besides the liquids which are secreted for the different purposes of healthy animals, there are others which make their appearance only during disease, and which may therefore be called morbid se. cretions. The most important of these are the following :

1. I'ils

2. The liquor of dropsy

3. The liquor of blisters.

To these we must add several solid bodies, which are occasionally formed in different cavities, in consequence of the diseased action of the parts. They may be called morbid concretions. The most remarkable of them are the following:

1. Salivary calculi

2. Concretions in the lungs, liver, brain, \&c.

3. Intestinal calculi

\section{ANI}

4. Biliary calculi

5. Urinary calculi

6. Gouty calculi.

Arimat substances, or those which have hitherto been detected in the animal kingdom, and of whicl the different parts of animals, as far as these bave been analysed, are found to be cumposed, may bc arranged under the following heads :
1. Gelatine
2. Albumen
3. Mucus
4. Fibrin
5. Urea
6. Saccharine mattex
7. Oils
8. Resins
9. Sulphur
10. Phosphorus
11. Acids
12. Alkalies
13. Earths
14. Metals.

See the several articles in theiralphabeti. cal order.

Aximat, functions of. Sec Assimultoz, Diazstoz, Penspination, RespiRATION, \&c.

Arimals, generation of. See the article Gesenatiox.

Aximals, in lieraldry, are much used, both as bearings and supporters. It is to be observed, that in blazoning; animals must be interpreted in the best sense, and so as to redound to the greatest 110 . nour of the bearers. For example, the fox being renowned for wit, and likewise given to filching for his prey ; if this be the charge of an escutcheon, we must conceire the quality represented to be his wit, and not his theft. All beasts must be figured in their most noble action; as a lion rampant, a leopard or wolf passant, a lorse running or vaulting, a greyhound coursing, a deer tripping, and a lamb going with a smooth pace. In like manner. every animal must be moving and looking to the right side of the shield, the right foot being placed foremost. These are the precepts given by Guillim, and yet we find that there are lions passant, couchant, and dormant, as well as rampant.

ANIMALCULF, an animal so minute in its size, as not to be the inmediatc object of our senses:

Animalcules are usually divided into two distinct sections, risible, and microscopical. The first, though visible, cannot be accurately discerned without the belp of glasses: the second are discover- 


\section{ANIMALCULE.}

able only by the microscope. Some have supposed there are others invisible. 'The existence of these cannot well be disputed, though it cannot be asserted, unless we conclude that the microscope has not yet arrived at its highest degree of perfection. Reason and analogy give some support to the conjectures of naturalists in this re. spect : animalcules are discerned of various sizes, from those which are visible to the naked eye, to such as appear only like moving points under the microscopic lenses of the greatest powers; and it is not unreasonable to imagine, therefore, that there are others, which may still resist the action of the microscope, as the lised stars do that of the telescope, with the greatest powcrs hitherto invented.

Animalcules, visible; amongst these are included an amuzing variety of creatures, by no means of analogous natures. Those numerous creatures which crowd the watcr in the summer munths, changing it sometimes of a deep or pale red colour, greell, yellow, \&c. are of this description. The large kiuds are chiefly of the insect, or vermes tribes, and of which the monoculus pulex is particularly remarkable, being found sometimes in such abundance, as to change the water apparently to a deep red. A similar appearance is likewise occasioned by the circaria mutabilis, when it varics in colour from green to red; vorticella fasciculata also changes it to green; and rotutoria to yellow. To this section we must also refer many of the acarus and hydrachna genera, and a multitude of other creatures that will be noticed hereafter.

Animalcules, microscopical. The microscope discovers legions of animalcules in most liquors, as water, vinegar, beer, dew, \&c. They are also found in rain and several chalybeate waters, and in infusions of both animal and vegetable substances, as the seminal fluids of animals, pepper, oats, wheat, and other grain, tea, \&cc. \&cc. The contemplation of animalcules has made the ideas of infinitely small bodies extremely familiar to us. A mite was anciently thought the limit of littleness; but we are not now surprised to be told of animals twenty-seven mil. lions of times smaller than a mite. Minute animals are found proportionably much stronger, more active and vivacions, than large ones. The spring of a flea in its leap, how vastly docs it outstrip any thing greater animals are capable of! i mite, how vastly faster does it run than a race-horse! M. de l'Isle has given the computation of the velocity of a little creature, scarcely visible by its smallness, which he found to run three inches in half a second: supposing now its feet to be the fifteenth part of a line, it must make five hundred steps in the space of three inches; that is, it must shift its legs five bundred times in a second, or in the ordinary pulsation of an artery. The excessive minuteness of microscopical animalcules conceals them from the human eye. One of the wonders of modern philosophy is, to have invented means for bringing creatures, to us so imperceptible, under our cognizance and inspection : an object a thousand times too little to be able to affect our sense should seem to have been very safe. Yet we have extended our views over animals, to whom these would be mountains. In reality, most of our microscopical animaicules are of so small a magnitude, that through a lens, whose focal distance is the tenth part of an inch, they only appear as so many points ; that is, their parts cannot be distinguished, so that thcy appear from the vertex of that lens under an angle not exceeding a minute. If we investigate the magnitude of such an object, it will be found nearly equal to $\frac{3}{0 \pi \delta}$ of an inch long. Supposing, therefore, these animalcules of a cubic figure, that is, of the same length, breadth, and thickness, their magnitude would be expressed by the cube of the fraction $\frac{3}{100 \delta \gamma}$, that is, by the number $\overline{1000,000}, 000,000,000$, that is, so many parts of a cubic inch is each animalcule equal to. Leeuwe nhoeck calculates, that a thousand millions of animalcula, which are discovered in common water, are not altogether so large as a grain of sand. This author, upon examining the male sperm of various animals, discovered in many infinite numbers of animalcula not larger than those above mentioned. In the milt of a single codfish there are more animals than there are, visible to the naked eye, upon the whole earth; for a grain of sand is bigger than four millions of them. The white matter that sticks to the teeth also abounds with animalcules of various figures, to which vinegar is fatal ; and it is known that vinegar contains animalcules in the shape of eels. In short, according to this author, there is scarcely any thing which corrupts without producing foorl to myriads of animalcules. Animalcules are said to be the cause of varions disorders. The itch is known to be a disorder arising from the irritation of a species of acarus, or tick, found in the pustules of that ailment : when the com- 
munication of it hy coulact from one to another is easily conceived, as also the reason of the cure being effected by cutaneous applications. In the Philosophical Trunsactions, vol. lix., is a curious account of the animulcules prodisced from an $i n-$ fusion of potatoes, and another of hempsecl, by the late Mr. Fillis. "On the 25th of May, 1768, Fahrenheit's thernometer. $70^{\circ}$, I boiled a potatoe in tlie New River water, till it was reduced to a mealy consisleuce. I put part of it, with as equal proportion of the boiling liquor, into a cyfinrlical glass vessel, that held something less than half a wine-pint, and covered it close immeclintely with a glass cover. At the same time I sliced an unboiled potatoe, aucl, as near as I could judge, put the same quantity into a glass vessel of the same kind. with the same proportion of New River water not boiled, and corered with a glass cover, and placed botl vessels close to eacli other." "On the 26 th of May, 24 hours afterwarls, I examined a small drop of each by the first magnifier of Wilson's microscope, whose focal distance is reckoned at 1.50 th part of an inch; and, to my amazement, they were both full of animalcula, of a linear shape, very distinguishable, moving to and fro with great celerity, so that there apfeared to be more particles of animal than vegetable life in cach clrop." "This cxperiment I have repeatedly tried, and alvays found it to succeed in proportion to the heat of the circumambient air; so that even in winter, if the liquors are kept properly warm, at least in two or three days the experiment will succeed." "I procured hemp-seed from different seedsmen in different parts of the town. Some of it I put into the New River water, some into clistilled water, and some into very hard pump-water. The result was, that in proportion to the heat of the weather, or warm th in which they were kept, there was an appearance of millions of minute animalcula in all the infusions; and, sone time after, oval ones marle tlicir appearance. Thesc wcre much larger than the first, which still continued: these wrig. gled to and fro in an undulatory motion, turning themselres round very quick all the time they moved forwards.

ANIME, a resin olntained from the hy. menar courbaril, or locust trec, which is a native of North-America. It resembles copal very much in its appcarance, but is readily soluble in alcohol, which copal is not. It is used as a varnish. Alcolool dissolves it completcly; and distilled over, rOL. I. it acquires botl the smell and taste of anime.

ANNAI.S, in matters of literiture, a species of history, wlich relates events in the clironological order wherein they happened. They differ from perfect history in this, that annals are a barc relation of what passes cvery year, as a journal is of what passes every day; whereas history relates not only the transactions themselves, but also the causes, motives, and springs of actions. Annals require nothing but brevity, history demands ornament. Cicero informs us of the origin of annals : to preserve the memory of events, the pontifex maximus, says he, wrote what passed each year, and exposed it on tablets in his own house, where every one was at liberty to read: this they called annales maximi; and lence the writers who imitated this simple method of narra. ting facts were called annalists.

ANNATES, amoug ecclesiastical writers, a year's income of a spiritual living. These were, in ancient times, given to the pope throughout all Christendom, upon the decease of any bishop, abbot, or parish.clerk, and were paid by his successor. In England, the pope clained them first of such foreigners as he conferred benefices upon, by way of provision; hut afterwards they were deinanicul of all other clerks, on their admission to bencfices. At the reformation they were taken from the popc, and vested in the king; and, funally, queen Anne restored them to the church, by appropriating them to the augmentation of poor liviugs.

ANNEALING, or Nralive, the burning or baking glass, earthen-warc, \&c. in an oven or furnace. Sce Guass.

ANNOTATION, in matters of literature, a bricf commentary, or remark upon a book or writing, in order to clear up some passage, or draw some conclusion from it: thus the critics of the last age luave made leamed aunotations upon all the classics.

ANNOTTO, in commerec, a kind of red dye, brought from the West-Indies. This is otherwise clenominated amatto. It is procured from the pulp of the seed capsules of a shrub called achiotte and urucu; the bixa orellana of Linnaus, which grows seven or eight feet high, and produces oblong hairy pods, somewhat re. semliling those of a chesnut. Within each of these are thirty or forty irregularly figured secds, which are enveloped in a pulp of a bright red colour and unpleasant smell, somewhit resemlding the paint ll li 
called red lead when mixed up with oil; and it was used as paint by some of the Indians, in the same manner as woad was used by the ancient Britons. The seeds, together witl the red tough matter that surounds them, are softened in a wooden trough with water, until, by a kind of fermentation, which spreads a very nauseous smell, and by diligent stirring and pounding, the kernels are separated from the pulp. This mass is then strained through a scive, and boiled; and upon which a thick reddish scum, which is the pigment, separates. When skimmed off, it is carefully inspissated in another kettle; and after being repeatedly cool, is moulded in roundish lumps, wrapt round with leaves of trees, and packed for sale. It scems to partake of the nature of vegetable albuminous matter. The method of extracting the pulp, and preparing it for market, is simply by boiling the seeds in clear water, till they are perfectly cxtricated; after which the seeds are taken out, and the water left undisturbed for the pulp to subside. It is then drained off; and the sediment distributed into shallow vessels, and dried gènerally in the shade. 'The annotto is now only prepared by the Spaniards. The English had formerly a manufacture at St. Angelo, now ruined. This drug is preferred by the dyers to indigo, and sold one-fourtli dearer. The double Gloucester cheese is coloured with this dye, not with marygolds. Some of the Dutch farmers use it to give - a rich colour to their butter, and great quantities are said to be applied to the same purpose in the English dairies. The poor people use it instead of saffron; and it is sometimes mixed as an ingredient in chocolate, during the grinding of the cocoa, in the quantity of about two drams to the pound, in order to give it a reddisls colour; but the opinion of its being an earth has brought it into disrepute, and this use of it has been discontinued. To water it gives only a pale brownish ycllow colour, and is not soluble in that liquid, nor in spirit of wine ; but, in order to be fit for dyeing, it requires an alkaline menstruum, to which it gives a bright orange colour; and hence it is useful as an ingredient in varnishes and lacquers, and in dying wax of a vermillion colour. Wool and silk, boiled in a solution of it by alkaline salts in water, acquire a deep, but not a durable orange dye ; for though it is not changed by alum or acids, it is discharged by soaps, and destroyed by exposure to the air. It is said to be an antidote to the poisonous juice of manihot, or cassada. The liquid, sold un- der the name of "Scott's nankeen dye," seems to be nothing but annotto dissolved in alkaline ley.

ANNOYANCE, in law, any injury done to a public place, as a high-way, bridge, or common river; or to a private way, as laying any thing that may breed infection, by encroaching, \&c.

ANNUAI. plants, generally called annuals, in gardening, signify such plants as are of one year's duration, or which continue for a few montlis only. Plants that rise from sced sown in the spring arrive at maturity in the summer or autumn following, producing flowers and ripe seed, and which afterwards perish in their tops and roots, are commonly regarded as annuals. The plants of this tribe are very numerous, as most of those of the herbaceous kinds, consisting of uncultivated plants, weeds, \&c. and also a great number of cultivated garden and field plants, both of the esculent and flowery ornamental kinds, are of this description. The last sort are often termed simply annuals. -These are divided into the hardy and tender kinds; the former are sown in places where they are designed to remain without transplanting, but the latter are usually sown in lot-beds, in orcler to be transplanted in the spring, either into pots or borders.

ANNUITIES, any income of a certain yearly amount, payable at particular periods, which may be either yearly, halfyearly, quarterly, monthly, weekly, or at any other intervals. They are usually distinguished into annuities certain, and contingent annuities, or such as are for an un. certain period, being determinable by some future event, such as the failure of a life or lives.

The present value of an annuity is that sum, which, if improved at compound interest, would be sufficient to pay the annuity; the present value of an annuity certain, payable yearly, and of which the first payment is to be made at the end of a year, may therefore be calculated in the following manner.

Suppose a person has $100 \mathrm{l}$. due to hin a twelve month hence, and he wishes to have the value of the same advanced $\mathrm{im}$ mediately, the sum which ought to be given as an equivalent thereto, allowing 5 per cent. interest, is $95 l$. $4 s .9 \frac{1}{4} d$ l. for this is the sum, which, put out to interest, at the rate of 5 per cent will, at the end of the year, amount to $100 \mathrm{l}$. So also, if a person has 100l. due to him at the end of two years, and he wishes to have the value of the same adranced immediately, the sum which ought to be given as an equiralent 


\section{ANNUITIES.}

thereto is 90 . 14s. 0 l. $l$. for this is the sum, which, put out at the same rate of interest, will, at the end of two years, amount to 100 . In like manner, if a person has $100 t$. due to him at the end of three years, and he wishes to lave the same advanced im. mediately, the sum which ought to be given as an erjuivalent thereto is $86 l .78$. $8 l$. for this is the sum which, at the same rate of interest, will at the end of three years anount to $100 \mathrm{~L}$. And if these three values are added together, they will make $272 l$. 68. Gd. being the sum which ought to be paid down for an annuity of $100 t$. for three years; as this sum improved at the given rate of interest is just sufficient to make the three yearly payments.

As the anount or present worth of $1 l$. for any given term is usually adopted as the foundation of calculations relating to annuities, let $r$ represent the amount of 11. in one year; that is, one pound increased by a year's interest; then ${ }^{-m}$, or ${ }^{\circ}$ raised to the power whose exponent is any given number of years, will be the amount of $1 l$. in those years; its increase in the same time is $m-1$; now the interest for a single ycar, or the annuity corresponding with the increase, is $r$ 1 ; therefore as $r-1$ is to $r n-1$, so is $u$ (any given annuity) to $a$ its amount: hence we have

$$
\frac{u \times \bar{r}-1}{r-1}=a
$$

Example. - To what sum will an annuity of $50 \mathrm{l}$ amount in 6 years, at $5 \mathrm{per}$ cent. per annum, compound interest ?

$$
\frac{50 \times \overline{1.05} \gamma^{6-1}}{.05}=340 l .198 .1 \mathrm{~d} \text {. }
$$

In this manner the amount of an annuity for any number of years, at any given rate of interest, may be found. liut when the term of years is considerable, it will be more convenient to work by logarithms, by which the labour of all calculations re. lating to compound interest is greatly abridged. There is, however, little occasion in general to calculate the amount or present worth of annuities, except for particular rates of interest, as the following tables, and others of a similar nature, for different rates of interest, which are given in most books on compound interest, save much time and labour in common pracice, and are therefore in general use.

\section{TABLE I.}

Shewing the amount of an annuty of 1 l. in any number of years not exceeding 100 , at 5 per cent. per annum com-

\begin{tabular}{|c|c|c|c|c|c|}
\hline Yrs & $\Lambda \mathrm{mo}$. & Yrs. & Amount. & Yrs & Ainount. \\
\hline 1 & 000 & 55 & 90,3203 & 69 & 510 \\
\hline & & 36 & & 70 & \\
\hline & 3,1525 & & $\mid: 01,6201$ & 71 & $61 . s, 9549$ \\
\hline & $4,31 \cup 1$ & 38 & 107,7095 & 72 & 650,9027 \\
\hline 5 & & 39 & & 73 & 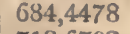 \\
\hline & 6,8019 & 40 & 120,7998 & 74 & 719,6702 \\
\hline & 8,1420 & 4.1 & $127,8.398$ & 75 & 756,6537 \\
\hline & 1 & 42 & 17 & 76 & 4 \\
\hline & 11,0 & 43 & 33 & 77 & 07 \\
\hline 10 & 12,5 & 44 & 30 & 78 & $87 y, 4738$ \\
\hline 1) & 14, & 45 & & $\mid 79$ & 74 \\
\hline 12 & 15,9171 & 46 & 16 & 80 & 288 \\
\hline 13 & 17,7 & 47 & 17 & $81 \mid$ & 903 \\
\hline 14 & 19, & 48 & 18 & & \\
\hline 15 & 21,5786 & 49 & 198,4267 & 831 & 13 \\
\hline 16 & $2 j$ & 50 & & 841 & 48 \\
\hline 17 & 25 & 51 & 22 & 85 & \\
\hline 18 & $28,1328 \mid$ & 52 & 232,8562 & $86] 1$ & 14. \\
\hline 19 & 30,5390 & 53 & 24 & $87 \mid$ & 585 \\
\hline 20 & 599 & 54 & 25 & & $10-4$ \\
\hline 21 & 35,7192 & 55 & 272,7 & & 12 \\
\hline 22 & 38,5052 & 56 & 28 & 90 & 073 \\
\hline 23 & 41, & 57 & 30 & & $16 \%$ \\
\hline 24 & $44,5 \cup 20$ & 53 & 318,8514 & 92 & 1760,1045 \\
\hline 25 & 47,7271 & 59 & 335,7940 & 93 & 095 \\
\hline 26 & 51,1135 & 60 & 353,6 & & 1942,5653 \\
\hline 27 & $54,6.691$ & 61 & 1372,2629 & 93 & 2040,693 \\
\hline 28 & 58,4026 & 62 & 391,876 & 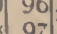 & $2143,-282$ \\
\hline 29 & 3227 & 63 & $\$ 12$ & & 2251,914 \\
\hline 3 & 66,4388 & 64 & $\begin{array}{l}134,093 \\
56709\end{array}$ & & 2365,5103 \\
\hline & 707 & 65 & & & \\
\hline $\begin{array}{l}32 \\
33\end{array}$ & $\begin{array}{l}75 \\
80\end{array}$ & 66 & 75 & 00 & 2610,025 \\
\hline 34 & 85,0670 & 68 & $|531,9533|$ & & \\
\hline
\end{tabular}
pound interest.
Exayple 1.-To what sum will an annuity of $105 l$. amount in 19 years, at 5 per cent. compound interest?

The number in the table opposite to 19 years is 30,5390 , which multiplied by 105 gives the answer $3206 \%$. 11s. $10 d$.

Examplx: 2.-In what time will an annuity of $25 \%$ amount to $3575 l$, at 5 per cent. compountl interest?

Divide 35751 . by 251 . the quotient is 143 ; the number nearest to this in the table is 142,9933 , and the number of years corresponding, or 43 years, is the answer.

The present worth of an annuity, or the sum to be given in one present payment as an equivalent for an annuity for any given number of years, is found on similar principles; for as $1 l$. is the present value of $r^{n}$ (its amount in $n$ years, and as the present value of any other amount, and consequently of $\frac{u \times r^{n}-1}{r-1}-$ must bear the same propor. tion to that amount, we hare 


$$
\frac{i-\frac{i}{r^{n}}}{r-1}=p .
$$

ExAMPLE.-What is the present value of $50 l$. per annum for 6 years, at 5 per cent. compound interest?

$$
\frac{50-\frac{50}{\overline{1.05} 7^{6}}}{.05}=2531.15 \mathrm{~s} .8 \mathrm{~d} \text {. }
$$

But sich questions are much more readily answered by the following table.

\section{TABLE II.}

Shewing the present value of an annuity of 11 . for any number of years not ex.

\begin{tabular}{|c|c|c|c|c|c|}
\hline Y. & e. & $\mathbf{Y}$ : & Value. & Y. & Value. \\
\hline 1 & 952381 & 35 & 16,374194 & 6911 & 19 \\
\hline 2 & & & & & \\
\hline 3 & & 37 & 87 & 71 & 1 \\
\hline 4. & & & & 72 & 88 \\
\hline & & & & & \\
\hline 6 & 5,0 & 40 & 086 & & \\
\hline 7 & & 41 & & 75 & \\
\hline & & & & & \\
\hline 9 & & & 912 & 77 & \\
\hline 10 & & & & 78 & \\
\hline 11 & & 45 & 17 & 79 & \\
\hline 12 & & 46 & & 80 & \\
\hline 13 & & 47 & & 81 & \\
\hline 14. & 9,8 & 48 & 18 , & 82 & 1 \\
\hline 15 & 10 & 349 & & 83 & \\
\hline 16 & & 50 & & 84 & 07 \\
\hline 17 & 11 & 51 & 18, & 85 & 16 \\
\hline 18 & 11, & 52 & 18 & 86 & 1 \\
\hline 19 & & 53 & & 87 & 3212 \\
\hline 2 & & 54 & 18, & 88 & \\
\hline 21 & 12 & 55 & 72 & & 1 \\
\hline 22 & & 56 & & 90 & is \\
\hline 23 & 13 & 57 & 19 & & 19 \\
\hline 24 & & 58 & 3542 & 92 & 94 \\
\hline 25 & & 59 & 754 & 93 & 19 \\
\hline 26 & & & 18 & 94 & 19,796185 \\
\hline 27 & & & 18 & & 19 \\
\hline 28 & & & & & 19 \\
\hline 9 & & & & 97 & 19,823937 \\
\hline 30 & & & & 8 & 19, \\
\hline 31 & & & & & 10 \\
\hline $\begin{array}{l}32 \\
33\end{array}$ & $\begin{array}{l}15, \\
16\end{array}$ & & & & \\
\hline 34 & 10 & & $1097 \%$ & & \\
\hline
\end{tabular}
ceeding 100 , at 5 per cent. per annum, compound interest.

Exaxple 1.-What is the present vaue of an annuity of 632 . to continue for 21 years?

The value in the table against 21 years is 12,821153 , which multiplied by 63 gives the answer $807 \mathrm{l}$. $14 \mathrm{~s}$. $\mathrm{r} \mathrm{d}$.

Fxauple 2-What present sum is equivalent to a nett rent of $20 l$. per annum for 69 years?

The value in the table against 69 years is $19,309,310$, which multiplied by 20 gives the answer $386 l$. 3s. $11 \mathrm{l}$.

If any of the annuities in the above ta. ble, instead of being for an absolute term of years, had been subject to cease, if a given life should fail during the term, it is evident that the value would have been lessened in proportion to the probability of the life failing; and that if, instead of being for a certain number of years, the annuity depended wholly on the uncertain continuance of a given life or lives, its value must be ascertained by the pro. bable duration of such life or lives. In order to compute the value of LrFE AxNUITI Es, therefore, it is necessary to have recourse to tables that exhibit the number of persons, which, out of a certain number born, are found to be living at the end of every subsequent year of human life, which thus shew what are termed the probabilities of life.

Various tables of this kind have been formed by the different writers on this subject, as Dr. Halley, Mr. Thomas Simpson, M. Kersseboom, M. de Parcieux, Dr. Price, Dr. Haygarth, Mr. Wargentin, M. Susmilch, and others; and the true method of computing the value of life annuities,according to the probabilities of any table of mortality, is laid down by Mr. William Morgan as follows :

"Was it certain that a person of a given age would live to the end of a year, the value of an annuity of $1 l$. on such a life would be the present sum that would increase in a year to the value of a life one year older, together with the value of the single payment of $1 l$. to be made at the end of a year; that is, it would be $1 l$. together with the value of a life aged onc year older than the given life, multiplied by the value of $1 l$. payable at the end of a year. Call the value of a life of one year older than the given life $N$, and the value of $1 l$. payable at the end of a year $\frac{1}{r}$; then will the value of an annuity on the given life, on the supposition of a certainty, be $\frac{1}{r}+\frac{1}{r} \times \mathrm{N}=\frac{1}{r} \times \overline{1+N}$. But the fact is, that it is uncertain whether the given life will exist to the end of the year or not; this last value, therefore, must be diminished in the proportion of this un- 


\section{ANNUITIES.}

certainty, that is, it must be multiplied by the probability that the given life will survive one year, or supposing $\frac{b}{a}$ to express this probability, it will be $\frac{b}{a r} \times$ $\overline{1-\mathrm{N}}$,

The values of anunities on the joint continuance of two lives are found by reasoning in a similar manner; and such values, both for single and joint lives, are given in the following tables.

\section{TABLE III}

Sliewing the value of an annuity of $1 L$ on a single life, at every age, according to the probabilities of the duration of life at Northampton, reckoning interest at 5 per cent. per annum.

\begin{tabular}{|c|c|c|c|c|c|}
\hline Age. & Value. & Age. & Value. & $A g c$ & Value. \\
\hline irth. & 8,863 & 33 & 12,740 & 66 & 7,034 \\
\hline year & 11,563 & 34 & 12,623 & 67 & 6,787 \\
\hline 2 & 13,420 & 35 & 12,502 & 68 & 6,536 \\
\hline 3 & 14,135 & 36 & 12,377 & 69 & 6,281 \\
\hline 4 & 14,613 & 37 & $12,249 \mid$ & 70 & 6,023 \\
\hline 5 & 14,827 & 38 & 12,116 & 71 & 5,764 \\
\hline 6 & 15,041 & 39 & 11,979 & 72 & 5,504 \\
\hline 7 & 15,166 & 40 & 11,837 & 73 & 5,245 \\
\hline 8 & 15,226 & 4.1 & $\{1,695$ & 74 & 4,990 \\
\hline 9 & 15,210 & 42 & 11,551 & 75 & 4,744 \\
\hline 10 & 15,139 & 43 & 11,407 & 76 & 4,511 \\
\hline 11 & 15,043 & 44 & 11,258 & 77 & 4,277 \\
\hline 12 & 14,93 & 45 & 11,105 & 78 & 4,035 \\
\hline 13 & 14,826 & 46 & 10,947 & 79 & 3,776 \\
\hline 14 & 14,710 & 47 & 10,784 & 80 & 3,515 \\
\hline 15 & 14,588 & 48 & 10,616 & 81 & 3,263 \\
\hline 16 & 14,460 & 49 & 10,443 & 82 & 3,020 \\
\hline 17 & 14,334 & 50 & 10,269 & 83 & 2,797 \\
\hline 18 & 14,217 & 51 & 10,097 & 84 & 2,627 \\
\hline 19 & 14,108 & 52 & 9,925 & 85 & 2,471 \\
\hline 20 & 14,007 & 53 & 9,748 & 86 & 2,328 \\
\hline 21 & 13,917 & 54 & 9,567 & 87 & 2,193 \\
\hline 22 & 13,833 & 55 & 9,382 & 88 & 2,080 \\
\hline 23 & $13,746 \mid$ & 56 & 9,193 & 89 & 1,924 \\
\hline 24 & 13,658 & 57 & 8,999 & 90 & 1,723 \\
\hline 25 & 13,567 & 58 & 8,801 & 91 & 1,447 \\
\hline 26 & 13,473 & 59 & 8,599 & 92 & 1,153 \\
\hline 27 & 13,377 & 60 & 8,392 & 93 & 0,816 \\
\hline 28 & 13,278 & 61 & 8,181 & 94 & 0,524 \\
\hline 29 & 13,177 & 62 & 7,966 & 95 & 0,238 \\
\hline so & 13,072 & 63 & 7,742 & 96 & 0,000 \\
\hline 31 & $12,965 \mid$ & 64 & 7,514 & & \\
\hline 32 & $|12,854|$ & 65 & 7,276 & & \\
\hline
\end{tabular}

The values in this and the following: tables suppose tire payments to be madc yearly, and to begin at the end of a year : but if all the payments are to be halfyearly payments, and to be made at the end of every half year from the time of purchase, the value will be increased about one-fifth of a year's purchase.

The above table is formed from the probabilities of life, as deduced from the rcgister of mortality at Northampton for 46 years, from 1735 to 1780 ; and as it gives the mean values of lives between the highest and lowest, it is better adapterl for general use than any other extant. It has of late years been generally adopted for calculating the rates of assurance on lires, and is well suited to this purpose ; but it is by no means a proper table for. individuals or societies to grant life annui. ties from ; for having been formed from a register comprehending persons of all ages and conditions, it cannot give a correct representation of the duration and value of such lives as usually form a body of annuitants, such persons being gene. rally a selection of the best lives from the common mass, the interest of every person who purchases an annuity on any life requiring that he should take care that it is a good life. The best table for regulating the grant of life annuities is that formed from the table of mortality pub. lished by Mr. D. Parcieux, from the lists of the French tontines, but even this table gives the values of the advanced ages considerably too low. 


\section{ANNUITIES.}

TABLE IV.

Shewing the valuc of an annuity of $1 l$. on a single life, at every age, according to the pro. babilities of life, in Mr. De Parcieux's table of the mortality. Interest at 5 per cent.

\begin{tabular}{|c|c|c|c|c|c|c|c|c|c|}
\hline Age. & Value. & Age. & Value. & Age & Value. & Age. & Value. & Age. & Value. \\
\hline 0 & $11, \overline{083}$ & 18 & 15,631 & 36 & 14,065 & 54 & $\overline{10}, \overline{418}$ & $\overline{72}$ & 5,540 \\
\hline 1 & 14,620 & 19 & 15,550 & 37 & 13,930 & 55 & 10,168 & 73 & 5,232 \\
\hline 2 & 15,135 & 20 & 15,474 & 38. & 13,786 & 56 & 9,930 & 74 & 4,942 \\
\hline 3 & 15,509 & 21 & 15,401 & 39 & 13,632 & 57 & 9,682 & 75 & 4,674 \\
\hline 4 & 15,750 & 22 & 15,328 & 40 & 13,466 & 58 & 9,431 & 76 & 4,429 \\
\hline 5 & 15,924 & 23 & 15,256 & 41 & 13,296 & 59 & 9,177 & 77 & 4,190 \\
\hline 6 & 16,041 & 24 & 15,184 & 42 & 13,116 & 60 & 8,923 & 78 & 3,953 \\
\hline 7 & 16,118 & 25 & 15,112 & 43 & 12,931 & 61 & 8,669 & 79 & 3,719 \\
\hline 8 & 16,169 & 26 & 15,040 & 44 & 12,738 & 62 & 8,413 & 80 & 3,501 \\
\hline 9 & 16,204 & 27 & 14,969 & 45 & 12,535 & 23 & 8,155 & 81 & 3,283 \\
\hline 10 & 16,210 & 28 & 14,893 & 46 & $12,33{ }^{\circ}$ & 64 & 7,893 & 82 & 3,072 \\
\hline 11 & 16,194 & 29 & 14,810 & 47 & $12,11 \mathrm{c}$ & 65 & 7,626 & 83 & 2,868 \\
\hline 12 & 16,145 & 30 & 14,722 & 48 & $11,89^{\prime \prime}$ & 66 & 7,351 & 84 & 2,668 \\
\hline 13 & 16,077 & 31 & 14,627 & 49 & 11,666 & 67 & 7,069 & 85 & 2,461 \\
\hline 14. & 15,994 & 32 & 14,527 & 50 & $11,4,5$ & 68 & 6,778 & 86 & 2,237 \\
\hline 15 & 15,901 & 33 & $14,4,21$ & 51 & $11,1 » 8$ & 69 & 6,479 & 87. & 1,976 \\
\hline 16 & 15,807 & 34 & 14,306 & 52 & 10,926 & 70 & 6,171 & 88 & 1,688 \\
\hline 17 & 15,716 & 35 & 14,189 & 53 & 10,673 & 71 & 5,856 & $\begin{array}{l}89 \\
90\end{array}$ & $\begin{array}{l}1,409 \\
1,164\end{array}$ \\
\hline
\end{tabular}

The calculation of the values of joint lives from any given table of mortality, for every combination of age, is so laborious a task, that no such table has yet been published. Mr. Simpson, in his select exercises, gave a table of the values of two joint lives, agreeable to the probabilities of life in London; but the tables founded on the London bills, representing the rate of mortality among the inhabi-

tants, taken in the gross, give the values of lives much too low for the middling and superior classes of the people in London itself, and are wholly improper for general use. A much more comprehensive table of the value of joint lives has since been calculated by Dr. Price from the Northampton table of mortality, from which the following table is taken.

TABLE V.

Shewing the value of an annuity of $1 l$. on the joint continuance of two lives, according to the probabilities of life at Northampton. Interest at 5 per cent.

\begin{tabular}{|c|c|c|c|c|c|c|c|c|c|c|c|c|}
\hline Ages. & Value. & Ages. Value. & Ages. & Value. & Ages. & Value. & Ages. & Value.| & Ages. & Value. \\
\hline $5-5$ & 11,984 & $10-45$ & 9,900 & $20-25$ & 10,989 & $25-80$ & 3,308 & $40-45$ & 8,643 & $55-55$ & 6,735 \\
$5-10$ & 12,315 & $0-50$ & 9,260 & $20-30$ & 10,707 & $30-30$ & 10,255 & $40-50$ & 8,177 & $55-60$ & 6,272 \\
$5-15$ & 11,954 & $10-55$ & 8,560 & $20-35$ & 10,363 & $30-35$ & 9,954 & $40-55$ & 7,651 & $55-65$ & 5,671 \\
$5-20$ & 11,561 & $10-60$ & 7,750 & $20-40$ & 9,937 & $30-40$ & 9,576 & $40-60$ & 7,015 & $55-70$ & 4,893 \\
$5-25$ & 11,281 & $10-65$ & 6,803 & $20-45$ & 9,448 & $30-45$ & 9,135 & $40-65$ & 6,240 & $55-75$ & 4,006 \\
$5-30$ & 10,959 & $10-70$ & 5,700 & $20-50$ & 8,861 & $30-50$ & 8,596 & $40-70$ & 5,298 & $55-80$ & 3,076 \\
$5-35$ & 10,572 & $10-75$ & 4,522 & $20-55$ & 8,216 & $30-55$ & 7,999 & $40-75$ & 4,272 & $60-60$ & 5,888 \\
$5-40$ & 10,102 & $10-80$ & 3,395 & $20-60$ & 7,463 & $30-60$ & 7,292 & $40-80$ & 3,236 & $60-65$ & 5,372 \\
$5-45$ & 9,571 & $15-15$ & 11,960 & $20-65$ & 6,576 & $30-65$ & 6,447 & $45-45$ & 8,312 & $60-70$ & 4,680 \\
$5-5$ & 8,941 & $15-20$ & 11,585 & $20-70$ & 5,532 & $30-70$ & 5,442 & $45-50$ & 7,891 & $60-75$ & 3,866 \\
$5-5$ & 8,256 & $15-25$ & 11,324 & $20-75$ & 4,424 & $30-75$ & 4,365 & $45-55$ & 7,411 & $60-80$ & 2,992 \\
$5-60$ & 7,466 & $15-30$ & 11,021 & $20-80$ & 3,325 & $30-80$ & 3,290 & $45-60$ & 6,822 & $65-65$ & 4,960 \\
$5-65$ & 6,546 & $15-35$ & 10,655 & $25-25$ & 10,764 & $35-35$ & 9,680 & $45-65$ & 6,091 & $65-70$ & 4,378 \\
$5-70$ & 5,472 & $15-40$ & 10,205 & $25-30$ & 10,499 & $35-40$ & 9,331 & $45-70$ & 5,195 & $65-75$ & 3,665 \\
$5-75$ & 4,362 & $15-45$ & 9,690 & $25-35$ & 10,175 & $35-45$ & 8,921 & $45-75$ & 4,206 & $65-80$ & 2,873 \\
$5-80$ & 3,238 & $15-50$ & 9,076 & $25-40$ & 9,771 & $35-50$ & 8,415 & $45-80$ & 3,197 & $70-70$ & 3,930 \\
$10-10$ & 12,665 & $15-55$ & 8,403 & $25-45$ & 9,304 & $35-55$ & 7,849 & $50-50$ & 7,522 & $70-75$ & 3,347 \\
$10-15$ & 12,302 & $15-60$ & 7,622 & $25-50$ & 8,739 & $35-60$ & 7,174 & $50-55$ & 7,098 & $70-80$ & 2,675 \\
$10-20$ & 11,906 & $15-65$ & 6,705 & $25-55$ & 8,116 & $35-65$ & 6,360 & $50-60$ & 6,568 & $75-75$ & 2,917 \\
$10-25$ & 11,627 & $15-70$ & 5,631 & $25-60$ & 7,383 & $35-70$ & 5,382 & $50-65$ & 5,897 & $75-80$ & 2,381 \\
$10-30$ & 11,304 & $15-75$ & 4,495 & $25-65$ & 6,515 & $35-75$ & 4,327 & $50-70$ & 5,054 & $80-80$ & 2,018 \\
$10-35$ & 10,916 & $15-80$ & 3,372 & $25-70$ & 5,489 & $35-80$ & 3,268 & $50-75$ & 5,112 & $85-85$ & 1,256 \\
$10-40$ & 10,442 & $20-20$ & 11,232 & $25-75$ & 4,396 & $4.0-40$ & 9,016 & $50-80$ & 3,140 & $90-90$ & 0,909 \\
\hline
\end{tabular}




\section{ANN UITIES.}

To find the value of any annuity cluring the continuance of a life of any given age, or during the joint continuance of two lives, it is only necessary to raultiply the value in the table, against the given age, by the annuity; or to find the annuity equivalent to any certain sum, divide the sum by the value in the table against the given age.

F.хмиреs. - What is the difference in value between an annuity of $50 \%$. during the life of a person ared 35 , and an annuity of $60 \%$. during two lives of 30 and 35 , to cease when either of the two lives shall fail ?

The value in Table III, against the age of 35 is 12,502, which multiplied by 50 gives 625.11 . the value in table $\mathbf{V}$. against the ages of 30 and 35 is 9.954 , which mul. tiplied by 60 gives 597.241 . the value of the fornes anmity therefore exceeds the latter by $27 \mathrm{~K} 17 \mathrm{~s} .2 \%$.

What annuity during his life, ought a person agerl 45 to receive in licu of an annuity of $20 \%$. certain for the term of 18 years?

The value of an annuity certain for 18 years, is by Table 11. 11.689587, which multiplied by 20 gives 233.7917 . this sum divided by 11.105, the value of an annuity during a life of 45 , by Table 111. gires the answer of 21\%.18.

What annuity during his life, ought a person aged 40 to reccive for $500 \%$.

The value of an annuity during a life of 40 years of age, is by Table III. 11.837, and $500 \%$. divided by this sum gives $42 \%$. 48. 9d. per annum ; but if the value of the life is taken, as in Table IV. (or 13.466), the sun to be received will be $37 l .28 .7 d$.

For the values of annuities which are not to commence till after a certain period, or after a given life or lives. Sec REvensions.

Anmuities are frequently granted by parishes, trusts, and public societies, for the purpose of raising money for the erection or repair of churches, cliapels, workhouses, bridges, or other expensive buildings, it being often found practicable to obtain money in this way, when it could not be procured at the ordinary rate of intcrest; it has likewise the recommendation of gradually extinguishing the debt, which might otherwise often remain a permanent burthen. I Ife annuities are also freciuently granted, for money borrowed by persons possessing life estates, and who, therefore, cannot give the lender a permanent security. As such amuities depend on the life of the grantor, few persons are disposed to purchase them, unless they can be obtained on sucli term, as, after allowing for the expense of suring the grantor's life, leaves an incone somewhat greater than the common rite of interest. It also frequently happens that the annuities are not very punctualy paicl, which, with other risks attendigg them, causes annuities of this description always to sell considerably under their real valuc; and in some instances the $x$ cessities of the borrowers have led them to make grants of this kind on the most exorbitant terms. To throw, howerer, some elieck upon improvident traniactions of this kind, which are usually zarried on with great privacy, the statute $\mathbf{1 7}$ Geo. III. c. 26, usually called the Ann iity Act, lias directed, that upon the sale of any life annuity of more than the value of 10l. (unless on a sufficient pledge of lands in fee simple, or stock in the public funds) the true consideration, which shall be in money only, and the names of the parties, shall be set forth and described in the security itself, in words at length; and a memorial of the date, the names of the parties, and of all the witnesses, and of the consideration moncy, shall, within twenty days after its execution, be enrol. led in the Court of Chancery, else the sccurity shall be null and void. All con. tracts for the purchase of annuities from persons under 21 years of age are utterly void, and incapable of confirmation after the party becomes of age. Procuring or soliciting a minor to grant any life annuity, or to promise or engage to ratify it when he becomes of age, is an indictable misdemeanor, and punishable by fine and imprisonment; as is likewise the taking more than ten shillings per cent. for procuring money to be advanced for any life annuity. Tlis act does not extend to annuities granted by any body corporatc, or undel any authority or trust created by act of parliament.

Notwithstanding these regulations, per. sons having occasion to raise money by the grant of life annuitics were obliged to submit to the most disadvastageous terns, as it seldom happened that individual purchasers would give for such amutics more than eight years purchase, on lives above 30 years of age; or 7 years pur. chase on lives above 40 ; while, on the other hand, persons desirous of inresting money in an amnuity on their own life were generally under the necessity of ac. cepting private security, or of waiting till an opportunity offered of obtaining the security of some local toll or rates. To remedy these inconveniences, an act was 
jassed in 1793, authorising the Foyal Ex. change Assurance Company to grant and purchase anmuities on lives, cither immedate or in reversion: the rates according to which transactions of this kind are resulated necessarily vary, in proportion to tie current rate of interest at which money can be improred: a short specimen therefore of the present (1808) rates, at vlich the Royal Fxchange Assurance grant life annuities, will be sufficient.

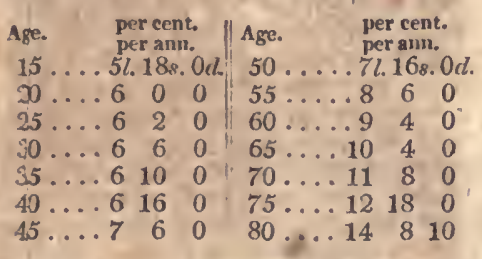

Several other societies, as the Globe Insurance, the Albion, the Rock, and the Eagle Insurance Companies, have lately granted life annuitios, but it is presumed they vary their grants according to circumstances, as they none issue a printed table of their rates.

ANOsLALIES, in music, are those false scales or interrals, which exist necessarily in all keyed instruments, from their incapacity of a true and perfect temperament.

ANOMALISTICAL year, in astronomy, the time that the earth takes to pass through her orbit: it is also called a periodical year. The space of time belonging to this year is greater than the tropical year, on account of the precession of the equinoxes.

ANOMALOUS verbs, in grammar, such as are not conjugated conformably to the paradigm of tieir conjugation: they are found in all languages; in Latin, the verb lego is the paradigm of the third conjugation, and runs thus, legro, legis, legit; by the same mile it should be, fero, feris, ferit, but we say, fero, fer's, fert; fers then is an ano. malois verb. In English, the inegularity relates often to the preter tense and pas: sive participle; for example, give, were it formed according to rule, would make giverl in the preter tense and passive participlc; whereas in the former, it makes gave, and in tlie latter given.

ANOMALY, in grammar, that quality in words which renilers them anomalous. See the preceding article.

Avomáx, in astronomy, an irregularity in the motion of the planets, whereby uley deviate from the aphelion or apogee: which inequality is either mean, eccen. tric, or cocquate and true.

ANOMIA, in natural history, a genus of worms, of the order Testacca. Animal an emarginate ciliate strap-shaped body, with bristles affixed to the upper-valve; two arms, linear, longer than the body, connivent, projecting, alternate on the valve, and ciliate each side, the fringe affixed to each valve; shell bivalve, inequivalve; one of the valves flattish, the other gibbous at the base, with a produced beak, generally curved over the hinge; one of the valves often perforated near the base; hinge with a lunear prominent cicatrix and a lateral tooth placed within, but in the flat valve on the very margin; two bony rays for the base of the animal. There are nearly fifty species enumerated by Gmelin, found in different parts of the world. A ephippium has a sliell, round. ish, pellucid, with wrinkled plaits; the flat valve perforated. It inhabits Furopcan and American seas, and is frequently found sticking to the common oyster. About two inches long, $2 \frac{1}{4}$ broad; the outside rugged and filmy, the inside smooth and pearly : varies in colour, but generally with a silvery hue.

ANONA, in botany, a genus of plants, belonging to the Polyandria Polygynia class of Linnzus. The perianthium is composed of three cordated, hollowed, and acuminated leaves; the corolla consists of six cordated sessile petals; three alternately interior and smaller; the sta. mina are scarce visible, but the antherr are numerous; the fruit is a large berry, of an oval figure; covered with a squamose punctuated bark; the seeds are numerous, hard, of all oblong figure, and are placed circularly.

ANSERES, in natural history, the tluird order of birds, according to the Linnzan system: they are distinguished by a smooth bill, corered with a soft skin and brodder at the point; feet formed for swimming; toes palmate, connected by a membrane; shanks short, and compressed; body fat and downy; flesh mostly tough; their food is fish, frogs, aquatic plants, worms, \&c. They make their nests generally on the ground; the mother takes but little care in providing for the young. They are frequently polygamous. They are divided into those genera having bills with, and those without, teeth: of the former are the
Anas, Phaëton, and Mergus, 


\section{ANT}

Of the latter are the

$\begin{array}{ll}\text { Alea, } & \text { Pelecanus, } \\ \text { Aptenodytes, } & \begin{array}{l}\text { Procellaria, } \\ \text { Colymbus, }\end{array} \\ \text { Prynchops, } \\ \text { Diomedea, and } \\ \text { Larus, } & \text { Stcria. }\end{array}$

This order comprehends all kinds of water.fowl whose feet are palmated. The webbed feet of these birds are admirably adapted to aid them in swimming; and the greater quantity of oil secreted by the glands near the tail, and rubbed by means of their bills over all the feathers of their body, enables them to live on the water, without ever being wet. They live mostly on fish, and some of them have been occasionally tamed to the catching of fish for the use of their masters. In some of the lakes of China, where the water-fowl abound, the natives have the following ingenious mode of catching them: For se. veral days before they attempt to take them, many empty gourd-shells are set afloat on the water, to habituate the birds to their appearance; and when they are observed to take no notice of these shells, but to swim among them, a man, with one of the same kind upon his head, goes into the lake, and wades or swims among the birds with nothing but his head above the water. He now begins his sport, and taking the birds by their legs, draws them under water, breaks their necks, and fastens them to his girdle, one after another, till he is sufficiently loaded, and then re. turns to the shore.

ANSWER, in law: On an indictment for perjury, in an answer in Chancery, it is a sufficient proof of identity, if the name subscribed be proved to be the hand-writ. ing of the defendant; and that the same was subscribed by the master, on being sworn before him.

ANT. See Forvica.

ANTECEDENCE, in astronomy, an apparent motion of a planet towards the west, or contrary to the order of the signs, vis. from Taurus towards Aries, \&ec.

ANTECEDENT, in grammar, the word to which a relative refers: thus, God whom we adure, the word God is the antecedent to the relative whom.

Astecenent term, in mathematics, the first one of any ratio: thus, if the ratio be $a: b, a$ is the antecedent term.

ANTEDATE, among lawyers, a spurious or false date, prior to the true date of a bond, bill, or the like.

ANTELOPE, in natural history, of the Mammalia class of animals, of the order Glires. The generic character is, horns VOL. 1.
ANT

hollow, seated on a bony core, growing upwands, annulated or wrcalling, per. manent. Front teeth in the lower jaw eight, and no canine tecth. Antelopes constitute a very numerous race: they were formerly, even by Linnzus, ranged under the genus Capra, but now have ob. tained a rank for themselres: their habits and manners are thus described. They inhabit, two or three species excepted, the hottest parts of the globe; or, at least, those parts of the temperate zone that lie so near the tropics as to form a doubtful climate. None, therefore, except the Saiga and the Chamois, are to be met with in Europe; and notwithstanding the warmth of South America is suited to their nature, but one or two species has yet been discovered in the new world. Their proper climates seem, therefore, to be those of Asia and Africa, where the species are very numerous. " $\mathrm{As}$ there appears a general agreement in the nature of the species that form this great genus, it will prevent needless repetition to observe, that the antelopes are animals generally of a most elegant and active make; of a restless and timid disposition; extremely watchful, of great vivacity, re. markably swift and agile; and most of their boundings so light and elastic, as to strike the spectator with astonishment. What is very singular is, that they will stop in the midst of their course, gaze for a moment at their pursuers, and then resume their flight. As the chase of these animals is a favourite amusement with the eastern nations, from that may be collected proofs of the rapid speed of the ante. lope tribe. The greyhound, the fleetest of dogs, is usually unequal in the course, and the sportsman is obliged to call in the aid of the falcon, trained for the purpose, to seize on the animal, and impede its motions, in order to gire the dogs an opportunity of overtaking it. In India and Persia a species of leopard is made use of in the chase: this is an animal that takes its prey, not by swiftness of foot, but by the greatness of its springs, by motions similar to those of the antelope; but, should the leopard fail in its first essay, the game escapes. The flectness of the antelope was proverbial in the country it inhabited, even in the earliest times: the speed of Asaliel (2 Sam, ii. 18.) is beauti. fully compared to that of the Tzebi ; and the Gadites were said to be as swift as the antelopesupon the mountains. The sacred writers took their similies from such ob. jects as were before the eyes of the people to whom they addressed themselves. I i 


\section{AN'TELOPE.}

There is another instance drawn from the same subject: the disciple raised to life at Joppa was supposed to have been called Tabitha, i. e. Dorcas, or the antelope, from the beauty of her eyes; and to this day one of the highest compliments that can be paid to female beauty, in the eastern regions, is Aine el Czazel, "You have the eyes of an antelope.' Some species of antelopes form herds of two or three thousands, while others keep in troops of five or six. They generally reside in hilly countries, though some inhabit plains : they often brouse like the goat, and feed on the tender shoots of trees, which gives their flesh an excellent flavour.' This is to be understood of those which are taken in the chace; for those which are fattened in houses are far less delicious. The flesh of some species are said to taste of musk, which perhaps depends on the qualities of the plants they feed upon." This preface (says Mr. Pennant) was thought necessary, to point out the difference in nature between this and the goat kind, with which most systematic writers have classed the antelopes : but the antelope forms an intermediate genus, a link between the goat and the deer; agreeing with the former in the texture of the horns, which have a core in them, and are never cast; and with the latter in elegance of form and swiftness.

The Common Antelope.-The Antelope, properly so called, abounds in Barbary, and in all the northern parts of Africa. It is somewhat less than the fallowdeer: its horns are about sixteen inches long, surrounded with prominent rings almost to the top, where they are twelve inches distant from point to point. The horns of the antelope are remarkable for a beautiful double flexion, which gives them the appearance of the lyre of the ancients. The colour of the hair on the back is brown, mixed with red; the belly and inside of the thighs white; and the tail short.

The Striped Antelope,-is a beautiful, tall gazelle, inhabiting the Cape of Good Hope; has long, slender shanks ; its horms are smooth, twisted spirally, with a prominent edge or rib following the wreaths; they are three feet nine inches long, of a pale-brown colour, close at the base, and at the points round and sharp. The colour of this animal is a rusty brown; along the ridge of the back there is a white stripe mixed with brown; from this are eight or nine white stripes pointing downwards; the forehead and the fore part of the nose are brown; a white stripe runs from the corner of each eye, and meets just abore the nose; upon each cheek-bone therc are two small white spots; the in. ner edges of the ears are covered with white hair, and the upper part of the neck is adorned with a brown mane, an inch long; beneath the neck, from the throat to the breast, are some long hairs hanging down; the breast and belly are grey; the tail is two feet long, brown above, white beneath, and black at the end.

The $\mathbf{G n u}$, the Hottentot name for a singular animal, which, with respect to its form, is between the horse and the ox.It is about the size of a common galloway, the length of it being somewhat above five feet, and the height rather more than four. This animal is of a dark brown colour: the tail and mane of a light grey: the shag on the chin and breast, and the stiff hairs which stand erect on the forehead and upper part of the face, are black; the curvature of the horns is singular; and the animal is represented in the figure in the attitude of butting, to give an idea of their form and position. The legs of the gnu are small; its hair is very fine : and it has a cavity beneath each eye, like most of the antelope kind.

The Chevrotain and Meminna.-The Chevrotain, or little Guinea Deer, is the smallest of all the antelope kind, the least of all cloven-footed quadrupeds, and, we may add, the most beautiful. Its legs at the smallest part are not much thicker than a tobacco-pipe; it is not more than seven inches in height, and about twelve from the point of the nose to the insertion of the tail; its ears are broad, and its horns, which are straight, and scarcely two inches long, are black and shining as jet; the colour of the hair is a reddish brown; in some a beautiful yellow, very short and glossy. These elegant little creatures are natives of Senegal and the hottest parts of Africa; they are likewise found in India, and in many of the islands belonging to that vast continent. In Ceylon, there is an animal of this kind, called Meminna, which is not larger than a hare, but perfectly resembling a fallow-deer. It is of a grey colour; the sides and haunches are spotted and barred with white; its ears are long and open; and its tail short. None of these small animals can subsist but in a warm climate. They are so extremely delicate, that it is with the utmost difficulty they can be brought alive into Europe, where they soon perish. They are gentle, familiar, most beautifully formed, and their agility is such, that they will 


\section{ANTELOPE.}

bound over a wall twelve feet high. In Guinea, they are called Guevei. The female has no horns.

The Springer Antelope, -is an elegant species, weighs about fifty pounds, and is rather less than a roe-buck; inhabits the Cape of Good. Hope; called there the Spring bock, from the prodigious leaps it takes on the sight of any bolly. When alarmed, it has the power of expanding the white space about the tail into the form of a circle, which returns to its linear form when the animal is tranquil. They migrate annually from the interior parts in small herds, and continue in the neighbourhood of the Cape for two or three months; then join companies and go off in troops, consisting of many thousands, covering the great plains for several hours in their passage : are attended in their migrations by numbers of lions, hyrnas and other wild beasts, which make great destruction among them : are excellent eating, and, with other antelopes, are the venison of the Cape. Mr. Masson in. forms us, that they also make periodical migrations, in seven or eight years, in herds of many hundred thousands, from the north, as he supposes from the interior parts of Terra de Natal. They are com. pelled to it by the excessive drought which happens in that region, when sometimes there does not fall a drop of rain for two or three years. These animals, in their course, desolate Caffraria, spread. ing over the whole country, and not leav. ing a blade of grass. Lions attend them : wherc one of these beasts of prey are, the place is known by the vast void visible in the midst of the timorous herd. On itsap. proach to the Cape, it is observed that the avant guard is very fat, the centre less so, and the rear guard almost starved, being reduced to live on the roots of the plants devoured by those which went before; but on their return they become the avant guard, and thrive in their turn on the re. newed regetation; while the former, now changed into the rear guard, are famished, by being compelled to take up with the leavings of the others. These animals are quite fearless, when assembled in such mighty armies, nor can a man pass through, unless he compels them to give way with a whip or stick. When taken young, they are easily domesticated; the males are very wanton, and are apt to butt at strangers with their horns. The expan. sile white part on the end of the back of this animal is a highly singular circumstance. It is formed by a duplicature of the skin in that part, the inside and edges being milk-white; when the animal is at rest, the edges alone appear, resembling a white stripe, but when alarmed, or in motion, the cavity, or white intermieduate space, appears in form of a large oval patch of that colour.

The Scythian Antelope, or Saigthwhich is the only one of the species tiat is to be found in Europe. The torm of its body resembles the domestic goat, but its horns are those of an antelope, being marked by very prominent riugs, with furrows between; they are a foot long, the ends smooth, of a pale yellow colour, almost transparent. The male is covered with rough hair, like the he-goat, and has a strong scent; the female is smoother, hornless, and timid. The general colour is a dirty white. When they are attacked by wolves or dogs, the males stand round the females, forming a circle, with their heads towards the enemy, in which posture they defend their charge. Their common pace is a trot; when they go faster, it is by leaps ; and are swifter than roe-bucks. When they feed, they are obliged to go backward, owing to the length of the upper lip, which they lift up. Their skin is soft and excellent for gloves, belts, \&c. They are found in flocks from six to ten thousand, on the banks of the Tanais and Boristhenes. The young are easily tamed, and will readily return to their master when turned out on the desert.

The Nilgau, or White-footed Antelope, -is a large and beautiful species, know'n only within the space of a few years past. Its height is four feet one inch to the top of the shoulders, and its length, from the bottom of the neck to the base of the tail, four feet. The colour of the nilgau is a fine dark grey, or slate-colour, with a large spot of white beneath the throat, and two white bands or marks above each foot: the ears are large, white within, and edged with the same colour, and marked internally by two black stripes; along the top of the neck rums a slight mane of black hair, which is continued to some distance down the back, and on the breast is 2 much louger mane or hanging tuft, of a similar colour; the tail is moderately long, and terminated by atuft of black hair : the horns are short, pointed, smooth, triangular at their base, distant from cach other, bent very slightly forwards, and of a blackish colour. The female resembles the male in general appearance, but is considerably smaller, of a pale brown colour, and is destitute of horns : the mane, pectoral tuft, and ears, resemble those of the male, and the feet are marked above the hoofs by three transterse bars of black 
and two of white. The nilgau is a native of the interior parts of India. According to Mr. Pennant, it abounded in the days of Aurengzebe between Delli and Lahor, on the way to Cashmire, and was called nylgau, or the blue or grey bull. It was one of the objects of the chace with that mighty monarch during his journey: they were inclosed by his army of hunters within nets, which, being drawn closer and closer, at length formed a small precinct, into which the king and his omrahs and hunters entered, and killed the nilgaus with arrows, spears, and muskets; and that sometimes in such numbers, that Aurengzebe used to send quarters as presents to all his grcat people. The nylgau has of late years been often imported into Europe, and has bred in England. In confinement it is generally pretty gentle, but is sometimes seized with fits of sudden caprice, when it will attack with great violence the objects of its displeasure. When the males fight, they drop on their knees at some distance from each other, and gradually advance in that attitude, and at length make a spring at each other with their heads bent low. This action, however, is not peculiar to the nilgau, but is observed in many other of the antelope tribe. The nilgau is said to go with young about nine months, and to produce sometimes two at a birth : the young is of the colour of a fawn.

Antelope Leucoryx, or White Antelope, -is entirely milk-white, except the markings on the face and linbs. It is an inhabitant of an island in the Gulf of Bassora. See Plate Mammalia, fig. 1-6.

ANTHEM, a church song performed in cathedral service by choristers, who sing alternately. It was formerly used to de. note both psalms and hymns, when sung in this manner. But at present, anthem is used in a more confined sense, being applied to certain passages taken out of the scriptures, and adaptêd to a particular solemnity.

ANTHEMIS, in botany, chamomile, a genus of the Syngenesia Superflua class and order. Receptacle chaffy; seeds generally crowned with a slight border ; calyx hemispherical, nearly equal; florets of the ray more than five, oblong. There are two divisions of this genus, namely, $\mathbf{A}$. with a differently coloured or white ray; and B. ray the colour of the disk, or yellow: there are about forty species.

ANTHERÆ, among botanists, denote the little roundish or oblong bodies, on the tops of the stamina of plants.

The antherz is the principal part of the male organ of generation in plants, an- swering the glans penis in animals. It is tumid and hollow, containing a fine pow:der, called farina focundans.

ANTHERICUM, in botany, a genus of plants of the Hexandria Monogynia class and order. Cor. six-petalled, spreading, pernıanent; filaments uniform; capsule supcrior, seeds angular. There are three divisions. A. leaves channelled; filaments mostly beardless : B. leaves fleshy ; fila. ments bearded : C. stamina dilated in the middle; root bulbous. There are between 50 and 60 species.

ANTHERYLIUM, a genus of the ICOsandria Monogynia class and order. Calyx inferior, four-parted; petals four; capsule one-celled, three-valved, manyseeded. There is but a single species, a tree found at St. Thomas's Island.

ANTHISTERIA, in botany, a genus of the Polygamia Monoecia class and order. Hermaphrodite; florets sessile, male florets pedicelled; calyx four-valved, three or four flowered, coriaceous; corol. glume two-valved, awnless; filaments three; styles two; stigmata clavate; seed one. There is but a single species.

ANTHOCEROS, a genus of the Cryptogamia Hepatica. Male; six parted or entire; antherr three to eight, obovate, in the bottom of the calyx. Female ; calyx sessile, cylindrical and entire. There are four species.

ANTHOLOMA, in botany, a genus of the Polyandria Monogynia class and order. Calyx two to four-leaved ; cor. cupshaped; many seeded. 'There is but a single species, a shrub found in Caledonia.

ANTIOLYZA, in botany, a genus of the Triandria Monogynia class and order. Corol. tubular, 'six-cleft, unequal, recurved; capsule inferior. There are six spe. cies, all found at the Cape.

ANTHOSPERMUM, in botany, the amber-tree, a genus of plants belonging to the Tetrandria class and order. It is male and female, in different plants, and some are hermaphrodites. The androgynous flower is of one leaf, with two pistils and four stamina, with the germen below the flower. The male flowers are the same with these, wanting only the pistils and germen. The female fiowers have the pistils and germen, but want the stamina. There are three species.

ANTIIOXANTHUM, in botany, a genus of the Dyandria Digynia class and order. Gen. char. calyx, glume two-valved, one flowered; corol. glume two-valved, pointed, awned; seed one. There are four species.

ANTHRENUS, in natural history, 2 


\section{ANT}

genus of insects of the order Coleoptera. Essen.char. antennze clavate, the club so. lid; feelers unequal, filiform; jaws mcmbranaceous, linear, bifid; lip entire ; head hidden under the thorax. "There are 13 species, of which the muscoreum is very destructive to collections of preserved animals, insects, \&cc.

ANTHROPOMORPHA, in the Linnx. an system of zoology, a class of animals, resembling in some degree the human form ; the distinguishing characteristic of which is, that all the animals comprehended in it have four fore teeth in each jaw, and the teats are situated on the breast. Besides the human species, which stands at the head of this class, it likewise com. prehends the monkey and sloth kinds.

ANTHYLLIS, the bladder lotus, in botany, a genus of the Diadelphia Decandria class of plants, the corolla where of is papilionaceous; the fruit is a small roundish legume, composed of two valves, and containing one or two seeds. This genus is scparated into the A. herbace. ous, and B. shrubby ; there are of the former 12 species, of the latter nine.

ANTICHORUS, in botany, a genus of the Octandria Monogynia class and order. Calyx four-leaved; petals four; capsule superior, subulate, four-celled, four.valved; seeds numerous. There is only one species, found in Arabia.

ANTIDESMA, in botany, a genus of the Dioecia Pentandria class of plants, the calyx of which is a pcrianthium, consisting of five oblong, concave leaves ; there is no corolla; the fruit is a cylindric berry, containing one cell, in which is lodged a single seed. There are three spe. cies, found in the East Indies and China.

ANTIMONY, in mincralogy, one of the metals that is britule and easily fused. No metal has attracted so much of the attention of physicians as antimony. One par. ty has extolled it as an infallible specific for every disease : while another decried it as a most virulent poison, which ought to be expunged from the list of medicines. Antimony, as it occurs under that name in the shops, is a natural compound of the metal with sulphur. To obtain it in a metallic state, the native sulphuret is to be mixed with two-thirds its weight of acidulous tartrite of potash, (in the state of crude tartar,) and one-thircl of nitrate of potash deprived of its water of crystal. lization. The mixture must be projected, by spoonfuls, into a red-lot crucible; and the dctonated mass poured into an iron mould greased with a little fit. The antimony, on account of its specific gravit?,
ANT

will be found at the bottom, adhering to the scorix, from which it may be separated by the hanmer. Or three parts of the sulphuret may be fused in a covered crucible, with one of iron filings. The sulphur quits the antimony, and combines with the iron. Antimony in its metallic state (sometimes called regulus of antimony) is of a silvery white colour, very brittle; and of a plated or scaly texture. It is fused by a moderate heat; and crystallizes, on cooling, in the form of pyramids. In close vessels it may be vola. tilized, and collected unchanged. It un. dergoes little change when cxposed to the atmosphere at its ordinary temperature; but when fused, with the access of air, it emits white fumes, consisting of ar oxide of the metal. This oxide had formerly the name of flowers of antimony. Antimony combines with phosplioms and sulphur. With the latter, an artificial sulphuret is formed, exactly resembling the native compound, which last may be employed, on account of its cheapness, for exhibiting the properties of this combination of antimony. Antimony is dis. solved by most of the acids. Sulphuric acid is decomposed, sulphurous acid being disengaged, and an oxide formed, of which a small proportion only is dissolved by the remaining acid. Nitric acid dissolves this metal with great rehemence; muriatic acid acts on it by long digestion; but the most conrenient solvent is the nitro-muriatic acid, which, with the aid of heat, dissolves it from the native sulphuret. With oxygenized muriatic acid, it forms a compound of a thick consistence, formerly called butter of antimony. This may be formed by exposing black sulphuret of antimony to the fumes of oxygenized muriatic acid, and subsequent distillation; or by distilling the powdered regulus with twice its weight of corrosive muriate of mercury. The metal becomes highly oxydized, and unites with muriatic acid in its simple state. On pouring this compound into water, a white oxide falls down, cal!ed powder of algaroth. Antimony is susceptible of various states of oxydizement. The first oxide may be obtained by wash. ing algaroth powder with a little caustic potash. It is composed of $18 \frac{3}{3}$ oxygen, and $81 \frac{1}{2}$ metal. That formed by the ac. tion of nitric acid on antimony contains 77 metal, and 23 oxygen. See Oras, analysis of.

ANTINOMIANS, in church history, a sect of Christians, who reject the moral law as a zule of conduct to believers, 
disown personal and progressive sanctification, and hold it to be inconsistent for a believer to pray for the forgiveness of sins. Although these principles will, by some, be thought to lead to mischievous consequences and practice, yet there are, unquestionably, worthy men and virtuous Christians, who avow Antinomian tenets. To the young, the giddy, and the thought. less, such sentiments might, if acted upon, be the source of much evil; but these, like the doctrine of necessity, are rarely believed, but by persons who have already attained to virtuous habits.

ANTIPATHES, in natural history, a genus of worms of the order Zoophyta. An animal growing in the form of a plant: stem expanded at the base, internally horny, beset with small spines, externally covered with a gelatinous flesh, beset with numerous polype-bearing tubercles. There are 13 species. A. spiralis inha. bits the Indian, Mediterranean, and North seas; of a hard, horny, black substance, exceeedingly brittle, very long, and variously twisted, about the size of a writing pen. A alopecuroides, with spinous setaceous closely panicled branclies; inhabits South Carolina; about two feet high, and rises from a broad spread base, dividing into several large branches, flat on one side, with a groove along the mid. dle; it then subdivides into smaller branches, forming close panicles, not unlike the fox-tail grass : the outside greyish, the inside black, and very brittle.

ANTIPODES, in geography, a name given to those inhabitants of the globe that live diametrically opposite to one another. They lie under opposite parallels, and opposite meridians. They have the same elevation of their different poles. It is mid-night with the one, when it is noonday with the other; the longest day with one is the shortest with the other; and the length of the day with the one is equal to the night of the other. See GLO BES, use of.

ANTIQUARY, a person who studies and searches after monuments and re. mains of antiquity.

There were formerly, in the chief cities of Greece and Italy, persons of distinc. tion, called antiquaries, who made it their business to explain the ancient inscriptions, and give every other assistance in their power to strangers, who were lovers of that kind of learning. Foundations of this kind have existed in England. Sir H. Spelman speaks of a society of antiquaries in his time, which had been instituted in 1572, by Archbishop Parker,
Camden, Sir Robert Cotton, Stowe, and others. Application was made in $\mathbf{1 5 8 9}$ to Queen Elizabeth for a charter, and house, in which they might hold their meetings, erect a library, \&c. But the death of the sovereign put an end to the design. In 17 17, this society was revived again, and has continued without interruption; and at present, it is in a very flourishing state, consiting of learned men in every rank of life. The society was incorporated in 1751 , and began to publish an account of its discoveries in 1770, under the titlo of "Archrologia:" fifteen volumes in quarto are already pub. lished.

ANTIQUITIES, $\dot{a}$ term implying all testimonies, or authentic accounts, that have come down to us of ancient nations. According to Lord Bacon, antiquities may be considered as the wrecks of history, or such particulars as industrious and learned persons have collected from genealo. gies, inscriptions, monuments, coins, names, etymologies, archives, instruments, fragments of history, \&c.: in this sense the study of antiquities leads us to inquire into the origin and early epochas of every nation and people, whether ancient or modern. Hence the study of antiquities, as a science, has become, in almost every civilized country, an interesting pursuit to men of leisure and curiosity. By many persons it has been sufficient to investigate the ancient remains of Greece and Rome ; but others, who have taken a more enlarged, and, what we deem, a more proper view of the subject, include in the science the antiquities of the Jews, Egyptians, Pbonicians, Carthaginians, and, in short, all those principal nations mentioned in ancient history. Our view of the subject must necessarily be contracted, and the most we can aim at is, to excite a laudable curiosity in the young, and to direct them to objects that may engage their attention, and to the authors most likely to furnish information under the several heads of inquiry and research.

This study has for its chief objects the ceremonies, customs, and usages, which obtained in ancient times, either with regard to persons, places, or things. Writers have accordingly divided antiquities into civil and ecclesiastisal; including under the former head whatever relates to political, military, literary, and domes. tic concerns; and under the latter, the subjects connected with religion as the worship, discipline, and faith of ancient times and people. Christians have usually 


\section{ANTIQUITIES.}

separated their antiquities into those which relate to the ancient state of the Christian church; and into whatever belongs to the ancient laws, ceremonies, events, \&c. that occur in the scriptures. These, indeed, farm a branch of ecclesiastical antiquitics, and bear a near relation to the Jewish antiquities, concerning which we have many respectable authorities. There are persons who would deduce most of the heathen antiquities from the manners and customs described in the Bible; while others, as Spencer, take the opposite course, and deduce the antiquities of the Bible from those of hicatherism. Perhaps a middle course would be nearer the truth, as it is absolutely necessary, in interpreting scripture, to attend to the heathen antiquities alluded to in them; and these not only such as are directly aimed at or approved, but also such as are purposely opposed. National antiquities are those employed in tracing the origin, ancient actions, usages, monuments, remains, \&cc. of some nation or people : and it may be observed, that almost every nation lays claim to a greater degree of antiquity than the rest of its neighbours. The Scythians, the Phrygians, the Chaldeans, Egyptians, Greeks, Chinese, \&cc. pretend each to have the honour of being the first inhabitants of the earth : several. of these nations, lest they should be surpassed in their pretensions by any of the rest, have traced up their origin to ages long before the received account of the creation. Ience the appellations, "sborigines," "indigenx," "terragenx," "antelunares," \& c.

The history and antiquities of nations and societies have been objects of inquiry: inasmuch as they enable the mind to se. parate truth from falsehood, and tradition from evidence; to establish what had pro. bability for its basis, or to explode what rested only on the vanity of the inventors and propagators : of this we have a striking instance in the Chaldeans, who pretend to astronomical observations of nearly 500,000 years. They mention the king who reigned over them at the time of the delige, and attribute to hin several things which we ascribe to Noah. The Chaldaic antiquities of Berosus are, however, lost, except a few fragments, which have been collected by Joseph Scaliger and Fabricius. To supp? the chasn, Annius Viterbo, a Dominican monk, towards the close of the 15tli century, forged the work of Berosus, which lie published at Rome in 1498. Ife went farther, and produced a supplement to Berosus; supposed to have been written by Manetho, containing details of what happened from the time of Egyptus, king of Egypt, to the origin of the IRoman state. ' Unfortunately for the credit of the industrious monk, Manetho lived before Berosus, by which the fraud was detected.

The first traces of every history were rude and imperfect, which renders the office of the antiquarian of the utmost im. portance to the faithful and diligent historian. Better methods of preserving facts succeeded. The unchsiseled stone, or the rudest hieroglyphic, accompanied the songs of the bards, to perpetuate the achievements of a whole nation, or a few individuals; till the use of letters, and the complicated transactions, claims, and interests of men, taught them to multiply memorials, and draw them up with more skill and accuracy.

The history contained in the Old Testament is unquestionably the most ancient well-authenticated collection of facts, that has come down to the present times. These records go much beyond the flood, the boundary to the annals of every other nation that lays a just claim to credit. The Jews, who are closely connected with this part of history, trace back their ancestry to the common parents of the human race. The antiquities of this wonderful nation have been treated of by numerous writers, whose works are monuments of great learning and indefatigable industry; and it will be admitted, that the fate of a people scattered over the globe, who have been subject to persecutions, more or less severe, for so many centuries, who have never amalgamated, if we may so speak, with any other nation under heaven, but have remained distinct, for wise and important ends, cannot but interest the curious inquirer. The history of their origin, ordinances, and vicissitudes, previously to the Christian $x \mathrm{ra}$, is to be had in the old Testament: their subsequent ruin and dispersion are predicted by Christ in the New Testament, and treated of at large by Josephus, who flourished at Rome under Vespasian, Titus, and Domitian, and who published his great work on the Jewish Antiquitics during the life and reign of the latter. On the same subject we have a multitude of more modem writers, from Ugolinus' Thesaurus, consisting of more than thirty volumes folio, and comprising all the best works written previously to the mid. dle of the last century, to the octavos Dr. Jennings evidently intended as a roere introduction to the subject. The antiquitics 


\section{ANTIQUITIES.}

of the Jews are supposed to be connected with those of Egypt, since Moses, their great lawgiver, was educated in the schools of Egyptian learning, and was deeply conversant in all their sciences. Many of the metaphors and other allu. sions, found in the first five books of the Bible, are supposed to have some refer. ence to the symbols of the Egyptian priests. If we were, therefore, able to come at a faithful account of the antiquities of Egypt, we might hope to attain an illustration of many things which are still obscure and dark, belonging to the Jewish economy, both civil and sacred. Of Egypt, alas! once renowned for its laws, the commerce of her cities, the grandeur of her buildings, and the fertility of territory, little is left to gratify the laudable curiosity of moderns. Those who have spent much time and labour, in appreciating the worth and merits of the ancients, admit that the earliest nations of the world were fed with the produce of Egyptian soil, and enriched with the wealth and wisdom obtained in that portion of Africa. Upper Egypt furnished the materials of marble and porphyry, with which the most supendous works of art were reared: and to Hermes Trismegistus, or, as he is sometimes called, Thoth, are ascribed, among the Egyptians, the inventions of chief use in human life. Their priests maintained, that from their hieroglyphic characters upon the pillars which he erected, and the sacred books, all the philosophy and learning of the world has been derived.

Egypt seems itself to have been indebted for its original population to the northern parts of Arabia and Syria, the Egyptians and Abyssinians having been always wholly distinct from the native nations of Africa. The Copts, or original inhabitants, it has been observed by tra. vellers, have no resemblance whatever of the negro features or form; but a strong likeness may be traced between the make of the visage in the modern Copts, and that presented in the ancient mummies, paintings, and statues. Their complexion, like that of the Arabs, is of a dusky brown. It is represented of the same colour in the paintings which may be seen in the tombs of Thebes. The chief antiquities are, the pyramids, and the tombs near Thebes, recently disclosed, with many ruins of temples, and other remains of ancient cities. Dr. White, in the "Egyptiaca," a work which contains much valuable information on the subject, says, the celcbrated column ascribed to Pompey ornamented a space opposite the temple of Serapis, in which was a great public library. Besides the ancient remains already noticed, we may mention the co. lossal sphynx; Cleopatra's needle; the marble Sarcophagus, reputed to be Alex. ander's tomb; and the triple inscription from Rosetta, in the hieroglyphic, the vernacular Egyptian, and the Greek characters. The writers on Egyptian antiquities are very numerous. Among the ancients may be noted, Herodotus, Pausanias, Strabo, Diodorus Siculus, and Plutarch. He. rodotus, Thales, and Pythagoras, were initiated into all the mysteries of the Egyptian priests. The mythology of the country is fully explained in Joblonski's "Pantheon Egyptiacum." On the Egypt of modern times we have the works of Pocock, Niebuhr, Sonnini, and Denon, which may be consulted with advantage. Greaves and Nordon have written on the pyramids, and the mummies are described by the celebrated Kircher.

The illustration of the antiquities of India is more difficult, but discoveries are still making in that vast extent of country. To that great patriot, philosopher, and legislator, Sir William Jones, we are greatly indebted for much valuable information on this subject. Mr. Halhed, indeed, in 1776, gave the first specimen which appeared of the early wisdom of the Indians, and their extensive skill in jurisprudence. In the year 1785, the Bhagvat Geeta was edited by Mr. Wilkins. The theological and metaphysical doctrines of this work were represented to be of the profoundest kind, and it was said to contain all the grand mysteries of the Hindoo religion, and laid claim to the antiquity of 4000 years. Other works of high reputation have succeeded; among these are the "Indian Antiquities," by Maurice, which have, in a great measure, cleared the ground for the student, and given him a sort of clue for farther inves. tigations. By his labours, the ancient geographical divisions of India, according to the classical writers of Greece and Rome, and of Hindostan, according to the Hindoos themselves, are reconciled; the analogies of the Brahmanic with other sys. tems of theology considered, and the grand code of civil laws, the original form of government, and the literature of Hindostan, are compared with the laws, government, and literature of Persia, Egypt, and Greece. From Sir William Jones's papers, published in the several volumes of the "Asiatic Researches," much solid information on Indian antiquities may be 


\section{ANTIQUITIES.}

had in a short compass. By that great man, wliose loss cannot be sufficiently lamented, a society was formed for in. quiring into the history, antiquities, arts, sciences, and literature of Asia. Having founded the institution, he gave it celebrity by his own admirable discourses; of these the first was on the orthography of Asiatic words in Roman lctters, a want of attention to which had occasioned much confusion in history and geograpliy. Not contented with pointing out radical defects, he proposed a system, which was useful to the learned, and essential to the progress of the student. His other dissertations, to which the reader may bo referred, werc all, in a greater or less degree, connected with the antiquities of India. By India is meant the whole extent of country in which the primitire religion and languagc of the Hindoos prevail at this day, and in which the Nagsari letters are still used, with more or less deviation from their original form. Its inhabitants have no resemblance, either in their figure or manners, to any of the na. tions contiguous to them. Their sources of wealth are still abundant. In their manufactures of cotton they surpass the other nations of the world; and though now degenerate and abascd, there remains enough to show, that in some early age they were well versed in arts and arms, happy in government, wise in legisla. tion, and eminent in various branches of knowledge.

In this place we may briefly notice the Sanscrit language, which, whatever may be its antiquity, is of a very singtlar structure; more perfect than the Greek, more copious than the Latin, and more refined than either, yet bearing to both a stronger affinity, both in the roots of verbs, and in the forms of grammar, than could possibly have been produced by accident. of their philosoplyy it has been observed, that in the more rctired scenes, in groves, and in scminaries of lcarning, we may perceive the Brahmans and the Sarmanas of Clemans disputing in the forms of logie, or discoursing on the vanity of human enjoyments, on the immortality of the soul, her'cmanation from the cternal mind, her debasement, wanderings, and final union with her source.

The ancient monuments of Hindostan are very numerous, and of various descriptions, exclusive of the tombs and other edifices of the Malıometan conquerors. Some of the most remarkable are, excavated temples, statues, relievos, \&ic. in an island near Bombay; but the most mag-

VOL. 1. nificentand extensive are ncar the town of Ellora, about two hundred miles cast of Bombay. The latter are minutely described, andillustrated with plates, in the sixth volume of the Asiatic Reserrches. The idols represented seem clcarly to belong to the present mytliology of Hindostan: but at what period these edifices were modelled, whether threc hundred or three thousand years ago, cannot be easily ascertained. Several ancient grants of land, some coins, and seals, have also been found, which, however, do not greatly correspond with the exaggerated icleas entertained concerning the early civilization of this renowned country; while the Egyptain pyramids, temples, and obelisks, strongly confirm the accounts preserved by ancient historians. Though the mythology of the Hindoos may pretend to great antiquity, yet their present form of religion is supposed to vary considerably from the ancient. It is inferred, that whilc the religion of Boodha, still retained by the Birmans and other adjacent nations, was the real ancient system of Hindostan, the religion of the Hindoos is artfully interwoven with the common offices of life; and the different casts are supposed to originate from Brahma, the immediate agent of creation, under the Supreme Power.

The remains of architecture and sculp. ture scem to prove an early connection between Inclia and Africa. Of the ancient arts and manufactures little is known, excepting the labours of the Indian loom and needlc. The Hindoos are said to have boasted of three inventions, viz. the method of instruction by "apologues," "the decimal scale," and "the game of chess"

Of the antiquities of Greece and Rome much lias been written that merits the attention of the student in literature: these are subjects, in which every well educated youth is made conversant at an carly period. They are taught in all our classical schools, as necessary to the elucidation of those works that are read in the attaimment of the ancient languages. Potter on the Greek antiquitics, and Kennet and Aclarus on those of Roman, are familiar to every ear: in their kind they are truly respectable, though they may bc regarded only as elementary treatises calculated rather to excite a taste for the study, than to satisfy the inquirer in pursuit of knowledge.

The first accounts of Greece are derived. from ages long before the common usc of letters in the country, so that it is difficult

kk 


\section{AN'TIQUI'TIES.}

to distinguish where fable concludes, and real history begins. From the Phœnician and Egyptian colonies, the Greeks first reccived the culture of humanity. By the Plocnicians, they were instructed in trade, navigation, and the use of letters; and by the Egyptians in civil wisclom, the politer sciences, and religious mysteries. The antiquities of such a country, which became in after ages so illustrious in the annals of mankind, cannot fail to have excited a considerable degree of interest in every age : they have accordingly been carefully and minutely investigated, by writers celebrated alike for their erudition and industry. Of these we can enumerate but a small portion, in comparison of the many that have treated on the subject. Bishop Potter, to whom we have already referred, Bos, and others, have drawn up systems or abridgments of the whole, or at least of whatever relates to the religion, the gods, the vows, and the temples of Greece : on the public weal and magistracy, Stephanus and Van Dale are well worthy of notice : on the laws and punishments of Greece, we have Meursius and Petit : on military concerns, Arrian and Elian are well known: on their gymnastic art, and exercises, Joubert and Faber may be mentioned: on the theatres and scenic exhibitions, Scaliger and the abbe Barthelemy have written : besides these, we have many writers on their entertainments, on their marriages, the education of their children, and their funeral ceremonies. The best relics, which display the former splendour of the Grecian states, have been preserved by Stuart in his Athens : in the Ionian Antiquities, and in the Voyage Pittoresque de la Greece. The finest specimens of its sculpture, in this country, are to be found among the Townly marbles : and of its coinage, in the cabinet of Dr. Hunter.

It may be worthy of notice, in connection with the antiquities of Greece, that the ancient monuments of European Turkey now exceed in number and importance those of any other country. The remains of ancient Athens, in particular, formerly the chosen seat of the arts, have attracted the attention of many travellers, and have accordingly been frequently described with accuracy and taste. The church dedicated to the Divine Wisdom, usually denominated in the page of history Sancta Sophia, is a venerable monument of antiquity, and has been preserved from the sixth century, when it was built by Justinian,' to the present period. The architecture is very inferior to that of the classical period, yet, by those who have witnessed it, we are told the effect is grand and impressive, and the cupola is admired as a bold and skilful effort of the art, while the seeming weight is diminished by the lightness of the materials, being bricks formed of a particular clay that will float in the water. The interior is adorned with columns of various and very beautiful descriptions, viz. the Phrygian purple, the Spartan green, the red and white Canan, and many others. To this may be added, that the French have recently discovered the remains of an ancient sea-port belonging to Sparta, near a promontory which projects from the south of the Morea, and we are informed that the antiquities of that part, now styled Albania, still present an extensive field of researcli to the student in this department of science.

" Nothing," says Dr. Adams, in the preface to his Roman Antiquities, "has more engaged the attention of literary men, than to trace from ancient monuments the institutions and laws, the religion, the manners and customs of the Romans, under the general name of Roman Antiquities. This branclı of knowledgre," continues he, " is not only curious in itself, but absolutelynecessary for the understanding the classics, and for reading with advantage the history of that celebrated people. It is particularly necessary for such as prosecute the study of the civil law. Scarcely on any subject havemore books been written, and many of them by persons of distinguished abilities." We may, as a guide to the student, enumerate the writersfrom whom Dr. Adams chiefly compiled his own work, as these will be the best au. thorities for those persons who would enter deeply into the study. To Manutius, Brissonius, and Middleton, he was indebted for his facts relating to the business of the senate: to Pignorius, on slaves : to Lidonius and Grucchius, Manutius, Huber, Gravina, Murula, Heineccius, for what re. lates to the assemblies of the people, the rights of citizens, the laws and judicial proceedings : with respect to the duties and privileges of magistrates, the art of war, the shows of the circus, and the feats of gladiators, he had recourse to Lipsius: - to Sheffer he applied for information on naval affairs, and earriages : to Kermannus, on funerals : to Arbuthnot, on coins: to Donatus, on the city : to Turnebus, Salmasius, Grevius, Gronovius, Montfaucon, Gesner, and others, upon different subjects scattered through his work. To these may be added one of the 


\section{ANTIQUITIES.}

oldest authors on the subject, ri:. Diony sius Ilalicarnassus, who traced the origin of the Romans, with great fidelity, back to the remotest ages. His accounts are generally preferred to those of Liry, because they are more ample, and his facts are described with more particulars; and on the ceremonies, worship, sacrifices, manners, customs, discipline, policy, courts, laws, \&c. he is perhaps the most autlentic writer.

These, and other authors that might be cited, have chiefly confuned their account to Rome, properly so called; we might digress, and notice the antiquities of those states, both in Europe and other parts of the globe, which were held under the dominion of the Roman power; but this would lead us into a very wide field: we slaall, however, in the connection, notice those belonging to Spain, which was 500 years under the Roman power.

Spain was originally peopled by the Africans and German Gauls : it then became the prey of the Cartliagenians : to these succeeded the Romans. It was afterwards held successively in subjection by the Vandals, the Visigoths, and the Arabs or Moors.

Of the first of these epochs few remains exist, excepting some tumuli, and other rude monuments. Nor are there any certain relics of the Carthagenians in Spain but coins, which have been found in considerable numbers. The Roman antiquities are numerous, of which, however, we shall notice but few. The aqueduct at Segovia is a noble edifice, consisting of 159 arches, extending about 740 yards, and is rather more than 94 fect in height where it crosses the valley. Morviedo, the ancient Saguntum, and Tarragona, the ancient Tarraco, afford many curious remains of antiquity. The theatre is capable of recciving 10,000 people, and is hewn out of a solid rock, the labour of which was less than might at first be ex. pected, as the Spanish rocks are general. ly calcareous, or of gypsum. The Visigroth kings have left few relics except their coins, which are struck in gold, a inetal at that period unknown to the other Furopean mints. Numerous and splendid are the monuments of the Moors in Spain. 'The mosque at Corlova is one of the chief; this surprizes travellers with the multitude of its columns, which are said to be 800: The Christian antiquities liere, as in other places, are, churches, castles, and monasteries.

The antiquities of Portugal consist also chiefly of Roman monuments, with some
Moorish remains. In the north is an estensive scries of arches, formerly a Roman aqueduct. At Evora are well-preserved ruins of a temple of Diana, and an aqueduct ascribed to Quintus Sertorius, whose life was written by Plutarcl. Among the antiquities of the middle ages may be no. ted the monastery of Batalha, in Fistremadura, 60 miles north of Lisbon, which is allowed on all hands to be one of the no. blest monuments of what is called the Gotliic style of architecture.

English antiquities fall into the following divisions, viz. those belonging to the primitive Celtic inhabitants; those of the Belgic colonies; those of the Romans; those of the Saxons; reliques of the Danes; and, lastly, Norman monuments. Few. of these remains are thought to throw much light upon the history of the country; but, being interesting and curious in themselves, they may, in this article, which is intended as a guide to the study, be briefly noticed. A radical mistake, according to Mr. Pinkerton, in the study of English antiquities, has arisen from the confusion of the Celtic and Belgic lan. guages and monuments. The Druids have deservedly attracted much curiosity and research; but it would be erroneous to impute to them, as is usial, the whole of our earliest remains. Cxsar speaks of Druidism as a recent institution; and if that be the case, it is not improbable that it originated from the Phouician factories, established in wooden fortresses, the usual practice of commercial nations when trading with savage or barbarous people. The tencts correspond with what little exists of Phonician mythology, and the missionaries of that refined people might have some zcal in their diffusion. Ancient authors, who give us all our information concerning the Druids, minutely describe their religious rights, but are totally silent concerning any honuments of stone being used among them. On the contrary, they mention gloomy groves and spreading oaks as the only scenes of the Druidic ceremonies; nevertheless, antiquaries have inferred that Stonehenge is a Druidic monument, though it be situated in an extensive plain, where not a vestige of wood appears, and where the very soil is reputed to be adverse to its vegetation. It would be a vain effort to attempt to discriminate the remains of the earliest inhabitants from those of the Druidic period, and if the opinion of the last-men. tioned author is to be regarded as binding, there is no foundation for any sound or real knowledge on the subject. The following hare been esteemed as the monu- 


\section{AN'TIQUITIES.}

ments of the 1)ruids:-1. Single stones erect. 2. Rock idols and pierced stones. 3. Rocking-stones, used as ordeals. 4. Sepulchres of two, three, or more stones. 5. Circular temples, or rather circles of crect stones. 6 Barrows, or tumuli. 7 . Cromlechs, or heaps of stones. 8. Rockbasins, imagined to have been used in Druidic expiations. 9. Caves, used as places of retreat in time of war. But as most of these relics may also be found in Germany and Scandinavia, it is difficult to say whether they are Gothic or Celtic; and as the Germans had no Druids, we cannot, with any degree of certainty, be. stow the name of Druidic upon such monuments. It is highly probable, that the earliest inhabitants, as is ever the practice in the infancy of society, made use of wood, not of stone, in their religious as well as in their domestic erections. If we survey the rarious savage regions of the globe, we shall seldom, if ever, perceive the use of stone; and it is certainly just to infer, that the savages of the west were not more skilful than those of the east, nor those of the old continents and islands than those of the new. But as many of these monuments are found in Germany, Scandinavia and Iceland, and as the Icelandic writers in particular often indicate their origin and use, which are unknown in the Celtic records, there is every reason to attribute them to a more advanced stage of society, when the Belgic colonies introduced agriculture, and a little further progress in the rude arts of barbarism. The nature of this work will not admit a formal investigation of such topics, but a few remarks may be offered on Stone. lienge, a stupendous monument of barbaric industry. Inigo Jones, in attempting to prove that it is Roman, only evinces that no talents can avail when science is wanting, and that antiquities require a severe and peculiar tıain of study. Doctor Stukely, a visionary writer, assigns Stonehenge to the Druids; while Dr. Charlton, perceiving that such monuments are found in Denmark, ascribed it to the Danes. If the latter liad considered, that the Belgx were a Gothic nation, of similar language and institutions, he might with more justice have extended his antiquity. From the Icelandic writers we learn, that such circles were called domh-ringr, that is lite. rally doom-ring, or circle of judgment, being the solemn places where courts were held, of all kinds and dignities, from the national council down to the baronial court, or that of a common proprietor of land, for adjusting disputes between his villani and slaves. The magnificence of
Stonehenge loudly pronounces that it was the supreme court of the nation, equivalent to the Champs de Mars et de Mai of the Franks, where the king and chiefs as. sembled in the circle, and the men capable of arms in the open plain; nor is it improbable that the chiefs ascended the transverse stones, and declared their resolves to the surrounding crowd, who, in the description of Tacitus, dissented by loud murmurs, or applauded by clashing their shields. This idea reccives confirmation from the circumstance, that the Belgx, peculiarly so called, as being the chief and ruling colony of that people, were seated in the surrounding province, and Sorbiodunum, now Old Sarum, was their capital city. Similar circles of stone, but far inferior in size, are found in many parts of Great Britain and Ireland, and several undoubtedly as late as the Danish inroads and usurpations, the practice being continued by that people at least till their conversion to Christianity, in the tenth and eleventh centuries. Some of the smallest, as we learn from the northern antiquaries, were merely places of family sepulture. At a later period, the circles of judgment, which had been polluted with human sa. crifices and other Pagan rites, were abandoned, and the great courts were held on what were called moot-hills, or hills of meeting, many of which still exist in the British dominions and in the Netherlands. They commonly consist of a central eminence, on which sat the judge and his assistants; beneath was an elevated platform for the parties, their friends and conpurgators, who sometimes amounted to a hundred or more; and this platform was surrounded with a trench, to secure it from the access of the mere spectators. of the other monuments of this period a more brief consideration must suffice. When a monarch or.distinguished general was buried, a barrow or hillock was erected, to preserve his name and memory to future ages; the size depending on the reputation of the person, which attracted a smaller or larger number of operators. Such monuments are very ancient, and even to this day denote the sepulchres of some of the heroes of the Trojan war. In. later times, a large single stone erected was estecmed a sufficientmemorial: such single stones also sometimes appear as monuments of remarkable battles, or merely as boundaries. The caves are familiar to most nations in an early state of society. The Belgic reliques are followed by those of the Romans, whicl are mostly objects of mere curiosity, and rarely throw the smallest light on the page 


\section{ANTIQUITIES.}

of history. Amphitheatres are said to be still visible at Silchester, in Hampshire, and some other places. The Roman castle at Richborough, the ancient Rutupix, in Kent, presents consiclerable remains of a massy wall cemented with surprising firmness. The Roman ruins in this country are commonly composed of stone or flint, with strata of flat bricks at consider. able intervals. The Mosaic pavements, lypocausts, \&:c. are generally the remains of the villas of opulent Romans, scattered over the country. The greatest number of Roman inscriptions, altars, \&cc. has been found in the north, along the great frontier wall, which.extended from the western sea to the estuary of the Tyne. This vast wall is justly esteemed the most important remain of the Roman power in England,as that of Antoninus is in Scotland. The extent was about 70 miles, and its construction, forts, \&c. have been illustrated by the labour of several antiquaries. Numerous are the more minute relics of the Romans in England, as coins, gems, weapons, ornaments, and the like; among which, however, the silver dish belonging to the Duke of Northumber. land deserves especial mention. One of the grand causes of the civilization introduced by that ruling people into the conquered states was the highways, which form, indeed, the first germ of national industry, and without which neither commerce nor society can make any considerable progress. Conscious of this truth, the Romans seem to have lent particular attention to the construction of roads in the distant provinees; and those of England, which may still be traced in various ramifications, present a lasting monument of the justice of their conceptions, the extent of their views, and the utility of their power. A grand trunk, as it may be called, passed from the south to the north, and another to the west, with branches, in almost every direction that general convenience and expedition could require. What is called the Watlingstrect, led from Richborough, in Kent, the ancient Rutupir, N. W. through I.ondon to Chester. The Ermin-street passed from London to Lincoln, thence to Carlisle, and into Scotland, the name being supposed to be corrupted from llerman, which means warrior, as the chief wars lay in the north. The Fosse Way is sup. posed to have led from Batl and the westem regions, N. E. till it joined the Ermin-street. The last celebrated road was the Ikenild, or Ikneld, supposed to have extended from near Norwich, S. WY. into Dorsetshirc. The Saron antiquitiey in England are chicfly edifices, sacred or secular: many churclies remain, which were altogether, or for the most part, constructed in the Saxon period, and some are extant of the tenth, or perhaps the ninth century. The vaults erected by Grimbald, at Oxford, in the reign of Alfied, are justly esteemed curious relics of Saxon arehitecture. Mr. King has ably illustrated the remains of the Saxon castles. The oldest seem to con. sist of one solitary tower, square or hexagonal : one of the rudest specimens is Couingsburg Castle, in Yorkshire; but as that region was subject to the Danes till the middle of the tenth century, it is probably Danisl. Among the smaller remains of Saxon art may be mentioned, the shrines for preserving relies, which some suppose to present the diminutive rudiments of what is styled the Gothic archi. tecure; and the illuminated manuscripts, which often afford curious memorials of the state of manners and knowledge. The Danish power in England, though of eonsiderable duration in the north, was in the south brief and transitory. The camps of that nation were circular, like those of the Belgre and Saxons, while those of Roman armies are known by the square form: and it is believed that the only distinet relics of the Danes are some castles to the north of the Humber, and 2 few stones with Runic inseriptions. The monuments styled Norman, rather to dis. tinguish their epoch than from any information that Norman architects were employed, are reputed to commence after the conquest, and to extend to the fourteenth century, when what is called the rich Gothic began to appear, which in the sixteenth century was supplanted by the mixed, and this in its turn yielded to thic Grecian. In general, the Norman style far exceeds the Saxon in the size of the edifices, and the decoration of the parts. The churches become more extensive and lofty, and though the windows retain the circular arch, they are larger and more diversified; the circular doors are festooned with more freedom and elc. gance; and uncoutl animals begin to yield to wreaths of leaves and flowers. "The solitary keep, or tower, of the Saxon castle is surrounded with a double wall, inclosing courts and dwellings of largo extent, defended by turrets and clouble ditches, with a separate watch-tower called the Barbican. Among others, the cathedrals of Durhum and Winchester may be mentioned as vencrable monu- 


\section{ANTIQUITIES.}

ments of Anglo-Norman architecture; and the castles are numerous and well known. What is called the Gothic, or pointed arch, is generally supposed to have first appeared in the thirteenth century, and in the next it became universal in religious edifices. The windows diffused to great breadth and loftiness, and divided into branching interstices, enriched with painted glass ; the clustering pillars, of excessive height, spreading into various fret-work on the roof, constitute, with decorations of smaller note, what is called the rich Gothic style, visible in the chapel of King's college at Cambridge, and many other grand specimens in this kingdom. The spire corresponds witl the interior, and begins about the thirteenth century to rise boldly from the ancient tower, and diminish from the sight in a gradation of pinnacles and ornaments.

We now proceed to Scotland, the original population of which is supposed upon yood authority to consist of Cimbri, from the Cimbric Chersonese. About two centuries before the Cliristian ara, the Cimbri seem to have been driven to the south of Scotland by the Caledonians, or Picti, a Gothic colony from Norway. The Cimbri, a congenerous people with the Welch, continued to hold the country south of the two firths of Forth and Clyde; but from the former region they were soon expelled by the Picti, who, in this comer, bccame subject for a time to the AngloSaxon kings of Bernicia. On the West, the Cumraig kingdom of Strath Clyde continued till the tenth century, when it became subject to the kings of North Britain; who at the same time extencled their authority, by the permission of the Finglish monarch, over the counties of Cumberland and Westmoreland, which, abounding with hills and fortresses on the south and east, were little accessible to the English power, and, while the Danes possessed the country to the north of Humber, could vield little revenue or support to the Anglo-Saxon mouarchs. From the Picti originates the population of the Lowlands of Scotland, the Lowlanders having been in all ages a distinct people from those of the westem Higllands, though the Irish clergy endeavoured to render theirlanguage, which was the most smooth and cultivated of the two, the polite dialogue of the court and superior classes. About the year of Christ 258, the Dalriads of Bedc, the Attacotti of the Roman writers, passed from Ireland to Argyleshire, and became the germ of the Scot- tish Highlanders, who speak the Irish or Celtic language, while the Lowlanders have always used the Scandinavian or Gothic. In reference to the antiquities of the country, Mr. Pinkerton divides the early history into seven distinct periods, $v i z .1$. The original population of Scotland by the Cimbri, and by the Picti. 2. The entrance of Agricola into Scotland, and the subsequent conflicts with the Romans, till the latter abandoned Britain. 3. The Settlement of the Dalliads or Attacotti, in Argyleshire, about the year 258 , and their repulsion to Ireland about the middle of the fifth century. 4. The commencement of what may be called a regular history of Scotland, from the reign of Drust, A. D.414. 5. The return of the Dalraids, A. D. 503, and the subsequent events of Dalriadic story. 6. The introduction of Christianity among the Caledonians, in the reign of Brudi II. A. D. 565. 7. The union of the Picti and Attacotti, under Kenneth, A. D. 843, after which greater civilization began to take place, and the history becomes more authentic. The monuments of antiquity belonging to these epochs may be considered in the following order. Of the first epoch, no monuments can exist except those of the tumular kind; and it is impossible to ascertain the period of their formation. The remains of the Roman period in North Britain chiefly appear in the celebrated wall built in the reign of Antoninus Pius, between the firths of Forth and Clyde, in the ruins of which many curious inscriptions have been found. Another striking object of this epoch was a small edifice, vulgarly called Arthur's oven, which seems rightly to have been regarded by some antiquaries as a small temple dedicated to the god Terminus, probably after the erection of the wall of Antoninus, for we are not to conceive these walls were the absolute lines beyond which the Romans possesscd no teritory; while, on the contrary, in the pacific intervals, the garrisons along the wall may have claimed the forage of the exterior fields; and the stream of Carron, beyond which this chapel stood, may have been considered as a necessary supply of water. The remains of the wall and forts, and other Roman antiquities, in Scotland, particularly their camps and stations, many of which are remarkably entire, are ably illustrated in a late publication of General Roy; but the ingenious author has perhaps too implicitly followed a common antiquarian error, in ascribing all these camps, stations, \&c. to Agricola, 
while they may be more justly assigned to Lollius Urbicus, A.D. 140 , or to the Emperor Severus, A. D. 207, especially in. deed to the latter; for the Emperor's appearance, in person, to conduct two cam. paigns, probably as far as Inverness, must have occasioned the erection of works more eminent and durable than usual, the soldiers being excited by the animating controul of a military monarch. Constantius Chlurus also, A. D. 306 , made a long progress into Scotland, if we trust the panegyrists. Nay, in the reign of Domitian, Bolanus, as we learn from Statius the poct, erected several works in Britain, probably in the north; so that it is idle to impute these remains to any one author; but to a judicious eye, the claims of Lollius Urbicus, and of Severus, seem preferable. The most northerly Roman camp, yet discovered, is that near the source of the river Ythan, Aberdeenshire; periphery about two English miles.

smaller station has also been observed at Old Mieldrum, a few miles to the S. E. Roman roads have been traced a considerble way in the east of Scotland, as far as the county of Angus, affording some evidence of the existence of the province of Vespasiana; but the chief remains are within the wall. A hypocaust was also discorered near Perth, and another near Musselburg, so that there was probably some Roman station near the Scotish capital. The smaller remains of Roman antiquity found in Scotland, as coins, utensils, \&c. are numerous. With the fourth epoch may be said to commence the likish monuments of antiquity. The tombs it would be difficult to discriminate from those of the first epoch; but as the Caledonian kings, when converted to Christianity, held their chief residence at Inverness, the singular hill in its vicinity, presenting the form of a boat reversed, may, perhaps, be a monument of regal sepul. ture. The places of judgment among the Gothic nations, or what are now styled Druidic temples, are numerous; and there is a remarkable one in the Isle of Lewis, where, probably, the monarchs resided in the most early times; but this, perhaps, rather belongs to the Norwegian settlement in the ninth century. Some of these monuments are of small circuit; and such are sometimes found at no great distance from each other; as they were not only sometimes erected merely as temples to Odin, Thor, Freyga, and other Gothic deities, but every chief, or lord of a manor, having jurisdiction over many servants and slares, such small courts be. came placesofnecessary awe. The louses seem to have been entirely of wood or turf; but in some spots singilar excavations are found, rudely lined with stone; these are called weems, and it is likely that. they were always adjacent to the wooden residence of some chief and were intended as depositories of stores, \&c. the roofs being too low for comfortable places of refuge. The stations and camps of the natives are distinguished by their round form, while those of the Romans belong to the square. Under the next epoch it would be difficult to discover any genuine remains of the Dalriads. The houses, and even the churches were constructed in wattlework; and the funeral monuments werc cairns or heaps of stones. It is probable that Christianity did not immediately dissolve ancient prejudices, and that even the Atticottic kings were buried in this rude manner; for the genuine chronicles do not affirm that they were conveyed to Hyona or Ilcolmkill; and the sepulchres there shewn, of Irish and Norwegian kings, must be equally fabulous. To the sixth epoch may probably belong a chapel or two, still remaining in Scotland, for Bede informs us that Nethan III. A. D. 715 , obtained architects from Ceolfrid, abbot of Jarrow and Weremouth, to build a church in his dominions, probably at Abernethy; but the round tower there remaining seems of more recent origin. About the year 830, Ungust II. founded the church of St. Andrew; and the chapel called that of St. Regulus, (who seems unknown in the Roman calendar) may, perhaps, claim even this antiquity. It is probable, that these sacred edifices in stone were soon followed by the erection of those rude round piles, without any cement; called Piks-houses; yet they may more properly belong to the seventh epoch, when the Danes may share in the honour of the erection, for such edifices hare been traced in Scandinavia. They seem to have consisted of a vast hall, open to the sky in the centre, while the cavities in the wall present incommodious recesses for beds, \&c. These buildings are remarkable, as displaying the first elements of the Gothic castle ; and the castle of Conings. burg in Yorkshire forms an casy transition. The engraved obelisks found in Forres, and in other parts of Scotland, have been ascribed to the Danish ravagers, who had not time forsuch erections. They are, probably, monuments of signal events, raised by the king or chiefs : and as some are found in Scandinavia, as 


\section{ANTIQUTTIES.}

recent as the fifteenth century, it is pro. bable that many of the Scottish obelisks are far more modern than is generally imagined.

We are next to consider the antiquities of Ireland. The original population of this country passed from Gaul, and was afterwards increased by theirbrethren the Guydil from England. About the time that the Belgre seized on the south of England, it appears that kindred Gothic tribes passed to the south of Ireland. These are the Firbolg of the Irish traditions, and appear to have been the same people whom the Romans denominated Scoti, after they had emerged to their notice, by not only extending their conquest to the north and east in Ireland, but had begun to make maritime excursions against the Roman provinces in Britain. But Ireland had been so much crowded with Celtic tribes, expelled from the continent and Britain, by the progress of the German Goths, that the Belgx almost lost their native speech and distinct character; and from intermarriages, \&c. became little distinguishable from the original population, except by superior ferocity, for which the Scoti, or those who affected a descent from the Gothic colonies, were remarkable, while the original Gael seem to have been an innocent and harmlesspeople. The epochsin Ireland, to which its antiquities are referrable, are the following: 1. The first historical epoch of Ireland is its original population by the Celtic Gauls, and the subsequent colonization by the Belgre. 2. The maritime excursions of the Scoti against the Roman provinces in Britain. 3. The conversion of Ireland to Christianity in the fifth century which was followed by a singular effect; for while the mass of the people retainedall the ferocity of savage manners, the monastaries produced many men of such piety and learning, that Scotia or Ireland became celebraed all over Christendom. 4. This lustre was diminished by the ravages of the Scandinavians, which began with the ninth century, and can hardly be said to have ceas. ed when the English settlement commen.ced. The island had been split into numerous principalities, or kingdoms, as they were styled; and though a chief monarch was acknowledged, yet his power was sel. dom efficient, and the constant dissensions of so many small tribes rendered the island an easy prey. 5. In the year 1170 Henry $\Pi$. permitted Richard Strongbow, earl of Pembroke, to effect a settlement in Ircland, which laid the foundation of the English possessions in that country.
There are however coins of Canute, king of England, struck at Dublin, perhaps in acknowledgement of his power, by the Danish settlers. After this period Ireland became, in some measure, a commercial country, and her history is to be looked for in that of England, with which it is interwoven. Upon a review of the more ancient of these historical epochs, and of the monuments which may be considered as belonging to each, it must be considered, that the edifices having been constructed of wood till the eleventh or twelfth century, it cannot be expected that any remains of them should exist. Stone was chiefly employed in the construction of funeral erections of various kinds; nor are barrows wanting in Ireland, being hillocks of earth thrown up in commemoration of the illustrious dead. Other monuments, commonly styled Druidic, may also be found in Ireland; such as single stones erect, circular temples, or rather places of judgment, and the like, which may more properly be ascribed to the Belgic colony. The conversion of Ireland to Christianity was followed by the erection of a vast number of churches and monasteries, the latter being computed to exceed one thousand in number; but all these edifices were originally small, and constructed of interwoven withs, or hewn wood; for St. Bernard, in the twelfth century, mentions a stone church as a singular novelty in Ireland. But the Scandinavian chiefs must before this period have introduced the use of stone into the castles, necessary for their own defence against a nation whom they oppressed; and sometimes even subterraneous retreats were deemed expedient, of which Ware and others have engraved specimens. To the Scandinavian period also belong what are called the Danes Raths, or circular intrenchments; and some chapels, such as those of Glendaloch, Portaferry, Killaloe, Saul Abbey, St. Doulach, and Cashel, if we may judge from the singularity of the ornaments, which, however, only afford vague conjecture. But of the round castles, called Duns in Scotland, and of the obelisks engraven with figures or ornaments, few or none exist in Ireland. Under the Scandinavians the Irish coinage first dawns. Of the eleventh and twelf th centuries many monuments castellated or religious, may probably exist in Ireland. Brian Boro, king of Munster, having been declared. sovereign of Ireland in the year 1002, he distinguished himself by his virtues and courage; and Dermid III. A. D. 1041- 
1073, was also an excellent and powerful prince. Under these monarclis, and their successors, Terdalvac and Moriertac, the power of the Scanclinavians was considerably weakened. The native chief's had been taught the necessity of fortresses, and were generally devoutly attached to religion; it is therefore to be inferred, that many castles, churches, and monasteries, now began to be partly constructed in stone, by architects invited from France and England; but perhaps the round tower's were erected by native builders. Among smaller relics of antiquity, the golden trinkets found in a bog near Cullen, in the south, deserve mention: as gold was found in Gaul, they are perhaps ornaments of the ancient clicfs, brought from that region.

It remains now to mention the names of some of those authors who have written on the antiquities of our own country. Tacitus was an eye-witness to the ceremo. nies of Druidism in England, as the IRomans wcre in Wales. To him, to Crsar already referred to, and to $D_{10}$ Cassius, we refer, as the chief authorities in regard to British history. To these may be added Flian, Diodorus Siculus, Strabo, and Pliny. Clurerius, Pezron, and Pelloutier, are more morlern, but respectable, writers on the same subject. Of the structures erected by the Britons, Abury and Stonehenge may be eleemed the principal. Relics of a smaller kind are continually discovered a few feet beneath the surface of the eartl. On these Stukely and lowland are the best authorities: the former has written a volume on Abury, a temple of the Druids, in which is a particular account of the first and patriarchal religion, and of the peopling of the British islands: besides his larger work, entitled "Itinerariun Curiosum," being an account of the antiquities, \&c. observed in travels through (ireat Britain, publislied in 1724. For the listory of the Britons under the Roman Government, Horsley's Brit. Rom. is a work that may be depended upon. Witl respect to the antiquities of the Sax. ons, the illuminated maunscripts are the loest records of their manners in the different centuries, and the most interesting in. formation respecting then has been collected by Turner and Strutt. The best collection of Saxon coins is in the British Museum, and of manuscripts in the same place, and in the Bodleian Library. Mr. King has treated of their military antiquities in his Ilistory of Castles; and, independently of our works out topography, which are numerous, and many of them of the first respectability, and which throw VOI. I. considerable light on the antiquities of the country, we may refer to Henry's History of England, where the subject is discussed systematically and in chronological order; and to tie works of Camden, Strutt, and Gough, to which may be ankled the whole series of the Gentleman's Magazine, and l'inkerton's Geography, to which we have been indebted for a part of this article.

As the antiquities of the united king. dom are in some respects connected with those of the Danes and other northern na. tions, we may suggest to the reader what are the principal remains of those people, as a clue to his future inquiries.

The ancient monuments of Denmark and Norway are chiefly Runic, thongh it is far from certain at what period the use of Runic characters extended so far north. Circles of upright stones are common in all the Danish dominions, the islands, Norway, and Iceland, in which latter country their origin is perfectly ascertained, as some were erected even in recent times of the Icelandic republie, being called domh-ring, or circles of judgment. Some also appear to have been the cemeteries of superior families. Monuments also occur of two upright stones with one across; and of the other forms supposed to be Druidic. The residences of the chiefs appear to have been generally constructed of wood, as there are very few ancient castles existing in Denmark or Norway.

Of Sweden the ancient monuments consist chiefly of judicial circles and other erections of unhewn stone, together with remains inscribed with Runic characters, none of which are imagined to bave exist. ed longer than the eleventh century.

In Russia the ancient monuments are neither numerous, nor afford nuch variety. There are to be met with the tombs of their pagan ancestors, containing weapons and ornaments. From the writings of IIerodotus we learn that the Scythians regarded the cemet eries of their princes with singular vencration: the Sarmatians or Slarous secm to lave imbibed the same ideas. The catacombs of kiow, it is believed, were formed in the pagan period, thongh they are now replete with marks of Christianity. They are labyrintlis of considerable extent, dug, as it should seem, through a mass of hardened clay, but they do not appear to contain the bodies of the sovereigns. The idols of $\mathrm{P}^{\mathrm{P}} \mathrm{a}$. gan Russia are soinctimes found east in bronze; and Dr. Guthrie has given a good account of the Slavonic mythology, to whose "Dissertations sur les Antiquites de Russie" we refer the reader. We may howeyer observe, that the pagan J. 1 


\section{ANTIQUITIES.}

Russians worslipped one god, supposed to be the author of thunder; ; another, that resembled the $\mathbf{P}$ an of the ancients; others, answering to the Sun, Hercules, Mars, Venus, and Cupicl. 'They liad also goddesses, corresponding with Ceres, Diana, and Pomona, and theirnymphs of the woods and waters. They worshipped Zniteh or Vesta in the form of fire, and venerated waters, the Bog being as highly regarded by the ancient Russians as the Ganges among the Inclians : the Don and the Danube were also cousidered as looly streams; and there was a sacred lakc, environed with a thick forest, in the isle of Rugen, which was adored by the Slavonic tribes.

\section{Antiquities in the Valley of the .Mississipgi.}

"Considerable curiosity has been excited by appearances on the Mississippi and its tributary waters, supposed to prove a more ancient population, than the state of the country, or the character of the tribes inhabiting it, when first visited by Eturopeans, would seem to indicate.

"The American bottom is a tract of rich alluvian land, extending on the Mississippi, from the Kaskaskia to the Cahokia river, about eighty miles in length and fire in breadth; scveral handsome streams meander through it; the soil of the richest kind, and but little subject to the effects of the Mississippi floods.-If any vestige of ancient population were to be found, this would be the place to look for it.-Accordingly, this tract, as also the bank of the river on the western side, exlibit proofs of an immense population.-If the city of Philardelphia* and its environs were deserted, there would not be more numerous traces of Juman existence.The great number of mounis, and the astonishing quantity of human boncs, every day dug up, or found on the surface of the ground, with a thousand other appearances, announce that this valley was at one periol filled with habitations and villages. The $w$ hole face of the bluff, or hill, which abounds to the east, appears to have been a continued burial ground.

"But the most remarkable appearances are, two groups of mounds or pyramids, the one about ten miles above Cahokia, the other nearly the same distance below it, which, in all, exceed one hundred and fifty, of various sizes. - A more minute ciescription of those above Cahokia will give a tolerable idea of them all.- They are mostly of a circular shape, and at a clistance resemble enormous haystacks scattered through a meadow. One of the largest is about two hundred paces in circumference at the bottom, the form nearly square. The top level, with an area sufficient to contain several hundred men. " $\Delta$ t the distance of threc niles along the bauk of the Caliokia there is the largest assemblage-the principat one of which is a stupendous pile of a mass of earth, that must have required years, and the labour of thousands, to accomplish. Were it not for the regularity and design which it manif'ests, the circumstances of its being on alluvial ground, and the other mounds scattered around, it could scarcely be believed to be the work of human hands.The shape is that of a parallelogram, standing from north to south; on the south sicle there is a broad apron, or step, about half way down, and from this, another projection into the plain, about fifteen feet wicle, which was probably intended as an ascent to the mound. The circumference at the base is at least eight hundred yards, and the height of the pyramid about ninety feet.

"Several of these mounds are almost. conical, and at regular distances from each other; about which are scattered pieces of flint, and fragments of earthen vessels.

"A curious' discovery, made a few years ago in the state of Tennessee, proves, beyond a doubt, that at some remote period the valley of the Mississippi had been inhabited by a much morc civilized people than when first known to us.-Two human bodies were found in a copperas care, in a surprizing state of preservation.They were first wrapped up in a kind of blanket, supposed to have been manufactured of the lint of nettles, afterwards with clressed skins, and then a mat of nearly sixty yards in length. They were clad in a bcautiful cloth, interwoven with feathers, such ás was manufactured by the Mexicans. They had been liere, perhaps, for centuries, and certainly were of a different race from the modern Indians. They might have belonged to the Olmec, who overran Mexico about the seventh century; to the Toultcc, who came centuries afterwards; or to the Aztecs, who founcled the great city of Mexico about the thirteenth century.

"In tracing the origin of institutions or inventions amongst men, we are apt to forget, that nations, however diversified

- "The Saline, below St. Genevieve, cleared out some time ago, and deepened, was found to contain waggon loads of earthen-ware, some fragments bespeaking vessels ga large as a barrel, and proving that the Salines had been worked before they were known to the whites." 
by manners 2nd languages, are yet of the same species, and that the same institu. tions may originate amongst twenty different people. The wonder would be, that they should not shew a resemblance. We find these mounds in every part of the globe; in the north of Europe, and in Great-Britain, they are numerous, and much resemble ours, but less considerable. The pyramids of Egypt are perhaps the oldest monuments of human labour in that country, so fitrourable to the production of a numerous population. The Pyramids of Mexico, which are but little known, and yet scarcely less considerable, like those of Figypt, have their origin hid in the night of oblivion.

"Who will assign, as the age of Ame. rica, a period of rears different from that allowed to, what has been denominated, the old world? The multiplicity of proofs contradict the recency of her origin; deeply imbetked stories of carbonated wood, the traces of ancient volcanoes! We could appeal to her time-worn cataracts, and channels of mighty" rivers, and to her venerable mountains,-Grant, then, that America may have existed a few thousand years; the same causes prevailing, like effects will be produced; the same revo. Intions as lave been known in the old world may lave taken place here." - -Sce Vieros of Louisiana, by" H. M. Brecken. ridge, iss.

ANTIIRIILNUM, mapelvagon, toadfax, in botany, a genus of the Didynamia Angiosperna. Calyx firc-parted; corol with a nectariferous prominence at its base, pointing downwards; the orifice closed aud furnished with a cloven convex palate; capsule two-celled. This genus is separated into five divisions, ris. A. leaves angular; capsules many valved $\mathbf{B}$. leaves opposite; capsules many valved. C. leaves alternate; capsules many valved. 1). corols without spur ; capsules perfora. ted with three pores. F. leaves pinnati firl. There are 12 species of the first division; nearly 40 of the second division : 11 of the third; 7 of the fourth; and 2 of the last.

AN'TISTROPIIE, in grammar, a figure, by which two things mutually dependent on one anothicr are reciprocilly converted. As the servant of the master, and the master of the servant.

Astustruphe, among lyric poets, that part of a song and clance in use among the ancients, which was performed before the altar, in returning from west to east, in opposition to strophe. See the articles STROPHE and OBE.

- ANTITILESIS, in rhetoric, a contrast drawn between two things, which thercby serve as shades to set off the opposite qualities of each other.

The pocts, historians, and orators, improve their subject, and greatly heighten the pleasure of the rearler, by the pleasing opposition of their characters and $\mathrm{de}$ scriptions.

The beautiful antithesis of Cicero, in his second Cartilinarian, may serve for an example; "On the one side stands modesty, on the other impudence; on the one fidelity, on the other deceit; here piety, there saorilege; here continency, there lnst, \&cc." And Virgil, in his admi. rable description of Dic'o's despair, the night before her death, represents all the rest of the creation enjoying profound tranquillity, to render the disquictude of that miserable queen the more afiecting.

ANTOECI, in geography, an appellation given to those inhabitants of the earth who live under the same meridian, but on different sides of the equator, and at equal distances from it.'

These have noon, and midnight, and all hours at the same time, but contrary sea. sons of the year; that is, when it is spring with the one, it is autumn with the other: when summer with the one, win. ter with the other. And the days of the one are equal to the niglits of the other, and vice versa.

ANTONOMASIA, in rhetoric, a figure, by which the proper name of one thing is applied to several others; or, on the contrary, the name of several things to one. Thus we call a cruel person, a Nero: and we say the philosoplier, to denote Aristotle.

ANTS, acid of. See Formic acid.

ANVIL, an iron instriunent, on which smitlis hammer or forge their work, and usually mounted on a firm wooden block. A forged anvil is reckoned better than one of cast work.

ANUS, in anatomy, the extremity of the intestinum rectum, or orifice of the fundiment. Sce Avatom r.

AOlRIST, among grammarians, a tense peculiar to the freek language, comprehending all the tcuses; or ratluer expressing an action in an incleternuinate masner, without any regard to past, present, or future. 
AORTA, in anatomy, called also arteria magna, a large arter, arising with a single trunk from the left rentricle of the heart above its valves, called semilınares, and serves to convey the mass of blood to all parts of the body.

After ascending a little upwards, its trunk is bent, in manner of an arch, and from this part it sends, in human subjects, usually three ascending branches. This is called the aorta ascendens.

The descendens is that part of the trunk, which,after the arch-like inflection, descends through the thorax and the $a b$ domen down to the os sacrum, and is ustally larger in women than in men. The aorta lath four tunics, a nerrous, a glandulous, a muscular, and a membranous one. See Aratom r.

APACTIS, in botany, a genus of the Dodecandria Monogynia class and order. No calyx ; petals four, crenate, unequal; germ superior; fruit. There is but a single species, riz. the Japonica, a tree found, as its name imports, in Japan.

APALUS, in natural history, a genus of insects of the order Coleoptera. Gen. char. antennx filiform; feelers equal, filiform; jaw horny, one-toothed; lip membranaceous, truncate, entire. There are two species : quadrimaculatus; rufous; head, and two spots on the shells, black ; inhabits North America : bimaculatus, of northern Europe.

APARGIA, in botany, a gents of the Syngenesia Equalis class and order. Receptacle naked; calyx imbricate; down feathery, sessile. There are 17 species.

APATITE, in mineralogy, one of the species of the phosphates, occurs in tin reins, and is found in Cornwall and Germany. Colours white, green, blue, and red, of various shades. The primitive form of its crystals is a regular six-sided prism. Specific gravity between 2.8 and 3.2. When laid on ignited coals it emits a green light, and is almost entirely soluble in nitric acid. By rubbing it shews signs of electricity. It was formerly considered as a species of schorl; afterwards, on account of its colour and crystallization, it was arranged with beryll; others described it as fllor, but Werner soon found that it was a new species. Its fal. lacious resemblance to other minerals induced Werner to give it this name, which is derived from $\alpha \pi \alpha 7 \alpha \omega$, "to deceive."

\section{APE. See Simia.}

APETAlOSE, or Aperslous, among botanists, an appellation given to such. plants as have no flower leaves.

APEX, in antiquity, the crest of a hel. met, but more especially a kind of cap worn by the flamens.

APHARESIS, in grammar, a figure by which a letter or syllable is cut off from the beginning of a word.

A prasResis, that part of surgery which teaches to take away superfinitics.

APHELIUM, or Aplizlox, in astronomy, is that point in any planet's orbit, in which it is farthest distant from the sun ; being, in the new astronomy, that end of the greater axis of the elliptical orbit of the planet, most remote from the focus wherein the sun is. The times of the aphelia of the primary planets may be known by their apparent diameters appearing least; as also by their moving 'slowest in a given time. They may likewise be found by calculation, the method of doing which is delivered in most astronomical writers.

Sir Isaac Newton' and Dr. Gregory have proved that the aphelia of the primary planets are at rest. See Princip. prop. 14. lib. 3. And in the scholium to the above proposition they say, that the planets nearest to the sun, viz. Mercury, Venus, the Earth, and Mars, from the actions of Jupiter and Saturn upon them, move a small matter in consequentia with regard to the fixed stars, and that in the sesquiplicate ratio of their respective distances from the sun.

APHIS, in entomology, a genus of the Hemiptera order, which has engaged the attention of naturalists for various reasons : their generation exhibits a singular and surprising phenomenon, and their instinctive economy differs, in some respects, from that of most other animals. Linnzis defines the generic character of the aphis thus; beak inflected, sheath of five articulations, with a single bristle a antennæ setaceous, and longer than the thorax; either four erect wings or none; feet formed for walking; posterior part of the abdomen usually furnished with two little homs. Geoffroy says, the aphides have two beaks, one of which is seated in the breast, the other in the bead; this last extends to and is laid upon the base of the pectoral one, and serves, as that writer imagines, to convey to the head a part of that nourishment which the insect takes, or sucks in, by means of the pectoral beak. Gmelin enumerates about 70 species, all of which, and doubtless many others, are found in different parts of Europe and America. They infest an endless variety of plants; and it is beliered each species is particularly attached to one kind of vegetable only; hence each 
sort has been litherto uniformly named after the individual species or genus of plants on which it feeds; or if that could not be ascertained, that on which it had been found; for some species are rather uncommon and little known, though others are infinitely ton numerous. The aphides are sufficiently known by the indiscriminate term of plant-lice; they abound with a sweet and grateful moisture, and are therefore eagerly sought after by ants, and are devoured by the larva of coccinel$l x$, and many other crcatures, or they would become, very probably, more destructive to the whole vegetable creation than any other race of insects known. If Bonnet was not the first naturalist (as is generally acknowledged) who discovered the mysterious course of generation in the aphides, or, as he calls them, pucerons, his experiments, together with those of his countryman Trembly, tended at least to confirm, in a most satisfactory manner, the almost incredible circumstances respecting it, that an aphis or puceron, brought up in the most perfect solitude from the moment of its birth, in a few days will be found in the midst of a numerous fanily; and tliat if the experiment be again repeated on one of the individuals of this farnily, a second generation will multiply like its parent; and the like experiment may be many times re. peated with the same effect, until at last the progeny becomes liarren, unless again impreginated by the niale; after which several generations may be again produced without further aid of the male, as before.

The history of aphides has also been very copiously treated upon by J). Jicl. ardson, in a paper printed in the $41 \mathrm{st} \mathrm{rol}$. of the Philosophical Transactions; and by the late ingeninus Mr. Curtis, in the sixth volume of the Transactions of the Linnzan Society. The tenor of Dr. Richarlson's remarks is uriefly this : the great variety of species which occur in the in. sects now under consideration may make an inquiry into their particular natures seem not a little perplexing, but by reducing them under their proper genus, the elifficulty is considerably diminished. We may reasonably suppose al] the insects, comprehended under any distinct genus, to partake of one general nature; and by diligently examining any particular spe. cies, may thence gain some insight into the nature of all the rest. With this view, Dr. Richardson clıose out of the various sorts of aplicles the largest of thiose found on the rose-tree; not only as its size makes it more conspicuous, but there are few of so long duration. This sort appears carly in the spring, and continues late in autumn, while several are limited to a much shorter term, in conformity to the different trees and plants whence they draw their nourishment. If, at the beginning of February, the weather happens to be so warm as to make the buds of the rosetree swell and appear green, small aphides are frequently to be found on them, though not larger than the young ones in summer when first produced. It will be found, that those aphides which appear only in spring proceed from small black oval eggs, whicl were deposited on the last year's shoot; though when it happens that the insects make ton early an appearance, the greater part suffer from the sharp weather that usually succeeds, by which means the rose-trees are some years in a manner freed from them. The same kind of animal is then at one time of the year viviparous, and at another oviparous. These aphides, which withstand the se. verity of the weather, seldom cone to their full growth before the month of A pril, at which time they usually begin to breed, after twice casting off their exuvia, or outwand covering. It appcars that they are all females, which produce each of them a numerous progeny, and that without having intercourse with any inale insect: they are viviparous, and, what is equally singular, they all come into the world back wards. When they first come from the parent, they are inveloped in a thin membrane, liaving in this situation the appearance of an oval egg; these egglike appearances adhere by one extremity to the mother, while the young nnes conltained in then extend to the other, and by that means gradually drag the ruptured membrane over the head and body to the hind fect. During this operation, and for some time after, the fore part of the head adheres, by means of something thit is glutinous, to the vent of the parent. B3e. ing thus suspended in the air, it sonn frees itself from the membranc in which it was confined; and after its limbs are a little strengthened, is set down on some tender shoots, and is left to provicle for itself. In the spring months, there appear on the rose-trees but two generations of aphides, including those which proceed inimediately from the last year's eggs; the warmtli of the summer adds so mueh to their fertility, that no less than five generations succed one another in the interval. One is produced in May, which casts off its covering; while the inonths of June and July each supply two more, 


\section{APHIS.}

which cast off their coverings three or four times, according to the different warmth of the season. This frequent change of their outward coat is the more extraordinary, because it is repeated more often when the insects come the soonest to their growth, which sometimes happens in ten days, when they have had plenty of warmth and nourishinent. Early in the month of June, some of the thirl generation, which were produced about the middle of May, after casting off the last covering, discover four erect wings, much longer than their bodies; and the same is observable in all the succeeding generations which are produced duiring the sum. mer months, but still without any diversity of sex: for some time before the aphicles come to their full growth, it is easy to distinguish which will have wings, by a remarkable fulness of the breast, which in the others is hardly to be dis. tinguished from the body. When the last covering is rejected, the wings which were before folded up in a very narrow compass, are gradually extended in a surprising manner, till their dimensions are at last very considerable. The increase of these insects in the summer-time is so very great, that by wounding and exhausting the tender shoots, they would frequently suppress all vegetation, had they not many enemies to restrain them. Notwithstanding these insects have a numerous tribe of enemies, they are not without their friends, if those may be considered as such, who are officious in their attendance for the good things they expect to reap thereby. The ant and bee are of this kind, collecting the honey in which the aphides abound, but with this difference, that the ants are constant visitors, the bee only when flowers are scarce; the ants will suck in the honey, while the aphides are in the act of discharging it; the bees only collect it from the leaves on which it has fallen. The aphides are often carried home by the ant, carefully attended, and regularly supplied with food. See Formica. In the autumn three more generations of aphides are produced, two of which generally make their appearance in the month of August, and the third be. fort the middle of September. The two first differ in no respect from those which are found in summer, but the third differs greatly from all the rest. Though all the aphides which have hitherto appeared were female, in this generation several male insects are found, but not by any means so numerous as the females. The females have, at first, the same appearance as those of the former generations, but in a few days their colour changes from a green to a yellow, which is gradually conrerted into an orange before they come to their full growth; they differ, also, in another respect, from those which occur in summer, for all these yellow females are without wings. The male insects are, howerer, still more remarkable, their outward appearance readily distinguishing them from this and all other generations. When first produced they are not of a green colour like the rest, but of a red. dish brown, and have afterwards a dark line along the back : they come to their full growth in about three weeks, and then cast off theirlast corering, the whole insect being, after this, of a bright yellow colour, the wings only excepted; but after this change they become of a deeper yellow, and in a very few hours of a dark brown, if we except the body, which is something lighter coloured and has a reddish cast. "The males no sooner come to maturity than they copulate with the females, who, in a day or two after their intercourse with the males, lay their eggs, generally near the buds. Where there are a number crowded together, they, of course, interfere with each other, in which case they will frequently deposit their eggs on other parts of the branches. It is highly probable that the aphides derive considerable advantages by living in society; the reiterated punctures of a great number of them may attract a larger quantity of nutricious juices to that part of the tree or plant where they hare taken up their abode. The observations of Mr. Curtis on the aphides are chiefly intended to shew that they are the principal cause of blights in plants, and the sole calse of the honey-dew. He therefore calls them the aphis, or blighter; and after observing, that in in point of numbers, the individuals of the several species composing it surpass those of any other genus in the country, speaks thus, in general terms, of the whole tribe. These insects live entirely on regetables. The loftiest tree-is noless liable to theirattacks than the most liumble plant. They prefer the young shoots on account of their tenderness, and on this principle often insinuate themselves into the very heart of the plant, and do irreparable mischicf before they are discovered. But, for the most part, they beset the foliage, and are mostly found on the underside of the leaf, which they prefer, not only on account of its being the most tender, but as it afforrls them protection from the weather, and various injuries to which they would otherwise be exposed. Sometimes the root is the 


\section{APIIIS.}

object of their choice, which, from the nature of these insects, orse would not, $a$ priori, expect; yct I have secul the roots of lettuces thickly beset with them, and the whole crop rendered sickly and of little value; but such instances are rare. They seldom attach themselves to the bark of trees, like the aphis salicis, which, being one of our largest specics, andlience posscssing superior strength, is c nabled to penetrate a substance harder than the leaves themselres. In the quality of the excrement voided by these insects, there is something wonderfully extraordinary. Were a person acciclentally to take up a book, in which it was gravely asserted, that in some countries there were certain animals which voicled liquid sugar, he would lay it down, regarling it as a fabulous tale, calculated to impose on the credulity of the ignorant; and yet such is literally the truth. Mr. Curtis collected some on a piece of writing-paper, from a brood of the aphis salicis, and found it to be sweet as sugar; and obserres, that, were it not for the wasps, ants, flies, and other insects, that derour it as quiekly as it is produced, it might, no doubt, be collected in considerable quantitics, and by the processes used with other saccharine juices, miglit be converted into the choicest sugar or sugar-candy. The sweetness of this excrementitious substance, the glossy appearance it gave the leaves it fell ipon, and the snarm of insects this matter attracts, led him to imagine that the ho. nev-dew of plants was no other than this secretion, which further observation has since firlly confirmed; and not, as its name implies, a sweet substance falling from the atmosphere. On this opinion it is further remarked, that it neither falls fiom the atmosphere, nor issues from the plant itseli, as is easily demoustrated. If it fell from the atmosiphere, it wonld cover every thing it fell upon indiscriminately, where. as we never tind it but on certain living plants and trees. We hind it aiso on plants in stoves and green-houses, covered with glass. If it exurled from the plunt, it would appear on all the leaves generally and $u$. nifoเmly; whereas its appcarance is extremely irregular, not alike on any two leaves of the same tree or plant, some having none of it, and others being evercal with it but partially. It is probable that there neverexists iny honey-dew but where there are aphicles; though such often pass unnoticed, being hidlen on the underside of the leaf: and wherever honcy-dew is observable upon a leaf, aphicles will be found on the under side of the leaf or leares immediately above it, and under no other circumstance whatever. If by ac. cident anytling shonld intervene between the aphides and the leaf next beneath then, there weil be no honey-dew on that leaf: and thus he conceires it is incontro. vertibly proved, that aphides are the true and only source of honey-dew. Of the British species of aphicles, one of the larg. est and most remarkable is the aplis salicis, which is found on the different kinds of willows. When bruised, these inseets stain the fingers with red. Towards the end of September multitudes of the full-grown insects of this specics, both with and with. out wings, desert the willows on which they feeth, and ramble over every neigh. beuring object in such numbers, that we can handle nothing in their vicinity with. out crushing some of them, while those if a younger or less adranced state still remain in large masses upon the trces. Aphis ros $x$ is very frequent, during the summer months, on the young shoots and buds of roses : it is of a bright green colour: the males are furnished with large transparent wings. A. vitis is most destrictive to vines; as $A$. ulmi is to the elm-trec. Plate 1. Entomology, fig. 3.

It is found, that where the saccharine substance has dropped from aphides for a length of time, as from the aphis salicis in particular, it gives to the surfice of the bark, foliage, \&cc. that sooty kinel of appearance, which arises from the explosion of gunpowder : it looks like, and is some. times taken for, a kind of black mildew. In most seasons the natural encmies of the aphides are sufficient to keep them in check, and to prevent them from doing essential injury to plants in the open air: but there are times, once perhaps in four, five, or six years, in which they are multiplied to such an excess, that the usual means of diminution fail in preventing them from doing irreparable injury to certain crops.

To prevent the calamities whicls woukl infallibly result from un accumulated multiplication of the more prolific animals. it has been orlained by the Author of nature, that such should be diminished by serving as food for others. On this principle, most animals of this kind liave one or more natural enenies. The helpless aphis, which is the scourge of the vegetable kingdom, has to contend with many: of these, the principal are, the coccinella, the ichneumon aphidum, and the musea aphiderora. The greatest destroyer of the aphides is the coccinella, or common lady-bird. During the winter this inscct secures itself under the bark of 
trees and elsewhere. When the spring expands the foliage of plants, the female deposits its eggs on them in great num. bers, from whence, in a short time, proceeds the larra, a small grub, of a dark lead-colour spotted with orange. These may be observed in the suminer season running pretty briskly over all kinds of plants, ank, if narrowly watched, they will be found to devour the aphides wherever they find them. The same may be observed of the lady-bird, in its perfect state. Another most formidable enemy to the aphis is a very minute, black, and slender ichneumon fly, which eats its way out of the aphis, leaving the dry inflated skin of the insect adhering to the leaf like 2 small pearl: such may always be found where aphides are in plenty. Different species of aphides are infested with dif. ferent ichneumons. There is scarcely a division of nature, in which the musca or fly is not found: of these, one division, the aphidivora, feeds entirely on aphides. of the different species of aphidivorous flies, which are numerous, having mostly bodies variegated with transverse stripes, their females may be scen hovering over plants infested with aphides, among which they deposit their eggs on the surface of the leaf. The larva, or maggot, produced from such eggs, feeds, as soon as hatched, on the younger kinds of aphis, and as it increases in size, attacks and derours those which are larger. The larva of the hemerobius feeds also on the aphides, and deposits its eggs on the leaves of such plants as are beset with them. The earwig is likewise an enemy to them, especially such as reside in the curled leaves of fruit-trees, and the purses formed by certain aphicles on the poplars and other trees. To these may be added the small. er soft-billed birds that feed on insects.

APHORISM, a maxim or principle of a science; or a sentence which comprehends a great deal in a few words. The term is seldom used but in medicine and law. We say, the aphorisms of Hippocrates, the aphorisms of the civil law, political aphorisms, \&c.

A PIRODITA, in natural history, a genus of worms, of the order Molusca. Body creeping, oblong, covered with scales, and furnislied with numerous bristly fasciculate feet on each side ; mouth terminal, cylindrical, retractile; feelers two, setaceous, annulate; and four eyes. There are nire species. A. aculeata has an oval body, brown, beneath flesh colour, with long silky changeable, hair on each side the body : it inhabits the European seas, is found in the belly of the cod-fish, and feeds on testaceous animals ; is from four to seven inches long.

APHYLI.ANTHES, the blue Montpelier pink, in botany, a genus of the Hexandria Monogynia class of plants, the calyx of which is composed of a number of imbricated, lanceolated spathx; the corolla consists of six petals, of an obversely oval figure, terminating at the base in very narrow ungues, and patent at the limb, forming a kind of tube below it : the fruit is a turbinated 'capsule of a triangular figure, and contains three cells; the seeds are oval. There is but a single species.

APHYTEIA, in botany, a genus of the Monadelphia Triandria, Calyx large, funnel-form, three-cleft; three petals inserted into and shorter than the calyx; germ inferior; berry one-celled, many. seeded; seeds imbedded.

APIAN, (PETER), in biography, an eminent astronomer and mathematician, called in German Bienervitz, was born at Loisnich, in Misnia, and became professor of mathematics at Ingolstadt, in 1524. He wrote several treatises on astronomy and the mathematics, and enriched these sciences with many instruments and ob: servations. His first work was a "Treatise on Cosmography, or Gcographical Instructor;" this was published in 1530 , and in three years after he constructed at Nuremberg a curious instrument, which shewed the hour of the day, by means of the sun's rays, in all parts of the earth. In the year 1540 , he published his princi$\mathrm{pal}$ work, entitled "Astronomic on Cæesaraum," containing many interesting observations, with the descriptions and divisions of instruments, calculations of eclip. ses, and the construction of them in plano. In a second part of the work is a description of the construction and use of an astronomical quadrant, to which is annexed observations on five different comets: in these he shews that the tails of comets are alwars projected in a clirection opposite to the sun. Our limits do not allow us to enumerate all the treatises of Apian : they were as respectable as numerous, and the anthor was treated with the kind. est attention by the emperor Charles $V$. who published several of his works at his own expense, conferred upon him the honour of nobility, and presented him with 3000 crowns. - A pian died at Ingolstadt in 1532 , leaving behind him a high reputation for learning, and a son Philip, who was also an eminent astronomer, and taught the scieuces both at Tubingen and Ingolstadt. Philip died in 1589, and 


\section{APIS.}

left a treatise on "Solar-dials." Ile gave an account of the new star that appeared in Cassiopeia in 1572, which is preserved.

APIARY, a garden or other convenient place where bees are kept. A sou. thern aspect is reekoned the most proper, and the bee-hives should be exposed as little as possible to the wind, and should enjoy as much of the influence of the sun as possible, as wind retards the bees in their work, while the beams of the sun invite them to it. In the vicinity of the apiary there should be plenty of Howers, wild thyme, and the like. The hives should be free from the droppings of trees, the annoyance of danghills, long grass and weeds; as from these inscets are bred, which are not only destructive to bees, but greatly retard them in the preparation of honey. See ArIs.

APIS, in natural history, a genus of insects of the order of Hymenoptera. Gen. char. month furnished with jaws, and an inflected proboscis, with two bi. valve sheaths : feelers 4 , unequal, hiliforns: antenne short, filifurm, thuse of the fem:le subclavate; wings flat or without plaits; sting in the fernale and neutral insects concealed.

This genus is distributed by Linnæus into two assortments, viz. those in which the body of the animal is but slightly covered with fine hair or down, and those in which it is remarkably villose or hairy : the insects of the latter division are conmonly distinguished by the title of humble-bees. In the lirst division, the principal or must important species is the apis mellifica, or common honey-bee, so long and justly eelebrated for its wonderful polity, the neatuess and precision with which it constructs its cells, and the diligence with which it provides, during the warmth of sunımer, a supply of food, for the support of the live during the rigours of the succeecling winter. The general history of this interesting insect has been amply detailed by various authors, as Swammerdam, Reaumur, \&c. \&c. A mong the most elaborate accounts of later times may be inentioned that of Mr. Jolın Huoter, which made its appearance in the I'hilosuphical Transactions for the year 1792 , of which the following is an abstract. There are three periods at which the his. tory of the bee may commence : first, in the spring, when the queen begins to lay ber eggs; in the summer, at the commencement of a new colony'; or in the autumn, when they go into winter quarters. We shall hegin the particular his. tory of the bee with the new colony, when

VOL. I. nothing is formed. When a live sends off a colony, it is commonly in the month of June; but that will vary accorling to the season, for in a mild spring bees sometimes swarm in the middle of Mav, and very often at the latter end of it. iBefore they come off, they commonly hang about the mouth of the hole or door of the hive, for some days, us if they had not sufficient room within for such lot weather, which we believe is very much the case; for if cold or wet weather come on, they stow themsclves very wcll, and wait for fine weather. But swarning appears to be rather an operation arising from necessity, for they would seem not' naturally to swarm, because if they have an eimpty space to fill they do not swarm; there. fore by increasing the size of the hive the swarming is prevented. This period is much longer in some than in others. For some evenings before they come off is often heard a singular noise, a kind of ring, or sound of a small trumpet; by comparing it with the notes of a piano forte, it seemed to be the same sound with the lower $A$ of the treble. The swarm commonly consists of three classes; a fe. male, or fenales, males, and those communly called mules, which are supposed to be of no sex, and are the labourers; the whole, about two quarts in bulk, making about six or seven thousand. It is a question that cannot easily be determined, whether this old stock sends off entirely young of the same seuson, and whether the whole of their young ones, or only part. As the males are entirely bred in thie sume season, part go off; but part Inust stay, and most probably it is so with the others. They commonly come off in the heat of the day, of ten immecliately after a shower. When one gaes off, they all immediately follow, and fly about seemingly in great confusion, although there is one principle actuating the whole. They soon appear to be directed to some fixed place; such as the branch of a tree or bush, the cavities of oll trees, holes of houses leacling into some hollow place; and whencrer the stand is made, they immecliately repair to it till they are all col. lected. But it would seem, in some cases, that they had not lixed upon any resting place before they come off, or, if they harl, that they were either disturbed, if it was near, or that it was at a great distance; for, after hovering some time, as if uniletermineil, they fly away, mount up into the air, and go off with great velocity. When they have fixed upon their future habitation, they immediately begin .II $\mathrm{m}$ 


\section{APIS.}

to make their combs, for they have the materials within themselves. "I have reasou," says Mr. Hunter, "to believe that they fill their erops with honey when they come away, probably from the stock in the live. I killed several of those that came away, and found their crops full, while those that remained in the hive had their crops not near so full : some of them came away with farina on their legs, which I conceive to be rather accidc.ntal. I may just observe here, that a hive commonly sends off two, sometimes three, swarms in a summer, but tliat the second is commonly less than the first, and the third less than the second; and this last has seldom time to provide for the winter.

"The materials of their dwelling or comb, which is the wax, is the next consideration, with the mode of forming, pre. paring, or disposing. of it. In giving a totally new account of the wax, I stiall first shew it can hardly be what it has becr supposed to be First, I shall ohserve that the materials, as they are found coniposing the comb, are not to be found in the same state (as a composition) in any vegetable, where they have been supposed to be got. The substance brought in on the legs, which is the farina of the flowers of plauts, is, in common, I believe, imagined to be the materials of which the wax is made, for it is called by most the wax: but it is the farina, for it is al. ways of the same colour as the farina of the flower where they are guthering; and indeed, we see them gathering it, and we also see them covered almost all over with it like a dust; nevertheless, it has been supposed to be the wax, or that the wax was extracted from it. Reaumur is of this opinion. I made several experiments, to see if there was such a quantity of oil in it as would account for the quantity of wax to be formed, and to learn if it was composed of oil. I held it near the cals. dle, it burnt, but it did not smell like wax, and liad the same smell, when burıing, as farina when it was burnt. I ob. serred that this substanee was of rlifferent colours on different bees, but ulways of the same colour on both legs of the same bee; whereas a new made comb was all of one colour. I observed that it was gathered with more avidity for old hives, where the comb is complete, than for those hives where it only begun, which we could hardly eonceive, if it was the materials of wax: also we may observe, that, at the very beginning of a hive, the bees seldom bring in any substance on their legs for two or three days, and after that the farina gatherers begin to increase; for now some cells are formed to hold it as $\mathbf{a}$ store, and some eggs are laid, which, when hatclied, will require this substance as food, and which will be ready when the weather is wet.

"The wax is formed by the bees themselves; it may be called an external secretion of oil, and I have found that it is formed between each scale of the under side of the belly. When I first observed this substance, in my examination of the working bee, I was at a loss to say what it was: I asked myself if it was new scales forming, and whether they cast the old, as the lobster, \&c. does? but it was to be found only between the scales on the lower side of the belly. On examining the bees througl glass hives, while they were climbing up the glass, I could see that most of 'hem had this substance, for it looked as if the lower or posterior edge of the scale was double, or that there were ilouble scales: but I perceived it was lonse, not attached. Finding tbat the substance brought in on their legs was farina, intended, as appeared from every circumstance, to be the food of the maggot, and not to make wax, and not lav. ing yet perceived any thing that could give me the least idea of wax, I conceived these scales might be it, at least I thought it necessary to investigate them. I therefore took several on the point of a needle, and held them to a candle, where they melted, and immediately formed themselves into round globules; upon which Ino longer doubted but this was the wax, which opinion was confirmed to me by not finding those scales bit in the building season.

"The cells, or rather the congeries of cells, which eompose the comb, may be said to form perpendicular plates, or partitions, which extend from top to bottom of the cavity in which they build them, and from side to sicle. They always begin at the top or roof of the vault in which they build, and work downwards : but if the upper part of this vault to which their combs are fixed is removed, and a dome is put over, they begin at the upper edge of the old comb, and work up into the new cavity at the top. They generally may be guided, as to the direc. tion of their new plates of comb, by forming ridges at top, to which they begin to attach their comb. In a long hive, if these ridges are longitudinal, their plates of comb will be longitudinal: if placed iransverse, so will be the plates; and if oblique, the plates of comb will be 


\section{APIS.}

vblique. Each plate consists of a double set of cells, whose bottons form the partition between each set. The plates themselves are not very regularly arranged, not forming a regular plane where they inight have done so; but are often adapted to the situation or shape of the cavity in which they are built. The bees do not endeavour to shape their cavity to their work, as the wasps do, nor are the cells of equal depths, also fitting them to their situation; but as the breeding cells mist all be of a given depth, they reserve a sufficient number for breeding in, and they put the honey into the uthers, as also into the shallow ones. The attachment of the comb round the cavity is not continued, but interrupted so as to form pas. sages; there are also passages in the middle of the plates, especially if there be a cross stick to support the conib; these allow of bees to go across from plate to plate. The substance which they use for attaching their combs to surrounding parts is not the same as the common wax; it is softer and tougher, a good deal like the substance with which they cover in their crysalis, or the humble-bee sur. rounds lier eggs. It is probably a mixture of wax with farina. The cells are placed nearly horizontally, but not exact. ly so; the mouth raised a little, which probably may be to retain the honcy the better; however, this rule is not strictly observed, for often they are horizontal, and towards the lower edge of a plane of comb they are often declining. The first combs that a hive forms are the smallest, and much neater than the last or lower. most. Their sides or partitions, between cell and cell, are much thinner, and the liexagon is much more perfect. The wax is purer, being probably little else but wax, and it is more brittle. The lower combs are considerably larger, and contain much more wax, or perhaps, more properly, more materials ; and the cells are at such clistances as to allow them to be of a round figure : the was is softer, and there is something mixed with it. I lave observed that the cells are not all of equal size, some being a degree larger than the others; and that the small are the first formed, and of course at the upper part, where the bces begin, and the larger are nearer the lower part of the comb, or last made : however, in hives of particular construction, where the bees may be. gin to work at one end, and can work both down and towards the other end, we often find the larger cells both on the lower part of the combs, and also at the oppo. site end. These are formed for the males to be bred in; and in thu: liurnets and wasps combs there are larger cells, for the queens to be bred in: these are also formed in the lower tier, and the last formed.

"The first comb made in a hive is all of one colour, viz. almost white; but is not so white towards the end of the seascon, having then more of a yellow cast.

"There is a cell which is called the royal cell, of ten three or four of them, sometimes more; I have seen eleven, and even thirteen, in the same hive; commonly they are placed on the edge of one or more of the combs, but often on the side of a comb; however, not in the centre along with the other cells, like a large one placed aniong the others, but often against the mouths of the cells, and projecting out beyond the common surface of the comb ; but nost of them are formed from the edge of the comb, which terminates in one of these cells. The royal cell is much wider than the others, but seldom so deep : its month is round, and appears to be the largest half of an oval in clepth, and is declining downwards, instead of being horizpntal or lateral. The materials of which it is composed are softer than common wax, rather like the last mentioned, ur those of which the lower edge of the plate of comb is made, or with which tha bee's cover the crysalis: they have very hitle wax in their compo. sition, not one third; the rest I conceive to be farina.

"The comb seems at first to be formed for propagation, and the reception of honey to be only a secondary use ; for if the bees lose their queen, they make no combs; and the wasp, hornet, \&ce. make combs, although they collect no honey; and the humble-bee collects the honey, and deposits it in cells slie never made.

"I shall not consider the bee as an excellent mathematician, capable of making exact forms, and having reasoned upon the best shape of the cell for capacity, so that the greatest number might be put into the sinallest space (finr the liornet and the wasp are much more correct, although not seemingly under the sanie necessity, as they collect nothing to occupy their cells); because, although the bee is pretty perfict in these respects, yet it is very incorrect in others, in the formation of the comb ; nor shall I consider these animals us forming combs of certain shape and size, from mere mechanical necessity, as from working round themselves; for such a moult would not form cells of dif- 


\section{APIS.}

ferent sizes, much less could wasps be guided by the same principle, as their cells are of very different sizes, and the first by much too small for the queen wasp to have worked round herself: but I shall consider the whole as an instinctive principle, in which the animal has no power of variation or choice, but such as arises from what may be called exterual necessity. 'l'he cell has in common.six sides, but this is most correct in those first formed; and the bottoni is commonly composed of those sides or planes, two of the sides making one; and they generally fall in between the bottoms of three cells of the opposite side; but this is not regular, it is only to be found where there is no external interruption.

"As soon as a few combs are formed, the female bee begins laying of eggrs. As far as I have been able to observe, the queen is the only bee that propagates, al. though it is asserted that the labourers do. Her first eggs in the season are those wluch produce labourers; then the males, and probably the queen; this is the progress in the wasp, hornet, humble-bee, \&cc. However, it is asserted by Riem, that when a hive is deprived of a queen, labourers lay eggs; also, that at this time some honey and farina are brought in, as store for a wet day. The eggs are laid at the bottom of the cell, and we find them there before the cells are half completed, so that propagation begins early, and goes on along witl the formation of the other cells. The egg is attached at one end to the bottom of the cell, sometimes standing perpendicularly, often obliquely ; it has a glutinous, or slimy covering, which makes it stick to any thing it touches. It would appear that there was a period or periods for laying eggs; for I have observerl in a new swarm, that the great business of laying eggs did not last above a fortuight; although the hive was not half filled with comb, it began to slacken. In tluose new formed combs, as also in many not half finished, we find the substance called bee-bread, and some of it is covered over with wax, which will be consider. ed further. By the time they have worked above half way down the hive with the comb, they are beginuing to form for the larger cells, and by this time the first broods were hatclied, which were small, or labourers; and now they hegin to breed males, and probalsly a queen, for a new swarm: because the males are now bred to impregnate the young queen for the present summer, as also for the next year. This progress in breeding is the same with that of the wasp, lornet, and humble-bee. Alihough this account is commonly allowed, yet writers on this subject liave supposed another mode of producing a queen, when the hive is in possession of maggots, and deprived of their queen.

"What may be called the complete process of the egs, namely, from the time of laying to the birth of the bee, (that is, the time of hatching) the life of the maggot, and the life of the crysalis, is, I believe, shorter than in most insects. It is not easy to fix the thme wlien the eggs liatch : I have been led to imagine it was in five days. When thcy hatch, we find the young maggot lying coiled up in the bottom of the cell, in some degree surrounded witly a transparent fluid. In many of the cells, where the eggs have just hatched, we find the skin standing in its place, eitlier not yet removed, or not pressed down by the maggot. There is now an additional employment for the labourers, namely, the feeding and nursing the young maggots. We may suppose the queen has nothing to do with this, as there are at all times labourers enough in the hive for such purposes, especially, too, as she never does bring the materials, as every other of the tribe is obliged to do at first; therefore she seems to be a queen by hereditary, or rather by natural, right, while the humble-bee, wasp, hornet, \&c. seem rather to work themselves into royalty, or mistresses of the commu. nity. The bees are readily detected feeding the young maggot; and, indeed, a young maggot might easily be brought up by any person who would be attentive to it. They open their two lateral pincers to receive the food and swallow it. As they grow, they cast their coats or cuti. cles; but how often they throw their coats, while in the maggot state, I do not know. The maggots grow larger and larger till they nearly fill the cell; and by this time they require no more food, and are ready to be inclosed for the crysalis state; when ready for the crysalis state, the bees cover over the mouth of the cell with a substance of a light brown colour, much in the same manner that they cover the lioney, excepting that, in the present instance, the covering is convex externally, and appears not to be entirely wax, but a mixture of wax and farina. The maggot is now perfectly inclosed, and it begins to line the cell and covering of the mouth above-mentioned witl a silk it spins out, similar to the silk-worm, and which makes a kind of pod for the chrysalis. 


\section{APIS.}

Having completed this lining, they cast off, or rather shove off, fiom the head backwards, the last maggut coat, which is deposited at the hottoni of the cell, and then they become chrysalises.

"In this state they are forming themselves for a new life : they are either entirely new built, or wouderfully changed, for there is not the sinallest vestige of the old form remaining; yet it must be the same naterials, for now nothing is taken in. How far this cliange is only the old parts new modelled, or gradually altering their form, is not easily deternined. 'T'o bring about the change, many parts must be re. moved, out of which the new ones are probably formed. As bees are not different in this state from the common flying insects in general, I sliall not pursue the subject of their changes further, altlough it makes a very muterial part in the natural history of insects.

"When the crysalis is formed into the coinplete bee, it then destroys the covering of its cell and comes forth. They are of a greyish colour, but soon turn brown.

"When the swarm of which I lave litherto been giving the history has come off early, and is a large one, more especially if it was put into too small a hive, it often breeds too many for the hive to keep through the winter; and in such case a new swarm is turown off, which, however, is commonly not a large one, and generally has too little time to complete its comb, and store it with honey sufticient to preserve them through the winter. This is similar to the second or third swarm of the old hives.

"I have already observed, that the new colony immediately sets about the increase of their numbers, and every thing relating to it. They had their apartments to build, both for the purpose of breeding, and as a store-house for provisions for the winter. When the season for laying eggs is over, then is the season for collecting honey; therefore, when the last chrysalis for the season comes furth, its cell is im. mediately filled with lioney; and as soon as the cell is full, it is covered over with pure wax, as it is to be considered as store for the winter. This covering answers two very essential purposes : one is to keep it from spilling, or daubing the bees; the other to prevent its evaporation, by which means it is kept fluid in such a warmth. They are also employed in lay. ing up a store of bee-bread for the young maggots in the spring, for they begin to bring forth much earlier than probably any other insect, because they retain a summer heat, and store up food for the young.

"In the month of August we may sup. pose the queen, or queens, are impregnaterl by the males; and as the males do not provide for theinselves, they become burdensome to the workers, and are therefore teased to death much sooner than they otherwise would die; and when the bees set about this business of providing their winter store, every operation is over, except the collecting of lioney and bee. bread. At this time it would seem as if the males were conscious of their danger, for they do not rest in the month of the hive, in either going out or coming in, but hurry either in or out : however, they are commonly attacked by one, two, or three at a time : they seem to make no resistance, only getting away as fust as possible. The labourers do not sting them, only pinch them, and pull them about as if to wear them out; but I suspect it may he called as muclı a natural as a violent death.

"When the young are wholly come forth, and either the cells entirely filled, or no more honey to be collected, then is the time or season for remaining in their hives for the winter.

"Although' I have now completed a hive, and no operations are going on in the winter months, yet the history of this hive is imperfect till it sends forth a new swarm.

"As the common bee is very susceptible of cold, we find, as soon as the cold weather sets in, they become very quiet or still, and remain so throughout the winter, living on the produce of the summer and autumn; and, indeed, a cold day iil the summer is sufficient to keep them at home, mure so than a shower in a warm day : and if the live is thin and much exposed, they will hardly muve in it, but get as close together as the comb will let them, into a cluster. In this manner they appear to live through the winter: howcver, in a fine day they become very lively and active, going abroad, and appearing to enjoy it, at which time they get rid of their excrement: for I fancy they sel. dom throw out thcir excrement when in the hive.

"Their life at this season of the year is more uniform, and may be termed simple existence, till the warm weather arrives again. As they now subsist on their sum. mer's inclustry, they would seem to feed in proportion to the coldness of the season; for, from experiment, I found the hive grow lighter in a cold week tlian it did in 


\section{APIS.}

a warmer, which led to further experiments.

"Although an indolent state is very much the condition of bees through the winter, yet progress is making in the quecin towarls a summer's increase. The eggs in the oviducts are begiuning to swell, and, I believe, in the month of March, she is ready to lay them, for the youıg bees are to swarm in June; which constitutes the queen bee to be the earliest breeder of any insect we know. In consequence of this the labourers become sooner employed than any other of this tribe of insects. This, both queen and labourers are enabled to accomplish, from living in society through the winter; and it becumes necessary in them, as they have their colony to form early in the summer, which is to provide for itself for the winter following. All this requires the pro. cess to be carried forward earlier than by any other insect, for these are only to have young, which are to take care of them. selves through the summer, not being under the necessity of providing for the win. ter.

"The queen bce, as she is termed, has excited more curiosity than all the others, although much more belong to the labourers. From the number of these, and from their exposing themselves, they have their history much better made out : but as there is only one queen, and she scarcely ever seen, it being only the effects of lier labour we can come at, an opportunity has been given to the ingenuity of conjecture, and more has been said than can well be proved. The queen, the mother of all, in whatever way produced, is a true female, and different from both the labourers and the male. She is not so large in the trunk as the male, and appears to be rather larger in every part than the labourers. The scales on the under surface of the belly of the labuurers are not uniformly of the same colour over the whole scale, that part being lighter which is overlapped by the terminating scale above, and the uncovered part being darker. This light part does not terminate in a straight line, but in two curves, making a peak; all which gives the belly a ligliter colour in the labouring bees, more especially when it is pulled out or elongated. We distinguish a queen from a working bee simply by size, and in some degree by colour, but this last is not so easily ascertained, because the difference in the colour is not so remarkable in the back, and the only view we can commonly get of her is on tbis part; but when a hive is killed, the best way is to collect all the bees, and spread them on white paper, or put them into water, in a broad, Hat-bottomed, shallow, white dish, in which they swim, and by looking at them singly, she may be discovered. As the queen breeds the first year she is produced, and the oviducts never entirely subside, an old queen is probably thicker than a utew-bred one, unless indeed the oviducts and the eggs form in the chrysalis state, as in the silk-worm, which I should suppose they did. The queen is perhaps at the smallest size just as she has done breeding; for as she is to lay eggs by the month of Murch, she must begin early to fill again ; but I believe her oviducts are never emptied, having at all times eggs in them, although but small. She has fat in her belly, similar to the other bees.

"It is most probable that the queen which goes off with the swarm is a young one, for the males go off with the swarm to impregnate her, as she must be impregnated the same year, because she breeds the same year.

"The queen bas a sting similar to the working-bee.

"I believe ahive, or swarm, has but one queen, at least I have never found more than one in a swarm, or in an old hive in the winter; and probably this is what constitutes a live; for when there are two queens, it is likely that a division may begin to take place. Supernumerary queens are mentioned by Riem, who asserts he has seen them killed by the labourers as well as the males.

"The male bee is considerably larger than the labourers : he is even larger than the queen, although not so long when she is in her full state with eggs : he is considerably thicker than either, but not longer in the same proportion: he does not terminate at the anus in so sirarp a point; and the opening between the two last scales of the back and belly is larger, and more under the belly, than in the female. His proboscis is much shorter than that of the labouring bee, which makes me suspect he does not collect his own honey, but takes that which is brought home by the others; especially as we never find the males abroad on flowers, \&c. only fying about the hives in hot weather, as if taking an airing; and when we find that the male of the humble-bee, ivhich collects its own food, has as long a pro. boscis, or tongue, as the female, I think it is from all these facts reasonable to suppose the male of the common bee feeds at home. He has no sting.

"The class of labouring bees, for we cannot call it either sex or species, is the 


\section{APIS.}

largest in number of the whole community: there are thousands of them to one queen, and probably some hundreds to each male. It is to be supposed they are the only bees which construct the whole bive, and that the queen has no other bu. siness but to lay the eggs : they are the only bees that bring in materials; the only ones we observe busy abroad; and inrleed the idea of any other is ridiculous, when we consider the disproportion in numbers, as well as the employment of the others, while the working bee has nothing to take off its attention to the business of the family. They are smaller than either the queen or the males : not all of equal size, although the difference is not very great.

"The queen and the working bees are so much alike, that the latter would seem to be females on a different scale : however, this difference is not so observable in the beginning of winter as in the spring, when the queen is full of egge. They are all females in construction; indeed, one miglit suppose that they were only young queens, and that they became queens after a certain agc; but this is not the case. They all have stings, which is another thing that makes them similar to the queen. From their being furnished with an instrument of defence and offence, they are endowed with such powers of mind as to use it, their minds being cxtremely irritable; so much so, that they make an attack when not mecllled wish, simply upon suspicion, and when they do attack they always sting; and yet, from the circumstance of their not being able to dis engage the sting, one should suppose they would be more cautious in striking with it. When tlicy attack one another, they scldom use it, only their pincers : yet I saw two bees engaged, and one stung the otlier in the mouth, or thereabouts, and the sting was drawn from the body to which it belonged, and the one who was stung ran very quickly about with it; but I could not catch tliat bee, to observe how the sting was situated.

"As they are the collectors of lioney, much more than what is for their own use either immediately or in future, their tongue is proportionably fitted for that purpose: $i t$ is consiclerably larger than that of either the queen or the male, which fits them to take up the lioncy from the hollow parts of flowers of consiler. able depth. 'l'he mechanism is very cu. rious, and will be explained further on.

"Bees certainly lave the five senses: sight none can doubt: feeling they also liave; and there is every reason for stlpposing they have likewise taste, smell, and hearing. Taste we cannot doubt ; but of smell we may not have such proufs; yet, from observation, I think they give strong signs of smell. When bees are hungry, as a young swarm in wet weather, and are in a glass hive, so that they can be examined, if we put some honey into the bottom, it will immediately breed a commotion; they all seem to be upon the scent: even if they are weak, and hardly able to crawl, they will tbrow out their probuscis as far as possible to get to it, although the light is very faint. This last appears to arise more from smell than seeing. If some bees are let loose in abee-hivc, and du not know from which honse they came, they will take their stand upon the outsicle of some hive, or hives, especially when the evening is coming on : whether this arises from the smell of the hives, or sound, I can hardly judge.

"Bees may be said to have a voice. They are certainly capable of forming several sounds. They give a sound, when flying, which they can vary according to circumstances. One accustomed to bees can immediately tell when a bee makes an attack, by the sound. 'This is probably made by the wings. They may be seen standing at the door of their hive, with the belly rather raised, and moving their wings, making a noise. I3ut they produce a noise independent of their wings; for if a bee is smearcd all over with honey, so as to make the wings stick together, it will be found to make a noise which is shrill and peevish. I have observed that they, or some of them, make a noise the evenings before they swarm, which is a kind of ring, or sound of a small trumpet : by coinparing it with the notes of the piano-forte, it seemed to be the same with the lower $\Lambda$ of the treble.

"I have observed, that it is only the queen and the labourers that have stings; and this provision of a sting is perhaps as curious a circumstance as any attending the bec, and probably is one of the characters of the bee tribe.

"The apparatus itself is of a very curious construction, fitted forinflicting a woumd, and at the same time conveying a poison into that wound. The apparatus consists of two piercers, conducted in a groove or di. rector, which appears to be itselt the sting. All these parts are mored by muscles, which we may suppose are very stroug in in them, much stronger than in other ani. mals; and these muscles give motion in almostall directions, but more particularly. outwarls. It is wonderful how deep they will pierce solid bodies with the sting. I have cxamined the length they have pierc. 


\section{APIS.}

ed the palm of the hand, which is covered with a thick euticle: it has often been abont the one-twelfth of an inch. To perform this by mere force, two things are necessary, power of muscles, and strength of the sting, neither of which they seem to possess in sufficient degree. I own I do not understand this operation. I am apt to conceive there is something in it distinct from simple force applied to one end of a body: for if this was simply the case, the sting of the bee conld not be made to pierce by any power applied to its base, as the least pressure bends it in any direction : it is possible the serrated edges may assist, by cutting their way in like a saw.

"The apparatus for the poison eonsists of two small ducts, which are the glands that secrete the poison: these two lie in the abdomen, among the air-cells, \&c.; they both unite into one, which soon enters into or forus an oblong bag, like a bladder of urine; at the opposite end of which passes out a duct, which runs to. wards the angle where the two stings meet, and entering between the two stings, is continued between them in a groove, which forms a canal by the union of the two stings to this point. There is another cluct on the right of that described above, which is not so circumscribed, and contains a thicker matter, which, as far as I have been able to judge, enters along with the other; but it is the first that contains the poison, which is a thin, clear fluid. From the stings laving serrated edges, it is seldom the bees can disengage them; and they immediately upon stinging endeavour to make their escape, but are generally prevented, as it were canght in their own trap; and the force they use commonly clrags out the whole of the apparatus for stinging, and also part of the bowels; so that the bee most frequently falls a sacrifice immediately upon having effected its purpose. Upon a superficial view, one conceives that the first intention of the bee having a sting is evident; one sees it has property to defend, and that therefore it is fitted for defence; but why it should naturally fall a sacrifice in its own defence does not so readily appear; bcsides, all bees have stings, although all bees have not property to defend, and therefore are not under the same necessity of being so provided. Probably its liaving a sting to use was sufficient for nature to defend the bee, withont using it liberally ; and the loss of a bee or two, when they did sting, was of no consequence, for it is seldom that more die."

Some naturalists suppose that the queen is formed from the larvx of the working bee; by a particular mode of treatment, or peculiarity or quantity of food, the bulk is augmen. ted, and the generative organs developed.

We now proceed to notice some of the species. The apis centuncularis, or car. penter-bee, is remarkable for its faculty of forming long, tubular, and slightly flexuose cavities in wood, even of the most solid kind, as oak, \&c. Sometimes it performs this operation in living trees, and some. times in dry wood, posts, \&cc. When the tube is properly finished, the animal proceeds to line each of the above-mentioned spaces with rose-leaves rolled over each other, the bottom of each being formed by several circular pieces of these lcaves, placed immediately over cach other to is sufficient thickness. The animal then deposits an egg at the bottom, and having left in the cell a sufficient quantity of a kind of honey for the nourishment if the young larva, when latched, proceeds to close the top with circular bits of rose-leaf; and, thus proceeding, finishes the whole series. This is usually done towards the close of summer; and the young, having passed the period of their larva state, change into that of chrysalis, and remain the whole winter, not making their appearance till pretty late in the ensuing season. This bee is about the size of the common, or honey.bee, but shorter and broader bodied in proportion, and is of a dusky colour above, the lower parts being covered with a bright ferruginous down or hair. In se:tsons when this species happens to be plentiful, it does considerable injury to the trees which, it attacks, large trunks of apparently healthy oaks having been found very materially injured by the numerous trains of cells distributed through them in different parts; thirty, forty, or fifty tubes sometimes lying within a very small distance of each other. In defect of rose-leares, the cavities are sometimes lined with the leares of elm, \&c. A species, very nearly allied to the preceding, pursues a similar plan of forming a continued series of cylindrical nests with rose or other leaves, rolling thein in such a man. ner as to resemble so many thimbles, the top of each being closed as before. Instead, however, of heing placed in the timber of trees, they are lidid in horizontal truins, at a certain distance beneath the surface of the ground. Of the villose, or hairy bees, popularly called humble-bees, one of the largest and most common in England is the apis lapidaria of Linnaus, so named from the circumstance of its nest being generally situated in strong or gravelly places. This speeies is entirely 
API

of a decp black colour, except the end of the abromen, which is red or orange-coloured, more or less decp in dillerent individuals. The fomale is of large size, measuring near an incls in length; the male is considerably smaller ; and the nesster, or labouring bee, still smaller than the male. The humble-bees in gencral live in small societies of 40 or 60 together, in an oval or roundish nest, cxcavated to a sinall depth beneath the surface of the ground, and formed of branches of moss, compacted together, and lined with a kind of coarse wax. In this ncst, which measures from foul to six inches in diameter, are constructed several oval cells, which, how. ever, are not the work of the complete in. sects, but are the cases spun by the larvx, and in which they remain during their state of chry salis: the eggs are cleposited among licaps of a kind of coarse honey or bec-bread, placed here and there at uncertrin intervals; on this substance the larix feell during their growing state: Jastly, in every nest are placed a few nearly cylindric cells or goblets of coarse wax, and filled with pure honey, on which the com. plete insects fecd. Sec Plate 1. Fntomology, fig. 4-6. For the management of bees, sec Ber.

Al'IUM, in botany, a genus of plants, including parslcy, smallage, and celery. Class, Pentandria Digynia; natural order of Umbellatx. Fssen. character, cal. general umbel of fewer rays than those of the partial; cor. gencral uniform; floscules almost all fertile; petals roundish, inflex, equal; stam. filaments simple; anthers, roundislı; pist. germ inferior; seeds two, ovate, striated on one side, plane on the other. $\Lambda$. petrosilinum, or common pars. lcy; both the varietics are in ise ; but it is remarked that the plane-leaved sort is most commonly cultivated, though nany prefer the curled kind, hecause its leaves are most easily distingruisherl finm the zethisa, or fool's parsley, a sore of hem. lock, and a poisonous garien weed, which, whilc young, has gre:tt resemblance to the common pline-leaved parsley. Besides, tlic curlecl parsley, from its liaving larger and thicker leaves, and being curiously fimbriated and curled, so as to slew full and clouble, nıakes a better appearance in its growth, and is more esteenied by conks for tlic pur|jose of garnishing lishes, se. It unay, however, be necessary to be-mark, that this sort, as being nnly a varicty, is liable to degenerate to the common planc sort, unless particular carc be taken to save the seed always ${ }^{7}$ from the perfect, fill curled plants. Both the varicties are propagated by seed sown innually in

VOL. 1 .
Al'L.

spring, where the plants are to remain; but the plants are biennials, rising from sced sown in March, April, May, and Junc. $\Lambda$. latifolium, or broad-icafeel parsley. The propagation of this species is also by secd sown annually in February, Marcli, April, or May, where the plasts are to remain. For this purpose, a spot of light rich cartl, in an open exposure, is to be preferred: the seed being sown broad-cast, and raked in, the plants generally appearing in about a month after being sown, and in May or Junc they re. quire to be thinned and cleared from weeds, which may he performed either by hand or hoc ; but the latter is nost eligible, as it will stir and loosen the surface of the earth, which may be beneficial to the plants, cutting thicin out to about six inches distance from each other. In the latter cul of July, the roots will mostly have attained a size proper for use, and may be drawn occasionally; but they seldom acruive their full growth till about Michaelmas. This is sometimes called Hamburgh parsley, probably from its be. ing much cultivated aboust that place. It is chicfly cultivated and estecmed for its large roots, which are white, and carrotshaped, being long, taper, and of downriglit growth, often attaining the size and appearance of small or middling parsnips; they boil exceedingly tender and palatable, are very wholesome, and may be used in soup or broth, or to eat like carrot's and parsnips, or as sance to flesh meat. A. dulce, or the common celery. The me. thod of propagation in all the varieties of this sort, is by sowing the seed in the spring, and when the plants have attained six or eight inclies in height, transplanting them into trenches, in order to be earthed up on eacliside as they advance in growth, and have their stalks blanched or whiten. ed, to render thein crisp and tender.

AI'LANA'TIC, in opties, a term :upplied be 1)r. I3lair, profe-susur of astronomy in Finburgh, to that kind of refiaction discovered by limself, which corrects the alscration of the rins of lighlit, and the colour alepending upon is, in contralistinction to the word acluromatic, which h:ts been appropriated to that refraction, in which there is monly a partial correction of colour. Sice Oiries. Br. Blair clis. covered a mixture of solutions of ammoni:cal and mercurinl salts, and also some other substances, w hich producel dispersions proportional to that of glass, with respect to the diflerent colours: and he eonstracted a compound lens, consisting of a semi-convex one of crown glass, with

Nin 


\section{APO}

its flat side towards the object, and a meniscus of the same materials, with its convex side in the same direction, and its flatter concave next the eye, and the interval between these lenses he filled with a solution of antimony in a certain proportion of muriatic acid. The lens thus adapted did not manifest tile slightest vestige of any extraneous colour. Ile obtained a patent for the invention in 1791.

APLUDA, in botany, a genus of the Polygamia Monoecia class of plants, the common calyx of which is an univalve, bifloral, ovated, concave, loose mucronated glume; the proper glume is bivalve, and placed obliquely; the corolla is a bivalre glume of the length of the cup; there is no periearpium; the seed, which is single, is involved in the glume of the corolla. Niale corol. two valsed; female florct sessile; stamina three. Female corol. two valved; one style; one seed, covered. There are four species.

APOCOPE, among gramniarians, a figure which cuts of a letter or syllable from the end of a word, as ingreni for ingenii.

APOCRYPH $\Lambda \mathrm{L}$, something dubious, is more particularly applied to certain books not admitted into the canon of scripture. Those are certain books of the old Testament extant only in Greek, admitted by the church of Ronie as canonical, but rejected by the reformed churches as no part of holy writ; such are the books of Judith, Wisdom, Tobit, Baruch, Maccabees, the third and fourth books of Es. dras. In this sense apocryphal stands distinguished from canonical, tliongh the Romish church disowns the distinction. Authors are divided as to the origin of the appellation apocryphal, and the rea. son why it was given to these books. The apocryphal books were not received into the canon, eitlier of the Jews, or ancient Christians, but were first made canonical by a decree of the council of Trent The apocryphal books, according to the sixtl article of the church of England, are to be read for example of life and instruction of manners; but it doth not apply then to establish any doctrine.

AI'OCYNUM, in botany, a genus of the Pentandria 1)y ginia class and order. Corol. companulate; nectareous filaments five, alternating with the stamina. There are 14 species.

APODES, the name of onc of the orders of fishes in the Linnzan distribution of animals. Thcir character is, that they.

\section{APO}

have no belly fins; there are 12 genera, viz.
Ammodytes,
Anarhichas,
Gymnothorax,
Ophydium,
Gymnotus,
Sternoptyx,
Stomateus,
Leptocephalus,
Murzena,
Stylephorus,
Trichiurus,
Xiphias,

which see under the several heads in the alphabet.

APOGEE, in astronomy, that point of the orbit of a planet, or the sun, which is farthest from the earth.

Ancient astronomy, which placed the earth in the centre of the system, was mucb taken up in ascertaining the apogee and perigee; which the moderns have clianged for aphelium and perihelium. See the article Apuzurum, \&c.

APOLLONIUS, of Perga, a city in Pamphilia, was a celebrated geometrician, who flourished in the reign of Ptolemy Euergetes, about 240 years before Christ; being about 60 year's after Euclid, and 30 years later than Archimedes. He studied a long tine in Alexandria under the disciples of Fuclid; and afterwards he composed several curious and ingenious geo. metrical works, of which only his books of Conic Sections are now extant, and even these not perfect. For it appears from the author's dedicatory epistle to Eudemus, a geometrician in Pergamus, that this work consisted of eight books ; only seven of which however has come down to us.

From the Collections of Papus, and the Commentaries of Eutocius, it appears that Apollonius was the author of various pieces in geometry, on account of which he acquired the title of the great geome. trician. His Conics was the principal of them. Some have thought that Apollonius appropriated the writings and disco. veries of Archimedes; Heraclius, who wrote the life of Archimedes, affirms it; though Eutocius endeavours to refute him. Although it should be allowed a groundless supposition, that Archimedes was the first who wrote upon conics, notwithstanding his treatise on conics was greatly esteemed, yet it is highly probable that Apollonius would avail himself of the writings of that author, as well as others who had gone before him; and, upon the whole, he is allowed the honour of explaining a difficult subject better than had been done before, having made several improvements, both in Archime. des's problems, and in Euclid. His work upon conics was doubtless the most perfect of the kind among the ancients, and 


\section{AP0}

in some respects among the moderns also. Before A pollonius, it had been customary, as we are informed by liutocius, for the writers on conics to require three different sorts of cones to cut the three different sections from; vi:. the parabola from a right-angled cone, the ellipse from an acute, and the hyperbola froin an obtuse cone; because they always supposed the scctions made by a plane cutting the cones to be perpendicular to the side of them: but Apollonius cut his sections all from any one cone, by only varying the inclination or position of the cutting plane; an improvement that has been followed by all other authors since his time. But that Arclumedes was acquainted with the same manner of cutting any cone is sufficiently proved, against Eutocius, Pappus, and othiers, by Guiclo Ubaldus, in the beginning of his Commentary on the second book of Archimedes's Equiponderantes, published at Pisa in 1588. Sec Corre Sections.

'The first four books of A pollonius's co. nics only have come down to us in their original Grcek language; but the next three, the 5th, 6th, and $7 \mathrm{th}$, in an Arabic version; and the 8 th not at all. These have been commented upon, translated, and published by various authors. Pappus, in his Mathematical Collections, has left some account of his various works, with notes and lemmas upon them, and particularly on the Conics. And Eutocius wrote a regular elaborate commentary on the propositions of several of the books of the Conics.

A neat edition of the first four books in Latin was published by Dr. Barrow, in 4to. at London, in 1675. A magnificent edition of all the books was published in folio, by Dr. Halley, at Oxford, in 1710; together with the Lemmas of Pappus, and the Commentaries of Eutocius. The first four in Greek and Latin, but the latter four in Latin only, the 8 th book being restored by himself.

APOLOGUE, in matters of literature, an ingenious method of conveying instruction by means of a feigned relation, called 2 moral fable.

The only difference between a parable and an apalogue is, that the former, being drawn from what passes among mankind, requires probability in the narration: whereas the apalogue, being taken from the supposed actions of brutes, or even of things inanimate, is not tied down to the strict miles of probability. Esop's fables are a model of this kind of writing.

APONOGETON, in botany, a genus of the Dodecandria Tetragynia. Ament, composed of scales; no calyx, no corol.; eapsules four; three sceded. There are four species.

Al'OPIITHF.G., a short, sententious, anil instructive remark, pronounced by a person of distinguished character. Such are the apophthegms of Plutarch, and those of tlic ancicints collected by L,jcosthenes.

APOPIIYSIS, in anatomy, an excres. cence from the body of a bone, of which it is a true continuous part, as a branch is of a tree.

APOTIECARY, one who practises the art of pharmacy, or that part of physic which consists in the preparation and composition of medicines.

A youth intended for this profession. should be a pretty good scholar, and have such a knowledge in the Latin tongue, as to be able to read the best writers upon the subject of botany, pharmacy, anatomy, and medicine. In London, the apothecaries are one of the city companies, and by an act, whicls was made perpetual in the ninth year of George I. are exempted from serving upon juries, or in ward and parish offices. They are obliged to make up their medicines according to the formulas described in the College I)ispensatory, and are liable to have their shops visited by the censors of the college, who are empowered to destroy such medicines as they think not good. In Pennsylvania, and we believe the United States generally, no obligation of this kind is imposed. Any person, however ignorant of the qualities and properties of medicines, or unskilful in the preparation of them, may nevertheless establish himself as an apothecary; the consequence is, the occurrence of many accidents; the inju. dicious application of drugs; and, as he is amenable to no authority, the consequent adulteration of his compounds.

The apothecaries have a IIall in Blackfriars, London, where there are two fine laboratories, from which all the surgeons' chests are supplied with medicines for the royal navy. In China, they have a singular mode of clispensing their medicines. In the public squares of their cities there is a very high stone pillar, on which are engraven the names of all sorts of medicines, with the price of cach; and when the poor stand in need of any relief from physic, they go to the treasury, where they receive the price each medicine is rated at.

Al'OTHFosis, in antiquity', a ceremony. \}y which the ancient Romans compli- 
mented their emperors and great men, after their death, with a place among the gods. It is described as follows : after the body of the deceased had been burnt with the usual solemuities, an image of wax, exactly resembling him, was placed on an ivory couch, where it lay for seven days, attended by the senate and ladies of the highest quality in mourning; and then the young senators and knights bore the bed of state through the Via sacra to the old Forum, and from thence to the Campus Martius, where it was deposited upon an edifice built in form of a pyramid. The bed being thus placed, amidst a quantity of spices and other combustibles, and the knights having made a procession in solemn measure round the pile, the new emperor, with a torch in his hand, sct fire to it, while an eagle, let fly from the top of the building, and mounting in the air with a firebrand, was supposed to conrey the soul of the deceased to heaven, and thenceforward he was ranked among the gods.

APOTOME, in geometry, the difference between two incommensurable lines: thus, E C, (Plate Miscel. fig. 6.) is the apotome of $\mathbf{A ~} \mathbf{C}$ and $\mathbf{A ~} \mathbf{B}$.

If we suppose $\mathbf{A} \mathbf{C}=a$, and $\mathbf{A} \mathbf{B}=b$. then will thcir apotome be $a-\sqrt{b_{;}}$or, in numbers, $2-\sqrt{3}$. Hence also the difference between the side $\mathrm{A} \mathrm{C}=2$ (fig. 7.) of an equilateral triangle $\mathbf{A} \mathbf{B ~ C}$, and the perpendicular $\mathbf{B} \mathbf{D}=\sqrt{3}$ is an apotome, viz. $=2-\sqrt{3 .}$ And universally, if A C (fig. 8.) be a semi-parabo$\mathrm{la}$, whose axis is $\mathrm{A} \mathrm{H}$, and its latus rectum $=1$, and if $A \mathrm{D}$ be a tangent to the vertex at $A$, and this be divided into the parts $\mathrm{A} a=2, \mathrm{~A} b=3, \mathrm{~A} c=5, \mathrm{~A} d=$ $6, \&$ c. and perpendiculars $a 1, b 2, c 3, d 4$, \&c. be drawn, these will be, from the natire of the curve, $\sqrt{ } 2, \sqrt{ } 3, \sqrt{ } 5, \sqrt{ }$, \&c. respectively: and so $\frac{1}{2} \mathrm{~A} a(=1)-$ $a 1$, will be $1-\sqrt{ } 2: A a-b 2$ will be $2-\sqrt{ } 3$, \&c. by which means you will lave an infinite series of different apo. tomes.

Apotone, in music, the difference between a greater and lesser semi-tone, expressed by the ratio $128: 125$.

APl'ARATUS, a term used to denote a complete set of instruments, orother uten. . sils, belonging to any artist or machine : thus we say, a surgeons' apparatus, a che. mist's apparatus, the apparatus of the air-pump, microscope, \&c.

APPAREN'T, among mathematicians and astronomers, denotes things as they appear to us, in contradistinction from real or true: thus we say, the apparent diameter, distance, magnitude, place, fig. ure, \&ec. of bodies.

APPARITOR, among the Romans, a general term to comprehend all attend. ants of judges and magistates appointed to receive and execute their orders. Apparitor, with us, is a messenger, that serves the process of a spiritual court, or a beadle in an university, who carries the mace.

APPAUMEE, in heraldre, denotes one hand extended with the full palm appearing, and the thumb and fingers at full length.

APPEAL, in law, the remoral of a cause from an inferior to a superior court or judge, when a person thinks himself aggrieved by the sentence of the inferior judge. Appeals lie from all the ordinary courts of justice to the House of Lords. In ecclesiastical causes, if an appeal is bronght before a bishop, it may be removed to the archbishop; if before an archdeacon, to the Court of Arches, and thence to the archbishop; and from the archbishop's court to the king in chancery.

Appeal, in common law, is taken for the accusation of a murderer by a person who bad interest in the party killed; or of a felon by an accomplice. It is prosecu. ted either by writ or by bill : by writ, when a writ is purchased out of the Chancery by one person against another, command. ing him to appeal some thircl person of felony, and to find pledges for doing it effectually; by bill, when the person himself gives in his accusation in writing, offering to undergo the burden of appealing the person therein named.

In military affairs, an appeal might formerly be made by the prosecutor, or prisoner, from the sentence or jurisdiction of a regimental to a general court-martial. At present no soldier has a right to appeal, except in cases where his immediate subsistence is concerned.

APPFiRANCF, in law, signifies a defendant's filing a common or special bail on any process issued out of a court of judicature. In actions by original, appearances arc entered with the philazer of the county; and by bill, with the prothonotary. Defendants may appear in person, where the party stands in contempt, for the court will not pernit him to ap. pear by attorney : also in capital and criminal cases : where an act of parliament requires that the party should appear in person, and likewise in appeal, or on attachment : by attorncy, in all actions, real, personal, and mixed, and for any crime whatever under the degree of capital, by 
farour of the court: by guardian and next friend, when under age.

API'ELLATIV 5 , in gTammar, a noun, or uame, which is applicable to a whole species or kind, as man, horse; in contradistinetion to a proper name.

APPRILLOR, or APPRLAYT, in law, he who has committed some felony or other crime, which he confesses and appeals, that is, accuses lis accomplices.

AI'l'F.NDANT, in law, any thing that is inheritable, belonging to some more worthy inheritance, as an advowson, common, or court, may be appendant to a manor, land to an office, \&c. luit land canuot be appendant to land, for both are corpnteal inheritances, and one thing corporeal cannot be appenclant to another.

API'LF, a well-known fruit, consisting of a rind, pill, or skin; the pulp, or parenchyma; the branchery, or seed-vessels; and the core. See Prnus.

APPLICATION, the act of applying one thing to another, by causing them to approach, or bringing them nearer togcther. Thus a longer line or space is measured by the application of a less, as a foot or yard by an inch, \&c.; and motion is determined by successive application of any thing to different parts of space. Application is sometimes also used both in arithmetic and geometry, for the operation of division, or for that which corresponds to it in geometry. Thus 20 applied to, or divided by $4, i$. e. 20 $\frac{20}{4}$, gives 5 . And a rectangle $a b$ applied to a line, $c$, gives the fourth proportional $\frac{a b}{c}$, or another line, as $d$, which, with the given line $c$, will contain a rectangle $c d$ $=a b$.

Applicatros, in geometry, denotes the act of placing une figure upon another, in order to determine their equality or inequality. In this way Euclid, and other geometricians, have demonstrated some of the primary and fundamental propositions in elementary geometry. Thus it is proved, that two triangles, laving two sides of the one equal respectively to two sides of the other, and the two included angles equal, are equal in all respects ; and two triangles, liaving one side and the adjacent angles of thic one respectively equal to one side, and the adjacent angles of the other, are also in the same morle of application shewn to be equal. Thus also it is demonstrated that a diameter di. vides the circle into two equal parts; and that the diagonal divides a square or párallelograin into two equal parts. The term is also used to signify the adapta. tion of one quantity to another, in order to their being compared, the areas of which are the same, but their figures different. Thus Euclid shews how, on a right line given, to apply a parallelogram that shall be equal to a right-lined figure given.

Applcarjos of one science to another, signifies the use that is made of the principles of the one for augmenting and perfecting the other. As there is a connection between all the arts and sciences, one of then may be made subservient to the illustration and improvement of the other: and to this purpose algebra has been applied to geometry, and geometry to algebra, and both to mechanics, astronomy, geography, navigation, \&c. See ALGE. BRA, application of.

APPLicatios of algebra and geometry to mechanics is founded on the same principles as the application of algebra to geometry. It consists principally in repre. senting, by equations, the curves describ. ed by bodies in motion, by determining the equation between the spaces which the bodies deseribe when actuated by any forces, and the times employed in describ. ing them. As a familiar instance, we may refer to the article Accrination, where the perpendiculars of triangles represent the times, the bases, the velocities, and the areas the spaces described by bodies in motion, a method first invented by $\mathbf{G a}$. lileo. As lines and figures may be treat. ed of algebraically, it is evident in what way the principles of geometry and al. gebra may be applied to mechanics, and indeed to every branch of mixt mathe. matics.

Aprlicatios of mechanics to geometry consists in the use that is made of the centre of gravity of figures, for determin. ing the contents of solid bodies described by those figures.

A Prication of geometry and astronomy to geography consists in determining the figure and magnitude of the earth; in determining the positions of places by ob. servations of latitudes and longitudes; and in cletermining, by geometrical operations, the positions of such places as are not fir distant from one another.

Applicatiox of geometry and algebra to natural philosophy was invented chiefly by Sir Isaac Newton, and upon this application are foutuded all the mixed sciences of mathematical and natumal philosophy. Here a single obestration or experiunent vill frequently produce a whole science, or branch of science. Thus when it is proved by experiment that the rays of 
light in reflecting, make the angle of incidence equal to the angle of reflection, we deduce the whole science of catoptrics; for, this fact being established, catoptries becomes a science purely geometrical, since it is reduced to the comparison of angles and lines given in position.

APPOLNTEE, in heraldry, the same as aguisée: thus we say, a cross appointée, to signify that which has two angles at the end cut off, so as to terminate in points.

APPORTIONMENT, in law, the division of a rent into parts, in the same manner as the land out of which it issues is divided: for example, if a person leases three acres of land for a certain rent, and afterwards grants away one acre thereof to another, the rent shall be apportioned between them.

APPOSITION, in grammar, the placing. two or more substantives together, in the same case, without any copulative conjunction between them; as, ardebat Alexin delicins domins.

APPRAISING, the valuing or setting a price on goods. This is usually done by a sworn appraiser, who, if he values the goods too high, is obliged to take them at the price appraised.

APPREHENSION, in logic, the first or most simple act of the mind, wherely it perceives, or is conscious of some idea: it is more usually called perception.

APPRENTICE, a young person bound by indenture to some tradesman, in order to be instructed in the mystery or trade. By the laws of England, a master may be indicted for not providing for, or for turning away, his apprentice : and upon complaint from a master, that he neglects his duty, an apprentice may be committed to Bridewell, or be bound over to the sessions. Apprentices may be bound to husbandmen, or even to gentlemen of fortune and clergymen, who, as well as tradesmen, are compellable to take the children of the poor, under a penalty of $10 l$. And the church-wardens and overseers, with the consent of two justices, may bind them till the age of 21 years. Justices may compel certain persons under age to be bound apprentices, and on refifal may commit them. Apprentices may be discharged on reasonable cause, either at their own request, or that of their masters. If any, whose premium has been less than tell pounds, run away from their masters, they are compellable to serve out the time of absence, or give satisfaction for it, any period within seven years after the expi. ration of the original contract. Indentures are to be stamped, and are cliargeable with several duties by act of parliament. APPRENTICESHIP, denotes the servitude of an apprentice, or the duration of his indenture. The competition in several employments is restrained to a smalier number than would otherwise be disposed to enter into them, partly by the limitation of the number of apprentices, which attends the exclusive privilege of incorporated trades; and partly by the long term of apprenticeship, which increases the ex. pense of education. Seren years seem formerly to have been, all over Europe, the usual term established for the duration of apprenticeships in the greater number of incorporated trades. Sucl incorporations were anciently called universities, which is the proper Latin name for any incorporation whatever. The university of smiths, the university of tailors, \&c. are expres. sions commonly occurring in the old char. ters of ancient towns. When those particu. lar incorporations, which are now peculiarly called universities, were first establish. ed, the term of years during which it was necessary to study, in order to obtain the degree of Master of Arts, appears evi. dently to have been copicd from the term of apprenticeship in common trades, of which the incorporations were much more ancient. As to lave wrought seven years under a master, properly qualified, was necessary to entitle any person to become a master, and to have himself apprentices, in a common trade, so to have studied seven years under a master properly qualified, was necessary to entitle him to become a master, teacher, or doctor, (words anciently synonymous, ) to study under him. By the 5th of Elizabeth, commonly called the statute of apprenticeship, it was enacted, that no person should, for the future, exercise any trade, craft, or mystery, at that time exercised in England, unless he had previously served to it an appren. ticeship of seven years at least; and thus, what before had been the bye-law of many particular corporations, became in England the general and public law of all trades carried on in market-towns. To country villages the term of seven years apprenticeship doth not extend; but the limitation of this statute to trades exercised before it was passed has given occasion to several distinctions, which, considered as rules of police, appear as foolish as can well be imagined. A coachmaker, for instance, has no riglit to make, or employ journeymen for making, coachwheels : but he must buy them of a master whecl-right, this latter trade haring 


\section{APPRENTI CESHIX.}

been exercised in England before the 5th of klizabeth. But a wheel-wright, though he bas never served an apprenticeship to a coachmaker, may, by himself or journeyman, make coaches, because this tracle, being of a later origin, is not within the statute. Thus also the manufactures of Manchester, Birmingham, and Wolverhampton, are, many of them, upon this account, not within the statute, not having been cxercised in England before the 5 th of Flizabetl.

The regulations of apprenticeship in Ireland are upon a different footing, and somewhat less illiberal than in England. Prohibitions, similar to those of the statute of the 5th of Filzabeth, obtain in all corporate towns, by authority of bye-laws of the several corporations: but these prohibitions extend only to natives of Ireland; for, by a regulation made by the lord lieutenant and privy-council, haring in this instance, by 17 and $18 \mathrm{Car}$. II. the force of a law, all forcigners and aliens, as well persons of other religious persuasions as Protestants, who are merchants, traders, artificers, \&ic. shall, upon coming to reside in a city, walled town, or corporation, and paying twenty shillings, by way of fine, to the chief magistrate and commoncouncil, or other persons authorised to admit freemen, be admitted to the freedom of that city, \&.c. and to the freedom of guilds of their respective trades, with the full enjoyment of all privileges of buy. ing, selling, working, \&ec.; and anv ma. gistrate refusing to admit foreigners, so applying, shall be disfranchised.

In Scotland, there is no ger.eral law which regulates universally the duration of apprenticeships. The term is different in different corporations; where it is long, a part of it may generally be redeemed by paying a small fine. In most towns, too, a very small fine is sufficient to purchase the freedom of any corporation. The weavers of linen and hempen cloth, the principal manufactures of the country, as well as all other artificers subservient to them, whecl-makers, reel-makers, \&c. may exercise their trades in any town corporate, without paying any fine, In all towns corporate, all persons are free to sell butchers' meat upon any lawful day of the weck. Three years are, in Scot. land, a conimon term of apprenticeslip, in some very nice tmodes; and, in general, there is no country in Europe, in which corporation laws are so little oppressive. In France the duration of apprenticeships is different in different towns, and in different trades. In Paris, 5 years are the term required in a great number; and before any person can be qualified to exercise the trade as a master, he must, in many of them, serve 5 yesrs more as a journeyman. During this latter time, he is called the companion of his master, and the termitself is called his companionship. The institution of long apprenticeslups, says Dr. Smith, can give no security that insufficient workmanship shall not frequently be exposed to sale; nor has it any ten. dency to form young people to industry. Apprenticeships were altogether unknown to the ancients: the Roman law is perfectly silent with regard to them. There is no Greek or Latin word, which expresses the idea we now annex to the word apprentice.

Long apprenticeslips are altogether unnecessary. The arts, which are much superior to common trades, such as those of making clocks and watches, contain no such mystery as to require a long course of instruction. In the common mechanic trasles, the lessons of a few days might certainly be sufficient. The dexterity of hand, indeed, even in common trades, can. not be acquired without much practice and experience. liut a young man would practise with much more diligence and at tention, if, from the beginning, he wrought as a journeyman, being paid in proportion to the little work which he could execute, and paying, in his turn, for the materials which he might sometimes spoil through awkwardness and inexperience. His echlucation would generally in this way be more effectural, and alwars less tedious and expensive. The master, indeed, would be a loser; he would lose all the wages of the apprentice, which he now saves for seven years together. In the end, perhaps, the apprentice himself would be a loser; in a trade so easily learnt he would have more competitors; and his wages, when lie came to be a complete workman, would be much less than at present. The same increase of competition would reduce the profits of the masters, as well as the wages of the workmen: the trades, the crifts, the mysteries, would all be losers; lut the public would be a gainer, the work of all artificers coming in this way much cheaper to market.

We cannot conclude this aricle better, than by inserting an adnirable paper oI the subject of apprentice laws, drawn up, and printed for private circulation, by : gentleman of high legal authority, and member of parliament, entitled " $\mathrm{A}$ few Opinions of some great and gond Men, am sound Lawyers, on the Apprentice laws of Queen Fizabeth, applicable to the Aira of $1806-7 . "$ 


\section{APPREN'TICESHIP.}

Lord Mansfield, in his arguments on the case, Rennard and Chase, brewers. 1 Bur. Rep. p. 2, says, "It hath been well observed that this act (viz. 5 Eliz. chap. 4.) is,

1. A penal law.

2. It is a restraint on natural right.

3 . It is contrary to the general right given by the common law of this kingdom.

4. The policy upon which this act was made is from experience become doubtful. Bad and unskilful workmen are rare. ly prosecuted. This act was made early in the reign of Queen Elizabeth, when the great number of manufacturers, who took refuge in England after the duke of Alra's prosecution, had brought trar!e and commerce with them, and enlarged our no. tions. The restraint introduced by this law was thought unfarourable; and the judges, hy a liberal interpretation, have extenrled the qualification for exercising the trade much beyond the letter of it, and confined the penalty and prohibition to cases precisely within the express letter." Burn's Justice, vol. i. Art. Apprentices.

3d Modern Reports, p. 317. Judge Dolben, in delivering his opinion, said, that "No encouragement was ever given to prosecutions upon the statute 5 Eliz. and that it would be for the common good, if it were repealed; for 110 greater punishment can be to the seller, than to expose to sale goods ill-wrought, for by such means he will never seli more."

2 Salk. 613. The Queen v. Maddox.It was held by the court, "that upon in. dietments upon the statute of 5 Eliz. the following of a trade for seven years to be sufficient without any holding; this being a hard law." And so held in Lord Ray: mond, 738.

Burn's Justice.-" So detrimental was this statute thought, that by 15 Car. II. all persons spinning, or making cloth of hemp or flax, or nets for fishing, or storin, or cordage, might exercisc those trades without serving apprenticeships. And so little did the legislature, at subsequent periods, think that any benefit was to be derived from the statute of $5 \mathrm{Eliz}$. or that manufactures were made better, or improved by this restraint; and the minds of men being more liberal, that trade should, as much as possible, be flung open; it is enacted by 6 and 7 William III. that any apprentice discovering two persons guilty of coining, so as they are convicted, shall be decned a freeman, and may exercise his trade as if he had serred out his time."

And, in oriler still stronger to shew how iittle the legislature esteemed the seren years binding ameliorated manufactures, it is enacted, by 3 George III. cap. 8 , that "All officers, marines, and soldiers, who have been employed in his majesty's service, and not deserted, may exercise such trades as they are apt for, in any town or place."

So dangerous and fatal has heen the evil of combinations and conspiracies among journeymen, that in particular instances, as in trades where many hands are required and very little skill, as dyeing, and such like, the legislature have made express laws to give relief to masters. See 17 Geo. III. cap.33.; which enables dyers, in Middlesex, Essex, Surrey, and Kent, to employ journeymen who have not served apprenticeships. And to such a pitch has this mischicf in the West Riding of Yorkshire increased, by the conspiracies facilitated by the act of $5 \mathrm{Filiz}$. that it goes to the total annihilation of our staple manufactures, and every otlier trade which hopes for suecess, not only by the home, but from foreign consumption. See the report from the committee of the House of Commons, on the woollen trade and manufacture of these kingdoms, made in the last session of parliament, 4th July, 1806.

After stating the above, let us quote the words of the immortal Lord Chief Justice Coke on this point.-"That, at the common law, no man could be prohibited from working in any lawful trade: for the law abliors idleness, the mother of all evil -Otium omnium viliomım mater-and especially in young men, who ought in their youth (which is their seed time) to learn lawful sciences and trades, which are profitable to the commonwealth, whereof they might reap the benefit in their old age : for 'idle in youth, poor in age'."

And therefore the common law abhors all monopolies, which prohibit any from working in any lawful trade. And that appears in 2 Hien. V. 5 b. A dyer was bound not to use the dyer's eraft for two years : and there Judge Hall held, "that tlue bond was agrainst the common law: and by $\mathbf{G}-\mathrm{d}$, if the plaintiff' was here, he should go to prison till he paid a fine to the king." And vicle 7 Fdw. III. 65 b. "And, if he who takes upon himself to work is unskilful, his ignorance is a sufficient punishment to him, for imperitia est maxima mecanicorum pana; et quilibet quee rit in quálibet arte peritos: which is, "that want of skill is the greatest punishment of inechanics; for cvery body will employ those that are the best skilled in their bu. siness.' And if any one takes upon himself to work, and spoils it, an action on the case lies against him." 


\section{APP}

II aving observed thus mucl, and stated the opinions of two such great men as Lord Coke and Lord Mansfield, we can only add one dixit of Lord Coke's, that "acts of parliament, which are made against the freedom of tracle, merchandizing, handicrafts, and mysteries, never live long." 4th Inst. 31.

It is to be obscrred that this very great check upon trade, by not being ablc to employ any liands that are able to perform the work required, and especially in those trades which are so easily learnt in a very short space of time, greatly enhances the prices of all articles, and that at a time when population is daily increasing, and the de. mand proportionably increasing. And this statute is not only a restraining statute, but also an enabling statute, as it empowers the workmen to enter into combinations against thcir masters, and to dictate their own terms, encouraging vice, idlcness, and drunkenness; demands bcing made on the masters for an increase of wages; those demands supported by dan. gerous combinations and conspiracies, and extorted by threats. And such increase, when obtained, not applied for the wholesome purpose of supporting themselves and their families, but to that very de. structive purpose, ruinous to their families, and highly detrimental to the public at large, the enabling of the parties to spend more days of the week in idleness, drumkenness, vice, and immorality. In many manufactures, so much money is extorted by the journeymen, by means of these combinations, from their employers, that the journeymen will work but three days in the week; so that 600 are necessarily required to do the work that 300 might do.

Until these laws, restricting the binding of apprentices, are repealed, all laws made for the prevention of combinations among workmen, can be of no aval, and will remain a dead letter in the law books: as in this free country, (however that freedom may be limited as to the checking of masters binding apprentices), no law on this point can be so worded, that the art, wickedness, and ingenuity of men, will not contrive to defeat. A bad and absurd law is made, vi: the "Apprentice Act," which, by the cxtension of trade, is found detrimental to trade; and then, to do away the mischiefs of that law, another absurd law is made, viz. the law to prevent combination,- so that mischief is heaped upon mischief, and absurdity upon absurdity. Trade should be as free as the air we breathe. This is an axiom, the truth of which every day convinces us.

VOL. I.

\section{APP}

APPROACHES, in fortification, the works thrown up by the besiegers, in order to get nearer a fortress, without being exposed to the enemy's cannon: such, in a more particular manner, are the trenches, which should be connected by parallels, or lines of communication.

This is the most difficult part of a sicge, and where most lives are lost. The ground is disputed inch by inch, and it is of the utmost importance to make the approaches with great caution, and to secure them as much as possible.

The besieged frequently make counterapproaches, to interrupt and defeat the enemy's approacbes.

Al'PROPRIATION, the annexing a bc. nefice to the proper and perpetual use of a religious house, bishopric, college, \&c. Where the king is patron, he may make appropriations himself; but in other cases, after obtaining his licence in chancery, the consent of the ordinary, patron, and incumbent, is requisitc. Appropriations cannot be assigned over, but those to whom they are granted may make leases of the profits. There are in England 2845 impropriations.

Al'PROVER, in law, a person, who, being indicted of treason or fclony, for which he is not in prison, confesses the indictment: and being sworn to reveal all the treasons and felonies he knows, enters before the coroner his appeal against all his partncrs in the crime. All persons may be approvers, except peers of the realm, persons attainted of treason or felony, or out-lawed, infants, women, persons non compos, or in holy orders.

APPIROXIMATION, in arithmetic and algebra, the coming nearer and nearer to a root, or other quantity sought, without expecting to be ever able to find it exactly. There are scveral methods for doing this, to be found in mathematical books, being nothing but infinitely converging series, some approaching quicker, others slower towards the trutb.

By such an approximation the value of a quantity may be found, though not to the utmost degrec of exactness, yet sufficiently so for practice. Thus $\sqrt{2}=1.41421356$, \&c. $=$ the approximating series $1+$

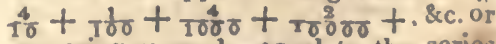
supposing $x=\frac{1}{10}$, equal to the series $1 \times \frac{4}{x}+\frac{1}{x^{3}}+\frac{4}{x^{3}}+\frac{2}{x}+, 8 c .=1+4 x^{-2}$ $+x^{-2}+4 x^{-3}+2 x^{-}+4$, \&c.

Again, supposing $a^{2}+b$ to be a non-quadrate number, and $a^{3}+b$ to be a noacubic one; then will $\sqrt{a^{2}+b}=a+$ Oo 


$$
\begin{aligned}
& \frac{a b}{2 a^{3}+\frac{1}{2} b} \text {, and } \sqrt[3]{a^{3}+b}=a+\frac{a b}{3 a^{3}+b} \\
& =\frac{3}{2} a+\sqrt{\frac{1}{4} a^{3}+\frac{b}{3 a}} \text { nearly. }
\end{aligned}
$$

There is a general method of investigating the value of such series, for which see SERIrs.

APPULSE, in astronomy, the approach of a planet towards a conjunction with the sun, or any of the fixed stars. The appulses of the planets to the fixed stars have always been of great use to astronomers, in order to fix the places of the former. The ancients, wanting an easy method of comparing the planets with the ecliptic, which is not visible, had scarce any other way of fixing their situations, but by observing their tract among the fixed stars, and remarking their appulses to some of those visible points. Dr. Halley has pub. lished a method of determining the places of the planets, by observing their near appulses to the fixed stars.

APPURTENANCES, in common law, signify things corporeal and. incorporeal, that appertain to another thing as principal ; as hamlets to a manor, and common of pasture and fishery. Things must agree in nature and quality to be appurtenent, as a turbary, or a seat in a church, to a house.

APRICOT, in botany, a spccies of prunus, with rosaceous flowers, and a delicious fleshy fruit, of a roundish figure. See Prexus.

APRON, in gunnery, the piece of lead which covers the touch-hole of a cannon.

The dimensions of aprons are as follows: viz. for 42,32 , and 24 pounders, 15 inches by 13 ; for 18,12 , and 9 pounders, 12 inches by 10; and for cannon of less calibre, 10 inches by 8 . They are tied by two strings of white marline.

APSIS, in astronomy, a term used indifferently for either of the two points of a planet's orbit, where it is at the greatest or least distance from the sun or earth. Hence the line comnecting these points is called the line of the apsides.

APTENODYTES, in ornithology, penguin, a genus of the order Anseres. The bill is "straight, rather compressed, and sharp along the edges; the upper mandible is obliquely sulcated, lengthwise; feet palmated, shackled; wings fin-shaped, and without quill-feathers; feet fettered, four-toed. This genus resembles the alca in colour, food, stupidity, eggs, nest, positions of legs belind the equilibrium, and consequent erect posture. ${ }_{1}$. They are to- tally unfit for flight, but swim dexterously: nostrils linear, hid in the groove of the bill, palate as well as the tongue beset with a few rows of conic, retroflected, stiff papilla; wings covered with a strong broad membrane ; tail short, wedged, the feathers very rigid. There are nine species according to Latham, but Gmelin enumerates eleven.

This genus of birds seems to hold the same place in the southern parts of the world as the awks do in the northern, and are by no means to be confourded the one with the other, however authors may differ in opinion in respect to this matter:" The penguin is seen only in the temperate and frigid zones, on that sicle of the equator which it frequents; and the same is observed of the awk in the opposite latitudes; and neitler of the genera has yet been observed within the tropics. The awk has true wings and quills, though small; the penguin mere fins only, instead of wings. This last has four toes on each foot; but the former only three. The penguin, while swimming, sinks quite above the breast; the head and neck only appearing out of the water, rowing itself along with its finny wings, as with oars; while the awk, in common with most othel birds, swims on the surface. Several other circumstances peculiar to each might be mentioned; but we trust the above will prove fully sufficient to characterize this genus. The bodies of the penguin tribe are commonly so well and closely covered with feathers, that no wet can penetrate ; and as they are in general excessively fat, these circumstances united secure them from the cold. They have often been found above seven hundred leagues from land; and frequently on the mountains of ice, on which they seem to ascend without difficulty, as the soles of their feet are very rough, and suited to the purpose.

A ptenodytes antarctica, is full 25 inches long, and weighs eleven or twelve pounds : it inliabits the south sea from $48^{\circ}$ to the antarctic circle, and is frequently found on the ice mountains and islands on which it ascends. It is a numerous tribe; and they were found in great plenty in the Isle of Deśolation.

The black-footed penguin is found in the neighbourhood of the Cape of Good Hope, but particularly in Robbean or Penguin Isles, near Saldanic Bay. Like all the geuus, this is an excellent swimmer and diver; but hops and flutters in a strange and aukward manner on the land, and, if hurricd, stumbles perpetually; and fre. quently runs for some distance like a quà-

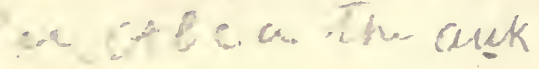




\section{AP'TENODYTES.}

druped, making use of the wings instead of legs, till it can recover its upright posture; crying out at the same time like a gonse, but in a much hoarser voice. It is said to clamber some way up the rocks in order to make a nest, in doing which it has been observed to be assisted with the bill. The eggs are 1 wo, and estecmed at the Cape very delicious.

Aptenodytes chrysocome. This beautiful species measures twenty-three inches in length. The bill is three inches long; the colour of it red, with a dark furrow running along on each side to the tip; the upper mandible is curved at the end, the under obtuse ; irides of a dull red; the head, neck, back, and sides are black; over each eve a stripe of pale yellow feathers, which lengthens into a crest behind, of near four inches in length: the feathers on each side of the head, above this stripe, are longer than the rest, and stand upward, while those of the erest are decumbent, but can be erected on cach side at will; the wings, or rather fins, are black on the outside, edged with white; on the inside white; the breast, and all the under parts, white; the legs are orange : claws dusky. The female has a streak of pale yellow over the eye, but it is not prolonged into a crest behind as in the malc. Inhabits Falkland's Islands, and was likewise met with in Kirguelin's Iand or Isle of Desolation, as well as at Van Dicmen's Land, and New Holland, particularly in Adventure Bay. Are called Hopping Penguins and Jumping Jacks, from their action of leaping quite out of the water, on meeting with the least obstacle, for three or four feet at least; and indeed, without any seeming cause, do the same frequently, appearing, clicfly to advance by that means. This species secms to have a greater air of liveliness in its countenance than others, yet is in fact a very stupid bird, so much so, as to suffer itself to be knocked on the head with a stick, when on land. When angered, it erects its crest in a beautiful manner. These birds make their nests among those of the pelican tribe, living in tolerable harmony with them; and lay seldom more than one egg, which is white, and lasger than that of a duck. They are mostly seen by themselves, seldom mixing with other penguins, and often met with in great numbers on the outer shorcs, where they have been bred. Are frequently so regardless as to suffer theinselves to be taken by the hand. The females of this species lay their eggs in burrows, which they easily form of themselres with their bills, throwing out the dirt with their feet.
In these holes the eggs are deposited on the bare earth. The general time of sitting is in October; but some of the species, especially in the colder parts, do not sit till December, or even January. IIow long they sit is not known.

Apterodytes magellanica, inhabits the Straits of Niagellan, Staaten Land, Terra del Fuego, and the Falkland isies; is a very numerous species, and is often seen by thousands, retiring by night to the highest parts of the islands. Its voice is not much unlike the braying of an ass. It is not a timid bird, for it will scarcely get out of the way of any one ; but will rather attack and bite a person by the legs. They were killed by hundreds by the crews of Captain Cooke's expedition, and were found not unpalatable food. They often mix with the sea-wolves, among the rushes, burrowing in holes like a fox. When they swim, only the neck and shoulders appear out of the water, and they advance with such agility, that no fish secms able to follow them; if they meet with any obstacle, they leap four or five feet out of the water; and dipping into it again continue their rout. It is supposerl by Latham that I'enrose alludes to this species, of which, he says the clief curiosity is the laying their eggs ; this they do in collective bodies, resorting in incredible numbers to certain spots, which their long residence has freed from grass, and to which were given the name of towns. The eggs are rather larger than those of a goose, and are laid in pairs. They lay some time in November, driving away the albatrosses, which have hatched their young in turn before them.

Aptenodytes patachonica. This is the largest of the genus yet known, being four feet three inches in length; and stands erect at least three feet ; the weight forty. pounds. This species was first met with in Falkland Islands, and has also been seen in Kerguelen's I.and, NeW Georgia, and New Guinea. M. Bougainville caught one which soon became so tame as to follow and know the person who had care of it; it fed on flesh, fish, and bread, but after a time grew lean, pined away, and died. The chief food, when at large, is thought to be fish; the remains of which, as well as crabs, shell-fish, and mollusca, were found in the stomach. This species is the fattest of the tribe ; most so in January; when they moult. Supposed to lay and sit in October. Are met with in the most deserted places. Their flesh is black, though not very unpalatable. This has been considered as a solitary species, but has now and then been met with in corr. 
sidlerable flocks. They are found in the same places as the papuan penguins, and not unfrequently mixed with them; but in general show a disposition of associating with their own species. See Plate III. Ares. fig. 6.

APTERA, in the Linnæan system of zoology, the seventh and last order of Insects, the distinguishing characteristic of which is, that the insects comprehended in it hare no wings. Of this order there are three divisions. In $\mathbf{A}$. the insects are distinguished by having six legs; head distinct from the thorax : there are five genera; viz. the

$\begin{array}{ll}\text { Lepisma, } & \text { Pulex, } \\ \text { Pediculus, } & \text { Termes. } \\ \text { Podura, } & \end{array}$

In the division $\mathrm{B}$, the insects have from 8 to $14 \mathrm{legs}$; head and thorax united : of these there are eight genera; viz. the

$\begin{array}{ll}\text { Acarus, } & \text { Monoculus, } \\ \text { Aranea, } & \text { Oniscus, } \\ \text { Cancer, } & \text { Phalangium, } \\ \text { Hydrachna, } & \text { Scorpio. }\end{array}$

In the division $\mathbf{C}$, the legs are nume. rous; head distinct from the thorax; of which there are two species; viz the

Julus, and

Scolopendra.

This order comprehends all kinds of spiders, the lice of different animals, scorpions and crabs. Upon these, we may make a few general observations. The nets spread out by spiders, to catch their prey, are composed of similar materials to the silk of the silk-worm, and are also spun from the animal's body. The cobwebs of the gossamer are frequently seen floating in the air in a sunny day, snd are sometimes so abundant as to fall in show. ers. Each of these has been compared to a balloon transporting the little acronaut that formed it, by means of its specific lightness. This species of spider attaching its first formed thread to the leaf or branch of a tree, by dropping to a certain distance lengthens it, then climbs up the thread, and dropping again, draws out another, and so on, till a sufficient quantity of this silk is formed to buoy the spider up in the air. He then separates the whole from the leaf, and running down to his seat at the bottom, trusts himself and his balloon to the mercy of the wind. Many species of spiders effect the same thing by attaching themselves to an eminence by their claws, and after ejecting a suffi. cient quantity of web, which is wafted onwards by the wind, they suddenly relax their hold and appear to spring into the air. By this nethod these animals are transported from tree to tree, and from wood to wood in search of food. The cobwebs that are spread over the surface of the grass, and that offer so beautiful an object to the eye early in the summer's morning, through the brilliancy of the dew-drops formed and suspended on their silken tlureads, and the reflexion of the sun's rays from each, are the work of another species of spiders.

The different kinds of lice are exceedingly numerous, almost every kind of animal having its particular sort of vermin. They are all carnivorous, or perhaps ra. ther sanguivorous insects, living on the blood of other animals. Their eggs are all nits. The Scorpio genus abound in hot climates, and are troublesome in neglected places, and where cleanliness is not attended to. The crab tribes cast their shells every year, and are then in a soft, helpless state, unable to make resistance, and therefore at that time become the. prey of many kinds of fish, when not provided with a guardian. It is a remarkable fact, that the edible crab of the United States, when in this state of imbecility, places itself, for security, under the protection of one of its own species whose shell is hard and firm. This confidence is never misplaced; his protector defends him against every assault at the risk of his own life or limbs; and even when taken in the net, and thrown on shore, is still firmly held by his faithful companion. Their shells, but more especially those of the class testacea, afford a principal constituent in the formation of chalk-beds, and beds of marl, which are formed at the bottom of the sea. Specimens of entire shells are frequently met with in chalkpits which are now many miles inland; and there is little doubt, that in a comminuted state they form a principal ingredient in most calcareous earth. Under each genus will be found an account of a few of the more remarkable species. See Acarus; Aranea, Caycer, Scorpio, \&cc.

APUS, in astronomy, a constellation of the southerm hemisphere, placed near the pole, between the Triangulum Australe and the Chameleon, supposed to represent the bird of paradise. There are four stars of the sixth, three of the fifth, and four of the fourth magnitude, in the constellation Apus. Dr. Halley, in 1677, ob. 


\section{$\mathbf{A Q U}$}

served the longitude and latitude of the stars in Apus, which Hevelius in his prodromus reduced with some alteration to the year 1700. P. Noel has also given the places of these stars, with their right ascensions and declinations for the year 1687 , but his observations differ wiclely from those of Dr. Halley. Hevelius has represented the figure of Apus, and its stars, in his Firmamentum Sobiescianum, according to Halley's account; Noel has done the like, according to his own account. Wolfus, with what justice we will not pretend to say, gires the preference to this last.

AQUA fortis. Another name for $\mathrm{N}_{\mathrm{I}}$ Tric Acro, which see. This name is applied to denote the common nitric acid used by workmen, which often contains a slight portion of muriatic acid. See CnzMISTRY.

Anva regia, another name for the nitro muriatic acid. See Merratic Acrd.

AQUEDUCT, a conthit of roater, in architecture and hydraulics, is a construction of stone or timber, built on an uneven stound, to preserve the level of water, and convey it, by a canal, from one place to another. Some of these aquaducts are visible, and others subterraneous. Those of the former sort are constructed at a great height, across vallies and marshes, and supported by piers and ranges of arches. The latter are formed by piercing the mountains, and constructing them bclow the surface of the earth. They are built of stone, brick, \&c. and covered abore with vaulted roofs or flat stones, serving to shelter the water from the sun and rain. Of these aquaducts, some are vlouble, and others triple; that is, supported on two or three ranges of arches. of the latter kind are the Pout-du-gard, in I.anguedoc, supposed to have bcen built by the Romans to carry water to the city of Nismes; that of Constantinoplc, and that which, according to Procopius, was constructed by Cosroes, King of Persia, near Pctra, in Mingrelia, and which had three conduits in the same direction, each elevated abore the other. Some of these aquaducts were paved, and others conveyed the water througli a natural channel of clay: and it was frequently conducted by pipes of lead into reservoirs of the same metal, or into troughs of hewn stone. Aquaducts of every kind were reckoned among the wonders of ancient. Rome; their great number, and the immense expense of bringing water 30,40 , or 60 , and even 100 miles, either upon continued arches, or by means of other

\section{AQU}

works, when it was nceessary to penctrate mountains and rocks, may well astonish us. If we consider the incredible quantity of water brought to Rome for the uses of the public, for fountains, baths, fishponds, private houses, gardens and country-seats; if we represent to ourselves thic arches constructed at a great expense, and carried on through a long distance, mountains levelled, rocks cut through, and vallies filled up, it must be acknowledged that there is nothing in the whole world more woonderful. For 440 years, the Romans contented themselves with the waters of the Tiber, and of the wells and fountains in the city and its neighbourhood. But when the number of houses and inhabitants was considerably augment. ed, they were obliged to bring water from remote places by means of aquxducts. Even Tiberius, Claudius, Caligula, and Caraccalla, though in other respects not of the best character, took care of thie city in this useful article. There are still to be seen in the country about Rome wonderful remains of the ancient aquaducts, some elevated above the ground by arches continued and raised one above the other, and others subterrancous, passing through rocks ; such is that seen at Vicovaro, beyond Tivoli, in which a canal picrces a rock to the extent of more than a mile, and about five feet deep and four broad. At certain distances vents werc provided, so that the water which was accidentally obstructed in its passage, might be discharged till its ordinary passage was cleared; and in the canal of the aquaduct itself there were cavities, into which the water was precipitated, and where it remained till its mud was deposited; and ponds, in which it might purifyitself. In the construction of these aquaducts, there was a considerable variety : that called the Aqua Martia had an arch of sixteen feet in diameter; it was constructed of three kinds of stone, and was formed with two canals, one above the other. The most elevated was supplied by the waters of the Tiverone, and Anionovus; the lowest by the Claudian water. The entire edifice was 70 Roman fect ligh. The arch of the aqueduch which brought to Rome the Clandian water, was constructed of beautiful hewin stone. This is represerted by I'liny as the most beautiful of all that had been built for the use of Rome. It conveyed the water through a vaulted canal, through the distance of 40 miles, and was so highi, that it supplicd all the hills of the city. According to lim, and the computation of I3udxus, the charge of this work amounted to $1,385,500$ crowns. 
This aquaduct was begun by Caligula, and finished by Claudius, who brought its waters from two springs, calted $\mathrm{C}$ æruleus and Curtius. Vespasian, Titus, Marcus Aurelius, and Antoninus Pius,repaired and extended it : it is now called Aqua Felice. The three chief aquaducts now in being are those of the Aqua Virginea; Aqua Felice, and Aqua Paulina. The first was repaired by Pope Paul IV. The second was constructed by Pope Sixtus V. and is called from the name which he as. sumed before he was exalted to the Papal throne. It proceeds from Palæstrina at the distance of twenty-two miles, and clischarges itself at the Fontana di Termini, which was also built at his expense, and consists of three arches, supported by four Corinthian pillars, and the water gushes out through three large apertures: Over the middle arch stands a beautiful statue of Moses striking the rock with his rod; over another arch is a basso-relievo of Aaron leading the people to the miraculous springs in the wilderness, and the third exhibits Gideon trying his' soldiers by their drinking water. Round it are four lions, two of marble, and the other two of oriental granite, said to be brought thitherfiom a temple of Serapis. All the four lions eject water, and on the front is an inscription, importing that this aquxduct was begun in the first and completed in the third year of the pontificate of Sixtus V. 1588. The third was repaired by Pope Paul V. in the year 1612. This clivides itself into two principal channels, one of which supplies Mount Janiculus, and the other the Vatican and its neighbourhood. It is conveyed throuigh the distance of thirty miles, from the district of Bracciano, and three of its five streams are not inferior to small rivers, and sufficient to tium a mill. The famous aquaducts of Constantinople, about six miles from the village of Belgrade, were built by Valentinian the First, Clearchus being prefect, and afterwards repaired by Solyman the Magnificent, who exempted twelve adjacent Greek villages frum the customary tribute of the empire, in conlsideration of their keeping these aquxducts in repair. Of these the most remarkable are three large and lofty fabrics, built over so many vallies betwixt the ad. joining hills, of which the longest has many but less arches, and may possibly be the entire work of Solyman. The other two have the appearance of a more ancient and regular architecture, consisting of two rows of arches onc over the other: and those of the second were enclosed by pillars cut through the middle, so as to render the fabric both passable like a bridge, and useful for the conveyance of water. The more considerable of these two consists of only four large arches, each twenty yards long, and somewhat above twenty high, supported by octangular pillars of about 56 yards in circum ference towards the bottom. For an inquiry into the nature and construction of the aquæducts of the Romans, see Governor Pownal's Notices and Descriptions of Antiquities of the Provincia Romana of Gaul, 4to. 1788. The aquxduct built by Lewis XIV. near Maintinon, for carry. ing the River Bure to Versailles, is perhaps the greatest now in the world. It is 7000 fathoms long, and its elevation 2560 fathoms ; containing 242 arcades.

AQUARIUS, in astronomy, a constellation which makes the eleventh sign in the zodiac, narked thus, $m$. It consists of 45 stars in Ptolemy's catalogue, of 4.1 in Tycho's, and in the Britannic catalogue of 108. It was called Aquarius, or the Water-bearer, as some say, because, during the sun's motion through this sign, it is generally rainy weather.

AQUARTIA, in botany, a genus of the Tetrandria Monogynia class and order. Calyx campanulate; corol. wheel-shaped, with linear segments; berry many-seeded. There are two species.

AQUATIC, in natural history, an appellation given to such things as live or grow in the water : thus we say, aquatic animals, aquatic plants, \&c.

AQUEOUS humour, or the watery humour of the eye; it is the first and outermost, and that which is less dense than either the vitreous or crystalline. It is transparent and colourless like water, and fills up the space that lies between the cornea and the crystalline humour. See Optics.

AQUILA, the eagle, in ornithology. See Falco.

Alzura, in astronomy, a constellation of the northem hemispliere, consisting of 15 stars in P'tolemy's catalogue, 19 in 'Tycho Brahe's, 42 in that of Hevelius, and 71 in Flamstead's; the principal star being Lucida Aquila, and is between the first and second magnitude:

ARUILARIA, in botany, a large tree, affecting a lofty situation. Class Decandria-Monogynia; cal. perianth one-leafed, peimanent; tube bell-shaped; limb fivecleft ; clefts ovate, acute, flat, spreading ; cor, none : nectary one-leafed, pitchershaped, of the length of the tube of the calyx, half five.cleft; clefts bifid, obtuse ; 
stam. filaments ten, alternating with the clefts of the nectary ; anthers oblong, ver. satile; jist. germ ovate, superior; style, none; stigna, simple ; per. capsule on a very short pecticle, obovate, woody, twocelled, two valved, with the partition con. trary, and bipartite; seeds solitary, oblong. There is but one species. Aquilaria ovata; leaves alternate, ovate mucronate. This is a large trec covered with greyish bark. Its leaves are entire, smooth, veined, about eight inches long, and stand on slıort hairy foot-stalks. The flowers terminate the branches, on many-flower. cd peduncles. A native of the mountains of Malacca and Cochin-China. The wood of this tree has been long used as a perfume; and was formerly an article of the materia medica under the name of agallochum, lignum aloes, or aloes wood. This wood in its natural state is white and inodorous. That which possesses the peculiar aroma, for which it is valued, is supposed to be the consequence of a diseased process in the tree, causing the oleaginous particles to stagmate and concrete into a resin in the inner parts of the trunk and branches, by which the natural appearance of the wood is altered, so as to becone of a darker colour and of a fragrant smell. At length the tree dies, and, when splitten, the resinous part is taken out. The perfumes which this wood afforc's are highly estecmed by the oriental nations; and from the bark of the tree is made the common paper which the Cochin-Chinese use for writing ; in the same manner the Japanese make use of the bark of a species of mulberry (moris pa. pyrifera). This perfume is said to be useful in vertigo and palsy : given in the form of powder, it is recommended to restrain vomitings and alvine fluxes. To us, however, it seems to contain little else than that camphoraceous matter common to many other vegetable substances. From its bitter taste it has the name of aloes, although no otherwise allied to it.

AQUULEGIA, columbine, in botany, a genus of the Polyandria Pentagynia class of plants, having no calyx; the corolla consists of five plane, patent, equal petals, of a lanceolate, ovate figure; the nectaria are five in number; they are equal, and stand alternately with the petals; the fruit consists of five straight, parallel, $\mathrm{cy}$. lindric, accuminated capsules, each of which consists of a single valve. The secds are numerous, oral, carinated, and adhere to the suturp. "There are five species.
ARA, in astronomy, a southern cun. stellation, consisting of eight stars.

A IRABIS, in botany, wall-crvse, a genus of the Tetradinamia Siliquosa class of plants, the calyx of which is a deciduous perianthium, consisting of four ovato-oblong, acute, gibhous, concare leaves; the corolla consists of four oval, patent, cruci. form petals; the fruit is a very long compressed pod, containing several roundislı compressed seeds. There are twenty-one species.

ARACHS, in boteny, grounclonut, a genus of the Diadelphia Decandria class of plants, the flower of which is papilionaceous, and consists of three petals; and its fruit is an oblong unilocular pod, contracted in the middle, and containing two oblong, obtuse, and gibbous seeds. There is but one species, found in the Indies, a tree, stem herbaceous, hairy, procumbent. The branches trail on the ground, and the germ, after flowering, thrusts itsclf uncler ground, where the food is formed and ripened.

ARACHNOIDES, in zoology, a name given to those echini marini,or sea-hedgehogs, which are of a circular form, but variously indented at the edges. See t.eHINes.

ARALIA, berry-bearing angelica, in botany, a genus of the Pentandria P'entagy. nia class of plants, the flowers of which are collected intó an umbel, of a globose figure, with a very small involucrum; the perianthium is very small, divided into five parts, and placed on the germen; the corolla consists of five, ovato-acute, ses. sile, reflex petals, the fruit is a roundish, coronated, striated berry; having five cells : the seeds are single, hard, and oblong. There are four divisions, vis. A. leaves entire; $\mathbf{B}$. leaves lobed; $\mathbf{C}$. leaves in finger-like divisions; D. leaves decompound, and more than decompound. In the first there are three species; in the sceond one; in the third two; and in the fourth four.

ARANEA, in natural history, the spider, a genus of insects of the orler Aptera. Gen. char. legs eight; eves eight, sometimes six; mouth furnished with two hooks, or holders ; feelers two, jointed, the tips of which in the male distinguish the sex; abdomen terminated by papillx, or teats, through which the insect draws the thread.

One of the largest of the Furopean spiders is the Aranea diadeusa of Linnxus, which is extremely common in Vingland, and is chicfly seen during the autumnal 


\section{ARANEA.}

Eeason in gardens, \&c. The body of this species, when full grown, is not much inferior in size to a small hazel nut : the abdomen is beautifully marked by a longitudinal serics of round, or drop-shaped milk-wlite spots, crossed by others of similar appearance so as to represent, in some degrec, the pattern of a small diadem. This spider, in the months of September and October, forms, in some convenient spot or shelter, a large, round, close, or thick web of yellow silk, in which it deposits its eggs, guarding the round web with a secondary onc of a looser texture. The young are hatched in the ensuing May, the parent insects dying towards the close of autumn. The Aranea diadema, being one of the largest of the common spiders, serves to exemplify some of the principal characters of the genusin a clearer manner than most others. At the tip of the abdomen are placed five papilla ol teats, through which the insect draws its thread; and as each of these papillz is furnished with a vast number of foramina or outlets, disposed over its whole surface, it follows, that what we commonly term a spider's thread, is in reality formed of a collection of a great many distinct ones, the animal possessing the power of drawing out more or fewer at pleasure; and if it should draw from all the foramina at once, the thread might consist of many liundred distinct filaments. 'The eyes, which are situated on the upper part or front of the thorax, are eight in number, placed at a small distance from each other, and having the appearance of the stemmata in the generality of insects. 'The fangs, or piercers, with which the animal wounds its prey, are strong, curved, sharp-pointed, and each furnished on the inside, near the tip, with a small oblong hole or slit, througlı which is evacuated a poisonous fluid into the wound made by the point itself, tliese organs operating in miniature on the same principle with the fangs in poisonous serpents. The feet are of a highly curious structure; the two claws with which each is terminated being furnished on its under side with several parallel processes, resembling the teeth of a comb, and enabling the animal to dispose and manage with the utmost facility the disposition of the threads in its web, \&c.

Aranea tarantula, or Tarantula spider, of which so many idle recitals have been detailecl in the works of the lcarned, and which, even to this day, continues in some countries to exercise the faith and ignorance of the vulgar, is a native of the warmer parts of Italy, and other warm European regions, and is generally found in dry and sunny plains. It is the largest of all the European spiders, but the extraordinary symptoms supposed to ensue from the bite of this insect, as well as their supposed cure by the power of music alone, are entirely fabulous, and are now sufficiently exploded among all rational philosophers. The gigantic Aranea avicularia, or Bird-catching spider, is not uncommon in many parts of the East Indies and South America, where it resides among trees, frequently seizing on small birds, which it destroys by wounding with its fangs, and afterwards sucking their blood. During the early part of the last century, a project was entertained by a French gentleman, Monsieur Bon, of Montpelier, of instituting a manufacture of spiders' silk, and the royal Academy, to which the scheme was proposed, appointed the ingenious Reaumur to repeat the experiments of Monsieur Bon, in order to ascertain how far the proposed plan might be carried; but, after making the proper trials, Mr. Reaumur found it to be impracticable, on account of the natural disposition of these animals, which is such as will by no means admit of their living peaceably together in large numbers. Mr. Reaumur also computed that 663,522 spiders would scarcely furnish a single pound of silk. Monsieur IBon, however, the first projector, carried his experiments so far as to obtain two or three pair of stockings and gloves of this silk; which were of an elegant grey colour, and were presented as samples, to the Royal Academy. It must be observed, that in this manufacture it is the silk of the eggbags alone that can be used, being far stronger than that of the webs. Monsieur Bon collected twelve or thirteen ounces of these, and having caused them to be well cleared of dust, by properly beating with sticks, he washed them perfectly clean in warm water. After this they were laid to steep, in a large vessel, with soap, saltpetre, and gum arabic. The whole was left to boil over a gentle fire for three hours, and were afterwards again washed to get out the soap; then laid to dry for some days, after which they were carded, but with much smaller cards than ordinary. The silk is easily spun into a fine and strong thread : the difficulty being only to collect the silkbags in sufficient quantity. There remains one more particularity in the history of spiders, viz. the power of flight. It is principally in the autumual season that 


\section{ARB}

these diminutive adventurers ascend the air, and contribute to fill it with tlat inlinity of flosting cohwc bs which are so peculiarly conspicuous at that period of the year. When inclined to make these aterial excursions, the spicler asce mls some slight cmincince, as the top of a wall, or the bisuch of a tree ; and turning itself with its head towards the wind, ejaculates several threads, and rising from its station, commits itself to the gale, and is thus carried far berond the height of the lofticst towers, and enjoys the pleasure of a clearer atmosphere. During their flight it is probable that spiders employ themselves in catching such minute wing. ed insects as may happen to occur in their progress : and when satisfied with their joumey and their prey, they suffer themselves to fill, by contracting their limbs, and gradually disengaging themselves from the thread which supports them. Sce l'late 1. Fintomology, fig. 7 and 8.

ARAUCARIA, in botany, a genus of the 1)ioecia Monadelphia class and order. Male, culyx scales of an ament, terminated by a leafict; 110 corol.; snthere 10 to 12, without filaments. Female, caly $x$, an ament with many germs; no corol.; stig. ma two-ralved, unequal; seeds numerous, in a roundish cone.

Al:BITER, in civil law; a judge nomimated by the magistrate, or cliosen volum. tarily by two parties, in order to decide their differences according to law.

'I he civilians inake this difference between arbiter and arbitrator; though both ground their power on the comprounise of the parties, yet their liberty is different, for an arbiter is to julge accord. ing to the usages of the law, but the arbitritor is permitted to use his own discre. vion, and acconmodate the difference in the manner that appeurs to him most just and equitable.

ARBITRATION, a power given by two or more contending parties to some per. son or persons to determine the dispute between them ; if the two do not agree, it is usual to add, that another person be called as umpire, to whose sole judgrnent it is then referred. The submission to arbitration is the anthority given by the parties in controversy to the arbitrators, to determine and end their gricunces; faul this being a contract or agreement, must not be strictly taken, but largely; according to the intent of the parties submitted. There are five things incident to an arbitration: 1. Matter of controver. sy. 2. Submission. 3. l'arties to the submission. 4. Arbitrators. 5. Civing up the . VOL. 1 .

\section{ARe}

arbituation. Matters relating to a free. fold, debts dive on bond, and criminal of fences, sure not to be arbitrated.

AIRISITIRATOR, a private extraordinary judgre, chosen liy the mutual conse ut of partics, to determine controversic s between them. Arbitrators are to awarl what is equal between buth parties, and the performance must be lawful and pose silsle. An action of debt nay be brought for money adjudiged to be paid by atbitra. tors.

A RBor Diune. Sce Cnfmistru.

Anbon vita. See Thusa.

Annur, in mechanics, the principal part of a machine which serves to sustain the rest; also the axis or spintle on which a machine turns, as the arbor of a crane, windrnill, \&c.

AliBU'U:, the strarden'y-tree, in bo. tany, a genus of the Dccandria Monogynia class of plants, the caly $x$ of which is a very small, obtuse, perinanent perianthi. uru, divided into five segments; the coml. la consists of a single oval petal, divided also into five segments; the fuit is a roundish bcrry, containing five cells, and small osseous secels. There are ten species.

AltC concentric, is that which has the same centre with anotlier arc.

Anc diumal, that part of a circle described by a lieavenly horly between its rising and setting; as the nocturnal arc is that described between its setting and rising: both these together are always equal.

Aurs equal, those which contain the same number of degrees, and whose radii are equal.

AleCA, in natural history, a genus of worms of the order Testaces : animal a tethys; slıell bivalve, equivalve; linge with numerous sliarp teeth, alternately inserted between each other. There are, according to Gmelin, 43 species; but they are separated into four divisions, vi:. $\Lambda$. margin very entire, beaks recuried; 13 . . margin entire, beaks inflected; C. nargin crenatc, beaks recurved; 1). margin erenate, beaks iullected: of the lattcr we sliald notice $\mathrm{A}$. nucleus; shell obliquely orate, smoothisl, with a triangular linge: inhabits European seas, anil is sometimes found fossilc, the size of a hazel nut, covcred witl an olivaceous skin, under which it is white, within silvery; shell unequally triangular, witl very tiue perpendicular strix, crossed by a few arclicd tratisverse ones; depression bethind the beak, heartshaped.

of the division $\mathbf{C}$. is the $\mathbf{A}$. antiquata, which occurs frequently on the coast of I p 
the United States, and is in many places called Bloody Clom ; when opened the included liquid has a dirty red appearance; shell oblicuely heart-shaped, with numerous unamed grooves; it is white, but covered with a brownish hairy skin : the anterior slope with a compressed prominent angle.

AlRCH, or Anc, in geometry, any part of the circumference of a circle, or curved line, lying from one point to another, by which the quantity of the whole circle or line, or some otlier thing sought after, may be gathered.

All angles are measured by arcs. For this purpose an arc is described having its centre in the point or vertex of the angle: and as every circle is supposed to be divided into $360^{\circ}$, an arc is estimated according to the number of degrces which it contains. Thus an arc is said to be of 30,50 , or 100 degrees, \&c.

Ancr, in architecture, a concave building, with a mould bent in the form of a curve, erected to support some structure. Arches are either circular, elliptical, or straight, as they are improperly called by workmen. Circular arches are also of three kinds : 1 . Semicircular, which have their centre in the middle of a line drawn betwixt the feet of the arch. 2. Scheme or skene, which are less than a semicircle, containing some 90 and some 70 degrees. 3. Arches of the third and fourth point, consisting of two arches of a circle ineeting in an angle at the top, being drawn from the division of a chord into three or inore parts at pleasure.

Elliptical arches consist of a semi-cllipsis, and have commonly a kcy-stone and imposts: they are usually described by workmen on tliree centres.

Straight arches are those used over doors and windows, having plain straight edges, both upper and under, which are parallel, but both the ends and joints point towards a centre.

The term arch is peculiarly used for the space between two picrs of a bridge, intended for the passage of water, vessels, \&:c.

Anch of equilitoration, is that which is in cquilibrium in all its parts, having no tendency to break in any one part morc than in another; and which is, therefore, safer and stronger than any other figure. No other arch than this can admit of a horizontal line at top : it is of a form both gracefil and convenient, as it may be made higher or lower at pleasure, with the same span. All other arches require extralos that are curved, more or less, either ur.wards or downwards; of these, the elliptical arch approaches the nearest to that of equilibration for strength and convenience, and it is the best form for most bridges, as it can be marle of a ny leeight to the same span, its haunclics being at the same time sufficiently elevated above the water, eren when it is very fat at top. Eiliptical arches also appear bold. er and lighter, are more uniformly strong; and are cheaper than most others, as they require less materials and labour. Of the other curves, the cycloidal arch is next in quality to the elliptical one, and lastly the circle.

ARCKLAGEL, in botany. See LA. MIM.

ARCHES, or Court of Ancues, the supreme court belonging to the Archbishop of Canterbury, to which appeals lie from all the inferior courts within his province.

- ARCHETYPE, the first model of a work which is copied after, to make another like it: Among minter's it is used for the standart weight by which the others are adjusted. The archetypal world, among Platorists, means the world as it existed in the idea of God, before the visible creation.

\section{ARCIILL. See LICHEN,}

ARCHIMEDES, in biography, one of the most celebrated mathematicians among the ancients, whlo flourished about 250 years before Christ, being about 50 years later than Euclid. He was born at Syracuse in Sicily, and was related to Ifiero, who was then king of that city. The mathematical genius of Archimedes set lim with such distinguished excellence in the vicw of the world, as rendered him both the honour of his own age, and the admiration of posterity. He was indeed the prince of the ancient mathe. maticians, being to them what Newton is to the moderns, to whom in his genius and character lie bears a very near resemblance. He was frequently lost in a kind of reveric, so as to appear hardly sensible; he would study for days and nights together, neglecting his food ; and Plutarch tells us that he used to be carried to the baths by force. Many particulars of his life, and works, mathenatical and mechanical, ure recorded by several of the ancients, as Polybius, Livy, Plutarch, Pappus, \&c. He was equally skilled in all the sciences, astronomy, geometry, mechanics, lydrostatics, optics, \&c. in all of which he excelled, and made many and great inventions.

Archimedes, it is said, made a sphere of glass, of a most surprising contrivunce 


\section{ARCHIMEDES.}

and workmanship, exhibiting the motions of the heavenly bodies in a very pleasing manner.

Many wonderful stories are told of his discoveries, and of his very powerful and curious machines, \&c. Hiero once al. miring them, Archimedes replied, these effects are nothing, "buit give me," said lie, "some other place to fix s machine on, and I will move the carth." He fell upon a curious device for discovering the deceit which had been practised by a workman, employed by the saicl king lliero to inake a golden crown. Ilicro, having a mind to make an offering to the gods of a golden crown, agreed for one of great value, and weighed out the gold to the artificer. After some time he brought the erown home, of the full weight; but it was afterwards discovered or suspected that a part of the gold had been stolen, and the like weight of silver substituted in its stead. ' Hiero, being angry at this imposition, desired Archimedes to take it into consideration, how such a fraud might be certainly discovered. While engaged in the solution of this difficulty; he happened to go into the bath ; where observing that a quantity of water overflowed, equal to the bulk of his body, it presently occirred to him, that Hiero's question might be answered by a like method; upon which lic leapcd out, and ran homeward, crying out \&vgrxa ! svgrxa! I have found it out! I have found it out! lie then made two masses, each of the same weight as the crown, one of gold and the other of silver; this being done, he filled a vessel to the brim witli water,and put the silver massinto it, upon which a quantity of water overflower equal to the bulk of the msss; then taking the mass of silver out he fill. ed up the ressel again, mcasuring the water exactly which he put in; this shewed him what measire of water answerel to a certain quantity of silver. Then lie tried the gold in like manner, and found that it caused a less quantity of water to overfiow, the gold being less in bulk than the silrer, though of the same weight. Fe thin filled the ressel a third time, and putting in the crown itself, he found that it caised nore water to overflow than the golden inass of the same weight, but less than the silver one; so that, finding its bulk between the two masses of gold and silver, and that in certain kuown proportions, he was able to compute the real quantities of gold and silver in the crown, and so manifes:ly discovered the frut.
Archimedes also contriverl many machines tor useful and beneficial purposes; ainung these, engines for launcling large ships; screw pumps, for calisusting the water out of ships, narshes or overfluwed lauds, as E.gJpt, \&.c. which they woukl do from any depth.

But lie became most famous by his cll. rious contrivances, by which the city of Syracise was so long defended, when be. sieged by the Jioman consul Aircellus: showering upon the enemy sometimes long darts and stones of vast weight and in great quantities; at other tines lifting their ships up into the air, that hal come near the walls, and dashing them to picers by letting them fall down again: nor could they find their safety in removing out of the reach of his cranes and levers, for there he contrivel to set fire to them with the rays of the sun reffected from burning glisses.

Howerer, notwithstanding all his art, Syracuse was at length taken by storm, and Archimedes was so verv intent upon some geometrical problen, that lie neillier heard the noise, nor regarded any thing else, till a soldier that found him tracing lines asked his name, and upon his request to begone, and not disorder his figures, slew him. "What gave Marcellis the grentest concern, says Plutarch, was the unhappy fate of Archimedes, who was at lhat time in his muscum; and his mixl, as well as his eres, so fixed and in. tent upon some geometrical figures, that the neither heard the noise and hurry of the Roinans, nor perceived the city to be taken. In the deptly of study and contemplation, a soldier came suddenly upon him, and commanded hin to follow him to Marcellus; which he refusing to rlo, till lie had finished his problem, the soldier in a rage drew his sword, and ran lim through." livy sars he was slain by a soldier, not knowing who he was, while he was drawing schemes in the dlust; that Marcellus was grieved at his death, and took cirre of lis funcral; and male his name a protection and honour to those who conld clain a relationship to him. Fris cleath it seems happened aloout the $142 \mathrm{~d}$ or $143 \mathrm{dl}$ olympiad, or 210 years be. fore the birth of Christ.

When Cicero was quastor for Sicily; he discovered the tomb of Arehimedes, all overgrown with bushes und brambles; which lie caused to be cleared, and the place set in orker. There were a sphere and cylindercut upon it, with an inscription, but the latter part of the verses were quite worn out.

Many of the works of this great man 


\section{ARCHIMEDES:}

are still extant, though the greatest parts of them are lost. The pieces remaining are as follow: 1. Two books on the Sphere and Cylinder. -2 . The Dinession of the Circle, or Proportion between the Diameter and the Circumference. - 3. Of Spiral lines. -4 . Of Conoids and Spheroids. -5 . Of Equiponderants, or Centres of Gravity. -6. The Quadrature of the Parabola.7. Of 13odlies floating on Fluids.-8. Lemmata_-9. Of the Number of the Sand.

Among the works of $A$ rchimedes which are lost may be reckoned the descriptions of the following inventions, which may be gathered from limself and other ancient authors. 1. His account of the Method which he employed to discover the Mixture of fold and silver in the crown mentioned by Vitruvius.--2. I Iis Description of the Coclslcon, or.engine to draw water out of places where it is staguated, still in use under the name of Archimedes's Screw. Atheraus, speaking of the prodigious ship buik by the order of Iliero, says, that Archimedes invented the coclileon, by means of whielı the hold, notwithstanding its depth, could be drained by one man. Anl Diodorus Siculiss says, that lie contrived this macline to drain Fggpt, and that, by a wonderful mechasism, it would exhaust the water from any depth. 3. The Helix, by means of which Athenxus informs us, he launchedHiero's great ship.-4.,The Trispaston, which, according to Tze the most stupendous weiglits. -5 . Thie Machines, which, according to l'olybius, Livy, and Hlutarch, lie used in the defence of Sirracuse against Marcellus, consisting of Tormenta, Balistr, Catapults, Sagittarii, Scorpions, Cranes, \& c.-6. His Burning Glasses, with which he set fire to the Roman gallies.-7. His Pneumatic and Hydrostatic Engines, concerning which subjects he wrote some books, according to Tzetzes, Pappus, and Turtul!ian.-8. His Sphere, which exhibited the celestial motions. And probably many others.

A considerable volume might be writ. ten upon the curious methods and invention of Archimedes, that appear in his mathematical writings now extant only. He was the first who squared a curvilincal space; unless Ilipocrates be excepted on account of his lunes. In lis time the conic sections were admitted into geometry, and he applied himself closely to thic measuring of them, as well as other figures. Accorlingly he determined the relations of spheres, spheroids, and conoids, to $\mathrm{cy}$ linders and cones; and the relations of parabolas to rectilineal planes, whosequad. ratures had long before been determined by Euclid. He has leftus also his attempts upon the circle: he proved that a circle is equal to a right-angled triangle whose basc is equal to the circumference, and its altitude equal to the radius; and consequently, that its area is equal to the rectangle of half the diameter and half the circunference; thus reducing the quadrature of tlfe circle to the determination of the ratio between the diameter and circumference; which determination how: ever has never yet been dome. Being disappointed of the exact quadrature of the circle, for want of the rectification of its circumference, which all his methods would not effect, lie proceeded to assign an useful approximation to it: this he effectcdby the numcral calculation of the perimeter's of the inscribed and circumscribed polygons: from which calcilation it appears that the perimeter of the circumscribed regular polygon of 192 sides is to the cliameterin a less ratio than that of $3 \frac{1}{7}$ or $3 \frac{10}{7}$ to 1 ; and that the perimeter of the inscriberl polygon of 96 sides is to the diameter in a greater ratio than that of $3 \frac{10}{71}$ to 1 ; and consequently that the $\mathrm{ra}$ tio of the circunference to the diameter lies between these two ratios. Now the first ratio, of $3 \frac{1}{7}$ to 1 , reduced to whole numbers, gives that of 22 to 7 , for $3 \frac{1}{4}: 1$ : : 22 : 7 ; which therefore is nearly the ratio of tlue circumference to the diameter. From this ratiobetween the circumference and the diameter, Archimedes computed the approximate area of the circle, and he found that it is to the square of the diameter as $\mathbf{1 1}$ is to 14 . He determined also the relation between the circle'and eclipse with that of their similar part. And it it probable that he likewise atterapted the hyperbola; but it is not to be expected that he met with any success, since approximations to its area are all that can be given by the various methods that have since been invented.

Besides these figures, lie determined the measures of the spiral, described by a point moving uniformly anng a right line, the line at the same time revolving with a uniform angular motion; determining the proportion of its area to that of the circumscribed circle, as also the proportion of their sectors.

Throughout the whole works of this great man, we every where perceive the deepest design, and the finest invention. He seems to have been, with Euclid, exceedingly careful of admitting into his clemonstrations nothing but principles perfectly geometrical and unexceptionable : 
and although his most general method of demonstrating the relations of curved fifurfsute straieht, noeq Jeuterinscrihios rclations, he does not increase the umm. ber, and climinish the magnitude, of the sides of the polygon ad infinitun; but from this plain fundamental principle, allowed in Euclid's Elements, ( $\tau i z$. that any quantity may be so often multiplied, or added to itself, as that the result shall exceed any proposed finite quantity of the same kind, l he proves, that to deny his figures to bave the proposed relations would involve an absurclity. And when he demonstrated masy geometrical pro. perties, particularly in the parabola, by means of certain progressions of numbers, whose terms are similar to the inscribed figures; this was still done without considering such series as continued ad infi. nitum, and then collecting or summing up the sterms of such infinite series.

There have been various editions of the existing writings of Arclimedes. But the most complete of any is the magnificent edition, in folio, lately printed at the cent edition, miss, uxrom, 1792. This edition was prepared ready for the press by the learned Joseph Torelii, of Verona, and in that state presented to the university of Oxford. The Iatin translation is a new one. Torelli also wrote a prefuce, a conmentary on some of the pieces, and notes on the whole. An account of the life and writings of Torelli is prefixed, by Clemens Sibiliat. And at the end a large appendix is added, in two parts: the first being a Commentary on Archi. medes's paper upon liodies that float on Fluids, bv the Rev. Adam Robertson, of Christ Church College; and the latter is a large collcction of various readings in the manuscript works of Archimedes, found in the library of the late king of France, and of another at Florence, as collated with the Basil edition above mentionel.

\section{ARCHITECTURE。}

General olservations on the history and practice of Civil Architecture.

All the varicty of edifices appropriated to the purposes of civil life is denominat. ed Civil Architecture.

It is a very difficult matter for us at this day to trace the earbiest stage of this art, so indispensible to our comlort and pro. tection in a natural or civilized state, un. til we find its permanence of construc. tion fixed on the basis of science and pro. portion.

The subterraneous cavern was without doubt the first habitation of man. Who eannot but contemplate with astonishment the varicty of inassy shapes, supporting arched roofs, decorated with innumerable surfaces of crystallized forms, excelling in splendour of design and ar. rongement the most magnificent productions of human art.

All our impressions of wisclom, strength and beauty, are derived from the exami. nation of the works of the God of nature: All our energy in art is employed to de. duce from these works the proximity of man to his Creator, and all our perfection a humble acknowledgment of our im. perfection.

In sculpture and painting, the closest imitation of a model in nature at once constitutes the excellence of the artist.
In architecture, invention is employed in the search of form and proportion, that is not so immediatcly" obvious, owing to the whimsicality in matters of taste, which is perhaps very justly regulated by antique proportion.

Itistory furnishes us with very vague and unsatisfactory accounts of the rise or progress of this science; althongh a vari. ety of speculation has been indulged, to locate and fix its origin and xra of construction in India and Egypt, we are at this late day left to doubt, whether the castern quarter of the world has any de. cided claim to originality over that of Eigypt.

The splendid excarations that constitute the temples or sacrerl edifices of the Hindoos, particularly the cave at Jile. phanta, which is sculptured out of the solid rock, exhibits a very early knowledge of the art with this barbarous peo. ple. The cave is 120 feet square, and contuins fonr rows of massy pillars, re. sembling a futed ballustrade, resting on a long right angular plintli: the whole pillar is surnounted by a broad projecting ca pital, in form of a flat vase, richly and highly decorated. Colossal statues and busts in alto relievo protrude from the sides of the cavern, some with four, and some with six arms, locaring sceptres, tmophies,and symbols of their mythology. The 


\section{ARCHITECTURE.}

altar is situated in the centre of one of the sides, the entrance to which is guarded by two huge figures, bearing very litof an octagonal shipe are sometimes mounted on the backs of elephants, horses and tygers, supporting a cornice decorated with human figures sitting crnsslegged. A gallery extends from pillar to pillar, profiusely sculptured with men in acts of devotion to serpents, tygers, and other animals. The base of the -columns being an elephant (their farourite beast) sometimes displays a man astride. of the trunk, which gives the general mass the effect of being put in motion by these mighty animals.

The whole may be considered original, and peculiar to the habits of an uncivilized people, intuitively representing natıral objects of their religions derotion, in crude, disproportioned sculpture.

From the magnificent mins of Persepolis in Persia, which, according to Le Brun, originally consisted of 205 columns, 70 feet in height, we are alone enabled to give any account of the ancient style of architecture in that country ; for the character and remains of this interesting pa. lace, the world is indebted to the able research of this gentlemar, who has left no stone unturned that could clucidate, or bring to light, a knowledge of the science at that early day.

The arrangement, construction, and proportions of Persepolis difier very ma. terially from the Indian or Egyptian style of building, yet we find Egyptian cloorways at its entrance, and Indian sculptured excavation in the tomb of Darius.

The Persians held Esyptian mythology in detestation, and it appears were not devoted to the erection of sacred edifices, as no remnant of a religious symbol, or hieroglyphic, is to be found in their ruins; but, on the contrary, they appear to have. been wholly absorbed in the erection of gorgeous palaces and tombs.

Their sculptures are very numerous, and consist of triumphal processions, offerings of horses to the sum, and oxen to the moon; figures bearing the parasol, and armed with the lance, in conflict with the lion. The number of men and animals found on their tombs are nearly thirteen hundred. Their columns hare no diminish, being uniform from top to bottom, and thirteen diameters in height, having a capital one-fourth their height, carved in imitation of feathers tied or banded witl silk; being the materials with which eastern monarclis formed their most splendid decorations. From the sien. der make of these columns, and no frag: ments of a cornice or roof being found that Persepolis was a summer residence, and that they supported a temporary cor: ering, sliglitiy constructed of wood, and lined with silken drapery.

These ruins bear incontrovertible eridence of antiquity, with features distinetly marked to characterise a separate sclıool of architecture. The devastation which followed the conquest of F.gypt by Cambyses, whose jealousy of the perfection of the Eggytians in art and science caused him to prostrate their palaces and temples, carrying off the artists as well as the spoils to grace this palace, accounts very satisfactorily for the mixture of Egyptian with Persepolitan ruins.

Thie whole of Upper Egypt furnishes prodigies in science and art, Their pyranids, palaces, temples, and excavated sepulchres. Their system of hieroglyplical sculpture is calculated to impress us with a very elevated idea of that once learned and powerful people; who, not. withstanding the inroads of frequent conquerors, jealous of their acquirements, and laying waste their works of art, rose, Phonix like, from her ashes, invigorated by persecution.

The pyramids of Cheops, Cephren, and Mycerines, are alone sufficient to call forth the attention of mankind, as stupen. dous monuments of industry and impe. rislıability. Although history can gire us no satisfactory date of their coustruction, many learned men have discussed their antiquity, and concluded that Cheops, which is the largest, (being 448 feet in leiglit and 728 feet square at the base) was erected 490 years before the first Olympiad, or about 3000 years ago.

The researches of Denon, and the French commission of arts, are the best authorities that can be quoted on the sub. ject of Egyptian architecture : they have examined with zeal and accuracy each well collected fragment, under the protection of an armed force : we will therefrom proceed in giving a general outline of its particular character in Upper Egypt.

On approaching the edifices of Karnac and Luxor, the first grand masses of build. ings are the moles, of an oblong plan, with battering or tapering sicles, from 50 to 60 feet in height, decorated on their facade profusely with hieroglyphics, in the front of which stand the obelisks, on each side of the principal entrance, also crowded with symbols of mythology, 
ARCHITECTURE.

astronomy, history and agriculture. The tapering moles are crowned by a cavetto or flat segment of a circle, richly fluted torus that covers the corncles of the pile. The entrance or cloor-way is between the moles, and is sumounted by a similar cavetto over the arcliture, upon which is frequently carved the globe, wings, and serpuent. This entrauce opens into a grand court, surrounded on all sides by a portico, consisting of two ranges of coJumns, 48 in number; at the extremity of this court, and opjosite the entrance, the sanctuary is placed, and contains apartments for the priests-two small porticos or covered ways conduct to those of the kings, and are distinguislied by doors of black granite. Otlier avemues lead to buildings of considerable magnitude, ornamented witl row's or alleys of lious, sphinxes and ranis, from 15 to 16 feet in length, couchant upou pedestals ten feet asunder.

Some of their sculpture is merely, a deep cut outline, and is no doubt the first dawning of the art. Basso relievo, semi relicf, and alto relief, is every where to be seen, producing bold and decisive cffects.

Although a perfect uniformity exists in all the echifices of Upper Egypt as to plan and general arrangement, it appears they were very capricious in the proportions and sculpture of columns. 'I'he capitals of the columns of the temple of A ppolinipolis, one of the largest and most magnificent buildings in Egypt, has two rows of leaves, bearing considerable resemblance to the Corinthian of the Greeks. At the tombs of Silsilis, the columns are in imitation of bundles of reeds bound together at the top by a cord, and gradually swelling into a capital, ornamcnted witli leaves and blossoms of the lotus, or lily of the Nile. At Tentyra, one entire column of lieroglyphics supports a capital, containing four heads of the goddess Isis. At the Memnonium, human figures are used as columus, called by the Greeks cariatides, at which place thic mins of a statue 64 feet in height is to be seen, and supposed to have been thrown down by Cambyses.

"Iheir edifices and statuary is principally composed of granite and sand stone quarried upon the Nilc, with aqueducts leading from them into the river, through which ineans, and its aunual rise, the huge masses of stone used in obclisks and columms were floated to their ruspective situations; but low these immense slabs and blocks were raised upon terraces and columns, of great height, is an exertion of the mechanic powers totally obsolete at the present day.

It is only from the indestructible re. we the arcnitecture or s: 53 pt, that we are enabled to form any distinct ides of the progress of science with this leam. ed people; who are said to have invented geometry; and applicd its principles to the motion of the heavenly bodies. At Tentyra, the great circle of the spliere is described upon the ceiling of the temple, containing the twelve signs of the zodiac, with many other asironomical figures iu the surrounding spaces.

Their knowledge of geometry, and the application of its principles to mechanics, was astonishing, from the size and weight of their materials, and principles of construction, by which they have ensured du rability; and transmitted to postority 5 palaces and 34 temples, as monuments of their science and industry 3000 years ago.

Upon an examination of the principles and practice of the architecture of the three conntries, India, Persia, and Egypt it will appear, upon investigation, that the edifices of Hindostan corrsist principally of excavation, where the column and hu. man figure are rudely carved, without reference to proportion or the nature of the subject, and although we cannot fail to bc disgusted with the effect of the perform. ance, we are compelled to admire their inclustry. The resemblance of many leacting features of Hindoo architecture to that of Egypt and Persia, particularly those of Elephanta and Vellore, has induced Sir William Jones and Dr. liobert. son to conclude that the castern quarter of the world lias a preferable elaim to originality; and that all rudiments of knowledye in the science was furnished by India to both the other countries: this is a mere inatter of opinion, and can only amount to evidence of an early intercourse or communication of architectural knowlcalge, as there is unquestionably sufficient distinction in the cliaracter and proportions of the whole or parts to form separate schools. That of India may be characterized by circular outlines resenibling the pagoda of the Clinese. The ancient Persian, consisting principally of edifices above gtound with slender columns of small diameter, lightly and delicately decorated with feathers and silk, om:unental pannels in basso relievo. resembling the sumptuous corinthian of the Romans.

That of Egypt, grand and massy fea. tures, diminishing from the base upward, forming pyramidal ligures, remarkable 


\section{ARCHITECTURE.}

for sameness of character and proportion. Temples generally peripteral, that is, surrounded on all sides by columns at some distance from the ert, itonns at some Lotus, Hawk, and Ibis, being farouniteemblems, and purely their own. Lpon the whole, we may conclude that the Figyptians borrowed no ideas, nor copied the style or practice of any other nation. A perfect uniformity in their sculpture and facarle is seen every where, from the most ancient down to the destructive inroad of Cambyses.

Before we proceed to point out the character and sublimity of Greek architecture, it will be necessary to give a few greneral ideas as to the principles of the science, and upon what Order is founded.

All the variety of objects that present themselves to our view in the material. world, are considered beautiful or deform: ed, in relation to their shape and size, corresponding with the fitness of the parts to the end designed. Proportion and symmetry always convey pleasureable ideas; and their adaptation to the expression of design should always coincide with the uses of the object in view. Skill and dexterity may be expressed, without accommodation or correspondence to the nature of the character, and must be admired as a part, without any reference to the whole: thus a building may be crowded with highly decorated motzld ings and pannel-work, where the nature of the subject is not consulted, and by many unacquainted with the science be pronounced beautiful, receiving the appellation from a close examination of a par. ticular part, when the fitness or proper correspondence of the minutix oughtit to be judged of with reference to the nature of the subject.

Therefore the sensations of pleasure that are felt, from the observance of an object well proportioned, must owe their existence to the proper distribution of all the parts combined in unison, to the expression of a decided character. Objects that are destitute of natural beauty are made so when regarded in the light of their uses.

The orders of arclitecture, in which all the variety of genius and art has evolved itself, and which is regulated by settled.proportion, with such certainty as to defy and mock all attempts at innova. tion, receive their sanction from the above remarks on the observance of design accommoduting itself to uses; whereby beauty and hamony is established.

There are five orders in architecture, riz, the Tuscan, Doric, Ionjc, Corinthiat, and Composite. These are, properly spealking, but thiee, the Doric, fonic, and

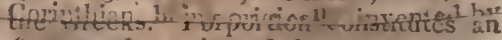
Oreer, and consists of three grand dirisionis, viz. the base, column, and entabla. sure. These are governing principles: and the proportions of the base and shaft are such, according to the character of the order, as appear, and are absolutely adequate to the support of the entabla. ture wlich rests upon them. The great object derived from the difference or variety of the orders is, the fitness of their respective parts to the support of the crowning weight, which must appear evident to all who have paid the least attention to the subject.

It is rather astonishing from what cause we feel pleasant sensations upon viewing the Greek structures, whether it is the nature of the architecture itself that im. parts pleasurable ideas, or the associations connected with them, that calls forth our admiration, knowing them to be reared upon classic grourid, and the relics of a - brave and enlightened people; but certain it is, their science, shill, and taste in the arts, far surpassed all other nations before,and since their time.

:This singular and industrious people, untrammelled with tyranny, situated in a rugged; country, of fine. climate, and abounding with forests, gave full scope to their imagination in the construction of wooden edifices; in the prosecution of which, the rude forest tree, covered with a block or tile, suggested the idea of the Doric order; the beams laid liorizontally on the top, and projecting over the trunk of the tree, and rafters rising to a point in the centre, composed the leading features of a primitive Greek edifice.

It has been supposed that the Greeks were originally colonies of Egypt and Persia, at the time when those empires existed in great splendour, and construct. ed edifices of great magnificence; being also the countries from whence their sages drew thcir earliest information, rendered it more than probable that they borrowed their frst ideas of building from those places; they unquestionably were acquainted with the state of architecture in those countries; but that they adopted or applied this infornation is very doubtful, from the circumstance of their materials, in the first instance, being altogether wood, and consequently requiring different principles and practice in its execution and arrangement Stone edifices 


\section{ARCHITECTURE.}

were afterwards constructed in conformity with the wooden model, and underwent, at different periods of time, such additional arrangement as their genius and taste suggested.

The Greeks, untaught by their more rich ncighbours, abounding in granite, porphyry, and marble, with a variety of other local adrantages, established a perfect school of architecture, by the invention of three complete orders, each having a peculiar and separate character, calculated for all kinds of structures, ascending from the most simple and robust, to those of a more delicate susceptibility of ornament; completing a perfect system in the art, that defies all human attempts to sur. .pass or amend.

The most magnificent temple at Athens, and one which exhibits the perfection of Greek taste, is that dedicated to Minerva Parthenon. It is situated on the summit of the rock of the citadel, within the Acropolis, which appears as though nature had formed it as a pedestal, express. ly for the purpose of supporting the beautiful edifices upon. its crown. It was executed under the direction of Phidias, by Callicrates and Ictinus; and from the description of Mr. Stuart, who spent seven years in the faithful delineation of the works of art in that once splendid city, is a perfect specimen of the Doric order. Its extreme length is 225 feet, and breadth 100 feet, surrounded by 46 columns, supporting an entablature of 12 feet in height, upon which is sculptured, in the finest alto relievo, the wars between the Lapithe and the Centaurs. The frize which surrounds the cell contains the Panathe. naic procession of Charioteers, horsemen, and the coronation of a youthful victor in the chariot races. On the eastern pediment is represented a convention of the gods, consisting of five and twenty figures : Jupiter presides, and is in the act of receiving lis daughter Minerva.

The blocks of stone with which the co. lumns are formed, being six feet in dia. meter, are so nicely and accurately wrought, that the most strict scrutiny is required to discover the joints, being no thicker than the finest hair. In order to attain this perfection, the marble is re. duced to the proper size by the chisel, after which two pieces are rubbed one upon the other, with sand and water placed between them as a cutting medium, until the top and bottom beds come so closely in contact, as to cxclude the atmosphere, and bed themselves together.

After which process, they were regulated VOL. I. by a square pirot of olive wood with astonishing accuracy; so much 50 , as to give the whole pillar the effiect of having passed through a lathe.

Chauteaubriand, seated on a fragment at the summit of the Acropolis, de-scribes the ruins of the Parthenon with all the enthusiasm of a poet and artist: "From the summit of the Acropolis, I beheld the sun rise between the two peaks of mount Hymettus. 'The crows, which build their nests around the citadel, but never soar to its summit, hovered below us; their black and polished wings were tinged with roseate hues by the first radiant beams of Aurora. Columns of light blue smoke ascended in the shade along the sides of the Hymettus. Athens, the Acropolis, and the ruins of the l'arthenon, were coloured with the most beautiful tints of peach blossom. The sculptures of l'hidias, struck horizontally by a ray of gold, started into life, and seemed to move upon the marble, from the mobility of the shadows of relief."

Athens abounds with numerous and prodigious relices of the works of art. Adjacent to the Parthenon stands the temple of Neptune and Minerva Polias, the temples of Theseus, Propylea, and Jupiter Olympus, which was composed of 128 columns, sixty feet in height; the dis. tance round this temple is said to be half a mile. The walls of the city extended over a space of nine leagues, and broad enough to admit of two chariots to run abreast, being equal to the huge fortified walls of the Romans.

Many of these masterpieces of antiquity, which excite the veneration of the modern world, 120 years ago were per. fect, and had suffered but little dilapidation from the attacks of time, until some penetrative and inrestigating trarellers paid them a visit, more from curiosity than information, and, not unlike children with a new toy, broke off the pretty parts, in order to discover how it was made, and, like Ulysses with his presents from the Phonicians, return home with large chests full of stones, to enrich museunis, and tickle connoisseurs.

The most daring outrage of this kind was committed by Lord Elgin, who employed the Turks to break off, and throw down part of the frize and pediment of the Parthenon. His sole object in bearing off the works of Phidias was, merely to show the British nation the wonderfil degree of perfection the Greeks liad arrived to in the art of sculpture; and, as a further extenuation of his conduct, to Q q 


\section{ARCHI'EC'IURE.}

preserve them unimpaired by the hand of ignorant barbarism, so peculiar to Musselmen and Frenchmen : for which his zeal and judgment, in literally robbing a church, has received the warmest acknowledgments of the British artists, who still suffer him to keep an Italian mercenary in Greece, destroying and pilfering what is termed the "Elgin Marbles."

Such inconsiderate love of the arts, contrasted with the laudable exertions of the scientific Stuart, is truly disgusting. This ingenious traveller was indefitigable in drawing, measuring, and accurately describing these interesting works of antiquity, and devoted seven years in the accomplishment of a work that does honour to the British arts, by transmitting to posterity the genius and taste of the Greeks, under the influence of Pericles and Adrian; in the perusal of whose pages we may exclaim, "There was a time, when Greece, when Athens, existed: now neither is there an Athens in Greece, nor is Greece itself any longer to be found." And when we search for architecture, we may find it buried in its owll ruins.

The Romans were humble copiers of Greek Architecture in every thing but its simplicity; théy laboured in complicated forms, and dressed out the cliaste orders into unmeaning frivolities. Columns were coupled, and piled on columns, enormous basements were erected on the tops of Porticoes, crushing all beneath with the superincumbent weight, plane surfaces were intersected with fluted pilasters, and the intermediate space filled up, and enriched with tablets of festoons, and perforated with stories of small windows.

The lRomans acquired all their knowledge of the arts by the prowess of their arms; and, not possessing any native taste, acquired by the unremitting attempts of rival artists, they could not be supposed to select the most chaste features, but eagerly seized upon the Corinthian, being the most sumptuous of the Greek orders, and applied it in their public buildings, almost to the total exclusion of all others, inventing an order still more riclı and profuse, called the Composite, which is compounded of the Corintlian leaves, surmounted by the Ionic Echinus and Volutes.

The edifices erected during the republican state of the country are known by their simplicity and usefulness, while those of the emperors are remarkable for orriament. The emperor Adrian journeyed over all bis provinces, building and restoring cities and public edifices. $\mathbf{\Lambda}$ t Athens he built the immense Temple of Jupiter Olympus, repaired the gates of the city, which by inscription he claimed as bis own. He built the aqueducts that supplied the city of Corinth with water, and the great wall across the Island of Great Britain, from New-Castle to Carlisle.

The emperor Augustus said he found Rome composed of brick, but he bad changed it into marble. Among the numerous edifices constructed during his reign were, the Temple and Forum of Mars the avenger; Jupiter Tonans in the capital pantheon, dedicated to all the gods; and a temple to Minerva composed. entirely of brass; and he brouglit the Aqua Virginis to Rome through an aque. duct 14 miles in length.

Dioclesian reared the stately corinthian in the ancient city of Tedmor in the wilderness, built by Solomon, and called by the Romans Palmyra.

Throughout the Roman dominions the Corintlian was the prevailing order. The Ionic appears to have been the favourite order in Asia Minor; the Corinthian in the colonies of Rome; and the sober Doric every where the most ancicnt and lasting of them all.

At Palmyra and Balbec their rectangular temples are very extraordinary in point of extent; and the superb style of decoration to which their arts were carriedthe immense size of the materials in the temple at Balbec; is perhaps greater than any employed in Egypt. In the quarry without the walls of the city lies a stone 70 feet in length, and 14 feet square, in the shape of a parallelopipedon, containing 14,128 cubic feet, and weighing upwards of 1130 tons.

Although the Romans can claim but little merit of originality in what relates to civil architecture, the modern world is very much indebted to them for a very important feature in the science of build. ing: that is, the invention of the arch, which was entirely unknown to the Greeks previous to the Roman conquest. The utility and grandeur of this important invention is fully demonstrated in the extensive vaults, domes, bridges, and aqueducts, with which their most superb edifices were constructed and adomed, the judicious arrangement of which never fails to produce the most pleasing effects, particularly when constructed on an extended span.

The profuse introduction of arches in the facades of edifices generally destroys the effect of other features, composed of 


\section{ARCHITECTURE.}

straight lines. The Romans became so enamoured with them, as to spring them from the base capital of a column, which is intencled solely for perpendicular support, and not to counteract lateral pressurc. From one absurlity to another more gross, their original purity became almost extinct. The orders, which had already become overloaded with ornament, were scarcely able to support the unmeaning trappings with which they were disguised, and theiringenuity, heing almost without bounds, discovered and addect traits to their character not much unlike the Gothic. This anarchy in the state of architccture was happily relieved by an interregnum of the Gothic style, which branched forth its delicate limbs and benutiful tracery. A sliort time previous to the incursions of the Goths and Huns, a decirledly new character appeared in the art. The basilica of all the great cities of the empire were converted into cluristian cluurches, keeping up the same form of rectangular parallelograms, dividing the cell into aisles by two rows of columns, with arches springing from their capitals to support the roof; wings were added to the flanks of these buildings, forming on the ground plan the Latin cross, which has continued to be the model of most christian cluurches to this day.

It is very certain that the declension of Roman architecture began to make its appearance in the reign of Constanstine, shortly after his conversion to christianity; but it does not appear that he favoured or promoted this style in the foundation of his city of Constantinople.

During this period, until the sixtcenth century, Gothic architecture continued to supplant all other styles, and during a few centuries was practised throughout Europe. Charlemagne introduced it into France, when many magnificent churches were erected, which continue to be the ablest specimens of the style to this day. 'The Roman style again revived, when the term Gothic was applied, in derision, by the Italian school of Palladio.

The variety of features it underwent, in its application to church architecture, has given rise to many speculations of men of science and lenrning, as to its rise and - progress. One of the theories, and not an improhable one, is, that, during the crusade, worship was conducted in the groves, and in orler to procure shelter and shade, they bent the limbs of opposite limbs together at the top, and bound them at the intersection, thereby producing the pointed arch, a continuation of which method from tree to tree woukl furnisly a complete Gothic arcade. The Saxon and Norman Gothic was the first practised, and seems to have been con. structed with considerable reference to the Roman style of its time. The pillars massy, and consisting of several shafts, cylindrical, and octagonal, supporting a heavy decorated cornice, ornamented with diamond net-work. The capitals composerl of leaves and flowers.

One of the finest features of this style, and which in many instances form the most striking ornaments of a city, is the tall tapering spire; they were first built of wood by the Normans, and since with as much dexterity, by their descendants in stone, as in Salishury 'Tower and spire, being 400 fect in height.

The most remarkable property be. longing to the Gothic is magnitude; as it never succeeds in producing its characteristic beauties when projected on a small scale, and should always be constructed of stone or wood.

Buildings of a public nature ought to express, in the design, the uses and purposes to which they are erected and ap. propriated, so that strangers, when they beliold a church, bank, court-house, prison, \&ic. may understand them to be so, from some external cliaracters, without the aid of a painted sign or inscribed tablet.

Allegorical representations, applied to architeeture, is a source through which we always derive pleasure and informa. tion, by calling forth the taste, judgment, and literary acquirements, to the inter. pretation of objects in the fine and dignified arts. In a young country like ours, where its inhabitants are scattered over an immense tract of territory, a great portion of which is unsettled and uncultivated; and where its only resourees are drawn from agriculture and commeree, distributing and equalizing wealth, it cannot be reasonably expected that architectural works of great magnificence and duration should be constructed, to bear any kind of comparison with those executed under the contmul of a despotic power, where materials, labour, and funds, are directed by sovereignty and an independent priesthood.

The associations of men of wealth for the construction of edifices of a public. nature, and in the establishment of institutions for the promotion of the fine arts and sciences, are lighluly honourable to the taste and liberality of the American cha. racter: and it is entirely owing to sucl, objects and cxertions, that we can trace 


\section{ARCHITECTURE.}

the advancement of them in this country to the summit of their present perfection.

The native enterprize and perscverance of the country at large, in the advance. ment of science and art, has fully evinced itself in the many flourishing and populous cities spread over an immense con. tinent, that two centuries ago was the abode of man in a state of nature.

The splendicl and extensive edifices at washington, Baltimore, Philadelphia, and New-York, exhibit great taste in the science of architecture. The capitol at Washington is perhaps the greatest effort of our republic, in point of extent and workmasship, and reflects great credit on the talents of Mr. Latrobe, ${ }_{\text {t }}^{\text {the archi- }}$ tect. 'The next in point of magnitude is the city hall in New-York, and a number of beautiful churches built of stone.

The Pennsylvania bank in Philadelphia, also from the designs of Mr. Latrobe, is the most beautiful building on the continent, and is a perfect model of a Grecian hexastyle temple; it has never failed to be universally admired, for its symmetry and proportion. "The value attached to works of this nature may be judged of, from the city of Ephesus refusing to suffer the temple of Diana to be inscribed with the name of Alexander the Great, although that prince offered to purchase that honour by defraying the whole expense attending its erection; from the Athenians rejecting a like offer from $\mathrm{Pe}$ ricles, with regard to the splendid and cxtensive edifices with which he had ornamented Athens; and from the city of Gnidia refusing to part with one statue, the Venus of Praxiteles, although king Nicomedes proposed to free them from tribute, if they complied with the request." [Wм. StrickLaxn, Architect.]

In the vast structures of Asia and Africa, greatness of design, ponderosity of parts, and stones of immense magnitude, scem to have been more regarded than elegance or utility : in all those great works there is no trace of an arch, but what is excavated ont of the solid rock, or may be made of a single stone. The Greeks profess to have derived the knowledge of architecture from the Egyptians, but the art of building has been so much improved by transplanting, that scarcely any trace of the original remains : their edifices were at first constructed of wood and clay, but they soon began to imitate the wooden posts and beums of the original hut in stone and marble : from this iuitation arose the first order in architec- ture, which also gave birth to two others. This ingenious people, favoured by nature with marble and other building materials, and, like the Egyptians, being anxious to make their works durable, employed very weighty stones in the construction, which, although laid without cement, as was the practice of all ancient natious, yet they were jointed with the utmost accuracy, which is the reason of the perfect state of their edifices at this day. There is little doubt but that the Greeks were the inventors of the arch, though they never considered it as an ornament: it is only to be found in the theatres and gymnasia, the apertures of walls and intercolumns being linteled.

Greece, though a mild climate, is sometimes liable to rain : the architects of this country, therefore, found it necessary to raise the roofs of their edifices to a ridge. in the middle, the section being that of a rectilineal isosceles triangle: the base being the span or distance between the opposite walls. This form of roof, called a pediment roof, was frequently covered with marble tiles.

The Grecians surpassed all contemporary nations in the arts of design ; the remains of their ancient structures are models of imitation, and confessed standards of excellence. They were the inventors of three orders of architecture, of which we have already hinted, and which we shall detail in a subsequent part of this article. The remains of their sculptures far exceed that of any other people, and are, even at this day, most perfect models. Modern artists have no means so certain, in attaining a just knowledge of their profession, as in the study of those exquisite mastcr-pieces.

The progress of Grecian architecture appears to have occupied a period of about three centuries, from the age of Solon to the death of Alexander; and in this period it advanced rapidly, particularly from the defeat of Xerxes to the death of Pericles, at which time it attained its utmost degree of excellence, and continued to flourish till the time it became a Roman province.

Prior to the Macedonian conquest, all the temples of Greece, and its colonies in Sicily and Italy, appear to have been of the Doric order : and of one general form, though slightly varied in particular parts, as occasional circumstances might require: their plan was an oblong, having one column more on the flank than double the number of those in front.

The ancient Etrurians havc left many excellent monuments of taste, and to them 


\section{ARCHITECTURE.}

is gencrally ascribed the method of build. ing with small stone and mortar, made of calcarcous stone; and this seems probable, as the most ancient vestiges of cementitious buildings are to be found in the country which the present Tuscans inhabit.

They were employed by the Romans in many public works; the walls of the city of Ronne were made of hewn stone, the capitol and the cloaca maxima are of their construction; the last of these is esteemed a very extraorlinary piece of architecture, as is sufficiently proved by its remains. To these pcople is attributed the invention of one of the orders of architecture, called after them the Tuscan.

We are told by Vitruvius, that the intercolumns of their temples were wide, and that they were linteled with wooden architraves.

The liomans appear to have had their first knowledge of archirecture from the Etrurians : but it was not till after the conquest of Greece, that they acquired a just relish for its beauties. It seems to have attained to its highest degree of excellence in the reign of Augustus, and continued to flourish till the seat of empire was removed to Bizantium. The works of the Romans were much more numerous than those of any other people. 'The remains of their palaces, theatres, amphitheatres, baths, mausoleums, and other works, excite at this day the admiration and astonishment of every judicious beholder. 'Their first temples were round and vaulted, and bence they are account. ed the inventors of the dome. . The plans of their buildings were more varied than those of the Greeks, who, excepting but in a few instances of small, but beautiful, specimens, such as the Tower of the Winds, and the monument of Iscicrates, erceted their principal edifices upon rectangular plans. The Romans constructed circular temples crowned with domes, anplitheatres upon elliptic plans, and their theatres, and many other buildings, upon mixt-lined plans. By this varicty they formed a style that was both elegant and magnificent. 13ut let it be remembered, that, notwithstanding the grandeur, the magnitude, and number of their works, their style was never so pure as in the flourishing ages of Greece. Among the Romans, entablatures were frequent. ly omitted: columns were made to support arches and groined raults; arcades were substituted for colonades, and vaults for ceilings. In sereral of their most magnificent public buildings, we find sto. ries of arcades upon each other, or in the same front with the solid parts of the ma. sonry, decorated with the orelers, which, instcad of forming an cssential part in the construction, are degraded to idle and ostentatious ornaments. This is very con. spicuous in the theatre of Marcellus, and in the Coliscum.

It is probable that the arch was invented in Greece, but was almost constantly einployed by the Romans, who not only considered it necessary in the construc. tion, but as an ornament, which they lavishly employed in the apertures of walls, and in the ceilings over passages and apartments of their buildings. Particu. larly in the decline of the empire, from the reign of Constantine, and upon the establishment of Christianity, external magnificence was every where sacrifieed to intemal decoration. The purity of taste in the arts of design declined rapid. ly, and finally perished with the extinc. tion of the cmpire. The most beautiful edifices, erected in the preceding reigns, were divested of their ornaments, to dc. corate the churches. In this age of spo. liation, architects, deficient in the knowledge of their professions, adopted the most rcady modes of constriction : to accomplish this, many beautiful structures were deprived of their columns, and placed at wide intervals in the new buildings; and over the capitals were thrown arches for the support of the superstructure : most of the ornamental parts were taken from other buildings, which were spoiled for the purpose. The edifices of Italy now assumed the same general fea. tures as those which characterised the middle ages. This disposition is the plan of the Roman basilicas, but is more near. Iy allied, in the eleration, to the opposite sides of the Figyptian oeci, which lias also the samc plan as the basilica, and which was of similar construction to the cluurches in after timcs, excepting in the want of arches : both had a nare, with an aisle upon each flank, separated from the nave by a range of columns, which supported a wall, pierced with windows for lighting the nave: against this wall, and over the columns, were placed other attached columns. This, when roofel over with a groined scaling, such as that of the Tem. ple of I'eace, will form the interior of a building similar to that of the Saxon churches.

The Corinthian order was the farourite order among the Romans, and, as far as existing cxamples enable us to juilge, the only oriler well understood, and happily exccuted. 


\section{ARCHITECTURE.}

What we now call the Composite order is of Roman extraction : it was employed in many of their buildings, but chiefly in the triumphal arches: from what we find in Vitruvius, it was never accounted a distinct order, but as a species of the $\mathbf{C o -}$ rinthian only. The only existing example that Rome affords, of the Doric order, is that executed in the theatre of Marseilles, and, though in the age of Augustus, is but a vitiated composition : the columus are meagre and plain, divested of that sublime grandeur and elegance which are so conspicuous in the solidity and flutings of the Grecian Doric. The dentils in the cornice are too effeminate a substitute for the masculine mutules, which are so cha. racteristic of the origin of this order.

The Ionic in the same building is ill executed. The channels of the volutes, of the capitals, of the Ionic columns on the Coliseum, and the dentil band of the cornice, are not cut. The Ionic order of the Temple of Fortune, though it has been held out as a model, is ill proportioned, and the spirals of the volutes are ungracefully formed. The Ionic of the Temple of Concord is out of character, the volutes are insignificantly small, and mutules supply the place of dentils in the cornice. The Romans placed one order upon another, on the extcrior, in the several stories of some of their buildings; but the Greeks only employed them around the cells of their temples, forming a peristyle.

The Romans carried the method of cementitious buildings, to the utmost degree of perfection. Their most considerable edifices liad the facings of their walls, and the arches and angles of brick, or small rubble stones squared; the cores built with pebble and rubble stones, grouted or run with liquid ınortar; and at regular intervals were strengthened with courses of bond stones. This construction of walls was frequently stuccoed, or incrust. ed with marble. It is much more expeditious and economical than that built of wrought stone, which occasions a greater waste of materials and loss of time. The durability and solidity of the Roman cementitious buildings is such, that mortar has acquired a hardness superior to the stones which are connected by it. 'This, when compared with the fragility and crumbling nature of the mortar used by modern builders, had led some to suppose that the ancients possessed processes in the making of ccments, which have, from the lapse of time, been lost to the present day. But the information and experiments of ingenious men have exploded this opinion; and there is no donbt, that, if proper attention be paid to the choicc of limestone and sand, to the burning of the lime, and above all, that care be taken in the mixing and tempering these materials, workmen will be enabled to rival those of Rome. This has been tried in some instances, though the lapse of ages maybe necessary to make the comparison complete ; howerer, it will appear, from the following account of Vitruvius, that the method of making lime by the liomans was not very different from what it is at the present day. "Lime should be burnt from white stone, or flint, of which the thick and hard sort are morc proper for building walls, as those which are porous are for plastering. When the lime is burnt, the ingredients are thus to be mixed : with three parts of pit sand, one part of lime is to be mingled; but if river or sea sand is used, two parts of sand and one of lime must be united; for in these proportions the mortar will have a proper consistence; if bricks, or tiles, pounded, and sifted, be joined with river or pit sand, to the quantity of a third part, it will make the mortar stronger and fitter. for use."

The works of wrought stone of the Romans, as well as those of the Greeks, were. constructed without cement; but cramps and ligatures of iron and bronze werc used in great abundance. The use of metal was not confined to cramps and bolts, for they even constructed roofs of bronze, which was also used in magnificent profusion in the decorations of build. ings. It excites regret, to reflect that the means employed by the ancients to increase the beauty, and ensure the duration of thcir edifices, have only, in many instances, served to accelerate their destruction.

These valuable materials have caused much dilapidation, and more bnildings have been ruined by rapine, than by the injuries of time. In the works of the Greeks and the Romans, of hewn stone, they appear to have wrought only the beds of the stoncs, before they were placed in the building, leaving the faces to be worked after the completion of the edifice. By this means, the arisses and the mouldings were preserved from injury, and the faces made exactly in the same plane, or surface, which is not generally the case in the facings of our modern works. Our workmen pass them over in the most slorenly manner, with 'the greatest indifference, by romding the stones which happen to project at the joints, which gives them a false and irre- 


\section{ARCIIITECTURE.}

zular appearance in sunshine. By this means, also, the ancients diminished and fluted their columns, which could not be done with the same accuracy any other way.

After the fall of the Roman empire, the Goths, haring now the dominion of those places formerly the seat of the arts, and having soon becoma converts to Christianity, but having no established rules of their own in tlie principles of architec. ture, either built their churches in the form of the Roman basilica, or converted the basilica into churches. Architecture continued during their government with little alteration, in the general forms, from that which had been practised at the decline of the Roman empire; but ignorance in proportion, and a depraved taste in the ornamental department, at last deprived their edifices of that symmetry and bcauty, which were so conspicuous in the works of the ancients. However, the knowledge of architectural elements was still preserved among them, and of the various forms of vaulting used by the Grecks and Romans, they adopted that of groins or cross-arching.

From what has been said, it will be easy to shew, that the Goths had no share in the invention of that style of building which still bears their name. The architecture of Italy, at the time they ceased to be a nation, was nothing but debased Roman, which was the archetype for the first Saxon churches erected in this coun. try. The term Gothic seems to have originated, in Italy, with the restorers of the Grecian style, and was applied, by the followers of Palladio and Inigo Jones, to all the structures erected in the interval between the beginning of the twelfth and end of the fifteenth centuries, probably with a view to stigmatize those beautiful edifices, and to recover the ancient man. ner. 'This term is therefore of modern application : it was not usel in Italy till the pointed style had gained the summit of perfection, nor yet in Fingland, when this species of architecture ceased to be in use, and the frecian restored. This manner of building, like most other arts, required s succession of ages to bring it to maturity, and the principal cause which seems to have effected this was, that desire of novelty so inherent in the unind of man to produce something new, and a total disregard to the proportions of ancient edifices. IIaving now traced the Grecian style from the place of its invention to its decline in Italy, we shall follow the steps by which this corrupted ill-proportioned
Italian style at last asstumed a character so different from the original, as to be. come in a few centuries a distinct specics of architecture, which not only exhibited beantiful proportions, and elegant decorations, but also majestic grandeur and sublimity in its fabrication. To do this it will not be necessary to seek abroad for those successire clianges, as the different gradations can be distinctly traced at home. The first Saxon churches here wcre either constructed, with however rude imitation, after models of Iloman temples, which we may presume then re. mained in Britain, or by foreigners brought from Rome and France. The manner of building at this time was called IRoman, the term Gothic not being applied till the end of several centuries.

It has been observed, that a quadran. gular walled enclosure, divided in the breadth into three parts, by two colonaded arcades, supporting, on the imposts of the arches, two other opposite higher walls, through which the light descended into the middle part, and upon which the roof rested, was known to the liomans before the Goths appeared in Italy. Now this construction is the general outline of the Saxon, Norman, and the pointed styles of building churches, and is also that form of structure most advantageous for lighting the interior, upon the same plan; for, though the roof might have been equally well supported by columns, instead of the interior walls, and extencling those of the exterior to the whole height, the intensity of light produced from the same number of windows on the sides, thus far removed from the micllle of the edifice, would have been greatly diminished. It may also be farther ob. served, that no other form of building was so favourable for vanlting: for : vaulted roof could neither hare been thrown to the whole breadth, nor in the three compartments, without walls of enormous thickness, which would not only have aclded to the brealeh, but would have been attended with prodigious additional expenses.

The Saxon style is easily recognized by its massive columns and senicircular arches, which usually spring from capitals without the intervention of the enta. blature. In the first Saxon buildings the mouldings were extremely simple, the greater part consisting of fillets and platbands, at right angles to each other, and to the general façade. The archivolts and imposts were similar to those found in Roruan edifices. The general plan and 


\section{ARCHITECTURE.}

disposition of the latter Saxon churches were as follow; the clief entrance was at the west end into the nave, at the upper end of which was a cross, with the arms of it extending north and south ; the east end, containing the choir, terminated in a semicircular form. A tower was erected over the centre of the cross, and to coiltain the bells another was frequently added, and sometimes two.

The large churches contaned a nave and two side aisles, one on each side of the nave, and were divided into three tiers or stories, the lower consisting of a range of arcades on each side ; the middle, a range of galleries between the roof and the vaulting of the aisles; and the uppermost, a lange of vindows. The pillars were either square, polygonal, or circular. Such was the thickness of the walls and pillars, that buttresses were not necessary, neither were they in use. The apertures are splayed from the mullions on both sides. The dressings are generally placed on the sides of the splayed jambs and heads of the arches, and but seldom agrinst the face of the walls, and when this is the case, the projectures are not very prominent. The dressings of the jambs frequently consist of one, or several, engaged columns upon "each side. The imposts, particularly those of the windows, have frequently the appearance of being a part of the wall itself. The doors in general are formed in deep recession, and a series of equidistant engaged columns placed upon each jamb, and were such, that two horizontal straight lines would pass through the axis of each series, and would, if produced, terminate in a point. Each column is attached to a recess formed by two planes, constituting an interior right angle. The angle at the meeting of every two of these recesses formed an exterior right augle, which was sometimes obtunded, and frequently hollowed. The archivolts resting on the capitals of the columns are formed on the soffit shelving, like the jambs below. The ornaments of columns and mouldings are of very simple forms. The rudely sculptured figures which often occur in door-cases, when the head of the door itself is square, indicate a Roman original, and are mostly referable to an rera immediately preceding the conquest.

After the Norman conquest, the general forms of the parts remained the same, though the extent and dimensions of the churches were greatly enlarged; the vaultings became much more lofty, the pillars of greater diameter, the ornaments more frequent and elaborately finished; towers of very large dimensions and great height were placed either in the centre, or at the west end of the cathedral and conventual churches. These were often ornamented with arcades in tiers of small intersecting arches on the outside. About the end of the reign of Henry 1 . circular arches, thick walls without prominent buttresses, and massive pillars with a kind of regular base and capital, generally prevailed; the capitals of the pillars were often left plain, though there were a few instances of sculptured capitals, foliage, and animals. The shafts of the pillars were usually plain cylinders, or had semicolumns attached to them. The first transition of the arch appears to have taken place towards the close of the reign of Stephen, its figure, which had hitherto been circular, becoming slightly pointed, and the heavy single pillar made into a pilastered cluster, which was at first ill formed, but gradually assumed a more elegant figure and graceful proportion, the archivolts still retaining many of the Saxon ornaments. It may here be observed, that, antecedent to this period, neither tabernacles nor niches with canopies, statues in whole relief, pinnacles, pediments, or spires, nor any tracery in the vaultings, were used; but at this time, or soon after, these began to obtain. Towards the close of the 13th century, the pillars, then supporting sharply pointed arches, were much more slender; the ceilings were seemingly sustained by groined ribs, resting on the capitals of the pillars, and the windows were lighted by several openings, in place of one.

After the reign of Stephen, the circular and pointed arches were frequently employed in the same building; but the pointed style, gaining more and more upon the circular, prevailed ultimately at the close of the reign of Henry III. and prevented all farther confusion of mixture. The architecture of this age now exhibited uniformity of parts, justness of proportions, and elegance of decoration; the arcades and pillars became numerous, the single shafts were divided into a multiplicity of equal, slender, distinct shafts, constructed of purbeck marble, and collected under one capital, luxuriantly decorated with leaves of the palm-tree. The east and west windows began to be widely ex. panded; these required a number of mullions, which, as well as the ribs and transomes of the vaulting, began to ramify, from the springing of the arches, into a 


\section{ARCHITECTURE.}

varicty of tracery, which was uniformly ornamented with rosettes or polyfoil, cuspidated figures, forming trefoils, quatrefoils, \&ec. Canopies were introduced over the arches, and in rich work were deco. rated with crockets and cree ping foliage, and terminated in a flower. The buttresses were marle in several diminislied stages towards the top, and mostly terminated with purfled pinnacles.

In the reign of Edward II. detached columns were laid aside, and pillars, nearly of the same proportion as formerly, with vertical or columnar mouldings wrought out of the solid, were adopted. The east and west windows were so enlarged as to take up nearly the whole breadth of the nave, and carried up al. most as high as the vaulting, and were be:utifully ornamented with lively colours on stained glass.

In the early part of the reign of Edward III. arcades with low arches and sharp points prevailed; over the arcades was generally placed a row of open galleries, originally introduced in Saxon churches.

About the end of the reign of Richard II., A. D. 1399, the pillars became more tall and slender, forming still more lofty and open arcades; the columns which formed the cluster were of different diameters, the capitals more complicated, the vaults at the intersection of the ribs were studded with knots of foliage, the canopies of the arches were universally purfled, and terminated with a rich knot of flowers: the pilastered buttresses flanking the sides were erowned with ela. borate finials, the Hying buttresses were formed on segments of circles, in order to give them lightness, and strength at the same time.

From the close of the 14 th century no remarkable change appears to have taken place ; the grander nembers continued their original dimengions and form, and the ornamental parts became distinguished by greater richness and exuberance.

Another change took place in the reign of Edurard IV. Its leading features are principally to be seen in the vaultings, the horizontal seccions of which had been generally projecting right angles, but were now arclies of circles; the surface of the vaults being such as might be generated by a concave curve revolving round a vertical line, as an axis which wis immediately over the pillars. This species of groining, unknown in preceding ages, was favourable for a beautiful dislay of tracery. Equi-distant concave ribs in rertical planes were intersected by VOl. I. horizontal convex circular ribs, and the included panucls were beantifilly orma. mented with cusps, forming an infinite variety of the inost elegant tracery; which, from its appearance, lias been denominat. ed firn work.

From the commencement of the reign of hing llenry V1Il. a mixed or debased style began to take place, from our intercourse with the Italians. The ingenious Mr. Britton, in his valuable architectural antiquities of Great Britain, has classed the various styles in the following order, which we shail adopt, and shall be bappy to find the same ap propriate terms adopted also in future publications, wherever ideas of the objects represeoted by them are the subjects of inquiry. We are sen. sible this is the only means of facilitating a knowledge of this study, by renoving equivocal words, and thereby making ar. chitectural language intelligible.

First Siyle. Anglo Saxon; this will $\mathrm{cm}$ brace all buildings that were erected be tween the times of the conversion of the Saxons and the Norman conquest, from A. D. 599 to A. D. 1066 .

Second Siyle. Anglo Norman, by wbich will be meant, that style which prevailed from 1066 to 1189 , including the reigns of W'illiams I. and $H_{\text {., }}$ Henry I, Stephen and Henry II.

Third Style. English, from 1189 to 1272, embracing the reigns of Richard I, John, and IIenry III.

Fourth Styls. Decorated English, from 1272 to 1461 , including the reigns of E.d. wards I., Il., Ill., lRichard II., Henrys IV., $\mathrm{V}$, and VI.

Fifth Style. Ilighly decorated florid English, from 1461 to 1509 , including the reigns of Edwards IV. and V., Richard III., and Ilenry VII.

From this xra we lose all sight of congruity : and the public buildings crected during the reigns of Henry Vill., Elizabeth, and James I., may be characterised by the terms of debased Pnglish, or An. glo-Italian. IIr. Britton observes, "that during the intermediate time, when one style was gruwing into repute and the other sinking in favour, there will be found a mixture of both in one building, which is not referahle to either, and which has constituted the greatest problem in antiquarian science."

Before we leave this subject, it will he necessary to give some account of the muterials esnployed in the fabrication, and of the principles in the construction of those inmense piles, which at once united grandeur, inagnificence, and awful sub. in $\mathrm{r}$ 


\section{ARCHITECTURE.}

limity in their structure. In the erection of these edifices, heavy cornices, entablatures, and lintels, werc omitted, and there was seldom occasion to use any stones larger than a man might carry on his back, up a ladder, from one scafiold to another, though spoke wheels and pullies were occasionally used. From the adoption of such light materials, and the emulation of the architects, edifices were raised to an incredible height. Hence the lofty towers, and the still mole elevated spires that occasion such awful grandeur, and sublime sensations in the mind of the astonished beholder. The ceilings of the churches viere formed by groined vaulting, a portion of the pressure of which was directed in the length to the cnds, and the remaining pressure to the springing points on the sides.

In the Roman buildings the walls were most commonly without projections, and of vast thickness, which was necessary in a vaulted building, erected upon a rectilineal plan, in order to counteract the efforts of the resisting arches. Hence, if the building had been groined, the weight of the arches would liave been thrown upon the springing points. From this it is evident that a vast quantity of materials must have been employed without effect; but this is not the case with the painted style of architecture, for the walls were thickened by buttresses opposed only to the pressing points; and,-to aid the resistance with still more powerful effect, the buttresses were surmounted with high pinnacles, and, from their sloping position, their general form was almost one continued prop, in a straight line to the bottom : this straight line was a tangent to the arch. Those that understand the nature of the centre of gravity will easily perceive, that a plain wall will be overturned with much more ease than one with buttresses, of the same length and height, the same quantity of materials being employed in botl. The extremity of the aisles was sustained by strong pilastered buttresses on the outside, and the other extremity rested on the imposts or capitals of the pillars. These pillars, with their superincumbent walls, not being assisted as on the outside with buttresses, were liable to be bent with the pressure of the arches; unless the sides of the nave liad been of sifficient thickness, which, in many of our churches, experience has proved to be the contrary, by the bending of the walls inwardly, which is a serious defect, and threatens ruin to many of those venerable piles of building. We cannot therefore expect these edifices to rival, in duration, the immortal constructions of Egypt, Greece, and Rome. As to the groining of tlie nave, the arclies were equally resisted on both sides by the flying buttresses, which pressed forcibly at the imposts of the arclies. It would appear, that the method practised in the erection of these edifices was, to insert the springing stones as the work went on, but to leave the vaulting to be turned after the walls had been carried up to their full height, and the whole roofed in. The roofs of Gothic buildings were very high pitched, a form more from choice than necessity, rather adopted in compliance with the pointed and pyramidal style of architecture, than rendered necessary by the climate, bcing generally covered with lead. 'These roofs are therefore faulty, in burdening the walls with an unnecessary load of timber and lead; and they are also deficient in the construction, by the omission of tyebeams, to counteract their tendency to spread and thrust out the walls.

After having thus discussed the several styles of building, which have been generally and unmeaningly classed under the appellation of Gothic, we must now make a retrogression to Italy, where the Grecian style had been revived for a consider able time, and was flourishing in great purity. Let us the refore retrace the steps by which it again rose to its ancient splendour and magnificence.

Fillipo Brunelleschi, born 1377, may be looked upon as the restorer of ancient architecture, and the founder of the modern style.

After having prepared his mind by the study of the writings of the ancient author's, and the ruins of Roman edifices, which he careftlly measured, he discovered the orders, and recognized the simple forms and constructions of the ancients, and having thus formel a system upon unshaken principles, he was enabled to construct works with beauty, solidity and durability. He erected the dome of St. Maria da Fiore at I'lorence, an undertaking beyond the abilitics of any other builder then living; Adnolfo, the original architect of this vast cathedral, having been two years dead. This dome, rising from an octangular plan, is of great clevation; and is only inferior in size to that of St. Peter's. It is constructed by two vaults, with a cavity betiveen them, and was erected without centering. It is the only elevated dome supported by a wall without buttresses. From this, and many 
othër buildings crected by Brunelleschi, the learned began to study the works of Vitruvius, and a gencral taste for the principles of the art began to warm the breasts of the Italians.

Leo Iattista Alberta, born A. D. 1398, was the first modern author who publish. ecl a learned treatise on architecture, from which he lias acquired great reputation, and is justly styled the modern Vitruvius. Following the steps of Brunelleschi, he reformed by his precepts and desigus many of the abuses and barbarous practices which then prevailed among his countrymen.

- Bramante had a considerable share in the restoration of ancient art, and built many magnificent edifices. Pope Julius II. having projected the rebuilding of St. Peter's upon a scale of unequalled mag. nificence, entrusted the exccution of the design, 1513, to Bramante, who conceived the idea of erecting the lofty cupola upon that immense structure. This vast undertaking was carried on successively by Raphael, San Gallo, and Michael Angelo, to whom the final design and completion of the work is principally due.

- Architecture continued to flourish in the 16 th century, under the great archi. tects Vignola, Serlio, Palladio, and Sca mozzi. To the unremitted assiduity of these distinguished artists in the study of the Roman erlifices, and to their iuraluable publications, the world has ben much indebted for the elucidation ot the principles of ancient art.

The list of the celebrated Italian artists closes with Bernini, who flourished in the 17 th century.

The Grecian style of building was revived in France in the beginning of the 16th century, and afterwards flourished under several architects of distinguished merit. Their principal works are, the palace of Versailles, St Cyr, the church of Inralids, the Facade of the Louvre, a most betustiful modern structure, the Porte St. Denuis, and the church of Gene. vieve, the present Pantheon.

Grecian architecture was restored in England under the celebrated InigoJ ones, born 1752. His distinguished works at Greenwich, Whitelsall, and corent Gar. den, will ever secure him a name among the architects of the highest reputation.

Sir Christoplier Wren, an eminent mathematician and philosopher, as well as an urehitect of the. first rank, has executed many of the finest buildings in London, and other parts of England, in the modern stylc. St Paul's cathedral, inferior to none but St. Peter's, in - point of magnitude, but perhaps superior both in skilful construction and figuration, will perpetuate his name to the latest posterity. The exterior dome of St. Paul's is constructed of wood, and sustained by a cone of 18 inch brick-work, which also supports the lantern abore.

The interior dome is also constructed of 18 inch brick work, which had a course the whote thickness for every five fect, and the intermediate parts had two bricks in length in the thickness. This dome was turned upon a centre, which supported itself without any standarkls from be. low. From the inclined position of its supporting walls it had little or no transverse pressure, yet, for the greater security, it was hooped with iron at the bottom. This is accurately represented in Gywn's Section.

Though morlern architecture is, for the far greater part, indebted to the constructions and decurations of Grecian and Roman edifices, yet we still retain consider. able traces of the Gothic style in many of our buikdings.

Tbe spire is of Gothic invention ; it is imicated in our cliurches and some other buildings, by erecting one, or two, or a se. res of Grecian tenples over each other, every superior one being less in its horizontal dimensions than that inmediately below.

Frustrums of pyramicls and cones are also the or'naments of our steeples; but whether the component parts be one, two, or a series of temples, continually diminished, or temules supporting truncated pyramids, the general contour of the aggregate is still pyramiclal.

The plans of firecian buildings were simple geometrical forms; but these of our structures are symmetrical and com. plex figures, more in imitation of those of the Romans.

The materials used in our modern buildings are stone, brick and timber. In rustic buildings, the stones are either laid dry or with mortar. In finished edifices, the stones of the facings are squared and laid in mortar, and the backs and cores are most generally made up with brick or rubble. Walls constructed entirely of squared stones are rare : for, allowing the innterials may be easily procured in great abundance, a vast expense will be incurred by enormous additional workmasship. This construction of walling is therefore seldom or never used but in aquatic buildings, where the greatest strength is frequently necessary.

The French have not only shown much ingeuuity in the binding and cementing 


\section{ARCHITECTURE:}

of walls, but also in the cutting of stones with geometrical exactness, so as to fit raulted surfaces, of varionsly formed figures.

Iron is used for cramping stones, sometimes in binding the face and back of a wall together, when there is little heart. In domes it is frequently used in circular claains, in order to remove lateral pressure, and make the weight of the superstructure act perpendicularly upon the. supports. It is also used in fastening wood together, and wood to stone work.

Timber is used also as ligatures to walls; in this situation it is called bond timber, which also serves for securing the internal finishings. Timber is frequently usedin foundations, in floors, in roofing, in internal finishing, \&c. Timber, besides being used in bond, flooring, and roofing, in conjunction with stone or brickwork, is sometimes used as the only material, excepting the chimnies, nails, and other iron fastenings.

Mouldings. In architectural decorations, the materials are formed into a va. riety of shapes; which have inany two places sections of equal and similas figures, at right angles to their surface, in these two places; thin forms of this property are called mouldings.

When the section is semicircular, or semielliptical, it is called a torus or astra$\mathrm{gal}$ : when large, it is called a torus; and when small, an astragal.

When the section is a concave curve, and when the concavity recedes beyond either of the extremities of the curre, the moulding is called a scotia or trochilus.

When the section is concave, one extremity being above the other and the upper extremity projecting out bejond the lower, and when the lower extremity recedes from a rertical line equal to the greatest recess of the concavity, or morc, the moulding is called a cavetto.

When the section is a convex curve with onc extremity below the other; and the upper extremity projecting farther than the lower, without any part of the convexity being lower than the lower extremity of the section, the moulding is called an ovolo or echinus.

Whenthe section is a curve of contrary flexure, like a flat $\mathbf{S}$, the moulding is called an ogee; and when the concave part of the ogee projects, and the convex part recedes, the ogee in this position is called a sima recta: but when the parts lie the contrary way, it is called a sima inversa.

When the section is straight, and is either perpendicular to the horizon, or nexrly so, then the flat memuer is called a fillet, plat.band, or facia, according to its breadth and comparison with other contiguous mouldings.

When it is very narrow, and either crowns an upper moulding, or divides onc member from another, it is called a fillet, or listello; when it is broader, it is called a plat.band or plinth; and when very broad, it is called a facia or face.

Compound.Mouldings. When one, two, or a collection of mouldings, with or without fillets, crown a broad flat member, this collection is called a cymatium. Other names are particularly applied to the orders, and are explained under that head.

\section{ORDERS OF ARCHTECTURE.}

An order is a decorated imitation of those primitive huts, which consisted of rows of posts, made of the trunks of trees, disposed in the ground around a quadran. gular plat; and supporting a covering, which consisted of four lintelling beams, placed on the top of the posts, with other transverse beams, supported again by two of the opposite lintels: and lastly, of three rows of transverse timbers support: ing each other, and the lowermost supported by the ends of the transverse beams on each side, in parallel inclined planes, rising from the ends of the transverse beums, till each plane of timbers on the one side met its corresponding plane on the other; the lowernost timbers on each side bein $r$ disposed in pairs, in the same vertical plains with tlje transverse: beams, forming the sides of a triangle, and projecting beyond the lintels, and the uppermost inclined planes of timbers, serving to fix the covering of tyle or stone. From this simple construction. arose the first order of architecture. called

Doric Order. The columns were imitated from the wooden posts tapering upwards, as trees do by nature, and placed upon a stone base, to prevent them from sinking : vertical channels, or flutes, were cut in the shafts, to hold the spears, or' staves, which the early Greeks carried along with them. The capital was formed by circular stones, laid on the tops of the columns, and square ones again upon these, to protect the shafts from rain, and to receive the lintelling beam, which became the architrare: the ends of the joists over the architrave were not in vertical channels, forming the triglyphs, for preventing the rain from adhering to them. The cornice was formed by the 


\section{ARCHITECTURE.}

projecting timbers of the roof; the ends of the bottom tier of these timbers forming the mutules : the lower sides of which, as well as the under side of the band of the triglyphs, were cut into thin cylinders, or conic frustrums, representing the drops of rain falling from the edges. These parts, which at first resulted from the primitive habitation, were afterwards converted into more elegant decorations of simple and natural forms. The general figure of the Attic Doric consists of but few parts, even as practised in the most refined ages of Greece: the fluted shaft, terminating with one, two, or three annular channcls; the capital, consisting of the fillets, and a bold echinus, having the same common axis with the shaft ; and the crowning abacus form thic entire column, which therefore consists of a basc and shaft. The spacious architrave, resting on the columns, consisting of a cruwning band, with the guttere and tenia pending therefrom, under the triglyphs; the frize, consisting of a eapital, or cymatium, and equidistant triglyph, leaving square recesses between thein, called metopes; and the comice, consisting of mutules over the triglyphs and over the metopes; the corona formed of a band and cymatum above; and the sima, or crowning moulding, formed of a large ovolo and fillet, compose the whole entablature; which therefore consists of a cornice, frize, and architrave. 'This is the general character of the Grecian Doric. It is almost constantly placed upon three steps, proportioned to the height of the orler, and not to the human step; the shafts of the columns diminish, with a beautiful curve line from the bottom to the cincture below the annulets; the flutes are without fillets, of a circular or elliptic section, and terminate immediately below the an. nulets: the annulets of the capital most commonly follow the contour of the oro10: above them, the band, crowning the top of the architrave, is one continued string without breaks; the gutta under the regula, and under the mutules, are generally of a cylindrical form, at least tapering upwards in a very small degree.

The triglyphs are placed upon the extremities of the frize, and not over the axis of the extreme columns; and eousist of two whole channels, and two half ones upon the edges; the sides of each glyph, or channel, are two vertical planes, meet. ing each other in a right angle at the back, and consequently the face of the triglyph at 135 degrees on each side of the glyph ; the tops of the channels are sometimes curved in the front, like a very eccentric semi-ellipsis, placed with its greater uxis horizontal, as in the temple of Theseus; and very frequently with 2 horizontal line, joined to each vertical line at the side, with a quadrant of a circle, and the tops of the two half channels on each edge of the triglyph are semi. circular, not only in front, but in the profiles also, leaving the angle pendant at the top, as in the temples of Minerva at Athers, and at Surium, and the temple of Jupiter Panellenius; and sometimes the head of the glyph is horizontal, as in the Doric portico at $A$ thens, and in the temple of Jupiter Nemaus, between Argos and Corinth.

In all these examples, the surface forming the head of a glyph is perpendicular to the front, or such that a right line, perpendicular to the face, and touching the top line of the head in any point, will coincide with the surface of the interior of the glyph. The capital of the triglyphs has a small projection on the face, which is not returned on the edges, and de. scends lower than that over the metopes: though both are on the same lerel at the top.

The mutules are thin parallelopipeds, their lower surface making an acutc angle with the upright of the frize, in the same manner as the under ends of the rafters of the primitive hut would; the pendant guttre, hung to them, are in three rows, from front to rear, having six on the front, and also in each of the tiro back rows. The soffit of the comona is parallel to that of the mutules, and consequently makes an acutc angle with the upright of the frize also. The lower part of the corona is most frequently wrought into a fillet; its cymatium is differently formed in clifferent examples, but most frequently with a small ovolo and fillet, both of which are channelled upwards, in order to pro. duce a greatcr variety of light and shade. The sima, or crowning moulding, most frequently consists of a large ovolo, and a fillet over it.

The general proportions of the Doric order are the following. The columns are six diameters in lieiglit : the superior diameter is four-fiftls, and the altitudinal dimension of the capital two-fiftlis of the inferior diameter, including the snuslets, echinus, and abacus. The height of the capital is divicled into two equal parts, giving the upper one to the abacus, and the lower one to the echinus and annulets : divide the lower one into five parts, giving one to the annulets, and four to the ovolo: divide the height of the entablature into four parts, giving one to 
the cornice, which compreliends the distance between the fillet of the echinus or crowning moulding and the under side of the gutta; divide the remaining three into twe equal parts, giving one to the lieight of the frize, as seen in front, and une to the architrave.

The Doric order was tlie only order known in Greece, or its colouies, anterior. to the Macedonian conquest. The Ionic succeeded, and appears to have been the farourite order, not only in Ionia, but all over Asia Minor. The Corinthian (says Mr. Wood) came next in rogue, and most of the buildings of this order seem posterior to the time of the conquest of those countries by the Romans. The first Doric building was the temple of Juno, erected by Dorus, king of Achaia, and Peloponnesus in the ancient city of Argos, from whom this order derives its name. It was also used in other cities of this prince's dominions, but its proportions were not established, till an Athenian colony erected a temple to Apollo Panionos, in Ionia, so called from lon, their leader, after the form of the temples they lad seen in Achaia. In this building the relative dimensions of the columns were adjusted, from the ratio which the foot of a man bears to his height, making their diameter one sixth part of their altitude.

Ionic Order: The ambitious desire of novelty soon led the way to the invention of another species; and, in erecting the temple of Diana, they sought a new or. der from similar traces, imitating the proportion and dress of women. The diameter of the columns was made an eighth part of their height; the base was made with folds representing the shoe; the capitals with volutes, in form of the curled hair worn upon the right and left; and the cymatium, for the locks pending on the forehead from the crown. Tlis new order they called Ionic, after the name of the country in which it was in. vented: so far we are informed by Vitruvius. It is probablc, that, in erecting this temple, the triglyphs and mutules, the bold characteristic marks of the original hut, would be omitted, and the more slelicate dentils, representing the ends of the lath to which the tyles were fixed, employed, representing a beautiful row of tecth; for in all the ancient Ionian fragments of this order we find the cornices constantly denticulated, and therefore the dentils are no less cliaracteristic marks than the capitals: they are generally omitted, however, in the remains of those to be found at Athens. The other parts and proportions of the Ionian order are more arbitrary than in the Dorian. The parts of the Ionic orrler on the temple by the Ilyssus are few, and of a bold character; the beight of the volutes is tliree-fiftls, and the whole heiglit of the capital two-thirds, of the diameter of the column.

The architrave consists of one broad facia, and its crowning crmatium : the parts of the cornice as seen in front are, the corona, including its eymatium, and sima. The capital, or cymatium of the frize, is wrought under the cornice, and consists of a sima réversa, and bead below it. The height of the architrave is about two-fifths of the entablature; and by dividing the upper three-fiftlıs again into five parts, the plain part of the frize will occupy thrce parts, and the cornice two parts.

In the Ionic order of the temple of Erechtheus, and of the temple of Minerva Polias, the architrave consists of three facix, and cymatim; the cymatium of the frize is mostly wrought under the corona. If the heiglit of the entablature from the bottom of the lower facia to the top of the cymatium of the corona be divided iuto ninetecn parts, the architrave and the part of the frize tlat is scen will each be eiglit parts, and the corona, including the larymer and cymatium, the other three parts. The volutes of the capitals of these orders, both for singularity and beauty, exceed every other remain of antiquity.

The Asiatic Ionian order differs greatly from the Attic one. In most of the remains of this order, as represented in the Ionian antiquities, tlue frizes are all wanting, except in one example ; and consequently the whole, heiglit of the entablature of those without thic frizes cannot be asccrtained, though the architraves and cornices bclonging to each otlier have been accurately measured. The one which has the entire entablature belongs to the grent theatre at Laodicea: tlje frize is pulvinated, and is something less in height than one-fifth of that of the entablature. The architrares of the temple of Bacchus at Teos, and the temple of Minerva Polias at Prienne, arc each divided into three facia below the cymatium. In all the Asiatic Ionics the crowning moulding is constantly a sima recta of a less projection than it has height: the rentils are never omitted, and their height is nearly a mean proportion between the height of the sima recta and that of the larimer, corona, or drip, being always greater than the height of the corona, and less than that of the sima recta. 


\section{ARCHTECTURE.}

The cymatium of the denticulated band is wrought almost entirely ont of the soffit of the corona, or recessed upwarls, and consequently its clevation is almost concealed. Tlie lieight of the cornice, from the top of the sima to the lower edge of the dentils, is equal, or very nearly so, to that of the architrave. 'The altitude of the frize, without its cymatium, or upper mouldings, may be supposed to be about a fourth part of the whole entablature; for if higher than this, the entablature would be too great a portion of the columns for any analogy we are acquainted with. In point of beautiful proportions and elegant decorations, the entablatures of these two last examples exceed every other remain; and though their proportions are very different from those remaining at Athens, yet they are still pleasing.

In all the Grecian Ionics there seems to be a constant ratio between the upper part of the comice, from the lower edge of the corona upwards, and the height of the cntablature: this is nearly as two to nine. If these members were regulated in any other manner, their breadtlis would be so variable, as sometimes to be so di. minutive that their forms could not be perceived, and at other times so enlarged as to overload the whole, when viewed from a proper station. Incleed the great recess of the mouldings under the corona makes this a very distinct division, and on this account we never think the cornice too clumsy, though the whole denticulated band and cymatium of the frize are introduced below the cornice, which seems to be the reason of so great an apparent difference between the Asiatic and Attic lonics. 'This order, as found in the Ionian territory, is complete; but those at Athens are deficient, from their want of the dentil band, though beautiful in many other respects.

Moderns have alded a diameter to the height of the Ionic column, making it mine instead of eight. The shaft is gene. rally striated into twenty -four flutes, and as many fillets. The lieiglit of the entablature in general may be two dianeters; but where grandeur as well as elegance is requirced, it slould not be less than a fourth. The base employed in the Athenian Ionics consists of two tori, and a scotis or trochilus between them, and two fillets, each separating the scotia from the torus above and below: the fillet above the torus generally projects as far as the extremity of the upper torus, and the low. er fillet beyond the upper torus; the sco- tia is very flat, and its section and eliptic curve joining the fillet on each sidc: the tori and scotia are nearly of equal heights: in the lonic temple on the llyssus, a bead and fillet are employed above the upper torus, joining the fillet to the scape ut the column: the upper torus of the basis of the sanie temiple, and that of the basis of the teinple of Erechteus, are both fluted, preserving the lower part, that joins the upper surface of the fillet above the sco. tia, entire. The upper scotia of the $(\mathrm{cm})$. ple of Minerva Polias is enriched with a beautiful guilloche. The lower torus of the base of the anta of the temple of Erechteus is receled, and that of the base of the anta of the temple of Minerva Po. lias is channelled with flutes, separated from each other by two small cylindric mouldings of a quadrantal section, having their convexities joining each other. Tlis form of a hase is by Vitruvius very pro. perly called the Attic base, being invent. ed and employed by the Athenians in all their lonics. It was also adopted by the Romans, and seems to huve been their most favourite base; for it is not only employed in all the examples of this or. der at lome, but most frequently in the Corinthian and Composite orders also. However, the proportions of the Attic base, as employed by the Romans, are clif. ferent from that employed by the Grecks, the upper torus of the fomner being al. ways of a less height than the lower one, both tori plain, and the scotia containing a much deeper carity. The proportion of the bases of the Ionic and Corinthi:un orders on the Coliseum, the Ionic on the theatre of Marcellus, and that on the temple of Fortuma Virilis at Rome, have nearly that assigned by Vitruvius. The Ionic bases, as employed in the t(mple of Minerva P'olias at l'riene, and in that of A pollo Dedymaus ncar Miletus, conslst of a large torus, three pair of astragals, and two scotix, inverted in respect of each other. The upper pair of astragals is disposed below the torus, and the sco. tix separate each pair of astragrals from each other. In the ten ple of Mnerva P'olias an astragal is employed above the torus, scparating it from lhe shaft; the toms itself is forned elliptically, and the under part of it is flutcd : it lias also 2 flute cut in the upper part, near to the beacl. In the (emple of Apollo Dedymx. us, the upper torus is of a semicireulas section and plain, and each bead of every pair is separated by a narrow fillct. The base of the Asiatic Innics differs little from that which Vitruvius appropriates to 


\section{ARCHITECTURE.}

this order. In the forner the scotiz are inverted, which gives a greater variety in the profile than when both stand in the same position, as in the Vitruvian base. The Ionians, besides the base which they appropriated to this order, sometimes used the Attic base also, as in the temple of Bacchus at Teos. This base seems not only to have been the most favourite one among the ancients, but is likewise so among the moderns. It is not so heavy in the upper part as that denominated Ionic: its contour is pleasing, and its ge. neral appearance elegant. In the capitals of the Athenian Ionics, and in that of Minerva Polias at Priene, the lower edge of the canal between the volutes is formed into a graceful curve, bending downward in the middle, and revolving round the spirals which form the volute upon each side. In the temple of Erectheus and Minerva Polias at Atliens each rolute has two channels, formed by two spiral borrlers, and a spiral division between them. The border which forms the exterior of the volute, and that which forms the under side of the lower canal, leaves between them a deep recess, or spiral groove, which continually diminishes in its breadth till it is entirely lost on the side of the eye. In the example of the temple of Erectheus, the column is terminated with a fillet and astragal a little below the lower edges of the rolutes, and that of Minerva Polias in the same manner with a single fillet; and the colorino or neck of each is charged with beautiful honeysuckles, formed alike in alteruate succession, but differing from ench other in any two adjacent ones. The npper annular moulding of the column is of a semicircular section, and embellished with a guilloche. The echinus, astragal, and fillet, are common to both Grecian and Roman Ionic capitals, and the echinus is uniformly cut into eggs, surrounded with borders of angular sections, and into tongues between every two borders. The astragal is formed into a row of beads, with two small ones between every two large ones. T'liese munldings are cut in a similar manner in all the Roman buildings, except the Coliseum, and what relates to the taste of the fuliage. In the temple of Bacchus at Teos, the great theatre at Iaodicea, and in all the Koman Ionics, the channel connccing the two vo. lutes is not formed with a border on the lower edge, but is terminated with a horizontal line, which falls a tangent to the second revolution of each voute at the commencement of this revolution. The reacler will find the description of the vo. lute among the descriptions of the plates. When columns are introduced in the flanks of a building as well as in the front, one of the capitals of each angular column is made to face both the contiguous sides of the building, with two volutes upon eacl side, projecting the two adjacent rolutes, by bending them in a concare curve towards the angle, as in the temple of Bacchus at Teos, of Minerva Polias at Prienc, of Erectheus, and that on the Ilyssus at Athens, as also that of the Manly Fortune at Rome. The capitals of all the columns are sometimes made to face the four sides of tlye abacus alike on each side, as in the temple of Concord at Rome, from which example the Scammozzian capital was formed. The ancients employed this order in temples dedicated to Juno, Bacchus, Diana, and other deities, whose character held a medium between the severe and the effeminate; and the modems employ it in churches consecrated to female saints in a matronal state ; also in courts of jus. tice, seminaries, libraries, and other structures which have a relation to the arts.

Corinthian Order. The invention of this order was attributed to one Callimachus, an Athenian sculptor, who, passing by the tomb of a young lady, observed an acanthus growing up by the sides of a basket, which was covered with a tile and placed upon the tomb, and that the tops of the leaves were bent downwards by the resistance of the tile, took the hint, and executed some columns with foliated capitals, near Corinth, which were made still of a more slender proportion than the Ionic, imitating the figure and delicacy of virgins. Vitruvius inentions that the shafts of Corinthian columns have the same symmetry as the Ionic, and that the difference of the symmetry bctween the entire columns arises only from the difference of the heights of their capitals, the Ionic being one third, and the corinthian the whole diameter of the shaft, which, therefore, makes tlie lieight of the Corinthian two thirds of a diameter nore than that of the lonic; hence, as he has allowed the Jonic to be eight diameters, the Corinthian will be eight and two thinds.

The sides of the abacus of the Corin. thian capital are concave, and moulded on the fironts.

The lower part of the capital consists of two rows of leares, and each row of eight plants; one of the upper leares 


\section{ARCHITECTURE.}

fronting each side of the abacus, and the stalk of each leaf springing between each two lower leaves. The height of the abacus is one seventh, the upper and lower tiers of leaves each two sevenths, and the branches and volutes, which spring from the stalks between every two leaves in the upper row, the remaining two sevenths of the diameter. The breadth of the capital at the bottom is one, and each diagonal of the abacus two, diameters of the column. Vitruvius makes no men. tion of obtunding the eorners of the aba. cus, as is generally practised by the ancients as well as the moderns: we are, therefore, led to suppose, that each pair of the four faces of the abacus were continued till they met in an acute angle, at each corner, as in the temple of V'esta at Rome, and the Stoa or portico at A thens; the division of the capital is the same as is frequently used by the moderss, but the entire height thereof is generally made one sixth more than the diameter of the column, and that of the entire column ten diameters. The best ancient specimens of the Corinthian orler are to be collected from the Stoa, the arch of Adri an, and that most exquisite and singrular specimen, the monument of Lysicrates at Athens; also in the Pantheon of Agrippa, and in the three columus of the Campo Vaccino at Rome; these two, and particularly the last, are allowed to be the most complete existing examples that are to be foundin all the remains of antiquity. The taste of the foljage of the Attic Corinthian differs considerably from that of the Roman: the small divisions of the leaves are more pointed, approaching nearer to the ucanthus than those at Ronne, which are for the most part olive; how: ever, in other respects, the capitals themselves are very similar, except in the monument of Lysicrates.

The Corinthian capital exhibits the ut. most degree of elegarice, beauty, richness, and delicacy, that has ever been attained in architectural composition, though mauy attempts have been made to excecd it. The columins of this orler do not appear to have had any appropriate entablature in the time of Vitruvius; for, in I3. IV. chap. i. he informs us, that both Doric and lonic entablatures were supported by Corinthi:n columns, and that it was the columns alone which constituted this order, and not the entablatures; however, in the remains of Grecian and Roman an. tiquity we find, almost constantly, Corinthuan columns supporting an entablature with a peculiar species of cornice ; a com-

VOL I. position which seems to be borrowed from those of the Doric and Ionic orders. In this entablature the figure of the mutules supporting the corona is clianged into the form of a console, and lughly decorated; and the denticulated lonic band, with its cymatium, and also that of the frize, are introduced below the consoles, which in this application are called madilitons. This disposition is inverting the orler of the original hut, and also the description given by vitruvius. TYhe only example, where dentils are placed above modiltions, is in the second cornice of the tower of thic Winds at Athens. As to the architrave and base of this orler, they may be the sanc as those used in the Ionic; indeed, the Ionic entablature itself would, on many occasions, be a very appropriate one for the Curinthian. When the colimuss are fluted, the number of the flutes and fillets is gunerally 24 , as in the lonic orver.

If the entablature be enriched, the shaft should be fluted, unless composed of ra. riegated marble; for a diversity of $\mathrm{co}$. lours confuses even a smooth surface, and, if decorated, the ornument increases the confusion to a muclı greater degree. When the columns are within reach, so as to be liable to be damaged, the lower part of the flutes, to aboit one thind of their leight, is sometimes filled with cables, as that of the interior onder of the Puntheon, with a view to strengthen the edgres.

In rich work of some modern buildings, the cal]les are coinposed of reeds, husks, spiral twisted jibbands, flowers, and various other ornaments; bit these niceries should only be emploved in the decora. tions of the interior, and even then very sp:uringly; as their cost would be much better employed in giving majesty and grandeur to other parts of the fabric. As the cornice which has obtained the name of Curinthian colısists of so many members, it will be neccssary on this account to increase the whole lieight of the entablature more than two climeters, so as to make the members distinct, and at the sane time to preserve a just proportion between the cornice, frize, and archi? travc; making the heiglit of the entabla. ture two-ninths of that of tbe column; but if the lonic curnice is to be employed, or the dentils and their cymatitum onitted, two diameters. or a fifth of the height of the column will be sufficient. From hence the absurdity of giving too many mem. bers to the cornice will appear, as these slight columns are incapable of s s 


\section{ARCHITECTURE.}

bearing an entablature of the same part of their height as columns of fewer diameters are : this absurdity will more readily appear, when the parts of both orders are made of the same altitudes.

The Corinthian order isappropriate for all buildings, in which magnificence, elegance, and gaiety, are requisite; it was empioyed by the ancients in temples dedicated to Venus, Flora, Proserpine, and also to the nymphs of the fountains, being the most splendid of all the orders, and bearing the most affinity to foliages, flowers, and volutes, which suited the delicacy and clegance of these deities.

Its splendor also recommends it in the decorations of palaces, squares, galleries, theatres, banqueting rooms, and other places consecrated to festive mirth, or convivial recreation; it is likewise employed in churches dedicated to saint Mary, and other virgin saints.

Tuscan orcler. There are no ancient remains of any entire order of this kind; the columns of Trajan and Antonine, and one at Constantinople, being defective from the want of their entablatures. We have the description of Vitruvius to the following purpose : the colımn is seven diameters in height, and is diminished at the top a fourth part of a diameter; their bases have a circular plinth, and are in height half a diameter, which is divided into two parts, giving one to the altitude of the plinth, and one to the torus. The capital has also half a diameter in height, and one in the breadth of its abacus. The height of the capital is divided into three parts, one of which is given to the plinth or abacus, one to the echinus, and the third to the hypotrachelian with the apo. phygis : the architrave is made with its vertical faces over the edge of the $\mathrm{co}^{-}$ lumn, at the neck of the capital, in two thicknesses, in its liorizontal dimension, with a space of two digits or $1 \frac{1}{2}$ inch between, for the admission of air, to prevent the beams from rotting, and joined together with mortise and tenon. Over the beams and over the walls the mutules are projected a fourth part of the heiglit of the columns, and antcpagments are fixed to their fronts. A correct specimen of Tuscan architecture may be seen in St. Paul's, Covent Garden, the work of the most distinguished Inigo Jones. This order is proper for all rustic structures.

Roman order. The character of this as 2n order is indicated by its capital ; the upper part of which being an entire Ionic capital of that species, which fronts the four sides of the column alike, and the lower part consisting of two rows of leaves, as in the Corinthian capital. Vi. truvius speaks of various capitals derived from that of the Corinthian ; but does not distinguish columns with such capitals supporting an entablature by the name of an order; indeed, he expressly says that they do not belong to any species of columns. Serlio was the first who added a fifth order, by compounding columns similar to that of the Arch of Titus, with the entablature of the uppermost order of the Coliseum. More recent authors have, for the greater part, either adopted the entablature of the frontispiece of Nero, which was supported by Corinthian columns, or have brought in adventitious parts of other orders, by introducing the denticulated band of the Ionic, with its cymatium between the modillions and the cymatium of the frize. It is something remarkable, that the columns of Roman buildings, with compounded capitals, support, for the greater part, Corinthian entablatures: the columns of the arches of Septimins Severus and of the Goldsmiths support Ionic entablatures; and those of the temple of Bacchus even support an entablature with what we now call a Tuscan cornice. In short, Rome affords no example of a composite order, with a similar colnice to any one found in the works of any distinguished modern author, except Vignola, who crowns his entablature with a bold Ionic cornice. The capital of this order is more bold and massire in its parts than that of the $\mathrm{Co}$ rinthian; the proportion of the other members should be corresponding thereto, and therefore more appropriate cornice than that of the frontispiece of Nero can hardly be applied: the modillions are very cliaracteristic, but the denticulated band, slewn in a modern work, should be omitted : and for this reason also the shaft of the columns should be a mediun between those of the Ionic and Corinthian, though the rery reversc has been assigned to it.

The medallions employed in this order differ from the Corinthian; they are more massy, being composed of two faces, and a cymatium like an architrave. The Romans decorated their composite capitals with acantlous leaves, and the saine practice is followed by the innderus. The pro. portions will be fully understood in those of the Ionic and Corinthian orders. It is prohahle that the Romans, employed the Composite order in their triumphal arches, and other buildings, to commemorate their victories, and to shew their domi- 


\section{ARCIITECTURE.}

nion over those whom they conquered; and for this purpose also it may be $\mathrm{cm}$ ploved in modern structures, to celebrate the achievements of conquerors and vir. tues of legislators.

\section{PRINCIPLES OP ECILUISG,}

A re those parts of geometry, meclanics, mensuration, and cliemistry, which shew how to design and construct the parts of a building, so as to be the most durable, the destination, situation, and other fixed clatis of the intended structure, being known. These parts of the sciences are the foundation of the art of construction.

Construction may in general be divided into two parts, the science of masonry, and that of carpentry; though there are other branches, as slatery, plumbery, \&ic. sometimes also employed as constituent parts; but these may be considered as rather arlventitions.

The science of masonry shews how to construct walls and vaults. A wall should be built so as to resist a given force, either acting uniformly over the whole, or partially upon the surface: such as to resist the pressure of s'aults or roofs unrestrained from the want of tie beams, acting along one continued butment, as in plain vaulting ; or to resist different forees, acting at intermitted points, as in groin vault. ing: or to resist the force of the wind, acting uniformly over the whole surface. An arch should be so constructed as to balance itself equally on all parts of the intrados, whether it be of unitorm thick. ness, or to support a given load.

The science of carpentry comprehends the sizing, cutting, disposition, and join. ing of timbers. Hy cliemistry we are en. abled to judge of the quality of materials, such as stone, mortar, wood, iron, slate, lead, \&c.

'Taste. Taste consists in introducing such forms in the construction and $\mathrm{em}$. bellishments, as appear agrceable to the eye of the beholder. The arrangement of the plan, figure of rooms, and contour of the whole building, and character, as to its destined purpose, depend much on taste.

Invention. Invention is the art of combining or arranging the various apartments in the most convenient order.

Basements. A basement is the lower story of a building on which an order is placed; its height will therefore be raria. ble, according as it is the cellar story or the ground story; or, when it is the ground story, according as t'iere are prinejpal rooms in both stories, or only in one of them. It is proper, however, to make the basement no higher than the orler of the next story; for this would be naking the base more principal in the cornposition than the borly to be supported. If the cellar story is the basement, and if the height does not exeed five or six feet at the most, it may be plain, or with rustics, or formed into a continued pedes. tal; but if the basement is on the ground story, the usual manner of decorating it is with rustics supported on a base, and surmounted with a crowning string-course: the base may either be a plinth alune, or with mouldings over it: in like mainer the string-course may either be a platband, or with mouldings under it ; or it may form a comice. The rustics are either made of a rectangular or triangular sec. tion, by imagining one of the sides of these sections to be a line extending across the front of the joint. The joints of the rustics may be from an eightin to a tentls part of their height. The depth of the joint of the triangular rustic may be laalf of its breadth, that is, making the two planes by which it is fornsed a right angle, and the depth of the rectangular sec. tioned rustics from one-fourth to one-third of their breadth. The ancicnts always marked both directions of the joints of the rustics; whereas the molems not only employ the ancient manner, but they sometimes make them with liorizontal joints alone. Those with horizontal joints represent rather a boarded surfice than that of a stone wall, which must have two directions of joints. The height of the string-course should not exceed the height of a rustic with its joint: the plinth, or zocholo, ought not to be less than the height of the string course. When the basement is perforated with arcades, the imposts of the arches niay be a platband, which may be equal to the height of a rustic, exclusive of the joint. When the string-course is a corn ce, the base may be moulded, and the projection of the cornice may be two-thirls of its licight; so as to be less prominent than that which fimshes the building. The height of the cornice may be about one. eighteenth part of the height of the basement, and that of the base about twico as much, divided into six parts, of which the lower five-sixths form the plinth, and the upper sixth the mouldings.

Pedeatuls. A pedestal is a part of some builclings, with a base, surmounted with a rectangular prismatic solid, called the die, and this die again crowned with a comice, for supporting a colonade, or pilastrade, or sometimcs for supporting 


\section{ARCHITECTURE.}

the upper part of a building as a basement. In the buildings of the Greeks pedestals never obtained : the columns of their temples generally stood on the uppermost of three steps; indeed, there is no existing example with any other number than three, except the temple of Theseus at Athens, which had only two, and was supposed to have been erected to an inferior deity : whatever innovations took place were after Greece lost its indepcndence. The Romans, in many of their temples and other edifices, raised the floors so very high, that they were under the necessity of discontinuing the front stairs, which otherwise would have been found inconvenient, in occupying too much ground around the edifice ; and of adopting a pedestal, or podium, as a basement; which was raised as high as the stain, and projected to the front of the steps which profiled on the sides of the pedestal.

It is remarkable, that Vitruvius, in treating of the Doric, Corinthisn, and Tusean orders, never mentions a pedestal: and in treating of the Ionic, he only speaks of it as a necessary part of the construction, and not as part of the order: several modern writers are also of this opinion.

Iţ must be confessed, wherever pedestals are introduced, the grandeur of the order is diminished, as all the parts are proportionably less; however, there are some situations, in which they are indispensably necessary, as in the interior of churches, where, if they were omitted, the beauty of the columns would be entirely lost, as so great a portion of them would be concealed by the pews. The proportions of pedestals in the ancient Roman buildings are very variable ; modern authors, however, have thought proper to bring them to a standard ratio, which Vignola makes one-third of the height of the column; but as this proportion appeared to make them too high, Sir William Chambers reduced it to three-tenths; these ratios, however, might vary as particular circumstances might require. 'The parts of pedestals may be thus proportioned: divide the height into nine equal parts, give one to the cornice, two to the base, and six to the die. The plan of the die is the same as that of the plinth of the column: the projection of the cornice may be equal to its height : the base may be divided into three parts, giving two to the plinth, and one to the mouldings, which in most cases may projeet equal to their height. These proportions are common to all pedestals. It is sometimes customary to adorn the dies of pedestals with sunk pannels, surrounded with mouldings: the pannels are frequently charged with bas reliefs or inseriptions. l'rojecting tablets should never be admitted, as they are not only clumsy, but confuse the contour. The dies of the pcdestals of the arches of Septimius Severus and Constantine have straight-headed niches, with statues. Pedestals should never be insulated, though, the columns which stand upon them were insulated. In the theatres and amphitheatres of the ancients, pedestals were userl in all the superior orders, while the inferior order stood upon steps. They were employed for the purpose of forming a parapet for the spectators to lean over, and for raising the base of the superior order so high, as to be seen upon a near approach to the building. In these situations the pedestals werc made no higher than to prevent accidents. When pedestals are continued with breaks under the columns, or pilasters in ancient buildings, the breaks were called stylobatz; and the recess between every two stylobatx, the podium, which had the same parts disposed at the same levels as the stylobatx.

Arcades. An arcadc is an aperture in a wall with an arched head; which term is also sometimes applied in the plural number to a range of apertures with arched heads. When an aperture is so large that it cannot be lintelled, it then becomes necessary to arch it over. Arcacies are not so inagnificent as colonades; but they are stronger, more solid, and less expensive. In arcades the utmost care should be taken of the piers, that they be sufficiently strong to resist the pressure of the arches, particularly those at the extremes. The Romans employed them in their triumphal arches, and many other buildings. Arcades may be used with propriety in the gates of cities, of palaces, of gardens, and of parks ; they are much employed in the piazzas or squares of Italian cities; and, in general, are of great use, in aftording both shade and shelter in hot and rainy climates; but, on the contrary, they are a great nuisance to the inhabitants, as they darken their apartments, and serve to harbour idle and noisy vagabonds. Lofty arcades may be employed with great propriety in the courts of palaces, and noblemen's houses. There are various ways of decorating the piers of arcades, as with rustics, columns, pilasters, caryatides, persians, or terms surmounted with appropriate entabla. tures; and sometimes the piers are even so broad, as to admit of niches. The arch is either surrounded with rustic work, or 


\section{ARCHITEC'TURE.}

with an archivolt; sometimes intermupted at the summit with a key-stone, in the form of a console, or marsh, or some other appropriate sculpured omament. The archivolt rises sometimes from a platband, or impost, placed on the top of the piers; and at other times from an entablature, supported by columns on each sicle of the arcli. In some instances the arches of arcacles are supported entirely by single or coupled colunns, without the entablature; as in the temple of Faunus at Rome. This form is far from being agreeable to the eyc; it wants sta. bility, as the columns would be incapable of resisting the lateral pressure of the arches, were they not placed within another walled enclosure, or in a circular colonade. In large arches the key-stones should never be omitted, and should be carried to the soffit of the architrave, where they will be useful in supporting the middle of the entablature, which otherwise would have too great a bearing.

When columns are detached, as in the triumphal arches of Septimius Severus and Constantine, at liome, it becomes necessary to break the entablature, making its projection over the intercolumns the same as if pilasters had been used insteart of columns; or so much as is just sufficient to relieve it from the nakedness of the wall. This is necessary in all intereolumns of great width, but should be prac. tised as little as possible, as it destroys the grenuine use of the entablature. When columns are without pedestals, they should stand upon a plinth, in order to keep the bases dry and clean, and prerent them from being broken.

Arcades should never be much more, nor much less, than double their breadth. The breadth of the pier should seldom excced two-thirls, nor be less than onethird, of that of the areade ; and the angular pier should have an addition of a third, or a half, as the nature of the design may require. The impost should not be more than one-seventh, nor less than a ninth, of the breadth of the arch; and the archivolt not more than one. eighth, nor less than one-tenth, of that breadth. The breadth of the bottom of the key-stone should be equal to that of the archivolt; and its length not less than one and a half of its bottoun breadth, nor more than double. In groined porticos, the thickness of the piers clepends on the width of the portico, and the superincumbent building; but with respect to the beauty of tic building, it slould not be less than one quarter, nor more than onethircl, of the breadth of the artuade. When the arcades form blank recesses, the backs of which are pierced with dnors or windows, or recessed with niches, the recesses slould be at least so deep, as to keep the most prominent parts of the dressings entirely within their surface. In the upper stories of the theatres and amplitheatres of the Romans, the arcades stood upon the podia, or inner-peclestals, of the columns ; perhaps as much for the purpose of proportioning the apertures, as to form a proper parapet for leaning over.

Colonndes. A colonade is a range of at tached or insulated columns, supporting an entablaturc. The interval between the columns, measured by the inferior diameter of the column, is called the in: tercolumniation; and the whole area between every two columns is called an in. tercolumn. When the intercolumuiation is one diameter and a half, it is ealled pycnostile, or columns thick set; when two diameters, systyle; when two and a quarter, custyle; when three, diastyle : and when four, arxostyle, or columns thin set. A colonade is also named according to the number of columns which support the entablature, or fastigium : when there are four columms, it is called tetrastyle: when six, hexastyle; when eight, octo. style; and when ten, decastyle. The intercolumniations of the Doric order are regulated by the number of triglyphs, placing one over every intermediate $\mathrm{CO}$ lumn: when there is one triglyph over the interval, it is called monotriglyph : when there are two, it is called ditriglyph; and so on, according to the pro. gressive order of the Greek numerals. The intercolumniation of the Grecian 1). ric is almost constantly the monotriglyph : from this practice there are only two de. viations to be met with at Athens, the one in the Doric Portico, and the other in the Propylaca; but these intervals only be. long to the middle intercolumniations, which are both ditriglyph, and became necessary, on account of their being op. posite to the principal entrances. As the character of the Grecian Doric is more massy and dignified than that of the Roman, the monotriglyphic succeeds best; bucin the Roman it is not so convenient, for the passage through the intercolumns would be too narrow, particularly in small buiklings, the ditriglyph is therefore more generally adopted. The arzostyle is only applied to rustic structures of Iinscan intercolumniations, where tbe 


\section{ARCHITECTURE.}

columns are lintelled with wooden architraves.

When the solid part of the masonry of a range of arcades are clecorated with the orders, the intercolumns become necessarily wide; and the intercolumniation is regulated by the breadth of the arcades, and that of the piers.

It docs not appear that coupled, grouped, or clustered colımns, evcr obtained in the works of the ancients; though, on many occasions, they would liave been much more usefu] : we indeed find, in the temple of Bacchus at Rome, columns standing as it were in pairs; but as each pair is only placed in the thickness of the wall, and not in the front, they may ra. ther be said to be two rows of columns, one almost immediately behind tlie otlıer. In the baths of Dioclesian, and in the temple of Peace at Rome, we find groin. ed ceilings, sustained by single Corinthian columns; a support both meagre and inadequate. Vignola uses the same intercolumniation in all his. orders: this prac. tice, though condemned by some, is founded upon a good principle; it preserves a constant ratio between the columins and the intervals.

Of all the kinds of intercolumniation, the custyle was in the most general request among the ancients; and though in modern architecture both the custyle and diastyle are employed, yet the former of these is still preferred in most cases : as to the pycnostyle interval, it is frequently rejected for want of room, and the aræostyle, for want of giving sufficien't support to the entablature.

The moderns seldom employ more than one row of columus, either in external or internal colonades; for the back range destroys the perspective regularity of the front range : the visual rays, coming from both ranges, produce nothing but confusion in the eye of the spectator. This confusion, in a certain degree, also attends pilasters placed behind a row of insulated columns; but in this the relief is stronger, owing to the rotundity of the column, and the flat surfaces of the pilasters. When buildings are executed on a small scale, as is frequently the case of temples, and of other inventions used for the ornaments of gardens, it will be found necessary to make the intercolumniations, or at least the central one, broader than usual, in proportion to thie diameter of the columns; for, when the columns are placed nearer each other than three feet, the space becomes too narrow to admit persons of a corpulent habit.
Pilasters and Antce. Pilasters are rec. tangular prismatic projections, advancing from the naked part of a wall, with bases and capitals like columns, and with an entablature supported by the columns; hence they differ from columns in their horizontal sections being rectangles, whereas those of columns are circles, or the segments of circles, equal to, or greater, than semicircles.

It is probable that pilasters are of $a$ Roman invent on, since there are but few instances in Grecian buildings where they are repeated at equal or regular intervals, and these only in the latter ages of Greece, as in the monument of Philopapus, (unless in that of Thrasyllus); but of their application in Roman works there are numberless instances: Vitruvius calls them parastatz. The Greeks used a kind of square pillars only upon the ends of their walls, which they called ant $x$, which antre projected sometimes to a considerable distance from the wall of the principal front, and formed the pronaos or vestibulum. The breadth of the ant $x$ on the flanks of the temples was always considerably less than on the front: these antre had sometimes columns between them, and when this was the case, the return within the pronaos was of equal breadth to the front. The capitals of the antre never correspond with those of $\mathrm{co}$. lumns, though there are always some characteristic marks, by which the order may be distinguislied.

Pilasters, or parastatx, when ranged with columis under the same entablature, or placed behind a row of columns, have their bases and capitals like those of the columns, with the corresponding parts at the same heights, and when placed upon the angles of buildings, the breadth of the returns is the same as that of the front. The trunks of pilasters have frequently the same diminution as the shafts of the columns, such as in the arches of Septimins Severus and Constantine, and in the frontispiece of Nero, and the temple of Mars the Avenger, at Rome; in this case, the top of the trunks of the pilasters is equal to the breadth of the soffit of the architrave, and the upriglit face of the architrave resting on the capital, in the same perpendicular as the top of the pilaster. When the pilasters are undiminished, and of the same breadth as the columis at the bottom, the face of the architrave resting on the capital retreats with.n the top of the trunk, as in the l'antheon of Agrippa.

Pilasters are either plain or fluted. In 


\section{ARCIHTECTLRE.}

ancient edifices this was not always regulated by the columms, but perliaps depencled on the taste of the architects, or destination of the celifice. 'The columns are plane on the portico of the Pantheon, while the pilasters ure fluted; and the contrary, on the portico of Septimius Severus. When pilasters are fluted, the angles or quoins are frequently beaded, sucli as those of the pantlicon, in order to strengthen the angles, and the flutes are generally of a seinicircular section. The tires of pilasters are somnetimes sunk within a margin, and the pannels charged with foliage, arabesque or grotesque ornaments, or instruments of music and war, or sometimes these compounded, according to the destined purpose of the place iu which they are cmployed.

The pannels of the pilasters, in the Arch of the Goldsmiths at Rome, are charged witls winding folitge and trophics of war. Pilasters, when placed on the front or outside of a building, should pro. ject one quarter of their breadth at the bottom; but when placed behind a range of columns, or in the interios of a build. ing, should not project more than the eighth part of the same breadth.

in a large recess, when two or any even number of insulated columns support an entablature, which terminates at each end upon a wall or picr, a pilaster is most commonly placed against each wall or pier, to support the extremities of the architrave. When the entablature over the columns is recessed within the surface of the wall or pier at each end, the pilaster projects towarls the column, its thickness is shewn on the front, and its breadth faces the void or aljacent column: in this case the architrave may either profile against the sides of the aperture or recess, or it muy return at each interior angle, and then agsin at the exterior angles, and proceed along each wall or pier.

If the intermediate columns and extreme pilasters are so ranged as to project a sinall distance beyond the face of the wall at eacli end, the pilasters shew the same breaclth towards the front as towarts the void, and the entablature may be continued unbroken, as in the chapels of the l'antheon; and if it breaks, it must be at the extreme or most distant angles. Pulasters are of great strength to a wall, as well as ornamental to the building; they are less expensive than columns, and in situations where they are cither placed behind a range of columns, or support the extremes of an entablature across an opening, they are more concordant with the walls to which they are attaclied.

Clustered pilasters, or those which lave both exterior and interior angles, and the planes of those angles parallel and perpendicular to the front, may be executed with goorl effect, when the order is plain, as in the Tuscan : but in the three (ire. cian and Coniposite orders, this junction should be avorled as much as possible, because the triglyphs and capitals of these orders always meet imperfectly in the in. terior angles. The same may also be saicl of louc and Corinthian capitals of lialf pilasters, meeting each other in the interior angles of rooms. In the Ionic order it becomes necessary to make 2 dif. ference between the capitals of pilasters and those of columns; for in the capitals of the cclumns the projection of the ovolo is greater than that of the volutes; but as the horizontal section of the ovolo is cireular, the ovolo itself is bent behind the hem or border of the volutes: now, supposing a vertical section through the axis of the column to be perpendicular to the face, and another thruugh the middle of the breacth of the pilaster, and that the corresponding mouldings are equal and similar in both section; then, be. cause the horizontal section, through the ovolo, is rectangular, as in the trunk, the ovolo would, if continued, pass over the volutes, or must terminate abruptly, and shew the profile of the moulding, which is a palpable defect. This therefore renders it necessary to give the ovolo so much convexity on the front, as to make its extremes retire, and pass belind the back of the border of the rolutes; or to make the ovolo of small pro. jection; or to twist the volutes from a pliun surface, which the ancient lonic has, and make every part of the spirals project more and inore towarls the eye; or, lastly, to project the whole abac us, with the volutes, beyond the projection of the ovolo. 'Tlie same thing is also to be ob. served with regard to the Corinthian and Composite capitals, where the upper part of the vase projects beyond the micldte of the abacus, and would, in the pilaster capitals, pass over the face of the spirals or volutes.

Persians and Caryatides. Instcad of columns, or pilasters, it is sometimes customary to support the entablature by hu. man figures : the males of which are called l'ersituns, T'alamones, or Atlantides : and the funales, Cauians, or Cayraticles. The history of these Vitruvius relates as follows: "Caria, a city of P'cloponnesus 


\section{ARCHITECTURE.}

having joined with the Persians against the Grecianstates, and the Greeks having put an end to the war, by a glorious victory, with one consent declared war against the Caryatides. They took the city, destroved it, slew the men, and led the matrons into captivity, not permitting them to wear the habits and ornaments of their sex; and they were not only led in triumph, but were loaded with scorn, and kept in continual servitude ; thus suffering for the crimes of their city. The architects therefore of those davs introduced their effigies sustaining weights, in the public buildings, that the remem. brance of the crime of the Caryatides might be transmitted to posterity: The Lacedxmonians, likewise, under the com. mand of Pausanias, the son of Cleombro. tus, having at the battle of Platea, with a small number, vanquished a mimerous army of Persians, to solemnize the triumph, erected with the spoils and plunder the Persian I'ortico, as a troply, to transmit to posterity the valour and honour of the citizens; introducing therein the statues of the captives, adorned with habits in the barbarian manner, supporting the roof."

There can be little doubt but that human figures, and those of inferior animals, had a very early introduction in architecture, and are of more remote antiquity than that assigned by Vitruvius; for we are informed by Diodorus Siculus, that in the sepulchre of Osymanduas there was 2 stone hall fourhundred feet square, the roof of which was supported by animals instead of pillars: the number of these supports is not mentioned. The roofs of several Indian buildings, supposed of the most remote antiquity, are sustained in the same manner. In Denon's travels in Egypt, among other frazments, are represented five insulated pilasters or pillars, bearing an entablature : the fronts of the pillars are clecorated with priests or di. vinities. The molten sea, recorded in Holy Writ, was supported by twelve bulls. In the Odyssey of Homer, translated by Pope (book vii. ver. 118, we find the effigies of animals, both rational and irrational, employed as decorations, which appears by the following extract.

'Two rows of stately dogs, on either hand,

In sculptur'd gold and labour'd silver stand.

'These Vulcan form'd with art divine, to wait,

Immortal guardians, at Alcinous' gate.
Alive each animated frame appears,

And still to live beyond the power of years.

Fair throncs within from space to space were rais'd,

Where various carpets with embroid. ery blaz'd,

The work of inatrons : these the prin. cess prest,

Day following day, a long continued feast,

Refulgent pedestals the valls surround,

Which boys of gold with flaming torches crown'd.

However, these representations of animals were not enployed as columns to support an entablature, but merely as ornaments.

In Stewart's antiquities of Athens, we find a most beautiful specirnen of Caryatic figures supporting an entablature, consisting of an architrave cornice of a very elegant profile. Among the Roman antiquities, there are likewise to be found rarious fragments of male figures, which may be conjectured, from their attitudes and ornaments, to have been the supports of the entablatures of buildings.

Besides Persians and Caryatides, it is sometimes customary to support the entablatures with figures, of which the upper part is the head and breast of the human body, and the lower part an inverted frustrum of a square pyramid, with the feet sometimes projecting out below, as if the body had been partly cased: figures of this form are called terms or termini, which owe their origin to the stones used by the ancients in marking out the limits of property belonging to individuals. Nu. ma Ponsilius, in oider to render these boundaries sacred, converted the 'I'erminus into a deity, and built a temple on the Tarpeian Iorint, which was dedicated to him, whom he represented by a stone, which, in course of time, was sculptured into the form of a human head and should. ers, and other parts, as has alveady been defined. IIe was on particular occasions adorned with garlands, with which he appeared of a very pleasant figure. Persian figures are generally charged with a Doric entablature; Caryatic figures with Ionic or Corinthian, or with an Jonic architrave cornice; and the Termini with an entablature of any of the three Grecian orders, according as they themselves are decorated. Male figures may be introduced with propriety in arsenals or galleries of armour; in giard rooms, and other military places, where they might repre- 


\section{ARCHITECTURE.}

sent the figures of captives, or else of martial virtues, such as Strength, Valour, IVisdorn, Prudence, Fortitude, and the like. As these figures should be of a st riking character, they may be of any colossal size that will agree with the architecture of the other parts of the buildings. In composing Caryatides, the most graceful attitudes and pleasant features should be chosen : and, to prevent stiffiness, their drapery and features should be varied from each other, in the different figures of the range; yet a general form of figure should be preserved throughout the whole of them.

Caryatides should always be of a moderate size, otherwise they might appear hideons to the fair sex, and destroy those endearments so fuscinating in the sex represented by them. They may be employed, as Le Clerc observes, to sustain the covering of a throne, and represented under the figures and symbols of heroic virtues : if to adorn a sacred building, they must have an affinity to religion; and, when placed in bauqueting rooms, ball rooms, or other apartments of recreation, they should be of kinds proper to inspire mirth and promote festivity. As Termini are susceptible of a variety of decorations, they may be employed as embellishments for gardens and fields, representing Jupiter as protector of boundaries, or some of the rural deities, as Y'an, Flora, Pomona, Vertumnus, Ceres, Priapus, Faumus, Sylvanus, Nymphs, and Satyrs.

They are also much employed in chimney-pieces, and other interior compositions.

Orders above Order's. When two or more orters are placed one above the other, the laws of solidity require that the strongest should be placed lowermost; and also, that their axes should be in the same vertical lines. When the columns of the orders are of the same diameter, their altitudes increase from the 'l'uscan, Doric, and Ionic, to the Corinthian ; and, consequently, in this progression, the T'uscan is stronger than the Doric, the Doric stronger than the lonic, and the Ionic stronger than the Corinthian: thercfore, if the Doric be the lowest order, the Ionic is the succeeding order; and if there be a thircl order, the Corinthian is in conse. quence the next. But since the difierent stories of a building should wather be of a decreasing progression upwards, than cren of an equal altitude to each other, it follows that the superior columns should not only be diminished, in order to lessen the insisting weight from the inferior, but

VOL. I. also to accommodate the heights of win. dow's.

The rule given by Vitruvius (b. v.c. 7.) for placing one orler above another, is, to make the columins of the superior order a fourth part less in heiglit than those of the inferior.

Scamozzi's rule is, to make the diame. ter at the botton of the sliaft of the superior order equal to the upper diameter of the inferior order.

Let us now suppose that the Ionic of nine diameters is to be raised upon the Doric of eiglit diumeters, as in the Roman Doric; according to the rule given by Vi. truvius, the bottom diameter of the Ionic will be two-thirds of that of the Doric, a quantity much less than is to be found in any ancient or moclern examples of the diminution of the Doric shaft; which diminution is the lower diameter of the su. perior order, by Scamozzi's rule.

In insulated columns, when the diminu. tion of the superior order is very great, the intercolumn becomes so wide, and the entablature so small, and consequently weaker, that it is in danger of breaking ; and if a thirl range is added, this defect must be increased. The Vitruvian rule is thierefore not so applicable as the Scamozziazl, which, for the above reasons, is universally estecmed the best, and is the same as if the several shafts had been cut out from one long tapering tree; on the other hand, when the diminution of the inferior dianeter of the superior order is too little, or nothing, the columns will not only be too ligh for the windows, but the lower order will be loaded with unneces. sary weight. Let the stronger onder be made the superior; for example, let the Doric be placed upon the Ionic, and al. lowing the shaft of it to diminish five. fixths of its bottom diameter, the height of the Doric column will be only $62-3 \mathrm{ds}$ diametcrs of the Ionic below : this would not only make a complete Attic of the Doric, but would render the application of the orders in this inverted way useless, is they could not be made to accommodate the storics of the building, nor could the upper ranges support their own citablar tures, which must be the consequence in insulated columus.

When the front of a building is to have two or more orders in the alcitude, the suc. cession ought to be complete, otherwise the harmony will be destroyed by the vio. lent contrast of the parts. When columns are attached, a recedure of the superior orler will not offend the eye in any great degree, nor will the solidity of the struc. 
ture be impaired; this is to beseen in the theatre of Marcellus ; but when the stories of orders are insulated, it is necessary that the axis of the superior and inferior columns should be in the same rertical lines. If the upper order only insists in the middle of that below in two equidistant parts from the middle, the portions of the entablature of the lower order, in which there is no superior order, are generally finished with a ballustrade, level with the sills of the windows.

In England we have few examples of more than two ranges of columns in the same front; for when there are three, it is difficult to preserve the character of each order in the intercolumnial decorations, without some striking defects. The furst and second orders should stand upon a plinth, and the third also, when there is one, the point of view regulating the two upper plinths. In this case pedestals should be omitted in the upper orders, and if there is one, or a ballustrade under the windows, the base and cornice should have but a small projection, and should be continued to profile upon the sides of the columns. In raising the stories of arcades upon each other, with orders decorating the piers, the inferior columns should be placed upon a plinth, and thesuperior ones upon a pedestal, in order that the arches may obtain a just proportion.

Pediments. A pediment is a part of a building having a horizontal cornice below, and two equally inclined ones, or an arched cornice, above, joined at the extremities of the horizontal one; the cornices including a plane surface within, called the tympanum, which is therefore either a triangle or the segmient of a circle.

This definition does not comprehend erery species of pediments which have been absurdly introduced; but it may be said to be the only genuine one, as pedi. ments represent the ends of roofs, and were originally intended to discharge the rain from the middle of the building, by compelling it to descend and fall over the flanks or extremes, and not over the front, which must be the case with every other figure that can be introduced, except those of a polygonal form, which présent their interior angles to the horizontal cornice, or the exterior ones upwards. To find the pitch of the pediment Vitruvius dirtets as follows: divide between the extremities of the cymatium of the corona into nine equal parts, and one makes the height of the tympanum; but this rule is not correct, as the tympanum will vary its angles according as there are more orless mouldings of the inclined cornices within the extremities of the cy. matium of the corona ; for since the middle part by this rule is invariable, and the broader the parts are of the inclined cornices within each extremity of the cymatium of the corona, or rather within the under edge of the fillet of the syma upon each inclined cornice, the less is the base of the tympanum, and consequently the vertical angle less obtuse, and the base angles less acute; but if this height extended to the meeting of the two under sides of the fillets of the syma, or crowning moulding, then the figure of the tympanum would be invariable. The Vitruvian rule has been thought by many to be toolow; bat it is to be recollected, that that of the Parthenon at Athens, which has an octostyle portico, is nearly of this proportion; that of the temple of Theseus, which has an hexastyle portico, is about one-eighth ; that of the Ionic temple on the Ilyssus, and of the Doric portico, which are both tetrastyle, are about one-seventh ; the tympanum of the pediment of the door on the Tower of the Winds is about one-fifth of the span. The edifices here mentioned are all Athenian buildings. From this comparison it would appear, that a kind of reciprocal ratio subsists between the extension of the base of the tympanum and its height. Indeed, if a fixed ratio were applied to windows, the pediment would frequently consist of a cornice, without the tympanum. It is therefore with great reason that we often make the pitch of pediments of windows more than those which crown porticos, or the fronts of buildings. The plinths by which pediments are sometimes decorated are called acroterions, or acroters: the two which present triangular faces at the extremes have their heights, according to Vitruvius, half of that of the tympanum, and the middle one saddled on the summit is one-eighth part higher than those at the extremes. Pediments owe their origin most probably to the inclined roofs of primitive huts. Among the Romans they were only used as coverings to their sacred buildings, till Cæsar obtainedleave to cover his house with a pointed roof, after the manner of temples. In Grecian antiquity we meet only with triangular pediments, and in Roman build. ings we meet with both the triangular and circular. In rows of openings, or niches, both kinds of pediments were employed in the same range, and disposed in alternate succession. The horizontal comices of pediments should never be discontinu- 
ed, as may be seen in many of the street houses of London, in order to give room for a fan light, and to lessen the expenses of the frontispiece, by introducing shorter columns aud a less massy entablature: for since the horizontal cornice represents the tic-beam, and the inclined ones the rafters, the columns will appear to have a tottering effect, by spreading them out at the top beyond the extremities of their bases.

Vitruvius obscrves, that the Greeks never used mutules, modillions, or dentils, in the front, in which the end of the roof, or fastigium, appears, because that the ends of the rafters and the ends of the latlis which support the tiles only appear at the eaves of the building. Now, as mutules and dentils originated from the projecting ends of the rafters and laths, following the course of nature, it would have been absurd to introduce them into the pediment.

However just this reasoning appears, we find, from the remains of Grecian antiquity, this assertion only verified in the inclined cornices of the pediment: for mutules are constantly employed in the horizontal cornice ; but neither mutules, modillions, nor dentils, on the sloping sides : at least, when any of the edifices in Greece appear with those innovations, they are introduced during the time it was a province of the Roman empire. Of this practice at Rome, the Pantheon and the frontispiece of Nero are examples of modillions; and the temple of Fortune one where dentils are used. In the in. clined cornices of pediments the sides of the modillions and dentils are planes, perpendicular to the horizon and to the front of the edifice; and in the same vertical planes with those of the modillions or dentils of the horizontal cornice.

Balustrades. A balustrade 'is a range of small columns, called balusters, sup. porting a cornice, used as a parapet, or as a screen to conceal the whole or a part of the roof: it is also sometimes used as a decoration for terminating the building. Balustrades are employed in parapets on the margins of stairs, or before windows, or to inclose terraces or other elevated places of resort, or on the sides of the passage way of bridges. It is remarkable, that there are no remains of balusters to be scen in any ancient building. In the theatres and am. phitheatres of the Romans, the pedestals of the upper orders were always continued through the arcades, to serve as a parapet for the spectators to lean over. The lowermost seats next to the arena in the ampitheatres, and those next to the orchestra in the theatres were guarded by a parapet, or podium The walls of ancient buildings generally terminated with the cornice itself, or with a blocking course, or with an Attic. In the monument of Lysicrates at Athens, which is a small beantiful building, the top is finished with fynials, composed of honeysuckles, solid belind, and open between each pair of fynials : each plant or fynial is bordered with a curved head, and the bot. tom of each interval with an inverted curre. Perhaps terminations of this nature might have bcen employed in many other Grecian buillings, as some coins seem to indicate; but this is the only ex. isting example of the kind. The temples in Greece are mostly finished with the cornice itself. This was also the case with many of the Roman temples; but as there are no remains of balustrades in ancient buildings, their antiquity may be donbted: they are, however, represented in the works of the earliest Italian writers, who perhaps may have seen them in the ruins of Roman edifices. When a balustrade finishes a building, and crowns an order, its height should be proportion. ed to the architecture it accompanies, making it never more than four-fiftlis, nor less than two-thirds, of the height of the onder, without reckoning the zocholo, or plinth, on which it is raised, as the balus. trade itself should be completely scen at a proper point of view. Balustrades that are designed for use should alurays be of the height of parapet walls, as they answer the same purpose, being nothing else than an ornamental parapet. This height should not exceed three feet and a half, nor be less than three feet. In the balusters, the plinth of the base, the most prominent part of the swell, and the aba. cus of their capital, are generally in the same straight line; their distance should not exceed half the breadth of the abacus or plinths, nor be less than one-thircl of this measure. On stairs or inclined planes the same proportions are to be observed as on horizontal ones. It was formerly customary to make the mouldings of the balusters follow the inclination of the plane ; but this is difficult to execute, and, when done, not very pleasant to the eye: though in ornamental iron-work, where it is confined to a general surface, passing perpendicularly by the ends of the steps, it has a very handsome appearance. The breadth of pedestals, when placed over an order, is regulated by the top of the 


\section{ARCHITECTURE.}

shafts, the die being always equal thereto. When balustrades are placed upon the entablature of an orler, over the intercolumns or interpilasters, and the base and cornice of the balustrade continued, so as to break out and form pedestals over the columus or pilasters, the breadth of the die of the pedestals should be equal to the breadth of the top of the shafts; and where there is no order, the breadth of the die is never more than its height, and very seldom narrower; and the dies of the pedestals are frequently flanked with half dies, particularly when the range of balusters is long. This is not only apparently necessary, but is in reality useful in shortening the rangc, and forming a better support for the ends of the rail.

Attics. An Attic is a part of a building standing on the cornice, similar in form to that of a pedestal ; and is either broken or continued. The use of an attic is to conceal the roof, and to give greater dignity to the design. The Romans employ. ed attics in their colifices, as may be secn in the remains of the triumphal arches, and piaza of Nerva. In the arch of Con. stantine, pedestals are raised over the co. lumns as high as the base of the attic, and these pedestals are again surmounted with insulated statues. In the ruins of Athons there are no attics to be found: there is one, however, over a Corinthian colonade at Thessalonica, with breaks forming dwarf pilasters over the columns ; and with statues placed in front of the pilasters, as in the arch of Constantine. 'The attic earried round the two courts of the great temple of Balbec is also broken into dwarf pillasters over the columns and pilasters of the orler ; and the dwarf pilasters have blocking courses over them, on which statues are supposed to have been placed. Attics are very disproportional in the ruins of these ancient edifices, some of them being nearly one-half of the heiglit of the order. The moderns make their height equal to that of the entablaturc; as to the proportion of the height of the members it may be the same as that for pedestals.

noors. Doors are apertures in exterior walls, used for passage into public and private buildings; and in the interior, for communication from one apartment to another. In the fourth book of Vitruvius rules are laid down for Doric, Ionic, and Attic doors, all of which have apertures narrower at the top than at the bottom. These trapazoidal closures of apertures have the property of shutting themselves, wbich, perhaps, might have occasioned the introduction of this form, and are use. ful in modern times for raising the door above the floor in the act of opening, in order to keep it clear of the carpet. Ex. amples of them are to be found among the ruins of ancient edifices; they have aiso been introduced by a few modern architects. The apertures of doors of small dimensions are most commonly closed with lintels. Doors, in general, are regulated in their apertures by the size of a man, so as never to bc smaller than that he might pass freely through them; they are seldom less than two feet nine inches in width, by six feet six inches in height, except in confined situations, and where utility is beyond any other consideration.

Doors of entrance vary in their dimensions, according to the height of the story, or magnitude of the building, in which they are placed. In small private houses fout feet may be the greatest width, and in most cases three feet six inches will be sufficient. The lintels of doors should range with those of tle windows; and the width of their aperture should not be less than that of the windows. A good pro. portion of cloors is, that where its dimen. sions las the ratio of three to seren; their height should nover be less than twice, nor more than twice and a half, their breadth. In the entrance doors of public edifices, where there is a frequent ingress and egress of people, and often crowded, their width may be from six to ten feet. Inside doors, or doors of com. munication, should be in some measure proportioned to the hcight of the stories ; however, there is a certain limit for the dimensions of their apertures, which they should not exceed; for the difficulty of shutting the door will be increased by its magnitude; therefore the apertures of doors, which are intended to shut in one breadth, should never exceed three fect six inclies. In palaces and in noblemen's louses, where much company resolt, and in state apartments, all the doors are frequently thrown open; they are made much larger than other doors, being from four to six feet in width, with folding leaves. The proportion of the apertures of such doors will often be of a less height than that of twice the breadth, as all the rooms in the same story have a communication with one another, the whole of the doors in that story will bave one common height.

The apertures of exterior doors placed in blank arcades are regulated by the imposts, the top of the aperture being 


\section{ARCHITECTURE.}

generally made level with the springing of the arch; or if the door has dressings which include a cornice, the top of tlie cornice ought to be on the same level with the springing of the arch. With regard to the situation of the principal entrance, it is crident that the door should be in the middle, as it is not only more symmetrical, but will communicate more easily with all the parts of the building. In principal rooms, doors of communication should at least be two feet distant from the walls, if possible, that furniture may be placed close to the door-side of the room. The most common method of adorning doors is with an architrave surrounding the sides of the aperture, or with the architrave sumounted with a cornice, forming an architrave cornice, or with the architrave frize and cornice forming a complete entablature. Sometimes the ends of the cornice are supported with consoles, placed one on each side of the architrave; and each console is most commonly attaclied to the head of a pilaster; sometimes the surrounding architrave is flanked with pilasters of the orders, or of some other analogical form. In this case, the projections of their bases and capitals are always within that of the architrave : the architrave over the capitals of the pilasters is the same as that of the head of the door, and the parts exactly of the same height, and projections profiling upon the sidles of the surrounding architrave. Sometimes, either with or without these dressings, the door is also adorned with one of the five orders, or with columns supporting a regular entablature, frequently surmounted with a pediment. Doors are also sometimes adorned with rustics, which may either be smooth, hatched, frosted, or vermicu. lated; but their outline must be sharp. The rustics are disposed in contigu:ty with each other, or are repeated by equal intervals : as to the shafts of columns, the rustic cinctures may either be cylindrical or with rectangular faces. In doors with rectangular apertures and rusticated heads, the rustics are drawn from the vertex of an equilateral triangle within the aperture. The entrance doors of grand houses are often adorned with porticos, frequently in the manuer of Grecian temples; sometimes the plan of the portico may be circular, which should never have less than three intercolumniations, as the entablature would appear to orerhang its base, in such a degrec as to offend the eye of a beholder.

Vindores $\boldsymbol{A}$ wiudow is an aperture in a wall for the admission of light. The size of windows depends on the climate, the aspect, the cubature, the proportion, the destination, and the thickness of the walls of the place to be lighted: as also on the number and distribution of win. dows in that place. It is not very easy; even with these data, to determine, with mathematical exactness, the necessary quantity of light ; but in private houses, where beauty and proportion are required, the widtl of the windows depends on the heiglit of the principal story ; otherwise the apertures will be disproportion. ate figures of themselves, and also to the whole facade in wlich they are placed.

The apertures of windows should not only be of shapely figures, and proportioned to the building, but the piers also should, in some measure, be regulated by the breadth of the apertures ; at least, certain proportionable limits of this breadth ouglit to be assigned to that of the piers, so as not to offend the eye by their being too clumsy or too small, and at the same time permit a less or greater quan. tity of light, for a greater or less depth of rooms. As to the size of the piers, considerable latitude may be taken; but in general, they should not be of less breadth than the apertures, nor more than twice that breadth. In a small building. with only three rooms and three windows in the length, the piers will necessarily be large.

In buildings with a great number of windows in the length, where there are at least three windows in one or more principal rooms; and where there are no breaks, the breadtlis of the piers may be from once the breadth of the window to once and a half that breadth ; but if there are columns, pilasters, or breaks, the breadth of the pier may be from once to twice that of the apertures, according as the breadth of the pilasters or columns may require, so as to leave a proper repose of walls upon the sides.

The sills of windows should be from three feet to three feet six inches distant from the level of the floor, forming a parapet for leaning upon: these limits are the natural heights of the breasts of windows; but it is now common, even in ordinary buildings, to make them from two feet to two feet six inches high only. In noblemen's houses the sills are frcquently upon the same level with the floor, and sometimes rise a step or two higher. These circumstances will alter the proportion of the windows, and make them 


\section{ARCHITEC'I'URE.}

much higher than the double square. The width of all the windows must be the same in the same facade; but the different heights of the stories will require different heights of windows. Were it required to find the quantity of light for a room of given dimensions, it is evident that this will depend upon the area of the inlet and the cubature of the room; therefore, supposing that an aperture containing 20 square feet is sufficient for a room 12 feet square and 10 feet high, that is 1400 cubic feet, the quantity of light will easily be ascertained for a room of any other given dimensions. Let a room be supposed 25 feet long, 20 feet broad, and 14 feet high, the cubature will be seven thousand feet; then, because the cubature of rooms should be as the area of the inlets, the proportion will stand thus :

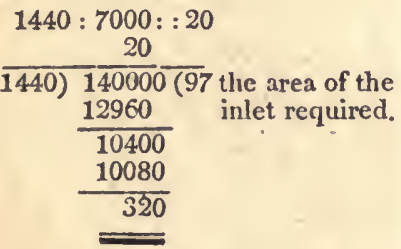

Or, instead of working the proposition, divide the cubature of the room by 72 , thus :

\begin{tabular}{l} 
72) 7000 (97 as before. \\
648 \\
\hline 520 \\
504 \\
\hline 16 \\
\hline
\end{tabular}

This quotient, divided into three parts, gives nearly 32 feet for each window, which is very sufficient for light; and after deducting 12 feet, the breadth of three windows, 13 feet will remain for the four piers, which is a very good proportion : there is also abundant room left for any kind of furnishing above the windows.

An odd number of windows, either in the same length of front, or in the same length of principal rooms, is always to be preferred to an even number; for, since it is necessary to have the door in the middle of the front, an even number of windows would occasion a pier to be above the opening of the door, contrairy either to regularity, or to the laws of solidity ; and in rooms nothing is more gloomy than 2 pier opposite the centre of the floor. Windows placed in blank arcades should have the under sides of their lin- tels in the same horizontal plane with the springing of the arch ; or if the windows have a cornice, the springing of the arch ought to be carried as high as the top of the cornice.

The aperture of the windows may be from two-fifths to three-fourths of the breadth of the arcade. In the principal floor, the windows are generally ornamented; the most simple kind of which is, that with an architrave, surrounding the jambs and lintels of the aperture, and crowned with a frize and cornice. In cases where the aperture is high, in order to make the dressing of a good composition, the sides of the architrave are frequently flanked with pilasters or consoles, or with both; and sometimes with columns, when there is a set-off or proper base, so as not to have a false bearing. When the principal rooms are in the one pair of stairs, the windows of the ground floor are sometimes left entirely plain, and at other times they are surrounded with an architrave; or the rusticated basement, where there is one, terminates upon their margins without any other finish. The windows in the third story are frequently plain, and sometimes surrounded with an architrave. When the windows in the principal story have pediments, the windows of the story immediately above have frequently their surrounding architraves crowned with a frize and cornice. The sills of all the windows in the same floor should be upon the same level. The sills of the windows in the ground story should be elevated 5 or 6 feet at the least. above the pavement. In the exterior of every building the same kind of finish or character should be preserved throughout the same story. Mixtures of windows should be avoided as much as pos. sible; or, where there is a necessity for introducing Venetian windows, they ought to stand by themselves as in breaks.

Gates. A gate is an aperture in a wall, which serves for the passage of horsemen and carriages. They are employed as inlets to cities, fortresses, parks, gardens, palaces, and all places to which there is a frequent resort of carriages. In gates which are closed at the top, the apertures being always wide, are generally made with arched heads: the usual proportion of the arcade is that which has its height double to its breadth, or a trifle more.

The usual ornaments of gates are rustics of several kinds, such as columns, pilasters, entablatures, pediments, attics, blocking courses, imposts, archivolts, 


\section{ARCHITEC'TURE.}

consoles, masks, niches, \&c. In gates which are not closed at the top, the breadth of the piers may be from twofifths to a quarter of their height, reckoning from the bottom of the plinth to the top of the cornice.

The rustics may either be plain, frosted, or vermiculated. The sm:llest width that can be given to the aperture of a gate is nine feet, which is but just sufficient for the free passage of coaches: but if waggons and loaded carts are to pass, it must not be less than ten or eleven feet; and if the gate is for the entrance of a city, it should not be of a less width than eighteen or twenty feet. The composition of gates should be characteristic of the place to which they are to open. Gates of cities and fortresses should have the appearance of strength and majesty; their parts should be large, few in number, and of bold relief. The same ought likewise to be observed in the gates of parks, public walks, or gardens; these succeed better when composed of rustic work and of the massive orders, than when they are enriched with nice ornaments or delicate profiles. However, triumphal arches, entrances to palaces, 'to magnificent villas, town or country houses, might with propriety be composed of the more delicate orders, and be adorned in the highest degree.

The gates of parks and gardens are commonly shut with iron folding grates, either plane or adorned : those of palaces should likewise be so, or else be left open all the day.

Niches. A niche is a recess in s wall, for the purpose of enshrining a statue or some other ornament, or as an ornament to the wall itself. Among the works of the Romans, niches have either that of a circular or rectangular plan : the heads of those which have circular plans are al. most always spherical. In the middle of the attic of the piazza of Nerva, at Rome there is a niche, with a rectangular eleration, and a cylindrical back and head: those upon elliptic plans were not much used by the ancients. In Wood's Ruins of Palmyra there are, however, two exhibited, with elliptic heads within the entrance portico of the temple of the Sun; but no plan is shewn. Niches upon rectangular plans have most frequently horizontal heads : there are a few to be found with cylindrical heads : those upon circular and rectangula plans are, for the most part, placed alternately, for the suke of varjety. The plans of niches with cy. lindrical backs should be semicircular, when the thickness of walls will admit of it ; and the depth of those upon rectangu. lar plans should be the half of their breadth, or as deep as may be necessary for the statues they are to contain ; their heights depend upon the character of the statucs, or on the general forms of groups introduced; seldom exceeding twice and a half of their width, nor les than twice. Niches for busts should have nearly the same proportion with regard to one another; their heights, in some cases, may be something more than their breadtl. jome niches may be formed with cy. lindrical backs and spherical heads ; some of them may be entirely formed with hemispherical backs ; others of spheroidal backs, with the transverse or conjugate axis of the elipsis vertical, as may be most suitable to the character of the thing to be enshrined: those with spheroidal backs may have their lorizontal sections all circles of different diameters, and, consequently, their sections through the vertical axes all equal semi-ellipses, similar to each other ; or all their horizontal sections may be similar ellipses, and the sections through the vertical axis of the niche will be dissimilar ellipses of equal heights, at least for one half of the niche ; but spheroidal niches with such sections are difficult to execute, and not so agreeable to the eye as those with circular horizontal sections. Niches for busts may be of any of these last forms, or of any other form used by the ancients.

Niches are susceptible of the same decorations as windows; and whether their heads be horizontal, cylindrical, or spherical, the inclosure may be rectangular. In the ruined edifices of antiquity, tabernacles are a very frequent ornament, and these often disposed with triangular and arched pediments alternately: the character of the architecture should be the same as that which is to be placed in the same range with them. Niches are sometimes disposed between columus and pilasters, and sometimes ranged alternately in the same levels with windows ; in either case they should be ornamented or plain, as the space will admit.

If the intervals between the columns or pilasters be very narrow, the niches will be much better omitted, than to make them either dimunutive, or of a disproportionate figure. When they are ranged with windows, their dimensions should be the same as the aperture of the windows. Niches being intended as repositories for statues, rases, or other works of sculpture, must be contrived to set of the things they are to contain to the best 


\section{ARCHI'IEC'TLRE.}

advantage, and therefore no ornaments whatever should be introduced : the body and hear of the niche being as plain as possible, every kind of ornament, whether mouldings or sculpture, tends to confuse the outline.

Statues. Besides decorations of mould. ings, columns, and pilasters, architecture is indebted to sculpture for a great part of its maguificence; and as the human body is justly esteemed the nost perfect original, it has been customary, in every period, to enrich different parts of buildings with representations thereof. Thus the ancients adorned their temples, basilicos, baths, theatres, and other public structures, with statues of their deities, philosophers, heroes, orators, and legislators ; and the moderns still prese $/$ ve the same custom, placing in their churches, palaces, houses, squares, gardens, and public walks, the busts and statues of ilhustrious personages; or bas reliefs and groups, composed of various figures, representing memorable occurrences, collected from the histories, fables, or traditions of particular times. Sometimes the statues or groups are detached, and raised on pedestals, and placed contiguous to the walls of buildings, by flights of steps or stairs, at the angles of terraces in the middle of rooms, or of courts, and public squares, but most frequently they are placed in niches. The size of the statue depends upon the dimensions of the niche : it should neither be so large as to seem crammed into it, nor so small as to be lost in it. The distance, between the outline of the statue and the sides of the niche, should never be less than one-third of a head, nor more. than the half, whether the niche be square or arched; and when it is a square, the distance from the top of the head to the soffit of the niche should not exceed the distance left on the sides. The statues are generally raised on a plinth, the height of which may be from one-third to one-half of the head; and sometimes, where the niches are very large, in proportion to the architecture they accompany, as may be the case where an order comprehends but one story. The statues may be raised on small pedestals to a proper height, and by this means the figure will not only have a better proportion to the niche but also to the order, to which it would other. wise appear too trifling. Statues are not only placed in niches, but they are also placed on the tops of walls, and before the dwarf pilasters of attics, as in the arch of Constantine, and the Corinthian colonade at Thessalonica
If there are two rows of niches in the same building, care must be taken to keep the statues of their proper attitudes. The character of the statue should always correspond to the architecture with which it is surromded. Thus, if the order be Doric, Jupiter, IIercules, Pluto, Neptune, Mars, Esculapius, or any male figures, representing beings of a robust and grave nature, may be introduced. If Ionic, then Apollo, Bacchus, Ceres, Minerva, Mercury : and if Corinthian, Venus and the Graces, Flora, or others of a delicate kind and slender make, may very properly have place.

Proportions of rooms. The proportions of rooms depend much on their use and dimensions; but with regard to the beauty, all figures, from the square to a sesquilateral, may be employed: some have even extended the length of the plan to double its breadth, but this disparity of dimensions renders it impossible to pro. portion the height to both length and breadth, though galleries are frequently three, four, or even five squares in length; but as the eye only takes in a portion of this length, the comparison is merely made in respect of the breadth. The height of rooms depends upon the dimensions of their plans and the form of the ceilings. In rooms with flat ceilings, if their plan be a square, their height may be from two-thirds to five-sixths of the side; and if an oblong, it may be equal to the width. In covered rooms, if the plan be a square, the height may be equal to the side; if oblong, it may be equal to the breadth only; or with a fifth, a quarter, or a third, of the difference of the length and breadth. In galleries, the height may be from one and a-third to one and three-fifths of the breadth. These are the general relative dimensions of rooms; but good proportions are not al. ways attainable, particularly in houses of great magnitude; since the same common height is that of all the rooms, whatever be the difference of their plans with regard to their size; however, to keep the best possible proportions, the princi. pal rooms may have flat ceilings, and the middle-sized ones may be reduced by coving the ceilings with a flat in the middle ; or by groins, or domes, as may answer their heights: but if the loftiest of these coved figures leaves still too great a height, recourse must be liad to mezzanines; which are not only necessary for this purpose, but may always be em. ployed with advantage, as they afford servant's lodgings, baths, powdering-rooms, wardrobes, and other conveniences. All 


\section{ARCHITECTURE.}

rooms of inferior classes may have mezzaniucs or intersoles.

In buildings, where beauty and magnificence are preferred to economy, the halls and galleries may be raised, making them occupy two stories. Saloons are frequently rased three stories, or the whole lieight of the builling, and have galleries around their interior at the height of the floors, for communicating with the various jalts of the building.

When rooms are adorned with an entire order, the entablature may occupy in lieight from one-sixth to one-seventh of that of the room; if the cntablature be without colunns, it may have from oneseventh to one-ciglith. If a cornice, frize, and astragal, are executecl, its lieiglit may be equal to a tenth; and if only a cornice, its height may be from a twenticth to a thirtieth part of that of the room. In general, all interior proportions and decorations must be less, and more delicate than those of the exterior. Arclitraves, in most cases, slould not be above oneserenth of the width.

Ceilings. The figures of ceilings are cither flat or coved : cored ceilings either have a concavity around the margins, and are flat in the middle, or have a vaulted surface. (Sce VActrs). Ceilings, that are coved and flat, may occulyy from one-fiftl to a fourth part of the lieight of the room: the priscipal sections of vaulted ceilings may be of various segments, equal to, or less than semicircles, as miy be most suitable to the lieiglit of the room. Flat ceilings are adorned with large compartments, or foliages, and other ornaments, or with both. Compartment ceitings are either formed by rasing mouktings on the surfice, or by depressing the pannels within the moulcled inclo. sure, wlich may be party raised upon, and partly recessed within the franing or entirely recessed: the figurcs of the panncls inay citherbe polygomal, circular, or elliptical. 'The ceilings of the prorticos and of the interior of ancient temples are comparted, and the pannels deeply recessed; the prominent parts between them representing the ancicnt manner of framing the beams of wood which composed the floors; the mouldings on the sides of the pamnels are sunk, by one, two, or several degrees, like inverted steps, and the bottomis of pannels are most freenuently decorated with roses; the figures of these compartinents are mostly equilateral, and equiangular. 'Viangles were seldom used, but we find squires, hexagons, and octagons, in great abundance. 'The framing around the parnels

VOL. I. in loman antiquity is constantly parallel, or of equal breadth, therefore, when square's are introduced, there is no other varicty; but hexngons will join in contignity with one annther, or form the interstices into lozenges, or equilateral triaugles. Octagons naturally form two varicties, riz. thist of their own figure, and squares in the interstices: this kind of compartment is called coffering, and the recessed parts coffers, which are used not only in plain ccilings, but alsn in cylindrical vaults. The borders of the coffering are generally terminated with bolts, charged most frequently with foliage; and sometimes again the foliage is bordered with gnillochis, as in the temple of Peace at rome. In the ceiling of the entirc temple at Balbec, coffer's arc disposed around the cylindrical vault, in one row rising over each intercolumn ; and between erery row of coffess is a projecting belt, ornamented with a guillochi, corresponding with two semi-attached culumns in the same vertical plane, one $\mathrm{co-}$ lunin supporting each springing of the belt. The moderns also follow the same practice in their cupolas and cradle vaults, omamenting them with coffers and belts : the belts are ornamenterl with frets, guillochis, or foliages; small pamels are ornamented with roses, and large ones with foliagre, or historical subjects, in a rariety of different manners.

The grounds may be gilt and the ornaments white, partly eoloured, or streaked with gold ; or the ornaments may be gilt and the grounds wlite, pearl, strawcolour, light-blue, or any tint that may agree best with the ornunents. Some ceilings are painted cither wholly, or in various compartments only : when a ceil. ing is painted in representation of a $s k y$, it ought cither to be upon a plane or splieric surface. A ceiling coved and flat, with the plane painterl to represent the sky, is extremely improper, as the cove represents the lialf of as arch upon every side of the room, it will seem as if falling, from the want of an apparent support in the midalle, unl'ss the ceiling rise from a circular plan. ('eilings corcd and Hat are mucl enployed in modern apartments : they seem to be a kind of nedium between the horizontal and the vatious arched forms practised by the ancicnts: they do not require so much loeight as the latter, but they are neither so graceful nor so grand. Vaulted ceilings are more expensire thum plane ones, but ticy are also susceptible if a greater varicty of embellishunents.

Chinuices. A chimney is an opening $\mathrm{U}$ u 


\section{ARCHI'IEC'I'URE.}

through a wall upwards, beginning at one side of a room, and ending at the top of a wall : its use is to warm the room, and sive passage to the smoke. That part of the opening which faces the room is the place where the fire is put, and consequently is called the fire place : the tube or hollow proceeding from the fire-place upwards, for giving vent to smoke, is callcal the fumel, or thue: the stone or marble laid level with the floor immediately before the fire-place is called the hearth or slab; and the one under the fire-place the back or inside learth. The project. ing parts of the walls on each side of the fire-place, forming also parts of the surface of the room, and standing at the extremities of the hearth, are called jambs : the head of the fire-place in the surface of a room, resting upon the jambs, is called the mantle : the mantle, and that part of the chimney resting upon it, forming a part of the side of the room, and also the whole side of the flue to the top, is called the breast; the side of the flue opposite to the breast is called the back; and the sides of the fire-place contained between the jambs and the back are called covings. When there are two or more chimnies in the same wall, the flues of which approach very near to each other, the thin division which separates one flue from another is either called a partition, or a with; that part of the opening or horizontal section opposite to the mantle of a fire-place is called the throat; and that turret above the roof of a house, containing one or more flues, is called the shaft.

In stone walls, the most common dimen. sions of the sections of flues are from 12 to 13 inches square, for fire-places about $3 \frac{1}{2}$ feet wide in front; and those in brick walls 14 inches by 9 inches. The area of the section of the flue should always be proportioned to the area of the fire usually put in the fire-place, that is, nearly equal to the area of the horizontal section of the fire itself, excepting at the throat. The throat should be immediately over the firc, and its horizontal dimensions in the thickness of the wall should not exceed $4 \frac{1}{2}$, or 5 inclies at most. The fuel grate, or stove, should be brought as near to the throat as conveniency may require. The coving should be placed bevelling nearer together at the back than at the jambs, making an exterior angle with the front of the jambs, and an interior angle with the back, of 135 degrees each. The back and covings forming the sides of the fire-place should be of white materials, such as white stone, or brick covered with plaster, which are most convenient- ly put up after the house is built. Most inetals are unfarourable for this puipose. The top of the throat should bc quite level, forming all abrupt plane. Some of the principlesin the construction of chimnies are very well ascertained, others are not easily discovered till tried. The more the air that goes into the flue is rarefied, with the more force it will ascend, and the higher the fluc the greater also will this force be; therefore the fire should have as little vacancy on either side as possible, and the flue, when conrenient, should be carried as high as possible, and not have too wide an aperture at the top. The situation of cloors in a room, the grate being placed too low, and other things, often occasion smoke; but whatever be the cause of it, if once discovered the evil may easily be remedied. Circular flues are more favourable for venting than those whose sections are rectangular.

Vaults. A vault is an interior roof over an apartment, rising in a concave direction from the walls which support it, either meeting the vertex in a point or line, as when the section of the arch is Gothic; or one continued arch from the one abutment to the other, as when the section is a semicircle, or a segment less than a semicircle.

The vertical sections of the intradoes of vaults may be formed by an infinite variety of curves; but the most elegant forms are either circular or elliptic; which forms of sections have been generally adopted by the ancients of remote antiquity, by our ancestors throughout the middle ages, and by European nations at the present day. We shall thercfore confine ourselves to those vaults which have their extradoes of circular and elliptic sections.

A cylindrical vault is a plain vault, the figure of the extradoes of which is a portion of a cylindric surface, terminating on the top of the walls which support it in a horizontal plane, parallel to the axis of the cylinder. This is also called a cradle vault.

A cylindroidal vault is a plain vault, the figure of the extradoes of which springs from a horizontal plane; its section perpendicular to those lines is every where a semi-ellipsis, equal and similar throughout, and its base is that of either axis; or it is sometimes a segment of an ellipsis, less than a semi-ellipsis, having an ordinate parallel to the axis for its base.

A dome may be defined to be a vault rising from a circular, elliptical, or po. lygonal plan or base, such that all horizontal sections of the intradoes are similar 


\section{ARCHITEC'TÚRE.}

figures, having their centres in the same vertical line or axis, and such that the pliuss of any two sections may have the sides of sinilar inscribed figures parallel to each other, or that the figures of these plaus may be concentric. If the dome is a portion of a splicre, that is, if its base be a eircle, and its vertical section through the ecntre of its base the segment of a circle, then it is also called a cupola.

When the portion of a spliere, or cupola, springs from a wall on a polygonal plan, and the vertical axis of the splicre passes through the middle of the plan, then the spandrels, or triangular splieric portions, comprehended between the springing lines and a horizontal plane passing through the different sumnits of the walls, are called pendentives.

When two or more plain vaults pone. trate or intersect eacl other, the figure of the inturdos formed by the several branches is called a groin, or cross vault.

When two opposite equal branches meet other two opposite equal branches in two intersecting vertical planes, passing through the cliagnnal lines, joining the four exterior angles of the plane, the groin may be called an equal pitched quadrilateral groin.

If two opposite branclies of an equal pitched groin lave cylindrical intradoes, and their plan of less breadth than that of the other two branches, the groin may be called cylindro-cylindroidal, or cylindroido cylindric groin, according as the cylindric branches or the other two are of the greatest breadth.

When a groin consisting of four branches is made by two equal portions of cylindric surfaces, with the axis of the one cutting that of the other, it is called an equal pitched cylindric groin.

when two opposite branches of a cylin. dric groin are of less breadth than the other two, it may be called an unequal pitched cylindric groin. This is called by workmen a Welsh groin.

When the branches of a cylindric groin are of equal breadth in the plan, the groin may be called an equilateral cylindric groin.

It is not easy to give a geometrical de. finition that will extend to all propertics of valting, called, by writers of the first eminence, groins. The first given is al. most unirersal. It applies not only to plain vaults intersecting cach other, but also to those that are annular, or in the form of semi-cylindric rings, intersected by eylindric or cylindroidal plain vaults, the axis of which tends to that of the an- nulus. It does not, however, comprehend that species used in King Henry VII's cliapel, Westminster, and King's Collego cliapel, Cambridge.

This species of groins, instead of the horizontal sections of the curved surfaces presenting exterior right angles, as is $\mathrm{ge}^{-}$ neraly the case, present convex arclies of circles. There is yet one property that is common to erery species of groins, that is, the several branches intersect and form arches upon each inclosing wall, and the perpendicular surface of the wall upon each side is continued till it is intercepted by the intradoes of the arches; consequently the upright of each wall is equal in lieight to the summit of the archcs. Hence the difference between groins and domes. A groin is a branched varit, and each brancli terminates against tho enclosing walls; wbereas a dome is a vault without branches, and the curves spring from the wall, or walls, from all points around its bottom circumference, whether the wallsstand upon a polygonal, circular, or elliptic plan.

The Grecks, it would appear, had few or no arches or vaults much prior to the reign of Augustus, from which time thicy sometimes employed plain vaults with cylindrical intradoes; we also find that they used quadrilateral, equal pitched groined vaults, with cylindrical or cylin. droidal intradoes, or mixed of both, over the passages of the theatres and gym. nasia.

The Romans, as would appear also, did not empoly vaults more early than the Grecks. The Pantheon, one of the earliest remaining structures with arches, was probably built by $\mathbf{A g r i p p a , ~ t h e ~ s o n - i n - l a w ~}$ of Augustus, though some maintain that lie only added the portico; but of this there is no proof, as no mention is made of this celebrated building before his time. We find from Vitruvius (lib. iii.c. 3, that the floors of temples were frequently sup. ported by vaults, and (lib. v. c. 1, ) that the roofs of basilicas were vaulted of the tortoise form, which he distinguishes by the name of testudo. This form of vault. ing is very flat, with four curved sides springing from each of the four walls, and it approaclies nearly to that of a flat dome upon a rectangular plan.

We also find, from the remains of Roman buildings, the ceilings of their apart ments vaulted. The side apartments, or chapels, of the Temple of I'eace, and of the baths of Dioclesian, hare vaults with cylindrical intradoes, while the great rectangular apartment in cach of thess edifi. 
ces is vaulted in the groined form; and it is remarkable that the groins are not formed by the intracloes of the vaults in the chapels, for the summits of the vaults in these rise but a sinall distance above the springings of the middle groins. It may also be renarked, that the piers between the chapels have small arcades, the summits of which arc considerably below the cylindrical intradoes of the side vaults. This circumstance is not peculiar to these buildings, as is to be found in many others. This is to be seen distinctly in the plates of the Temple of Peace, by Desgodetz. The Romans employed annular vaults, as in the temple of Bacchus; and in this, as in the temple of Peace, and the baths of Dioclesian, the summits of the arcades supporting the cylindric wall and dome of the central apartments do not intersect the annular intradoes, but the convex side of the cylindric wall which supports this anmular intrados, and consequently do not form groins. The intradoes of the Roman domes are of a semicircular section, as may be seen in the Pantheon, the temple of Bacchus at liome, the temple of Jupiter, and restibule of the palace of Dioclesian, at Spalatro, in Dalmatia, while the vertical section of the extradoes through the axis is a much less segment, as the Pantheon at Jiome, and the vestibule and palace of Dioclesian, exhibit. We have no instances among the Roman or Grecian buildings of pendentives or spandrels which are supported by four pillars, or by quadrangular or polygonal walls, and which support themselves on a spheric dome or cylindrical wall. Pendentives rising from four pillars, and a dome from the top of the pendentives, were first put in practice, it is said, in the celebrated church of Sancta Sophia at Constantinople.

In the rectangular buildings of the middle ages, quadrangular, equal pitclied groins were generally used; and in circular buildings we have annular groins, as in the Church of the Holy Sepulchre at Cambridge, and Temple Church, London. We have also mentioned those curious groins which are exhibited in the ceilings of King's College Chapel, Cambridge; St. George's Chapel, Windsor; and King Henry the Seventh's Chapel, Westminster, of modern invention.

In the present day, every species of vaulting, that were either used by the ancients or throughout the middle ages, are employed, both for the sake of variety, and for elegance.
It does not appear that the ancients were acquainted with cylindrical, unequal pitched groins, at least by way of ornament; this form is, however, very beautiful, as tlie arcades above the passage through the front of Somerset-House clearly exhibit.

ARCIIYTAS, of Tarentum, in biography, a celebrated mathematician, cosmographer, and Pythagorean philosopher, of whom IIorace says,

\section{WLaris ac terra, mumeroque caren- tis arence}

Mensorem colabent, Archyta, Éc.

Ife flourished about four hundred years before Christ, and was the master of Plato, Ludoxus, and Philolaus. He gave a method of finding two mcan proportionals between two given lines, and thence the duplication of the cube, by means of the conic sections. His skill in mecharies was such, that he was said to be the inventor of the crane and the screw ; and he made a wooden pigeon that could fly about, when it was once set off; but it could not rise again of itself, after it rested. He wrote several works, though none of them are now extant, particularly

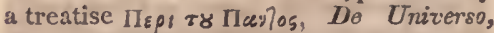
cited by Simplicius in Arist. Categ. It is said he invented the ten categories. He acquired great reputation both in his legislative and military capacity ; having commanded an army seven times witlout ever being defeated. He was at last shipwrecked, and drowned in the Adriatic sea.

Archytas was distinguished through life by modesty and self-command. He maintained, that virtue was to be pursued for its own sake in every condition of life ; that all excess is inconsistent with virtue; that the mind is more injured by prosperity than by adversity; that there is no pestilence so pernicious to human happiness as pleasure ; and that the love of it is a discase destructive to the human mind.

ARCTIC, in astronomy, an epithet given to the north pole, and like wise to a circle of the sphere parallel to the equator, and 23 degrees 30 ininutes distant from thic north pole.

ARC'TUM, the burdock, in botany, a cenus of the Syngenesia Polygamia Equalis class of plaints; the common calyx of which is globose and imbricated; the compound flower is tubulated and uniform, with equal hermaplirodite corollulx: the proper flower is monopetalous and tubulous, with a slender and very long 
tube; there is no pericarpium; the cup is connivent and the seed single, vertically pyramidical, and crowned with a simple down, shorter than the seed. There are two species; vi=. the Laffa and Bardana.

ARCTONYS, the marmot, in natural history, a genus of the Mammalia class of animals, of which the generic character is, front teeth two in each jaw, strong, sharp, and cuneated; grinders in the upper jaw, five on eacls sicle, in the lower jaw four; clavicles or collar bones perfect. This genus differs but little from the Mus tribe, so that naturalists have sometinies doubted whether they should be separated into distinct genera. They are diurnal animals; feed on roots, grain, and fruits, which they often collect in heaps. They reside in subterraneous holes, and become torpid in the winter. The head is gibbous, or rounded, with short ears, or none; body thick; tail short; lairy; fore feet four-toed, with a very short thumb; hind feet tive-toed; cocum large. There are cleven species, of which we shall notice the following: 1. Arctomys marmota, or Alpine marmot: ears short, round; body brown, beneatlı reddish. It inhabits dry open places, on the summits of the Alps and Pyrences; feeds naturally on roots, herbs, and insects; when tamed it will eat any thing that is offered; drinks little; basks in the sun; lives among small tribes, with a cen. tinel placed, to give notice of danger, which is done with a hiss; forms a burrow, with many chambers and entrances, for the summer; another lined with soft grass, in which it remains torpid during winter; it eats with its fore paws; walks on its heels, often erect ; is easily caught when out of its burrow; in a tame state very destructive of food, closths, and furniture; hardly kept awake in winter, even in warm chambers; gravid seven weeks, and brings from two to four at a time. These animals make no provision for the winter, but as soon as the firosts set in they carefully stop up the entrances to their mansions, and gradually fill into a state of torpidity, in which they con. tinue till the beginning of spring, when they awake and commence their excursions. Lefore they retire to winter quarters they grow excessively fat, and appear very emaciatel on first emerging fom thein. If carefully dug up during the winter, they may be conveyed away in their slecping state, and when brought into a warm chamber gralually awaken.

A. Empletra, ur Quebec masmot, is rather larger than a rabbit, with short ears and a round bead. It inhabits Ilurlson's Bay and Canada. A. mouax, or ground-hog, is found in various parts of North $\Lambda$ merica, and in its habits and manners is very like that already noticed. 'I'he marmot, wlien taken young, may be easily domesticated, and taught to peiform various gesticula. tions, such as holding a stick, dancing, \&.c. Sec Hlate II. Mammalia, in which will be seen the hamster and lemming, sometimes called the lapland marmot; descriptions of these will be found in the article Mus. A bobac, or grey marmot, is a native of the high, but milder and sumny sides of mountainous countries, which abound with free-stone rocks, where it is found in dry situations. It frequents l'oland and Russia, among the Carpathian hills : it strarms in the Ukraine, about the Boristhenes, and between this river and the Don, and along the range of hills which extend to the Wolga. It is found about the Yaik, and inhabits the southern desert in Great Tartary. It is not to be seen in Siberia, on account of its northern situation, and rarely reaches in Kamscliat$k a$ as ligh as $55^{\circ}$. The colour is grey above, with the throat, inside of the limbs, and under parts of the body, fulvous or" ferruginous; the tail is slort, rather slen. der, and full of laair. Its manner of life resembles the Alpine marmot. The holes of these animals are lined with the finest. hay, and in such quantities, that, it is said, enough lias been found in a single receptacle to feed a horse for a night. A. citillus, or variegated mamot, is the most beautiful of all the species: in size it differs very much: sume are as large as the Alpine marmot, and others not larger than a common water rat. The variega. ted marmot inlrabits Bohemia and other parts of Germany, trom the banks of the Wolga to India and Persia, through Siberia and Great Tartary to Kamschatka, and even the continent of America. It is not certain that these sleep in the winter like others of the Arctomys genus. They breed in the spring, and proluce from five to eight at a time. They are said to be irrascible and quarrelsome among themselves, and their bite is rery severe. They feed not only on animal foorl, but on snall birds and otlyer animals, which they will kill. 'They are easily tamed, and will grow fumiliar in a fetv days. They are extremely clean, and ufter feeding ge. nerally wash their faces, and clean their fits. Like other domestic animals, they are fond of being caressed, and will feed from the hand. Their sleep is profound 
during the whole night, and in cold and rainy weather through the greater part of the day. See Plate II. Mammalia, flg.1, 2 , and 5 .

ARCTOPUS, in botany, a genus of the Polygamia Dioecia class of plants, the general umbel of which is long and unequal; the partial umbel is shorter; the involucra consists of five leaves ; the corolla of five petals; the fruit is single and bilocular, and stands under the recepta. cle of the floscule; the seed is single, cordated, and accuminated. There is but one species.

ARCTOTHEC $A$, in botany, a genus of the Syngenesia Necessaria; receptacle cellular and chaffy; calyx imbricate. 'There is but one species.

AlCTOTIS, in botany, a genus of the Syngenesia Necessaria class of plants, the common calyx of which is roundish and imbricated; the compound flower is radiated; the hermaphrodite corollula are tubulous and numerous in the disk: the proper hermaphrodite flowers are fumnel-shaped; there is no pericarpium; the seed is single, roundish and hairy. This genus is separated into the following divisions : A. receptacle villous, 31 species; B. receptacle chaffy, 11 species; C. doubtful, 18 species.

ARCTURUS, a fixed star of the first magnitude, in the skirt of Boötes, so called fiom the circumstance of its being near the tail of the Bear. It has been thought to be the nearest fixed star to our system visible in the northern hemisphere, because the variation of its place, in consequence of a proper motion of its own, is more remarkable than that of any other of the stars; and by conparing a variety of observations respecting the quantity and direction of the motion of this star, he infers, that the obliquity of the ecliptic decreases at the rate of $58^{\prime \prime}$ in 100 years, a quantity that neariy corresponds to the mean of the computations framed by the celebrated Euler and Lalande upon the more unerring principles of attraction.

ARC'I'US, in astronomy, the Greek name for the Ursa Major and Minor.

ARDEA, in natural history, a genus of birds of the order of Gralla. The cliaracters of this genus are, a long, strong, sharp-pointed bill; nostrils linear; tongue pointed; toes connected by a membrane as far as the first joint; the middle claw of some of the species, of which there are 79 , pectinated. This genus is separated into five divisions, viz. A. crested; bill liardly longer than the head; $B$. cranes, bald; C. storks, orbits naked; D. herons, middle claw serrate inwardly; E. bill gaping in the middle.

Some ornithologists have separated the herons from the storks and cranes; others, prefering the Linnxan system, class the whole under one genus, which, according to Gmelin, consists of nearly 100 species, though I atham enumerated but 79. They are widely distributed over various parts of the globe, differing in size, figure, and plumage, and with talons adapted to their various places of residence, or their peculiar pursuits. But, notwithstanding the variety in their bills and plumage, the manners of all are nearly the same, so also is their character, which is stigmatized with cowardice and rapacity, indolence, and yet insatiable hunger; and it has been observed, that, from the meagrelooking form of their bodies, one would suppose the greatest abundance almost insufficient for their support.

Ardea payonia. This is as large as the common heron; the length two feet nine inches; the bill is two inches and a half long, straight, and of a brownish colour : irides grey; the crown of the liead covered with soft black feathers like velvet; on the hind part is a tuft composed of hair, or rather bristles, arising near each other at the base, and spreading out on all sides in a globular form; this is four incles in length, and of a reddish brown colour; the sides of the head are bare of feathers, being covered only by a fleshy membrane of a reddish colour at the lower part, and in shape not unlike a kidney; on each side of the throat hangs a kind of wattle; the general colour of the bird bluish-ash ; the feathers on the fore part of the neck are very long, and hang over the breast; wing coverts white; the greater onesincline to rufous, and those farthest from the body to black; the greater quills and tail are black, and the seconda. ries chesnuts; the legs and the bare part above the knee are dusky. The female is black where the male is blue-ash; and the wattles on the throat are wanting; the long featliers on the breast are also less conspicuous. This beautiful species is an inlabitant of Africa, particularly the coast of Guinea, as far as Cape Verd; at this last place they are said to be wonderfully tame, and will often come into the courtyards to feed with the poultry. Why the name of Balearic crane has been given to this bird is not well ascertained, as it is certainly not met with in the Balearic Islands at this day. These birds are often kept in our menigeries, and with shelter at night often live a good while. Their 
chief food is supposed to be worms, and such otluer things as the herontribe usually feed un; also regetables of all kinds. It often sleeps on one leg, juns very fast, and is said not ouly to $\mathrm{Hy}$ well, but to sustain it for a long time together. The flesh of this bird is said to be very tough.

Ardea virgo, or tlie Numidian crane. Size of the crane; length three feet three inclies : the bill straight, two inclies and a lialt long, greenish at the base, then yellowish, with the tip red; irides crimson. 'Ihe crown of the liead is asl-colour; the rest of the head, the upper part of the neck behind, and all the under parts to the breast, black; on the list, the teathers are long and hang downwards; the back, runp, and tail, and all the under part flom the breast, are of a bluish ash-colour; behind cach eye springs a tuft of long white feathers, which decline downwards, and hang in an elegant manner; the quills and tail are black at the ends; the legs are black. This species is found in many parts of Atrica and Asia. In tle first it has beell met with on the cosst of Guinea; but is most plentiful about Bildulgerid, (the ancient Numidia), and Tripoli ; from thence along the cuasts of the Mediterranean Sea, and pretty common in Egypt. They are also at Aleppo, and in the southerı plain about the Black and Caspian Seas; and are seen frequently beyond Lake I3aikal, about the rivers Se. lesiga and Argun, but never venture to the northward. In all places they prefer marshes and the neighbourhood of rivers, as their food is fish, like most of the heron genus. It is frequently kept in menageries, being endowed with great gemleness of manners, added to its being an clegant bird. $\Lambda$ t various times it puts itself into strange and uncoutl attitudes, and especially those which imitate danc. ing: and Keysler mentions one in the Great Duke's Gallery at Florence, which had boen taught to dance to a certain tune when played or sung to it. The name this bird is known by in the east is Kurki, or Querky. See I'late II. Aves, fig. 7.

Ardea grus. This is a large bird, not unfrequently weighing ten pounds, and measures more than live feet in length. This species seems tar spread, being inet with in great llocks throughout northern Europe and Asia, in Sweden, Russia throughout, and Siberia as fur as the river Anadyr, nigrating even to the $\Lambda$ retic Circle. In Kamtschatka only seen un the southerı promontury; are migratory, returning northward to breed in the spring, and generally choosing the same places which had been occupied by them thie season before. In the winter they inlabit the warmer regions, sucli as Egypt, A leppo, India, \&c. they are also met with at the Cape of Good Hope, changing place with the season. In their migrations frequently fly so high as not to be visible, their passage only being known by the noise they make, being louder than that of any other bird. In France they are seen in spring and autumn; but for the most part are mere passengers. We are told that they frequented the marshes of Loncolnshire and Cambridgeshire, in vast flocks, formerly; but the case is altered, as of late none have been met with, except, a few years since, a single bird shot near Cambridge. We are told that they make their nests in marshes, and lay two bluish eggs. The young birds are thouglit very good food. They feed on reptiles of all kinds, and in turn on green corn; of which last they are said to make so great havock, as to ruin the farmers wherever the flocks of these de. predators alight.

Ardea ciconia, or white stork, is the size of a turkey, inhabits in turns the various parts of the old continent, avoid. ing alike the extremes of heat and cold, being never met with between the tro. pics, nor scarcely ever seen more north than Sweden, or in Russia beyond $50^{\circ}$. It never frequents Siberia, though it is sometimes found in Bucharia, where it makes its nest, teisding towards the south in autumn, to winter in Egypt. It is rarely met with in England, though well known in France and IJolland. They every where build on the tops of houses, and the good natured inhabitants provicic boxes for them to make their nests in ; they not only do this, but are particularly careful that the birds suffer no injury, resenting it as done to themselves. Ai Bag. clad they are to be secn on every house, wall, and tree, quite tame. At Persepolis the remains of the pillars serve them to build on, every pillar having a nest. They are thought to have two bruods in a year, the first towards the north, the latter in warmer places; and are seen in vast flocks during their migrations. The fe. male makes a large nest, and lays from two to four eggs. The young are hatch. ed in a montli ; the inale and female watch them by turns till they can provide for thenselres. The stork sleeps on one leg, and snaps witl its bill in a singular man. ner. Its food consists in suakes and other reptiles; hence the veneration of all persons fur this bird, which frees them from such pests. 
Ardea stellaris, or bittern. This is an elegant species, and is somewhat less than the heron; length two fect six inches; the bill brown, beneath inclining to green; irides yellow; the head feathers are long, and those of the neck loose and waving; the crown of the head black; the lower jaw on each side dusky; the plumage in general is beautifully variegated; the ground a ferruginous yellow, palest beneath, marked. with numerous bars, streaks, and zigzag lines of black ; the legs are pale grcen; claws long and slender; and the inner edge on the middle claw serrated. The female is less, darker $c \theta$. loured, and the feathers on the head and neck less flowing than in the male. This is a common bird, we believe, in most of the temperate parts of the continent of Europe ; in some of the colder, migratory; with us it remains the whole year; frequents marshy places, and especially where reeds grow, among which it makes its nest, in April, which is chiefly composed of a bed of rushes, \&c. The female lays four or five eggs, of a pale greenish ash colour; the young are hatched in twenty-five dars. It is an indolent bird, stirring very little in the day unless disturbed; though if once roused is not difficult to shoot, as it flies heavily. In the evening, after sun-set, it is seen to soar aloft in a spiral ascent, till quite out of sight, and this chiefly in autumn, making a singular kind of noise ; it has also another noise, like that of a bellowing bull, beginning in February, and ceasing after breeding-time; but this is done while on the ground. If attacked by dogs or men, it defends itself well; and is said to strike at the eyes of the enemy. The food is frogs, mice, and other reptiles, which it swallows whole, as well as fish. Latham remembers to have found two middlesized trouts in the stomach of one, perfectly whole. It is reckoned pretty good eating. See Plate III. Aves, fig. 7. and Plate IV. fig. 1.

ARDISIA, in botany, a genus of the Pentandria Monogynia class and order. Calyx five-leaved; corol. salver-shaped, with the border reflected; antherx large, erect; stigma simple; drupe superior; one-seeded. There are nine species.

ARDUINA, in botany, a genus of the Pentandria Monogynia class and order. Corol. one-petalled; stigma bifid; berry two-celled; seeds solitary; a shrub of the Cape of Good Hope.

ARF, in French measure, is a superficial unit, or a square, the side of which is 100 metres in length, or 10,000 square metres; the rectilineal metre being 3.281 feet, the are will be 1076.49 square feet. The tenth of an are, called deciare, is a superficies 100 metres long, and 10 broad; or 1000 square metres $=1076.49$; and the centiare equal to 100 square me. tres, is 1076.49 square feet. See MraSURE.

AREA, in geometry, denotes the superficial content of any figure; thus, if we suppose a parallelogram six inches long, and four broad, its area will be $6 \times 4=24$ square inches.

ARECA, in botany, a genus of plants, the cliaracters of which are not perfectly ascertained; the calyx of the male flower is a biralre spatha, the spadix is ramose; the corolla consists of three acuminated petals; the stamina are nine filaments, of which the three exterior ones are the longest; the female flowers are in the same spadix and spatha; the corolla is like the male corolla; the fruit is a sub. oral fibrose drupe, surrounded at the base with an imbricated calyx, and containing an oval seed.

There are three species, of which the oryzxformis is the cabbage-tree of the East Indies. The oleracea is found in the West Indies, the green tops of which are cut and caten as a cabbage.

ARENARIA, sand-wort, in botany, a genus of the Decandria Trigynia Calyx five-leaved, spreading; petals five, entire; capsule superior, one-celled, manyseeded. There are 36 species.

ARENARIUS, the name of a book of Archimedes, in which is demonstrated, that not only the sands of the earth, but eren a greater quantity of particles than could be obtained in the immense sphere of the fixed stars, might be expressed by numbers, in a way invented and described by himself.

AREOMETER, an instrument by which the density and gravity of fluids are measured. The invention of this instrument is ascribed to Hypatia, the daughter of Theo, in the fourth century. It is usually made of glass, consisting of a round hollow ball, which terminates in a long slender neck, hermetically sealed at top, there being first as much running mercury put into it as will serve to balance, or keep it in an erect position. The neck or stem is clivided into degrees, and by the depth of its descent into any liquor the lightness of that liquor is estimated, for the fluid in which it sinks least is the heariest; and that in which it sinks low. est is lightest. See HrDRourtar. 


$$
\text { . }
$$

$i^{-}+i^{6}$

$6-10$

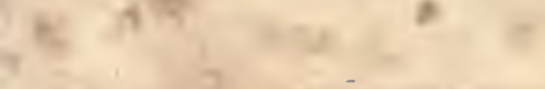

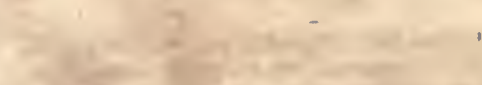

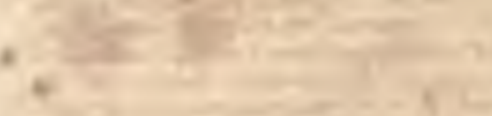

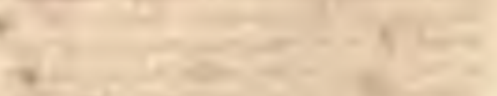

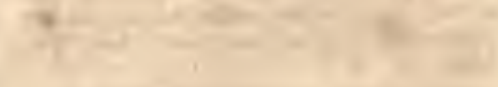

$$
\text { , }
$$

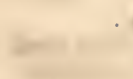

$\cdot+$

and

$+$

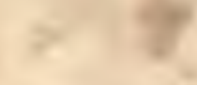
$=$

$x^{2}+7$.

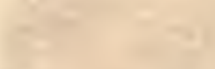

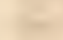

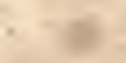
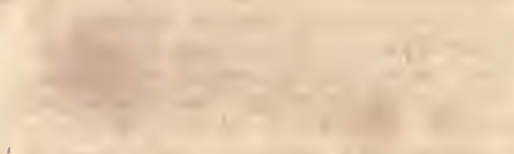

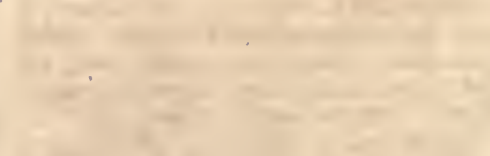

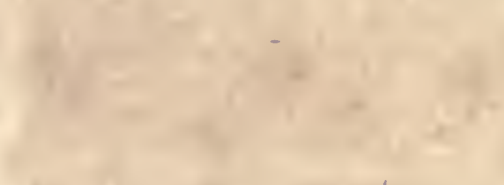

$+$

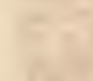

$+2$

zat

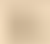

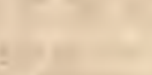

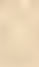

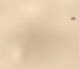

$=0$

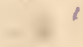

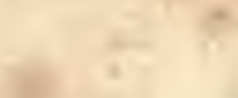

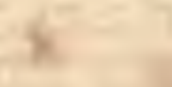

$+$

\section{4}

(2)

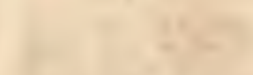

y.

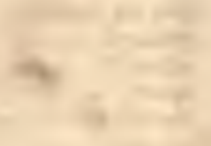

1

p $x-y+2-x$ 


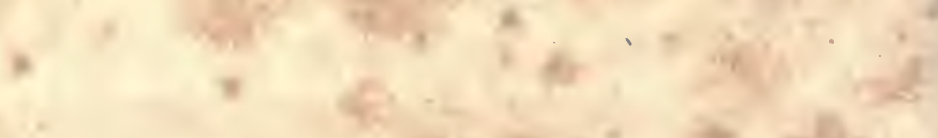

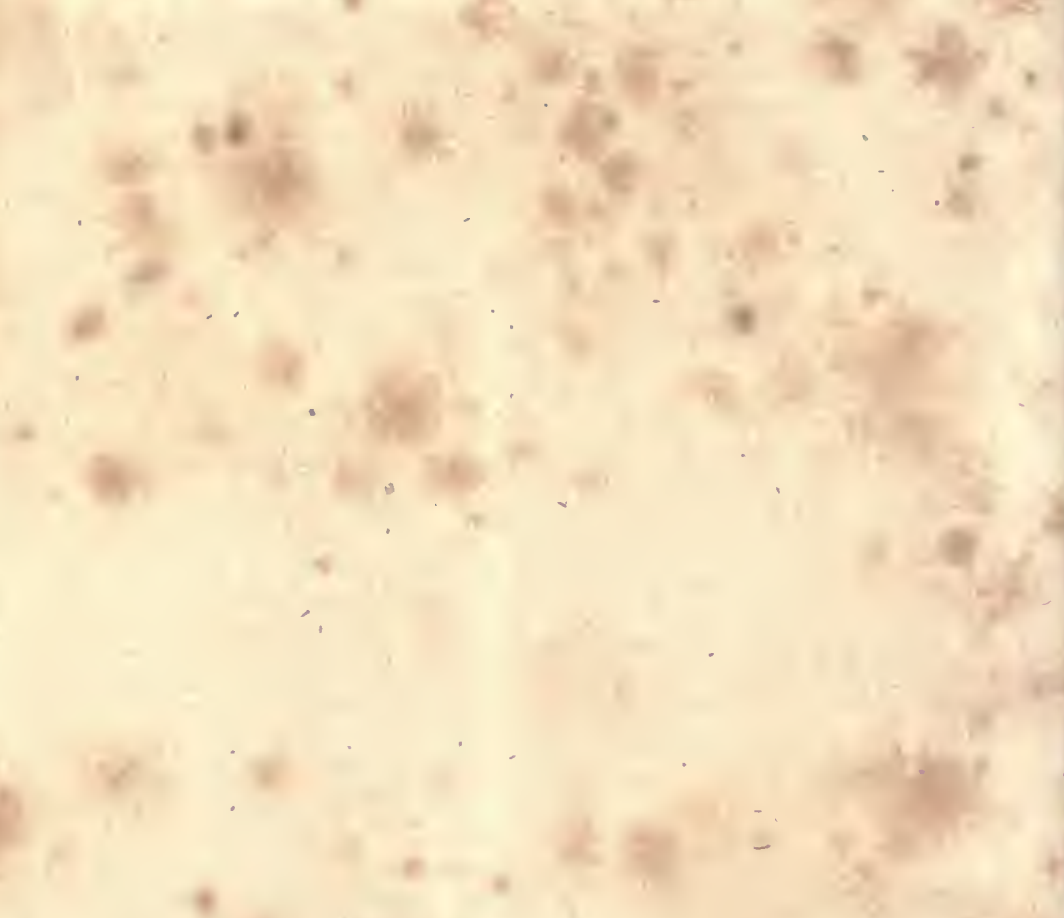

$+$<smiles>[CH]1[CH]CC1</smiles>

$\mathrm{As}$

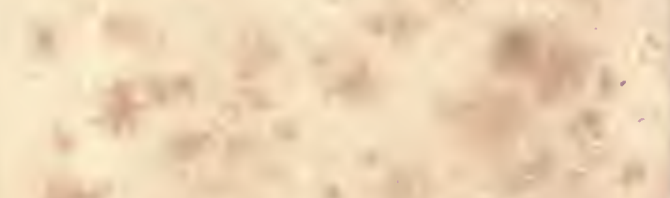

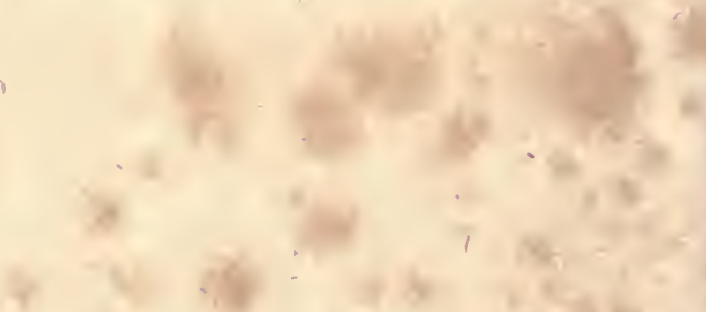

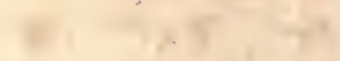

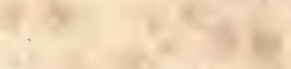

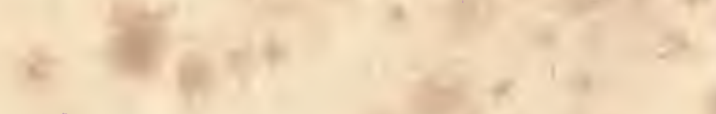
a

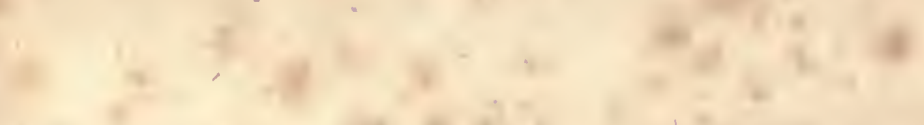
.587 
a

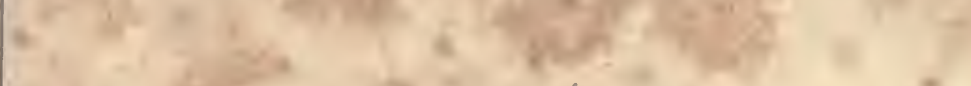

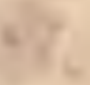

$$
=
$$

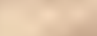

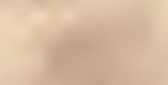

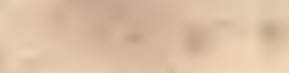

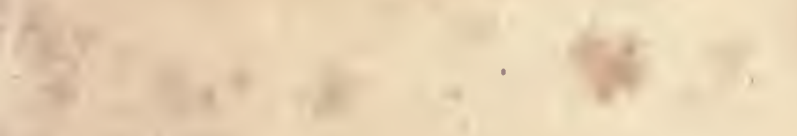

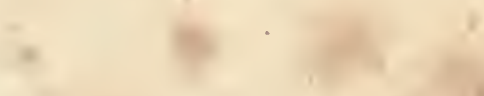

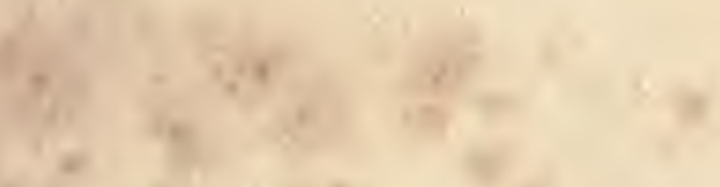

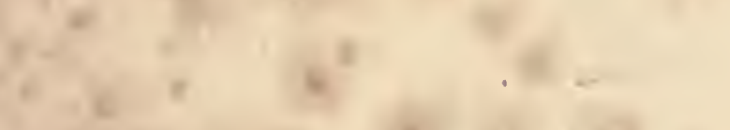$$
\text { (n) }
$$$$
\text { is }
$$

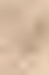

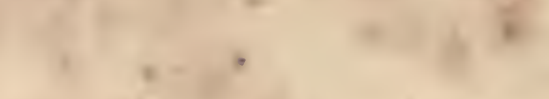

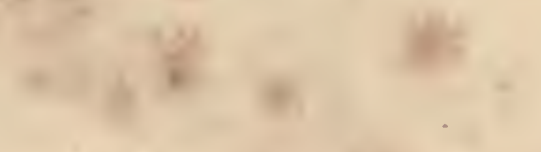

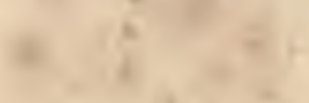




\section{University of California}

SOUTHERN REGIONAL LIBRARY FACILITY

305 De Neve Drive - Parking Lot 17 - Box 951388

LOS ANGELES, CALIFORNIA 90095-1388

Return this material to the library from which it was borrowed.

thed.



A 0008096513 
$=2-x^{2}=0$ 